The copyright of this thesis vests in the author. No quotation from it or information derived from it is to be published without full acknowledgement of the source. The thesis is to be used for private study or noncommercial research purposes only.

Published by the University of Cape Town (UCT) in terms of the non-exclusive license granted to UCT by the author. 


\title{
The Response of Circular Plates to Repeated Uniform Blast Loads: An Experimental and Numerical Study
}

\author{
Travis Foster Ilenchie
}

of MSc. in Mleshadical Jnginesing

Supervisurs:

[)] S. Chung Kim Yuctr

Prof. G.V. Yurick

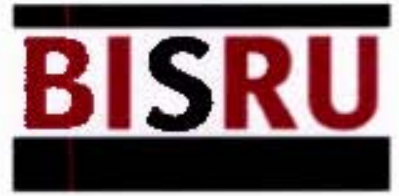

Blasi Inupact and Surqivithility Reseirch Init

Depastmetnt of Mechanical Ențineering

Aniversity of Cape lown

Fobruary 2013 
Declaration

I realise that plagiarism is wrong and know the meaning of plagiarism: to use another's work whilst taking full credit that it is one's own. I declare that all the work in this document is my own except for the information, statements and data that have been appropriately acknowledged, cited and referenced accordingly.

Signed by candidate

Travis Henchie

Date: $23 / 05 / 2013$

i 
3. ABAQUS CONWEP Loading: Using CONWEP to simulate the blast load on a three dimensional Lagrangian shell element mesh, representing the test plate. CONWEP requires TNT relative equivalency values for PE4 and a scaling factor to account for the loading conditions. A number of repeated CONWEP interactions are specified at specific start times in a single simulation step.

The resultant numerical impulses, test plate midpoint deflections and deformation profiles are validated against the experimental data. Further numerical analyses on the effects of repeated blast loading on plastic strain and residual stress states occurring in the test plates are also carried out.

In general, the plates show large inelastic global deformation, typical of uniform loading, with thinning occurring at the clamped boundary and in some cases tearing. The results of deflection versus impulse for the various charge masses show an increasing linear relationship, for all repeated blast series. The progressive midpoint deflection between each subsequent blast shows a decreasing power trend relationship. The Vickers hardness tests indicate an increase in material hardness as the number of repeated blasts increase with a maximum hardness occurring at the clamped boundaries and central region

The numerical results show good correlation to the experimental results with regards to impulse, midpoint deflection and deformation profiles. The numerical plastic strain shows good qualitative correlation with the experimental Vickers hardness tests, where an increase in strain occurs at the clamped boundaries and central region of the test plate. The peak plastic strain increases with increasing repeated blast loads, indicating an increase in work hardening. Residual stresses in the test plates as a result of repeated blast loading, inhibit the deformation (midpoint deflections), decreasing the progressive deflections between each blast. 


\section{Table of Contents}

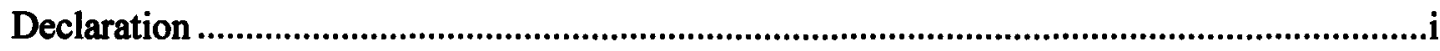

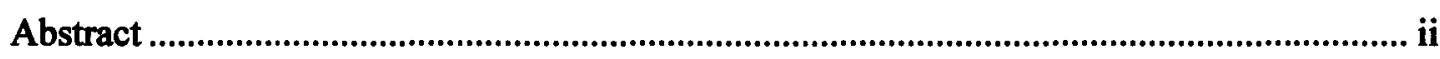

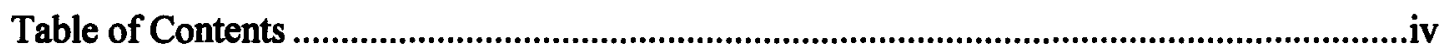

List of Tables..................................................................................................................... viii

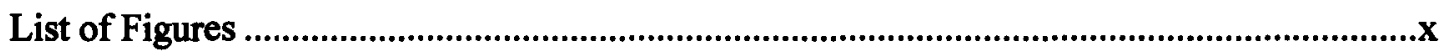

Acknowledgements ...........................................................................................................

$1 \quad$ Introduction ..................................................................................................

$2 \quad$ Literature Review...........................................................................................

$2.1 \quad$ Blast Loading …………....................................................................................

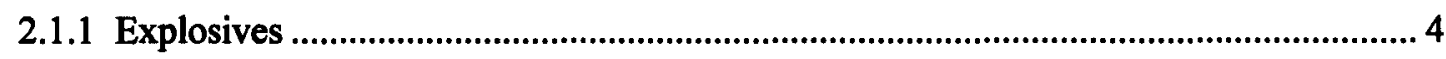

2.1.2 Detonation ............................................................................................................. 6

2.1.3 Blast Waves................................................................................................................ 8

2.1.4 Uniform Impulsive Blast Loading .............................................................................. 10

2.1.5 Reflected Pressure ............................................................................................... 14

2.2 Blast Wave Pressure Measurement .........................................................................19

2.2.1 Pressure Transducers................................................................................................... 19

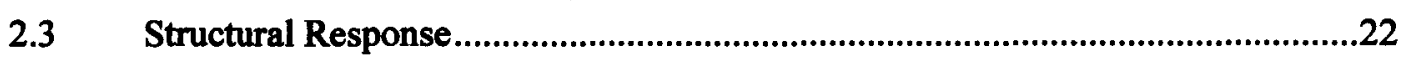

2.3.1 Modes of Failure …................................................................................................. 22

2.3.2 Thin Circular Plates Subjected to Impulsive Blast Loading .......................................... 24

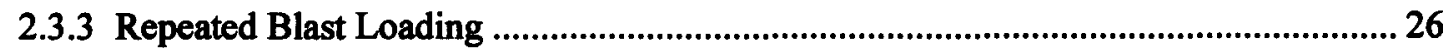

$2.4 \quad$ Theoretical Predictions...........................................................................................28

2.4.1 Jones Damage Number for fully clamped rigid circular Plates...................................... 28

2.4.2 Nurick and Martin's Damage Number .................................................................... 30

2.4.3 Stand-off Distance Parameter....................................................................................... 32

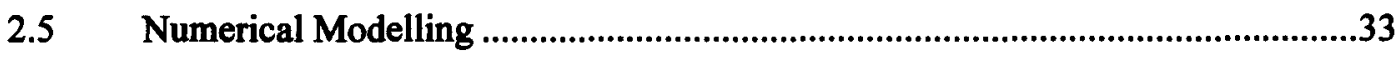

2.5.1 Numerical Blast Loading …………............................................................................. 34 
2.5.2 Geometric Modelling and Test Plate Response.

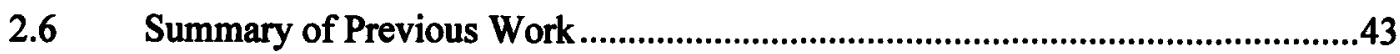

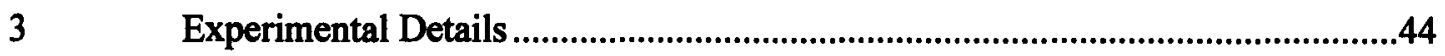

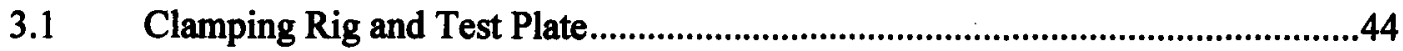

3.1.1 Material Characteristics of the Domex Steel Test Plates ............................................46

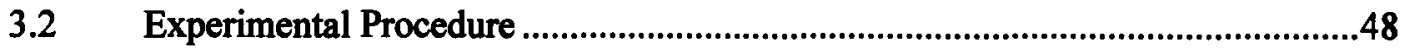

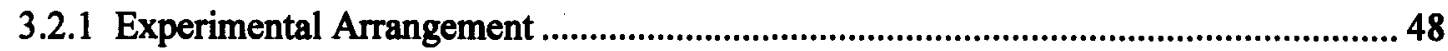

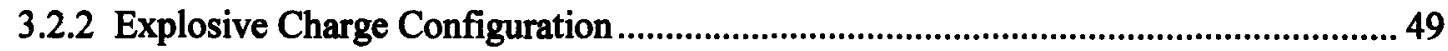

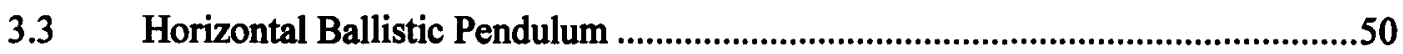

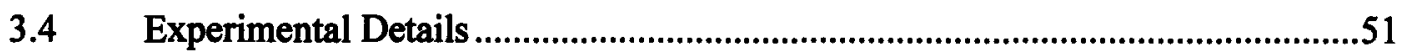

$4 \quad$ Experimental Results and Observations..........................................................52

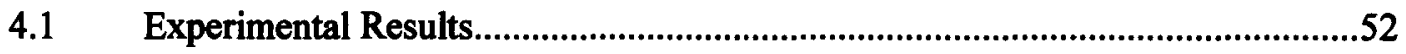

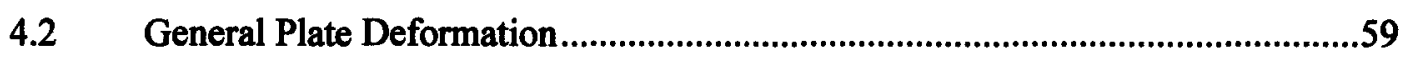

4.3 Observations on Midpoint Deflection and Plate Profiles ..................................63

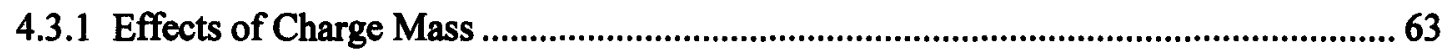

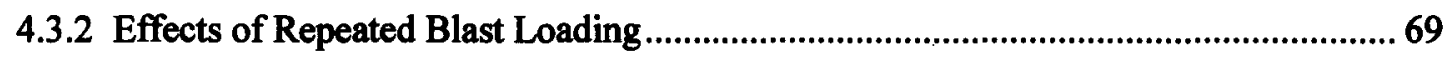

$5 \quad$ Experimental Results Analysis and Discussion ................................................75

$5.1 \quad$ Relationship between Impulse and Charge Mass .................................................75

5.2 Relationship between Impulse and Repeated Blast Load....................................79

5.3 Relationship between Midpoint Deflection and Impulse ...................................81

5.4 Relationship between Midpoint Deflection and Repeated Blast Load..................86

5.4.1 Equivalent Midpoint Deflections of Repeated Blast Loads ....................................... 88

5.5 Relationship between Progressive Deflection and Repeated Blast Load ..............90

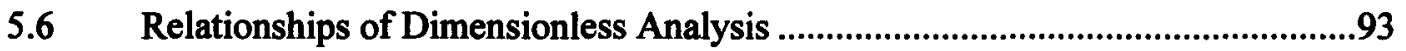

5.6.1 Relationship between Modified Jones Number and Deflection-Thickness Ratio....... 93

5.6.2 Relationship between Modified Dimensionless Impulse and Deflection.................... 95

5.7 Relationship between Repeated Blast Load and Strain Hardening ......................98

$6 \quad$ Numerical Simulations of Repeated Blast Loads................................................103

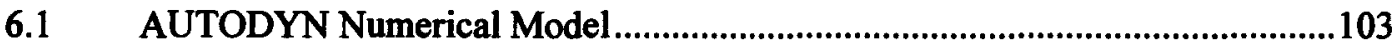


6.1.1 Material Models

6.1.2 AUTODYN Blast Loading.

6.2 ABAQUS Numerical Models.

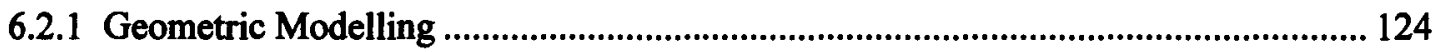

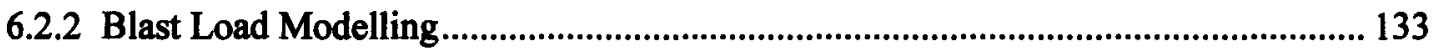

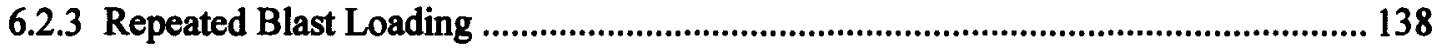

$7 \quad$ Numerical Results and Discussion ....................................................................140

7.1 Comparison of Experimental and Numerical Impulse Results .........................140

7.2 Effect of Repeated Blast Loading on the Impulse Distribution across the Test Plate 143

7.3 Comparison of Experimental and Numerical Midpoint Deflections...................146

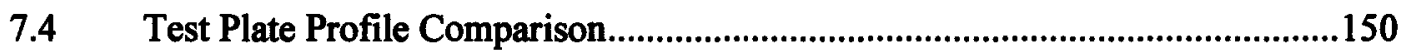

7.5 Comparison of Numerical Strain Components................................................

7.5.1 Comparison between Experimental Vickers Hardness and Numerical Strain .......... 155

7.5.2 Strain Comparisons between ABAQUS Rectangular Pressure Pulse Loading and

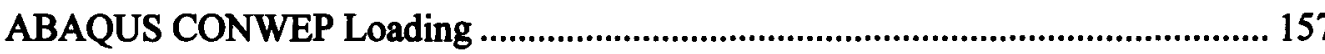

7.5.3 The Effect of Repeated Blast Loading on the Plastic Strain ................................... 159

7.6 Effect of Blast Loaded Residual Stress on Plate Deformation ............................163

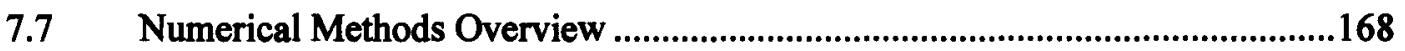

7.7.1 Blast Loading and Repeated Blast Loading ............................................................ 168

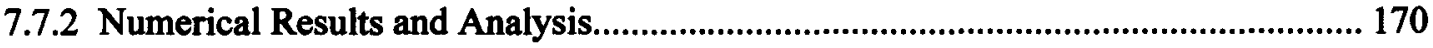

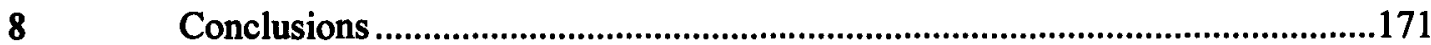

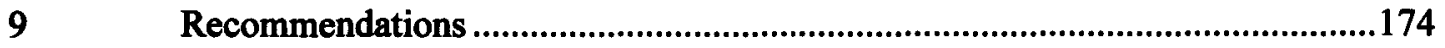

10 References ........................................................... Error! Bookmark not defined.

Appendix A-Johnson Cook Parameters ............................................................................184

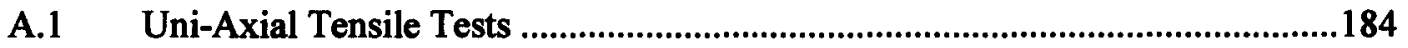

A.2 Machine Compliance Correction................................................................185

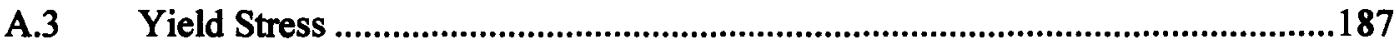

A.4 Post Ultimate Tensile Stress Characteristics ........................................................189

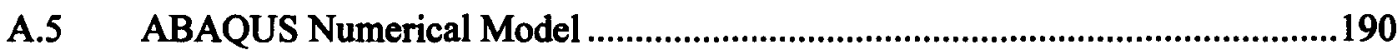




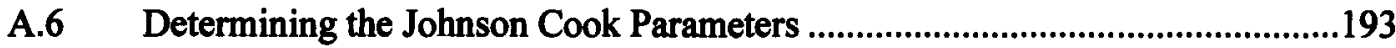

Appendix B- Horizontal Ballistic Pendulum..........................................................................195

Appendix C- Pressure Measurement Blast tests...............................................................198

C.1 Experimental Configuration ...........................................................................198

C.2 Pressure Transducer Set Up .............................................................................199

C.3 Pressure Measurement Results....................................................................204

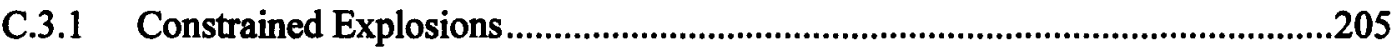

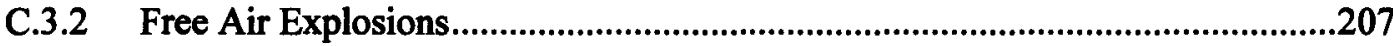

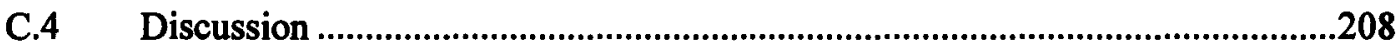

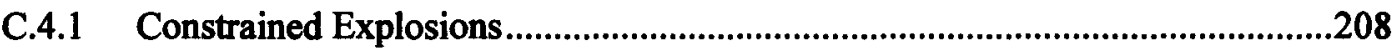

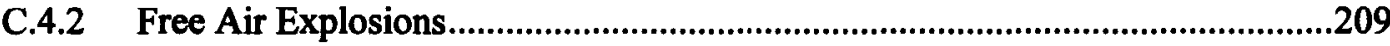

C.5 Comparison with Numerical Pressure ..........................................................210

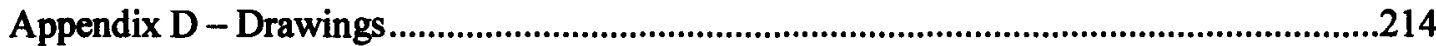

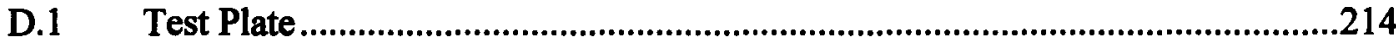

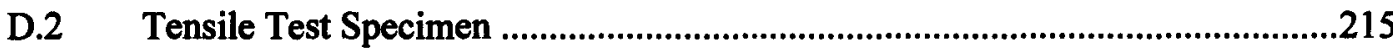

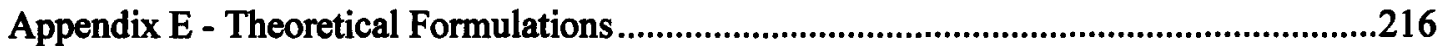

E.1 Rankine - Hugoniot Jump Equations for Detonation Wave Conservations ......216

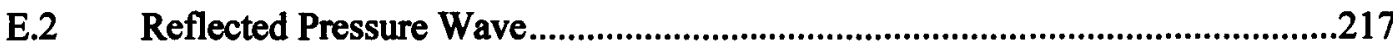

Appendix F - Additional Experimental Results and Graphs ..........................................221

F.1 Relationship between Impulse and Charge Mass for each Repeated Blast Series 221

F.2 Relationship between Midpoint Deflection and Repeated Blast........................224

F.3 Equivalent Midpoint Deflections of Repeated Blasts ........................................226

F.4 Relationship between Progressive Deflection and Repeated Blast Load ...........227

F.5 Relationship between Vickers Hardness and Repeated Blast Loading ..............229

Appendix G - Additional Numerical Results and Graphs ..................................................231

G.1 Comparison of Experimental and Numerical Impulse Results .........................231

G.2 Comparison of Experimental and Numerical Midpoint Deflections..................239 


\section{List of Tables}

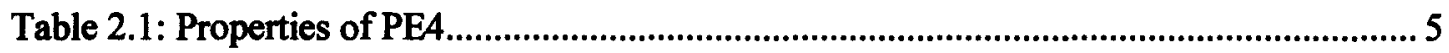

Table 2.2: List of modes of failure and their corresponding descriptions [51] ......................24

Table 3.1: Summary of material properties for Domex 700 steel ..........................................47

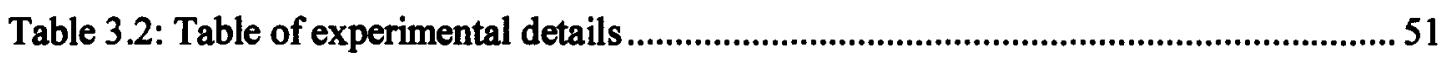

Table 4.1: Table of results for repeated blast loading experiments carried out on $2 \mathrm{~mm}$ thick test plates, for charge masses $5 \mathrm{~g}$ to $25 \mathrm{~g}$...................................................53

Table 4.2: Table of results for repeated blast loading experiments carried out on $3 \mathrm{~mm}$ thick test plates, for charge masses $5 \mathrm{~g}$ to $40 \mathrm{~g}$..................................................55

Table 4.3: Plates which experienced boundary tearing before 5 blasts..................................60

Table 5.1: Variation in measured Impulse between the initial and final repeated blast loads for all charge masses and plate thickness $2 \mathrm{~mm}$............................................ 79

Table 5.2: Variation in measured Impulse between the initial and final repeated blast loads for all charge masses and plate thickness $3 \mathrm{~mm}$........................................8 80

Table 5.3: Midpoint Deflection Equivalencies....................................................................8

Table 6.1: AUTODYN material properties for Air as an ideal gas.................................... 103

Table 6.2: AUTODYN material properties for $\mathrm{C} 4$ used to model the detonation of PE4

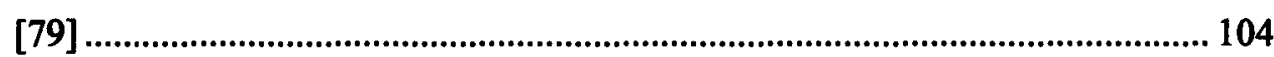

Table 6.3: Linear equation of state material properties for Domex 700.............................. 105

Table 6.4: Johnson Cook material properties for Domex 700 steel ..................................... 106

Table 6.5: Comparison of detonation pressure and Impulse between varying detonation mesh densities [15] ..................................................................................... 110

Table 6.6: Johnson Cook material properties for Domex 700 steel (ABAQUS) ................. 126

Table 6.7: Results of mesh density effects on impulse and midpoint deflection .................. 127

Table 6.8: Uniform pressure values for time, $t$................................................................. 135

Table 7.1: Peak plastic strains for the plate centre and clamped boundary for charge masses $5 \mathrm{~g}$ to $25 \mathrm{~g}$ and plate thickness $2 \mathrm{~mm}$.

Table 7.2: Results for blasted and non-blasted progressive deflections for numerical simulations carried out on $3 \mathrm{~mm}$ thick test plates

Table 7.3: Results for blasted and non-blasted progressive deflections for numerical simulations carried out on $3 \mathrm{~mm}$ thick test plates

Table A.1: Johnson Cook material parameters...................................................................194

Table C.2: Constant experimental parameters...............................................................199 
Table C.3: Peak pressures for constrained explosions

Table C.4: Peak pressures for free air explosions

Table F. 1: Results for the progressive deflection between each successive blast load, for $2 \mathrm{~mm}$ thick plates

Table F. 2: Results for the progressive deflection between each successive blast load, for $3 \mathrm{~mm}$ thick plates

Table G. 1: Comparison of experimental and numerical impulse results for a plate thickness $2 \mathrm{~mm}$, charge masses $5 \mathrm{~g}$ to $25 \mathrm{~g}$ and all repeated blast loads

Table G. 2: Comparison of experimental and numerical impulse results for a plate thickness $3 \mathrm{~mm}$, charge masses $5 \mathrm{~g}$ to $40 \mathrm{~g}$ and all repeated blast loads

Table G. 3:Comparison of experimental and numerical midpoint deflection results for a plate thickness $2 \mathrm{~mm}$, charge masses $5 \mathrm{~g}$ to $25 \mathrm{~g}$ and all repeated blast loads ...244

Table G. 4: Comparison of experimental and numerical midpoint deflection results for a plate thickness $3 \mathrm{~mm}$, charge masses $5 \mathrm{~g}$ to $40 \mathrm{~g}$ and all repeated blast loads ...245 


\section{List of Figures}

Figure 2.1: Energy levels of an explosive reaction indicating the activation energy [47] .............6 6

Figure 2.2: Pressure profile of a detonation wave [54] ............................................................. 8

Figure 2.3: Illustrative graph of pressure vs. time of a blast wave [47] ....................................... 9

Figure 2.4: Diagram of charge stand-off distance and loading condition [51] .............................. 11

Figure 2.5: Diagram of simplified shock tube [61] ....................................................................... 12

Figure 2.6: Explosive arrangement for uniform loading of circular plate................................... 13

Figure 2.7: Transverse pressure reflection waves in a tube [63] .................................................... 14

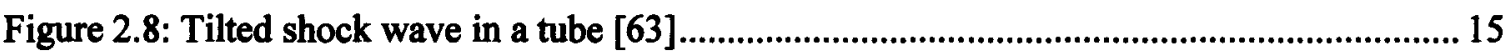

Figure 2.9: Diagram of Incident and reflected pressure waves displaying angle of incidence Blast wave Topography inside a Blast Tube............................................................. 15

Figure 2.10: Illustration of uniform blast load in a tube.............................................................. 16

Figure 2.11: Cross section view of blast wave curve in a tube [63] ........................................... 17

Figure 2.12: True Scale experimental shock shape [63] ................................................................... 18

Figure 2.13: Schematic of piezoelectric pressure transducer [67]................................................. 19

Figure 2.14: Fibre optic photodiode displaying diaphragm [69] ................................................... 20

Figure 2.15: Simple schematic of blast pressure gauge [70] ......................................................... 21

Figure 2.16: Failure associated with clamped metal beams loaded impulsively............................ 23

Figure 2.17: Sequential layout of test specimens for increasing stand-off distance for

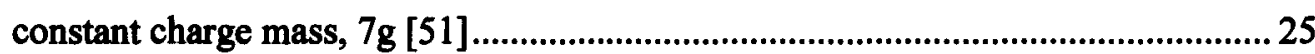

Figure 2.18: Hardness versus plate radius for a plate thickness $1.6 \mathrm{~mm}$ for charge diameter $25 \mathrm{~mm}$ and five blasts [73]

Figure 2.19: Wave propagation for $15 \mathrm{~g}$ equivalent of $\mathrm{C} 4$ and $200 \mathrm{~mm}$ of stand-off distance [29].

Figure 2.20: Pressure-time history of overpressures for $4 \mathrm{~g}$ of PE4 and $300 \mathrm{~mm}$ of stand-off distance [29].

Figure 2.21: Simplified pressure-time loading histories for rectangular and triangular pulses [83]

Figure 2.22: Stainless steel 3D plate model, displaying CONWEP loading source [32]. 39

Figure 2.23: Schematic views of the AUTODYN model construction (mm), (a) Geometry of the blast tube model. (b) Insertion of the target plates (zero blockage ratio). (c) Insertion of the perforated and target plates [15].

Figure 2.24: (a) Typical contour plot of equivalent plastic strain for test plate [44].................... 42

Figure 3.1: Photograph of horizontal ballistic pendulum with illustration of clamping rig .......... 45 
Figure 3.2: Graph of Engineering strain versus Engineering stress for each tensile test strain rate

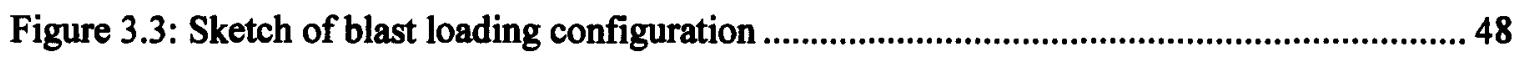

Figure 3.4: Photograph of polystyrene with attached charge and leader..................................... 49

Figure 3.5: Photograph of the horizontal ballistic pendulum ......................................................5 50

Figure 4.1: Photograph of test plate cross sectional profile for test T2R3M15B3 $(\mathrm{m}=15 \mathrm{~g}) \ldots \ldots . .59$

Figure 4.2: Photograph of test plate boundary thinning for the $3 \mathrm{~mm}$ thick plate subjected to charge mass $35 \mathrm{~g}$ and 2 blasts.

Figure 4.3: Photograph showing partial boundary tearing of $2 \mathrm{~mm}$ test plate subjected to 4 blasts of charge mass $15 \mathrm{~g}$

Figure 4.4: Photograph showing full boundary tearing of the $3 \mathrm{~mm}$ thick test plate subjected to 4 blasts of charge mass $40 \mathrm{~g}$.

Figure 4.5: Photograph of deformed test plate profiles for 1 blast load subjected to charge masses $5 \mathrm{~g}$ to $25 \mathrm{~g}$ and plate thickness $2 \mathrm{~mm}$

Figure 4.6: Digitized graphical representation of the deformed test plate profiles for 1 blast load using charge mass of $5 \mathrm{~g}$ to $25 \mathrm{~g}$ and plate thickness $2 \mathrm{~mm}$.

Figure 4.7: Photograph of deformed test plate profiles for 2 blast loads subjected to charge masses $5 \mathrm{~g}$ to $20 \mathrm{~g}$ and plate thickness $2 \mathrm{~mm}$

Figure 4.8: Digitized graphical representation of the deformed test plate profiles for 2 blast loads using charge mass of $5 \mathrm{~g}$ to $20 \mathrm{~g}$ and plate thickness $2 \mathrm{~mm}$

Figure 4.9: Photograph of deformed test plate profiles for 3 blast loads subjected to charge masses $5 \mathrm{~g}$ to $15 \mathrm{~g}$ and plate thickness $2 \mathrm{~mm}$

Figure 4.10: Digitized graphical representation of the deformed test plate profiles for 3 blast loads using charge mass of $5 \mathrm{~g}$ to $15 \mathrm{~g}$ and plate thickness $2 \mathrm{~mm}$ 66

Figure 4.11: Photograph of deformed test plate profiles for 4 blast loads subjected to charge masses $5 \mathrm{~g}$ to $10 \mathrm{~g}$ and plate thickness $2 \mathrm{~mm}$

Figure 4.12: Digitized graphical representation of the deformed test plate profiles for 4 blast loads using charge mass of $5 \mathrm{~g}$ to $10 \mathrm{~g}$ and plate thickness $2 \mathrm{~mm}$

Figure 4.13: Photograph of deformed test plate profiles for 5 blast loads subjected to charge masses $5 \mathrm{~g}$ to $10 \mathrm{~g}$ and plate thickness $2 \mathrm{~mm}$

Figure 4.14: Digitized graphical representation of the deformed test plate profiles for 5 blast loads using charge mass of $5 \mathrm{~g}$ to $10 \mathrm{~g}$ and plate thickness $2 \mathrm{~mm}$.

Figure 4.15: Photograph of deformed test plate profiles for 5 blast loads using charge mass of $5 \mathrm{~g}$ and plate thickness $2 \mathrm{~mm}$

Figure 4.16: Digitized graphical representation of the deformed test plate profiles for 5 blast loads using charge mass of $5 \mathrm{~g}$ and plate thickness $2 \mathrm{~mm}$. 
Figure 4.17: Photograph of deformed test plate profiles for 5 blast loads using charge mass of $10 \mathrm{~g}$ and plate thickness $2 \mathrm{~mm}$

Figure 4.19: Digitized graphical representation of the deformed test plate profiles for 5 blast loads using charge mass of $10 \mathrm{~g}$ and plate thickness $2 \mathrm{~mm}$.

Figure 4.20: Photograph of deformed test plate profiles for 5 blast loads using charge mass of $10 \mathrm{~g}$ and plate thickness $3 \mathrm{~mm}$ as used by Ranwaha [74]

Figure 4.21: Photograph of deformed test plate profiles for 5 blast loads using charge mass of $15 \mathrm{~g}$ and plate thickness $2 \mathrm{~mm}$

Figure 4.22: Digitized graphical representation of the deformed test plate profiles for 5 blast loads using charge mass of $15 \mathrm{~g}$ and plate thickness $2 \mathrm{~mm}$

Figure 4.23: Photograph of deformed test plate profiles for 5 blast loads using charge mass of $15 \mathrm{~g}$ and plate thickness $3 \mathrm{~mm}$ as used by Ranwaha [74] (visible lines on specimens as a result of the machining process)

Figure 4.24: Photograph of deformed test plate profiles for 5 blast loads using charge mass of $20 \mathrm{~g}$ and plate thickness $2 \mathrm{~mm}$

Figure 4.25: Digitized graphical representation of the deformed test plate profiles for 5 blast loads using charge mass of $20 \mathrm{~g}$ and plate thickness $2 \mathrm{~mm}$

Figure 4.26: Photograph of deformed test plate profiles for 5 blast loads using charge mass of $20 \mathrm{~g}$ and plate thickness $3 \mathrm{~mm}$ as used by Ranwaha [74]

Figure 4.27: Photograph of deformed test plate profiles for 5 blast loads using charge mass of $35 \mathrm{~g}$ and plate thickness $3 \mathrm{~mm}$

Figure 5.1: Graph of impulse versus charge mass for all experiments for $2 \mathrm{~mm}$ and $3 \mathrm{~mm}$ thick test plates

Figure 5.2: Graph of impulse versus charge mass comparing linear trends to Jacobs [51] results.

Figure 5.3: Illustration of the effective mass of a charge

Figure 5.4: Graph of impulse versus number of blast loads for the $2 \mathrm{~mm}$ and $3 \mathrm{~mm}$ thick test plates 80.

Figure 5.5: Graph of midpoint deflection versus charge mass for plate thickness $2 \mathrm{~mm}$ 82

Figure 5.6: Graph of midpoint deflection versus charge mass for plate thickness $3 \mathrm{~mm}$ 82

Figure 5.7: Graph of midpoint deflection versus impulse for plate thickness $2 \mathrm{~mm}$ and all repeated blast loads.

Figure 5.8: Graph of midpoint deflection versus impulse for plate thickness $3 \mathrm{~mm}$ and all repeated blast loads, displaying linear trend lines

Figure 5.9: Graph of midpoint deflection versus number of blasts for all charge masses and plate thickness of $2 \mathrm{~mm}$ 
Figure 5.10: Graph of midpoint deflection versus number of blasts for all charge masses and plate thickness of $3 \mathrm{~mm}$

Figure 5.11: Graphical illustration of midpoint deflection equivalencies for $2 \mathrm{~mm}$ thick test plate subjected to $510 \mathrm{~g}$ blasts and $115 \mathrm{~g}$ blast

Figure 5.12: Graph of progressive deflection versus the number of blasts for plate thickness $2 \mathrm{~mm}$, displaying power trends.

Figure 5.13: Graph of progressive deflection versus the number of blasts for plate thickness $3 \mathrm{~mm}$, displaying power trends.

Figure 5.14: Illustration of stress-strain graph, showing the stress state of the plate material after 2 blasts

Figure 5.15: Graph of deflection-thickness ratio versus modified Jones number for single blast load displaying differences in plate thicknesses.

Figure 5.16: Graph of deflection-thickness ratio versus modified jones number for all repeated blast loads.

Figure 5.17: Graph of Deflection-thickness ratio versus dimensionless impulse for 1 blast load displaying differences between plate thicknesses

Figure 5.18: Graph of Deflection-thickness ratio versus dimensionless impulse for all

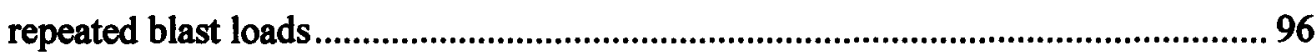

Figure 5.19: Locations of Vickers hardness tests as carried out on the plate profile ....................99

Figure 5.20: Graph of Vickers Hardness on plate profile for charge mass $5 \mathrm{~g}$ and plate thickness $3 \mathrm{~mm}$ (almost no deflections)

Figure 5.21: Graph of Vickers Hardness on plate profile for charge mass $5 \mathrm{~g}$ and plate thickness $2 \mathrm{~mm}$ (smaller deflections)

Figure 5.22: Graph of Vickers Hardness on plate profile for charge mass $10 \mathrm{~g}$ and plate thickness $2 \mathrm{~mm}$ (larger deflections).

Figure 5.23: Graph of maximum peak Vickers hardness at the clamped boundary region for each charge mass, showing increasing trends.

Figure 5.24: Graph of maximum peak Vickers hardness at the clamped boundary region for all the repeated blast loads ................................................................................. 102

Figure 6.1: Overview of detonation model for phase I 108

Figure 6.2: Detonation model at time $0 \mu$ s for remap detonation file, displaying $\mathrm{C} 4$ material location

Figure 6.3: Detonation model stopped at $7.355 \mu$ s for detonation remap file, displaying mitigating pressure wave

Figure 6.4: Impulse model with mitigating pressure wave and gauge locations at a time of $0.199 \mu \mathrm{s}$. 
Figure 6.5: Illustration of gauge positions with respect to their corresponding area on the blast surface.

Figure 6.6: Integral of pressure-time for the gauge at the centre of the blast area ..................... 113

Figure 6.7: Overview of Loading Model with remapped detonation and test plate

Figure 6.8: Graph of transient plate velocity for an extended run time of $4 \mathrm{~ms}$, for plate thickness $2 \mathrm{~mm}$ and $10 \mathrm{~g}$ charge mass.

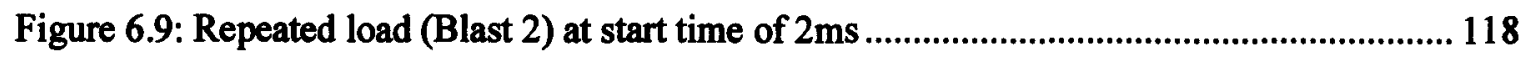

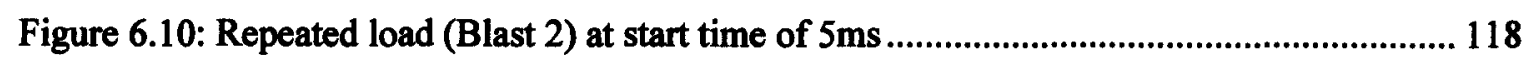

Figure 6.11: Repeated load (Blast 2) at start time 10ms ........................................................ 119

Figure 6.12: Velocity and Midpoint Deflection graphs for le-4 damping fraction..................... 121

Figure 6.13: Velocity and Midpoint Deflection graphs for le-5 damping fraction..................... 121

Figure 6.14: Velocity and Midpoint Deflection graphs for le-6 damping fraction...................... 122

Figure 6.15: Velocity and Midpoint Deflection graphs for no damping ................................... 122

Figure 6.16: Overview of reloaded test plate (Phase IV) with remapped detonation of charge

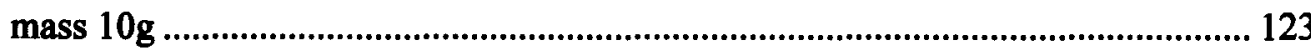

Figure 6.17: Top view of modelled test plate dimensions............................................................. 125

Figure 6.18: Visual difference in mesh densities for the fine and coarse meshes ...................... 127

Figure 6.19: Graphs of impulse and midpoint deflection comparing results from coarse mesh, fine mesh and experiments ................................................................ 128

Figure 6.20: Schematic of clamp cross section ( $3 \mathrm{~mm}$ thick plate) relative to revolution axis

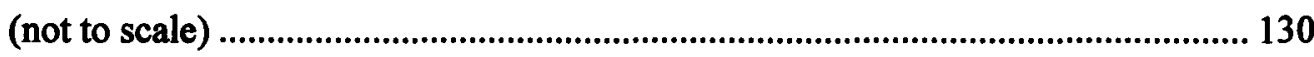

Figure 6.21: 3D rendition of clamp with reference point illustrated ........................................ 130

Figure 6.22: Contact forces for the top and bottom clamps (charge mass $30 \mathrm{~g}$ ) .......................... 131

Figure 6.23: Resultant impulse ( $27 \mathrm{Ns}$ ) from the sum of the contact forces (charge mass $30 \mathrm{~g}$ ).. 131

Figure 6.24: ABAQUS model assembly including clamp and meshed plate. 132

Figure 6.25: Graph showing the pressure-time history for a charge mass $10 \mathrm{~g}$, in the centre of the test plate .................................................................................................. 134

Figure 6.26: Uniform rectangular pressure distribution with respect to time ............................. 135

Figure 6.27: Numerical model showing CONWEP reference start point relative to the blast

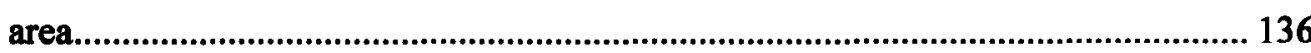

Figure 6.28: Graph comparing the resultant impulse of the scaled CONWEP load versus the non-scaled load

Figure 6.29: Graph of midpoint deflection for 5 blast loads with charge mass $30 \mathrm{~g}$ and plate thickness $3 \mathrm{~mm}$, for uniform loading.

Figure 6.30: Graph of midpoint deflection for 5 blast loads with charge mass $30 \mathrm{~g}$ and plate thickness $3 \mathrm{~mm}$ for CONWEP loading 
Figure 7.1: Graph of numerical impulse versus experimental impulse for all charge masses and repeated blasts for both plate thicknesses $2 \mathrm{~mm}$ and $3 \mathrm{~mm}$

Figure 7.2: Graph of impulse versus charge mass for experimental and numerical results for a single blast load on $2 \mathrm{~mm}$ thick test plates

Figure 7.3: Graph of impulse versus charge mass for experimental and numerical results for a single blast load on $3 \mathrm{~mm}$ thick test plates.

Figure 7.4: Graph of specific impulse versus distance from the test plate centre for charge mass $15 \mathrm{~g}$ and loaded 5 times

Figure 7.5: AUTODYN axisymmetric render of propagating blast wave with transverse reflection off the tube wall

Figure 7.6: Graph of numerical midpoint deflections versus experimental midpoint deflections for plate thickness $2 \mathrm{~mm}$ and all repeated blast loads

Figure 7.7: Graph of numerical midpoint deflections versus experimental midpoint deflections for plate thickness $3 \mathrm{~mm}$ and all repeated blast loads

Figure 7.8: Graph of midpoint deflection versus charge mass for both experimental and numerical results for $2 \mathrm{~mm}$ thick test plates subjected to a single blast load of charge masses $5 \mathrm{~g}$ to $25 \mathrm{~g}$

Figure 7.9: Graph of midpoint deflection versus charge mass for both experimental and numerical results for $3 \mathrm{~mm}$ thick test plates subjected to 5 blast loads of charge masses $5 \mathrm{~g}$ to $35 \mathrm{~g}$

Figure 7.10: Illustrations of experimental and AUTODYN numerical test plate subjected to 3 blasts of $15 \mathrm{~g}$ charge mass

Figure 7.11: Comparison of deformed plate profiles obtained from the experiments and simulations for the $2 \mathrm{~mm}$ thick deformed test plates subjected to a single blast of charge mass $5 \mathrm{~g}$

Figure 7.12: Comparison of deformed plate profiles obtained from the experiments and simulations for the $2 \mathrm{~mm}$ thick deformed test plates subjected to 2 blasts of charge mass $5 \mathbf{g}$

Figure 7.13: Comparison of deformed plate profiles obtained from the experiments and simulations for the $2 \mathrm{~mm}$ thick deformed test plates subjected to 3 blasts of charge mass $5 \mathrm{~g}$.

Figure 7.14: Comparison of deformed plate profiles obtained from the experiments and simulations for the $2 \mathrm{~mm}$ thick deformed test plates subjected to 4 blasts of charge mass $5 \mathrm{~g}$.

Figure 7.15: Comparison of deformed plate profiles obtained from the experiments and simulations for the $2 \mathrm{~mm}$ thick deformed test plates subjected to 5 blasts of charge mass $5 \mathrm{~g}$ 
Figure 7.16: Comparison of deformed plate profiles obtained from the experiments and simulations for the $2 \mathrm{~mm}$ thick deformed test plates subjected to a single blast of charge mass $15 \mathrm{~g}$.

Figure 7.17: Comparison of deformed plate profiles obtained from the experiments and simulations for the $2 \mathrm{~mm}$ thick deformed test plates subjected to 2 blasts of charge mass $15 \mathrm{~g}$

Figure 7.18: Comparison of deformed plate profiles obtained from the experiments and simulations for the $2 \mathrm{~mm}$ thick deformed test plates subjected to 3 blasts of charge mass $5 \mathrm{~g}$.

Figure 7.19: ABAQUS illustration of strain at various time intervals for 5 blast loads and charge mass $30 \mathrm{~g}$

Figure 7.20: Graph of Experimental Vickers hardness and ABAQUS plastic strain components for 3 blast loads with charge mass $15 \mathrm{~g}$.

Figure 7.21: Graph of Experimental Vickers hardness and ABAQUS plastic strain components for 2 blast loads with charge mass $20 \mathrm{~g}$

Figure 7.22: Graph of strain comparisons between ABAQUS CONWEP and ABAQUS Rectangular Pressure Pulse Loading for charge mass $10 \mathrm{~g}$, blasts 1 and 5.

Figure 7.23: Graph of strain comparisons between ABAQUS CONWEP and ABAQUS

Rectangular Pressure Pulse Loading for charge mass 15g, blasts 1 and 3. 158

Figure 7.24: Graph of plastic strain profiles for 5 blast loads with charge mass $5 \mathrm{~g}$ 159

Figure 7.25: Graph of plastic strain profiles for 5 blast loads with charge mass $10 \mathrm{~g}$ 160

Figure 7.26: Graph of strain versus number of blasts for strains occurring at the centre of the test plate for charge masses $5 \mathrm{~g}$ to $25 \mathrm{~g}$

Figure 7.27: Graph of strain versus number of blasts for strains occurring at the clamped boundary of the test plate for charge masses $5 \mathrm{~g}$ to $25 \mathrm{~g}$

Figure 7.28: Illustration of deformed orphan mesh for a charge mass $30 \mathrm{~g}, 4$ blast loads and plate thickness of $3 \mathrm{~mm}$.

Figure 7.29: Graph of plate deflection, comparing BMP and NBMP simulations for charge masses $5 \mathrm{~g}, 15 \mathrm{~g}$ and $35 \mathrm{~g}$ for various repeated blast loads

Figure A.1: Graph of force displacement output data for the tensile test carried out at $100 \mathrm{~mm} / \mathrm{min}$

Figure A. 2: Graph of force-displacement curve post compliance adjusted for tensile test carried out at $100 \mathrm{~mm} / \mathrm{min}$

Figure A 3: Graph showing the $0.2 \%$ offset yield on the engineering stress-strain curve 187

Figure A 4: Image of eighth symmetry ABAQUS tensile test specimen showing bias, defect and planar boundaries 
Figure A.5: Post-UTS stress strain curves fitted to the chosen data points for the tensile test simulations

Figure A.6: Graph of force versus displacement for the various data points chosen, plotted against the experimental force-displacement data

Figure A.7: Stress-strain graph showing the Johnson Cook power curve fitted against the post-UTS curve

Figure B.1: Photograph of horizontal ballistic pendulum 195

Figure B.2: Schematic of ballistic pendulum

Figure C.1: Diagram of blast loading rig with pressure transducer inserted

Figure C.2: Graph of blast pressure charge located at centre (Tube)

Figure C.3: Graph of blast pressure charge located at radius of $25 \mathrm{~mm}$ (Tube)

Figure C.4: Graph of blast pressure charge located at radius of $49 \mathrm{~mm}$ (Tube)

Figure C.5: Graph of blast pressure charge located at the centre of the test plate (free air explosion)

Figure C.6: Graph showing the decrease in pressure from the centre of the blast area to the outer region

Figure C.7: Graph comparing experimental and AUTODYN numerical pressure-time histories for the centre of the blast area

Figure C 8: Graph comparing experimental and AUTODYN numerical pressure-time histories for a radius of $25 \mathrm{~mm}$ from the centre.

Figure C.9: Graph comparing experimental and AUTODYN numerical pressure-time histories for a radius of $49 \mathrm{~mm}$ from the centre.

Figure C.10: Graph comparing experimental and AUTODYN numerical pressure-time histories for free air blast loads

Figure E. 1: Flow Situation Before and After the Reflection of a Shock Wave from a Rigid Wall. Region 5 is Behind the Reflected Shock Wave [105]

Figure G. 1: Graph of impulse versus charge mass for experimental and numerical results for 2 blast loads on $2 \mathrm{~mm}$ thick test plates

Figure G. 2:Graph of impulse versus charge mass for experimental and numerical results for 3 blast loads on $2 \mathrm{~mm}$ thick test plates 
Figure G. 3:Graph of impulse versus charge mass for experimental and numerical results for 4 blast loads on $2 \mathrm{~mm}$ thick test plates

Figure G. 4:Graph of impulse versus charge mass for experimental and numerical results for

5 blast loads on $2 \mathrm{~mm}$ thick test plates

Figure G. 5:Graph of impulse versus charge mass for experimental and numerical results for

2 blast loads on $3 \mathrm{~mm}$ thick test plates

Figure G. 6:Graph of impulse versus charge mass for experimental and numerical results for

3 blast loads on $3 \mathrm{~mm}$ thick test plates

Figure G. 7:Graph of impulse versus charge mass for experimental and numerical results for 4 blast loads on $3 \mathrm{~mm}$ thick test plates

Figure G. 8:Graph of impulse versus charge mass for experimental and numerical results for 5 blast loads on $3 \mathrm{~mm}$ thick test plates

Figure G. 9: Graph of midpoint deflection versus charge mass for both experimental and numerical results for $2 \mathrm{~mm}$ thick test plates subjected to 2 blast loads of charge masses $5 \mathrm{~g}$ to $25 \mathrm{~g}$.

Figure G. 10: Graph of midpoint deflection versus charge mass for both experimental and numerical results for $2 \mathrm{~mm}$ thick test plates subjected to 3 blast loads of charge masses $5 \mathrm{~g}$ to $25 \mathrm{~g}$.

Figure G. 11: Graph of midpoint deflection versus charge mass for both experimental and numerical results for $2 \mathrm{~mm}$ thick test plates subjected to 4 blast loads of charge masses $5 \mathrm{~g}$ to $25 \mathrm{~g}$.

Figure G. 12:Graph of midpoint deflection versus charge mass for both experimental and numerical results for $2 \mathrm{~mm}$ thick test plates subjected to 5 blast loads of charge masses $5 \mathrm{~g}$ to $25 \mathrm{~g}$.

Figure G. 13:Graph of midpoint deflection versus charge mass for both experimental and numerical results for $3 \mathrm{~mm}$ thick test plates subjected to a single blast load of charge masses $5 \mathrm{~g}$ to $40 \mathrm{~g}$

Figure G. 14:Graph of midpoint deflection versus charge mass for both experimental and numerical results for $3 \mathrm{~mm}$ thick test plates subjected to 2 blast loads of charge masses $5 \mathrm{~g}$ to $40 \mathrm{~g}$

Figure G. 15:Graph of midpoint deflection versus charge mass for both experimental and numerical results for $3 \mathrm{~mm}$ thick test plates subjected to 3 blast loads of charge masses $5 \mathrm{~g}$ to $40 \mathrm{~g}$

Figure G. 16:Graph of midpoint deflection versus charge mass for both experimental and numerical results for $3 \mathrm{~mm}$ thick test plates subjected to 4 blast loads of charge masses $5 \mathrm{~g}$ to $40 \mathrm{~g}$ 


\section{Acknowledgements}

Special thanks are extended to the following people, in alphabetical order:

- Adam Ozinsky

- Carlo Geretto

- Gerald Nurick

- Greg Sinclair

- Erik Pickering

- Steeve Chung Kim Yuen

- Victor Balden

- Wei Chi Lee

All of whom played an important role in the completion of this thesis, which would not have been possible without them. Their assistance, advice, support and wisdom were greatly appreciated.

Additional acknowledgements are extended to the following people:

- Dylan Smit

- Murray Watt

- Steve Martin

- Thomas Knight

- Thomas Pretorius

Their support throughout the duration greatly enhanced the productivity and completion date of this thesis.

Final thanks go to my family. Their unwavering support and motivation was necessary in times of low morale. 


\section{Introduction}

On-going war and terrorist attacks contribute to a variety of impulsive loading of structures that often result in life changing injury or death. Improvised explosive devices (IEDs) and landmines accounted for 1761 deaths in Afghanistan during 2009 [1], with many more casualties as a result from conflict occurring throughout the world. Landmine vehicles and armoured personnel carriers (APC) with specialised under carriages used in war stricken areas greatly reduce the death tolls from IEDs and landmines. In its lifecycle, whether on peacekeeping missions or in the battle field an armoured vehicle can be subjected to multiple blast loads from either IEDs or landmines. It is therefore imperative to protect the personnel and cargo on board. A better understanding of the response of structures to multiple blast loads would lead to the improvement of blast resistant structures, increasing the level of safety for personnel and cargo in threatening explosive environments.

The response of structures with various geometries and boundary conditions subjected to uniform and localised impulsive loading conditions has been researched for many years. However, the majority of the studies available in the open literature report on structures that have been subjected to a single blast load. Jones [2], Nurick and Martin [3] and Rajendran and Lee [4] presented an overview of the theoretical and experimental results of plates that are loaded uniformly over the entire plate area. The results reported and discussed the geometrical effects of circular, square and rectangular plates subjected to blast loads. Further studies [5-13] have been conducted on beams and plates of different geometries (circular, quadrangular, $\mathrm{V}$ shaped plates) with and without stiffeners, different boundary conditions (clamped or built-in), welded seems [14] and perforations [15]. Other works include the blast loading of composite sandwich panels [16], aluminium foam cores [17] and concrete panels [18].

Numerous attempts with varying degrees of success have been made to model impulsively loaded plate structures using finite element models. In most cases commercially available software packages have been used to model the large inelastic deformation or complete failure (tearing) of the structure with insights gained into the blast wave-structure interaction and transient response of the structure. Finite element codes used to investigate these characteristics include the work of Langseth et al [19,20], Otubushin [21] and Marsolek and Reimerdes [22] who used LS-DYNA. Abah et al [23] and Markiewicz [24] used PAM-CRASH. Miyazaki et al [25] used the Finite Element package, MARC K6.2. Nannucci et al [26] and Karagiozova et al [27,28] used ABAQUS. In most of the studies, an explicit integration scheme was used. 4-noded shell elements with reduced integration, multiple integration points through the thickness of the element and hourglass control were used. Simulations using the detonation capabilities of AUTODYN have been conducted to numerically impart an 
impulsive load using the Jones-Wilkins-Lee equation of state $[11,15,29,30,31]$. Software "Addon's" such as CONWEP have been used to blast load structures under various loading conditions, implementing TNT equivalency ratios, simulating blasts with many types of explosives [32-35].

Hitherto, these studies have been carried out under single blast loading conditions, with little knowledge on the effects of multiple blast loading on the material and deformation response of the test plates. It is therefore necessary for a repeated blast loading investigation.

The objectives of this dissertation were to:

1. Investigate the midpoint deflection and resulting Vickers hardness of circular plates subjected to repeated blast loads.

2. Compare numerical analyses to the experimental results.

3. Asses the different numerical results to model repeated blast loading.

4. Draw conclusions and make recommendations based on the findings.

In this thesis experiments and numerical simulations were carried out to investigate the response of circular steel plates to repeated uniform blast loads. The blast loads were produced from the detonation of PE4 plastic explosive at a constant stand-off distance on a horizontal ballistic pendulum. Test plates were manufactured from Domex 700 steel with a circular area of $106 \mathrm{~mm}$ in diameter and thicknesses of either $2 \mathrm{~mm}$ or $3 \mathrm{~mm}$. The test plates were repeatedly blast loaded up to 5 blast loads or until failure (tearing).

Numerical analyses of the experiments were carried out using ANSYS AUTODYN and ABAQUS. Three different techniques were implemented:

1. AUTODYN: Blast loaded with a built in detonation model for PE4

2. ABAQUS: rectangular pressure pulse loading, to represent a uniformly distributed blast load

3. ABAQUS: to blast load the test plate using the built in CONWEP interaction. 
The numerical results were compared to the experimental results with regards to the resultant impulse, midpoint deflections and deformed plate profiles. Qualitative numerical analyses were carried out into the effects of repeated blast loading on strain hardening and residual stress states.

The research of an extensive literature review, which summarises the important and relevant studies and experimental work by various researchers, is presented in Section 2 . The experimental procedure, experimental testing rig and test plate material properties are described in Section 3. The tabulated experimental results and plate deformation observations are reported in Section 4. Section 5 contains a detailed analysis of the experimental results. The formulation of the numerical models, including the material models, mesh refinement and discussion on the loading techniques are discussed in Section 6. The results of the numerical models are presented and compared to the experimental results, with a detailed discussion on the outcomes, are presented in Section 7. Conclusions are drawn and recommendations are made, based on the findings in Section 8 and 9, respectively. 


\section{Literature Review}

The structural response of thin plates subjected to impulsive loading, in both localised and uniform blast loading conditions, has been extensively researched over many years, as reported by $[3,9,14$, 36-41]. Many variations of experiments have also been conducted to investigate the behaviour of different materials and structures under various loading conditions, with regards to the permanent ductile deformation and ultimate failure of such materials and structures $[17,18,42,43]$. The experimentally recorded structural responses of the test specimens and blast loading dynamics have been numerically predicted and compared. Numerical work has also been carried out by various researchers $[44,45,46]$. A summary of the pertinent literature relating to circular steel plates subjected to impulsive blast loading is presented.

\subsection{Blast Loading}

\subsubsection{Explosives}

An explosive is a substance that produces a sudden release of its potential energy, when it undergoes a rapid physical transformation or change of state. An explosive is a purposefully manufactured material with a view to produce a practical effect by explosion, as stated by Davis [40].

There are two classifications for explosives:

\section{Low Explosives}

\section{High Explosives}

Low explosives are used primarily to propel projectiles [47]. High explosives, when detonated, create a high energy shock wave. High explosives burn at a faster rate and shorter period of time than low explosives.

There are two sub categories for high explosives:

1. Primary Explosives

2. Secondary Explosives 
Primary explosives are known as initiating explosives and are used to initiate high explosive charges as a detonating substance. Primary explosives are usually used in small quantities, due to their relatively high cost [48]. These explosives consist of materials that can be easily detonated by the addition of heat as an ignition source, in the form of impact, spark or flame. An example of this material is Lead Azide [47]. Secondary explosives have a high energy output compared to primary explosives, producing high intensity blast waves [47]. The secondary explosives are stable under storage conditions and only explode when required in use, by a detonation device. Examples of these explosives are TNT and RDX. PE4 is a British Military explosive and consists primarily of RDX, which has a large energy output of $5130 \mathrm{~kJ} / \mathrm{Kg}$ [47]. PE4 is classified as a high explosive and requires a detonator to initiate the explosive reaction. PE4 can be moulded into any specific shape, is very stable, has a high melting point, and has low sensitivity towards impact and friction [49], making PE4 very practical for military and experimental use. Table 2.1 lists the properties of PE4.

Table 2.1: Properties of PE4

\begin{tabular}{|c|l|}
\hline $\begin{array}{c}\text { Velocity of } \\
\text { Detonation [50] }\end{array}$ & $7500 \mathrm{~m} / \mathrm{s}$ \\
\hline Density [51] & $1.6 \mathrm{~g} / \mathrm{cm}^{3}$ \\
\hline & $88 \%$ RDX \\
Composition [52] & $11 \%$ Wax Plasticizer \\
& $1 \%$ Pentaerythritol diolate \\
\hline
\end{tabular}

An explosion is defined as a phenomenon resulting in a rapid release of energy, generating high temperature and volumetric expansion of gases [37]. This release of energy is dissipated in the form of blast waves [38]. A massive pressure difference of finite amplitude occurs before and after the rapidly travelling blast wave [39]. 


\subsubsection{Detonation}

A detonation is a self-propagating reaction that produces a shock wave, which results in an increase in temperature, pressure and density of an explosive reaction zone. This reaction energy changes the state of an explosive so that an exothermic reaction is established and initiates a shock wave that travels at a requisite velocity, as stated by Smith and Hetherington [47].

The detonation of an explosion is carried out by applying heat energy to an explosive charge. The rate at which heat energy is supplied must be greater than the rate of heat dissipated. This heat dissipation leads to an exothermic chemical chain reaction within the explosive material. In an ideal explosion the entire explosive charge ignites. The heat can be supplied in various ways and is known as the activation energy required for ignition. Figure 2.1, as illustrated by Smith and Hetherington [47], depicts the nature of the post blast reaction energy and also indicates the required activation energy for ignition. The energy during the explosive reaction decreases exponentially from a maximum peak to a minimum once the explosive charge has fully reacted and the detonation is complete, as observed in Figure 2.1.

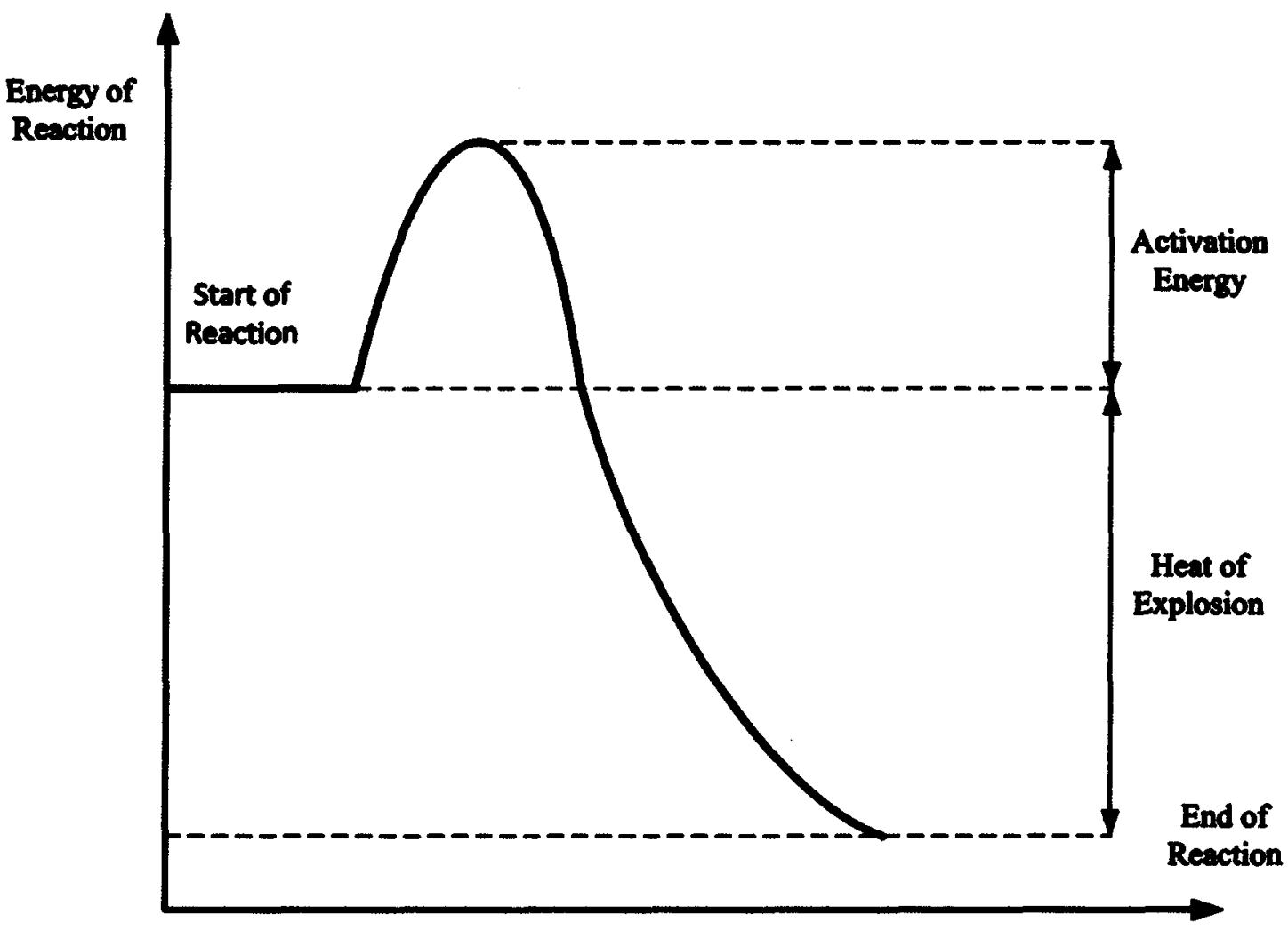

Extent of Reaction

Figure 2.1: Energy levels of an explosive reaction indicating the activation energy [47] 
In steady state detonation, the propagation wave velocity is faster than the speed of sound in the unreacted material that has not yet been detonated. The wave velocity is dependent on the density and geometry of the explosive material, where the velocity will be proportional to the density of the material and slower for smaller explosive charges. A critical charge size exists where the detonation wave fails to propagate, below a specific minimum charge diameter [53].

The chemical reaction that occurs during an explosion can be described as the finite small area preceding the wave front and is known as the reaction zone. In this reaction zone, energy is liberated from the reaction, by compressing the charge material as the wave travels through it [47]. This compression causes the localised heating of the material, initiating a chemical reaction for detonation and hence, continually regenerates itself. This regeneration reinforces the shock front. Regeneration occurs at the front of the reaction zone. The pressure profile changes to account for the energy liberation at every point in the reaction zone to maintain a steady flow [47]. At the rear of the reaction zone however, most of the chemical energy has already been liberated. Consequently flow is unsteady in this region [47].

Ideal detonation is a plane detonation wave, where the explosive reaction is completed in the Chapman-Jouguet (CJ) plane. The CJ plane, depicted in Figure 2.2, is the boundary between the steady and unsteady flow regions. The front of the detonation wave that is travelling at a detonation velocity (D) initiates the explosive reaction. This initiation is caused by a pressure spike at the detonation front, known as the Von Neumann spike [54] and is illustrated in Figure 2.2.

As the detonation wave moves through a reactive material, the mass, energy and momentum of the moving particles in the shock front are conserved. These conservations can be quantified by the Rankine - Hugoniot jump equation (Appendix E) for detonation waves and ultimately describes the detonation process. 


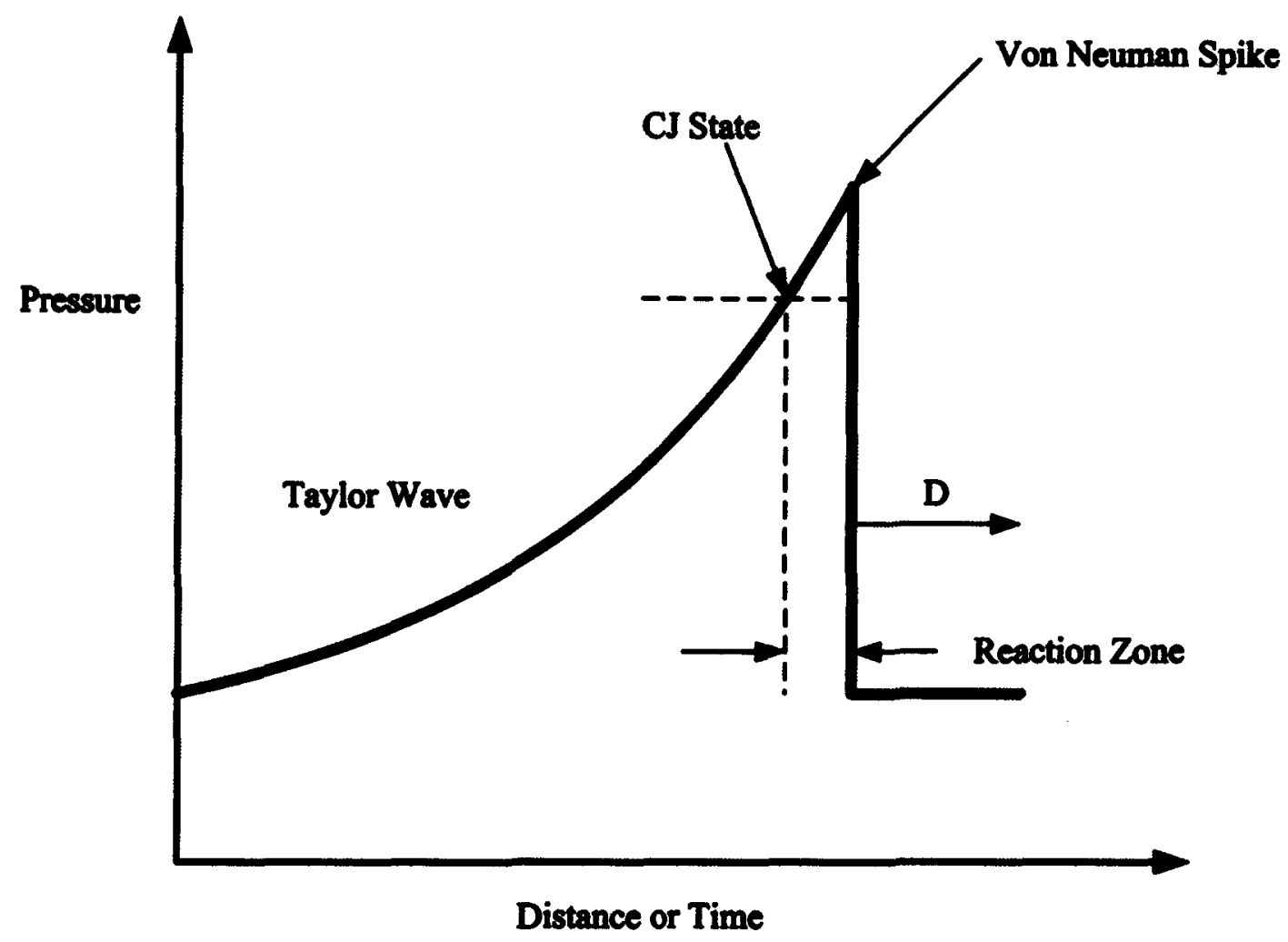

Figure 2.2: Pressure profile of a detonation wave [54]

\subsubsection{Blast Waves}

If all the detonation criteria are met, a blast wave will mitigate from the detonation point as a result of the rapid release of energy that increases the temperature, which in turn increases the pressure, causing localised areas of high pressures. Consequently, a layer of gas particles in the explosive medium naturally move down the pressure gradient, compress the adjacent air particles and ultimately displace the air from its original volume [47]. This layer of compressed air forms in front of the high energy gases, moving at high speeds and is referred to as a blast wave [47]. As the gas particles move down the pressure gradient and away from the explosive initiation point, cooling occurs, causing the gas and air pressures to drop below atmospheric. This pressure drop is a result of the momentum of the mass of the gas particles causing a pressure variation between the gas pressure and atmospheric pressure, resulting in particle flow reversal, which leads to blast 'under pressure' [47]. 


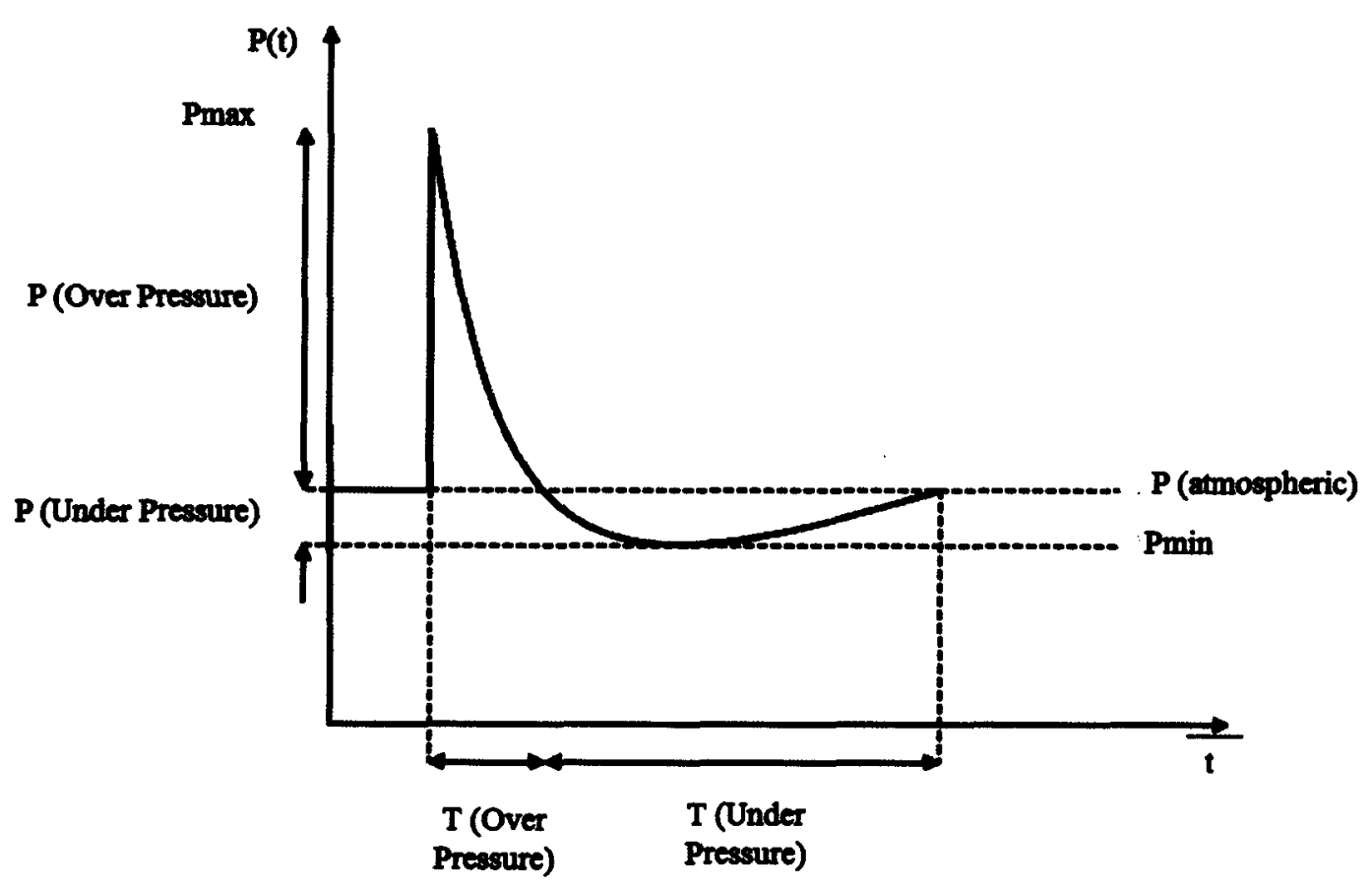

Figure 2.3: Illustrative graph of pressure vs. time of a blast wave [47]

A typical blast wave pressure history is displayed graphically in Figure 2.3, showing the areas of 'over pressure' and 'under pressure'. Specific impulse of the 'over pressure' can be calculated by integrating the area of the positive segment of the pressure profile. Under pressure is relatively small compared to the over pressure and is often assumed to have negligible influence [55]. The blast over pressure-time history can be described by exponential decay functions, such as the Friedlander equation (Equation 2.1) [39].

$P(t)=P_{S}\left(1-\frac{t}{T}\right) e^{-\left(\frac{a t}{T}\right)}$

where, $a$ - waveform parameter, $P_{s}$ - peak over pressure, $T$-blast duration, $t$ - time.

In contrast, a shock wave is a high pressure disturbance travelling in front of a blast wave through a detonated material [54]. This high pressure disturbance is not smooth and uniform, but is discontinuous throughout its volume.

The pressure disturbance caused by the shock wave stresses the material far beyond its elastic limit and undergoes permanent deformation [56]. The shock wave loses energy and pressure as it advances over a travelled distance or period of time.

From a shock wave, there are two relevant (to this thesis) structural loading conditions, namely localised loading (load at central area) and uniform loading (load over entire exposed area). Localised 
loading of plates has been experimentally carried out by various researchers $[16,51,57]$. The target plates were uniformly loaded in this report, therefore the majority of the content is catered towards uniform loading conditions.

\subsubsection{Uniform Impulsive Blast Loading}

When a structure is exposed to a blast wave generated by the detonation of an explosive charge, the resultant blast wave imposes an impulsive dynamic load on the structure, causing it to deform, fail and move, as in rigid body motion, providing the structure is movable. A blast load is considered impulsive due to the nature of the interaction of the blast wave and the target structure, where the energy of the load that causes the structure to deform is transferred to the structure in an extremely short period of time. The entire effective load from the blast is transferred to the target before it responds, due to mass inertia. The deformation response of the test plate is therefore transient implying that the shape of the incident pressure pulse (spatial) is less influential, as long as the resultant incident pressure and corresponding time integral correlate to the impulse imparted by the blast (temporal distribution). The spatial distribution of the incident pressure wave has an effect on the deformation of the target structure, where typically more deformation occurs where the concentration of incident pressure is highest. Shen and Jones [58] characterised impulsive loading as a pressure pulse having a finite impulse with an infinitely large magnitude and infinitesimally short duration. A uniform impulsive load is such that the blast load pressure is evenly distributed over the entire blast area, with regards to location and time.

Uniformly loading a target plate can be achieved in three different methods:

- Detonating an explosive charge mass at a great stand-off distance $(S \geq D / 2)$ [51].

- Loading the target plates with the use of a shock tube [59].

- Using concentric annuli of explosive charge in close proximity to the target plate [36] 


\section{Stand-uff Distance}

According to Mareliand and Alfwathiri [60], if the stand-off distance of the charge is greater than half of the larget structures width or height. then the blast load eas be reasonably averaged aver the exposed surface of the structure, provided the charge is centred on the structure. In the case of circular litget plates, if the stand-off distanec (S) is greater than the plate diatmeder (D). then it is assumed the plate is uniformly ioaded ( $>D / 2$ ). Ihis is conversely rrue for localised hiast loading. Jacob et ai [51] made similar observations of the plate response, investigating the effect of stand-of distitsee on the deformation of mild stecl plates. An illustration of the charge stand-off distance with regards to the loading condition is illuslratled in Figure 2.4.

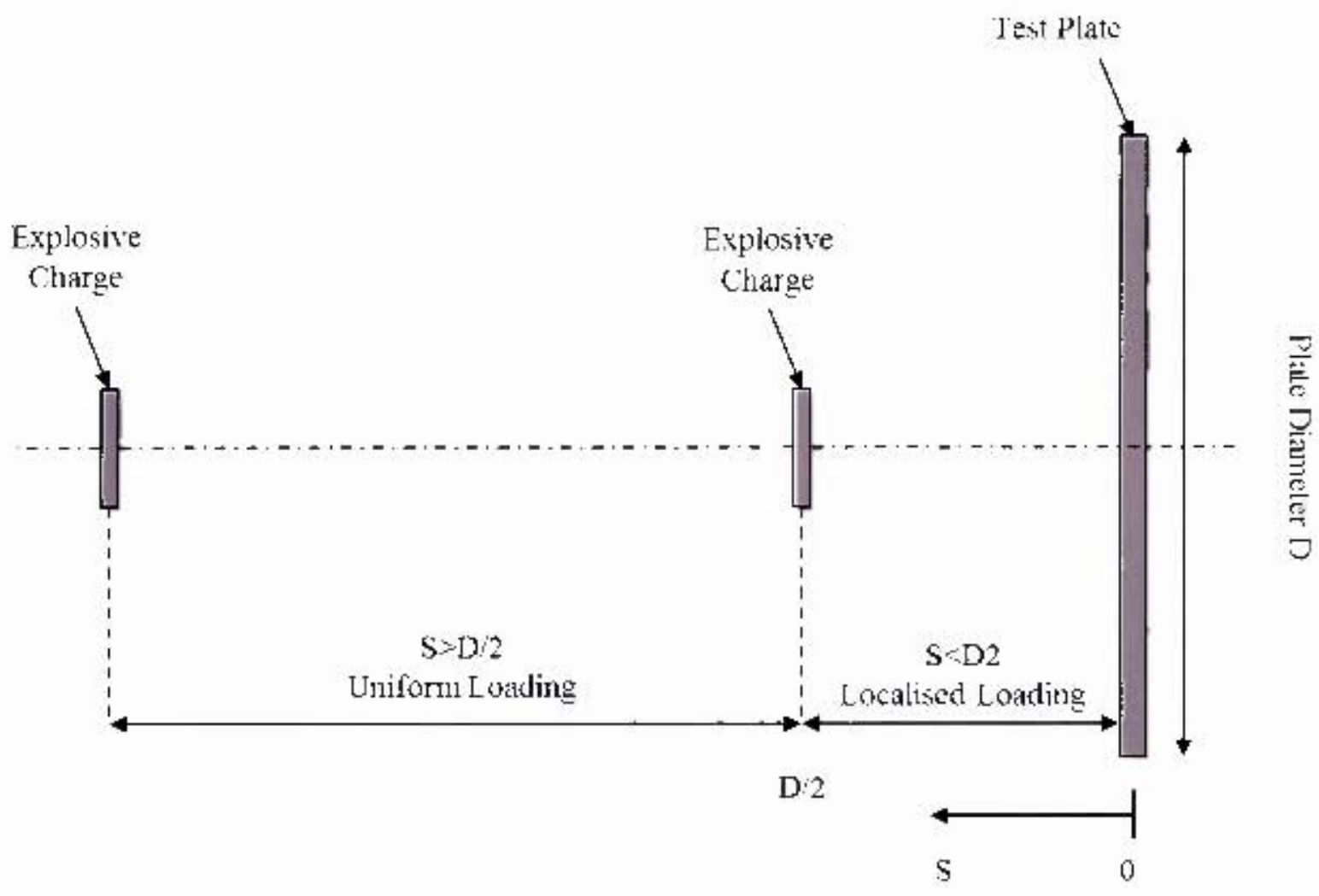

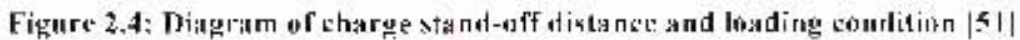




\section{Shock Tubes}

A shock tube uses a similar principle to blast loading at far stand-ofi distances, as the length of the fube (stand-off distance) is greater than the diameter of the exposed test plate area, uitimately resulting in uniform loaditng of the test specimen.

A shock tube is a device that is used to replicale and direct a blast wave at at desired structure. It typically consists of a metallic tube made up of two compartments, a high pressure and a low pressure compartment, separated by a diaphragm. Once the gas in the high pressure compartment is increased to a predeterninited high pressure, the diaphragm is ruptured, ereating a propagating pressure wave that travels down the low pressure compartment toward the test specimen, placed at the shock lube exit. Shock tube expetiments can bo carricd out is at salk and experimentally ideal environment. This allowy for accurate measurement of the simulated blast wave, as it is possille to direct the blast wave at various sensots, measuring devices and observing the structural response of target plates [59]. The showk tube is illustrated in Figure 2.5 .

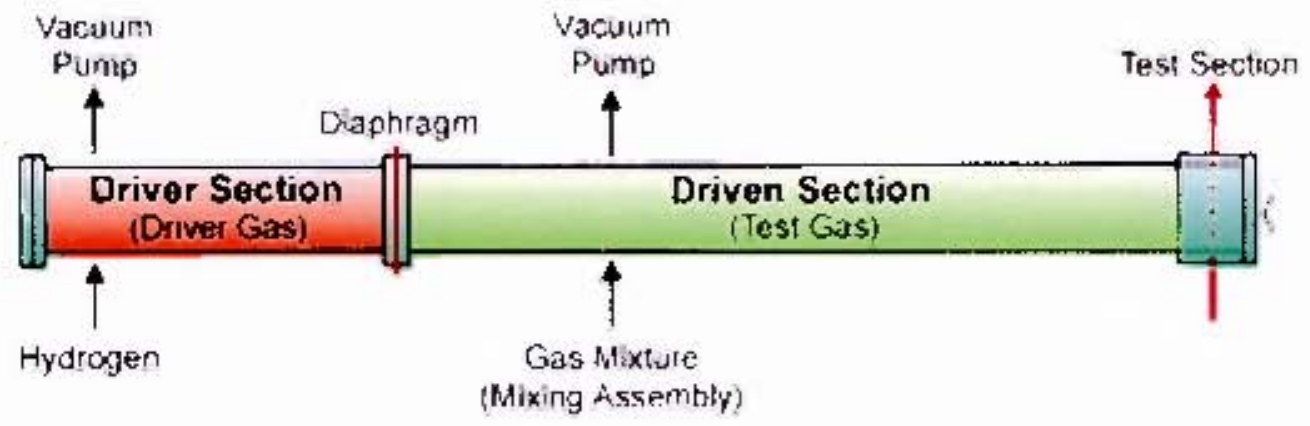

Fijgure 2.5: Diagram of simplified shock tube $|61|$ 


\section{Concentric Annuli of Plastic Explosive}

The plastic explosive is arranged in concentric anuli corresponding to the shape of the blast area. The antuli are contected by interstitial leaders of explosive. The annuli are arranged such that there is a presumed uniform distribution of explosive over the blast area, with the distance between each expiosive anmulus dependant on the area ratio of the exposed surlace. This metherd was used by Nurick ot al $[3,5,36,62]$. The explosive amu[i relative to the circular blast area are depicted in Figure 2.6 .

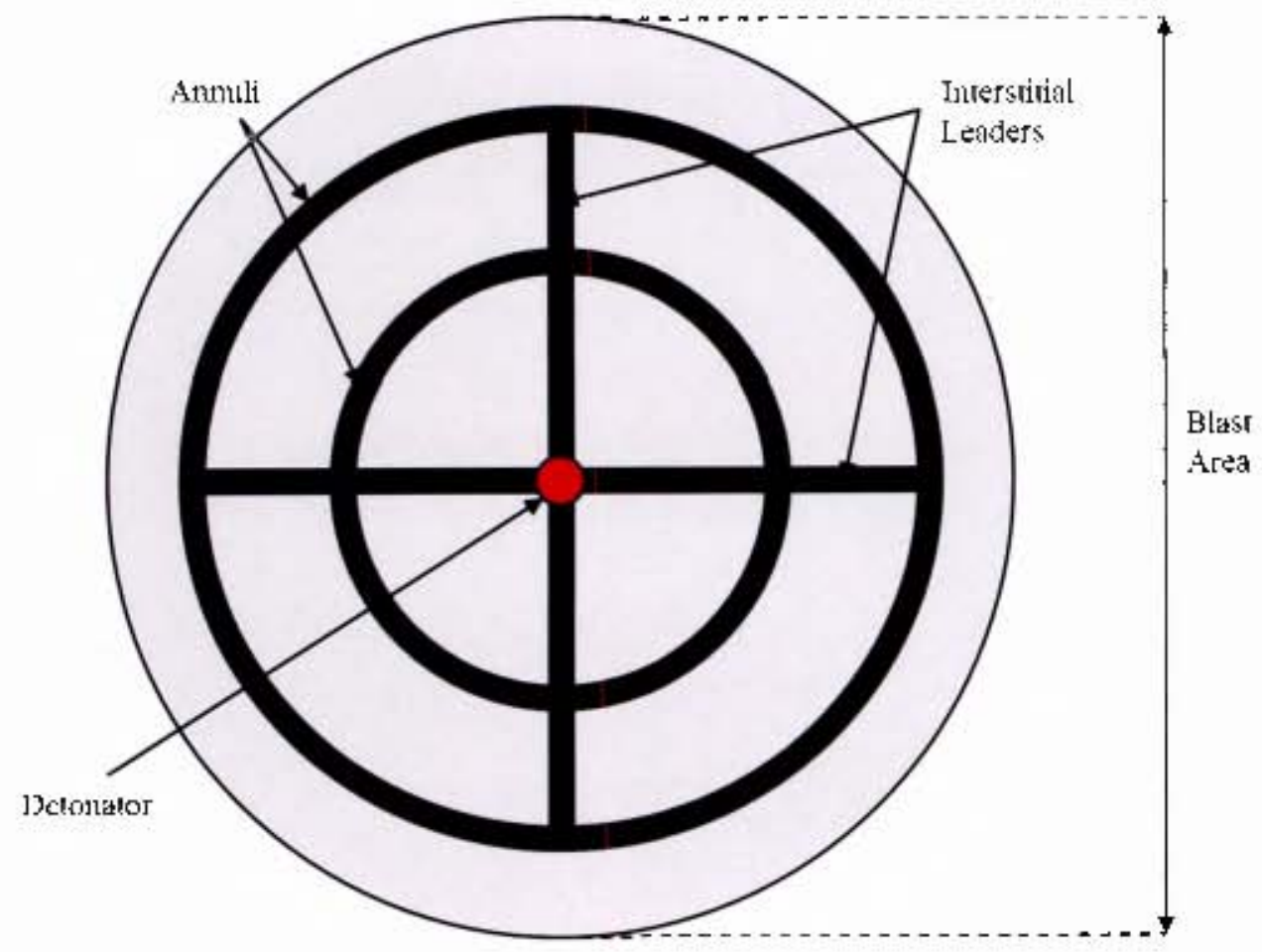

Figure 2.6: Explosive arrangement for unifusm loading of circular plate 


\subsubsection{Reflected Pressure}

Reflected pressure is the occurrence of the resultanl pressure wave from a blats as it encounters a medium or surface with a density greater than air and reflects off. Within at symmetrical tuhe, as used in lis project, the shock wave produced by a cylindrical charge, located on the ecritre of the tube's longitudinal axis, ideally travels down the luhe with regligible pressure reflection ofl the tube walls. Dus to the nalure of the detonation in a confined space, initially there will he substantial pressure reflections off the tuhe walls, before the shock wase is fully engaged in travelling down the length of the tube. 'lhe pressure reflection off the 1.uhe walls is known as transwerse pressure reflection, ats investigated by Bowfnan [6i] slown in Figure 2.7, where the mitigating shock wave is illustrated moving down the lengtly of the tuhe accompanied by the transverse shoek waves reflected of the tuhe walls from the initial detonation. Less nolithle instances of trinswerse pressure setlections can oceur due to irregularities present on the tube wall [63]. Bowman $[63]$ reported occurrences of eddy currents hehind the shoek front. at the explosive tube wals, as a fesult of friction. The eddy currents are considered negligible to the outcome of the resultatl shock wave when due tube walls atre snooth, with minimal physical impedanees. However, incorreet or partial detonation and non-symmetrical charge placement in a tube may cause tilted slock watves [64]. A tilted shock wate is determined by measuring the axially symmetrical wave arrital limes, which may not be the same. This is jllustrated in Figure 2.8. Various experiments have been conducted to gauge the eflects of non-symmetrical shock waves inside a luhe, by varying the placement of the pressure sensors 1591 . Typical pressure sensors include piezo electric, fibre optic and blast pressure gauges (referred in Chapter 2.2.1). For the blast experimen1.5 carricd out in a cylindrical tube, it is accoptable to assume the shock wave symnetricaliy inpacts the lest specimen.

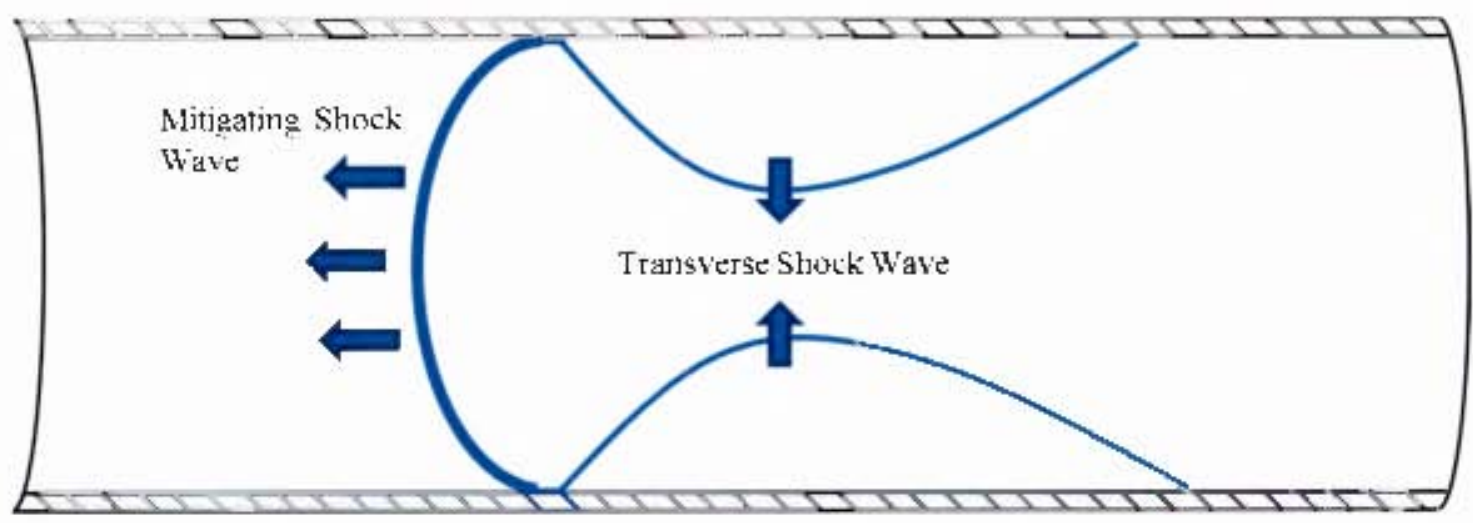

Figure 2.7: Transwerse pressure rellection waves in a tube [63] 


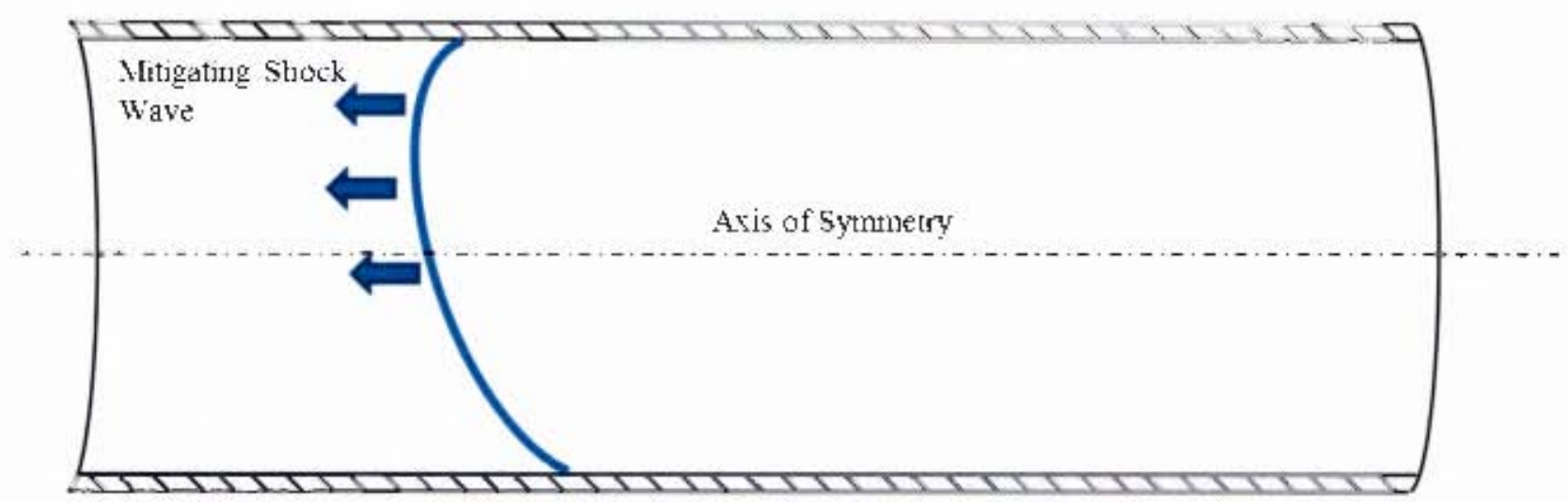

Figure 2.x: Tilted slooch wave in a tulue [6.3]

The most televant blast loadimg pressure reliection, in a tube, is the large pressure tellection off the test plate at the end of the tube, which acts perpendicularly to the fongitudinal axis of the tube. This creates at least two large pressure peaks that can be measured by pressure serusers strategically placed on the lest plate. The inilial pressure peak is the primary incident pressure wave travelling towards and impacting the test plate. The other pressure peak is the secondary reflected pressure waye, travelling away from the test platc. The shock wave travelling down the tube ideally impacts the test plate with zero angle of incidenee [59|. The angle of incidence is the angle at which a wave of aty sort interacts with a structure, before it is reflected $|65|$. As the slowe wave impacts the test plate, the leading air molecules come tor rest. The following ais molecules behind the leading molecules are still travelling at high speed and further compress the leading air molecules. [his induces an even greater reflected overpressure than the incident coverpessure. This is true for reliections oecurring on a perfectly rigid body of intinite area. In the case of a test plate deforming under blast foading, portions of the shock wave energy are absorthed and fissipated by the detorming test plate. A diagram of the incident pressure wave, reflecled off at rigid body is illustrated jn tigure 2.9 .

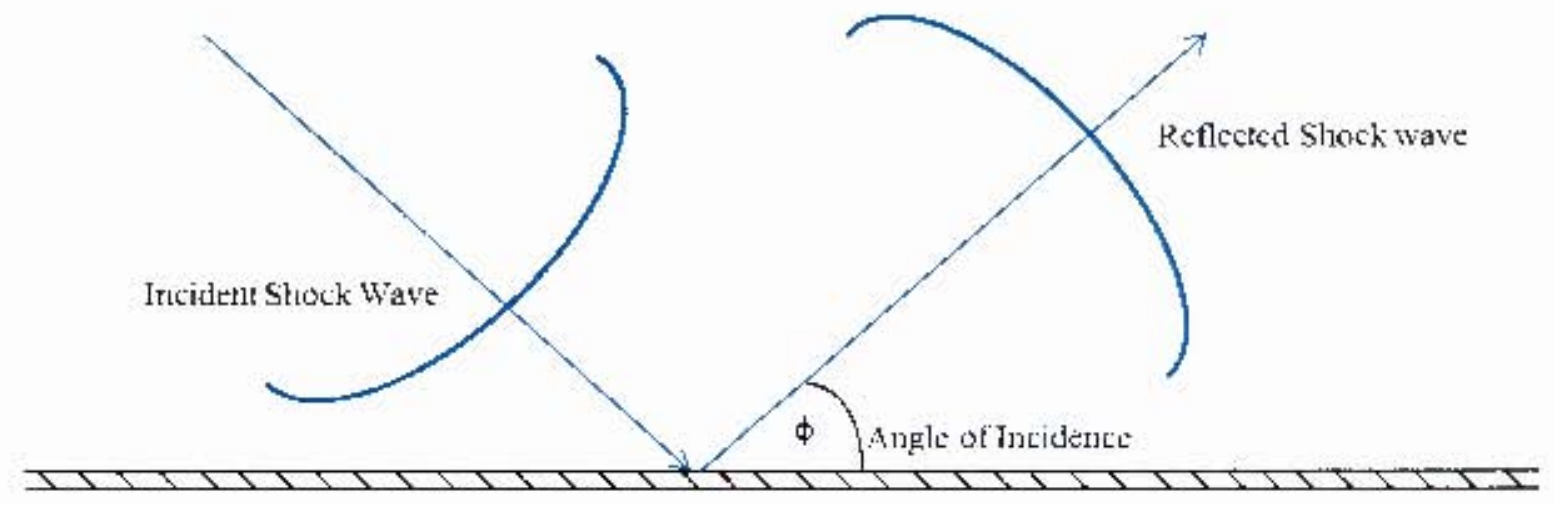

Figure 2,9: Diagram of Ineident and refleced joressure waves displaying angle of inciderce Blast wave Copograplyy inside a Blast Tube 
One method of uniformly loading a test specimen is carricd out by detonating an explosive at a great Standi-ofl distance at one end of a rigid steel tube to contine and diree the mirigating blast wave toward the test specimen $|5| \mathrm{j}$. It is assumed that resultant blast wave impacts the specimen with a unifonn pressure distribution over the entire test area, as illustrated in Figure 2.10.

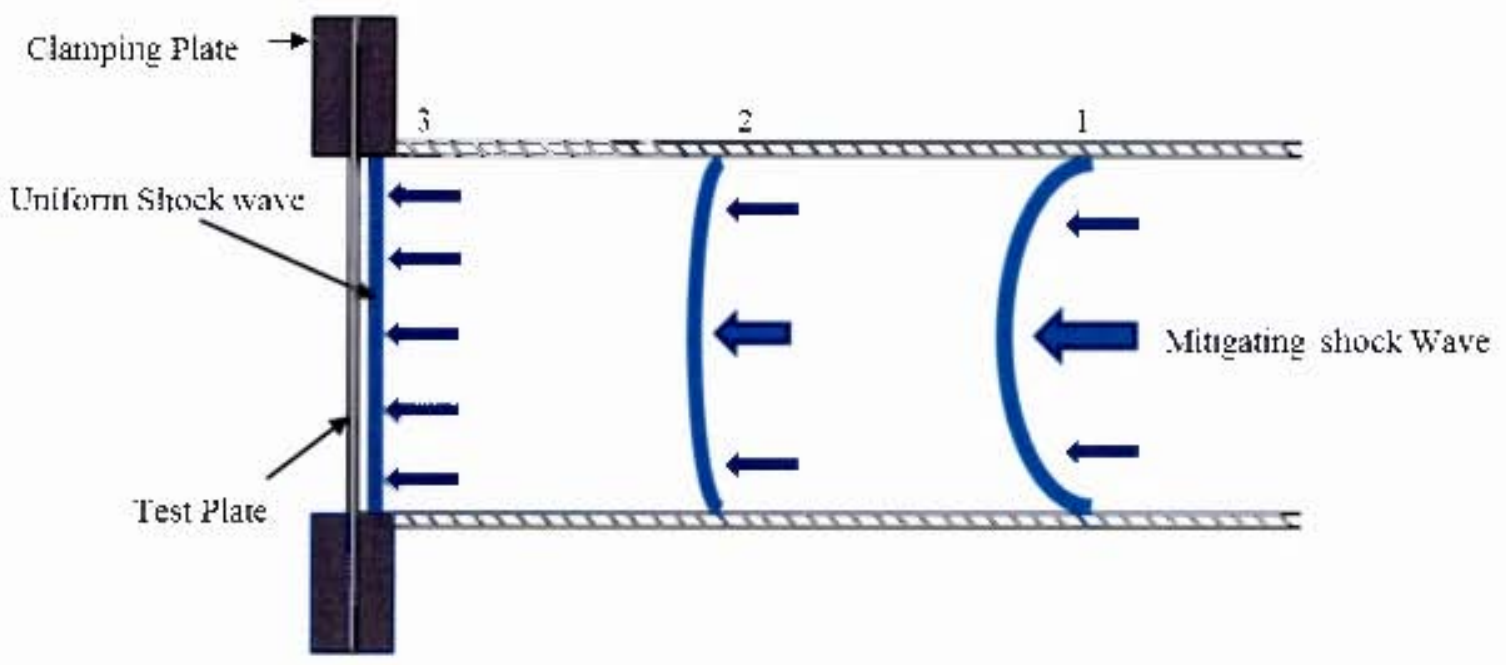

Figure 2.10: Illusaration of anifurm blast load in a tube

In reakity there are pressure loses from the tube walls and various geometric impedanees, which results in a curved blast wave [63]. I he section of the blast wave closest to the tube wall will travel down the tube with less velocity than the section of blast wave travelling down the centre of the tube. This causes a curved blast wave pofile. The final blast wave shape that impacts the test specimen will theretione not be perfectly unifotm from the centre of the blast area to the outer radius. This blast wave 'curve' cat be measured by placing pressure tratisducers located at the centre and the outer radius [63]. The time delay of the blast wave impacting the pressure sensors between the centre of the blast area and the outer radius, will allow for the quantif cation of the effects of the pressure time delays on impulsive loading of the tesc plates. 


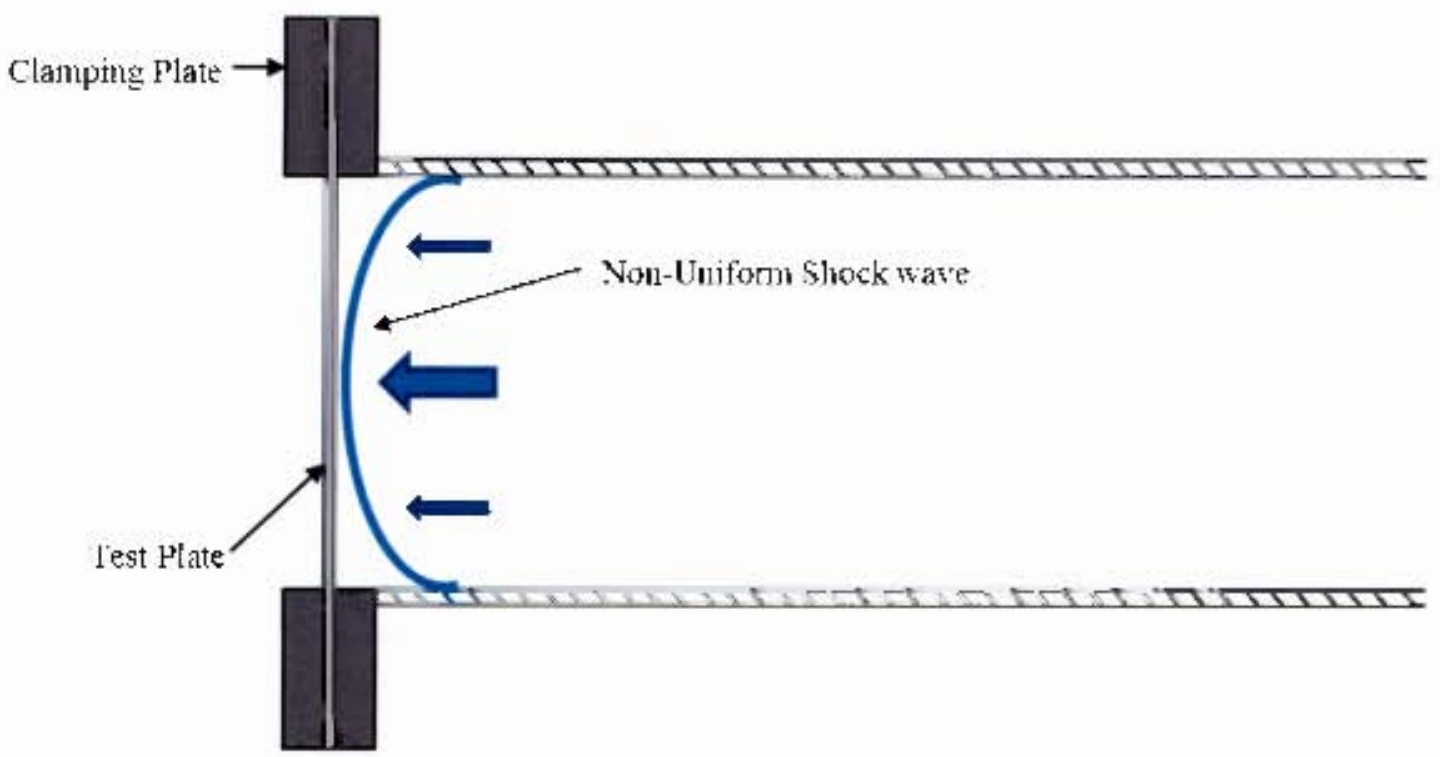

Figure 2.11: Cross section yiew of blast waye turye in a tube [63]

Bousmatr [63] catricd out an experimental jnqestigation into the shape of shock fronts trave]ling down a lube, with the use of a shock tuhe, studying various parameters that affect the blast wave and the resaltanl blast wave fellections. These parancers included the transwese reflections inside at blast tube as a result of irregularities in the tube and retlections caused by the boundary layers within the tube. The shock shape measurements were al] carried out by recording arrival times of the shock front at various locations on the end plate of the shock rube.

The results of these experiments comlimed that the boundary watls of the blase tube affect the shape of the blast wave travejling down the tube 63 . This is confirmed by the varying arrival times of the blast wave from the central axis to the outer boundary. Typical profite of the shoch wave in Bowman's report for the boundary condition regime, reported by Bowman [6.3].is illusirated in Figure 2.12. The "shock thickness" as referred in Figure 2.12 , is the estimated thickness of the shock watse that has a significant effect on the target structure. The $X$-axis $\left(X_{\text {sll }} / R\right)$ refers to the distance tratvellid down the tube and the $Y$-axis $(r K)$ refers to the radius from the centre of the tube. 


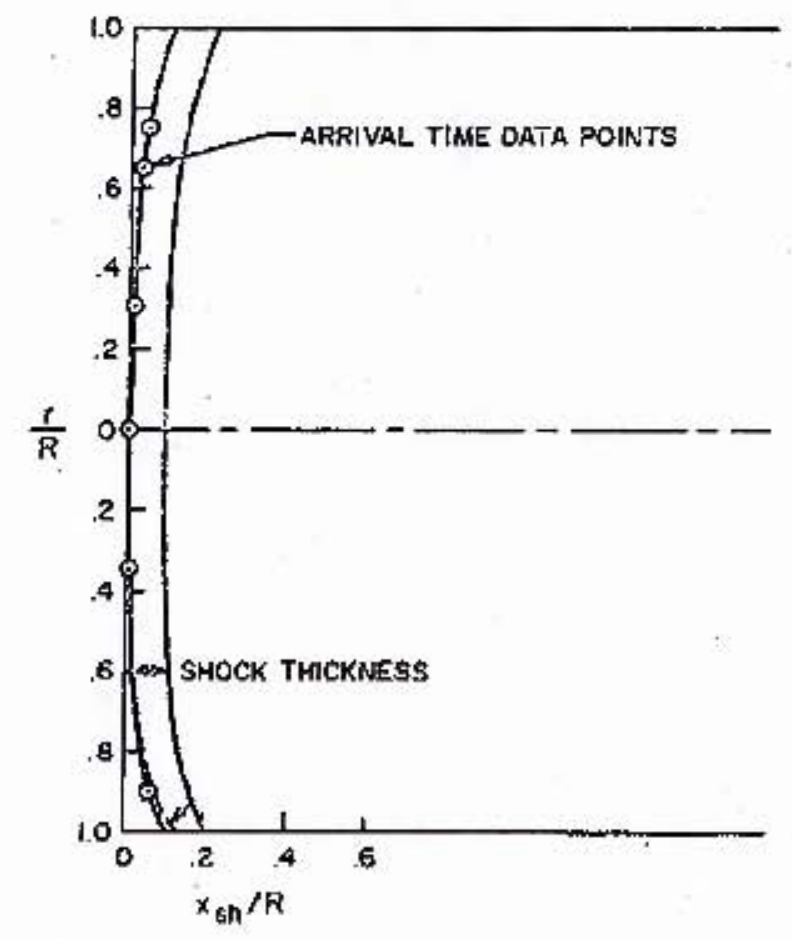

Figure 2.12: True Scaic experimental shock shape [63] 


\subsection{Blast Wave Pressure Measurement}

Pressure transducers are used to measure changes jn pressure Jevels in a specific medium. There are many types of transducers to measure different pressures in different environments. Pressure transducers have been used to measure the rapid, extensive pressure changes that oecur during am explesive blast [66]. Measmeng the pressure at various locations on the boundarics of a blast experiment provides an greater understanding of the blast wave behaviour. This information can leat to a beter understanding of the explosive pressure-time histories.

\subsubsection{Pressure Transducers}

\section{Piezoelectric Pressure Transdacer}

A priezoelectric pressure transducer is a device that is used to meitsure dynamic pressure. These pressure 1cansduers have been designed to measure explosive air blasts and other high pressure measurements in an extreme shock enviromment, where utera-fast. micro second response is required [66]. Piczoelectric pressure transducers are constructed from various components. These components are illustrated in Figure 2.13. The transducers contain an acceleration compensated quartz element consisting of four quartz crystals, two for accelcration compensation and wo for the active production of tharge when subjected to the measurable pressure. Also it has a machined diaphragm, capable of picking up pressures even below 1000 psi [66]. The pressure transduecr used in this report is typically used for small scale blast experiments in laboratory conditions, and is known as PCB series $119 \mathrm{~B}$ quarts pressite transducers [66].

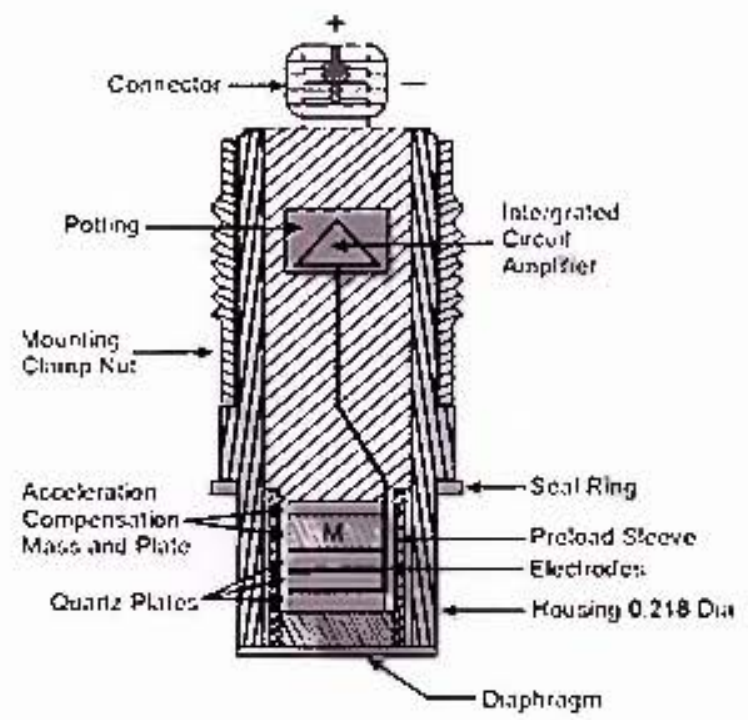

Figure 2.13: Schematic of piezoelectric pressure transducer $|67|$ 


\section{Fibre Optic l'ressure Transducers}

Oplical fibres are used to measure strain, temperature and pressure by modifying a fitos to measure the desired output by controlling wave length, phase, incensity or the change in light focused on the fibre, Optical libre sensors are exurcmely useful in measuring parameters in small areas where precise locating is necessary. Chavko et al $[68]$ used a fibre optic pressure transducer to measure the pressure changes inside a rat brain exposed to a blast wase. $\wedge$ diagran of a fibre oplic sensor is illustrated in Figure 2.14 .

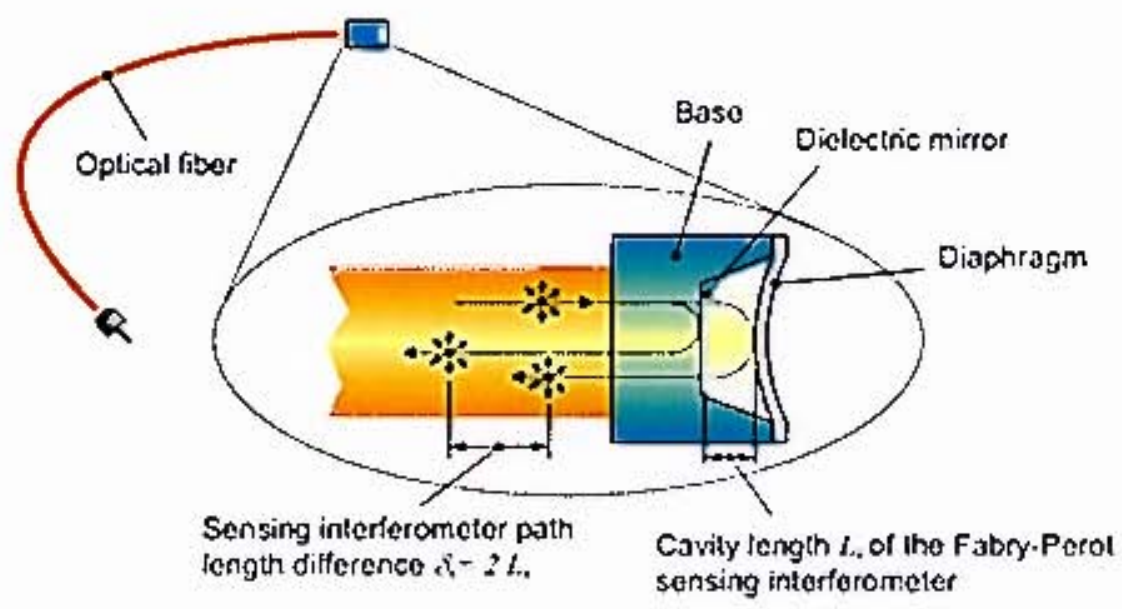

Figure 2.14: Fibre optic phutenlinde displaying diaphragm |69| 


\section{Blast Pressure Gauge}

Blast pressure gauges are used to measure pressure and resultant acceleration of a mitigating blast wave. This is achieved by use of a cylinder and piston. A cylindrical tube with an open and closed end contains a piston, positioned at the ofen end. An accelemeter is attached to the piston and a pressure semsor (unspecified) is plated at the clused cnd of the cylindrival tube to measure the presisure between the cylinder and the closed end of the cylinder [70]. This device is capable of measuring the pressure for an extended period of time, even after the injtial peak is recorded.

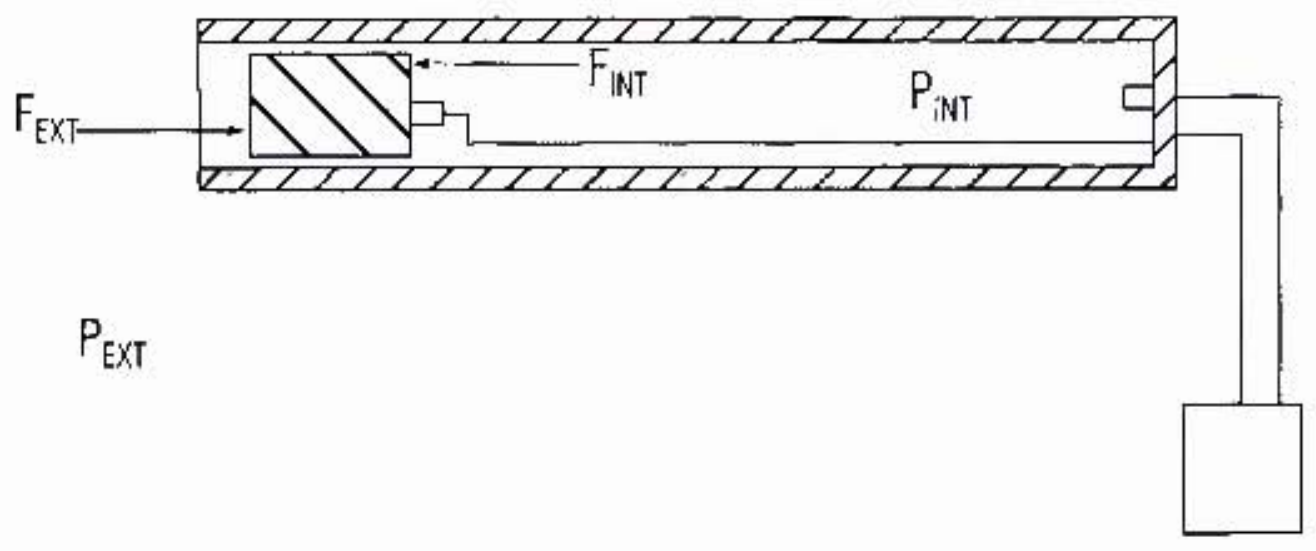

Figure 2.15: Simple schematic of blast pressure gauge $|70|$ 


\subsection{Structural Response}

The investigation into the structural response of steel plates, subjected to localised and uniform blast loading has been reported on by several researchers $[5,32,36,42,51]$. Various test specimen geometries have been experimented on, including beams, square plates and circular plates $[5,6,71]$, all with varied parameters, including complex stiffener geometries and welded regions [14, 36]. Various clamping boundaries, including fully clamped, partially clamped and built in boundaries have been defined and implemented [7]. These variations in the test specimen parameters has resulted in the implementation of defining the failure and deformation characteristics observed in each experiment. Due to the nature of the blast loading experiments carried out for this report, the research has been focused on the structural response of circular steel plates under uniform loading conditions.

\subsubsection{Modes of Failure}

Menkes and Opat [71] defined three distinct modes of failure for beams subjected to uniform impulsive blast loads, shown in Figure 2.16. Experiments were carried out, incrementally increasing impulsive loads to yield the three failure modes.

- Mode I: $\quad$ Large Inelastic deformation with no material rupture.

- Mode II: Tensile tearing of the material at its boundary supports.

- Mode III: Transverse shearing at the boundary supports. 

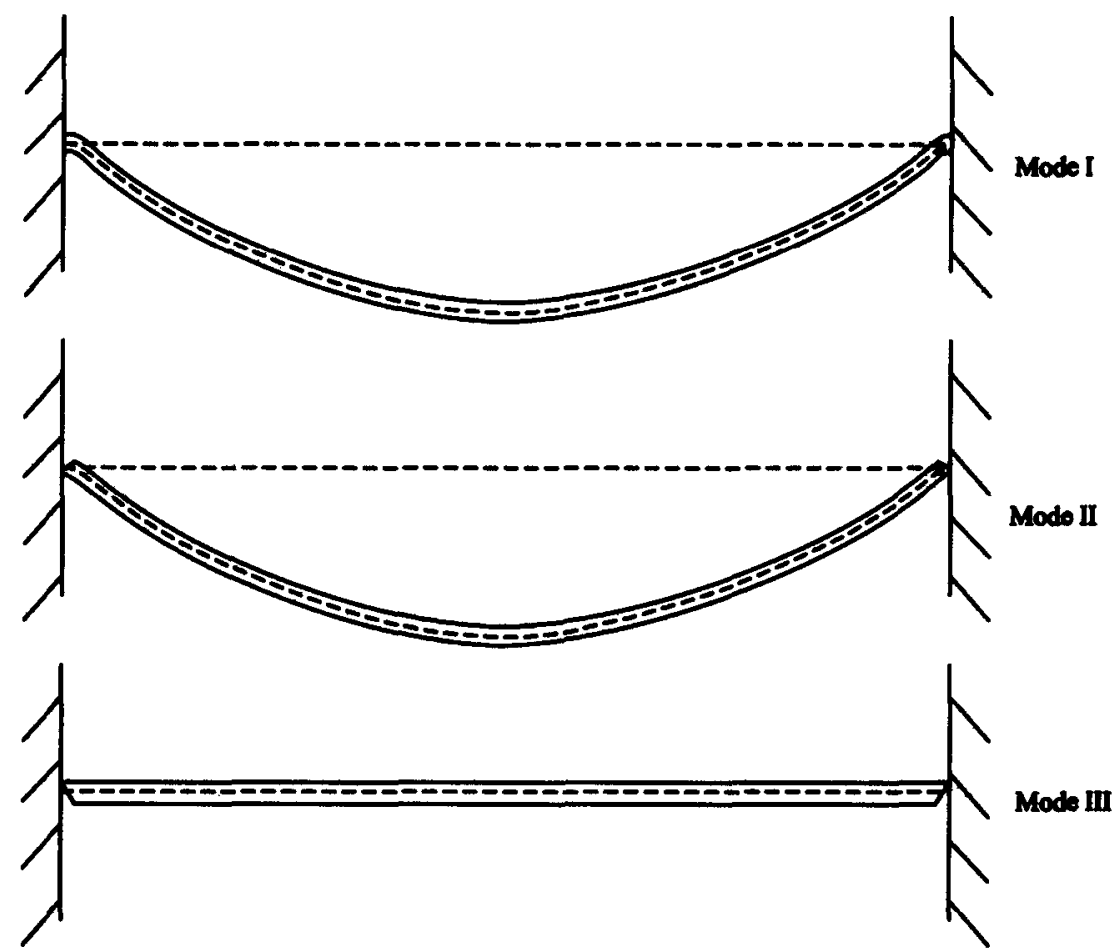

Figure 2.16: Failure associated with clamped metal beams loaded impulsively

These modes of failure were found to be applicable to the blast loading of plates with varying geometries, including circular and quadrangular shaped plates [12, 36]. Other modes of failure summarized in Table 2.2, were further defined by and Teeling-Smith and Nurick [5] and Nurick and Shave [62]. 
Table 2.2: List of modes of failure and their corresponding descriptions [51]

\begin{tabular}{|l|l|l|}
\hline $\begin{array}{l}\text { Mode of } \\
\text { Failure }\end{array}$ & Description of Failure & $\begin{array}{l}\text { Loading } \\
\text { Condition }\end{array}$ \\
\hline Mode I & Large Inelastic deformation & $\begin{array}{l}\text { Uniform \& } \\
\text { localised }\end{array}$ \\
\hline Mode Ia & $\begin{array}{l}\text { Large inelastic deformation with necking around part of the } \\
\text { boundary }\end{array}$ & Uniform \\
\hline Mode Ib & Large inelastic deformation with necking around the entire boundary & Uniform \\
\hline Mode Itc & Large inelastic deformation with thinning in the central area & Localised \\
\hline Mode II* & $\begin{array}{l}\text { Large inelastic deformation with partial tearing around part of the } \\
\text { boundary }\end{array}$ & Uniform \\
\hline Mode II*c & Partial tearing in the central area & Localised \\
\hline Mode II & Tensile tearing at the boundary & Uniform \\
\hline Mode IIa & $\begin{array}{l}\text { Tearing with increasing mid-point deflection, with increasing } \\
\text { impulse and with complete tearing at the boundary }\end{array}$ & Uniform \\
\hline Mode Ilb & $\begin{array}{l}\text { Tearing with decreasing midpoint deflection with increasing impulse } \\
\text { with complete tearing at the boundary }\end{array}$ & Uniform \\
\hline Mode IIc & Complete tearing in the central area capping & Localised \\
\hline Mode III & Transverse shear failure at the boundary & Uniform \\
\hline Petalling & $\begin{array}{l}\text { Tearing at centre with petals of material folded away from blast } \\
\text { location }\end{array}$ & \\
\hline
\end{tabular}

\subsubsection{Thin Circular Plates Subjected to Impulsive Blast Loading}

Experiments on thin circular mild steel plates subjected to impulsive loading were investigated by Nurick et al $[5,7,8,62]$. It was reported that plate deflection increased with an increase in impulse, resulting in thinning at the clamped boundary. Further increasing the impulse resulted in partial tearing along the boundary, and in some cases, complete tearing. The midpoint deflection starts to decrease as impulse is further increased beyond the point of complete tearing at the boundary, as the plate tends towards complete shearing (Mode III). Gharababaei et al [12] reported the midpoint deflection of circular plates is influenced by the pressure distribution of the incident wave and varies with variations in important loading parameters. Kazemahvazi et al [13] reported various failure modes of fully clamped circular copper plates subjected to various decaying underwater blast waves, with peak pressures ranging from $10 \mathrm{MPa}$ to $300 \mathrm{MPa}$. At low pressures, the plates underwent bending 
and stretching without rupture. At internediate pressures, pelalling failures 10 tearing at the clamped boundaries were observed with increasing blast pressures. At the highest pressures, the plates tore at the clamped boundaries. Neuberger et al [72] carried out at experimsttat and numerical investigation on the springback of circular clamped armour steel plates subjected to spherical air-blast foading. The transient deformation response of the test plates was studied and it was reported that the magnitude of the springback, from the maximum transient deflection to the final residual deflection. was dependant on the slatid-oll distance of the explosive source.

Jacob et al [51] carried out blast load experiments on circulas lest plates at yaricd sland-off distances. Various deformed plate protiles for the range of stand-off distances were reported. An inner dome imposed on top of a global dome is observed for closer slatid-off distafiess, rangitig from $13 \mathrm{~mm}$ to $40 \mathrm{~mm}$, indicative of localised blast loading. Thinning at the central area (Mode Itc) wats obseryed for Incalised Joading conditions. for stand-ofr dislance greater that) the plate radius ( $53 \mathrm{~mm}$ ) ranging from $100 \mathrm{~mm}$ to $300 \mathrm{~mm}$, the plate deformation is characterised by a larger global dome, concurrent with uniform leading. Thinning at the boundary (Mode lb) was observed and partial or complete tearing (Mode II and Wode [[*) was noted for test plates subjected to grealer inpu]ses. The transition of uniform loading to losalised loading as the stand-off distance decreases, is illustrated in Figure 2.17 1517

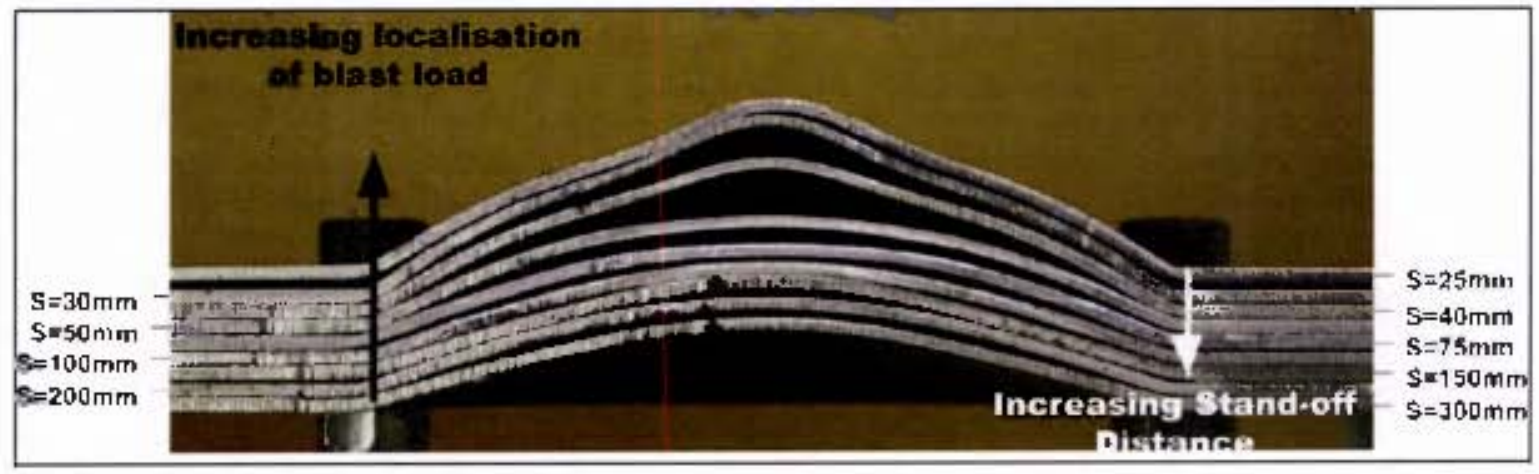

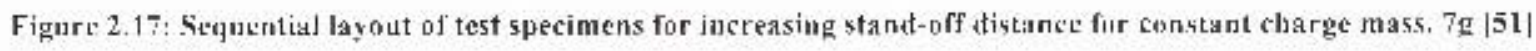




\subsubsection{Repeated Blast Loading}

Structures subjected to blast loading or blast related impacts, such as landmine vehicles and armoured personnel carriers are often exposed to multiple blasts. These vehicles need to be robust against repeated loading from landmines and improvised explosives in war stricken areas. Hitherto most studies reported on have been subjected to a single blast load. Bwalya [73] and Ranwaha [74] have carried out studies on localised and uniform repeated blast load experiments, respectively.

In the study by Bwalya [73] the charge diameter was varied between $25 \mathrm{~mm}$ and $33 \mathrm{~mm}$ and varied the charge mass. Mild steel test specimens, $1.6 \mathrm{~mm}$ and $3 \mathrm{~mm}$ thick, were used. An increase in midpoint deflection was noted for an increase in the number of blasts [73]. The general deformation trends correlate to findings observed by Ranwaha [74] on repeated uniform blast loading. Hardness tests carried out on the post loaded test plates showed an increase in hardness as the plate was subjected to more blasts [73]. For repeated localised loading, Vickers hardness was greatest at the central region of the test plate [73], whereas for repeated uniform loading, Vickers hardness was greatest at the clamped boundary [74]. Hardness test results for a $1.6 \mathrm{~mm}$ test plate subjected to 5 localised blast loads of charge diameter $25 \mathrm{~mm}$ and charge mass $1.7 \mathrm{~g}$ is shown inFigure 2.18 .

Ranwaha [74] reported that as the test specimens were subjected to more blast loads, the hardness increased until the specimen failed. Ranwaha [74] carried out preliminary repeated blast experiments on $3 \mathrm{~mm}$ thick Domex 700 steel test plates, under uniform loading conditions. This thesis is a continuation of work carried out by Ranwaha [74]. 
Handinese Ve. Plete Radlus

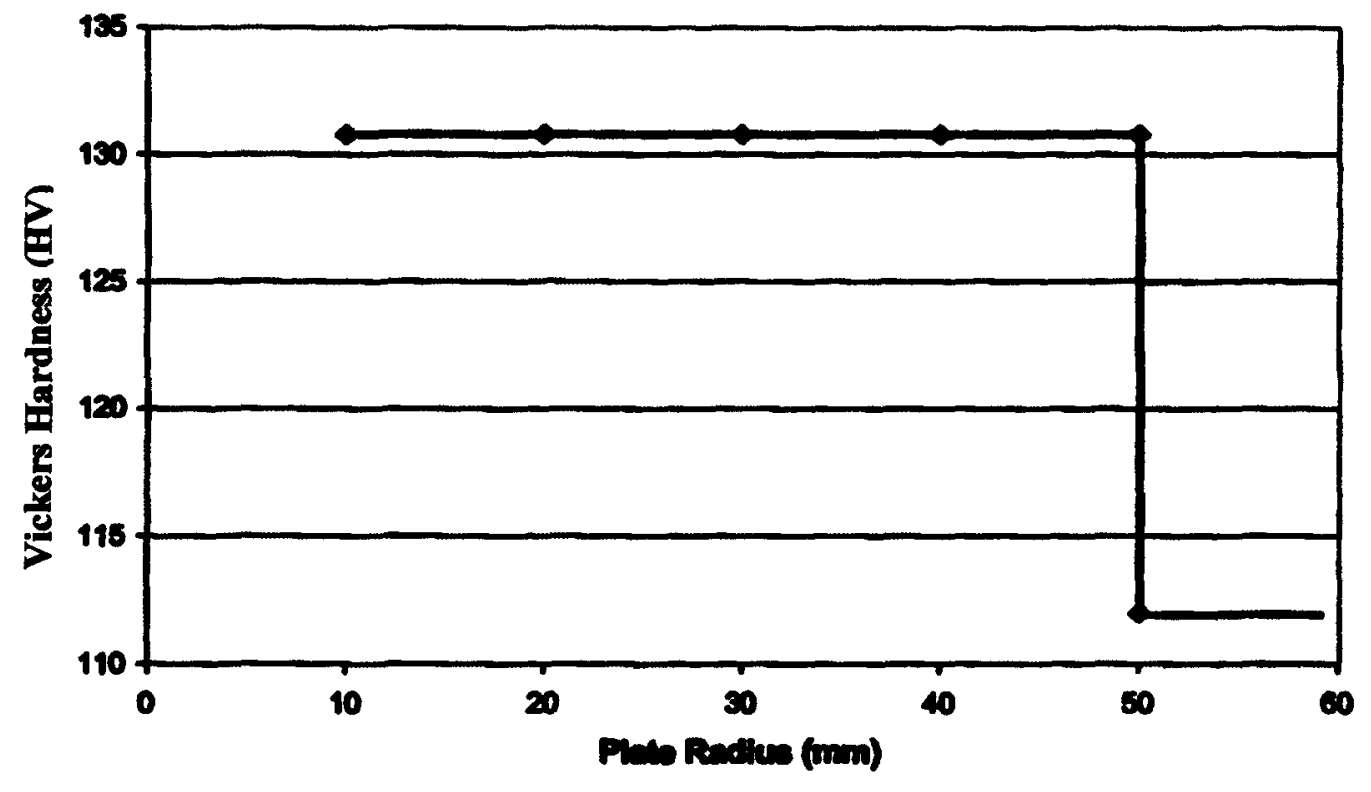

Figure 2.18: Hardness versus plate radius for a plate thickness $1.6 \mathrm{~mm}$ for charge diameter $25 \mathrm{~mm}$ and five blasts [73] 


\subsection{Theoretical Predictions}

Theoretical predictions for the analysis of metal plates, subjected to impulsive loading, have been developed for comparative applications on observing the behaviour of the metal. The predictions for impulsive blast experiments carried out on thin clamped plates include the final midpoint deflection, deformation shape of the plates and the response time. The correlations between the predictions and experiments have shown sufficiently good results for the predicted parameters.

\subsubsection{Jones Damage Number for fully clamped rigid circular Plates}

Jones [2] proposed a damage number $(\lambda)$ to predict large inelastic deformation (Mode I, Table 2.2) of fully clamped circular plates, loaded impulsively by a uniformly distributed velocity, $V_{0}$ [2]. This formed the basis of theoretical predictions, which were later modified by Nurick and Martin [3].

Jones' Damage number [2] can be given as:

$$
\lambda=\frac{\mu V_{0}^{2} R^{2}}{M_{0} H}
$$

where: $\quad \mu=\rho H \quad$ mass per unit area

$\begin{array}{ll}\mathrm{V}_{0} & \text { initial velocity } \\ R & \text { plate radius } \\ \mathrm{M}_{0}=\frac{\sigma_{0} H^{2}}{4} & \sigma_{0} \text { is the static yield stress }\end{array}$

$\mathbf{H}$

plate thickness

Equation 2.2 can be written in terms of impulse by simple substitution, where:

Substituting for equations $\mathrm{M}_{0}$ and $\mu, \lambda$ becomes 


$$
\lambda=\frac{\mu V_{0}^{2} R^{2}}{M_{0} H}=\frac{(\rho H) V_{0}^{2} R^{2}}{\left(\frac{\sigma_{0} H^{2}}{4}\right) H}=\frac{\rho V_{0}^{2} R^{2}}{\sigma_{0} H^{2}}
$$

Impulse is given as,

$I=m V_{0} \quad$ re-written as, $\quad V_{0}=\frac{I}{m}$

Where $m$ is the mass of the plate, which can be calculated from the volume and density $(\rho)$ of the steel plate and velocity is now given as,

$$
V_{0}=\frac{I}{\pi R^{2} H \rho}
$$

Substituting equation 2.5 into equation 2.3 , gives,

$\lambda=\frac{\rho\left(\frac{I}{\pi R^{2} H \rho}\right)^{2} R^{2}}{\sigma_{0} H^{2}}$

this can be simplified to,

$$
\lambda=\frac{4 I^{2}}{\pi^{2} R^{2} H^{4} \sigma_{0} \rho}
$$

The mid-point deflection $(\delta)$ of the plate can be predicted by [2],

$$
\frac{\delta}{H}=\frac{\sqrt{\left(1+\frac{2 \lambda}{3}\right)}-1}{2}
$$




\subsubsection{Nurick and Martin's Damage Number}

Nurick and Martin [3] developed a modified form of Johnson's damage number ( $\alpha$ ) for circular plates subjected to impulsive loading. Johnson's damage number is used in the comparison of the behaviour between metals under impulsive loading [3]. This number incorporated the material density ( $\rho$ ), impact velocity $(v)$ and damage stress $\left(\sigma_{d}\right)$ :

$$
\alpha=\frac{\rho v^{2}}{\sigma_{d}}
$$

Johnson's damage number did not consider the method of impact, the target dimensions and geometry or the boundary conditions. This led to the necessity for the modification of the damage number, by Nurick and Martin [3].

Johnson's damage number can be written in terms of impulse:

$$
l=m v
$$

where, $\mathrm{m}$ - mass of plate, I - impulse imparted on the plate.

$$
v=\frac{I}{m}=\frac{I}{A_{0} H \rho}
$$

where, $\mathrm{A}_{0}$ - load area, $\mathrm{H}$ - plate thickness

Therefore, substituting equation 2.10 into equation 2.8 , gives:

$$
\alpha=\frac{I^{2}}{A_{0}^{2} H^{2} \rho \sigma_{d}}=\frac{I_{0}^{2}}{H^{2} \rho \sigma_{d}}
$$

where $I_{0}$ is impulse per area $\left(I / A_{0}\right)$

Nurick and Martin introduced a damage number ( $\Psi)$, given by:

$$
\Psi=\frac{I}{A H \sqrt{\rho \sigma_{d}}}
$$

where $A$ is the plate area

A relationship was established between the distance from the plate centre to the nearest boundary and the thickness of the plate. This relationship is known as the aspect ratio $(\lambda)$ and for circular plates is given as [3],

$$
\lambda=\frac{R}{H}
$$


where, $\mathrm{R}$ - plate radius, $\mathrm{H}$ - Plate thickness

A loading parameter for the consideration of the loaded area with regard to the total plate area was introduced for circular plates and is given as the relationship:

$$
\zeta=1+\ln \left(\frac{R}{R_{0}}\right)
$$

where, $R_{0}$ is the radius of the loaded area.

This relationship controls the loading parameter for circular plates, as $R_{0}$ tends to $R$, so $\zeta$ tends to 1 . This indicates that the plate is uniformly loaded over the entire plate area.

Nurick and Martin [3] combined the equations 3, 4 and 5 to obtain a modified damage number that incorporates both the plate dimensions and the loading conditions.

$$
\phi=\Psi \lambda \zeta
$$

For a circular plate subjected to a uniform impulsive load $(\zeta=1)$,

$$
\phi_{c}=\frac{I}{\pi R H^{2} \sqrt{\rho \sigma_{0}}}
$$

Note: Static stress and not damage stress is used in this equation.

In addition, Nurick and Martin [3] proposed an empirical relationship between the mid-point deflection to thickness ratio, $\frac{\delta}{H}$ and the corresponding damage number, $\varphi_{c}$.

$$
\frac{\delta}{H}=0.425 \phi_{c}
$$

This empirical formula has been subsequently used for other experiments and showed good correlation [3]. 


\subsubsection{Stand-off Distance Parameter}

A modification to the Nurick and Martin [3] dimensionless impulse was introduced, to account for the effect of stand-off distance on plate response and therefore a stand-off distance parameter was introduced [51].

$$
\zeta_{s}=1+\ln \left(\frac{s}{R_{0}}\right)
$$

where, $S$ - stand-off distance, $\mathrm{R}_{\mathbf{0}}$ - charge radius

This parameter only needs to be considered and introduced, if the charge radius is less than the standoff distance $\left(R_{0}<S\right)[51]$.

The new parameter is incorporated into the dimensional analysis,

$$
\phi_{c}=\frac{I\left(1+\ln \frac{R}{R_{0}}\right)}{\pi R H^{2} \sqrt{\rho \sigma_{0}}} \frac{1}{\zeta_{s}}
$$

The equation can be re-written as,

$$
\phi_{c}=\frac{I \gamma}{\pi R H^{2} \sqrt{\rho \sigma_{0}}}
$$

where,

$$
\gamma=\frac{\left(1+\ln \frac{R}{R_{0}}\right)}{\left(1+\ln \frac{s}{R_{0}}\right)}
$$

A stand-off distance parameter for the Jones damage number was introduced by Jacob et al [51]. The parameter is based on the relationship between the Jones damage number and the Nurick and Martin dimensionless impulse parameter. The empirical prediction is given in Equation 2.23.

$$
\frac{\delta}{H}=0.213 \lambda_{s}^{0.5}
$$




\subsection{Numerical Modelling}

There are different commercially available software packages, used to simulate the structural response of a target subjected to blast loading. Various studies successfully implementing software packages to simulate blast related experiments and metallic deformation responses include Langseth et al $[19,20]$, Otubushin [21] and Marsolek and Reimerdes [22] who used LS-DYNA. Abah et al [23] and Markiewicz [24] used PAM-CRASH. Miyazaki et al [25] applied the Finite Element package, MARC K6.2. Nannucci et al [26] and Karagiozova et al [27, 28] modelled in ABAQUS. Larcher [75] carried out the numerical simulation of loading structures with free air blasts, using the software package EUROPLEXUS. Numerous authors have successfully carried out numerical studies on the response of thin circular plates subjected to blast loads $[13,44,72,76,77]$. The experiments in this thesis are simulated using both ABAQUS and AUTODYN; therefore the pertaining literature is kept relevant to the respective software packages.

AUTODYN is a hydrocode specialising in non-linear dynamic analysis and utilizes Lagrange, Arbitrary Lagrange Euler (ALE) and Euler mesh solvers [78]. In AUTODYN the Jones-Wilkins-Lee equations of state is used to model the explosion. LS-DYNA has similar capabilities to AUTODYN, with regard to running models with Eulerian and Lagrangian meshes interacting with one another. ABAQUS [79] a software package that accounts for non-linear geometry, strain rate sensitivity, adiabatic temperature effects and material effects, is efficient at modelling materials subjected to short duration impulsive loads. Numerical modelling techniques used to simulate blast wave behaviour and predict plastic deformations of structures, subjected to impulsive blast loads have been reported on by various researchers $[32,36,80]$. Xing Luo et al [81] successfully modelled air blasts in LS-DYNA, using the CONWEP algorithm to compare the resultant numerical pressure distribution to experimental results. 


\subsubsection{Numerical Blast Loading}

There are various numerical ways to apply impulsive blast loads to a structure, depending on the software package used.

\subsubsection{Multi-Material ALE, Lagrangian and Eulerian Modelling}

Software packages such as AUTODYN and LS-DYNA have built in detonation models (code) that are ideal for simulating blast loading. AUTODYN in particular has an extensive range of pre-coded explosive materials available in the material library (including PE4). AUTODYN is a hydrocode specialising in non-linear dynamic analysis and utilizes Lagrange, Arbitrary Lagrange Euler (ALE) and Euler mesh solvers, making it possible to simulate the interaction of fluids and solids in the same model.

The Lagrangian solver is predominantly used for modelling solid bodies. A Lagrangian mesh fixes nodes on a structure, dividing the structure up into block elements. These nodes are not constantly relative to one another, resulting in the distortion of elements as the structure deforms. The nodes follow the position of the material surface, giving feedback on the extent of the material distortion. For rapidly deforming materials such as fluids or gasses, large node density losses would occur resulting in undesired inaccuracies. [78]

Eulerian meshes implement a fixed structured mesh, where the nodes are fixed on a grid relative to one another. This grid allows the designated material to flow through each element and the state of change of each element is determined by the amount of material present in the corresponding element. This approach deters the large distortion problems associated with the Lagrangian mesh; Eulerian solvers are therefore suited to modelling hydrodynamic situations involving fluid materials.

The capabilities of AUTODYN make it possible for the simulated detonated blast to travel through the explosive material and air and successfully loaded onto the solid plate. Due to the typically large size and complexity of the combined meshes, the memory allocation can become enormous. Also, the lack of parallel processing capabilities (unlike ABAQUS) prohibits the use of extensively fine global meshes as the computational expense would be too great, noted by Pickering [10]. Efficient modelling of the experiment, such as using axisymmetric boundaries and pre-run detonation models can considerably decrease the computational expense, whilst still maintaining accuracy. 
fairlie and Bergeron [30] repost good numerical-experimental impu]se correlation, by modelling C4 with the Iones-Wilkins-1 ee equation of state, in AI!TODYN. Numerical models involving defonating an explosive charge inside a lully vented tube have been carried ouc by Ambrosini et al [29] and Langdon et al $[15 \mid$. Aubrosini et al $|29|$ used TVT equivalency tables to convert the equivalent mass of PE4, therefore detonating INT' as the explosive material. The INT charge was detonated at various stand-off distances including $25,50.75,100,200$ and $300 \mathrm{~mm}$ with the use of a cylindrical tube. A portion of the air mesh was assigned a T.Y. material fill, which uses the Jones-Wilkins-Lee equation of state to simulate the TVT detonation. The resultant propagating pressure wave is illustrated in Figure 2.19 .

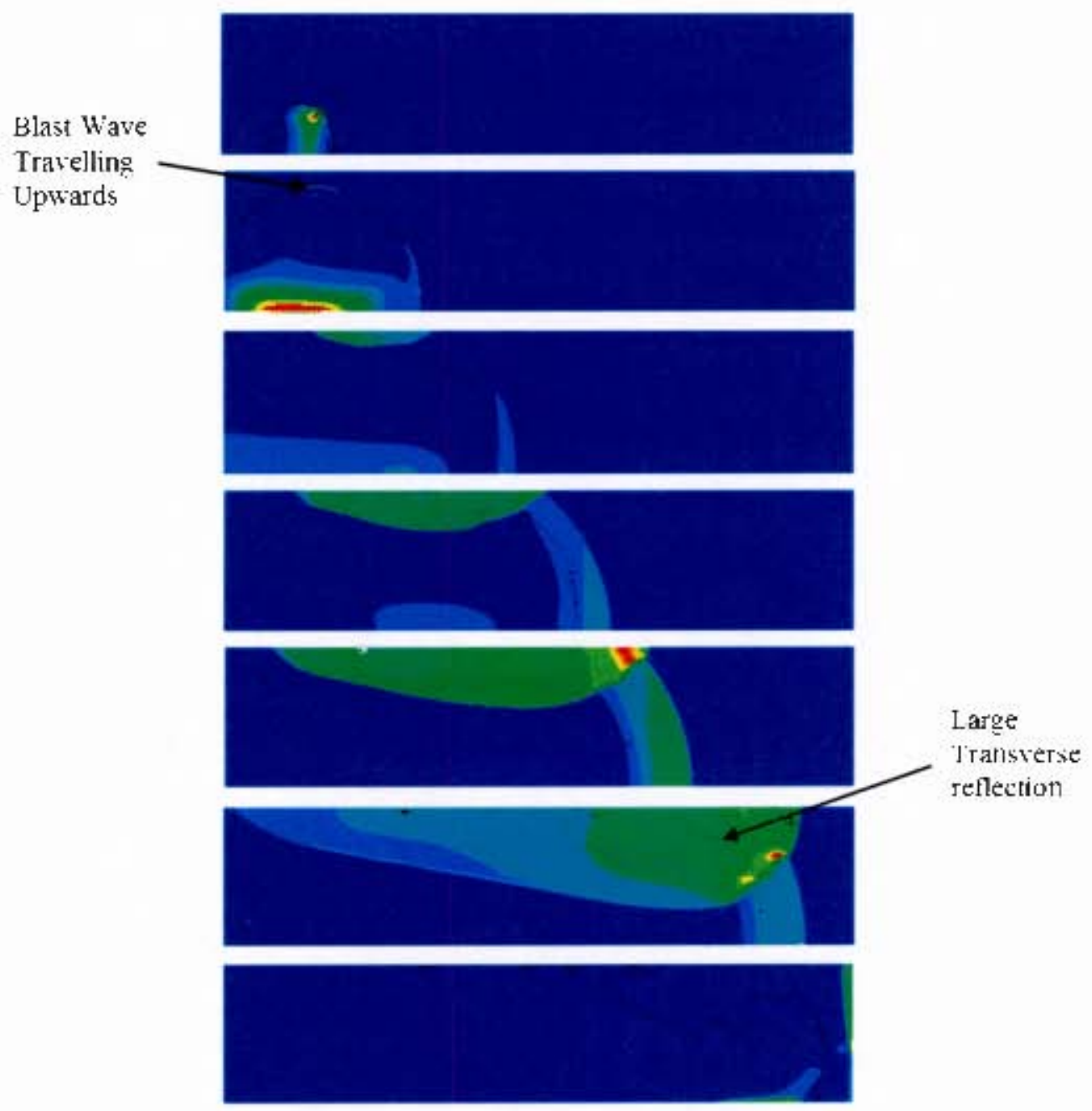

Figure 2.19: Waye propagation for $15 \mathrm{~g}$ equivalent of $\mathrm{C} 4$ and $200 \mathrm{~mm}$ of statul-0 ff distance $|29|$.

The TXT was detenated by a point detonation on the bottom left comer af the explosive mesh. Ambrosini et a reported [29] "It can be clearly observed how the reflection from the wall al the tube (an enhanced shosk) interacts with the original shock wave to produce a resultant shock front known 
as the "Mach tront"." Ambrosini et al $|29|$ obtained good correlation between the simulation and experimental results. The pressure-time history, for $4 \mathrm{~g}$ of PE4 and $75 \mathrm{~mm}$ stitnd-off distance are displayed in rigure 2.20. A massive secondary reflected pressure spike for gallge 1 that does not follow the rends of the oher gauge's pressure-lime listories was observed. Gatge 1 cortesponds to the centre of the blast areal. No explanation of the secondary pressure spike was given.

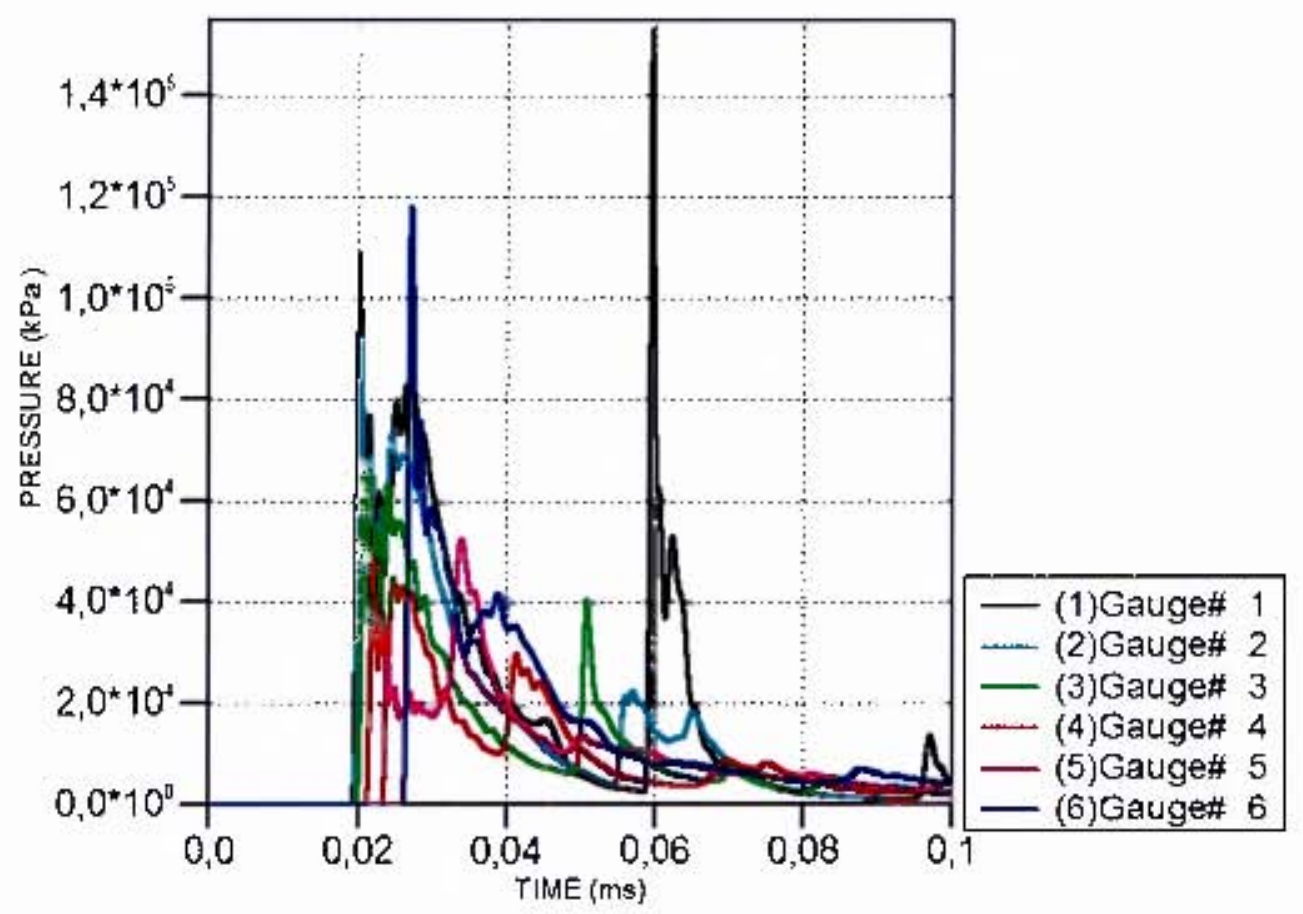

Figure 2.20: Pressure-time history of overpressures for 4 gof $\mathrm{PE} 4$ and $300 \mathrm{~mm}$ of stand-off distance $|29|$

I.angdon et al [15] carried out simulations comparing the numerical and experiment results, using AUTODYN. A similar approach to Ambrosini et al [29] was undertaken. In this case $\mathrm{C} 4$ wads used to model the Pr:4 used in the experiments, giving favourable results.

\subsubsection{Idealised Pressure Pulse Loaling}

The astual explosive prosure-time loading is a rather complex decaying pressure oscillation that requires simplifications when applyirg blast loads to structures for analysis. The impulsive losding assumption, allows for the simplification of the pressure-time load, so long as the impulse is represented accurately. A pproximating the true blast pulse (pressure-time load) 1o a rectangular pulse with cquivaletl impulse has rendered favourable results. especially under unifonm loadirng conditions. Fintow el at $[82]$ used both rectangular and triangular pressure pulse loading 10 predict midpoint deflections. delonrmation shapes. resjdual strains and dymamic yjeld stress of circular plates subjected 
to uniform blast loading, using ABAQUS finite element software. The rectangular pulse produced better results than the triangular pulse. The simplified blast loading pulses (rectangular and triangular) are displayed in Figure 2.21.

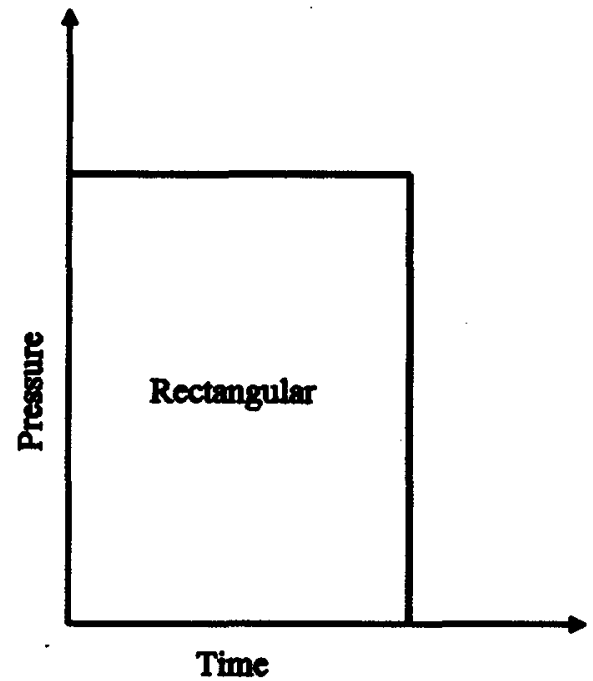

Time

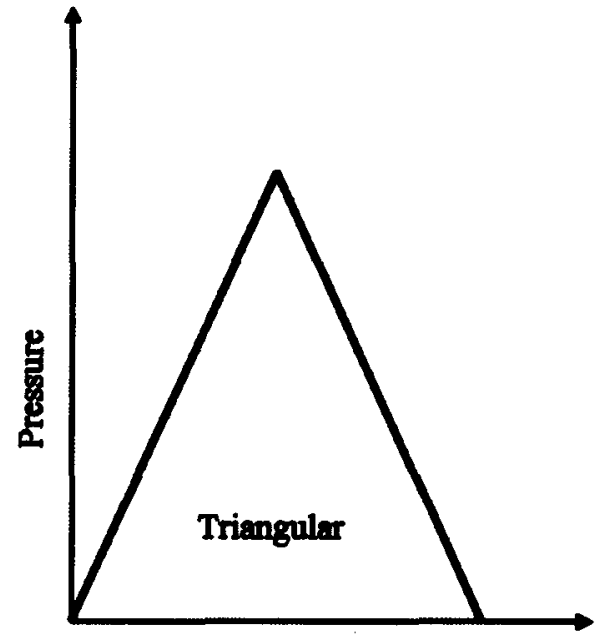

Time

Figure 2.21: Simplified pressure-time loading histories for rectangular and triangular pulses [82]

In a study by Nurick and Chung Kim Yuen [36] the uniform blast load was modelled as a rectangular pressure pulse with regards to pressure and time. The rectangular pulse was applied to the exposed blast area of the built in test plates over a specified time. The loading duration was determined by the burn time of the explosive and the length of the explosive annuli from the centre to the edge [36]. The pressure loading was assumed to be uniformly distributed over the blast area, pressure magnitude $P$, was determined by correspondence with the known experimental impulse and blast area. The results from the numerical model showed good correlation to the experimental results, using the uniform loading assumption. The pressure was determined with the Equation 2.23 [36]:

$P=\frac{l_{m}}{A t}$

Eq. 2.23

In ABAQUS, there is also the capability to simulate the detonation of an explosion using an equation of state. Grobbelaar and Nurick [83] carried out the numerical study of the response of thin circular steel plates subjected to localised impulsive blast loads. The explosive was modelled using the JonesWilkins-Lee (JWL) equation of state, where the JWL equation of state was implemented in the form of a programmed burn, using a lagrangian mesh. The numerical model predicted trends similar to the experiments, with regards to midpoint deflection and plate profiles. The time stepping required manual manipulation to avoid excessively distorting elements. 
Mougeotte et al [84] conducted a numerical analysis using the Coupled-Eulerian-Lagrangian (CEL) capability of ABAQUS/Explicit 6.12. The simulation involved surrounding a Lagrangian structure with an Eulerian body of air, importing a blast wave as a boundary condition. This method negated the need to approximate reflected pressures when simulating models with complex geometries. The corresponding pressure results showed good initial results, with further results yet to be concluded.

\subsection{Blast Simulations using additional calculation software}

Other methods of modelling the blast load include the use of empirically developed applications such as CONWEP (Conventional Weapons Effects Program) and TM5-1300 (available in LS-DYNA). CONWEP is made of a collection of conventional weapons effects calculations from empirical relationships and curves defined by the convention TM5-855-1 [85]. The program was developed by the United States Government for military purposes and has since been made publically available. CONWEP is used primarily to predict the magnitude of the peak pressure and impulse delivered to a target [33]. These empirical equations are widely used as engineering predictions for determining free-field pressures and loads on structures subject to spherical air bursts [34]. CONWEP assumes an exponential decay of the pressure with time as described by the Friedlander equation, Equation 2.24 .

$P(t)=P_{0}\left[1-\frac{t-T_{a}}{T_{0}}\right] \exp \left[\frac{-A\left(t-T_{a}\right)}{T_{0}}\right]$

Where $P(t)$ is the pressure at time, $t ; P_{-} 0$ is the peak incident pressure; $T_{-} 0$ is the positive phase duration; $A$ is the decay coefficient and $T_{-} a$ is the arrival time [34]. CONWEP can accommodate for a variety of explosives, by using TNT equivalency tables. TNT equivalency is a method used to quantify the energy released by a mass of a certain explosive, compared to the same mass of TNT, also known as the relative effectiveness factor (R.E.). The R.E. number for PE4 is 1.33 , i.e. $1 \mathrm{~kg}$ of PE4 is equivalent to $1.33 \mathrm{~kg}$ of TNT [56].

CONWEP is readily available in many finite element analysis software programmes including, AUTODYN, ABAQUS and LS-DYNA. Extensive research has been carried out with the use of CONWEP as a blast loading technique $[32,81]$.

Huntington-Thresher and Cullis [33] reported on TNT blast scaling for small charges, investigating the concern over the validity of empirical TNT blast equivalence data, such as CONWEP, for small charge masses, because of the significant oxygen deficiency of TNT. The results showed good agreement between the CONWEP and experimental results, for peak pressures and shock arrival times, with experimental pressures being slightly lower and arrival times slightly later [33]. Good 
agremsint was observed between the experimental and CONWEP impulse. Huntington-1 lor sher and Cullis [3.3 noted that CONWT.P data should be used with caution at smal] stand-off distances and a scaling factor is required to produce the correct resultant impulse.

Cabello [32] made use of CONWEP in conjunction wit] ABAQUSExplicit to investigate the dynamic stress analysis of the effect of an air blast wave on a stainless stcil plate. CONWEP is defincd as at incraction in $\triangle B A Q U S$, where an initiating time and source point is required. The CONWEP source with reference to the target plate for Cabello's report [32] is illustrated in Figure 2.22. Cabello 1321 reperted good conclation between experimental and numerical midpoint deflections for CONWEP loading. For lower charge masses Cabello [32] noted that the plate deformed elastically as opposed to plastically. The results were measured after 1.5 millistionds, where it was determined the plate had sufficiently stabilized after a few oscillations [32].

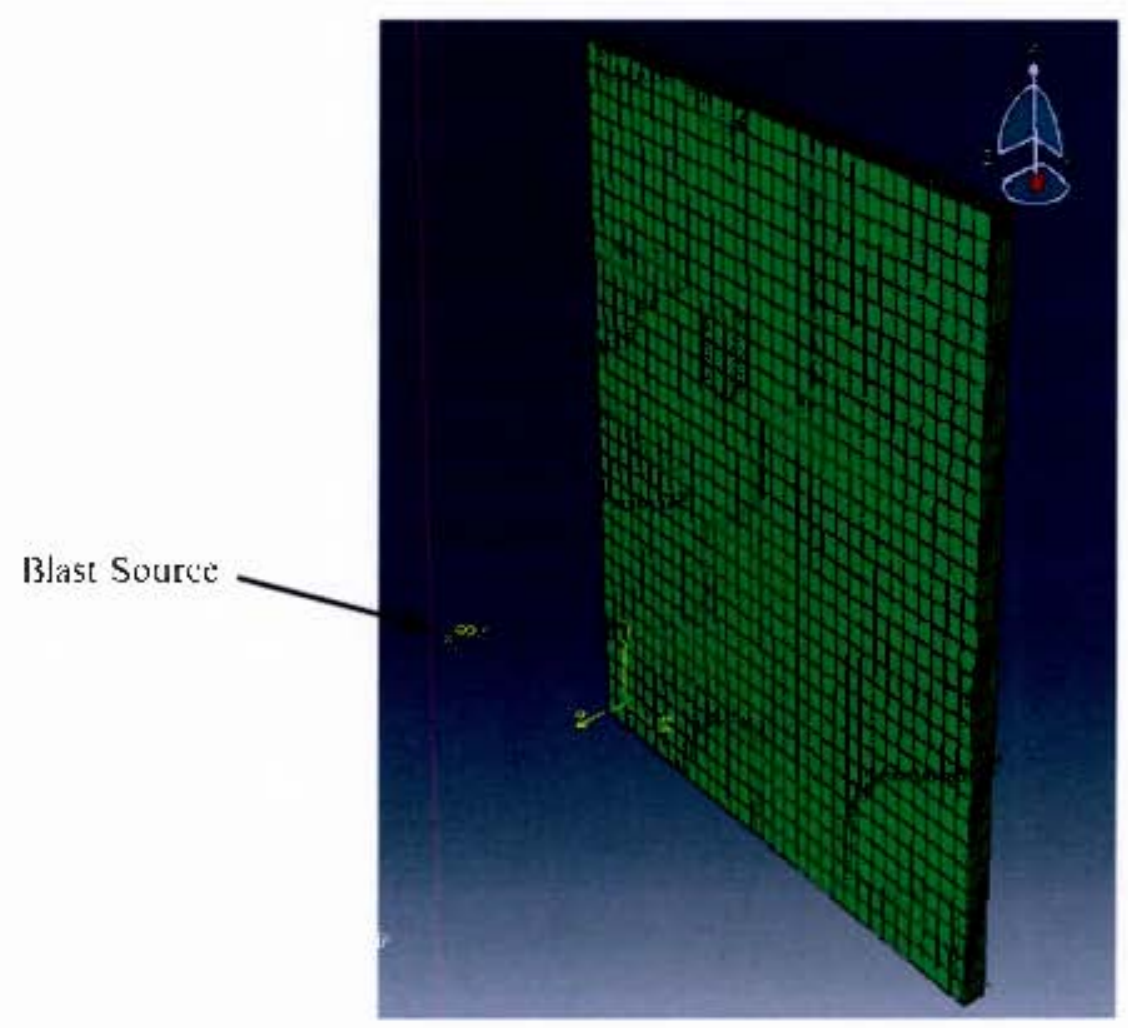

Figure 2.22: Stainles stetl 31) plate model, displaying CONWEP Ioading source |32|.

'Tabatabaei and Volz [35] reported on a tomparison butween three different blast methods in 1.SDyna. One of those comparisons involved the use of CONWEP in a purcly I agrangian approach to simulating an air blast pressure. The report concluded that the CONWEP data underestimared the peak pressure of the blast and overest imated the impulse at various stand-of $\int$ distances [35]. 


\subsubsection{Geometric Modelling and Test Plate Response}

There are many commercially available software packages such as AUTODYN, ABAQUS, LSDYNA, C-SAFE, FLACS, CartaBlanca and ATBlast, which have been used to predict the response of a structure subjected to blast loading. Numerous studies have shown that certain software packages are more successful in modelling certain loading conditions and take into account strain rate effects, temperature effects and fragmentation. The experiments relating to this thesis were modelled using AUTODYN and ABAQUS; therefore the relevant literature regarding the methods used for the geometrical modelling of thin steel plates subjected to uniform blast loads, within the respective software packages is included and focused on.

AUTODYN has been successfully used to predict the response of many different types of structures to air blast loading [86-89]. Luccioni et al [31] carried out AUTODYN simulations of experiments on concrete pavements subjected to blast loads produced by the detonation of high explosive charges above them. An AUTODYN 2D propagated detonation wave was imported into the AUTODYN 3D loading model, containing the 3D Lagrangian concrete plate and Eulerian air volume. Flow out air boundaries were specified at all borders of the simulation. The simulation approximately reproduced the experimental deformation and resultant failure shape of the concrete plate under the blast load.

Langdon et al [15] modelled blast load experiments investigating the influence of hole size and thickness on the performance of mild steel perforated plates as a blast wave mitigation technique, inside a tube. Langdon et al modelled the simulation as an axisymmetric model, with a similar approach to Ambrosini [29]. The blast tube wall was modelled with reflective boundaries, whilst the open air regions of the experiment were modelled with 'flow out' boundaries, allowing the explosive material and expanding air to escape the confines of the model. The clamped plates were modelled using zero velocity boundaries in both the $\mathrm{x}$ and $\mathrm{y}$ directions. The dimensions and specifications of the AUTODYN numerical model are shown in Figure 2.23. Strategically placed gauges inside the tube were used to measure the incident pressure wave, to determine the resultant impulse. The numerical simulation showed good correlation with the experiments with regards to the resultant impulse and midpoint deflection of the test plates. 


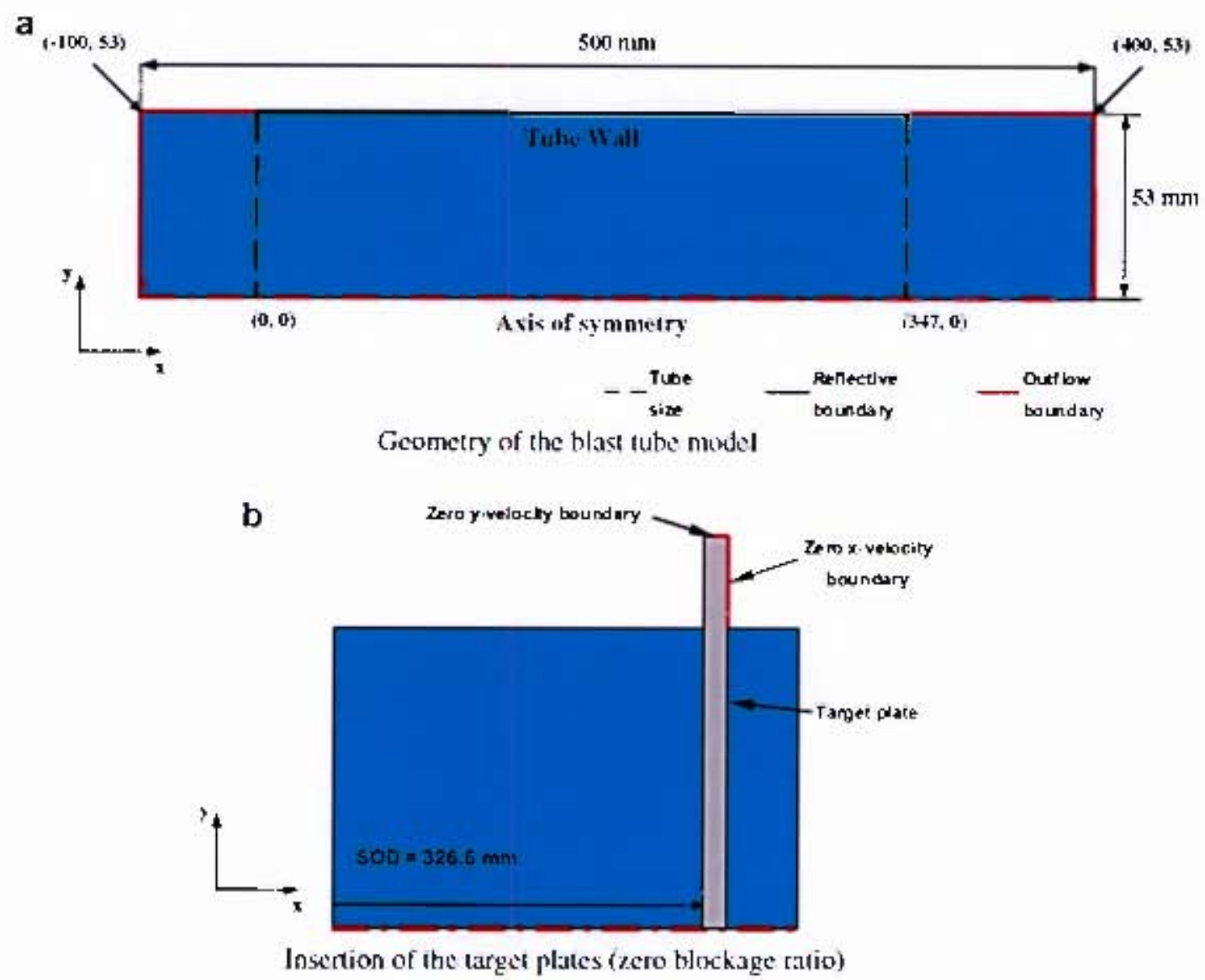

Figure 2.23: Sebematic views of the Al TODYN modet construction (mm), a a) (ieom Liry of the Blast 1ube model, (b) Insertion of the target plates (atro blos'iage ratio). (c) Irsertion of the perforated and tareet plates |15|

Langdon et al [11] Earried out AL'IODYN numerical simulations of "V" shape Domex 700 stecl plates subjected to localised blast loads and validated the numerical results to experiments. The "V" shaped plate was modelled as a quarics model, applying symmetry boundares to save on computational expense. The Johnoon Cook material model was used to simulate the material characteristics of the Domex 700 test plites. The numerical predictions showed satisfactory cortelation with the experiments.

Ackland et al $[90]$ used the Johnson Cook materiat model to simulate the responsc of D36 steel plates subjected to blast loading in ATHODYN. To obtain the litual deflection a static damping comstant of $5.5 \times[10,(-4)$ was introduced into the mode] at $10 \mathrm{~ms}$, to converge the model to a state of stress equilibrium Good agreenent was found for the maximum numerical permanent deformation which was within $10 \%$ of the experimental results. 
Blast loading of structures and the corresponding deformation responses has been numerically simulatcd by several rescarchers using ABAQUS and implementing various impulsive loading tec]niques $[80,9], 92,93 \mid$. Chung K Kim Yucu |36] successfully modelled large inefastic deformation using ABAQL'S. The modelled parts were constructed with eight-node brick, C3D8R, and six-node prism, C306 reduced integration elements. The stiffencd plate wats simulated with al quarter symmetry arrangement to increase computational efficiency [36]. To simulate the fully built in boundary conditions, constraints limiting all the degrees of fredom were assigned to the boundary of the built in plate edtges [36]. The numerical modelling allowed for the analysis of temperature effects and transient response of the blast lodded plates, which caruot be investigated in experiments [36]. Kadid 194] used ABAQUS to model stiffened plates subjected to unifom blast Ioads. where it wats found that the loading duration had a significant influence on the strain rate. The inclusion of strain rate eftects resulted in a much stiffer response. resulting in lower midpoint de[lections [94].

Bonorishis and Nurick [14] carried out an experimental and numerical investigation into the effects of welding on blast loaded stiffened plates. The stiffencd plates were modelled (ABAQUS) with fully clamped rigid boundarics, with an initial clamping force specified on the clamp part. 1 lard contact with separation was defined between the clamp and plate parts, with a tangential friction co-eflicient of 0.5 [1 47 . Simulating the actua] classp allowed for slight pull-in of the plate during forading which was more realistic. The numerical predictions correlated well with the experimental trends of large Mode I dellections.

A numerical and experimental study on the ductile blast response of mild stect plates was camied out by Batden et al [44]. The Iesl plate lemperalure increases during large inelastic deformation that wccurs during blast loading. These themal softening effects were included in the numerical model. Balden et al [44] implemented the modified Johnson Conk fluw stress model to define the material characteristics of the simulated test plate and oblained static yiefd parameters from experimental urilaxial punch tests. Figure 2.24 shows the areas of high plastic strain present in the deformation profile of the numserieadly simulated test plate and capping failuse as observed in the experiments.

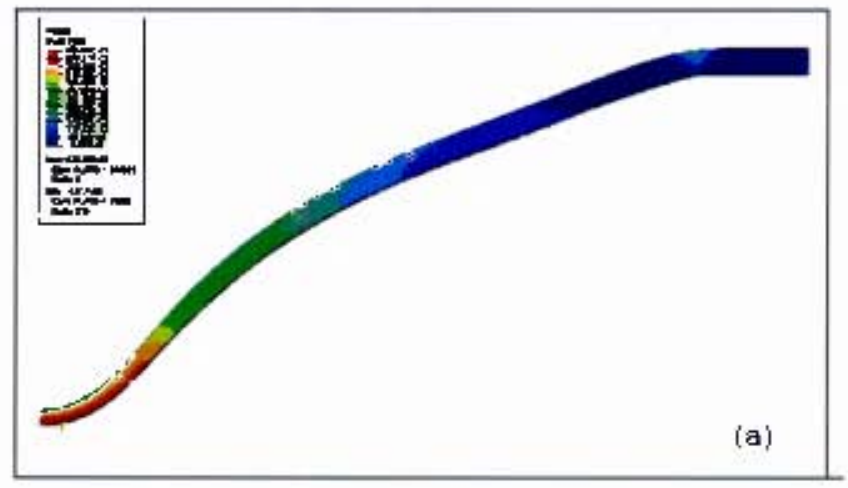

Figure 2.24: (a) Typical contour plot of egaivalent plastie struin for test plate [44] 


\subsection{Summary of Previous Work}

The response of structures with various geometries and boundary conditions subjected to uniform and localised impulsive loading conditions has been extensively. Many theoretical and experimental results have been published of plates that were loaded uniformly over the entire plate area and locally in the central region of the target structure. Many results have been reported, discussing the geometrical effects of circular, square and rectangular plates subjected to blast loads. Further studies have been conducted on beams and plates of different geometries (circular, quadrangular, $\mathrm{V}$ shaped plates) with and without stiffeners, different boundary conditions (clamped or built-in), welded seems and perforations. Other works include the blast loading of various material combinations including composite sandwich panels, aluminium foam cores and concrete panels.

Many attempts with varying degrees of success have been carried out to model impulsively loaded plate structures using finite element models. In most cases commercially available software packages have been used to model the large inelastic deformation or complete failure (tearing) of the structure with gained insights into the blast wave-structure interaction and transient response of the structure.

Hitherto, these studies have been carried out under single blast loading conditions, with little knowledge on the effects of multiple blast loading on the material and deformation response of the test plates. It is therefore necessary to carry out an investigation into the effects of repeated blast loading. 


\section{Experimental Details}

Repeated blast load experiments on $2 \mathrm{~mm}$ and $3 \mathrm{~mm}$ thick plates (163 blast tests) were conducted on a horizontal ballistic pendulum, located in the BISRU laboratory. The experimental design and specifications are presented in this chapter.

\subsection{Clamping Rig and Test Plate}

The clamping rig consisted of two thick mild steel clamping plates, a cylindrical tube, four spacer rods and a back plate, which as a whole were all fastened onto the front of the pendulum. The clamping plate was $244 \times 244 \mathrm{~mm} \times 22 \mathrm{~mm}$. The clamping plates were assumed to be rigid bodies, as the clamp experienced no permanent deformation compared to the test plate, due to their thickness. On the front clamping plate a $150 \mathrm{~mm}$ diameter threaded hole was bored out, to allow for the cylindrical tube to be fitted onto the front of the test rig. On the rear clamping plate, a $106 \mathrm{~mm}$ diameter hole was bored out, to allow for the deformation of the plate when subjected to blast loads. The $106 \mathrm{~mm}$ diameter hole defined the fully clamped boundaries for the blast experiments. The cylindrical tube was made of mild steel, had an outer diameter of $150 \mathrm{~mm}$, inner diameter of $106 \mathrm{~mm}$ and length of $150 \mathrm{~mm}$, defining the constant stand-off distance used in all experiments. The tube provided a means of directing the blast towards the test plate. The cylindrical tube was also considered a rigid body in the experiments. The spacers provided a separating distance from the back plate to allow for the plastic deformation of the test plate. The back plate served as protection for the pendulum, against the blast load and prevented any damage from shrapnel. The clamping rig is illustrated in Figure 3.1.

The test plates were manufactured from Domex $700 \mathrm{MC}$ sheet metal. that has a relatively high yield stress, and is certified for consistent material characteristics, making it favourable for repeatable results between different experiments. Tensile test specimens were cut from the same sheet metal as the test plate to characterise the material quasistatically.

The test plates in two different thicknesses ( $2 \mathrm{~mm}$ and $3 \mathrm{~mm}$ ) were laser cut to $244 \times 244 \mathrm{~mm}$ squares and have an exposed area with a diameter of $106 \mathrm{~mm}$. 


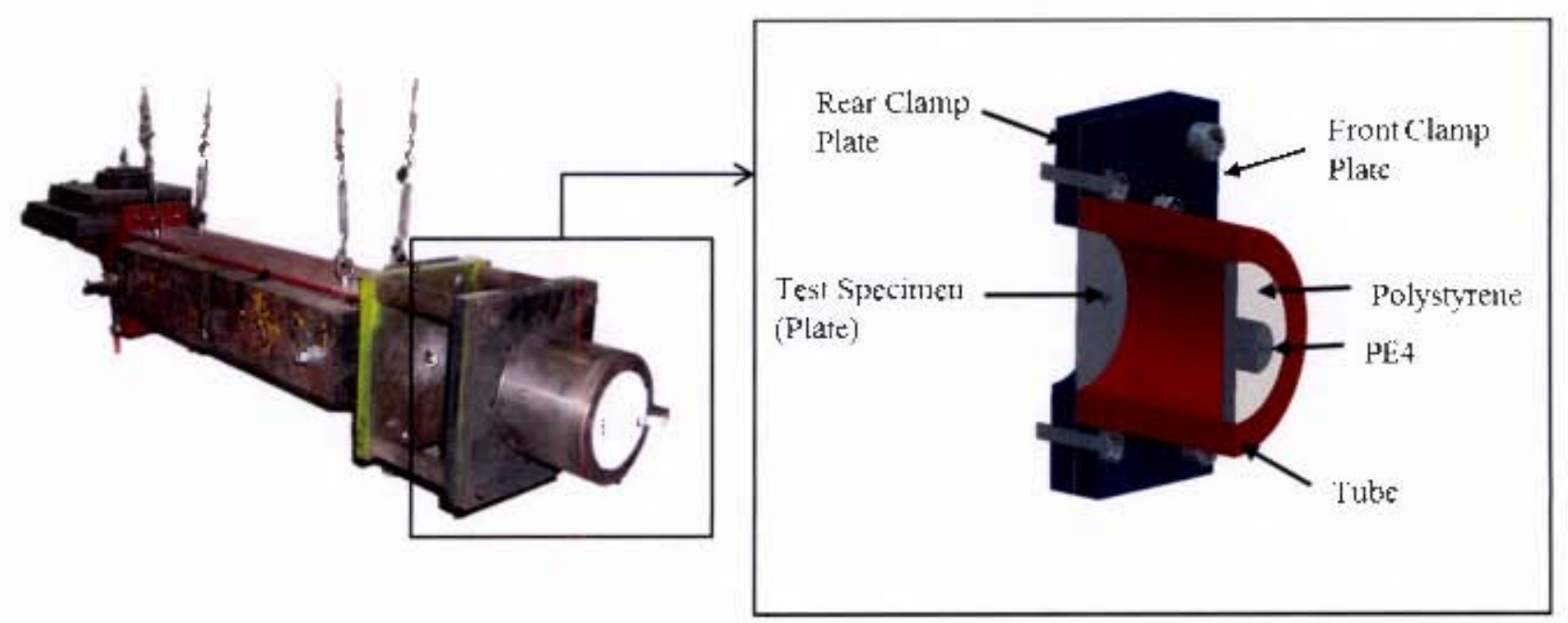

Figure 3.1: Photograph of horizontal ballictic pendulum with illustration of cla mpines sig 


\subsubsection{Material Characteristics of the Domex Stcel Test Plates}

Uni-ixial lensile lest (dog bone) specimens were cut fjom the Domex 700 steel sheets used in the mamufiaclure of the test specimens. The dimensions of the uri-axial test specimens are illustrated in Appendix A.

The uni-axial tensile tests were carricd out on the 7 wick/Rocll 1484 machinc. Five crosshead speeds (5mmimin, $10 \mathrm{~mm} / \mathrm{min}, 20 \mathrm{~mm} / \mathrm{min}, 50 \mathrm{~mm} / \mathrm{min}$ and $100 \mathrm{~mm} / \mathrm{min})$ were used in the tensile lests. Three tensili tests per erosshead speed were carricd out. for repeatability. The gauge length used in the tensile tests was 50 mum

Typical results for the engincuing stress versus enginecring strains for the tensile test results at the different crosshead speeds are shown in Figure 3.2. This data is the rat utprocessed dala, still having the machine compliance inaccuracies and serves as an indicator of the comsistency of the test results. For this range of tests the stress-strain results showed good repeatability with little variation in the yield stress. $\Lambda$ full discussion and analysis deriving the marcrial properties are available in Appendix A.

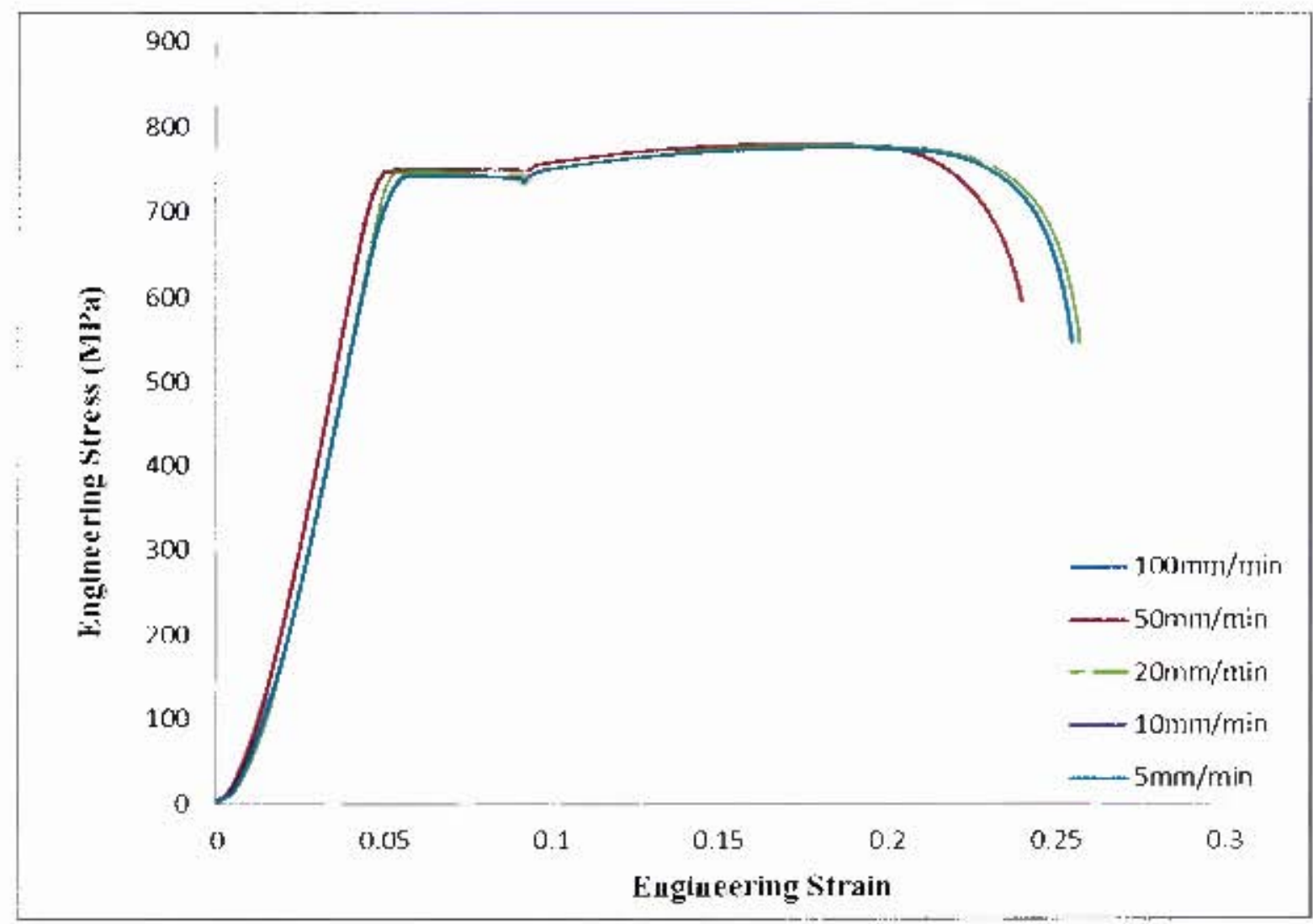

Figure 3,2: Graph of Fnyinecring stairh versus lingineering stress for each tensile test strain rate 
The material properties of the Domex 700 steel are listed in Table 3.1. Machine compliance accountability and post ultimate tensile stress analysis data processing was carried out and discussed in Appendix A.

Table 3.1: Summary of material properties for Domex 700 steel

\begin{tabular}{|c|l|}
\hline Density & $7870 \mathrm{~kg} / \mathrm{m}^{3}[78]$ \\
\hline Poisson's Ratio & $0.3[78]$ \\
\hline $\begin{array}{c}E \text {-Young's } \\
\text { Modulus }\end{array}$ & $200 \mathrm{MPa}$ \\
\hline $\begin{array}{c}A-\sigma_{\mathbf{y}} \\
\text { (Yield Stress) }\end{array}$ & $750 \mathrm{MPa}$ \\
\hline $\boldsymbol{B}$ & $270.6 \mathrm{MPa}$ \\
\hline $\boldsymbol{n}$ & 0.263 \\
\hline$\dot{\epsilon}_{\mathbf{0}}$ & $0.001[11]$ \\
\hline $\boldsymbol{C}$ & $0.014[11]$ \\
\hline $\mathbf{m}$ & 1.03 \\
\hline $\boldsymbol{T}_{\text {melt }}$ & $1750 \mathrm{~K}[78]$ \\
\hline
\end{tabular}




\subsection{Experimental Procedure}

\subsubsection{Experimental Arrangement}

Circular Domex 700 steel test plates were subjected 10 explosive blasi loads that are dise shaped plastic explosives (1P4) of Radius. $R_{0}$, and charge mass, $m$. Detonation was eatried out at a consrant stand-off distance of 150mm. A sketch of the explosive charge and test plate is shown in Figure 3.3 . The explosive charge was attached on ane end of a steel tube, whilst the test plate was mounted on the opposite end. The eylindrical tube directed the resultant blast wave towards the test plate. The set-up was similar to that of facob |51]. The impulse imparted to the specimen from the explosive charge was determined from amplitude of the oscillation of the horizontal ballistie pendulurr.

Orice the initial explosive sharge had been tetonated, an additional charge was placed at the relevant end of the tube and the test plate was subjected to further blasis. This provess was repeated for a rumber of blasts, depending on the requised number of blasts in repeated blast series. The impulse was delermined for each blast. The midpoinl detteution was measured after the final repeated blast of the serics.

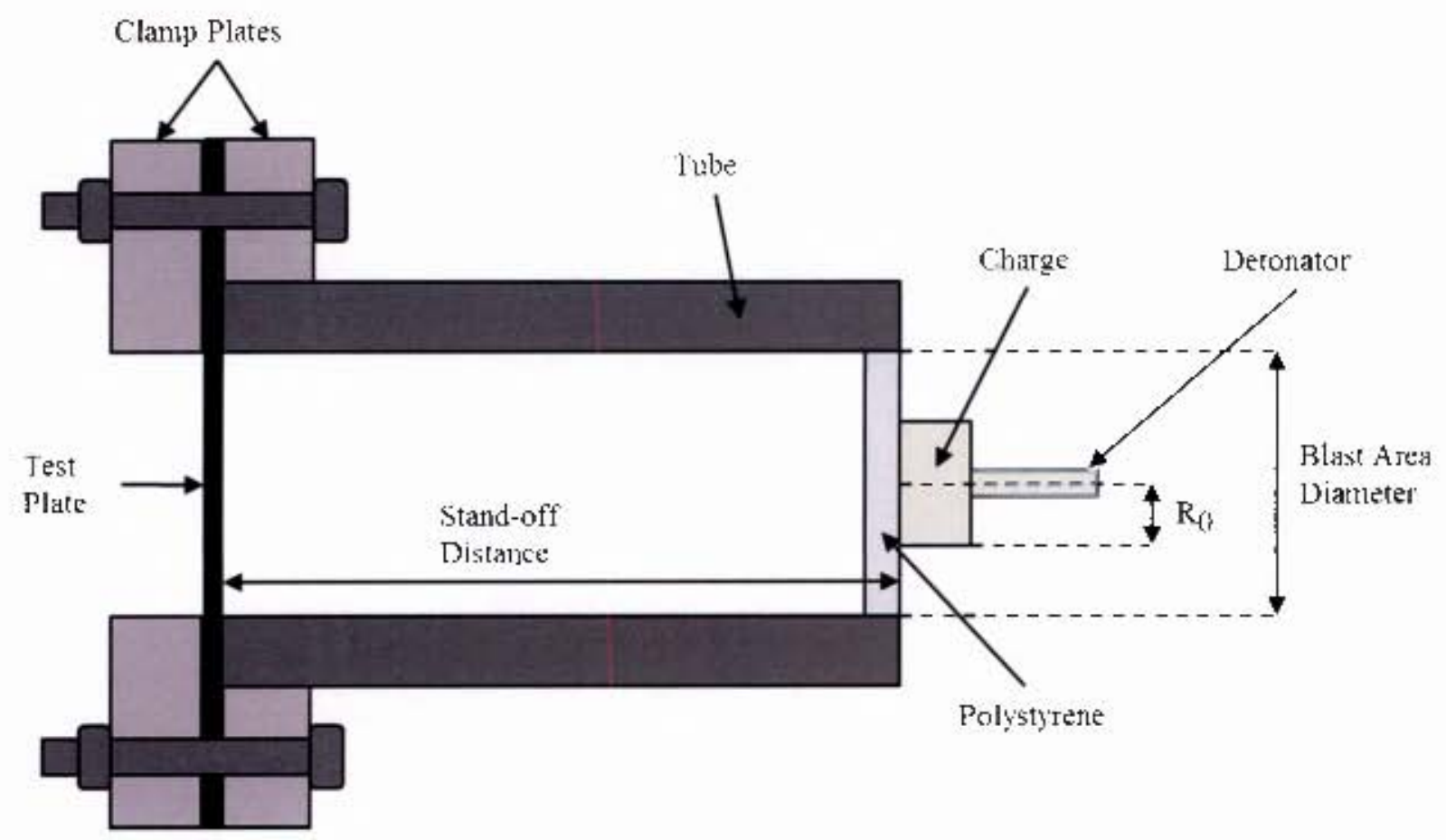

Figure 3.3: Sketch of blast loading canfigutation 


\subsubsection{Explosive Charge Configuration}

The explosive (PE4) was moulded into cireular dises with a constant charge diameter of $34 \mathrm{~mm}$. A detenator was attached to the explosive charge, on the face futthest from the test plate and included a $1 \mathrm{~g}$ leader charge used to attach the detonator to the main charge. The mass of PE4 was increased in $5 g$ increments for the fiul range of experiments, from $5 \underline{\mathrm{g}}$ to $2,5 \mathrm{~g}$ for the $2 \mathrm{~mm}$ thick test plates and from $5 \mathrm{~g}$ $1040 \mathrm{~g}$ for the $3 \mathrm{~mm}$ thick 1 es 1 plates. The mass of the explosive was presented as its linal trass, including the Io leader. in all the tables and graphs presented it thrs repent. The explosive charge was laid out otto a $13 \mathrm{~mm}$ thick polystyrene disk. The polystyrene disk was securely titted into the cylindrical tabe. The polystyrence was assumed to burs upen detonation of the explosion having negligible effect on the hlast experiments, with regards to the measurable parameters [5]]. The explosive and polystyrene are illustrated in Figure 3.1, with respeer to the resi of the blast pendulum and clamping rig. A photograph of the charge and polystyrene is shown ju tigure 3.4.

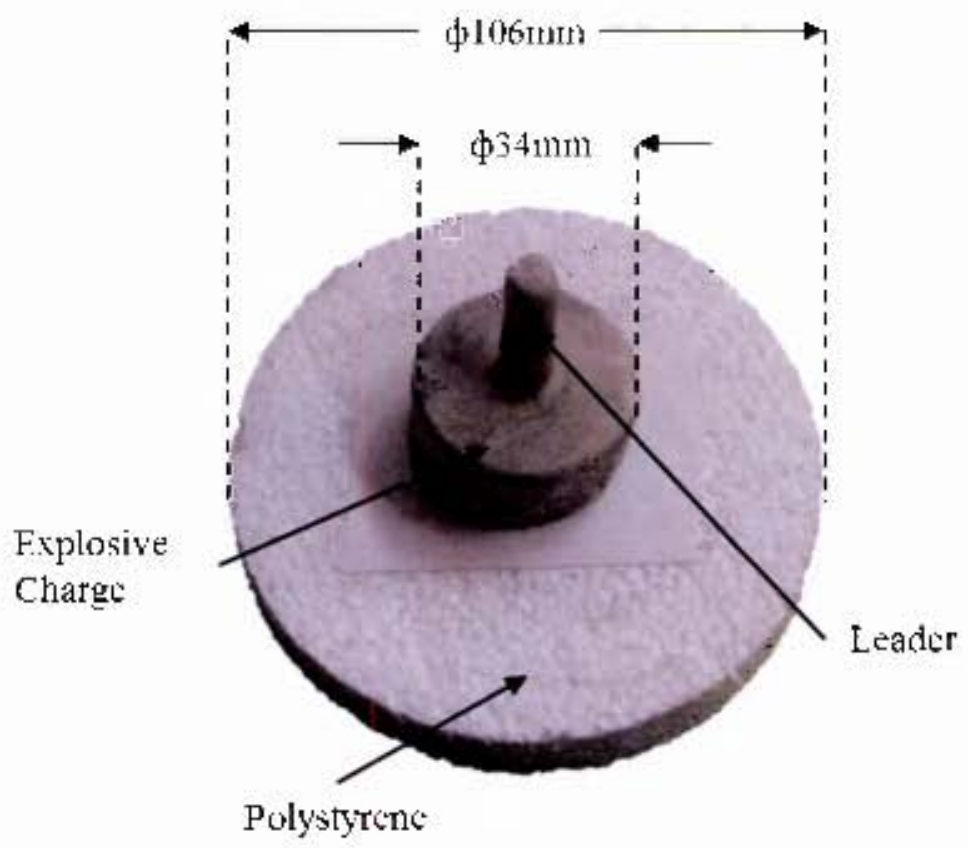

Figure 3.4: Phutogeraph of pulystyrene with altached charge and leader 


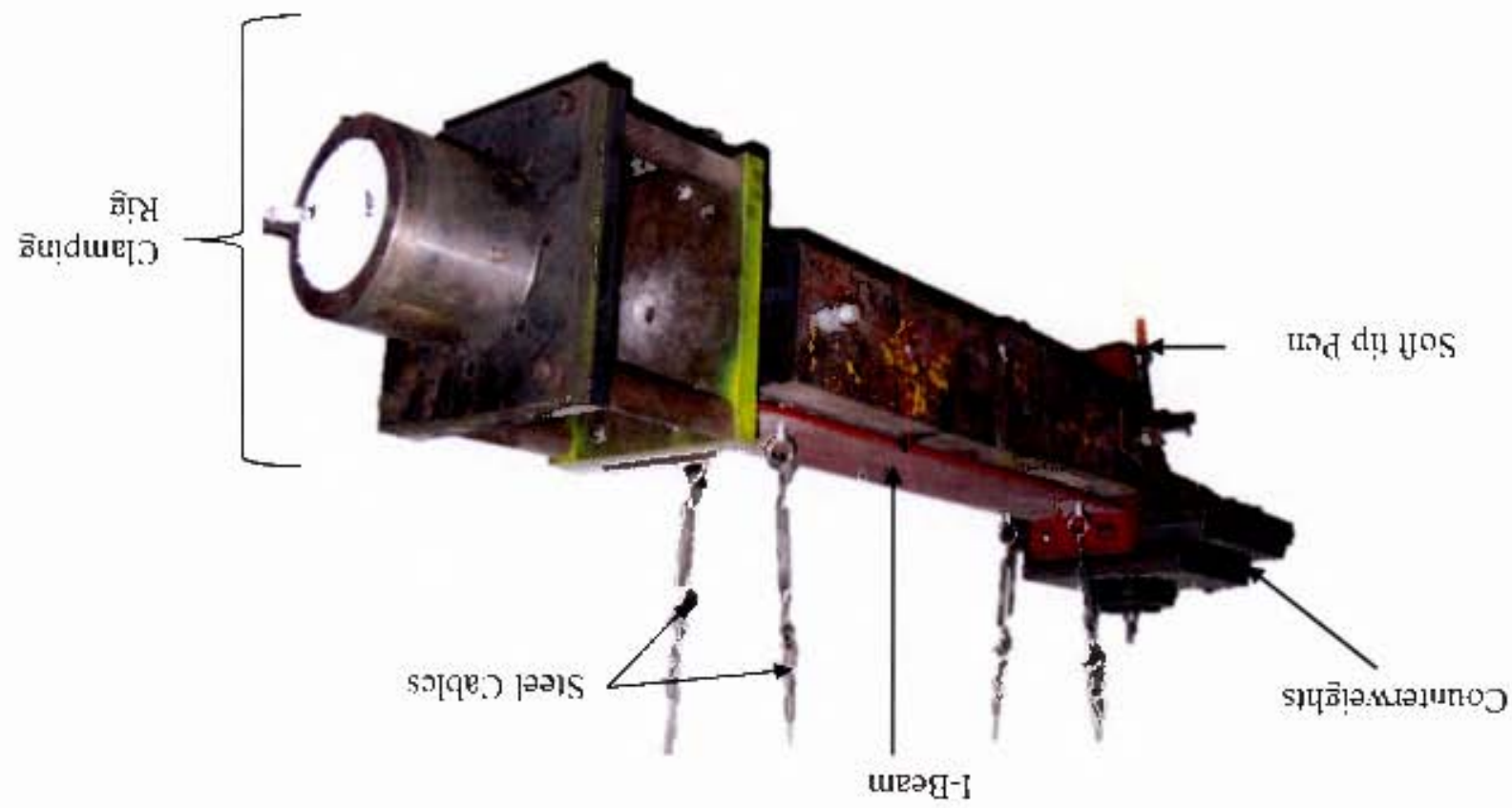

'g xipuadd

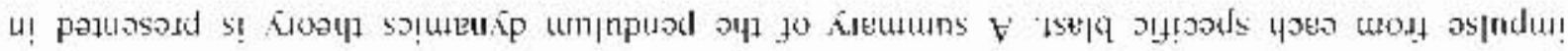

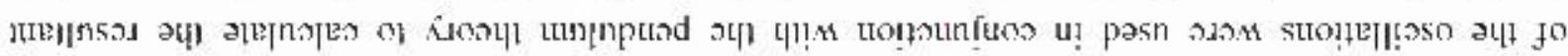
sop

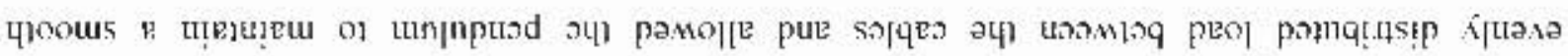

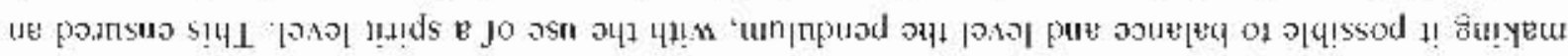

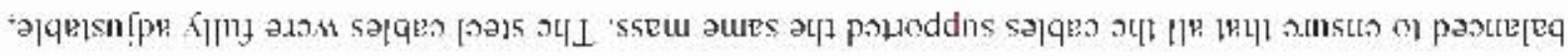

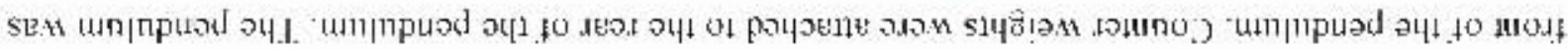

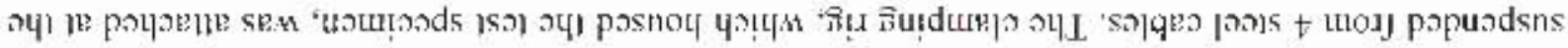

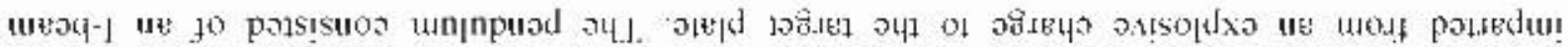

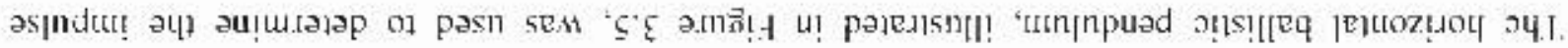




\subsection{Experimental Details}

$A$ summary of the experimental details are listed in lable 3.2 .

Table 3.2: Table of experimetal detailz

\section{Test Plate}

\begin{tabular}{|c|c|}
\hline Dimensions $(\mathrm{mm})$ & $24+\times 244$ \\
\hline Thickuess (mm) - & 2 and 3 \\
\hline Exposed Diatneter (mu) & 106 \\
\hline Exposed Area $\left(\mathrm{mm}^{2}\right)$ & 8824.7 \\
\hline Boundary Condition & Chmpel \\
\hline Material & Domex 700 Stecl \\
\hline
\end{tabular}

\section{Repeated Blast Loading}

\begin{tabular}{|c|c|}
\hline Charge diameter (mm) & 34 \\
\hline Mass of explosive (g) & $\begin{array}{l}5,10,15,20,25, \\
30,35,40\end{array}$ \\
\hline $\begin{array}{l}\text { Number of Blasts per eharge } \\
\text { mass }\end{array}$ & 5 \\
\hline Stand-off Distance (mm) & 150 \\
\hline
\end{tabular}




\section{Experimental Results and Observations}

This chapter presents the results of multiple blast loads on both $2 \mathrm{~mm}$ thick and $3 \mathrm{~mm}$ thick fully clamped, circular Domex Steel test plates. A tabular summary of all the measured test data is presented in Table 4.1 and Table 4.2.

\subsection{Experimental Results}

The data from all the blast tests conducted on the deformable test plates, including both the $2 \mathrm{~mm}$ and $3 \mathrm{~mm}$ thick plates, are summarized and presented in Table 4.1 and Table 4.2. The test plates are labelled according to:

- T - thickness of the test plate

- $\mathbf{R}$ - total number of blasts

- $\mathbf{M}$-charge mass

- B - specific number of blasts

For example, test T2R3M25B2 represents a $2 \mathrm{~mm}$ thick test plate subjected to a total of three blast loads of charge mass $25 \mathrm{~g}$ and currently subjected to 2 blasts. The charge mass indicated in the tables, include the $1 \mathrm{~g}$ of charge (referred to as the leader) used to attach the detonator to the explosive.

In Table 4.1 and Table 4.2, the following variables are denoted as follows:

- Dimensionless Impulse:

$\phi_{\mathrm{cs}}$

- Midpoint Deflection:

$\delta$

- Midpoint Deflection-plate thickness ratio: $\delta / \mathrm{H}$

For completeness of the series of experimental tests, experimental results from Ranwaha [74] have been included in the results section and are denoted by an asterisk $\left({ }^{*}\right)$. 
Table 4.1: Tatble of results for repeated blast loading experiments carried out on $2 \mathrm{~mm}$ thick test plates, for charge masses $5 \mathrm{~g}$ to $25 \mathrm{~g}$

\begin{tabular}{|c|c|c|c|c|c|c|c|}
\hline $\begin{array}{c}\text { Test } \\
\text { Number }\end{array}$ & $\begin{array}{l}\text { Total } \\
\text { Number of } \\
\text { Blasts }\end{array}$ & $\begin{array}{l}\text { Blast } \\
\text { Number }\end{array}$ & $\begin{array}{l}\text { Charge } \\
\text { Mass (g) }\end{array}$ & $\begin{array}{c}\text { Inupulse } \\
\text { (Ns) }\end{array}$ & $\phi_{\mathrm{cs}}$ & $\delta(\mathrm{mm})$ & $\delta H$ \\
\hline I2R1:M5B1 & 1 & 1 & 5 & 12.07 & 5.02 & 3.73 & 1.865 \\
\hline $\mathrm{T} 2 \mathrm{R} 2 \mathrm{M} 5 \mathrm{~B} 1$ & \multirow{2}{*}{2} & 1 & 5 & 12.32 & 5.12 & \multirow{2}{*}{5.15} & \multirow{2}{*}{2.575} \\
\hline T2R2M5B2 & & 2 & 5 & 12.31 & 5.12 & & \\
\hline T2R3M5BI & \multirow{3}{*}{3} & 1 & 5 & $10.9 \%$ & 1.55 & \multirow{3}{*}{5.1} & \multirow{3}{*}{2.7} \\
\hline $\mathrm{T} 2 \mathrm{R} 3 \mathrm{M} 5 \mathrm{~B} 2$ & & 2 & 5 & 12.07 & 5.02 & & \\
\hline T2R3M5B3 & & 3 & 5 & 12.6 & 5.24 & & \\
\hline $12 \mathrm{R} 4 \mathrm{M} 5 \mathrm{~B} \mathrm{I}$ & \multirow{4}{*}{4} & 1 & 5 & 12.21 & 5.08 & \multirow{4}{*}{5.56} & \multirow{4}{*}{2.78} \\
\hline $12 \mathrm{R} 4 \mathrm{M} 5 \mathrm{~B} 2$ & & 2 & 5 & 12,32 & 5.12 & & \\
\hline T2R4M5B3 & & 3 & 5 & 12.6 & 5.24 & & \\
\hline T2R4M5T34 & & 4 & 5 & 12.75 & 5.30 & & \\
\hline T2R5M5B] & \multirow{5}{*}{5} & 1 & 5 & 13.11 & 5.15 & \multirow{5}{*}{5.83} & \multirow{5}{*}{2.915} \\
\hline T2R5M5B2 & & 2 & 5 & 12.07 & 5.02 & & \\
\hline $12 \mathrm{R} 5 \mathrm{M} 5 \mathrm{~B} 3$ & & 3 & 5 & 31.05 & 4.59 & & \\
\hline T2R5M5B4 & & 4 & 5 & 12.07 & 5.02 & & \\
\hline T2R5M5B5. & & 5 & 5 & 12.85 & 5.34 & & \\
\hline$[2 \mathrm{R} 1 \mathrm{M} 10 \mathrm{~B}]$ & 1 & 1 & 10 & 21.02 & 8.74 & 9.25 & 4.625 \\
\hline [2R2MIUBI & \multirow{2}{*}{2} & 1 & 10) & 21.28 & 8.85 & \multirow{2}{*}{10.61} & \multirow{2}{*}{5.305} \\
\hline 12R2M10B2 & & 2 & 10 & 21.01 & 8.73 & & \\
\hline T2R3M10B। & \multirow{3}{*}{3} & 1 & 10 & 21.27 & 8.84 & \multirow{3}{*}{11.64} & \multirow{3}{*}{5,82} \\
\hline T2R3M!OB2 & & 2 & 10 & 20.75 & 8.63 & & \\
\hline $12 \mathrm{R} 3 \mathrm{M} 10 \mathrm{~B} 3$ & & 3 & 10 & 20.24 & $8.4 \mathrm{l}$ & & \\
\hline T2R $1 \mathrm{MiOBI}$ & \multirow{4}{*}{4} & 1 & 10 & 21.01 & 8.73 & \multirow{4}{*}{11.68} & \multirow{4}{*}{5.84} \\
\hline $12 \mathrm{~K} 4 \mathrm{MlOB} 2$ & & 2 & 10 & $20.50^{\circ}$ & 8.52 & & \\
\hline T2RMMJOB3 & & 3 & 10 & 19.74 & 8.21 & & \\
\hline T2R $1 \mathrm{M} 10 \mathrm{~B} 4$ & & 1 & 10 & 19.61 & 8.15 & & \\
\hline $12 \mathrm{R} 5 \mathrm{MI0B} 1$ & \multirow{5}{*}{5} & 1 & 10 & 22.59 & 9.39 & \multirow{5}{*}{12.27} & \multirow{5}{*}{6.135} \\
\hline T2R5M10132 & & 2 & 10 & 21.82 & 9.06 & & \\
\hline $\mathrm{T} 2 \mathrm{RSN} 10 \mathrm{OB} 3$ & & 3. & 10 & 21.81 & 9.06 & & \\
\hline $\mathrm{T} 2 \mathrm{R} 5 \mathrm{M} 10 \mathrm{~B} 4$ & & 4 & 10 & 19.74 & 8.21 & & \\
\hline $12 \mathrm{R} 5 \mathrm{M} 10 \mathrm{~B} 5$ & & 5 & 10 & 20.24 & 8.41 & & \\
\hline
\end{tabular}

* experimental results from Ratnwaha $17+1$ 
Table 4.1 continued:

\begin{tabular}{|c|c|c|c|c|c|c|c|}
\hline $\begin{array}{c}\text { Test } \\
\text { Number }\end{array}$ & $\begin{array}{c}\text { Total } \\
\text { Number of } \\
\text { Blasts }\end{array}$ & $\begin{array}{c}\text { Blast } \\
\text { Number }\end{array}$ & $\begin{array}{l}\text { Charge } \\
\text { Muss (g) }\end{array}$ & $\begin{array}{c}\text { Impulse } \\
\text { (Ns) }\end{array}$ & $\phi_{\mathrm{cs}}$ & $\delta(\mathbf{m m})$ & $6 / H$ \\
\hline $\mathrm{T} 2 \mathrm{R} 1 \mathrm{M} 15 \mathrm{~B} 1$ & 1 & 1 & 15 & 26.79 & 11.14 & $: 3.02$ & 6.51 \\
\hline $\mathrm{T} 2 \mathrm{R} 2 \mathrm{M}|5 \sqrt{3}|$ & \multirow{2}{*}{2} & 1 & 15 & 30.10 & 12.51 & \multirow{2}{*}{14.43} & \multirow{2}{*}{7.215} \\
\hline $12 \mathrm{R} 2 \mathrm{M}\{5 \mathrm{BZ}$ & & 2 & 15 & 29.04 & 12.07 & & \\
\hline $12 \mathrm{R} 3 \mathrm{M} 15 \mathrm{BI}$ & \multirow{3}{*}{$\hat{i}$} & 1 & 15 & 29.83 & 12.40 & \multirow{3}{*}{16.12} & \multirow{3}{*}{8.06} \\
\hline T2R3M15B2 & & 2 & 15 & 27.52 & 11.44 & & \\
\hline T2R3M15ß33 & & 3 & 15 & $\overline{26.45}$ & 10.99 & & \\
\hline $12 \mathrm{R} 4 \mathrm{M} 15 \mathrm{Bl}$ & \multirow{4}{*}{4} & ] & 15 & 27.87 & 11.58 & \multirow{4}{*}{ Tom } & \multirow{4}{*}{ NA } \\
\hline $\mathrm{T} 2 \mathrm{R} 4 \mathrm{M} 15 \mathrm{~B} 2$ & & 2 & 15 & 27.88 & 11.59 & & \\
\hline $12 \mathrm{R} 4 \mathrm{M} 15 \sqrt{3} 3$ & & 3 & 15 & 29.04 & 12.07 & & \\
\hline T2R $4 \mathrm{MiSB} 4$ & & 4 & 15 & 29.59 & 12.30 & & \\
\hline T2R IM 20:31 & 1 & 1 & 20 & 37.32 & 15.51 & 16.28 & 8.14 \\
\hline T2R2M20BI & \multirow{2}{*}{2} & 1 & 20 & 35.33 & 14.69 & \multirow{2}{*}{17.58} & \multirow{2}{*}{8.79} \\
\hline Г2R $2 \mathrm{M} 20 \mathrm{H} 2$ & & 2 & 20 & 36.13 & 15,02 & & \\
\hline T2R3M20B। & \multirow{3}{*}{3} & 1 & 20 & 36.00 & 14.96 & \multirow{3}{*}{ Torn } & \multirow{3}{*}{ NA } \\
\hline T2R $3 M_{1} 20 \mathrm{~B} 2$ & & 2 & 20 & $35 . \overline{47}$ & 14.74 & & \\
\hline $12 \mathrm{R} 3 \mathrm{M} 20 \mathrm{~B} 3$ & & 3 & 20 & 33.50 & 13.92 & & \\
\hline T2RIM25B1 & 1 & 1 & 25 & 38.33 & 15.93 & 17.73 & 8.865 \\
\hline $12 k 2 \mathrm{M} 25 \mathrm{~B}]$ & 2 & 1 & 25 & 40.38 & 16.78 & Torm & $\mathrm{NA}$ \\
\hline
\end{tabular}

* experimental resulis from Ranwaha [74] 
Table 4.2: Table of results for repeated blast loading experiments carried out on 3 m m thick lest plates, for charge masses $5 \mathrm{~g}$ to $40 \mathrm{~g}$

\begin{tabular}{|c|c|c|c|c|c|c|c|}
\hline Test Yumber & $\begin{array}{l}\text { Total } \\
\text { Number of } \\
\text { Blasts }\end{array}$ & $\begin{array}{c}\text { Blast } \\
\text { Yumber }\end{array}$ & $\begin{array}{l}\text { Charge } \\
\text { Mass (g) }\end{array}$ & $\begin{array}{l}\text { Impulse } \\
\text { (Ns) }\end{array}$ & $\phi_{\mathrm{cs}}$ & $\delta(\mathrm{mm})$ & $\delta / H$ \\
\hline $13 \mathrm{R} 1: \mathrm{M} \mathrm{B}{ }^{*}$ & 1 & 1 & 5 & 11.89 & 2.20 & 1.28 & 0.43 \\
\hline T3R2M5Bi* & \multirow{2}{*}{2} & 1 & 5 & 11.63 & 2.15 & \multirow{2}{*}{.82} & \multirow{2}{*}{0.61} \\
\hline 13R2M5B2* & & 2 & 5 & 12.40 & 2.29 & & \\
\hline T3R3M5Bl* & \multirow{3}{*}{3} & 1 & 5 & 12.15 & 2.24 & \multirow{3}{*}{$\therefore .98$} & \multirow{3}{*}{0.66} \\
\hline [3R3M5132* & & 2 & 5 & 11.76 & 2.17 & & \\
\hline $13 \mathrm{R} 3 \mathrm{M} 5 \mathrm{~B} 3 *$ & & 3 & 5 & 12.28 & 2.27 & & \\
\hline $13 \mathrm{R} 4 \mathrm{M} 5 \mathrm{~B} 1^{*}$ & \multirow{4}{*}{4} & 1 & 5 & 12.68 & 2.34 & \multirow{4}{*}{2.72} & \multirow{4}{*}{0.91} \\
\hline $13 \mathrm{R} 4 \mathrm{M} 5 \mathrm{R} 2 *$ & & 2 & 5 & 12.15 & 2.24 & & \\
\hline $13 \mathrm{R} 4 \mathrm{M} 5 \mathrm{B33*}$ & & 3 & 5 & 11.76 & 2.17 & & \\
\hline $13 \mathrm{R} 4 \mathrm{M} 5 \mathrm{~B} 4 *$ & & 4. & 5 & 13.13 & 2.43 & & \\
\hline T3R5M5B1* & \multirow{5}{*}{5} & 1 & 5 & 12.15 & 2.24 & \multirow{5}{*}{ 2. 1} & \multirow{5}{*}{0.70} \\
\hline $73 R^{2} 5 \mathrm{M5132*}$ & & 2 & 5 & 11.37 & 2.10 & & \\
\hline T3R5M5B3* & & 3 & 5 & 12.03 & 2.22 & & \\
\hline T3R5MS134* & & 4 & 5 & 12.17 & 2.25 & & \\
\hline $13 \mathrm{R} 5 \mathrm{M} 5 \mathrm{~B} 5^{*}$ & & 5 & 5 & 11.6 .3 & 2.15 & & \\
\hline T3R1M10BI* & 1 & 1 & 10 & 21.91 & 4.05 & 6.85 & 2.28 \\
\hline [3R2MIOR ]* & \multirow{2}{*}{2} & 1 & 10 & 21.25 & 3.93 & \multirow{2}{*}{7.46} & \multirow{2}{*}{2.49} \\
\hline T3R2M10R2* & & 2 & 10 & 21.31 & 3.93 & & \\
\hline $13 \mathrm{R} 3 \mathrm{M} 10 \mathrm{B1} 1^{*}$ & \multirow{3}{*}{3} & $I$ & 10. & 21.64 & 4.00 & \multirow{3}{*}{6.85} & \multirow{3}{*}{2.28} \\
\hline T3R3M10B2* & & 2 & 10 & 21.91 & 4.05 & & \\
\hline T3R3M1UB3* & & 3 & 10 & 21,12 & 3.90 & & \\
\hline T3RAM10131* & \multirow{4}{*}{4} & i & 10 & 21.21 & $3.93^{-}$ & \multirow{4}{*}{7.46} & \multirow{4}{*}{2.49} \\
\hline T3R4M!0132* & & 2 & 10 & 21.25 & 3.93 & & \\
\hline $13 \mathrm{R} 4 \mathrm{M} 10 \mathrm{OB} 3^{*}$ & & 3 & 10 & 21.64 & 4.00 & & \\
\hline $13 R 4 \times 110134 *$ & & 4 & 10 & 21.38 & 3.95 & & \\
\hline $\mathrm{T} 3 \mathrm{R} 5 \mathrm{M}: 0531^{*}$ & \multirow{5}{*}{5} & 1 & 10 & 21.77 & 4.02 & \multirow{5}{*}{7.91} & \multirow{5}{*}{2.64} \\
\hline $13 \mathrm{R} 5 \mathrm{MI0B2}$ & & 2 & 10 & 20.99 & 3.88 & & \\
\hline T3R5M10133* & & 3 & 10 & 21.38 & 3.95 & & \\
\hline T3R5MIOR44* & & 4 & 10 & 22.04 & 4.07 & & \\
\hline T3R5W10135* & & 5 & 10 & 21.91 & 4.05 & & \\
\hline
\end{tabular}


Tiable 4.2 continued.

\begin{tabular}{|c|c|c|c|c|c|c|c|}
\hline Test Number & $\begin{array}{c}\text { Total } \\
\text { Number of } \\
\text { Blasts } \\
\end{array}$ & $\begin{array}{c}\text { Blast } \\
\text { Number }\end{array}$ & $\begin{array}{l}\text { Charge } \\
\text { Mass (g) }\end{array}$ & $\begin{array}{c}\text { Impulse } \\
\text { (Nis) }\end{array}$ & $\phi_{\mathrm{cs}}$ & $\delta(\mathbf{m m})$ & $\delta / H$ \\
\hline T3R $\left.|\mathrm{M}| 5 \mathrm{~B}\right|^{*}$ & 1 & 1 & 15 & 29.40 & 5.39 & 7.27 & 2.42 \\
\hline [3R2M15B]* & \multirow{2}{*}{2} & 1 & 15 & 29.17 & 5.39 & \multirow{2}{*}{8.73} & \multirow{2}{*}{2.91} \\
\hline$\left[3 R_{2} \mathrm{M} 15 \bar{B} 2^{*}\right.$ & & 2 & 15 & 29.18 & 5.39 & & \\
\hline TiRiM15B|* & \multirow[t]{3}{*}{3} & 1 & 15 & 28.1 .1 & 5.20 & \multirow[t]{3}{*}{9.38} & \multirow[t]{3}{*}{3.13} \\
\hline [3 $32 \mathrm{M} 15 \mathrm{Bz}=$ & & 2 & 15 & 29.79 & 5.50 & & \\
\hline T3R.M $15 \mathrm{~B}^{3 *}$ & & 3 & 15 & 30.11 & 5.62 & & \\
\hline T3R4M15B1"* & \multirow{4}{*}{4} & 1 & 15 & 28.24 & 5.22 & \multirow{4}{*}{10.28} & \multirow{4}{*}{3.43} \\
\hline $13 R+M 15132 *$ & & 2 & 15 & 30.83 & 5.70 & & \\
\hline $\mathrm{T} 3 \mathrm{R}^{2} 4 \mathrm{M} 15 \mathrm{~B} 3 *$ & & 3 & 15 & 29,99 & 5.54 & & \\
\hline T3R4ML5B4* & & 1 & 15 & 30.11 & 5.62 & & \\
\hline 1.3R 5M15R1* & \multirow{5}{*}{5} & 1 & 15 & 29.99 & 5.54 & \multirow{5}{*}{10.76} & \multirow{5}{*}{3.59} \\
\hline TiR5N15B2* & & 2 & 15 & 29.17 & 5.39 & & \\
\hline T3R5M15B3* & & 3 & 15 & 29,76 & 5.50 & & \\
\hline TIR5M15B4* & & 4 & 15 & 29.81 & 5.50 & & \\
\hline T3R5M15I35* & & 5 & 15 & 29.37 & 5.43 & & \\
\hline $13 \mathrm{R} 1 \mathrm{M} 20 \mathrm{Bl}$ * & 1 & 1 & 20 & 34.19 & 6.32 & 9.07 & 3.02 \\
\hline T3R2M20B।* & \multirow{2}{*}{3} & 1 & 20 & 36.73 & 6.78 & \multirow{2}{*}{10.64} & \multirow{2}{*}{3.55} \\
\hline T3R2M20B2* & & 2 & 20 & $35 . \overline{48}$ & 6.55 & & \\
\hline T3R3M20B L* & \multirow{3}{*}{3} & 1 & 20 & 36.10 & 6.67 & \multirow{3}{*}{11.84} & \multirow{3}{*}{3.95} \\
\hline T3R3M20B2* & & 2 & 20 & 35.82 & 6.62 & & \\
\hline $13 \mathrm{R} 3 \mathrm{M} 20 \mathrm{~B} 3 *$ & & 3 & 20 & 35.28 & 6.52 & & \\
\hline T3R4M20ß1* & \multirow{4}{*}{4} & 1 & 20) & 36.10 & 6.67 & \multirow{4}{*}{12.68} & \multirow{4}{*}{1.23} \\
\hline $13 \mathrm{R} 4 \mathrm{M} 20 \mathrm{OB2} 2^{*}$ & & 2 & 20 & 36.12 & 6.67 & & \\
\hline $\mathrm{T} 3 \mathrm{R} 4 \mathrm{M} 20 \mathrm{B3} 3^{*}$ & & 3 & 20 & 36.11 & 6.67 & & \\
\hline T3R $1 \mathrm{M} 20134^{*}$ & & 4 & 20 & 36.95 & 6.83 & & \\
\hline 'J'3R5M20B1* & \multirow{5}{*}{5} & 1 & 20 & 3.4 .24 & 6.33 & \multirow{5}{*}{13.14} & \multirow{5}{*}{4.38} \\
\hline $13125 \mathrm{M20132*}$ & & 2 & 20 & 36.55 & 6.75 & & \\
\hline $13 \mathrm{R} 5 \mathrm{M} 20 \mathrm{R}_{3}{ }^{*}$ & & 3 & 20 & 35,51 & 6.56 & & \\
\hline T3R 5M20B4* & & 4 & 20 & 35.55 & 6.56 & & \\
\hline $13 \mathrm{R} 5 \mathrm{M} 20 \mathrm{~B} 5 \div$ & & 5 & 20 & 36.12 & 6.67 & & \\
\hline
\end{tabular}

* experimential results from Ranwaha 174] 
Table $\$ .2$ continued.

\begin{tabular}{|c|c|c|c|c|c|c|c|}
\hline \multicolumn{8}{|c|}{ 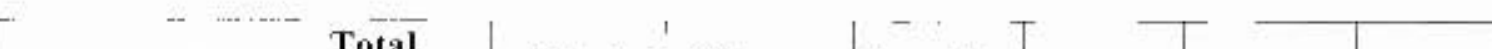 } \\
\hline Test Number & $\begin{array}{c}\text { Total } \\
\text { Number of } \\
\text { Blasts }\end{array}$ & $\begin{array}{c}\text { Blast } \\
\text { Number }\end{array}$ & $\begin{array}{l}\text { Charge } \\
\text { Mass (g) }\end{array}$ & $\underset{\text { (Ns) }}{\text { Impulse }}$ & $\phi$ & $\delta(\mathrm{mm})$ & $\delta / I I$ \\
\hline T3R 1M25R/* & 1 & 1 & 25 & 41.69 & 7.70 & 11.84 & 3.95 \\
\hline $13 \mathrm{R} 2 \mathrm{M} 25 \mathrm{~B} \mathrm{l}^{\circ}$ & \multirow[t]{2}{*}{2} & 1 & 25 & 43.76 & 8.08 & \multirow[t]{2}{*}{12.43} & \multirow[t]{2}{*}{4.14} \\
\hline T3R2M25B2* & & 2 & 25 & 44.60 & 8.24 & & \\
\hline 13R.3M25RL* & \multirow[t]{3}{*}{3} & 1 & 25 & 42.12 & 7.78 & \multirow[t]{3}{*}{13.8} & \multirow[t]{3}{*}{4.60} \\
\hline T3R3M25132* & & 2 & 25 & 40.65 & 7.51 & & \\
\hline $13 R 3 \mathrm{M} 25 \mathrm{~B} 3 *$ & & 3 & 25 & 44.19 & 8.16 & & \\
\hline T3R4M25B।* & \multirow[t]{4}{*}{4} & 1 & 25 & 43.56 & 8.05 & \multirow[t]{4}{*}{15.79} & \multirow[t]{4}{*}{5.26} \\
\hline $\mathrm{T} 3 \mathrm{R} 4 \mathrm{M} 25 \overline{\mathrm{B} 2^{*}}$ & & 2 & 25 & 42.91 & 7.93 & & \\
\hline $13 \mathrm{R} 4 \mathrm{M} 25 \mathrm{~B} 3^{*}$ & & 3 & 25 & 44.62 & 8.24 & & \\
\hline $\mathrm{T} 3 \mathrm{R} 4 \mathrm{M} 25 \mathrm{~B} 4 *$ & & 4 & 25 & 44.02 & 8.13 & & \\
\hline T3R5M25B|* & \multirow[t]{5}{*}{5} & 1 & 25 & 43.76 & 8.08 & \multirow[t]{5}{*}{15.85} & \multirow[t]{5}{*}{5.28} \\
\hline $13 \mathrm{R} 5 \mathrm{M} 25 \mathrm{~B} 2^{*}$ & & 2 & 25 & 44.62 & 8.24 & & \\
\hline T3R $5 M \overline{25 B 3^{*}}$ & & 3 & 25 & 43,96 & 8.12 & & \\
\hline T3R5M25B4* & & 4 & 25 & 42.51 & 7.85 & & \\
\hline $13 \mathrm{R} 5 \mathrm{~W} 25 \mathrm{~B} 5 *$ & & 5 & 25 & 44.85 & 8.28 & & \\
\hline T3RIM30B ${ }^{*}$ & 1 & 1 & 30 & 47.00 & 8.68 & 12.8 & 4.27 \\
\hline T3R2M30B1* & \multirow{2}{*}{2} & 1 & 30 & 51.76 & 9.56 & \multirow{2}{*}{15.36} & \multirow{2}{*}{5.12} \\
\hline $\mathrm{T} 3 \mathrm{R} 2 \mathrm{M} 30 \mathrm{~B} 2^{*}$ & & 2 & 30 & 50.26 & 9.28 & & \\
\hline T3R3 $430 \mathrm{~B}]^{*}$ & \multirow{3}{*}{3} & 1 & 30 & 48.06 & 8.88 & \multirow{3}{*}{16.73} & \multirow{3}{*}{5.58} \\
\hline T3R $3 \mathrm{M} 30 \mathrm{~B} 2 *$ & & 2 & 30 & 49.39 & 9.12 & & \\
\hline 1'3К3.430B3* & & 3 & 30 & 48.33 & 8.93 & & \\
\hline T3R4 $430 \mathrm{BI}$ & \multirow{4}{*}{4} & 1 & 30 & 47,46 & 8.77 & \multirow{4}{*}{16.86} & \multirow{4}{*}{5.62} \\
\hline T3R4M30B2* & & 2 & 30 & 49.83 & $9.26)$ & & \\
\hline [3R4M30B3* & & 3 & 30 & 49.43 & 9.13 & & \\
\hline T3R4 130R4* & & 4 & 30 & 48.14 & 8.89 & & \\
\hline $13 \mathrm{R} 5 \mathrm{M} 30 \mathrm{Bl} *$ & \multirow{5}{*}{5} & 1 & 30 & 48.96 & 9.04 & \multirow{5}{*}{18.11} & \multirow{5}{*}{6.04} \\
\hline T3R5M30B2* & & 2 & 30 & 47.66 & 8.80 & & \\
\hline T3R5M30B 3* & & 3 & 30 & 49.79 & 9.20 & & \\
\hline [3R5M30B4* & & 4 & 30 & 48.14 & 8.89 & & \\
\hline T3R5M30B5* & & 5 & 30 & 49.39 & 9.12 & & \\
\hline
\end{tabular}

* experimental results from Ranwaha [74] 
Iable 4.2 continued.

\begin{tabular}{|c|c|c|c|c|c|c|c|}
\hline Test Number & $\begin{array}{l}\text { Total } \\
\text { Number of } \\
\text { Blasts }\end{array}$ & $\begin{array}{c}\text { Blast } \\
\text { Number }\end{array}$ & $\begin{array}{l}\text { Charge } \\
\text { Mass (g) }\end{array}$ & $\begin{array}{c}\text { Impulse } \\
\text { (Ns) }\end{array}$ & $\phi_{\mathrm{cs}}$ & $\delta(\mathrm{mm})$ & $\delta / H$ \\
\hline I 3 R3M $35 \mathrm{~B} 1$ & 1 & 1 & 35 & 51.40 & 9.50 & 15.69 & 5.23 \\
\hline T3R2M3รB 1 & \multirow{2}{*}{2} & 1 & 35 & 52.57 & 9.50 & \multirow{2}{*}{18.21} & \multirow{2}{*}{6.07} \\
\hline T3R2M 35132 & & 2 & 35 & 49.32 & 9.71 & & \\
\hline [13R3M35I3] & \multirow{3}{*}{3} & 1 & 35 & 50.17 & 9.11 & \multirow{3}{*}{18.47} & \multirow{3}{*}{6.16} \\
\hline T3R3M $3 5 \longdiv { B 2 }$ & & 2 & 35 & 50.32 & 11.12 & & \\
\hline T3R3M35B3 & & 3 & 35 & 52.75 & 9.30 & & \\
\hline $13 R+M 135 B 1$ & \multirow{4}{*}{4} & 1 & 35 & 51.92 & 9.74 & \multirow{4}{*}{19.96} & \multirow{4}{*}{6.65} \\
\hline T3R4.435B2 & & 2 & 35 & $\$ 1.15$ & 9.45 & & \\
\hline $13 \mathrm{R} 4 \mathrm{M3} 5 \mathrm{B3}$ & & 3 & 35 & 50.32 & 9.30 & & \\
\hline $\mathrm{T} 3 \mathrm{R} 4 \mathrm{M} 35 \mathrm{~B} 4$ & & 4 & 35 & 49.22 & 9.09 & & \\
\hline T3R5M35B1 & \multirow{5}{*}{5} & 1 & 35 & 50.57 & 9.34 & \multirow{5}{*}{21.28} & \multirow{5}{*}{7.09} \\
\hline T3RSM35R? & & 2 & 35 & 50.11 & 9.36 & & \\
\hline T3R5M35133 & & 3 & 35 & 49.52 & 9.15 & & \\
\hline T3R5M $35 \mathrm{~B} 4$ & & 4 & 35 & 50.32 & 9.30 & & \\
\hline T3R.5M35135 & & 5 & 35 & 46.39 & 8.57 & & \\
\hline 13R IM40I31 * & 1 & 1 & 40 & 59.84 & 11.05 & 16.2 & 5.40 \\
\hline T3R2M40R]* & \multirow{2}{*}{2} & 1 & 40 & 57.68 & 10.66 & \multirow{2}{*}{17.97} & \multirow{2}{*}{5.99} \\
\hline T3R2M40132* & & 2 & 40 & 58.56 & 10.82 & & \\
\hline $13 \mathrm{R} 3 \mathrm{M} 140 \mathrm{Bl}$ & \multirow{3}{*}{3} & 1 & 40 & 56.85 & 10.50 & \multirow{3}{*}{21.36} & \multirow{3}{*}{7.12} \\
\hline T3R3M40ß2 & & 2 & 46) & 56.63 & 10.46 & & \\
\hline $13 R 3 M 40133$ & & 3 & 40 & 54.10 & 9.99 & & \\
\hline I'3R4M40RI & \multirow{4}{*}{$*$} & 1 & 40 & 63.98 & 11.82 & \multirow{4}{*}{ Torn } & \multirow{4}{*}{ NA } \\
\hline $\mathrm{I} 3 \mathrm{R}+\mathrm{M} 40 \mathrm{I} 2$ & & 2 & 40 & 57.98 & 10.71 & & \\
\hline $13 R 4 M 40 B 3$ & & 3 & 40 & 59.84 & 11.05 & & \\
\hline T3R4M40I34 & & 4 & 40 & $\$ 2.57$ & 9.71 & & \\
\hline
\end{tabular}




\subsection{General Plate Deformation}

In general. the plate delumation was chemacterived by a large glubal plastic dome indicative of uniform blast loads, as observed by Jacob et al $[51]$, for uniform blast loading. $\Lambda$ pholograph of the global dome shaped deformation is displayed in Figure 4.1, for the test T2R3M15B3 (third blast). with a charge mass $(m)$ of $15 \mathrm{~g}$.

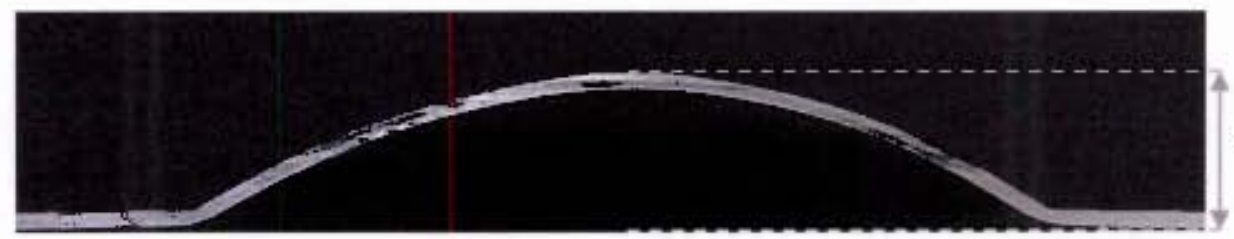

$\delta=16.12 \mathrm{~mm}$

Figure 4.1: Photograph of test plate cross sectional profile for test T2R.3115B3 $(\mathrm{m}=15 \mathrm{~g})$

\section{Thinning}

Thituing at the clamp boundaries, shown in Figure 4.2, was observed for some of the tesl plates. Thimning occurred for the test plates subjected to ejther a cumbinalion of repeated blast loading or for higher impulsife loads, elose to the tearing threshold. The test plate thinning showed characteristics as observed in tensile test specimens when necking started to ocsur.

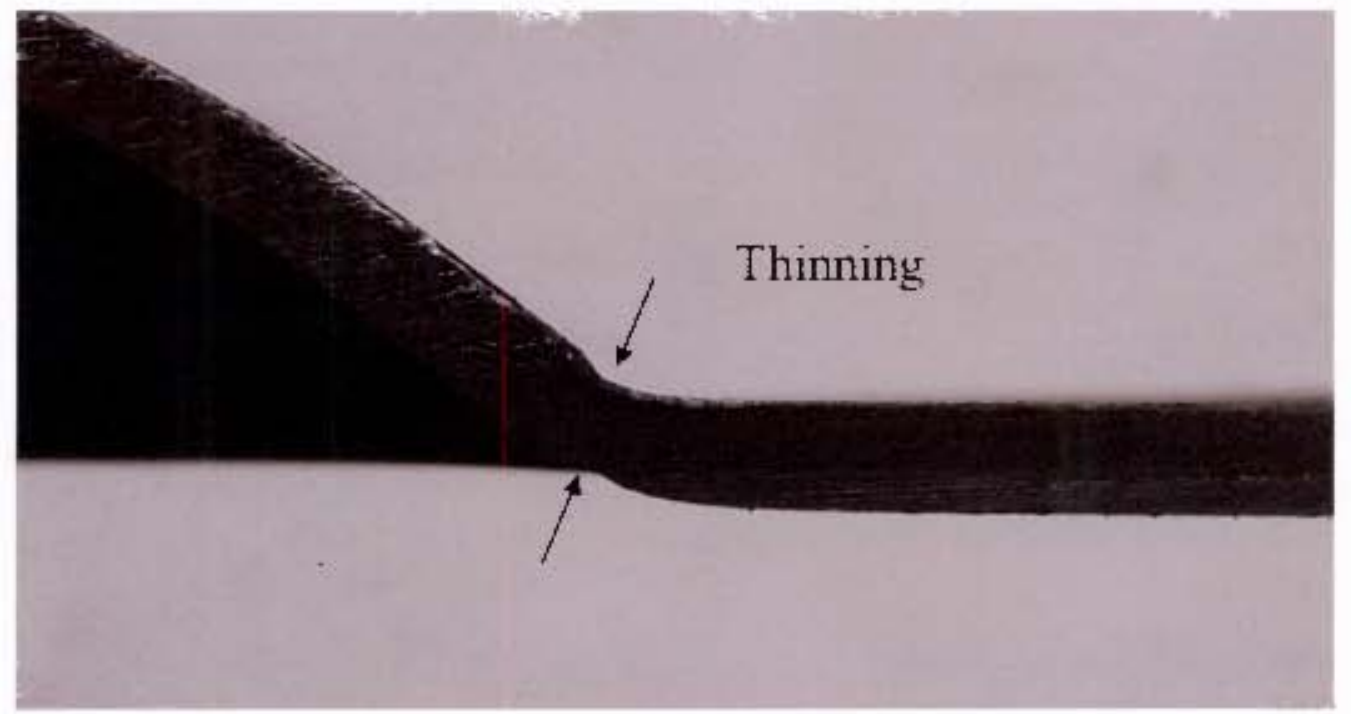

rigure 4.2: Plotograph of test plate boundary thinning for the $3 \mathrm{~mm}$ thick plate subjected to charge iniss $35 \mathrm{~g}$ and 2 blasts 
For the 2 mm thick test plates, thinning was observed at the boundary after:

- 5 blasis of 10 g of explosive (average $1-21,23 \mathrm{Ns}$ )

- 2 blasts of $15 \mathrm{~g}$ of explosive (average [-29.57 $\mathrm{Ns}$ )

- 1 blast of $20 \mathrm{~g}$ of explosive (average $I=37,32 \mathrm{As}$ )

- 1 blast or $25 \mathrm{~g}$ of explosive (atcrage I $-38.33 \mathrm{vs}$ )

For the $3 \mathrm{~mm}$ thick lest plates, thinning was observed at the botndary after:

- 2 blasts of $35 \mathrm{~g}$ ol explosive (average $\mathbf{I}=50.95 \mathrm{Ns}$ )

- 2 blasts of $40 \mathrm{~g}$ of explosive (average $1-58.60 \mathrm{NS}$ )

Only the experiments carried out for this dissertation were considered, as previous observations have been supplied by Ranwaha [7.1].

\section{Tearing}

Some test plates exhibited either full or partial tearing at the boundarics, indicating Mode $\left[{ }^{*}\right.$ and Mode II failure [62]. Tearing at the boundaries oceurred as the threshold imptise for the test plates was surpassed |5l] or the resultant damage incurred by the consecutive repeated blast loads was enough to cause boundary tearing.

For the $2 \mathrm{~mm}$ and $3 \mathrm{~mm}$ thick tesl plates, tearing at the boutidary was observed for the experimental tests listed in Table 4.3.

Table 4.3: Plates whicl experienced boundary tearing before 5 Iflasts

\begin{tabular}{|c|c|c|c|}
\cline { 2 - 3 } $\begin{array}{c}\text { Plate } \\
\text { Ihickness } \\
(\mathbf{m m})\end{array}$ & $\begin{array}{c}\text { Chargc } \\
\text { Mass (g) }\end{array}$ & $\begin{array}{c}\text { Failure } \\
\text { Blast }\end{array}$ & $\begin{array}{c}\text { Average } \\
\text { Impulsc } \\
\text { (c) }\end{array}$ \\
\hline 2 & 15 & 1 & 28.60 \\
\hline 2 & 20 & 3 & 34.99 \\
\hline 2 & 25 & 2 & 39.36 \\
\hline 3 & 40 & 1 & 58.59 \\
\hline
\end{tabular}


Chapter 4 - Experimental Results and Observations

The observations made on boundary tearing suggested a basic trend of the number of blasts needed to induce boundary tearing decreased as the charge mass increased. Partial and complete boundary tearing of the test plates are shown in Figure 4.3 and Figure 4.4. 


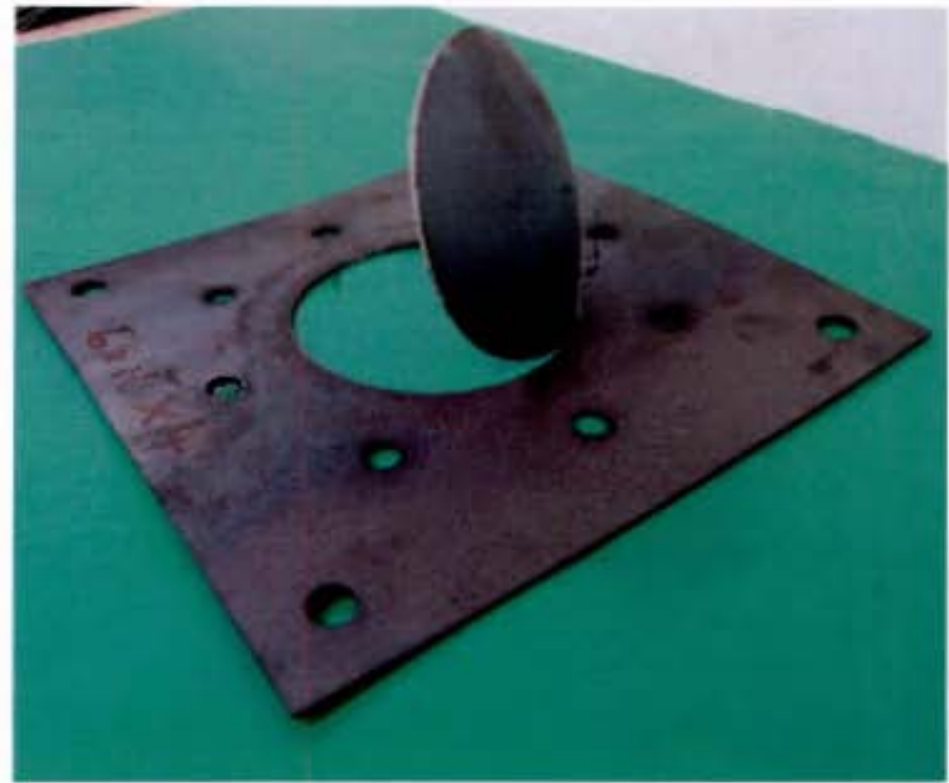

Figure 4.3: Photograph showing partial boundary tearing of $2 \mathrm{~mm}$ test plate subjected to 4 blasts of charge mass isg

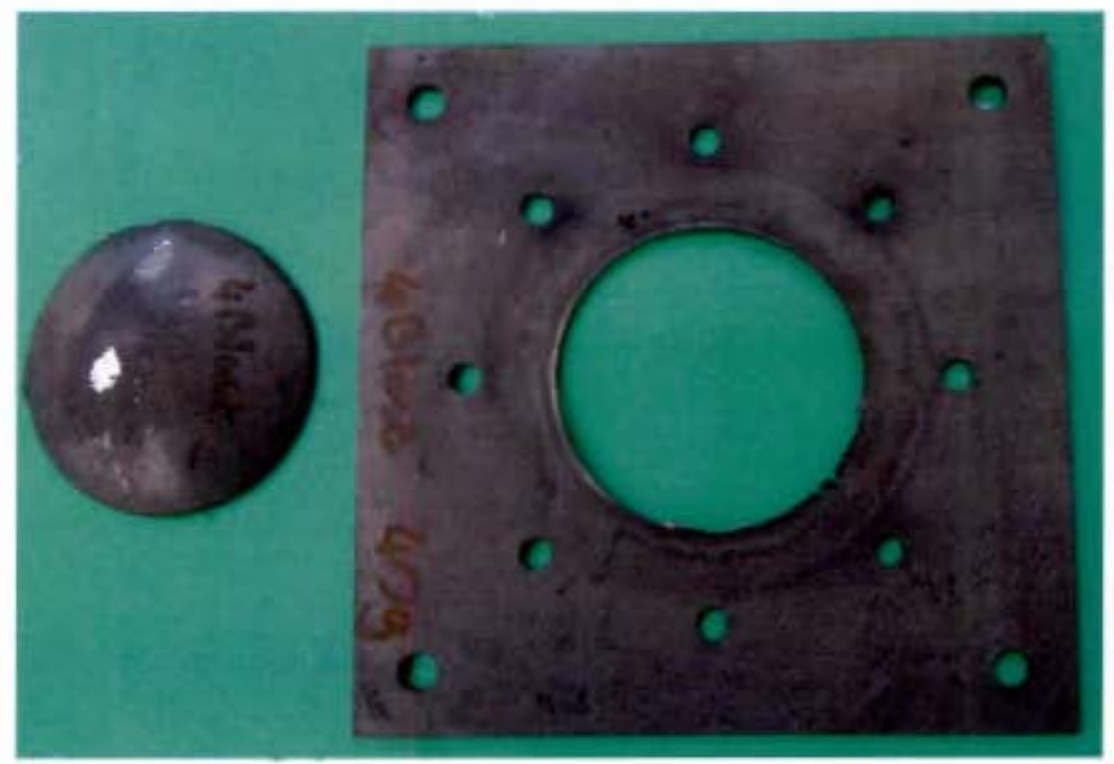

Figure 4.4: Photograph showing full boundary tearing of the 3 men thich text plate subjected to 4 blasts of charge mass $40 \mathrm{~g}$ 


\subsection{Observations on Midpoint Deflection and Plate Profiles}

\subsubsection{Effects of Charge Mass}

Generally, the results show the midpoint deflection increased with an increase in charge mass; shown in Figure 4.5 -Figure 4.14. The photographs and digital profiles show the comparisons between the deformations of plates subjected to varying charge masses, for the same repeated blast load series (Figure 4.5 -Figure 4.14). The digital profiles were obtained by digitally scanning the cross sectional profiles of the test plates. Only test plates subjected to $5 \mathrm{~g}$ and $10 \mathrm{~g}$ charge masses for the $2 \mathrm{~mm}$ thick test plates were able to withstand 5 blast tests without tearing. For a charge mass of $15 \mathrm{~g}$, only three blast tests were carried out before the plate experienced tearing. For $20 \mathrm{~g}$, only 2 blasts and $25 \mathrm{~g}$, only one blast was carried out before tearing.

Comments: torn plates were excluded from the photographs of the deformed plate profiles. 


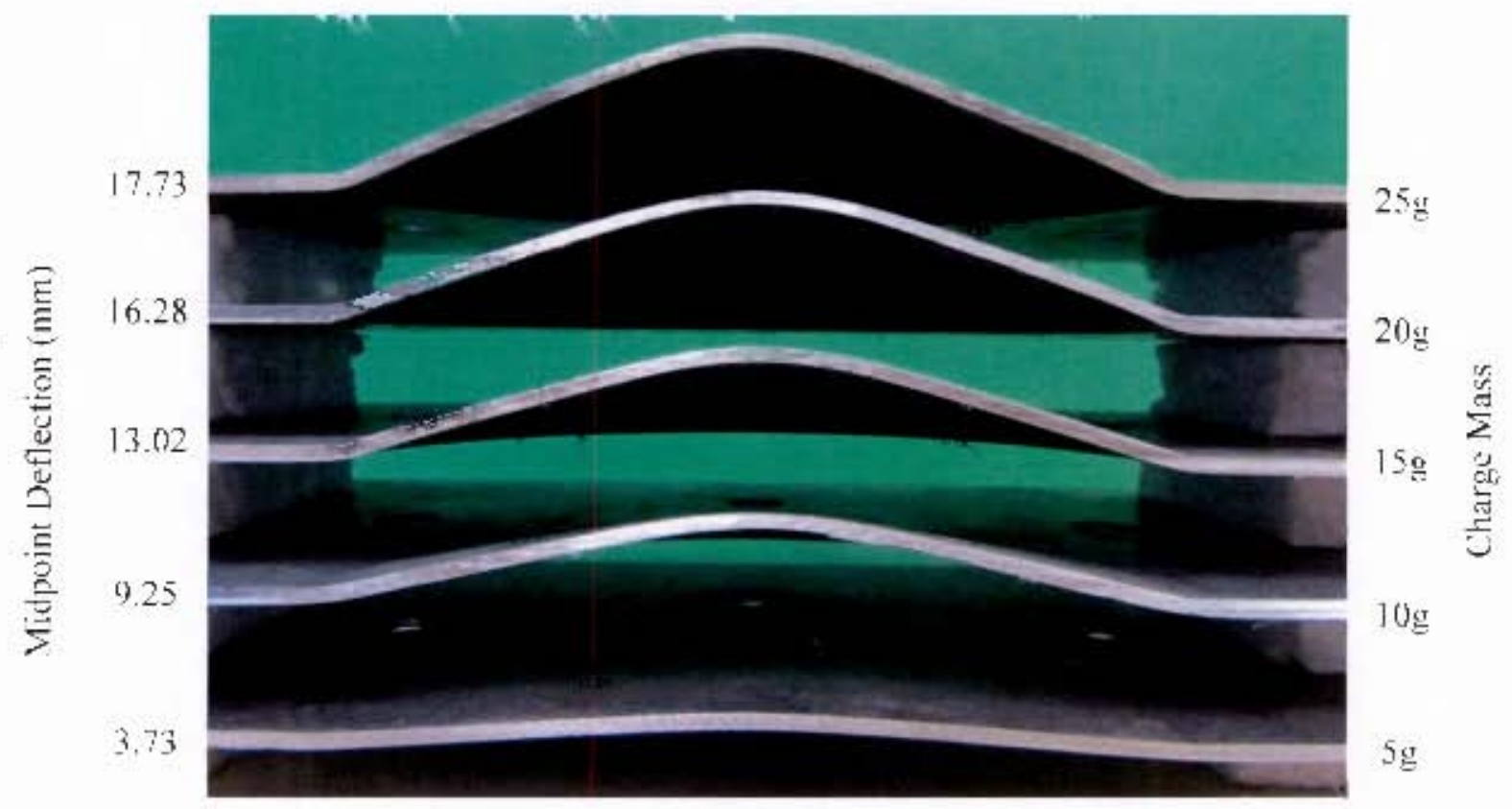

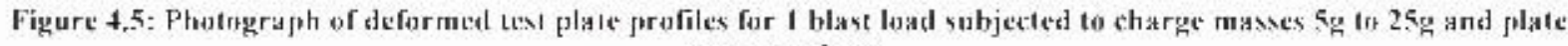
thickiness $2 \mathrm{~mm}$

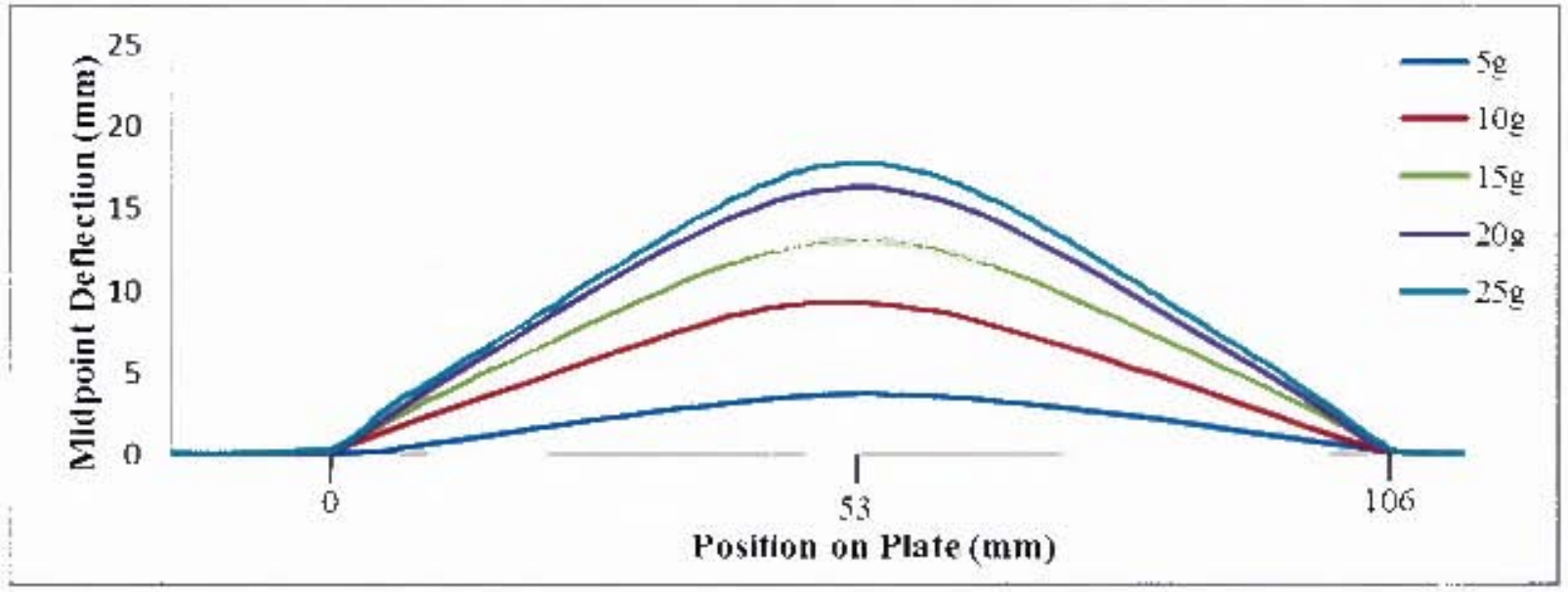

Figure 4.6: Bogitized graphical representation of the defor need test plate profiles for 1 blast load using sharge mass of $5 g$ to $25 \mathrm{~g}$ and plate thickness $2 \mathrm{~min}$ 


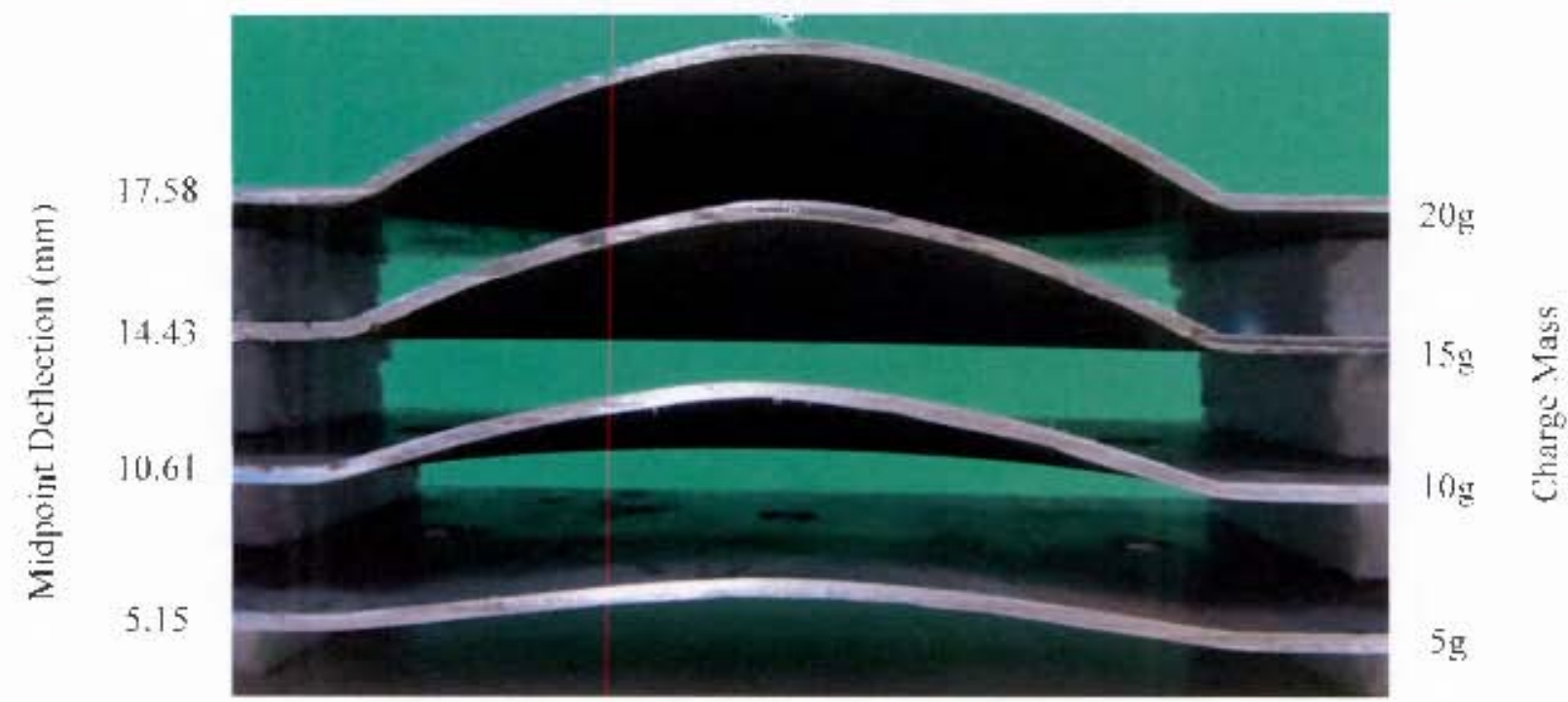

Figure 4.7: Photograph of deformed test plate profiles for 2 blast loads subjected to charge masses $5 g$ to $20 \mathrm{~g}$ and platc 1hickness $2 \mathrm{~m}$ III

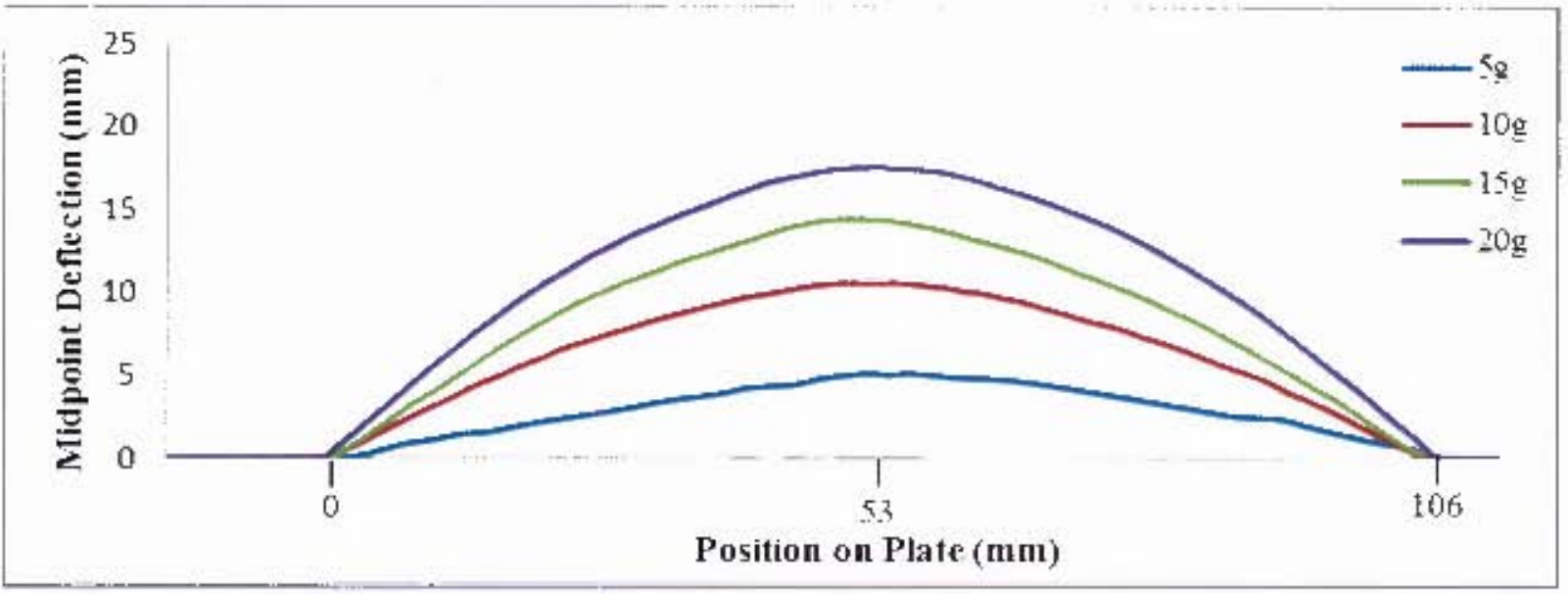

Figure 4.X: Degitized graphical representation of the defurmed test plate profiles for 2 blast loatls using charge mass nit $5 \mathrm{~g}$ to $20 \mathrm{~g} \mathrm{and} \mathrm{plate} \mathrm{dbickress.} 2 \mathrm{~mm}$ 


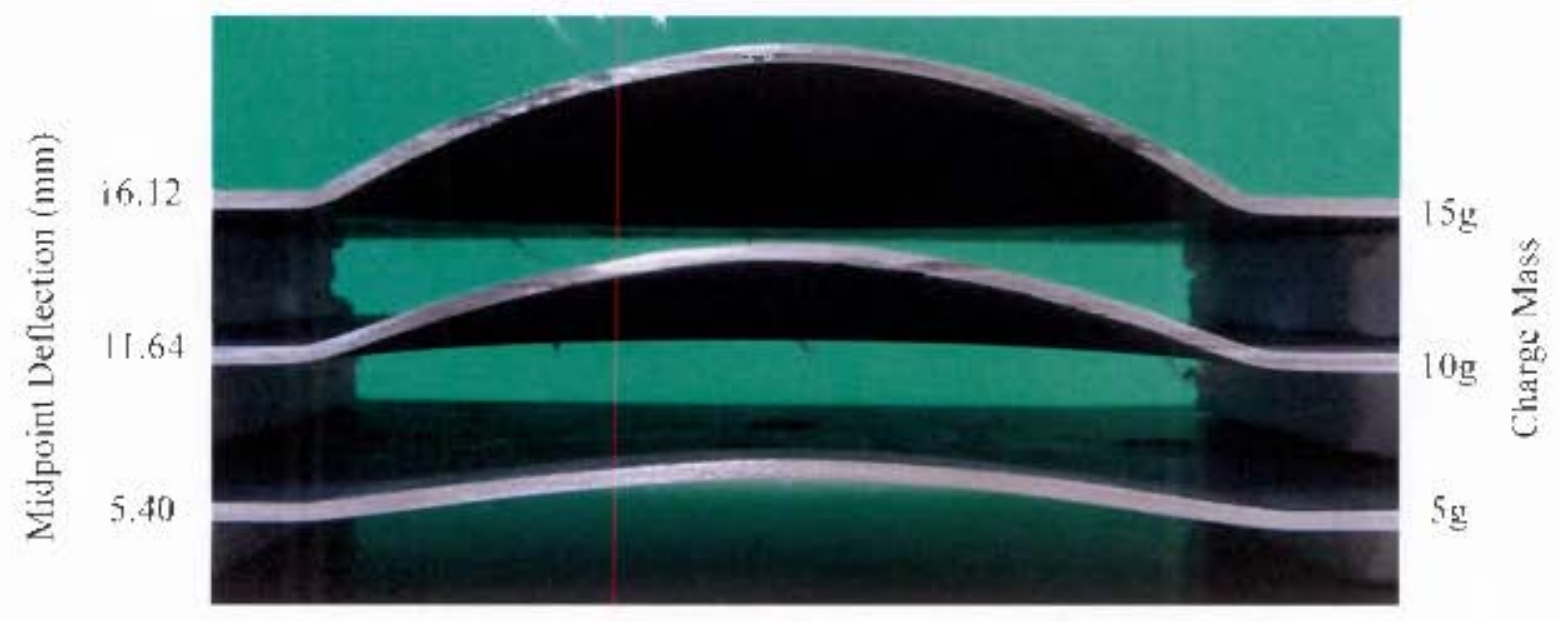

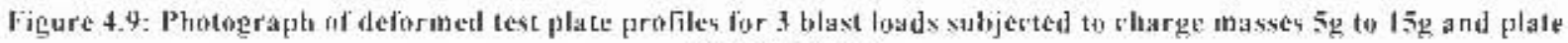
thickness $2 \mathrm{~mm}$

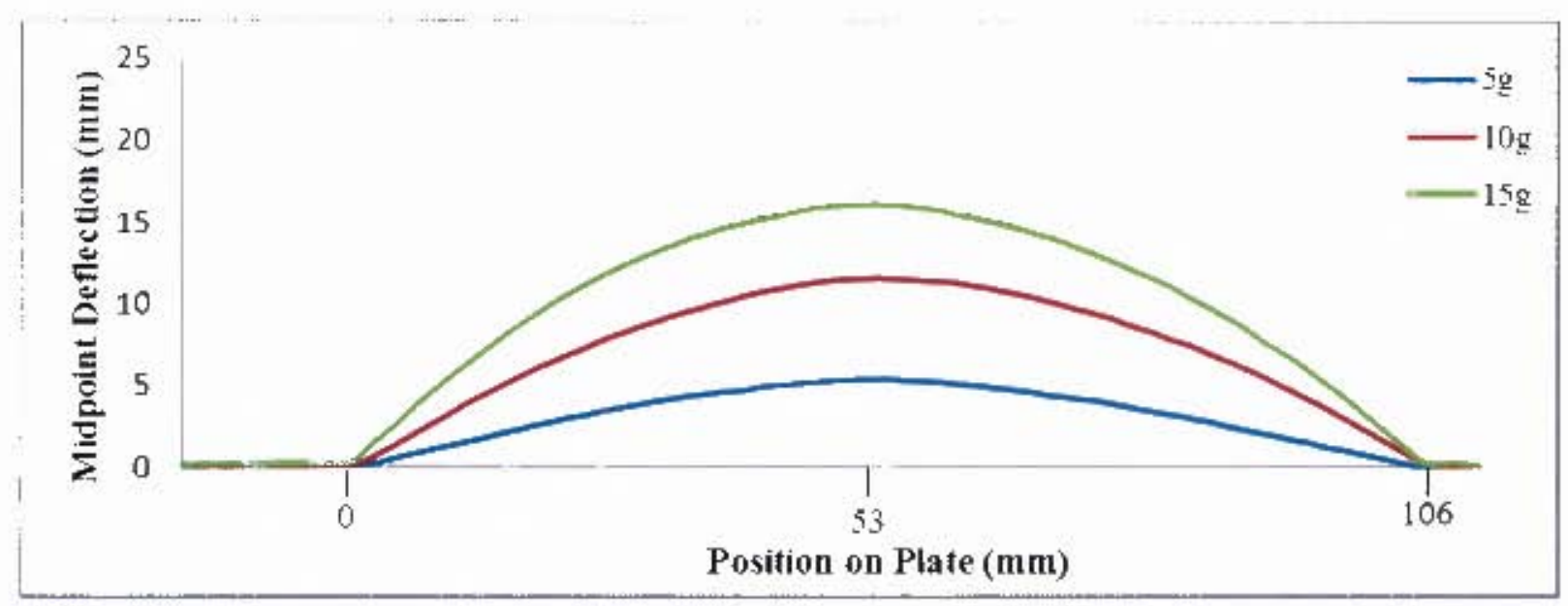

Vigure 4.11: Digitized graplaical representation of the deformed test plate profiles for 3 blast londs using charge mass of 5 g tis 15 gand platt thichness $2 \mathrm{~nm}$ 


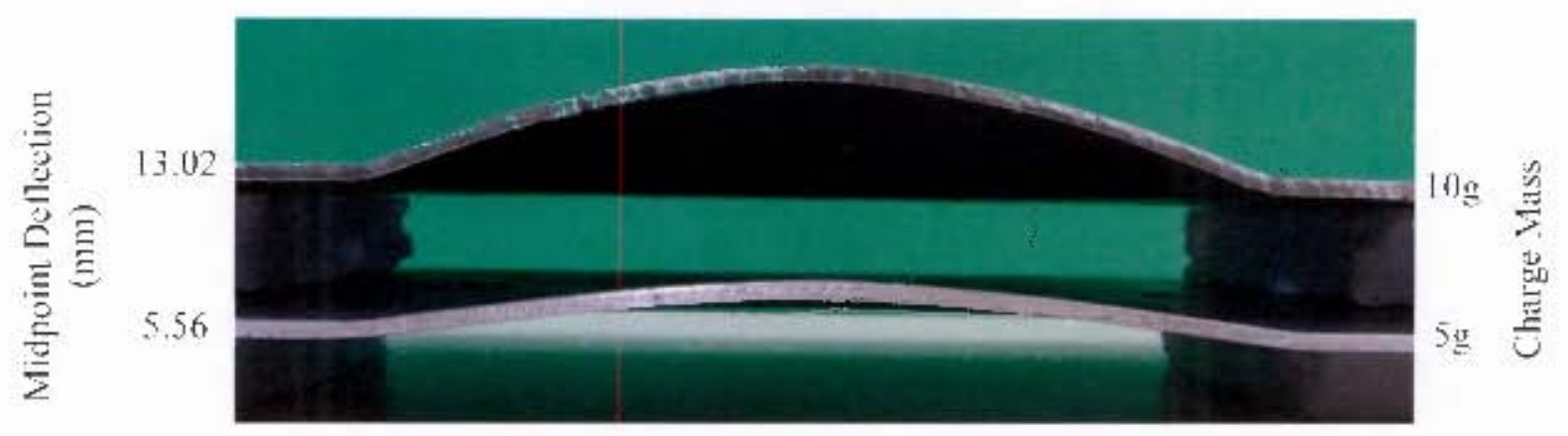

Figure 4.11: Phitograph of deformed lest plate profiles for 4 blasl loads subjected to charge masses 5 g to $10 \mathrm{~g}$ and plate 1 hit:kness $2 \mathrm{~mm}$

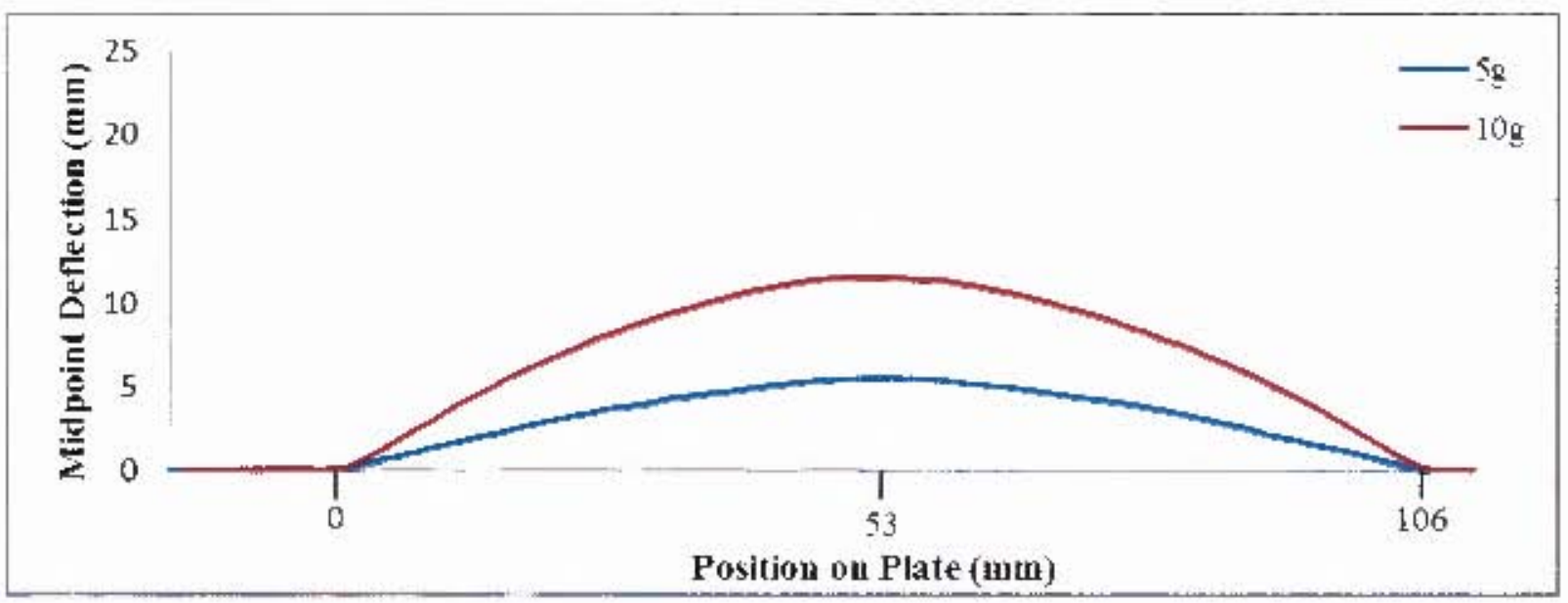

Figure 4,12: Digitized graphical representation of the deformed tesl plate profiles for 4 blast loads using charge mass of $5 \mathrm{~g}$ to $\mathrm{t}(\mathrm{gg}$ and plate thickness $2 \mathrm{cmm}$ 


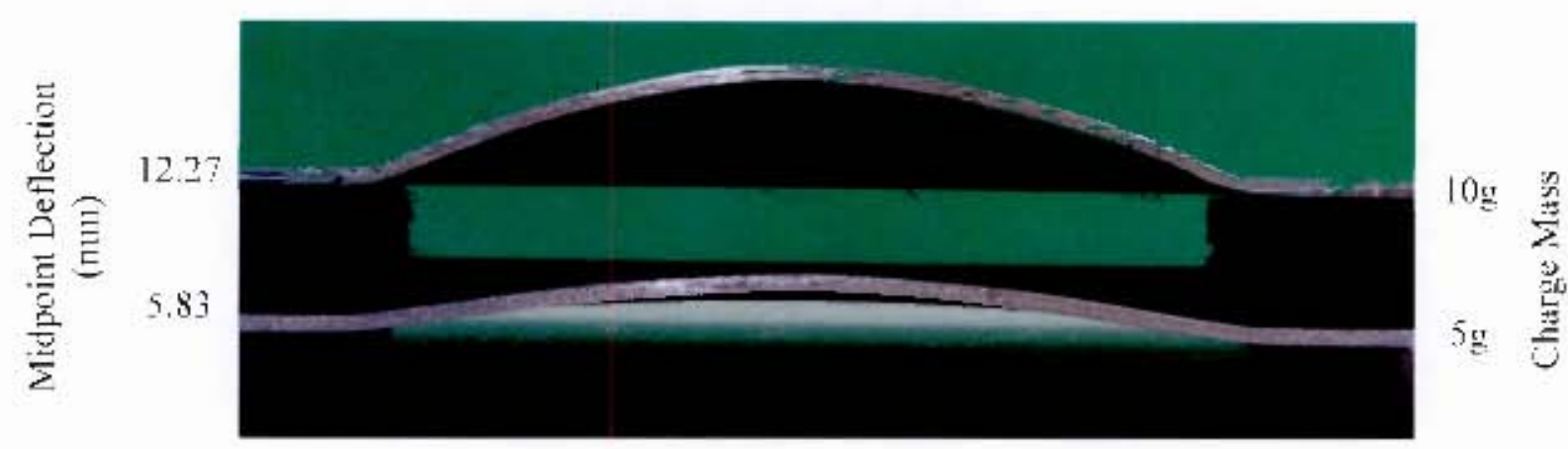

Figure 4.13: PJjotograph of deformed test plate protiles fot 5 blast lnads subjtctel to elarge masses $5 g$ en Itg ant plater thickness 2 rum

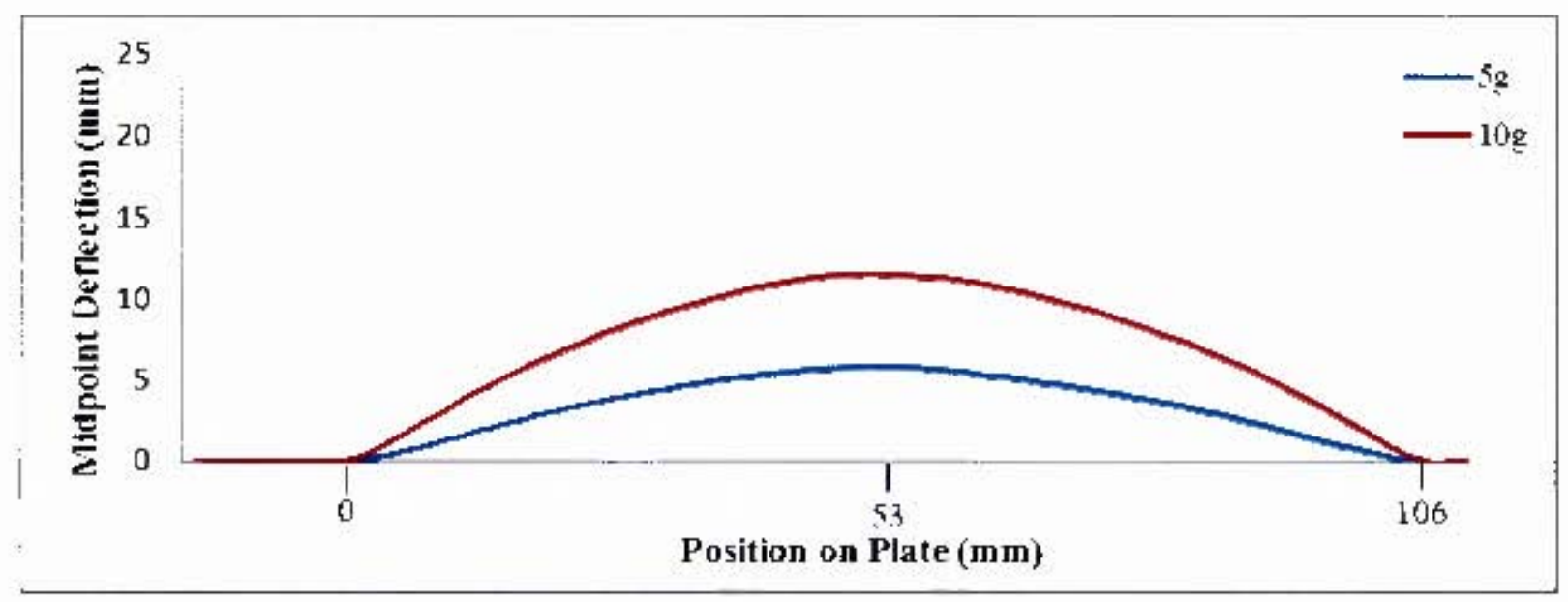

Figure 4.14: Digitized graplical representation of the deformed test plate profiles for 5 blast loads using charge mass or $5 \mathrm{~g}$ to $10 \mathrm{~g}$ and plate thickness $2 \mathrm{~mm}$ 


\subsubsection{Effects of Repeated Blast Loading}

Photographs of the deformed cross sectional plate profiles are displayed in conjunction with digital graplical representations of the protiles. The midpoin deflection gencrally increased with itn increase in the number of blast loads, shown in Figure 4.15 - Figure 4.26 , for the test plates $(2 \mathrm{~mm}$ and $3 \mathrm{~mm}$ thick).

For a charge mass $5 \mathrm{~g}$, the 2 mn plates deformed plastically with no thiming or tearing observed. I'he deformation profiles were all of similar global shape for each repeated blast series, as observed in Figure 4.15 and Figure 4.16. Minimal differences in dellection occurred from blast 2 to blast 5 , as is shown in rigure 4.16 . For the plate thickness $3 \mathrm{~mm}$, the final deflection for blast $5(2.10 \mathrm{~mm})$ was 0.62 mus less than the deflection for blitsi $4(2.72 \mathrm{~mm})$. This anomsty can be accounted for by repeittitbility of the blitst experiments, where the differences in midpoint deflections were less than one plate thickness. It was reported that the blasting experiments can be carricd out to within a 'repeatability confidence hactor" of one plate thickness [95].

Comment: Jorn plates were excluded from the photographs of the plate profiles.

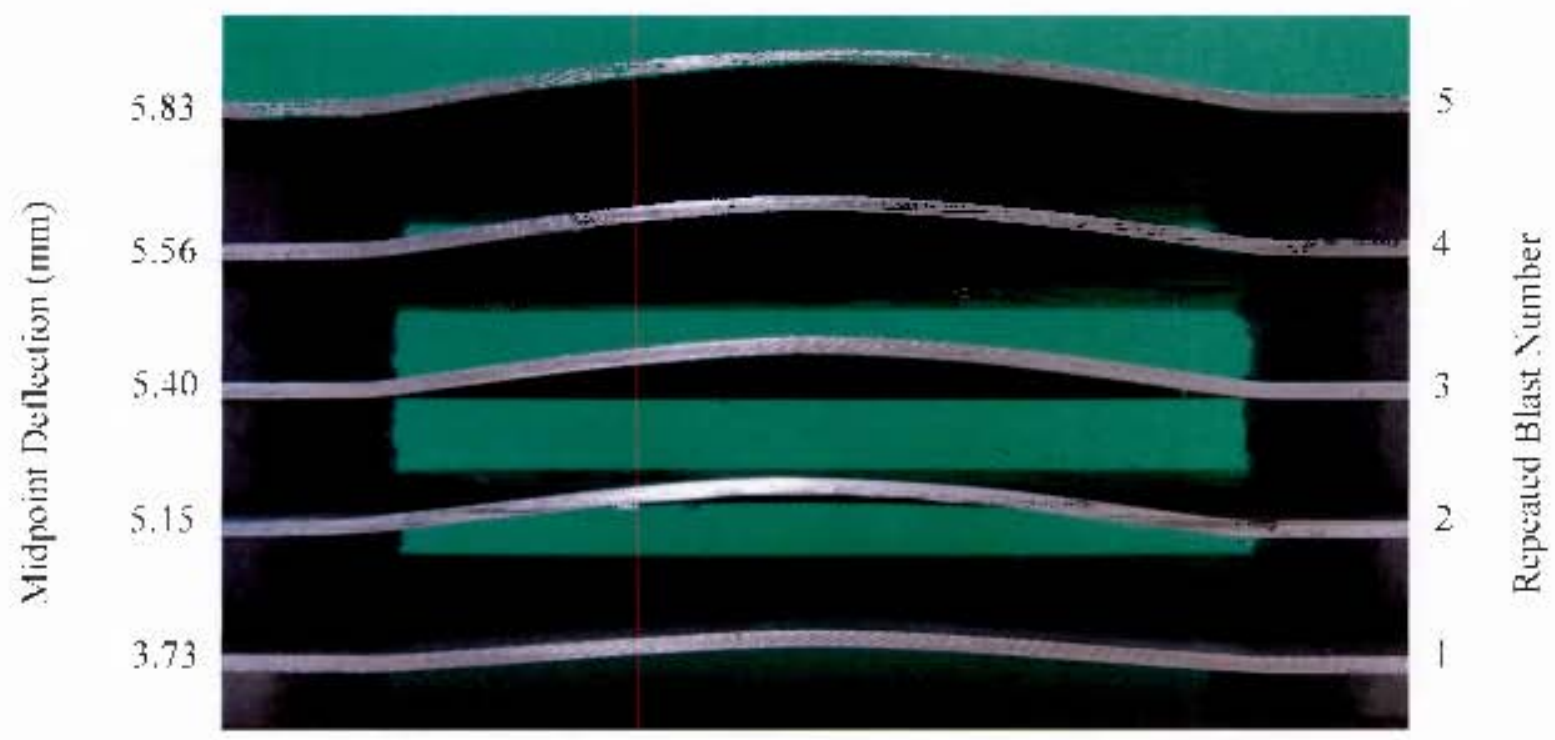

Figure 4.15: P'hotograph of deformel test plate profilex for 5 blast loads using charge mass of 5 g and plate thickiness $2 \mathrm{~mm}$ 


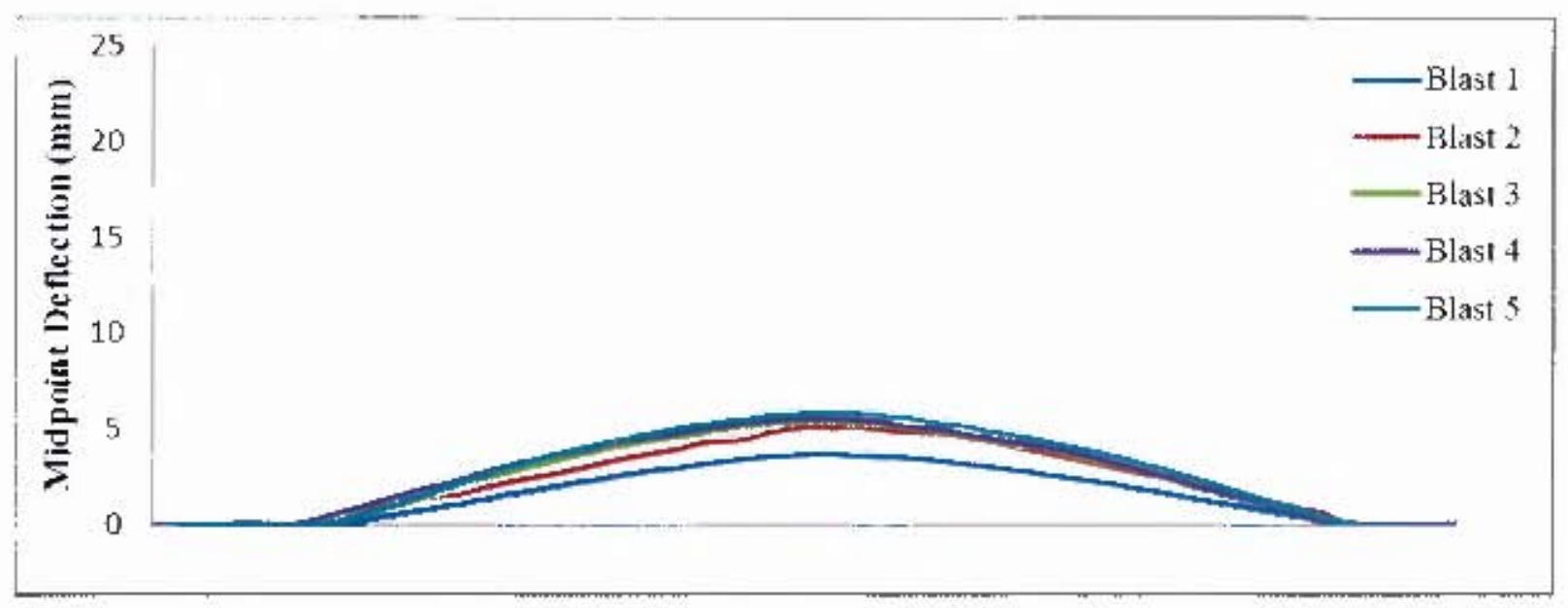

Figure 4. If: Digitized graphisal representation of the deformed teat plate profiles for 5 blast loads using cliarge mass of 5 g and plate thickness $2 \mathrm{~mm}$

The deformation shapes for the $2 \mathrm{~mm}$ and 3mm thich test plates subjected to chiatge masses $10 \mathrm{~g}$ and $15 \mathrm{~g}$ were similar, with the characteristic global dome (typical of uniform blast loading) visible in rigure 4.17, figure 4.19, Figure 4.20 and figure 4.22. As the number of blasi loads increased. the deformation profile started to change for charge masses $10 \mathrm{~g}$ and $15 \mathrm{~g}$. For a single blast, the plate profile was "linear" from the boundary deformation to the ecniral midpoint deformation. Onte the repeated blats increase the profile became 'rounder', as is highlingted in Figure 4.21, between blasts 1 and 3. The 2mm plate lailed at four blast loads for at charge mass $15 \mathrm{~g}$.

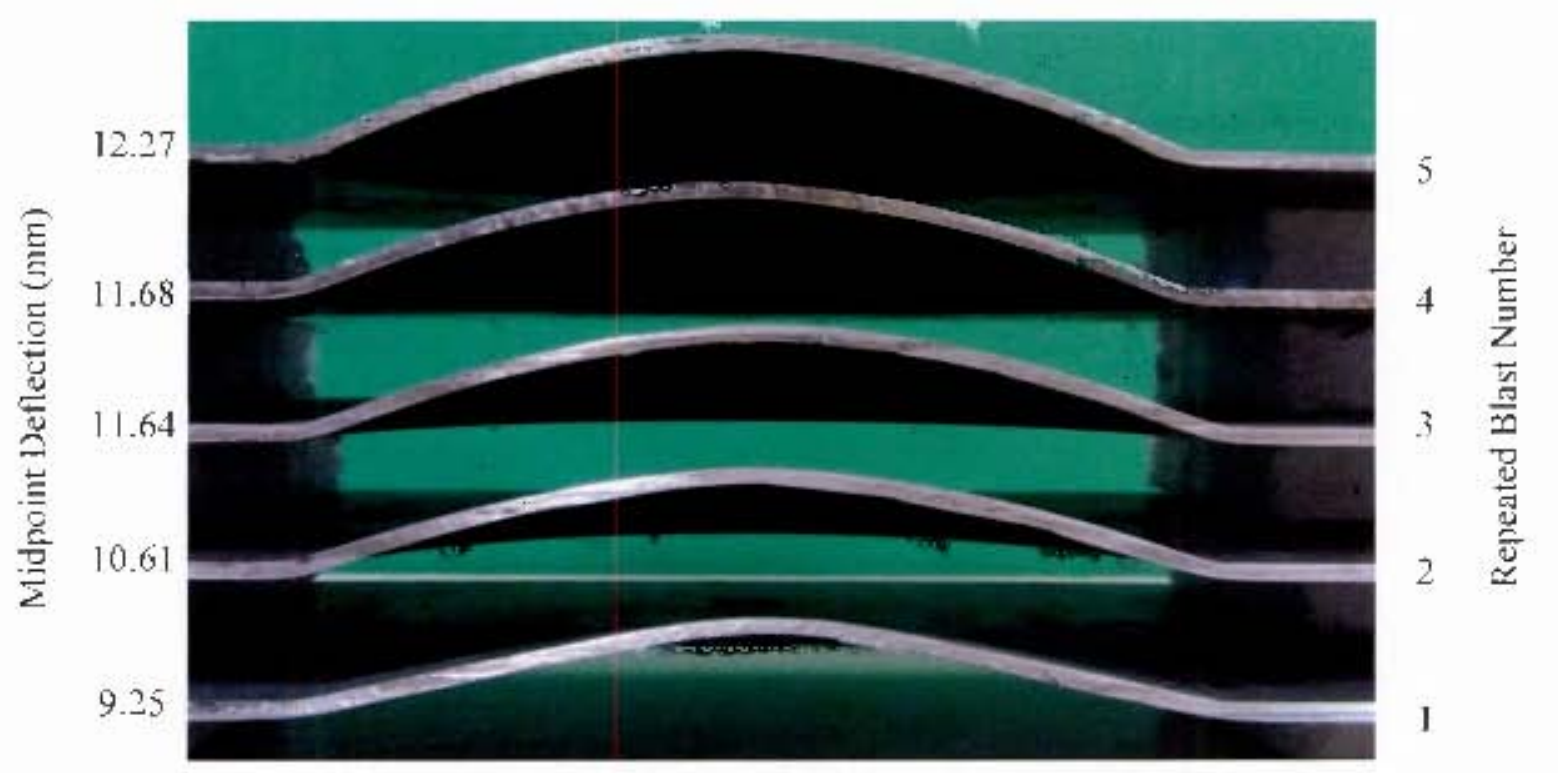

Figure 4.17: Photograph of deformed test plate profiles for 5 blast loats using charge mass of ling and plate dhiskinesa $2 \mathrm{~mm}$ 


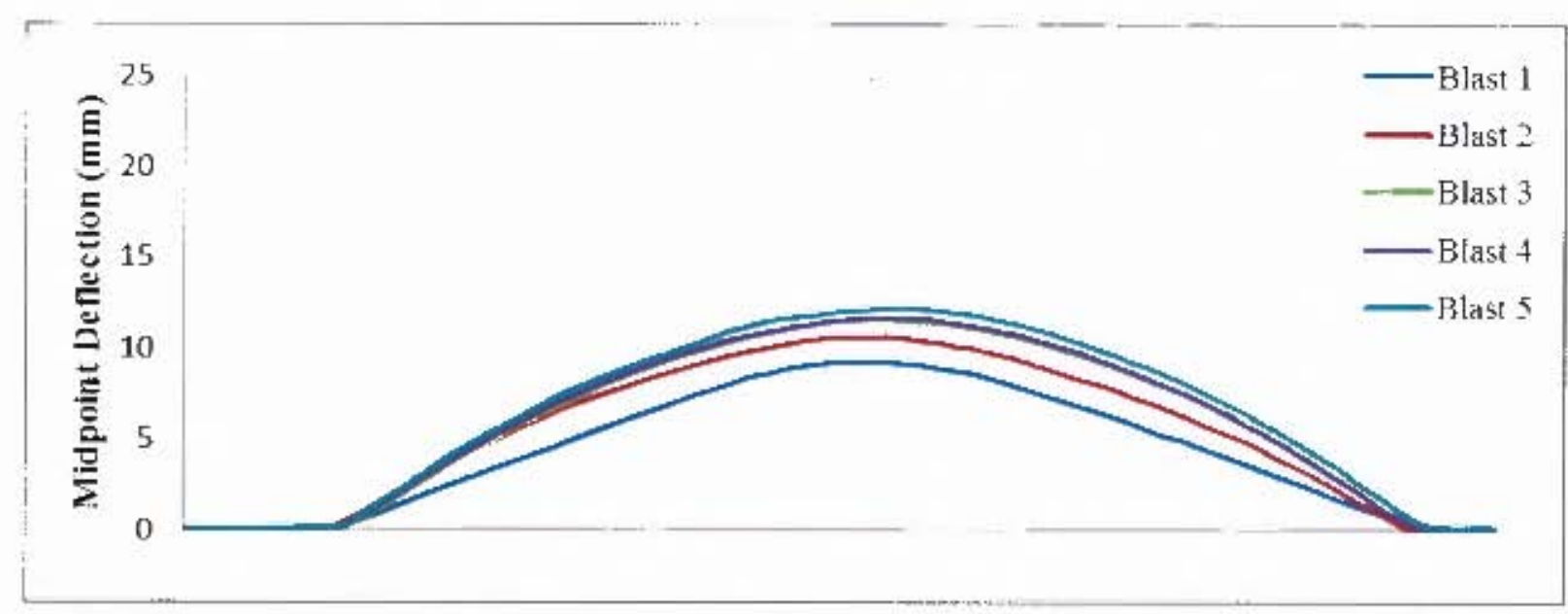

Figure 4.18: Digitized graphical representatiou of lhe deformed test jate profiles for 5 blast loads using charge mass of $10 \mathrm{~g}$ and plate thickness $2 \mathrm{~mm}$

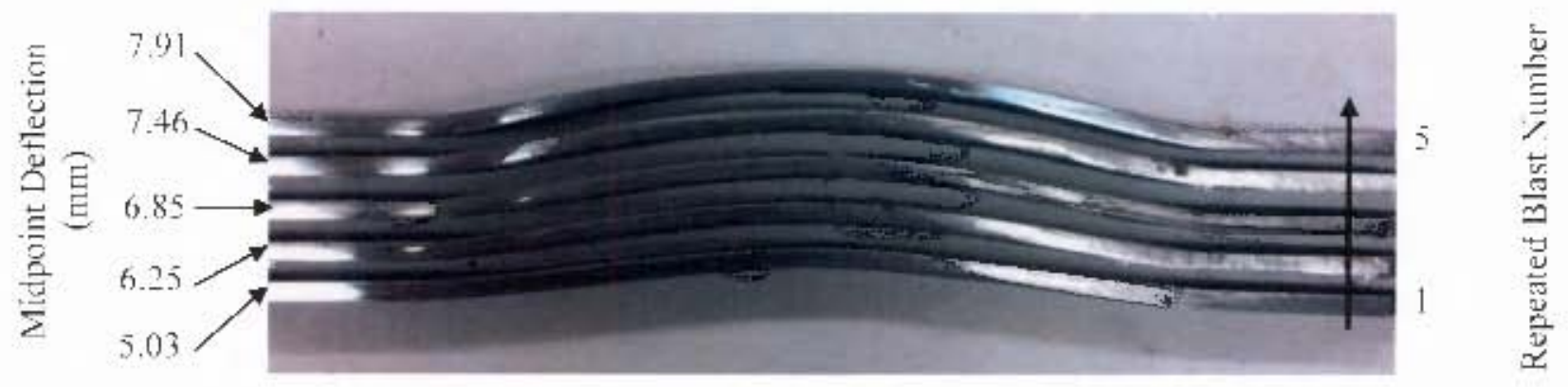

ligure 4.14: Photograph of detormed test plate profiles for 5 blast loads using charge mass of $10 \mathrm{~g}$ and plate thicliness $3 \mathrm{~mm}$ as used by Ranwaha $|? 4|$

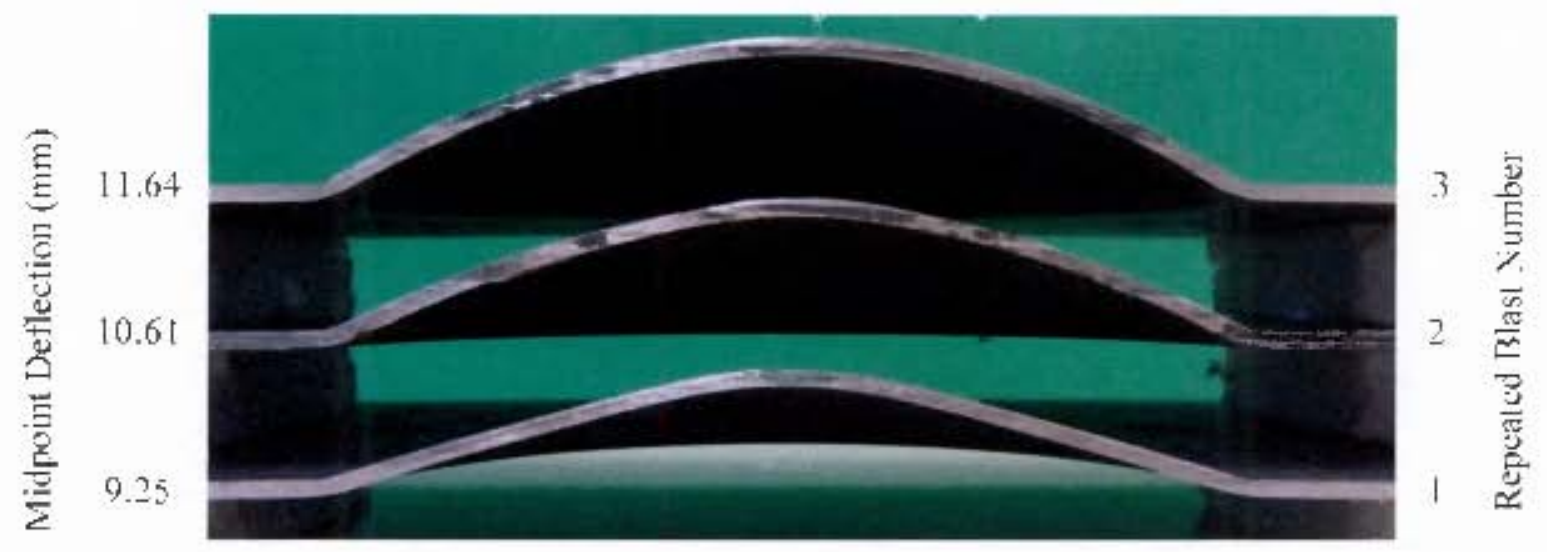

ligure 4.21: Photograph of deformed dest plate profiles for 5 blast loads using charge mass of $15 \mathrm{~g}$ and plate thickness $2 \mathrm{~mm}$ 


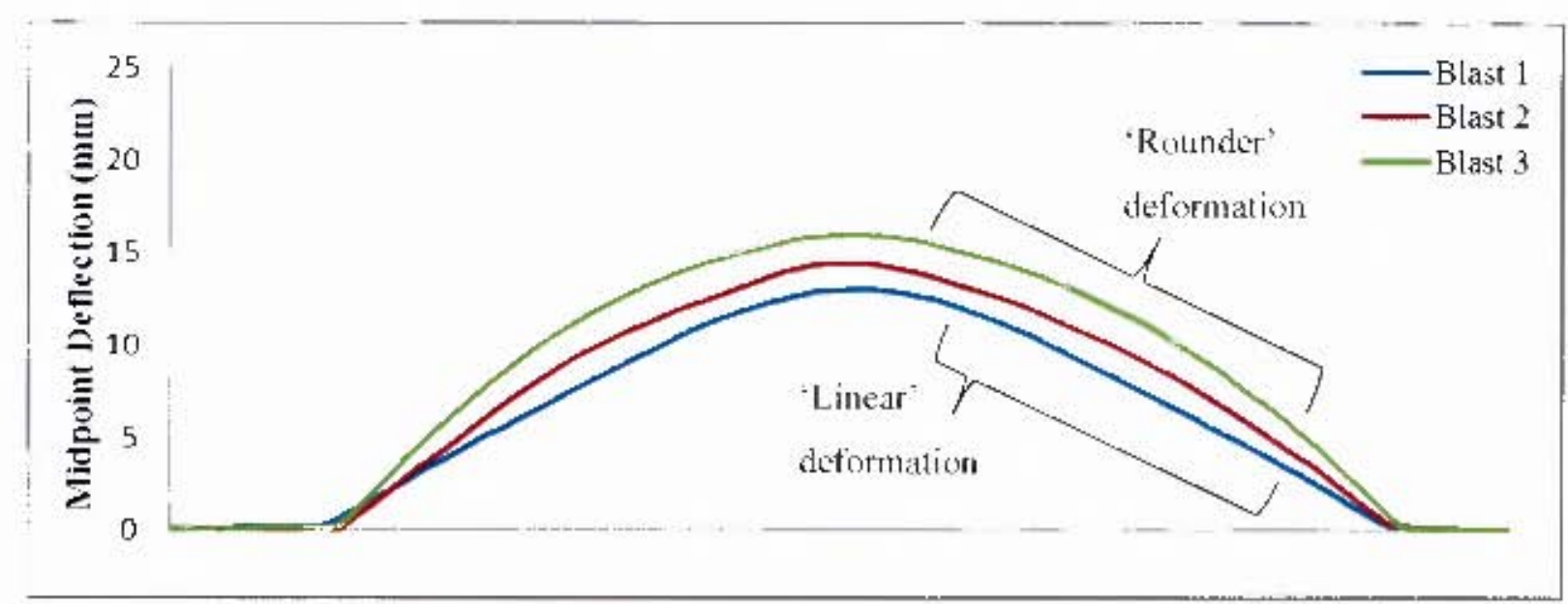

Figure 4.21: Digitized graphical representation of the deFormed test plate profilex for 5 blast loads using charge mass of $15 \mathrm{~g}$ and plate thickness $2 \mathrm{~mm}$

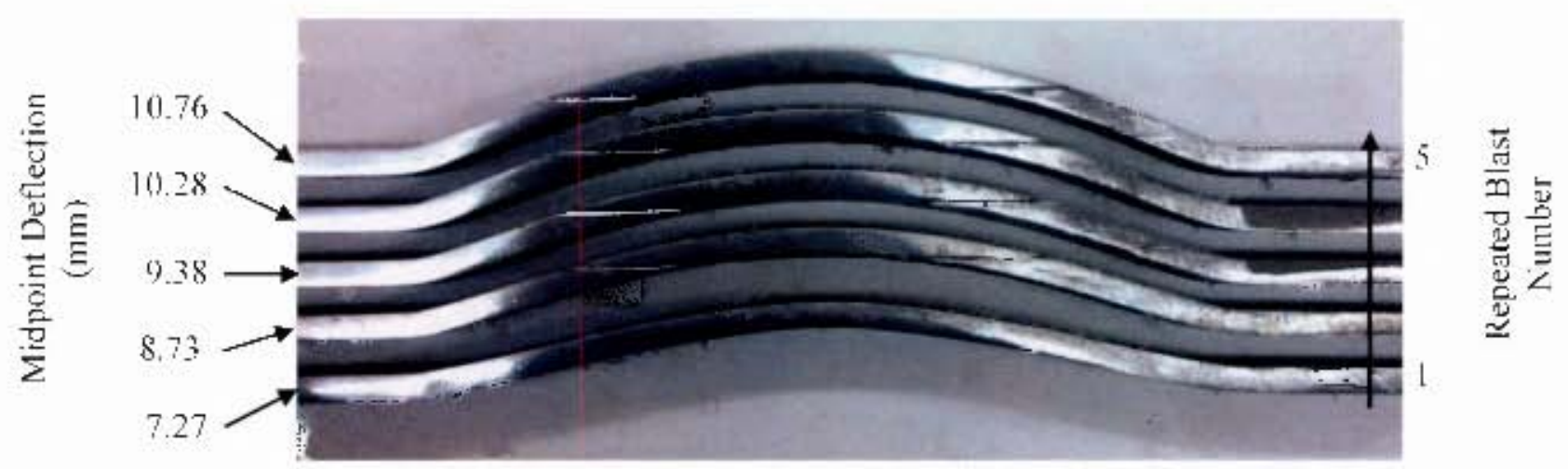

Jigure 4.22: Photograph of defirmed text plate profilex for 5 blast loads using charge mass of 159 and plate thickness $3 \mathrm{~mm}$ as used by Ranwiaha |74] [visible lines on specintens as a result of the machining process)

The 2 mim plate failed after three blast lodds of charge mass $20 \mathrm{~g}$. There was boundary thinning, predominantly present in the test plate subjected to various repeated blast loads and charge masses, as discussed in Section 4.2 and illustrated in Figuse 4.2. Ranwaha 74 / reported no thinning for the $3 \mathrm{~mm}$ thick test plates subjected to 5 btasts of $20 \mathrm{~g}$ of explosive. The profile shape of the deformation between blast $\mathrm{L}$ and 2 for a clarge mass of $20 \mathrm{~g}$ and plate thickness $2 \mathrm{~mm}$, was similar to the shapes for th charge mass $15 \mathrm{~g}$, where the global deformation progressed from "linear" to "founder" as the number of blasts increased. For a charge mass $35 \mathrm{~g}$. 1he midpoint deflection, for the 3 mm thick plate, increased after each blast load, as illustrated in Figure 4.26 . 'T here was evidence of thinning after 3 blasts of 35. of explosive on the $3 \mathrm{~mm}$ thick plate. 


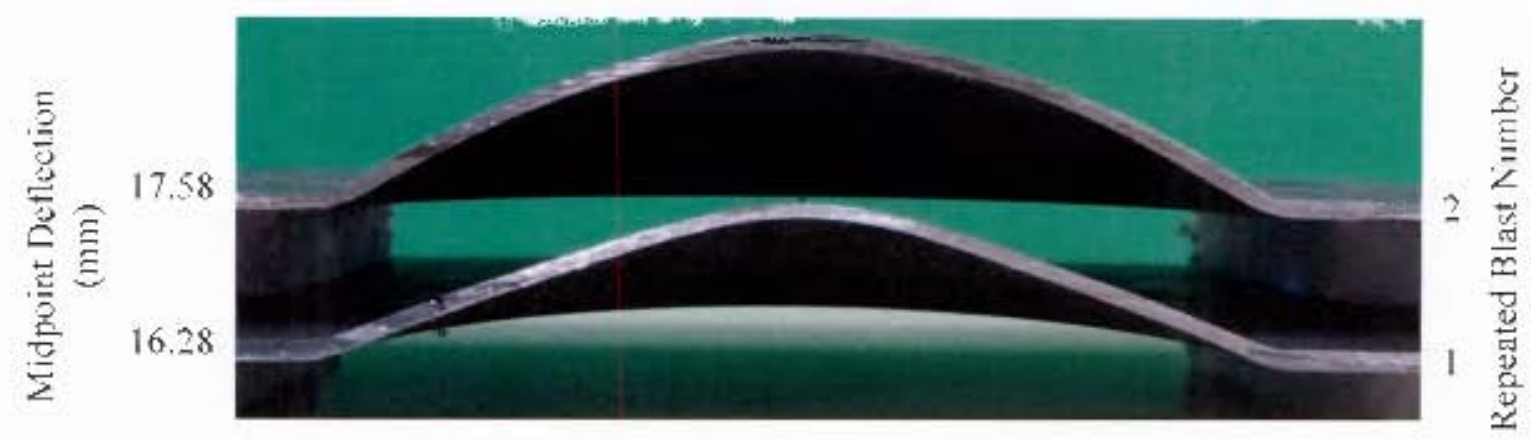

Figure 4.23: Photograph of deformed test plate profiles for 5 biast doads using clarge mass of 20ig and plate thichness 2 m ri!

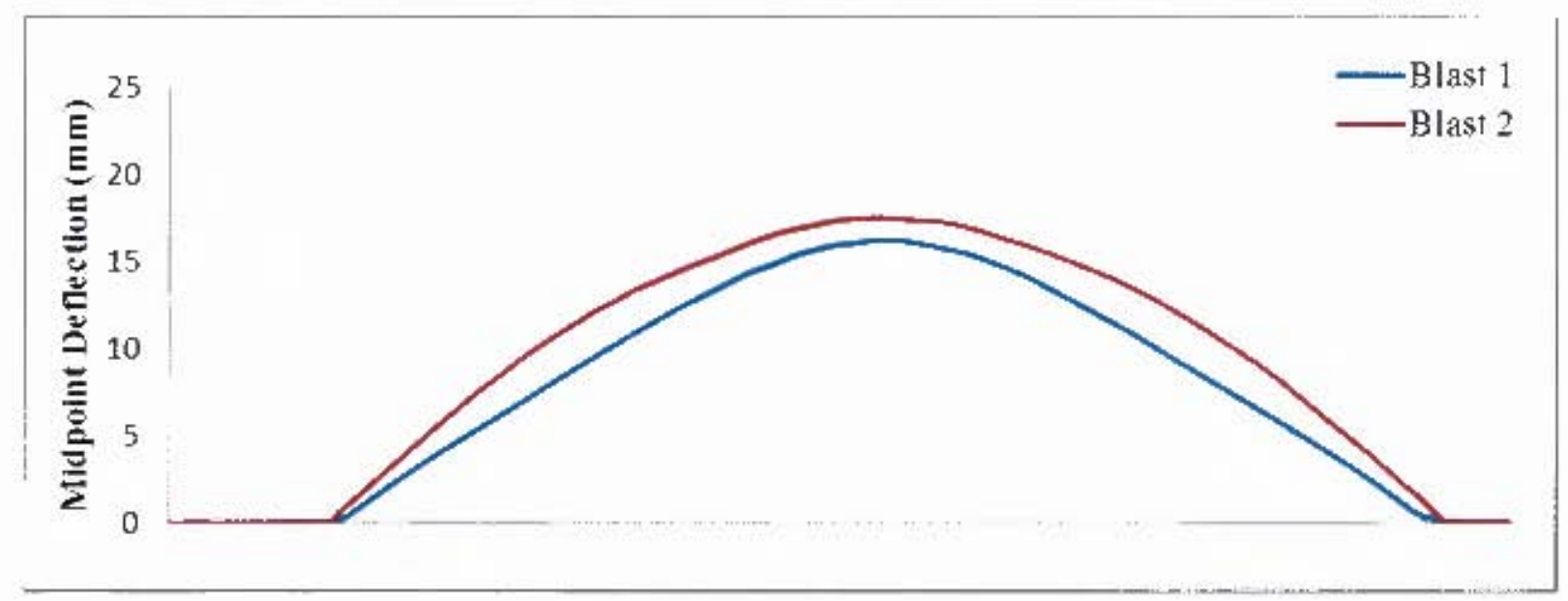

Figure 4.24; Digitized graphical representation of the deformed test plate profiles for 5 blast loads using charge mass of $20 \mathrm{~g}$ and plate thickness $2 \mathrm{~mm}$

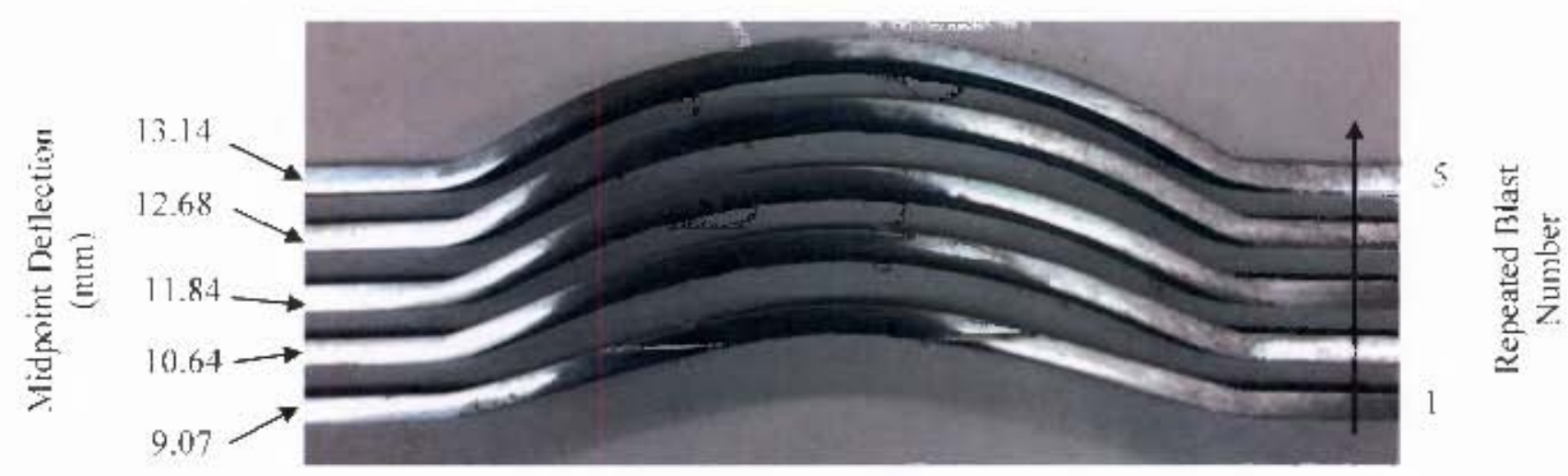

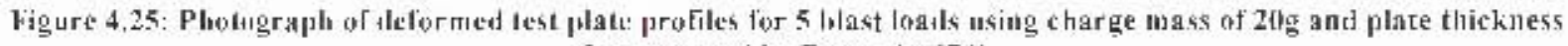
$3 \mathrm{~mm}$ as used by Raunaha $[74]$ 


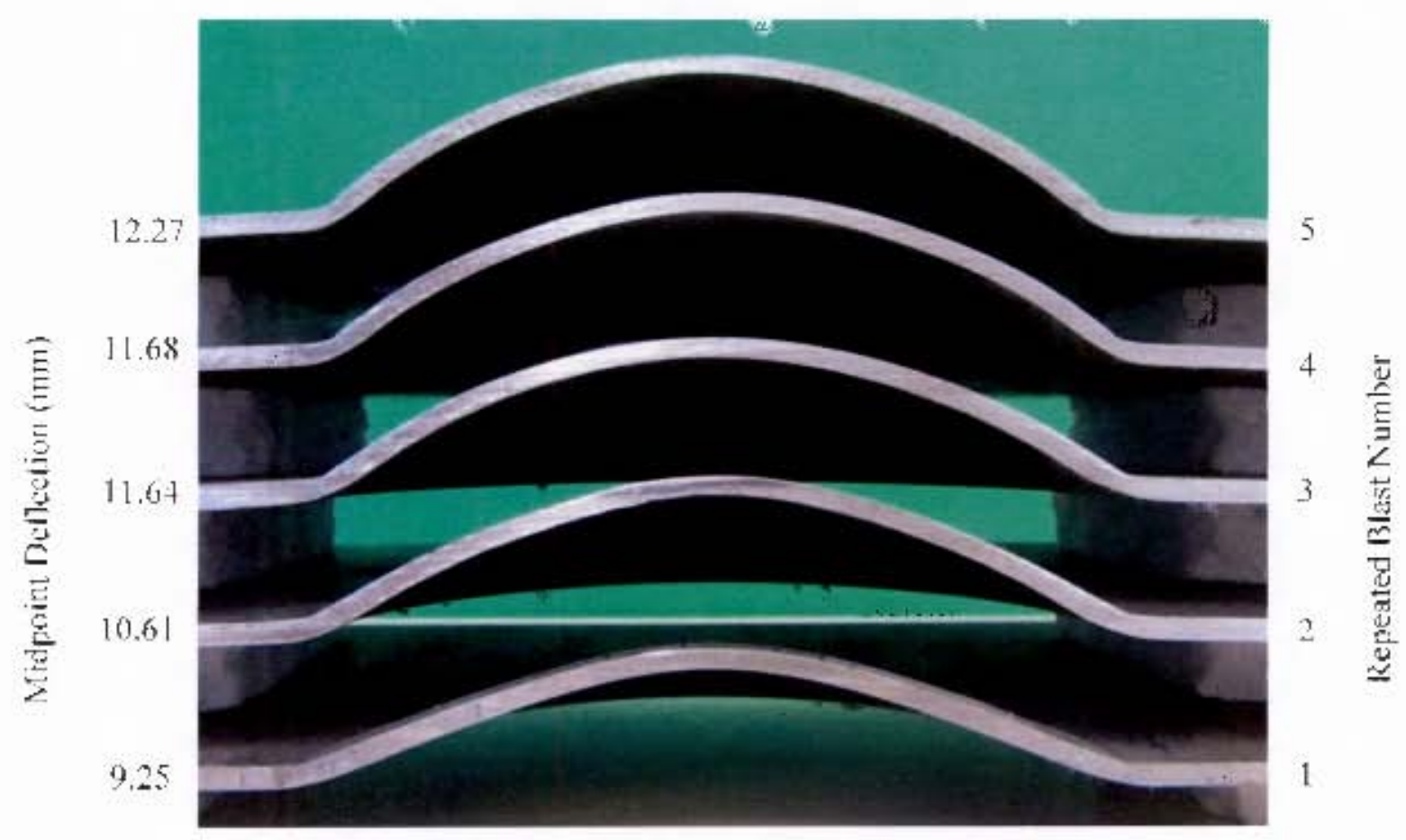

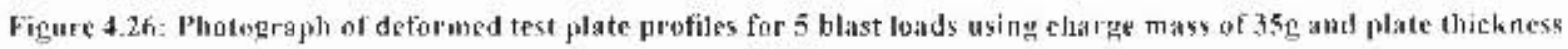
$3 \mathrm{~mm}$ 


\section{Experimental Results Analysis and Discussion}

[his section examines the relationships between the experimental data captured from the repeated blast load tests (impulse and midpoint deflection) to the known iujut variables, such as stand-otf distance, charge mass and plate thickness. The analysis was carried out from the results listed in lable 4.1 and Table 4.2.

\subsection{Relationship between Impulse and Charge Mass}

The relationship between impulse (I) and charge mass (m) was such that impulse increased with an increase in charge mass, as observed by Nurick and Martin [3] and faceb et al [96]. The relationship between charge mass and impulse is shown in Fingure 5.1 for all the experiments.

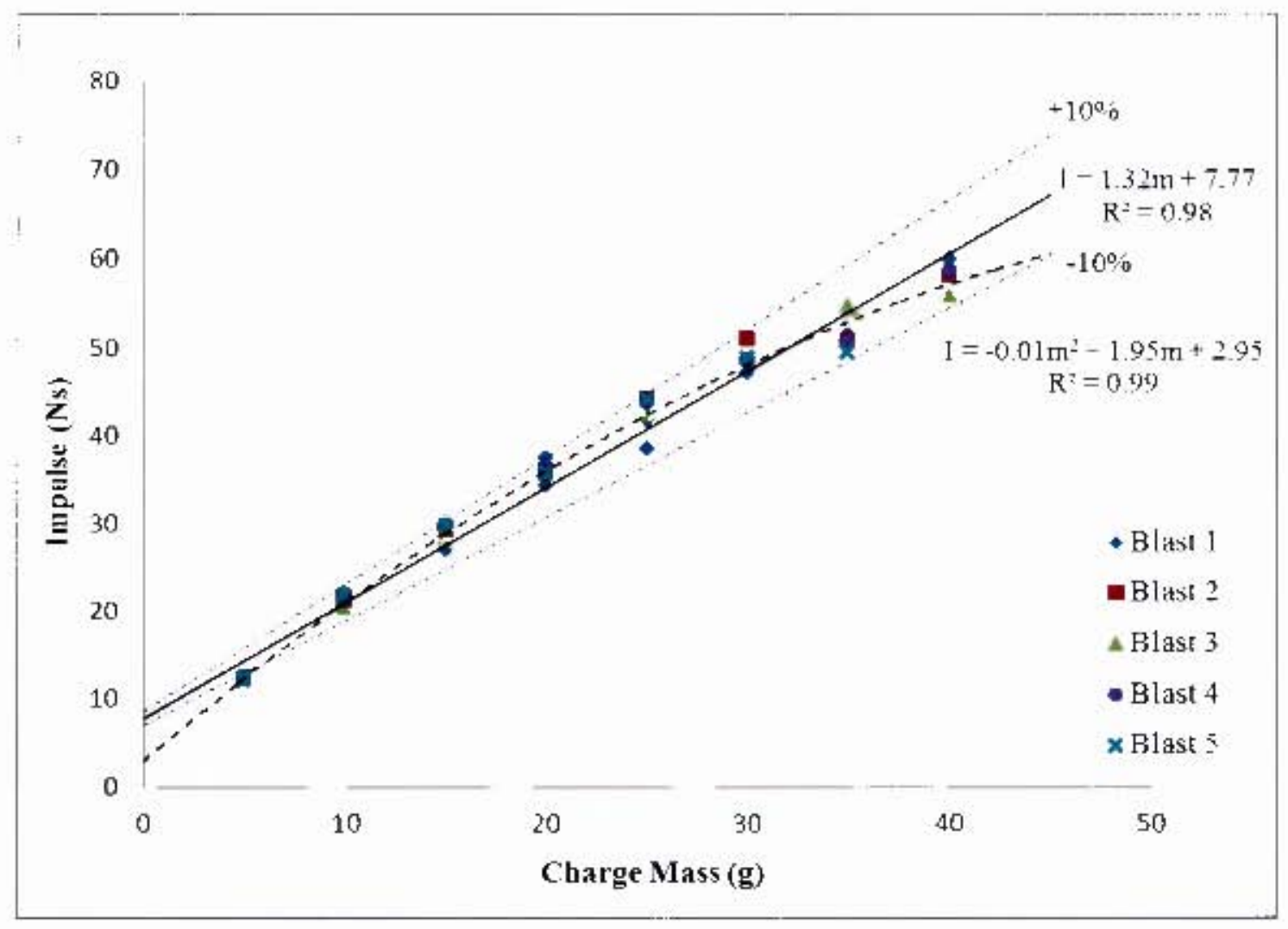

Figure 5.1: Graph of impulse versus charge imass for all experiments for 2 inm and 3 inm thick test plates 
The relationship between explosive impulse and charge mass can lse described by a linear trend, which is displayed in Figure 5.1 as a linear best ji curve with Foguation 5,1 .

$1-1.32 m+7.7$

Г.q. 5.1

The linear trend between impulse and charge mass was suitable for the range of charge masses specified in these experiments, as reported by Nurick and Martin |3|. The lincar trend for the data collected in this report was compared with results from experiments carried out by Jacob et al [51] at a stand-elf distance of $150 \mathrm{~mm}$, shown in Figure 5.2 . The resulss reporled by lacob el al [s।] displayed a linear trend (dashed line) with a gradient that was acceptable. as $1 \mathrm{~g}$ charge mass resulted itt approximately $2 \mathrm{~N}$ s impulse. The lincat relatiotship reported by Jacob et al 1511 was aceeptable for the range of charge masses reported on, up to a charge mass of $20 \mathrm{~g}$. but divergence from the linear trend pccurred for higher charge masses.

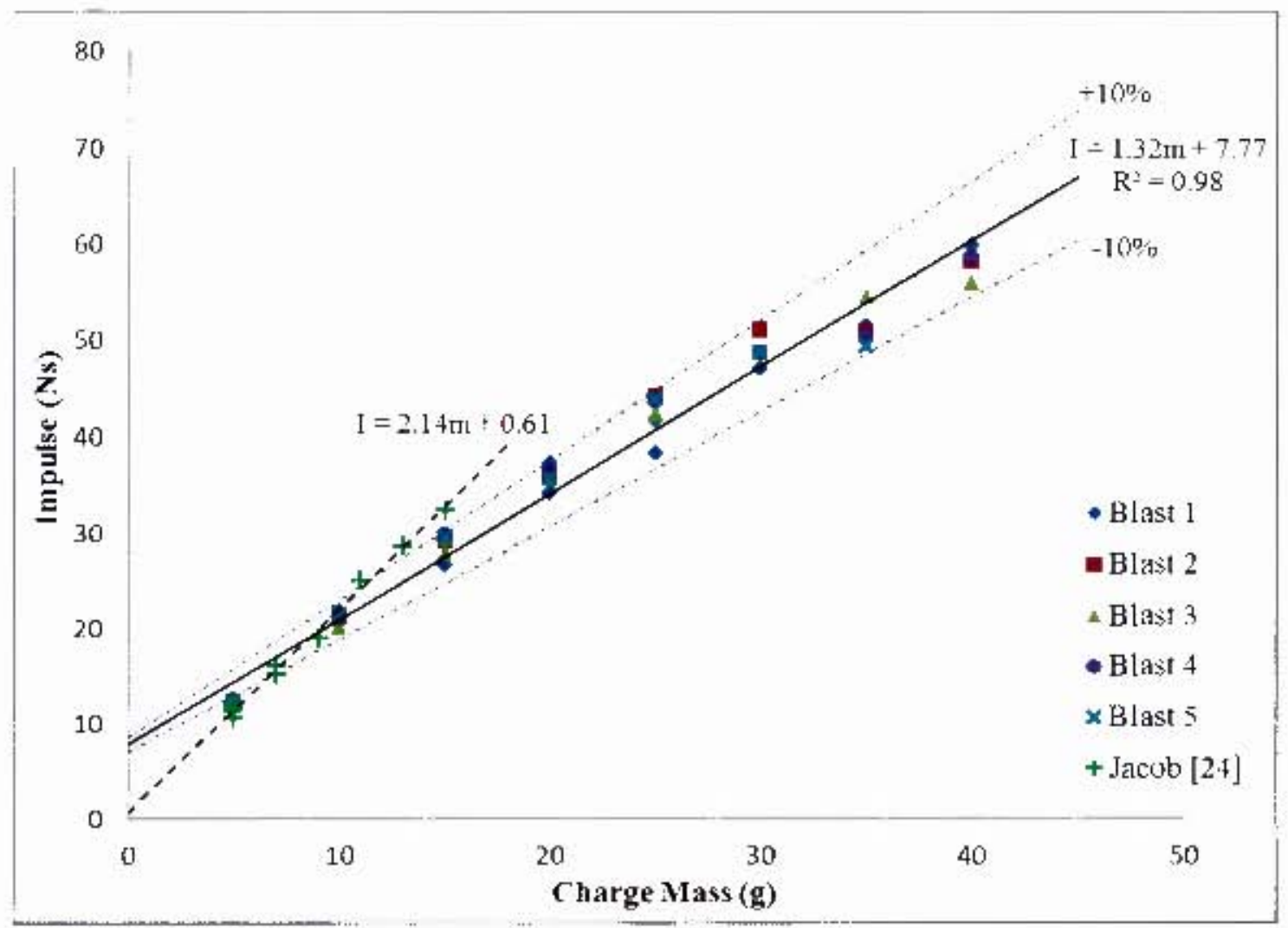

Figure 5.2: Graph of impulse versus charge mass comparing linear trends to lactobs |51| results 
For the higher charge masses $(>25 \mathrm{~g})$ the impulse began to asymptote at a 'maximum' imparted impulse, as reported by Langdon et al [15].

A $2^{\text {nd }}$ order polynomial was fitted to the experimental data in this report and is described by Equation 5.2.

$I=-0.01 m^{2}+1.95 m+2.95$

The impulse reaches an asymptote as the charge mass was continuously increased, because of the effective mass of an explosive. Kennedy [53] described the explosive charge had an effective mass dependant on a cylindrical charge diameter, detonation point and height of the charge. The effective mass of a charge is the mass that transfers the maximum energy to the test plate giving the test plate its maximum velocity. The effective mass was calculated be removing the unreactive explosive, lying outside the area measured $60^{\circ}$ from the point of detonation, from the total charge mass. This description was clearly illustrated by Mahoi [97]. Experiments conducted by Mahoi [97] provided suggestive proof of the effective mass of an explosive. The effective mass of a charge relative to the total charge mass is illustrated in Figure 5.3. The effective mass can be determined by the following equation:

$h_{M E}=\frac{d}{2 \tan 30^{\circ}}$

For a charge diameter of $34 \mathrm{~mm}$ the height of the maximum effective mass is equal to $29.4 \mathrm{~mm}$, which corresponds to a charge mass of $42.7 \mathrm{~g}$. This falls just outside the experimental range with a maximum charge mass of $40 \mathrm{~g}$, suggesting that experiments need to be carried out at higher charge masses to confirm the effective mass of the charge follows a polynomial trend. 


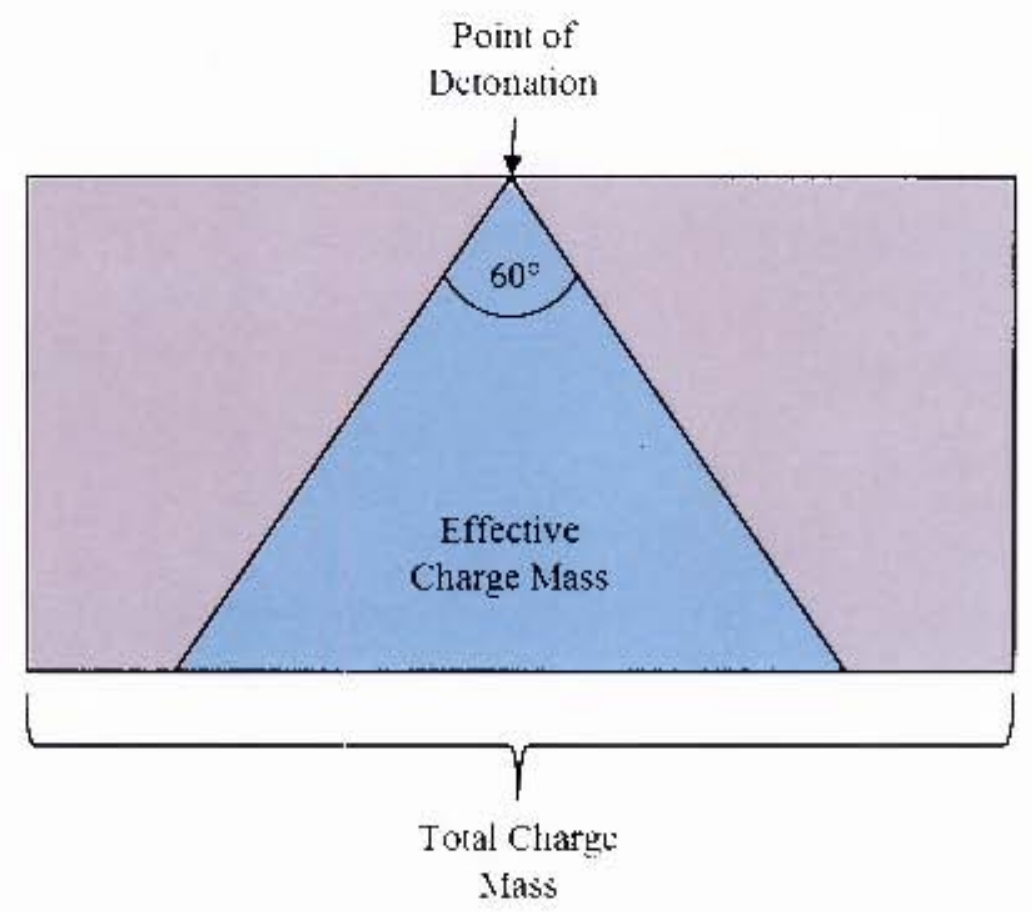

Figure 5.3: Illustration of the effectiye inass of a charge

Graphs of Impulse versus charge mass for each repeated blast series are atailable in $A$ ppendix $F$. Thi impulse measured for test plates subjected to 1 blast load resulted in a linear trend with gradient 1.314. As the number of blasts increased, the linear gradienls decreased (blast $1-1.314$. blast 2 1.3075 , blas $13-1.271$, blas $4-1.2052$ ). This may have been due to the slight inercase in stand-off distance as the plate was further plastically deformed after each subsequent blast load. Ihe resultant blast surface area changed as the plate plastically deformed, possibly causing a clange in impulse. However, the projeced blast area did not change. 


\subsection{Relationship between Impulse and Repeated Blast Load}

The Domex steel test plates underwent large inelastic deformation when subjected to blast loads, forming a global dome shaped deformation (Mode I). This change in shape of the test plate changed the blast surface area and stand-off distance for each subsequent blast. These changes in the initial loading conditions, despite a constant projected blast area $(\$ 106 \mathrm{~mm})$, were thought to change the impulse imparted on the already deformed test plate when repeated blast tests were conducted.

Table 5.1 and Table 5.2 show the differences in measured impulse between the initial (Blast 1) and final blast (Blast 5 , except for plates where tearing occurred), for the $2 \mathrm{~mm}$ and $3 \mathrm{~mm}$ thick plates. The results yielded relatively negligible differences in impulse between the initial and final blast, with the majority of the variations being $7 \%$ and below (charge masses $5 \mathrm{~g}$ to $30 \mathrm{~g}$ ). For charge masses $35 \mathrm{~g}$ and $40 \mathrm{~g}$, there was an impulse difference of $10 \%$ and $12 \%$ respectively. The greater impulse differences for higher charge masses could be accounted for by the experimental repeatability or the greater change in stand-off distance from the increased progressive deflections.

Table 5.1: Variation in measured Impulse between the initial and final repeated blast loads for all charge masses and plate thickness $2 \mathrm{~mm}$

\begin{tabular}{|c|c|c|c|c|}
\hline $\begin{array}{c}\text { Charge } \\
\text { Mass (g) }\end{array}$ & \multicolumn{2}{|c|}{$\begin{array}{c}\text { Range of Impulse } \\
\text { (Ns) }\end{array}$} & $\begin{array}{c}\text { Difference in } \\
\text { Impulse (Ns) }\end{array}$ & $\begin{array}{c}\text { \% } \\
\text { Difference in } \\
\text { Impulse }\end{array}$ \\
\hline & I = Initial & I = Final & I $_{\text {initial }}-\mathbf{I}_{\text {fimal }}$ & \\
\hline 5 & 12.07 & 12.85 & 0.79 & 6 \\
\hline 10 & 21.02 & 19.61 & 1.42 & 7 \\
\hline $15^{*}$ & 26.79 & 26.45 & 0.34 & 1 \\
\hline $20^{*}$ & 37.32 & 36.13 & 1.19 & 3 \\
\hline $2^{*}$ & 38.33 & NA & NA & NA \\
\hline
\end{tabular}

*Tearing 
Table 5.2: Variation in measured Impulse hecween lue inicial a ma final repicacod blast foals for all charoe masses and plate thickness $3 \mathrm{~mm}$

\begin{tabular}{|c|c|c|c|c|}
\hline \multirow[t]{2}{*}{$\begin{array}{l}\text { Charge } \\
\text { Mass (g) }\end{array}$} & \multicolumn{2}{|c|}{ Range of Impulse (Xs) } & \multirow{2}{*}{$\begin{array}{c}\text { Difference } \\
\text { in Impulsc } \\
\text { (Ns) } \\
I_{\text {initial }}-1_{\text {finta] }}\end{array}$} & \multirow[t]{2}{*}{$\begin{array}{c}\% / \% \\
\text { Difference in } \\
\text { Impulse }\end{array}$} \\
\hline & I-Inilial & I = Final & & \\
\hline 5 & 11.89 & 11.63 & 0.26 & 2 \\
\hline 10 & 21.91 & 21.91 & 0.00 & 0 \\
\hline 15 & 29.17 & 29.37 & 0.20 & -1 \\
\hline 20 & 34.19 & 36.12 & 1.93 & -5 \\
\hline 25 & 41.69 & $42.51^{\circ}$ & $0 . \overline{82}$ & -2 \\
\hline 30 & 47.00 & 49.39 & 2.39 & -5 \\
\hline $35 *$ & 51.40 & 46.39 & 5.01 & 10 \\
\hline $40^{=}$ & 59.84 & $52.5 \bar{i}$ & $7.2 \overline{7}$ & 12 \\
\hline
\end{tabular}

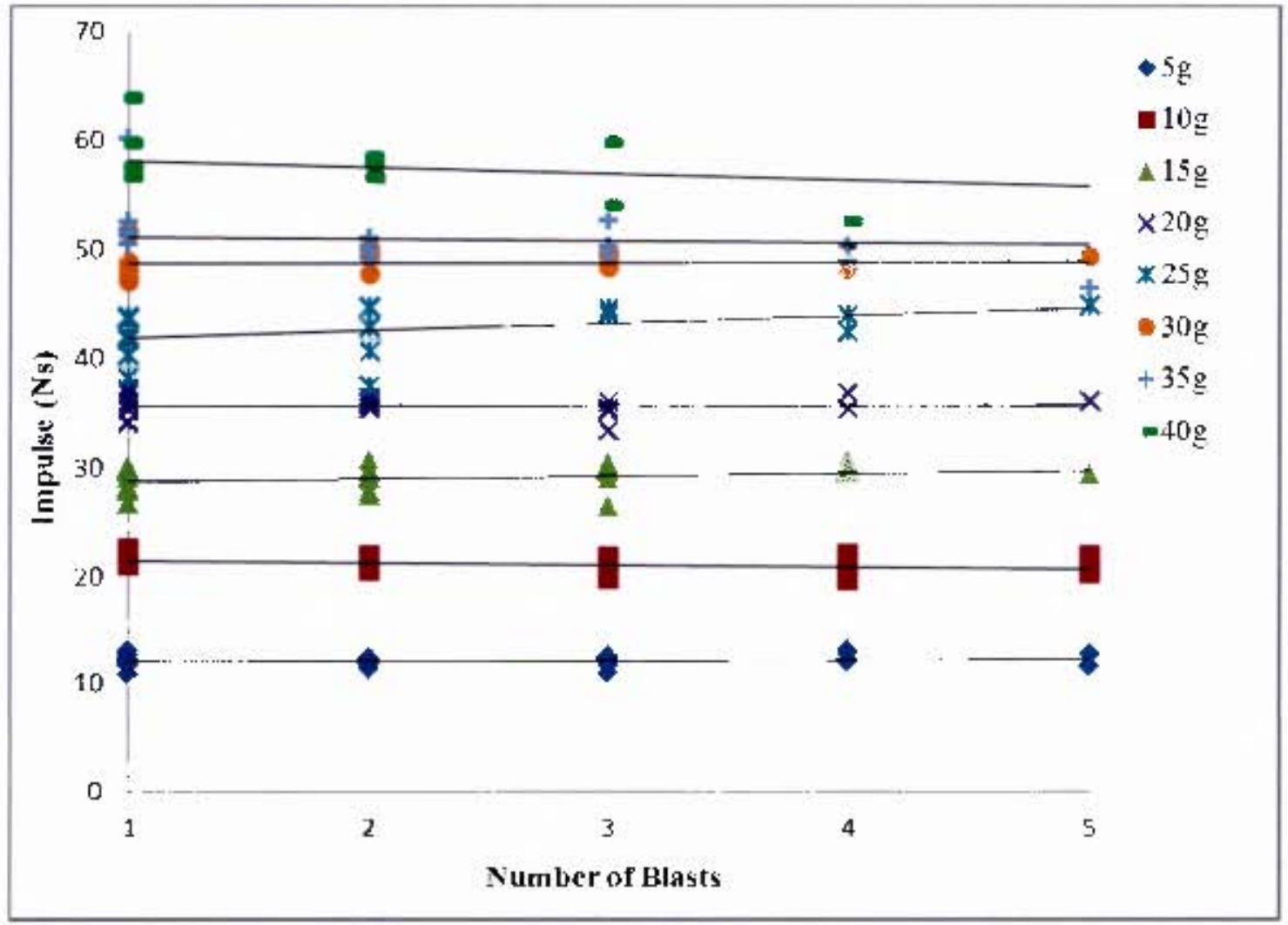

F'igure 5.4: Graph of impulse versus number of blast loads for the $2 \mathrm{~mm}$ and $3 \mathrm{~mm}$ thick lest plates

Figure 5.4 graphically represenls the impulse dala from Table 5.1 and Table 5.2 for each repsated b]ast for the various charge masses. It was observed. for charge masscs ranging from $5 \mathrm{~g} 1030 \mathrm{~g}$, that there were very little variation in impulse imparted to the test plate for all repeated blast tests. I he lincar terend lines illustrates relatively zero gradients, indicating that the changed shape of the 
deformed plates and the small change in stand-off distance had little effect on the impulse. The data points in Figure 5.4 displayed good repeatability for repeated blast loads carried out from charge masses $5 \mathrm{~g}$ to $35 \mathrm{~g}$. There were greater deviations in impulse for the charge mass $40 \mathrm{~g}$. For the charge masses $35 \mathrm{~g}$ and $40 \mathrm{~g}$, there was a decrease in impulse as the number of blasts increased, possibly due to the increase in stand-off distance.

\subsection{Relationship between Midpoint Deflection and Impulse}

The graphs of midpoint deflection versus charge mass are shown in Figure 5.5 and Figure 5.6, for the $2 \mathrm{~mm}$ and $3 \mathrm{~mm}$ thick test plates respectively. The midpoint deflection increased linearly with an increase in charge mass for each blast series and plate thickness. The linear trends, for both plate thicknesses, displayed a gradual increase in gradient as the number of blasts was increased. For the $2 \mathrm{~mm}$ thick test plates, linear gradients increased from 0.7 for blast 1 to 1.07 for the blast 3 series ( 3 blasts). For the $3 \mathrm{~mm}$ thick test plate, linear gradients increased from 0.41 for the single blast series, to 0.59 for 5 blasts. 


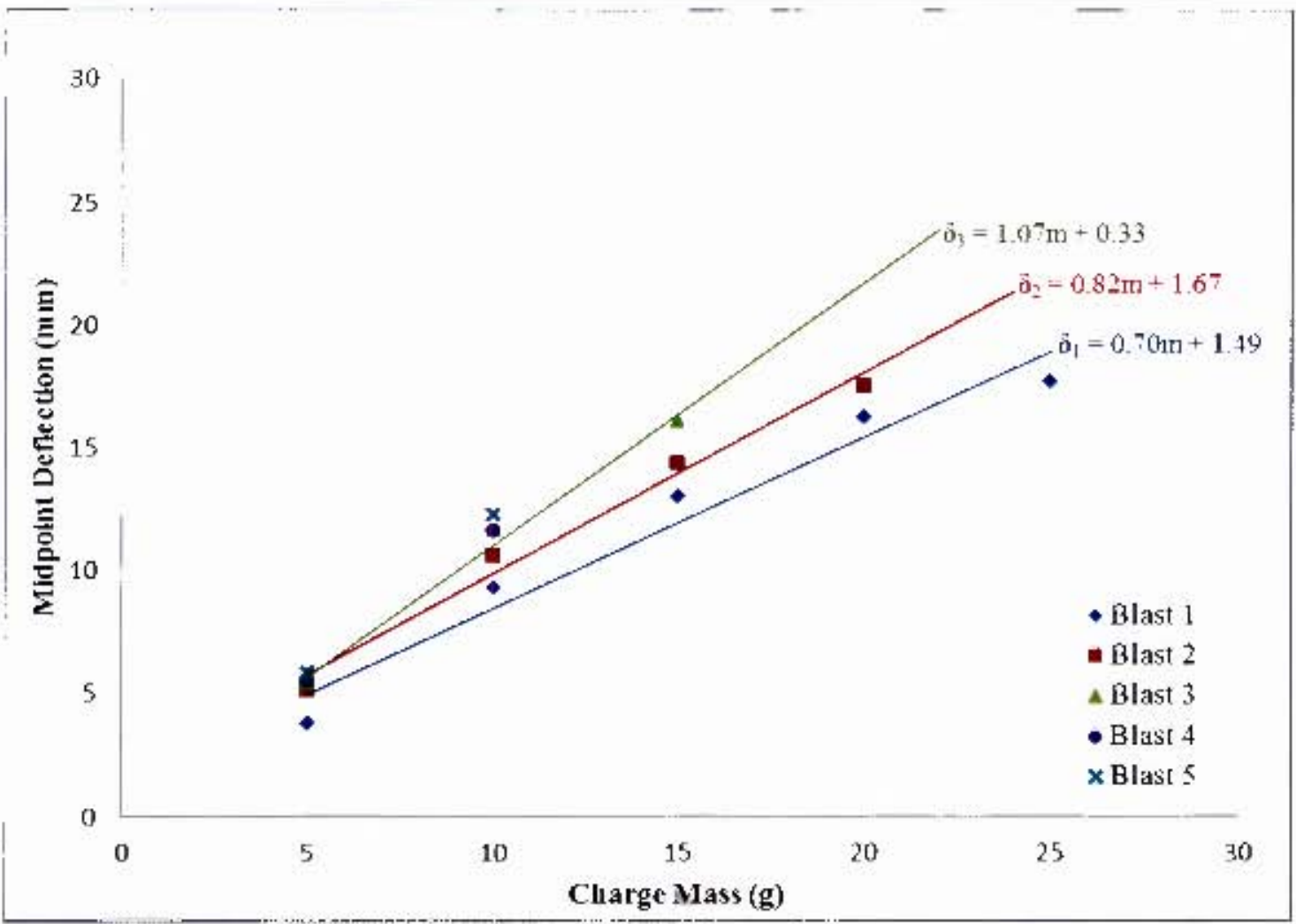

Figure 5.5: Grapls of midpoint deflection versus charge mass for plate thickness $2 \mathrm{~mm}$

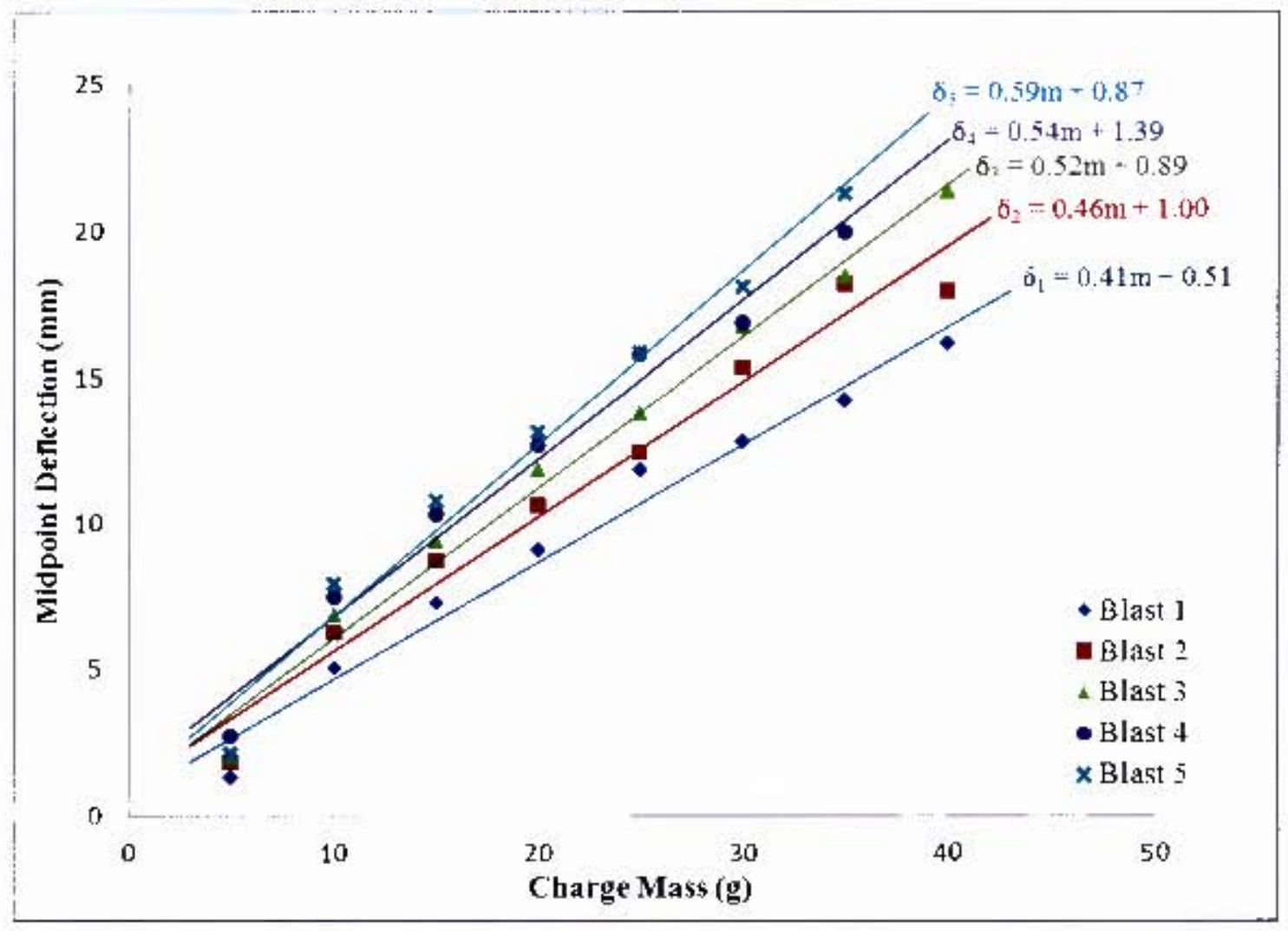

Figure f.6: $_{\text {: }}$; raph of midpoint detlection versus charge mass for plate thickness $3 \mathrm{~mm}$ 


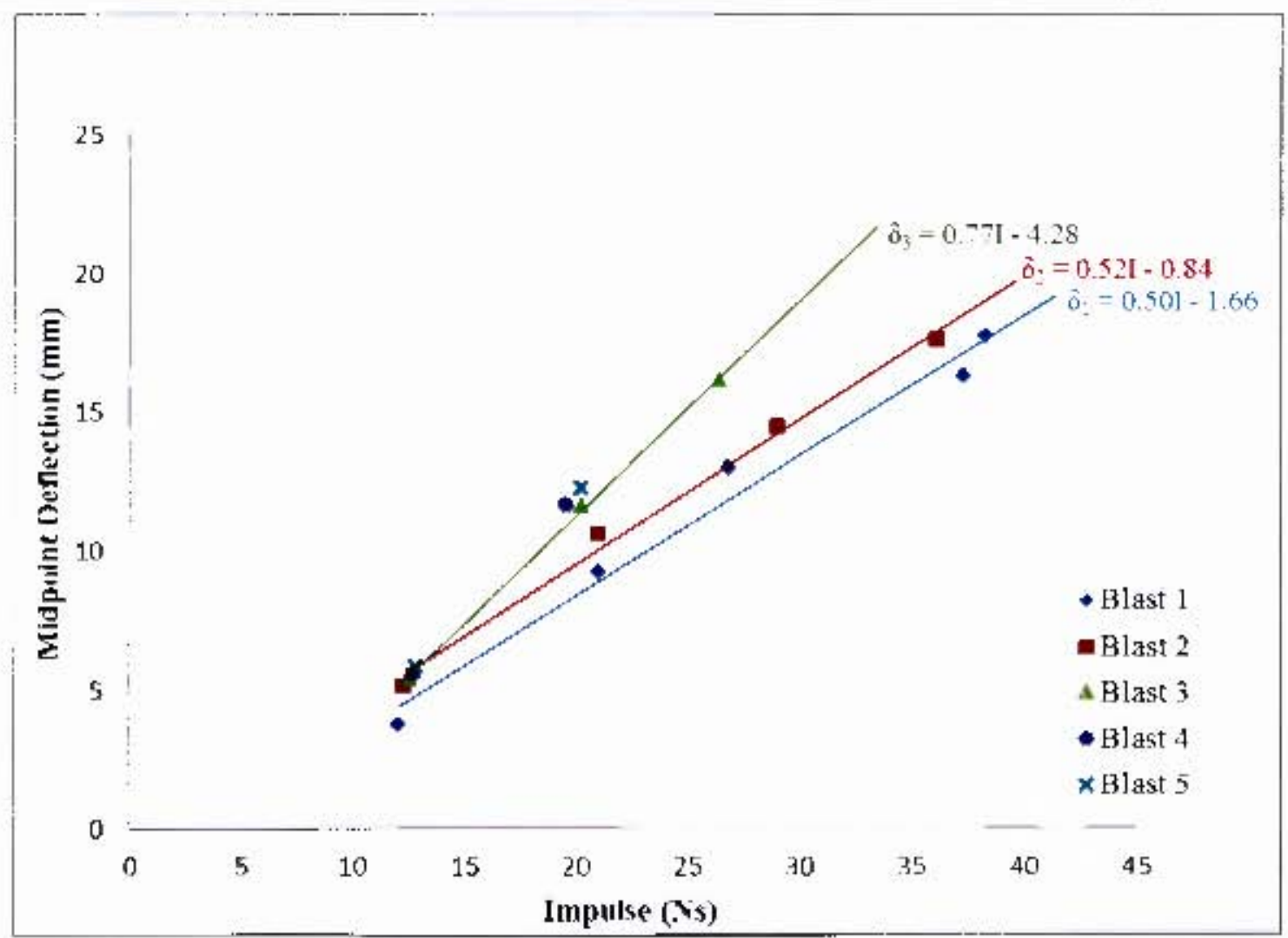

Figure 5.7: Graph of nidpoint deflection Fersus impulse for plate 1 hichnews $2 \mathrm{~mm}$

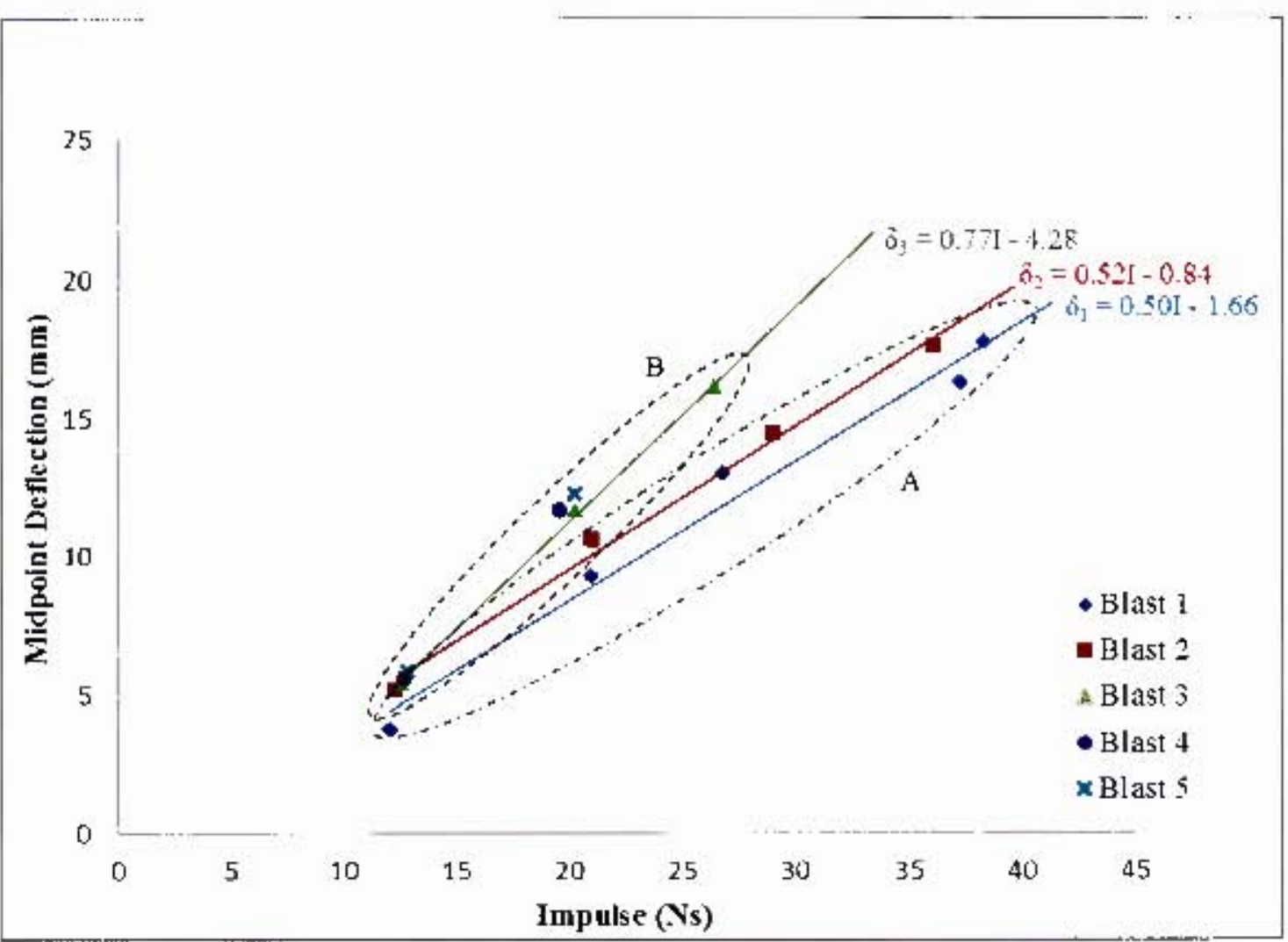

Figure 5.8: Graph of nudpoint deflection yersus impulse for plate thickness $2 \mathrm{~mm}$ and all repeated blast loads 
For the $2 \mathrm{~mm}$ thick test plates, linear trends existed betwecn midpoint deflection and impulse, With an increase in impulse there was a resultant increase in midpoint deflection. Ihe linear trend line gradients increased from 0.50 for a single blast load $w 0.89$ for 5 blast lnads. The increase in gradicnts corresponding to similar tindings observed for the midpoint deflection tersus clarge mass.

The linear trend lims's (2mm thick plates) for blasts 1 and 2 (gradients 0.50 and 0.52 ) showed a distinctly different gradient to blasts 3,4 , and 5 (gradients $0.77,0.87$ and 0.89 ), as shown in Figure 5.8. The data points representing blasts 1 and 2 were dillerentiated from blasts 3,4 , and 5 by envelopes, marked ' $A$ ' and $\cdot \mathrm{B}^{\prime}$ respectively. The distinct difference in linear trend gradicnts could be accounted for by the prescnce of observable boundary thinsing in the $2 \mathrm{~mm}$ thick test plates subjected to a greatur number of blast loads $(3,4$ and 5$)$ at higher resultant impulses, as discussed in Section 4.2 .

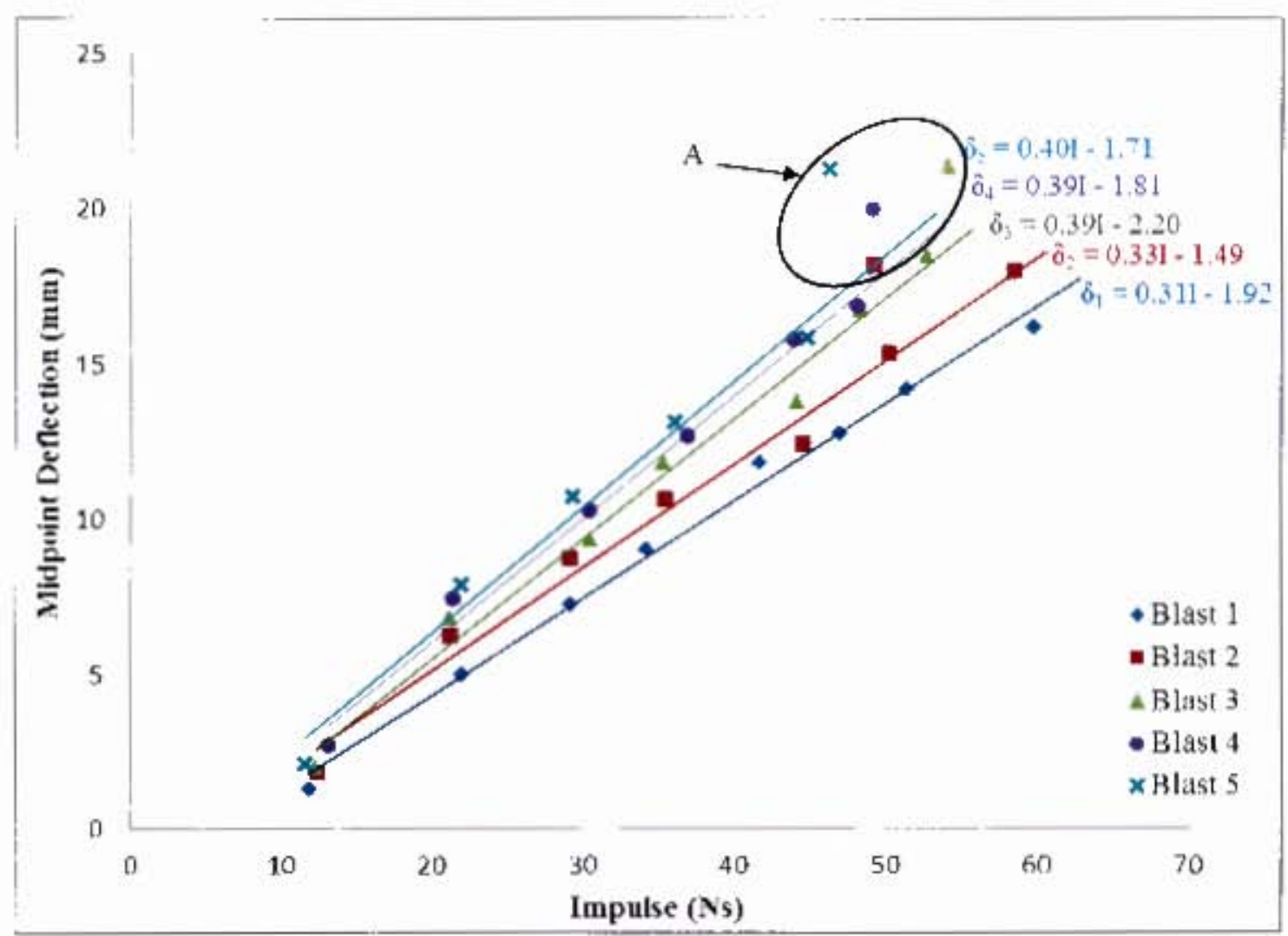

Figure 5.9; Graph of midpoint deflection versus impulse for plate thichness $3 \mathrm{mu}$ and all repeated blast loads, displaying linear trend lines

The midpoint deflections of the $3 \mathrm{~mm}$ lest platcs also increased. with an increase in resultant impulse. In Figure 5.9. a lincar relationship was observed for the midpoint deflection and impulsc, illustratcd by the trend lines for wach reptatud blast series. The gradient of the linear trends gradually inercased, similarly to the trends notid for midpoint deflection versus charge mass. 
The data points enclosed in the area marked ' $A$ ' in Figure 5.9 were excluded from the analysis. The ' $A$ ' data points corresponded to the results from the experiments carried out on the $3 \mathrm{~mm}$ thick plates for charge masses $35 \mathrm{~g}$ (impulse of approximately $50 \mathrm{Ns}$ ) and blast loads 2, 4 and 5 . The data point corresponding to a charge mass of $40 \mathrm{~g}(52.57 \mathrm{Ns})$ subjected to 3 blast loads was also included in the area marked ' $A$ '. These deviations can be accounted for by experimental variation. 


\subsection{Relationship between Midpoint Deflection and Repeated Blast Load}

The results indicated a linear relationship between the midpoint deflection and the repeated blast load number, such that the midpoint deflection for each successive blast load increased linearly from blast 1(a single blast load) through to blast 5 . The linear trends for the various charge masses and both plate thicknesses are shown in Figure 5.10 and Figure 5.11.

In Figure 5.10 the midpoint deflection for blast 1 was $3.73 \mathrm{~mm}$ and blast 5 was $5.83 \mathrm{~mm}$. The difference between the midpoint deflections for blast 1 and 5 was greater than a plate thickness. The difference in midpoint deflection between blasts $2(5.15 \mathrm{~mm})$ and blast $5(5.83 \mathrm{~mm})$ was $0.68 \mathrm{~mm}$, only $34 \%$ of the plate thickness.

The linear trends for the repeated blast loads carried out on the $3 \mathrm{~mm}$ thick plates showed a consistent increase in linear gradients from blast $1(0.25)$ to blast 5 (2.58). For a charge mass $5 \mathrm{~g}$, there was a slight gradual increase in the progressive deflection after each repeated blast. The midpoint deflection after the first blast was $1.28 \mathrm{~mm}$ and the midpoint deflection after 5 blast loads was $2.10 \mathrm{~mm}$. The difference between the midpoint deflection for blast 1 and blast 5 was $0.82 \mathrm{~mm}$, which was $27 \%$ of the plate thickness $(3 \mathrm{~mm})$. The $3 \mathrm{~mm}$ thick test plate deflections between each $5 \mathrm{~g}$ blast was within a plate thickness, indicating that the plate experienced a small amount of inelastic deformation when subjected to blast loading from a charge mass $5 \mathrm{~g}( \pm 12 \mathrm{Ns})$.

The linear trend lines do not allow an estimation of the midpoint deflections for very small charge masses and very high charge masses. Therefore power trends were fitted to the data and are presented in Appendix F.2. The $\mathbf{R}^{2}$ values for the power trends were generally higher than the equivalent linear trends, indicating the power curves were in greater agreement with the data than the linear trends. 


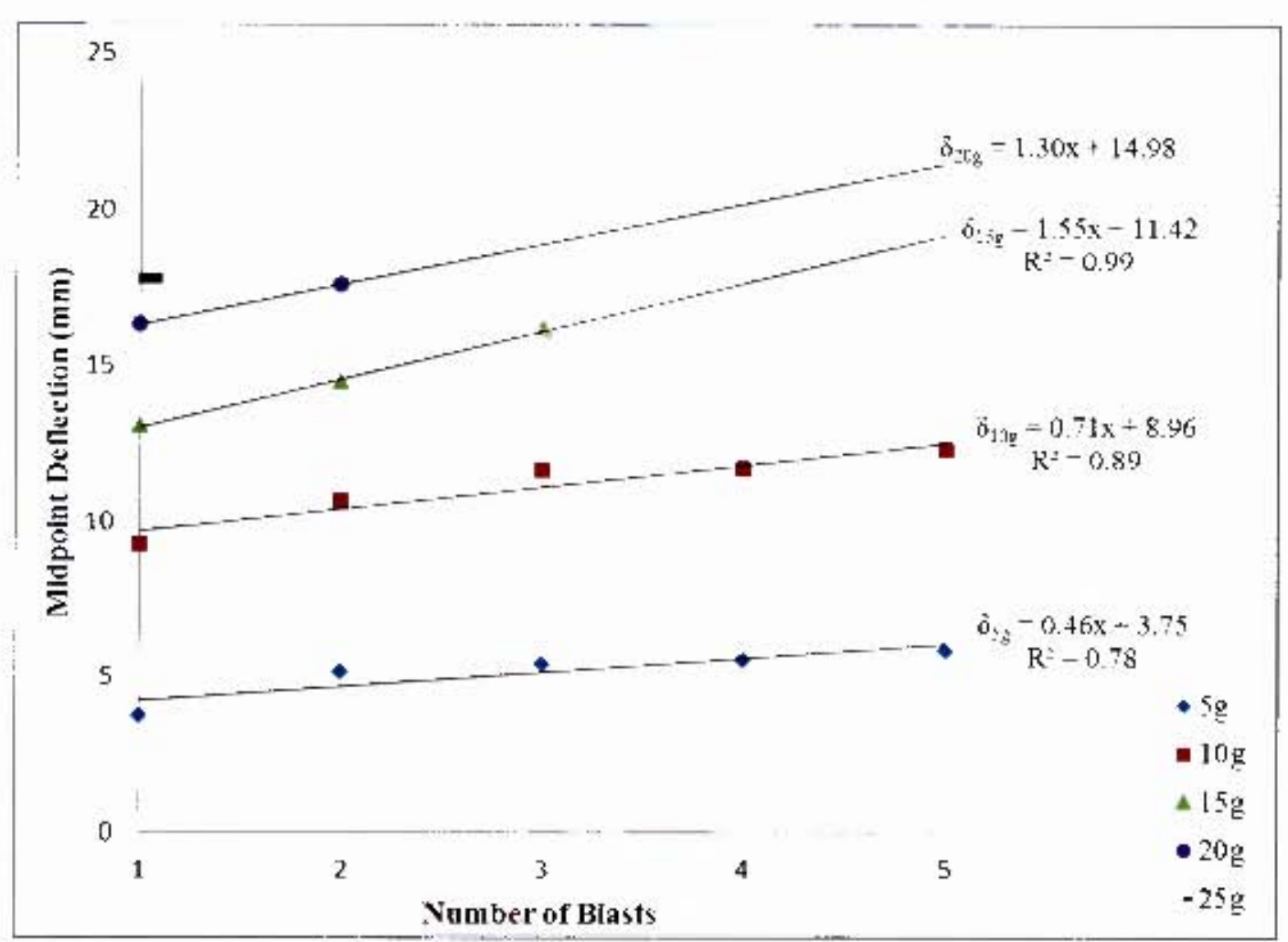

Figure 5.10: Graph of inidpoint detlection versus uumber of hlasLs for all charge masses and plate thickness of 2 mm

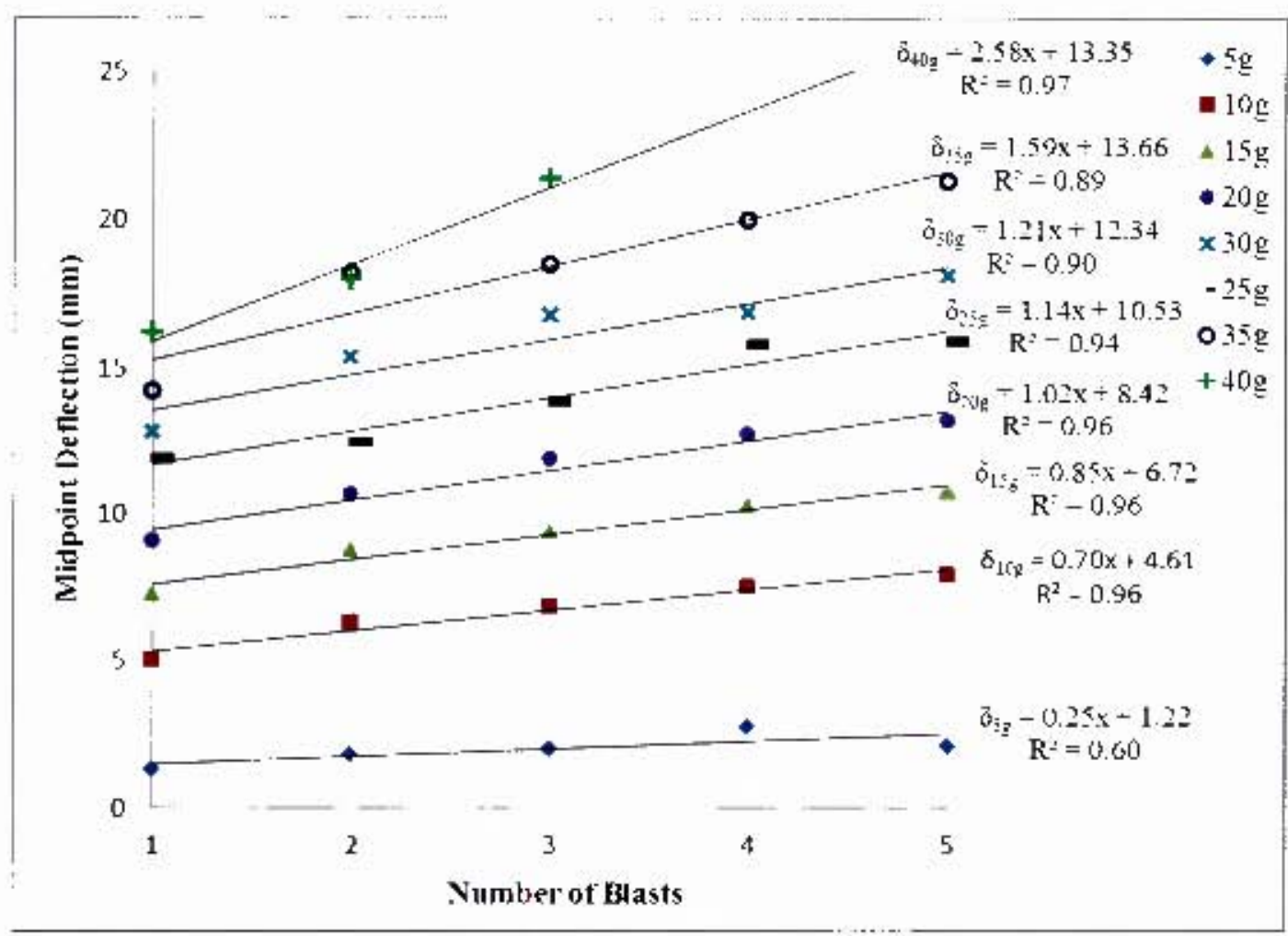

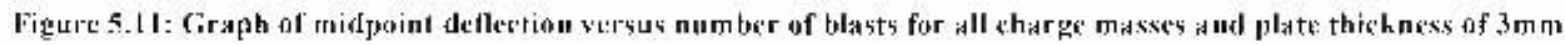




\subsubsection{Equivalent Midpoint Deflections of Repeated Blast Loads}

An increase it charge mass or an increase in the number of blast loads on the lest plates resulted in atn increase in midpoint deflection. Equivalent midpoint deflections existed between test plates subjected to varying charge masses and varying number of blast loads. It thust be noted that only the midpoint deflections were similar and the general inelastic deformation shape (profije) might differ. the 2 mm thick test plate subjected to 5 blast loads with a charge mase $l 0 \mathrm{~g}$ had a midposint deflection of $12.27 \mathrm{~mm}$, which was similar to the midpoint deflection of the $2 \mathrm{~mm}$ thick test plate subjected to a single blast load with a charge mass of $15 \mathrm{~g}$. measured at $13,02 \mathrm{~mm}$ ( $0.75 \mathrm{~mm}$ or $6 \%$ differenec). This implied that the test plate underwent a similat amount of damage from 5 blast loads of charge thass $10 \mathrm{~g}$, as a single $15 \mathrm{~g}$ blast load, shown in Figure 5.12 . The midpoint deflection was more affected by the chatge mass of the lirst blast than the mumber of blasts. This was an indicatian of worh/strain hardening of the steel when plastically deforming under repeated blast loading. Similar fundings can be observed for different lastding conditions listed in Table 5.3 .

Table 5.3: Vidpoint Deflection Equivalencies

\begin{tabular}{|c|c|c|c|c|}
\hline $\begin{array}{c}\text { J'late } \\
\text { Thickness } \\
\text { (mım) }\end{array}$ & $\begin{array}{l}\text { Charge } \\
\text { Mass } \\
\text { (g) }\end{array}$ & $\begin{array}{l}\text { Number of } \\
\text { Blasts }\end{array}$ & $\begin{array}{c}\text { Midpoint } \\
\text { Deflection } \\
\text { (mm) }\end{array}$ & $\begin{array}{l}\text { Difference } \\
\text { (mm) }\end{array}$ \\
\hline 2 & 10 & 5 & 12.27 & \multirow{2}{*}{0.75} \\
\hline 2 & 15 & 1 & 13.02 & \\
\hline 2 & 15 & 3 & 16.12 & \multirow{2}{*}{0.14} \\
\hline 2 & 20 & ] & 16.26 & \\
\hline 2 & 20 & 2 & 17.58 & \multirow{2}{*}{0.75} \\
\hline 2 & 25 & 1 & 17.73 & \\
\hline 3 & 10 & 4 & 7.46 & \multirow{2}{*}{0.19} \\
\hline 3 & 15 & 1 & 7.27 & \\
\hline 3 & 15 & 3 & 9.38 & \multirow{2}{*}{0.31} \\
\hline 3 & 20 & 1 & 9.07 & \\
\hline 3 & 15 & 5 & 10.76 & \multirow{2}{*}{0.12} \\
\hline 3 & 20 & 2 & 10.64 & \\
\hline 3 & 20 & 3 & 31.84 & \multirow{2}{*}{0} \\
\hline 3 & 25 & 1 & 11.84 & \\
\hline 3 & 20 & 4 & 15.79 & \multirow{2}{*}{0.43} \\
\hline 3 & 30 & 2 & 15.36 & \\
\hline 3 & 30 & 5 & 18.11 & \multirow{2}{*}{0.1} \\
\hline 3 & 35 & 2 & 18.21 & \\
\hline 3 & 335 & 5 & 21.28 & \multirow{2}{*}{0.08} \\
\hline 3 & 40 & $i$ & 21.36 & \\
\hline
\end{tabular}




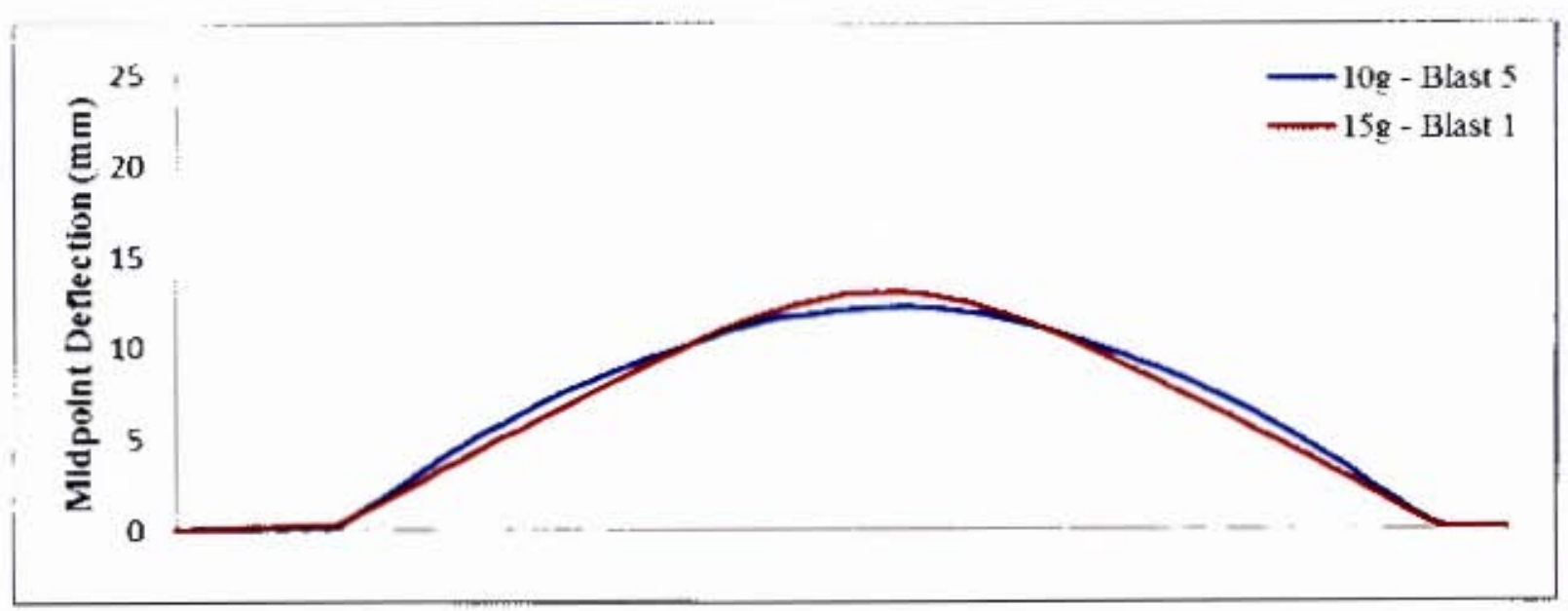

Figure 5.12: Graphical illustration of midpoint deflection equivalencies fur $2 \mathrm{~mm}$ thick test plate subjected to $510 \mathrm{~g}$ blasts and $115 \mathrm{~g}$ blast

Other graphs illustrating equivalent midpoint deflections for various repeated blasts are presented in Appendix F.3. 


\subsection{Relationship between Progressive Deflection and Repeated Blast Load}

The progressive deflection defined as the difference in total test plate deflection between an initial midpoint deflection and the subsequent blast loaded midpoint deflection are listed in Table F. 1 and Table F. 2, presented in Appendix F.4. For example, a charge mass $10 \mathrm{~g}$ and plate thickness $2 \mathrm{~mm}$ produced a midpoint deflection of $10.61 \mathrm{~mm}$ for 2 blasts and $11.86 \mathrm{~mm}$ for three blasts, resulting in a progressive deflection of $1.25 \mathrm{~mm}(11.86 \mathrm{~mm}-10.61 \mathrm{~mm})$. The midpoint deflection from 1 blast was assigned a progressive blast load as the initial midpoint deflection from a single blast, implying the progressive deflection for a single blast was the difference between $0 \mathrm{~mm}$ (no deflection) and the first midpoint deflection.

The progressive deflections followed a decreasing power trend from the initial large midpoint deflection to the smaller variations of the final midpoint deflection, after five blasts. The progressive deflections versus the number of blast loads are graphically represented in Figure 5.13 and Figure 5.14 , for the $2 \mathrm{~mm}$ and $3 \mathrm{~mm}$ thick plates.

The decreasing trends of progressive deflection were a result of the test plate material undergoing work hardening after each blast load. It was noted in Section 5.2, there were insignificant changes in impulse between each blast load, suggesting work hardening and residual stresses had a greater influence on the plate deformation than the increase in stand-off distance, after each blast load. The test plate experienced a high amount of strain whilst plastically deforming when subjected to blast loading. 


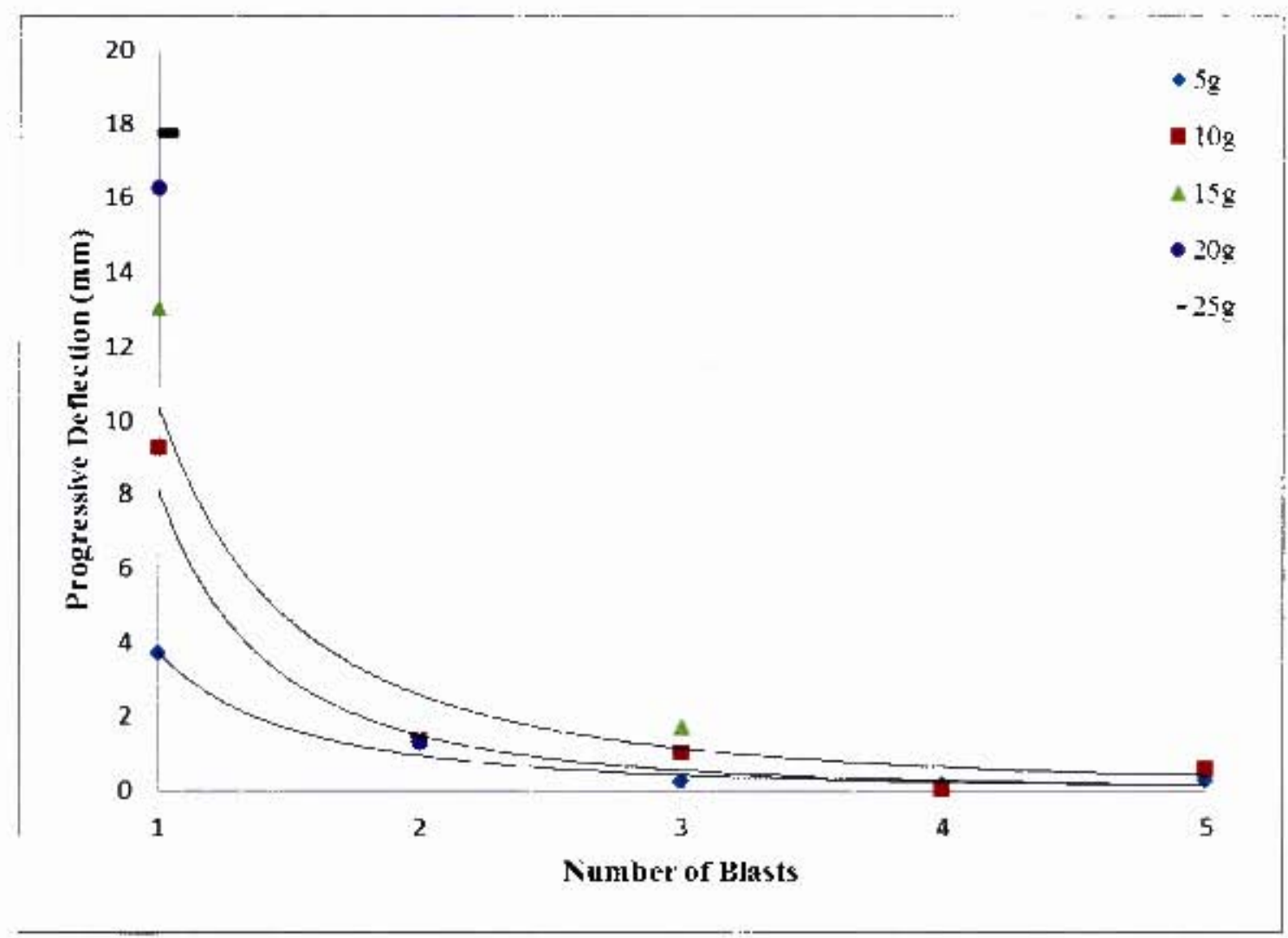

Higure 5.13: Graph of progressive deflection yersus the number of blasts for plate thickuess $2 \mathrm{~mm}$. displaying power trents

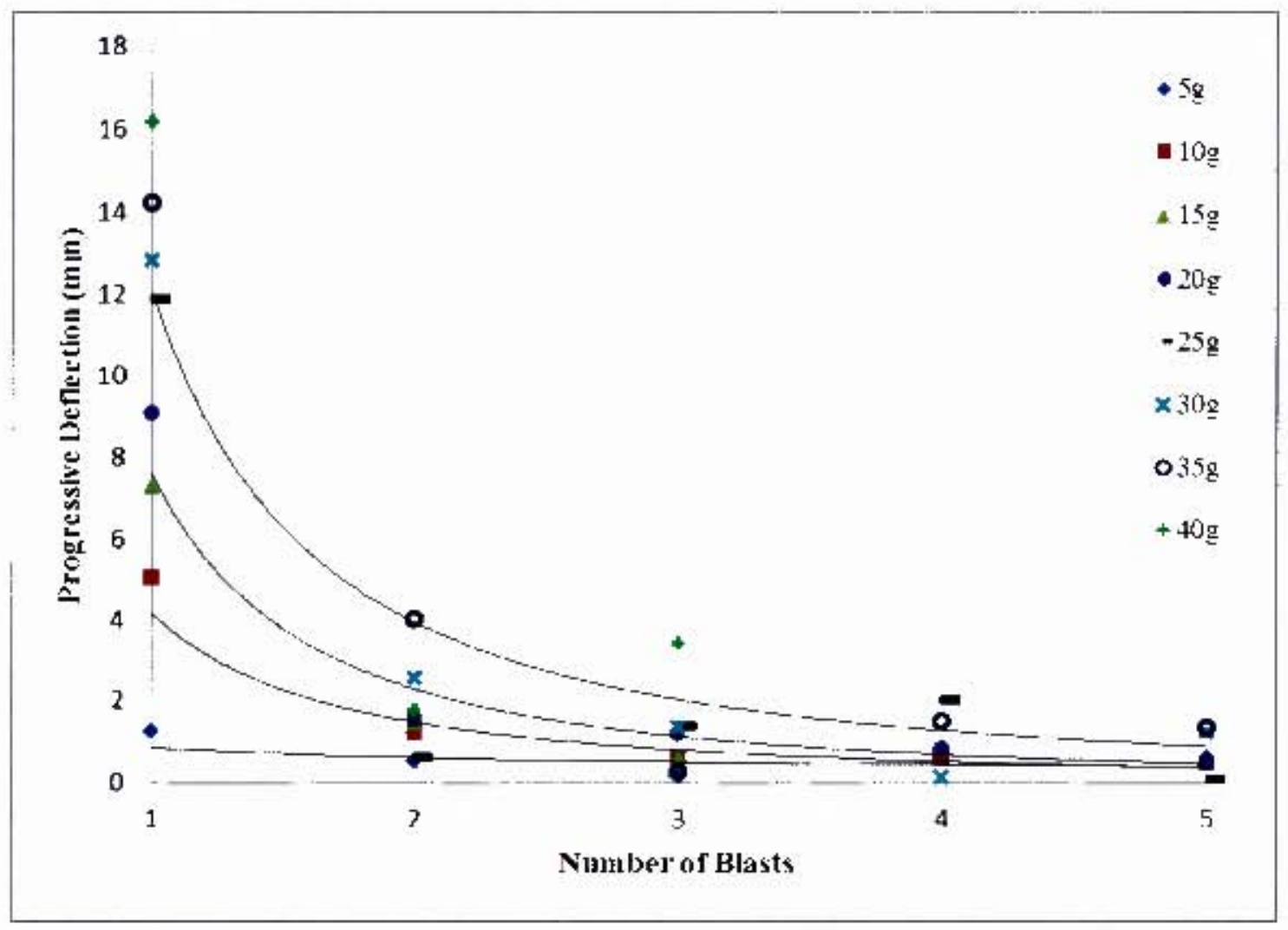

Figure 5. 14: Grapli of progressive deflection versus the number of blasts for plate thich ness 3 mm, displaying powter trends 
When hlase loaded, the plates were loaded beyond their respective yield points, experiencing high strairs, resulting in residual stresses and worh hardeming of the material. Aficr subsequent blast loads, the plates further deformed in the plastic region, starting with the initial residual stresses of the single blast. The strain hardening and residual stresses were further increased with the additional plastic deformation of the repeated blast (blast 2). This process reoccurred for each repeated blast load in the series (up to 5 blasis), with strain hardenimy and residual stresses present in the Domex steel from cach preceding load. Thereforc, the progressive deflection decreased after each blast toad, as the strain hardening and residual stresses increased in similat increments atter each repeated blast. This concept is illustrated in Figute 5.15 , which shows the process of reloading the test plate, with regards to stressstrain and the change in residual stress in the plastic region, for two blasts.

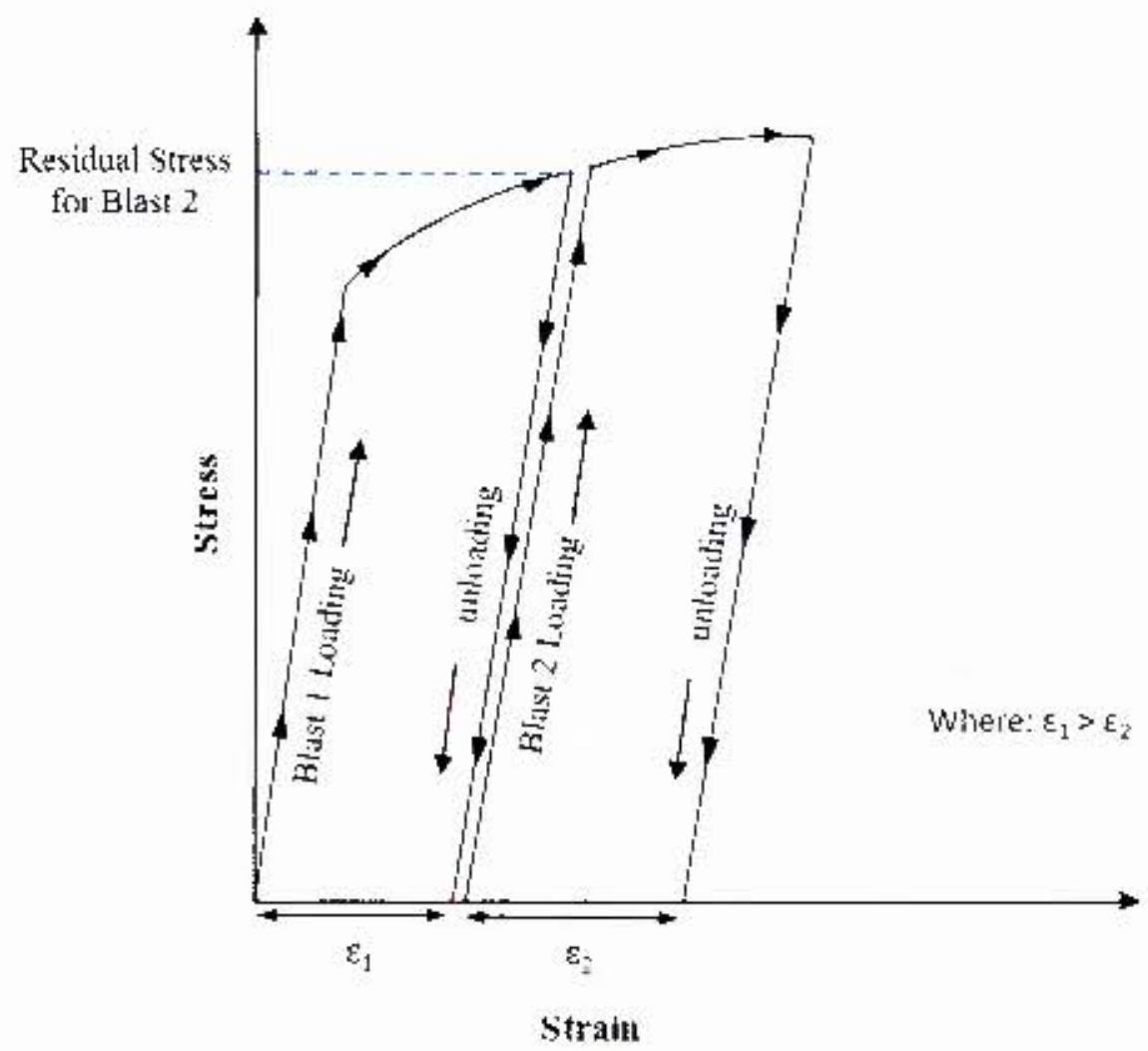

Figure 5.15: Illustration of stress-strain graph. showing the stress stace of the plate material after 2 blasts 


\subsection{Relationships of Dimensionless Analysis}

Using dimensionless numbers allows for the direct comparison between different experiments using different loading parameters. Empirical and theoretical analyses were carried out on the experimental results and presented in this section. Analytical predictions using the modified Jones damage number [2] were performed and compared with the results from Jacob et al [51]. Dimensionless analysis using the modified dimensionless impulse parameter, developed by Nurick et al [3,51] was also investigated.

\subsubsection{Relationship between Modified Jones Number and Deflection-Thickness Ratio}

Jones [2] developed a damage number $(\lambda)$ to predict large inelastic deformation (Mode 1 ) of fully clamped circular plates, loaded impulsively by a uniformly distributed velocity. Jones damage number in its original form did not account for the effects of large stand-off distances; subsequently a modification to the damage number was introduced by Jacob et al [51]. The modification factor $(\gamma)$ was assimilated into the Jones damage number based on the relationship between Jones damage number and Nurick and Martin dimensionless impulse parameter [51]. The modified Jones damage number, accounting for stand-off distance is given in Equation 5.7.

$\lambda=\frac{4 I^{2} \gamma^{2}}{\pi^{2} R^{2} H^{4} \sigma_{0} \rho}$

The empirical prediction as proposed by Jones [2] is expressed in Equation 5.8.

$\frac{\delta}{H}=0.213 \lambda_{s}^{0.5}$

Eq. 5.8 


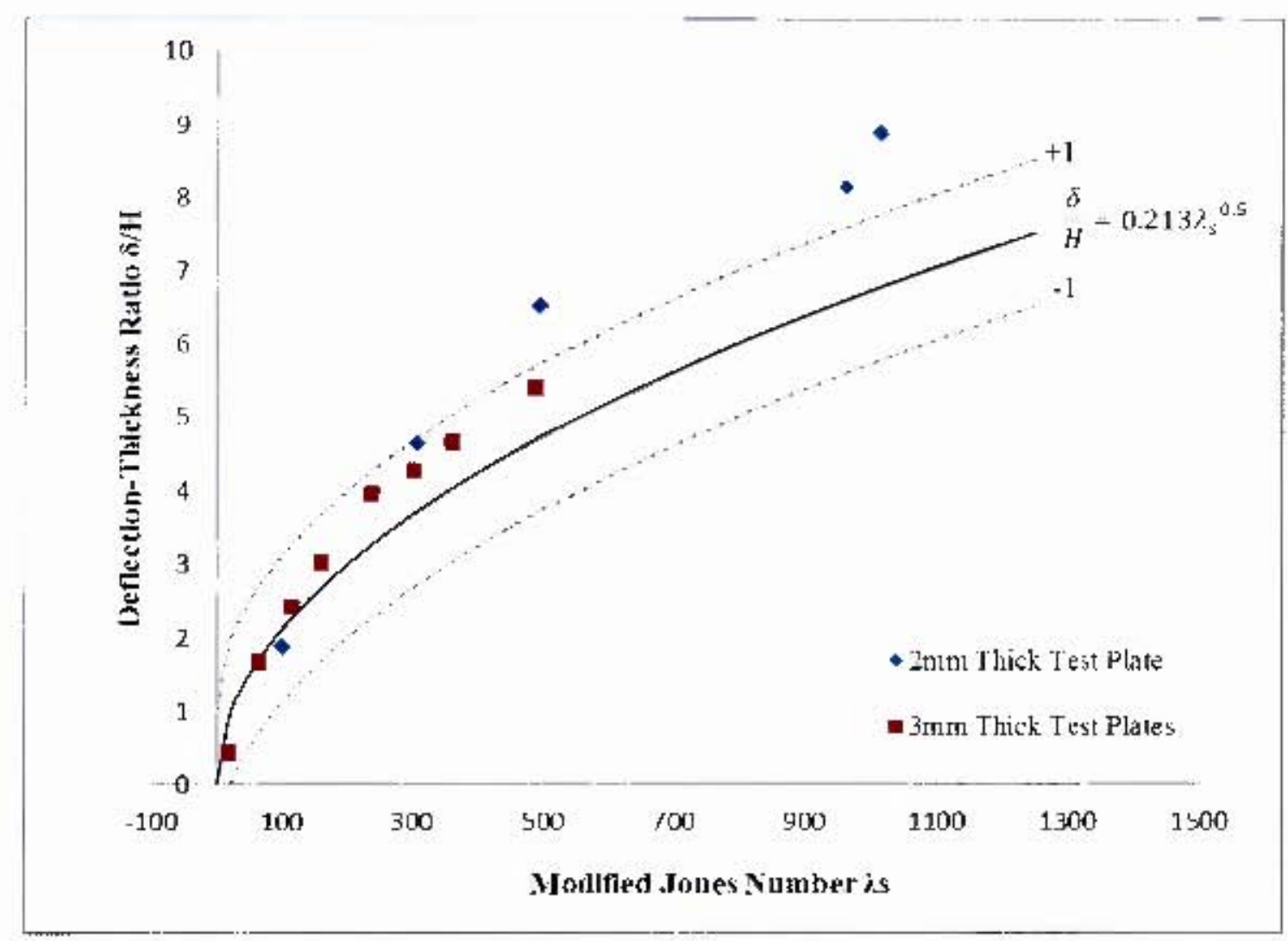

Figure 5.16: Graph of deflection-thichness ratio versus nodified Jores number for singta blast load displaying differences in plate thicknesses

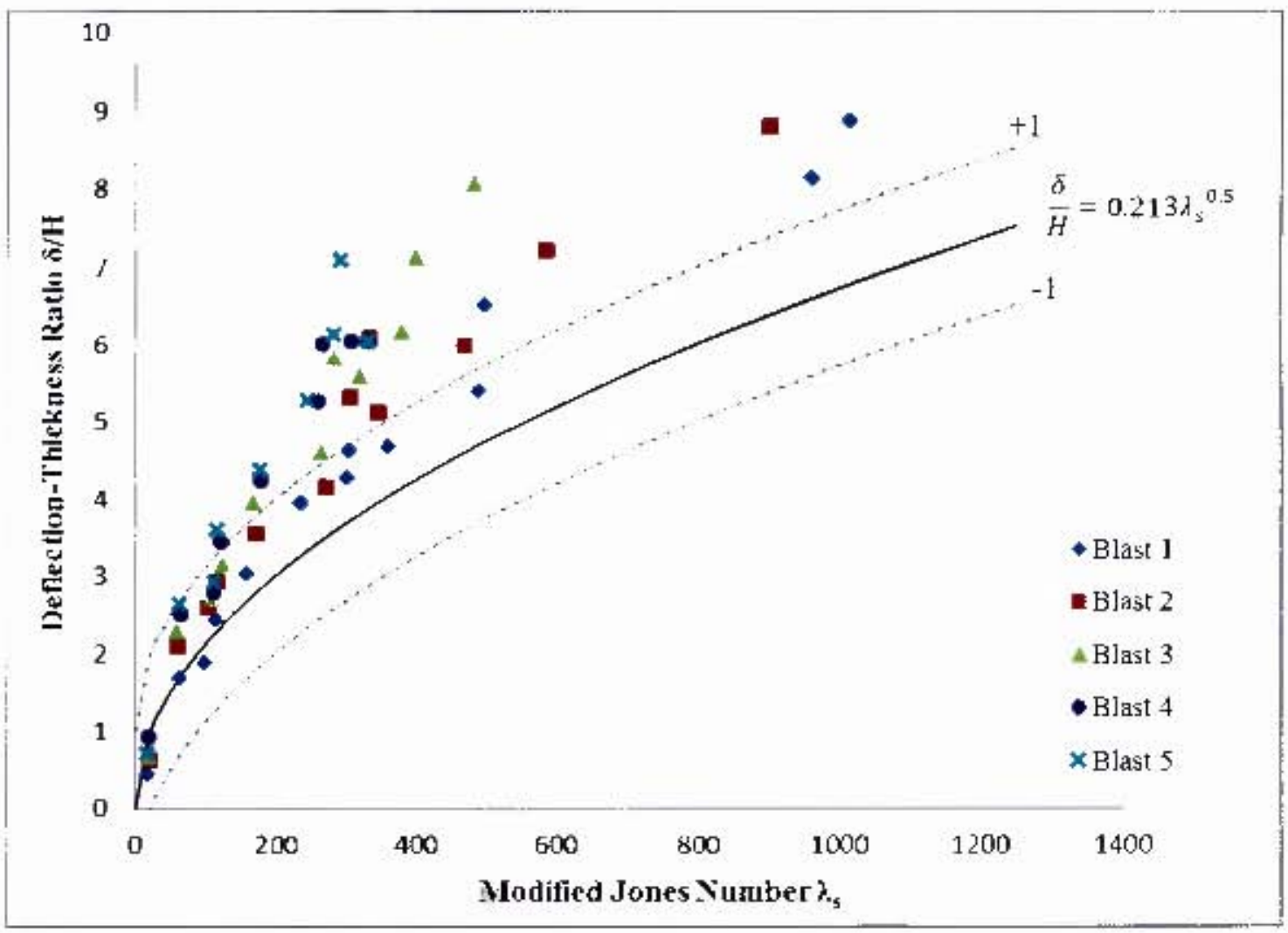

Figure 5.17 ; (iraplu of detlection-thichess ratio versus nodified jones number for all repeated blast toats 
Figure 5.16 shows the relationship between the midpoint deflection-thickness ratio and the modified Jones damage number for single blast load, displaying the differences occurring between each plate thickness. The results from this report were compared to those reported by Jacob et al [51] for experiments carried out for a stand-off distance of $150 \mathrm{~mm}$. In Figure 5.16 the results for the $3 \mathrm{~mm}$ thick plate, were within the $\pm 1(90 \%)$ confidence range, whereas 3 data points of the $2 \mathrm{~mm}$ thick plate results were above the empirical relation for higher deflection-thickness ratios. This may be due to extensive boundary thinning visible in the post blasted test plates at higher charge masses (tending towards threshold failure), causing the midpoint deflections to become unpredictable with regards to following an empirical relationship. The empirical relationships do not account for failure. The results of the Jones damage number relation for all repeated blast loads are shown in Figure 5.17. The data showed a great deal of scatter, with data points falling above the $90 \%$ confidence range, because the Jones damage number was developed for single blast load conditions and does not take into account repeated blast load conditions. Jacob et al [51] noted that the empirical relations did not take into account the strain rate sensitivity of the steel. The plates were manufactured from Domex $\mathbf{7 0 0}$ steel, which is strain sensitive at high strain rates.

\subsubsection{Relationship between Modified Dimensionless Impulse and Deflection}

Nurick and Martin [3] developed a dimensionless impulse parameter $\varphi_{c}$ for predicting large inelastic deformation of fully clamped circular plates subjected to blast loads. Jacob [51] modified the dimensionless impulse to take into account, the effect of stand-off distances. The modified impulse was given by the empirical relationship (Equation 5.4).

$\phi_{c}=\frac{I \gamma}{\pi R H^{2} \sqrt{\rho \sigma_{0}}}$

Where:

$\gamma=\frac{\left(1+\ln \frac{R}{R_{0}}\right)}{\left(1+\ln \frac{S}{R_{0}}\right)}$

And $S$ - stand-off distance and $R_{0}$ - charge radius.

The relationship between the modified dimensionless impulse and the deflection-thickness ratio is shown in Figure 5.18 and Figure 5.19. Figure 5.18 illustrates the dimensionless impulse for a single blast load for each plate thickness, whereas Figure 5.19 illustrates the dimensionless impulse results of all the repeated blast loads for both plate thicknesses. The results from this report were compared to the results reported by Jacob [51]. 


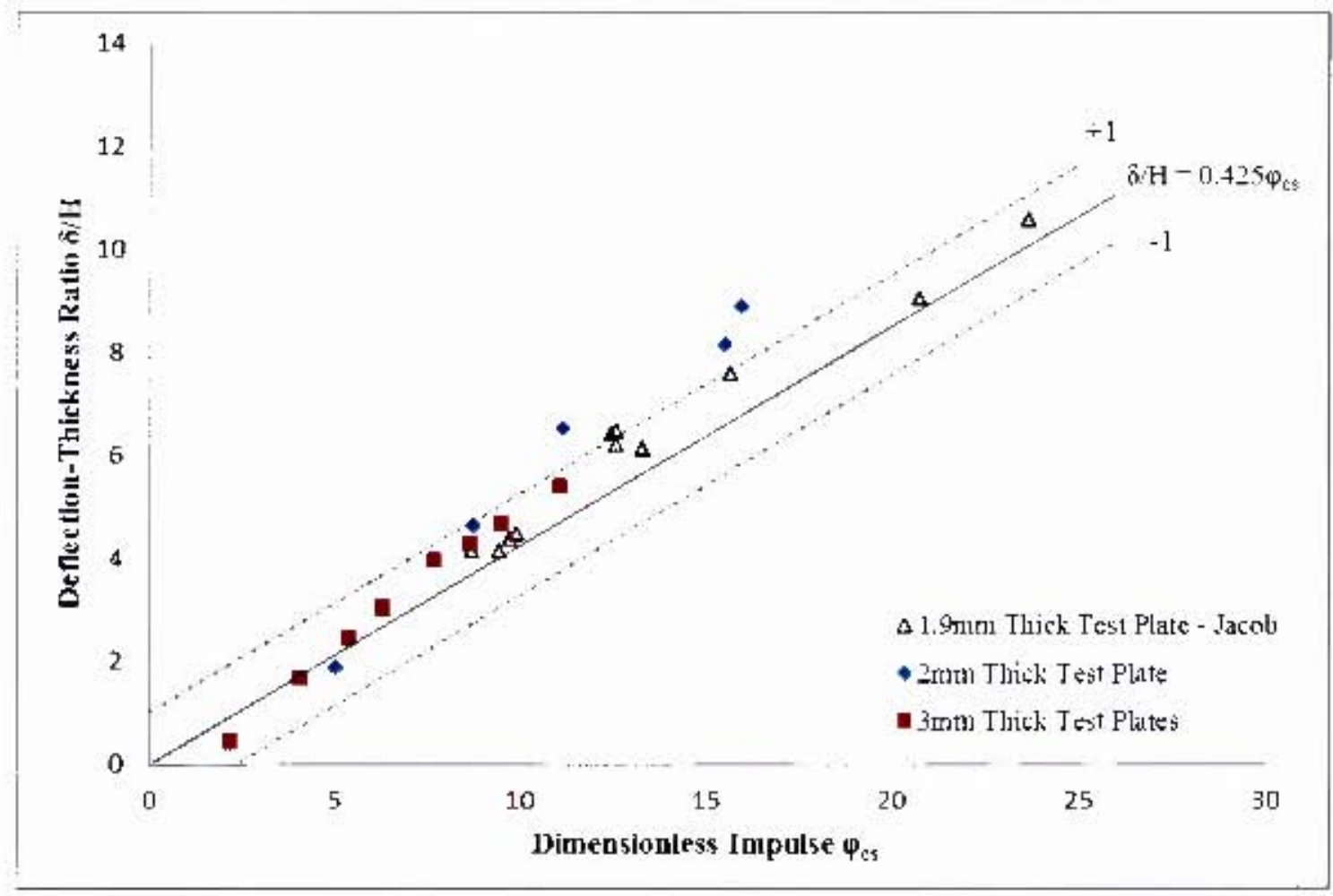

Figure 5.16 : Kirapl of Deflection-thicknes. ratio versus dimensionless impulse for 1 blast inad displaying differences between plattc thich nesscts

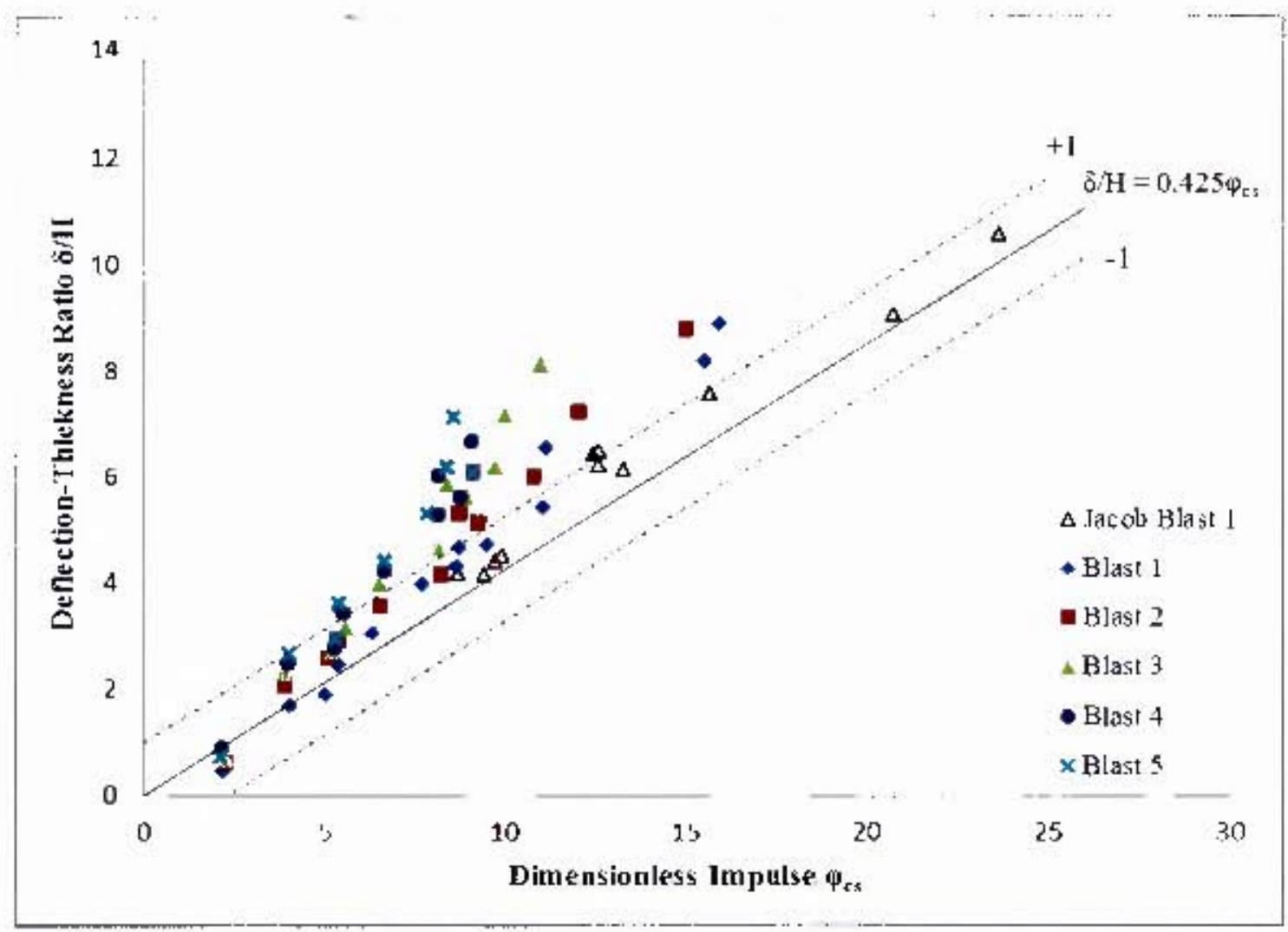

Figure 5.19: (iraph of De-flectirn-thiskemes ratio wirsus dimensitrnless impulse far all repeated blast loads 
Nurick and Martin [3] reported a relationship between the deflection-thickness ratio and modified dimensionless impulse, represented by the linear trend shown in Equation 5.6.

$\frac{\delta}{H}=0.425 \varphi_{c s}$

For the single blast load results, the majority of the data points were within \pm 1 confidence factor $(90 \%$ confident), as shown in Figure 5.18. Three data points from the $2 \mathrm{~mm}$ thick test plate results, for a single blast load, were not within the $90 \%$ confidence factor, but could be accounted for by experimental variation. Further accountability can be noted in the fact that the empirical relationships do not take into account strain rate sensitivity. The initial tests used in the formulation of the empirical relations used mild steel as the target plate material, which has a different strain rate sensitivity to Domex 700 at high strain rates. Also, the $2 \mathrm{~mm}$ thick test plate results show a greater deviation from the empirical trend at higher deflection thickness ratios, where it was visually noted that significant amounts of boundary thinning were present on the post blasted test plates as the resultant impulse reached threshold capacity. The empirical relations do not take into account target failure (extensive thinning or tearing) giving a possible reason for the deviations. Further testing of a larger sample should be undertaken to confirm the data trends. All the data points from the $3 \mathrm{~mm}$ thick test plate results fell within the $90 \%$ confidence factor. The results for the repeated blast loads (Figure 5.19) displayed less agreeable results than the single blast load results. This was expected, as the dimensionless impulse was defined for a single blast. The results seemed to increasingly deviate from the empirical linear trend (Equation 5.6) as the number of blast loads increased. This indicated that repeated blasts had a significant effect on the deflection-thickness ratio and dimensionless impulse and a modification factor needed to be included in the dimensionless impulse equation, to account for the repeated blast load effects. 


\subsection{Relationship between Repeated Blast Load and Strain Hardening}

Strain hardening or work hardening is the process of strengthening metal by plastic deformation [98]. Strain hardening, occurs when the metal is deformed beyond its respective yield point. As the metal plastically deforms, it is strengthened by dislocations of the crystalline structure [99]. The greater the metal is deformed by this process, the greater the hardening, until ultimate failure occurs [99]. The microstructure of metal consists of an intricate crystal lattice. When the metal is subjected to a blast load, dislocations occur in the crystal lattice. As the crystal lattice dislocates, the microstructure of the lattice starts to intertwine, which increases the density of the metal, therefore making it harder and stronger [100]. The extent to which the metal has been hardened can be determined by analysing the stress strain curve of a tensile test performed on the pre and post loaded plates and by performing hardness tests on plate samples that have been loaded and not loaded.

Hardness is the measure of resistance by a material to plastic deformation. Metal plates subjected to blast loading underwent work (strain) hardening when large plastic deformation occurred. It was, therefore, expected that after being subjected to a blast load, the plate was work hardened, resulting in a "stronger" material. This section examines the extent to which the blast loads work hardened the Domex 700 test plates, by carrying out Vickers Hardness tests on the deformed plates. For this report macro hardness tests (over multiple grain sizes) were carried out. Vickers Hardness tests can be related to the approximate ultimate tensile stresses of a material, using conversion tables, but is used predominantly as a comparative measure between metals.

The macro hardness tests were carried out in incremental distances from the centre of the plate to the outer boundaries of the clamped area. The locations of the Vickers hardness tests (red dots), as were carried out on the test plate profiles, is shown in Figure 5.20. Hardness tests were initially performed on a section of a test plate that had not undergone blast test loading. The resultant hardness of the nonblasted test plate was $296 \pm 2 \mathrm{HV}$ and was used as the base line reference hardness. Furthermore a transparent, blue 'band' was superimposed onto the Vickers hardness graphs (kept constant) and represents the experimental variation for the Vickers hardness tests (approximately $\pm 20 \mathrm{HV}$ ). Figure 5.21 - Figure 5.23 show the results of the Vickers hardness tests for the test plates with three different ranges of deformation. Figure 5.21 represents the plates where almost no deflection occurred, Figure 5.22 represents the plates with small deflections and Figure 5.23 represents the plates that underwent larger deflections. Vickers hardness tests for charge masses $5 \mathrm{~g}(2 \mathrm{~mm}, 3 \mathrm{~mm})$ and $10 \mathrm{~g}$ are shown in Figure 5.22 and Figure 5.23. Additional Vickers Hardness test graphs for the remaining test plates are presented in Appendix F.5 and similar trends were observed. 


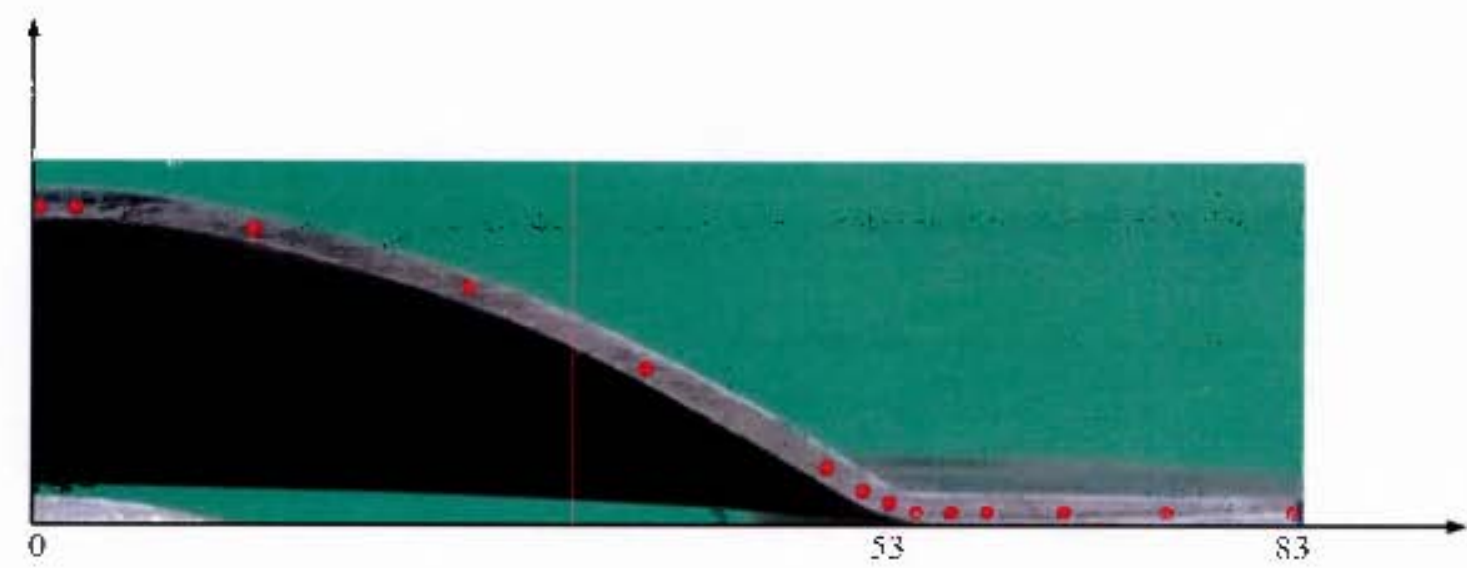

Kadius from Plate Cen1re (mm)

Figure 5.20: Locations of tichers lar alness tests as carried ant on the platte profile

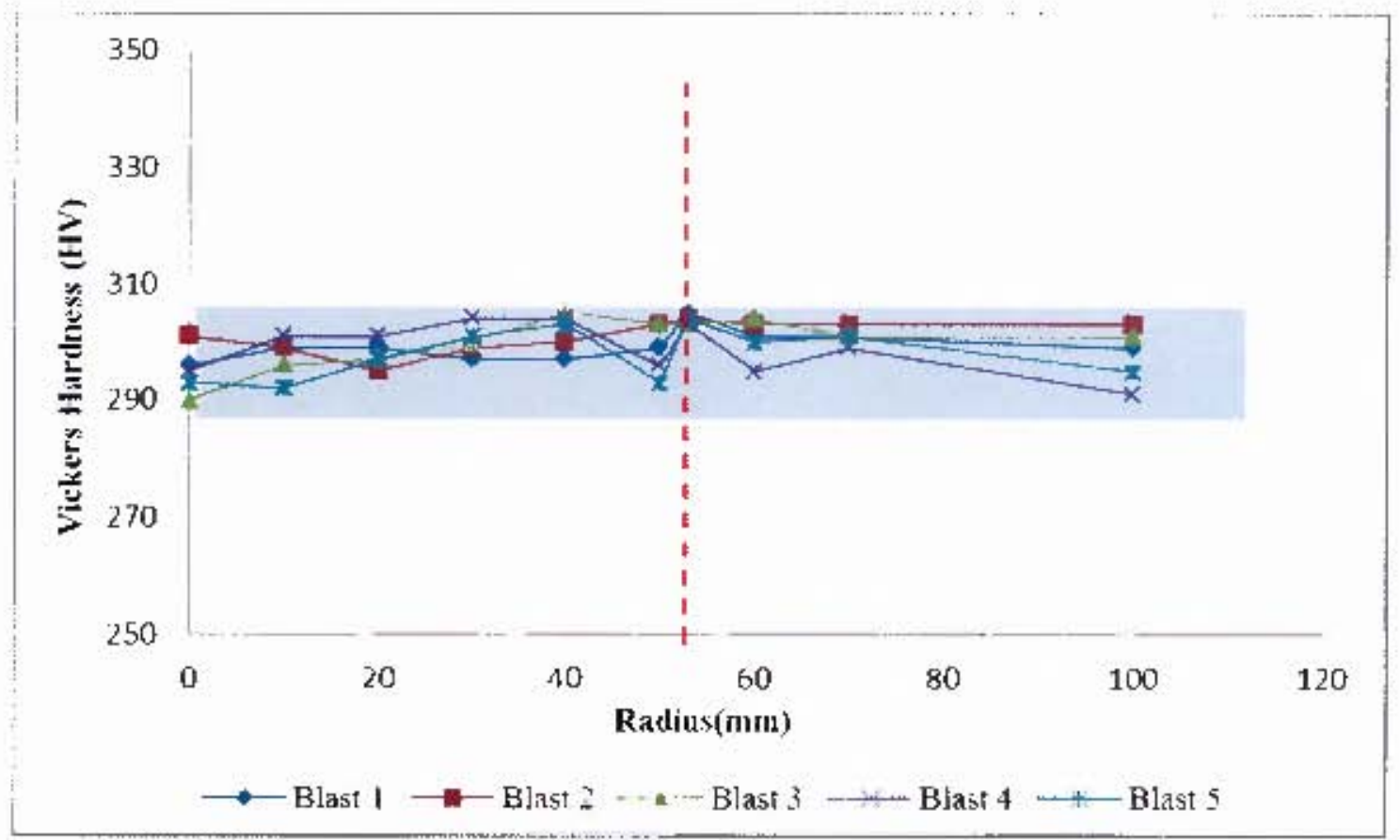

Figure 5,21: Griaph of Yickers Hardness on plite profĩe for charge mass $5 \mathrm{~g}$ and plate thickuegs $3 \mathrm{~mm}$ (almost no defections) 


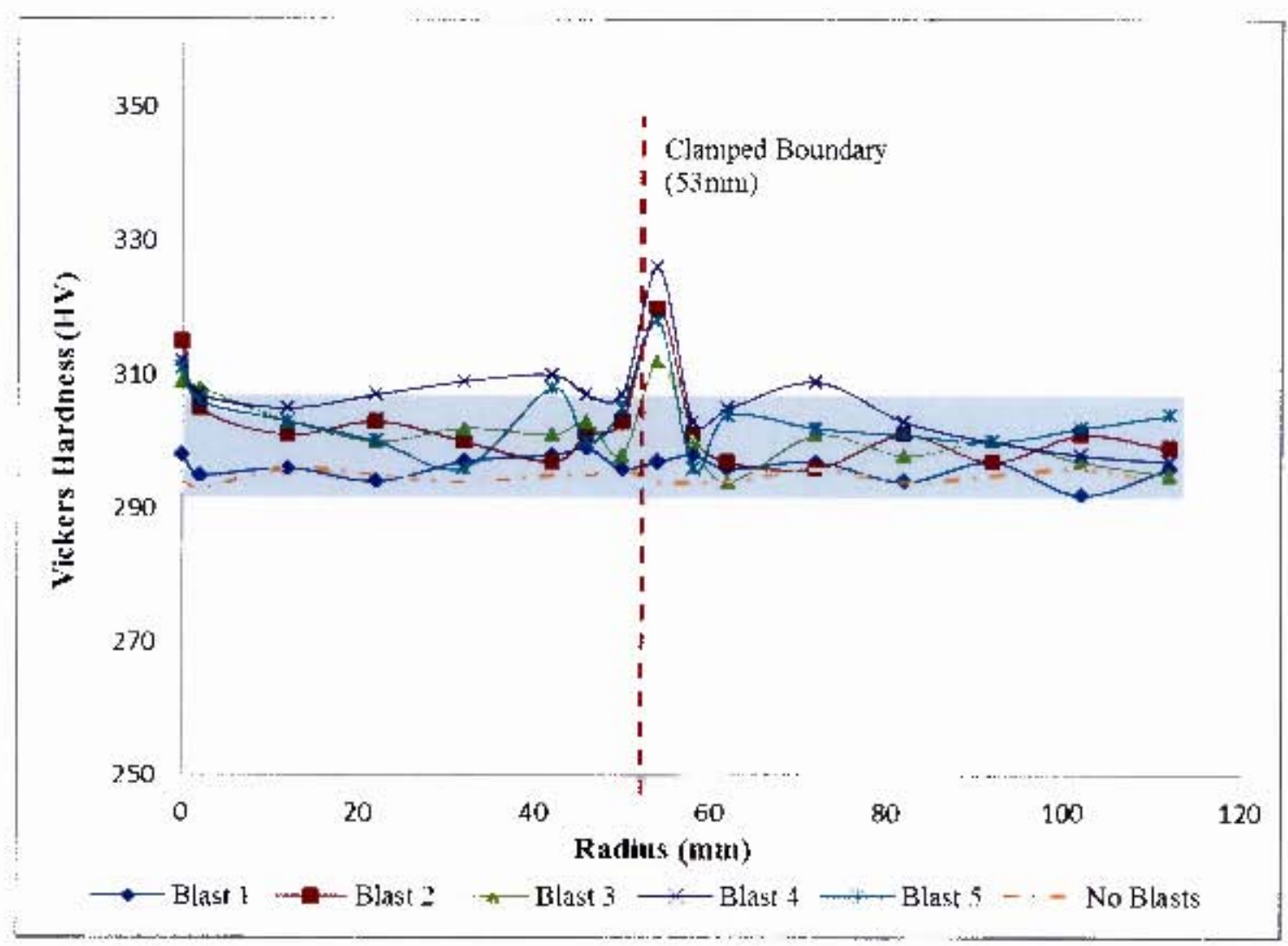

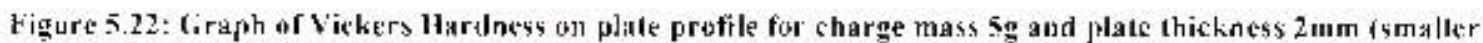
deflections)

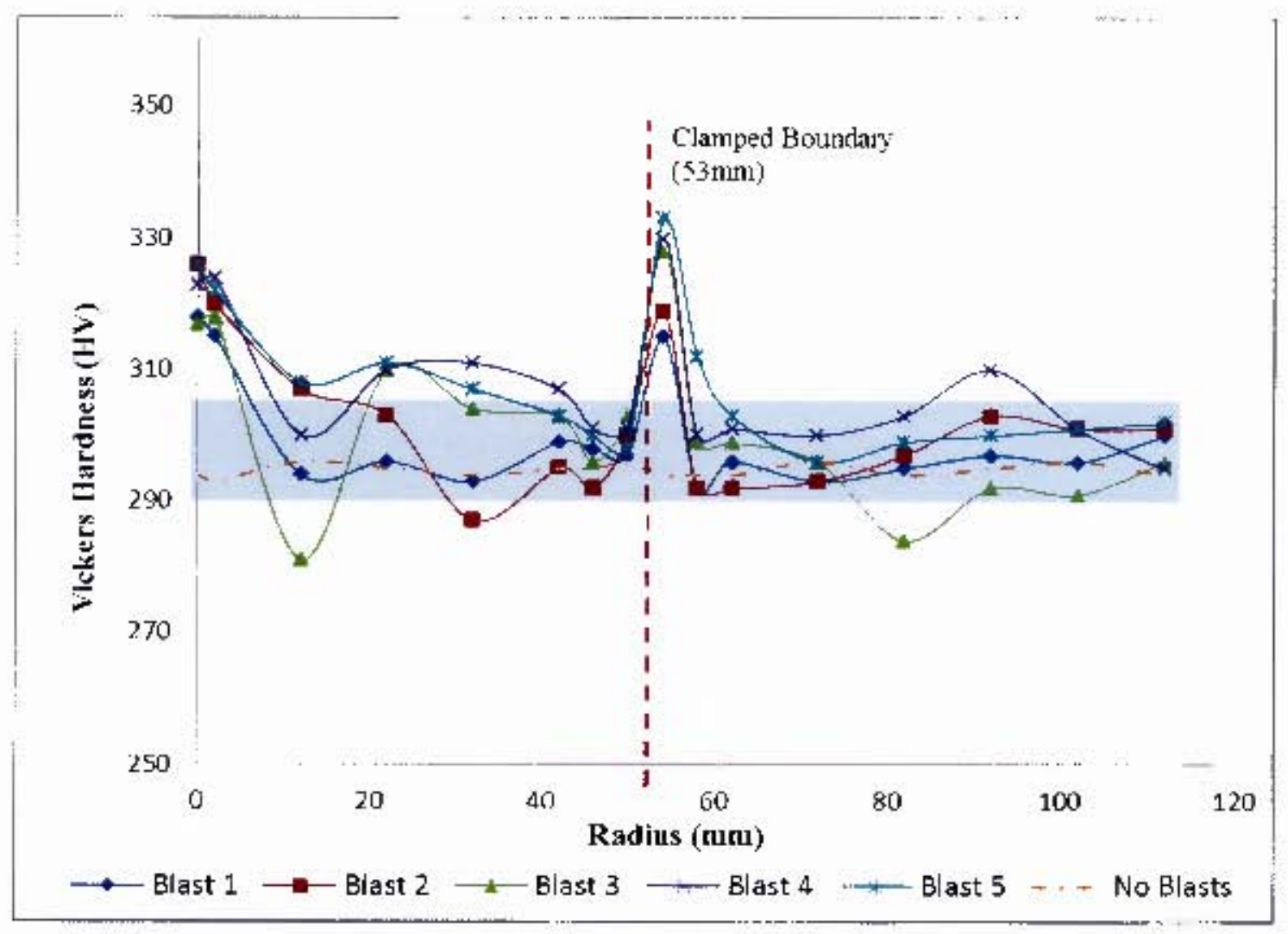

Figure 5.23: Graph af Viekers Hardness on plate profile for charge mass 10) and plate thicknesi 2 mim (larger detlections) 
The hardness test results generally showed an increase in Vickers hardness at the centre of the test plates and the clamped boundary region, with the maximum hardness predominantly occurring at the boundary region. This was expected, as the boundary region experiences large changes in deformation when blast loaded, due to the shearing effect of the clamped boundaries. For a charge mass of $5 \mathrm{~g}$ (Figure 5.22) the hardness for a single blast showed no significant increase, indicating the plate underwent very little permanent inelastic deformation, corresponding to the progressive deflections within one plate thickness of each other.

The maximum peak hardness at the boundaries was compared for varying charge masses and number of blast loads, shown in Figure 5.24 and Figure 5.25. A linear increase in peak Vickers hardness per blast load for each charge mass was observed. There was also a general increase in peak Vickers hardness between each charge mass for an increase in the number of blasts. 


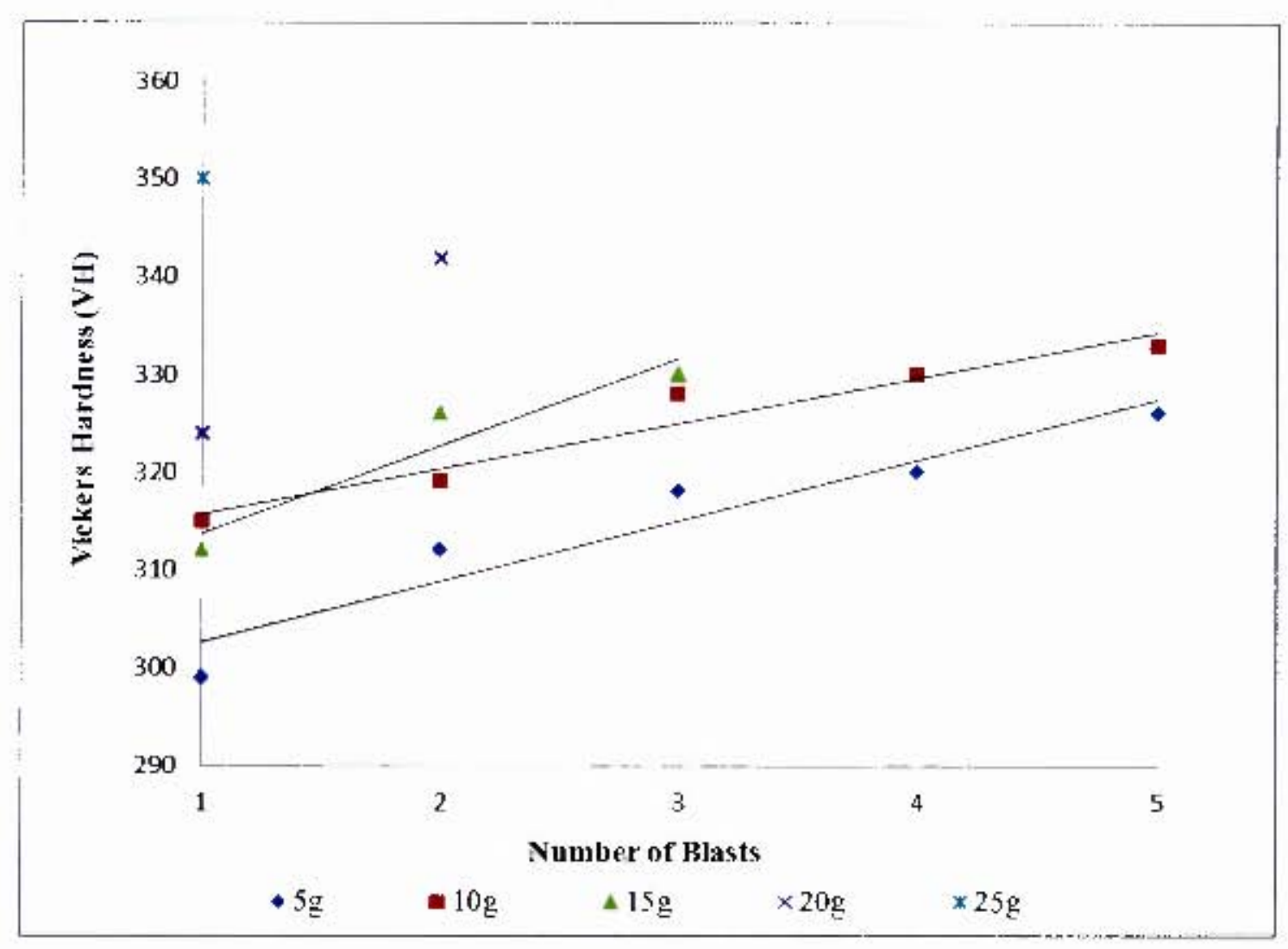

Figure 5.24: Graph 11 maxim um peak Vickers hardness at the clamped boundary region for eacla clarge mass. slowing increasing trends

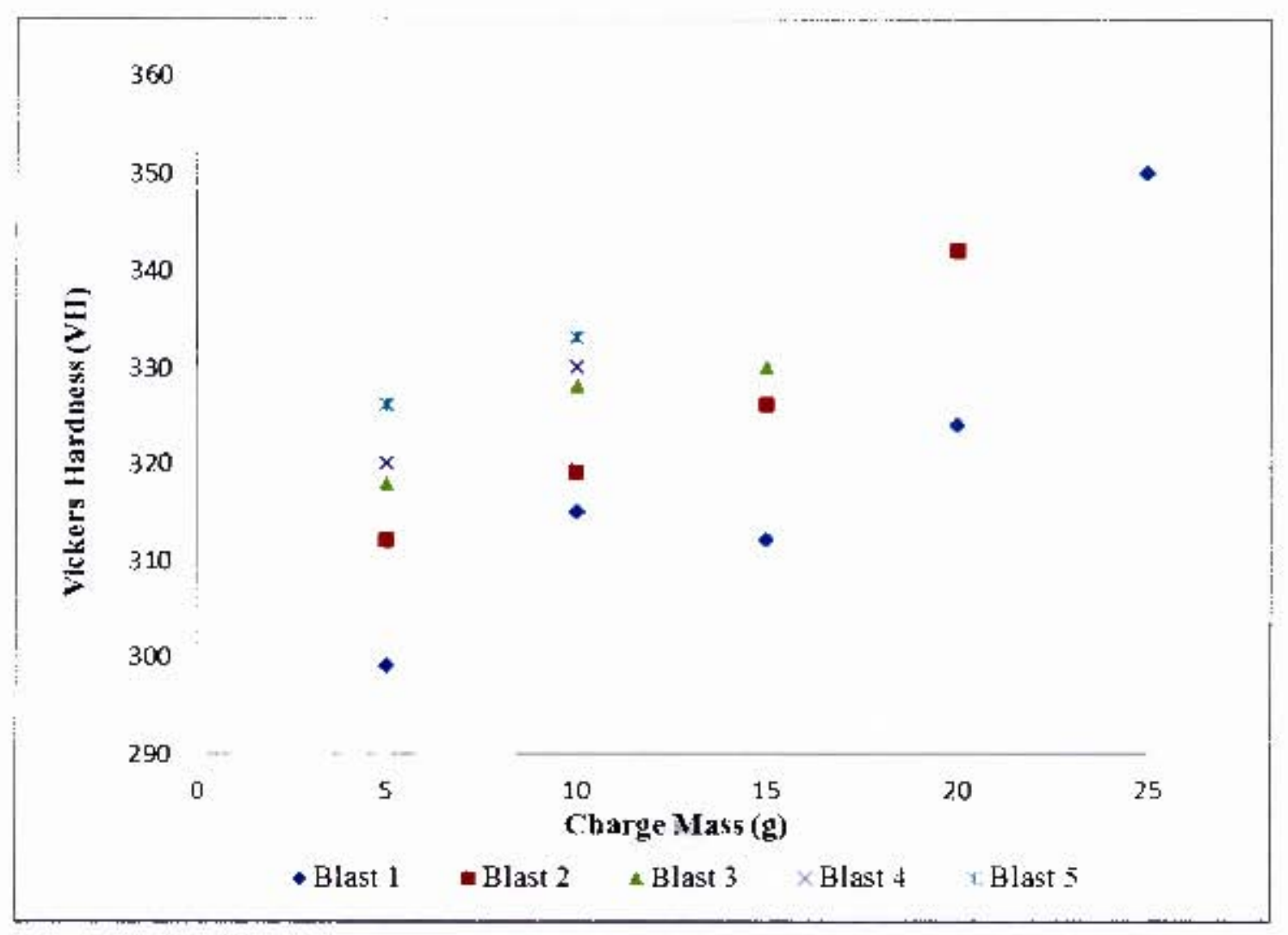

Figure 5.25: Graph of maximum peak Vickers hardatss at the clamped boundary region for all the replated blast loads 


\section{Numerical Simulations of Repeated Blast Loads}

Numerical simulations were carried out to simulate the experiments, to gain further insight into the deformation of plates subjected to repeated blast loading. In this thesis, the numerical simulations were carried out using two different software packages: AUTODYN v13 and ABAQUS/Explicit v6.10.1 and the experiments were modelled using three different methods:

1) AUTODYN (ALE multi-material analysis)

2) ABAQUS Rectangular Pressure Pulse Loading (applying a rectangular pressure pulse to approximate the blast)

3) ABAQUS CONWEP Loading (use of CONWEP to simulate the blast)

The different material models, geometric set-up and sensitivity analyses of the various loading techniques in both AUTODYN and ABAQUS are discussed.

\subsection{AUTODYN Numerical Model}

\subsubsection{Material Models}

\subsubsection{Air}

The air was modelled as an ideal gas, given by Equation 6.1, using data available in the AUTODYN material library. It was required to define the initial conditions of the air before the explosive event took place. The air was considered to have an atmospheric pressure of $101.3 \mathrm{kPa}$, which corresponded to an internal energy of $2.068 \times 10^{5} \mathrm{kJkg}^{-1}$ and initial temperature of $288.2 \mathrm{~K}$. The air parameters as defined by the AUTODYN material library [78] are listed in Table 6.1.

$P V=n R T$

Eq. 6.1

Table 6.1: AUTODYN material properties for Air as an ideal gas

\begin{tabular}{|c|c|c|c|}
\hline$\rho_{\text {air }}\left(\mathrm{kgm}^{-3}\right)$ & Temperature (K) & $C_{v}\left(\mathrm{kJkg}^{-1} \mathbf{K}^{-1}\right)$ & $\mathbf{Y}$ \\
\hline 1.225 & 288.2 & 0.7176 & 1.4 \\
\hline
\end{tabular}




\subsubsection{Explosive}

The plastic explosive PE4 used in the blast experiments was modelled as C4. PE4 and C4 have the same detonation characteristics with the only difference being the amount plasticizer used in the explosive formulation. The explosive material C4 is well defined in AUTODYN's material library and has been successfully used by Pickering et al [10], Langdon et al [11], Langdon et al [15] and Ambrossini et al [29]. The explosive $\mathrm{C} 4$ was simulated in the model, by using the fill option, where a certain portion of the air mesh elements were filled with $\mathrm{C4}$, corresponding to the desired geometry and mass of $\mathrm{C} 4$ used in each specific blast series.

The Jones-Wilkins-Lee (JWL) equation of state (Equation 6.2) [101] was used to model the detonation of the $\mathrm{C} 4$. Once the explosive material had detonated and approached ideal gas behaviour, AUTODYN automatically converted the explosive products to an ideal gas maintaining accuracy and reducing computational expense throughout the simulation. The values for the JWL equation of state as available in the AUTODYN library are listed in Table 6.2.

$$
P=A\left(1-\frac{\omega \rho_{P}}{R_{1} \rho_{e}}\right)^{\left(-\frac{R_{1} \rho_{e}}{\rho_{P}}\right)}+B\left(1-\frac{\omega \rho_{P}}{R_{2} \rho_{e}}\right)^{\left(-\frac{R_{2} \rho_{e}}{\rho_{P}}\right)}+\omega \rho E_{0}
$$

Table 6.2: AUTODYN material properties for C4 used to model the detonation of PE4 [78]

\begin{tabular}{|c|c|c|c|c|c|c|c|c|}
\hline $\begin{array}{c}\rho_{e} \\
\left(\mathrm{kgm}^{-3}\right)\end{array}$ & $\begin{array}{c}\mathbf{A} \\
(\mathbf{G P a})\end{array}$ & $\begin{array}{c}\text { B } \\
(\mathbf{G P a})\end{array}$ & $R_{1}$ & $R_{2}$ & $\begin{array}{c}\omega \\
\text { C-J V detonation } \\
\left(\mathrm{ms}^{-1}\right)\end{array}$ & $\begin{array}{c}\text { C-J } \\
\frac{\text { Energy }}{\text { Volume }}\left(\mathbf{k J m}^{-3}\right)\end{array}$ & $\begin{array}{c}\text { C-J Pressure } \\
(\mathbf{G P a})\end{array}$ \\
\hline 1601 & 609.8 & 12.95 & 4.5 & 1.4 & 0.25 & 8193 & $9 \times 10^{6}$ & 28 \\
\hline
\end{tabular}




\subsubsection{Test Plate- Domex 700 Steel}

Domex 700 steel was not a material available in the AUTODYN library and therefore, much of the material strength properties for Domex700 had to be derived from uni-axial tensile tests and post ultimate tensile test simulations. Uni-axial tensile tests were carried out on specimens, using the Zwick/Roell machine to determine the yield strength of the material (750MPa). Post ultimate tensile strength properties and true strength-strain characteristics were obtained from the simulations of the tensile tests carried out using ABAQUS, as described in Appendix A.1. The strain rate sensitivity of Domex 700 was researched by Pickering [10], who gathered some information from the Knowledge Service Centre of SSAB Tunnplt AB [102], before processing it for implementation into the respective simulations. Other material properties, such as the thermal properties, were approximated to Steel 4340 , because of the similarity in yield strength to Domex 700 . The Steel 4340 properties are available in the AUTODYN material library [78].

Domex 700 steel is considered a solid and it was therefore assumed that the pressure was independent of the internal energy; the steel was thus modelled with a linear equation of state that approximates the response of the material to Hooke's Law (Equation 6.3). The parameters (including thermal properties) used to model the steel, were the same as the Steel 4340 material properties found in the AUTODYN library. Table 6.3 shows the AUTODYN values used in relation to the linear equation of state for Domex 700.

$P=K u$

Eq. 6.3

Where: $P$-pressure, $K$ - bulk modulus and $u$ - strain.

Table 6.3: Linear equation of state material properties for Domex 700

\begin{tabular}{|c|c|c|c|c|c|c|}
\hline$K$ & $G$ & $V$ & $T_{\text {ref }}$ & Specific Heat & $k_{\text {thermal }}$ & $\rho$ \\
\hline $159 \mathrm{GPa}$ & $81.8 \mathrm{GPa}$ & 0.29 & $300 \mathrm{~K}$ & $476.99 \mathrm{~kg}^{-1} \mathrm{~kg}^{-1}$ & $42 \mathrm{Wm}^{-1} \mathrm{~K}^{-1}$ & $7870 \mathrm{kgm}^{-3}$ \\
\hline
\end{tabular}

The Johnson Cook strength model was specified to simulate the strength properties of the Domex 700 steel test plate. The material properties $A, B$ and $n$ were derived from the uni-axial tensile tests and post ultimate tensile strength numerical analyses using ABAQUS. The reference strain rate of $0.001 \mathrm{~s}^{-1}$ was chosen, which correlates to a $C$ value of 0.014 as was successfully used by Langdon et al [11] to model Domex steel plates subjected to localised blast loading. The thermal properties $m$ and $T_{\text {melt }}$ were taken as the values used for Steel 4340 as found in the AUTODYN material library. The Johnson Cook relation is given in Equation 6.4 with the corresponding constants listed in Table 6.4. 


$$
\sigma^{0}=\left(A+B \epsilon_{p l}^{n}\right)\left[1+C \ln \left(\frac{\epsilon_{p l}^{\prime}}{\epsilon_{0}}\right)\right]\left(1-T^{m}\right)
$$

Table 6.4: Johnson Cook material properties for Domex 700 steel

\begin{tabular}{|c|c|c|c|c|c|c|}
\hline$A$ & $B$ & $n$ & $\epsilon_{0}$ & $C$ & $m$ & $T_{\text {melt }}$ \\
\hline $750 \mathrm{MPa}$ & $270.6 \mathrm{MPa}$ & 0.263 & $0.001 \mathrm{~s}^{-1}$ & 0.014 & 1.03 & $1795 \mathrm{~K}$ \\
\hline
\end{tabular}

\subsubsection{AUTODYN Blast Loading}

An Eulerian solver was used to model the plastic explosive and air, as large displacements and extensive volume changes were experienced. The test plate underwent relatively consistent small deformations suitable for a Lagrangian mesh solver that was better suited for the structural response of the steel test plate. The method of modelling the explosive and air as an Eulerian solver, whilst modelling the test plate as a Lagrangian solver, has been successfully implemented by Pickering [10] and Langdon et al [15].

The numerical model was made up of four phases when simulating the repeated blast loads:

\section{Detonation \\ II. Plate Loading \\ III. Unloading \\ IV. Repeated Loading}

Each phase is discussed and the formulation of the final model of each individual phase is explained. The detonation model used a finer mesh $(0.25 \times 0.25 \mathrm{~mm})$ to attain Chapman-Jouguet pressure of 28.1 $\mathrm{MPa}$ [103], as closely as possible, whereas the loading model used a coarser $(0.5 \times 0.5 \mathrm{~mm}) \mathrm{mesh}$, in order to decrease the run time in the loading phase. The detonation phase was saved as a remap file, which was imported into the loading phase. The loading phase was allowed to run for a certain period of time until the blast pressure had sufficiently decreased to the point where it had little effect on the impulsive loading of the test plate. The air mesh was then deactivated allowing the plate to deform under its own inertia. The plate was allowed to oscillate for an extended period of time until the plate's transient velocity had decreased as close to $0 \mathrm{~m} / \mathrm{s}$ as possible, before importing a new detonation phase for a subsequent blast load. This process was undertaken 5 times for 5 consecutive blast loads. 


\subsubsection{Detonation Model -Phase I}

The detonation phase was modelled in 2D axisymmetric model including the detonation of the explosive material until the resultant shock wave interacted with the confined boundaries of the cylindrical tube. To model the detonation of an explosive in AUTODYN, a volume of air was first generated with the required geometry. The air mesh elements were then filled with $\mathrm{C} 4$ material, relative to the simulated charge mass and geometry of the explosive. A mesh sensitivity analysis was carried out, in order to obtain Chapman-Jouguet pressure in the air mesh. Once the desired mesh had been established, the explosive was detonated and allowed to run for a certain period of time, after which the detonation model was saved as a remap file. The detonation remap file was then imported into the loading phase.

The geometry of the detonation model, illustrated in Figure 6.1, corresponded to the geometry of the experimental set-up, including the cylindrical tube, taking into account the axis of symmetry. Within all the figures shown in this section, $\mathrm{X}$ and $\mathrm{Y}$ axes are labelled respectively. The mesh sizes are represented in millimetres and denoted as ' $\mathrm{i}$ ' and ' $\mathrm{j}$ ' for the $\mathrm{X}$ and $\mathrm{Y}$ axes respectively, as is typically carried out in modelling practises. The area of the air mesh accommodated for the area inside the experimental cylindrical tube and a finite amount of air behind the explosive charge. The height of the model related to the circular blast area in the experiment, with a radius of $53 \mathrm{~mm}$. The length of the entire model was $200 \mathrm{~mm}$. The 'tube' section of the model contained reflective rigid boundaries to simulate the rigid steel tube and was $150 \mathrm{~mm}$ in length (stand-off distance). At one end of the tube, a reflective rigid wall was modelled to resemble a rigid test plate. At the other end of the tube $(150 \mathrm{~mm}$ away), the explosive charge was modelled. The explosive charge geometry was modelled as the experiments, a cylindrical shape with a diameter of $34 \mathrm{~mm}$ and $1 \mathrm{~g}$ leader, used to house the detonator. The $1 \mathrm{~g}$ leader was assumed to have a diameter of $8 \mathrm{~mm}$ and was detonated at the free end. Behind the charge (left in Figure 6.1), there was a volume of air to allow for the explosive material to expand once detonated and resembled the 'free air' in the experiments. On the edges of the air mesh, 'flow out' boundaries had been assigned to allow the explosive material and shock wave to leave the confinements of the model. 


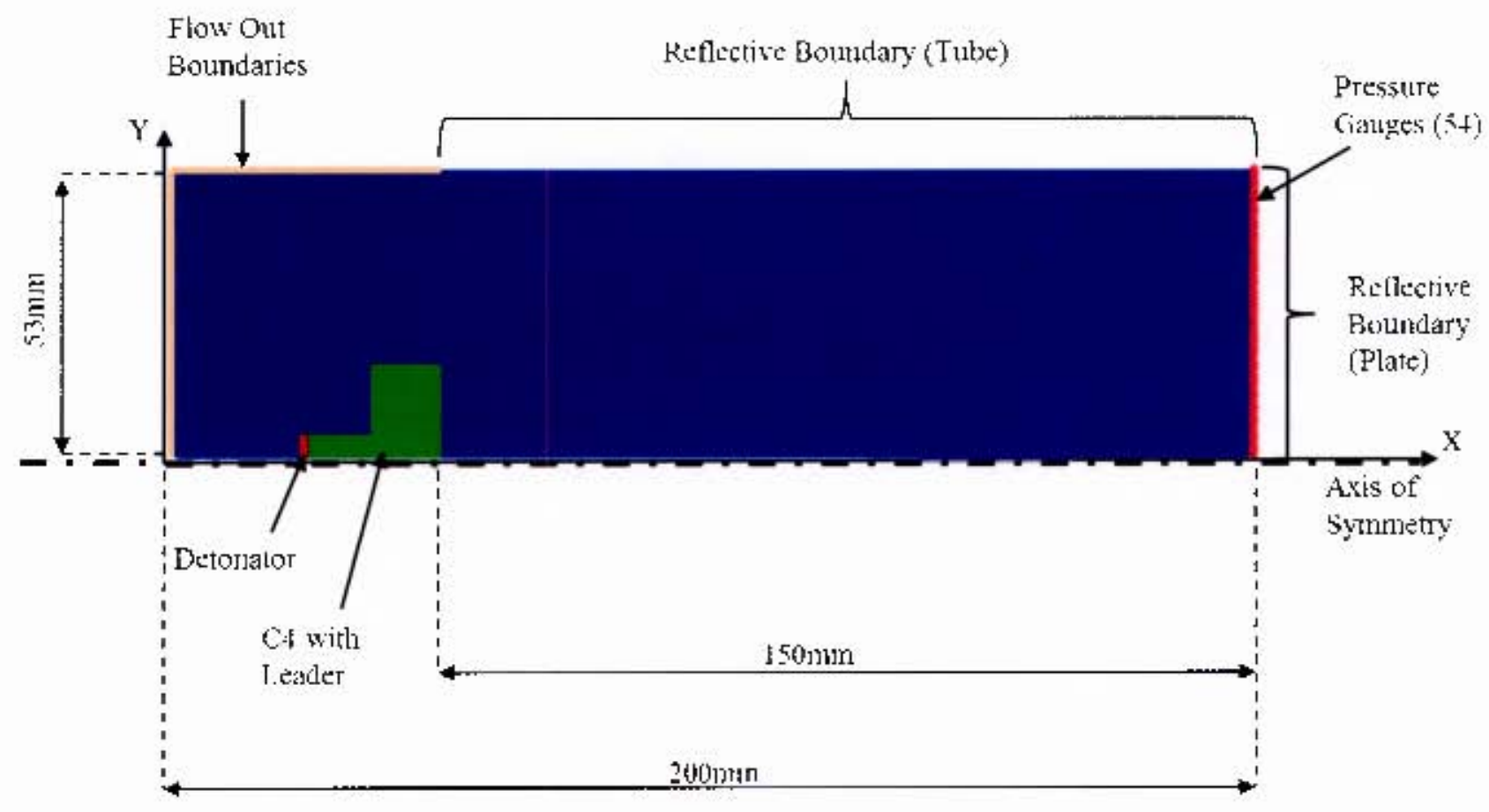

Figure 6.1: Overviesi of detonatiun modtal for plose I

The detonation model was run for a finite poriod of lime, betore it interacted with the 'flows out' and reflective boundaries. The run time wits dependest at the explosive charge mass used in the detonation model. I.arerer charge masses had a shorter run time as the explosive material and shock

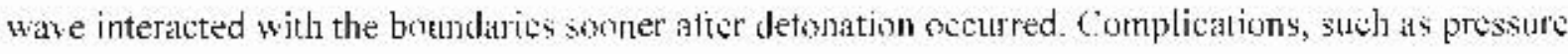
losses may oucur if the detonation model was imported ats a rtwap file, after the pressure wave interacted with the boundarics [104]. Orsce, the detonation model had reached its maximum possible run lime, before boundary interaction, the model was saved as a temap file in ALITODYN. The remip Cilc was inportled into the loading model (nexl phasc). siving on computational expense and allowing for the easy manipulation of the loading model whon varying the charge masses. The detonition model for a tharge mass of $10 \mathrm{~g}$. saved ats a remap file at lime $7.355 \mu$, is displayed in Figure 6.2 and Figure 6.3. 


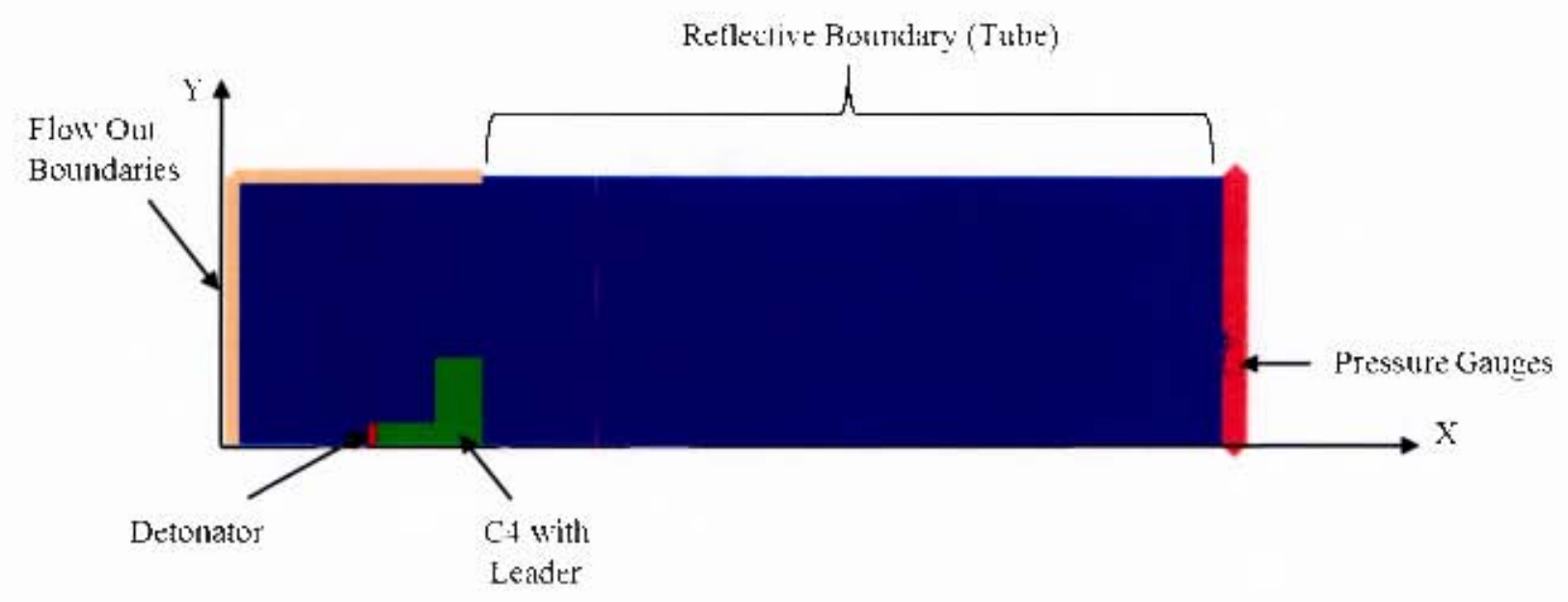

Figure 6.2: Detonation model at time ous for remap detouation file, displaying C+ material location

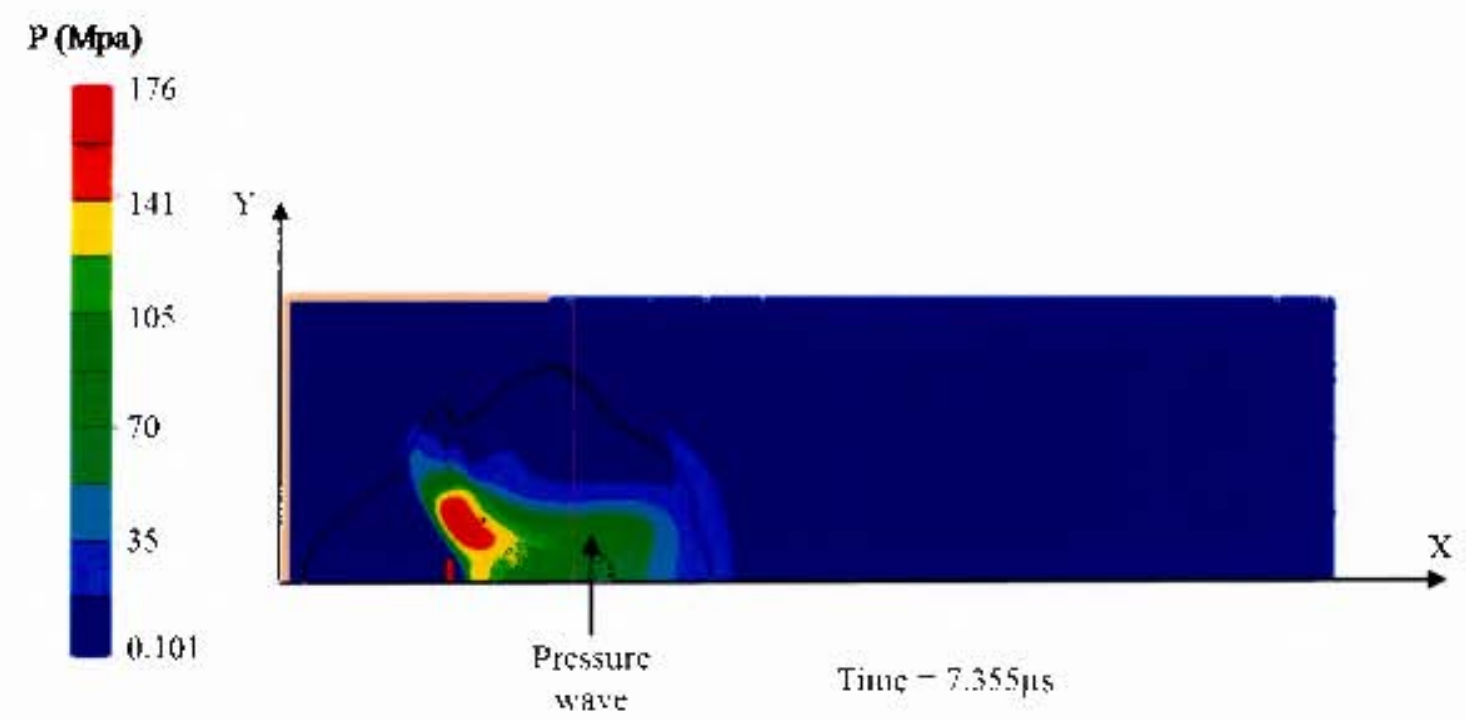

Figure 6.3: Detoenation model stopped at $7.355 \mu$ s tor detonation remap file, displaying mitigatieg presure wave

\subsection{Detonation Mesh Retinement}

Modelling an explosive reguires that varicus properties such as pressure, detonation velocilies and tomperature correspond is the Chapmatr-Jinguet (C.) values of the specitic explosive, once detonation has taken place. P'revious sludies an explisive modelling hat been successtully carried out

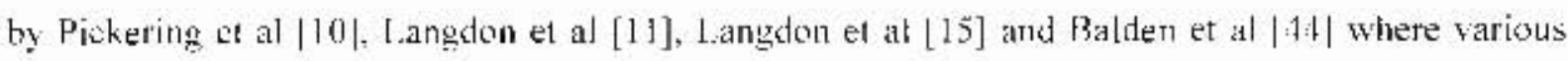
mesh densities had been shosen relating to the geometric dimensions of the explisive and the 
necessary number of elements required. It was important to ensure the correct mesh density was chosen in order to attain $\mathrm{CJ}$ pressure once the explosive had been detonated.

Langdon et al [15] carried out an extensive investigation into the effects of mesh density with regards to attaining $\mathrm{CJ}$ pressure versus computational expense. The numerical model developed by Langdon et al [15] had similar geometries and loading conditions to the model presented in this report. Based on the results of the sensitivity analysis presented by Langdon et al [15], the mesh size was selected accordingly. It was found that $0.25 \times 0.25$ and $0.1 \times 0.1$ mesh densities were acceptable for attaining an acceptable detonation pressure, comparable to $\mathrm{CJ}$ pressure for PE4. The computational expense between each mesh density was significant, with the $0.1 \times 0.1$ mesh having a run time 6 times that of the $0.25 \times 0.25$ mesh [15]. The results for detonation pressure and impulse differences between the meshes $0.1 \times 0.1$ and $0.25 \times 0.25$ are shown in Table 6.5 [15].

Table 6.5: Comparison of detonation pressure and Impulse between varying detonation mesh densities [15]

\begin{tabular}{|c|c|c|}
\hline $\begin{array}{c}\text { Detonation Mesh Size } \\
(\mathrm{mm})\end{array}$ & $\begin{array}{c}\text { Detonation Pressure } \\
(\mathrm{MPa})\end{array}$ & $\begin{array}{c}\text { Impulse } \\
(\mathrm{Ns})\end{array}$ \\
\hline $0.25 \times 0.25$ & 22.32 & 7.48 \\
\hline $0.1 \times 0.1$ & 25.42 & 8.08 \\
\hline
\end{tabular}

From Table 6.5, the difference between the impulses is $7.5 \%$. The difference in impulse between the two mesh densities at a greater stand-off distance of $300 \mathrm{~mm}$ was $1.5 \%$, as found by Langdon et al [15]. This reduced the dependence of very fine mesh densities with regards to resultant impulse when dealing with relatively large models. Furthermore, Pickering [10] established that a mesh density of $0.5 \times 0.5$ was acceptable for the detonation mesh, thus validating the use of a $0.25 \times 0.25$ mesh density.

For this project a resultant impulse comparison, at a stand-off distance of $150 \mathrm{~mm}$ and charge mass of $10 \mathrm{~g}$ between mesh densities of $0.1 \times 0.1$ and $0.25 \times 0.25$, was carried out. The resultant impulse for a mesh density of $0.1 \times 0.1$ was $23.26 \mathrm{Ns}$, whereas for a mesh density of $0.25 \times 0.25$ the resultant impulse was $22.14 \mathrm{Ns}$. The difference in impulse was $5 \%$ and the computational difference was approximately 5 times longer for the finer mesh. Therefore a mesh size of $0.25 \mathrm{~mm} \times 0.25 \mathrm{~mm}$ was chosen for the detonation model. The resulting air mesh density thus consists of $800 \mathrm{i} \times 212 \mathrm{j}$ elements, representing the dimensions of the detonation model, displayed in Figure 6.1. 


\subsection{Impulse Model}

To validate the numerical model, the AUTODY $\mathrm{V}$ simulated impulses were comparal in the impulses determined from the experimental tests. This chsural the numerical test plates were equivalcutly loraded to the experimental test. plates. Once the numerical resulls correlated with the experimental values. other aspects which were nol oblaindble from the experiments, such as pressure distributions, lorading limes and plastic deformation properties of the lest plate could be mestigated by means of the tumerical simulation.

The impulse was calculated from the pressure distribution across the tod plate area. The dimensions and details are illustrated in Figure 6.1. The impulse was caleulated fiom the integrated pressure impacting the retlective boundary on the deloriation model. This reflective boundary represented the circular blast area of the experiment. Presiure gauges were focated on the reflective boundary at $1 \mathrm{~mm}$ intervals, giving a total of 51 gauges. Between edch gauge a smalt specilje area existed on the blast area. The specilic areas were dependent on the radius from the enentre of the bast area. The impulse model with gauges is illustrated in Figure 6.4 and the speilic areas relative to the gauge positions are illustrated in Figure 6.5.

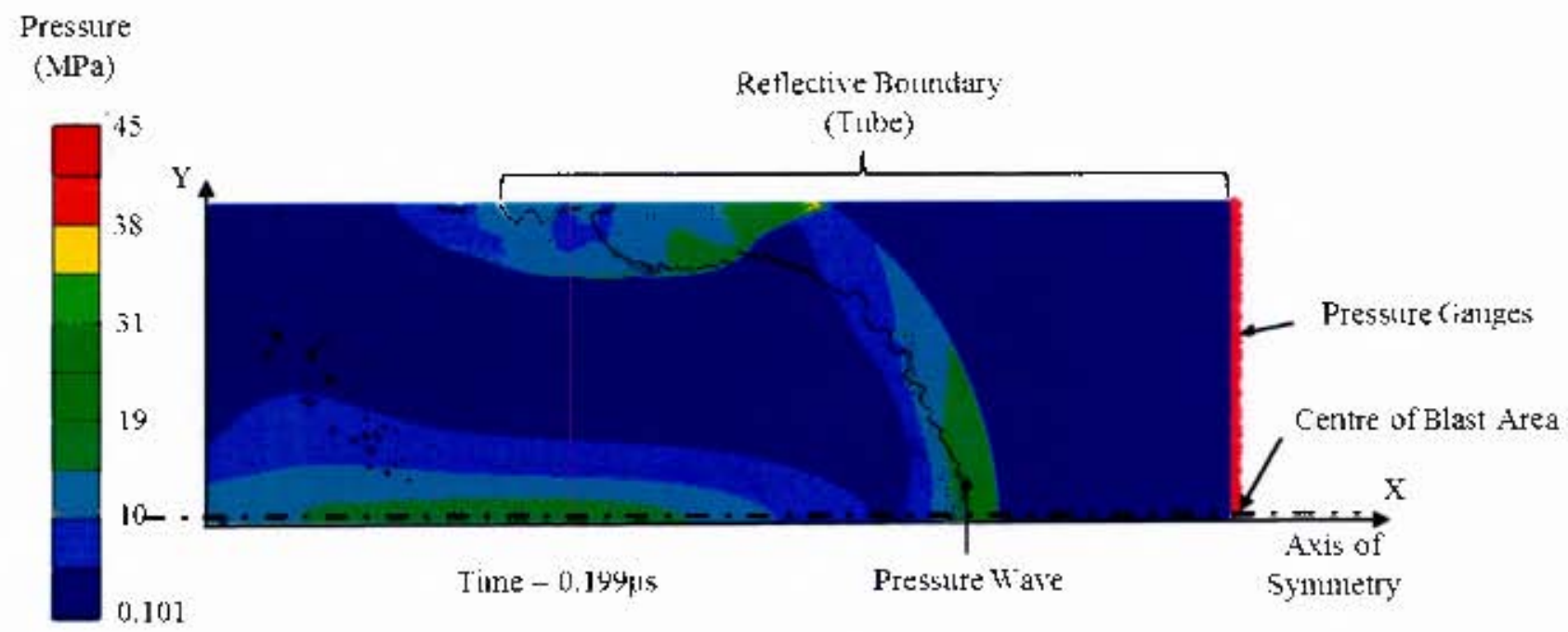

Figure 6.4; Im pulat: mudel with mitigating pressure wave and gange Irkationas at a time of $0.199 \mu 5$ 


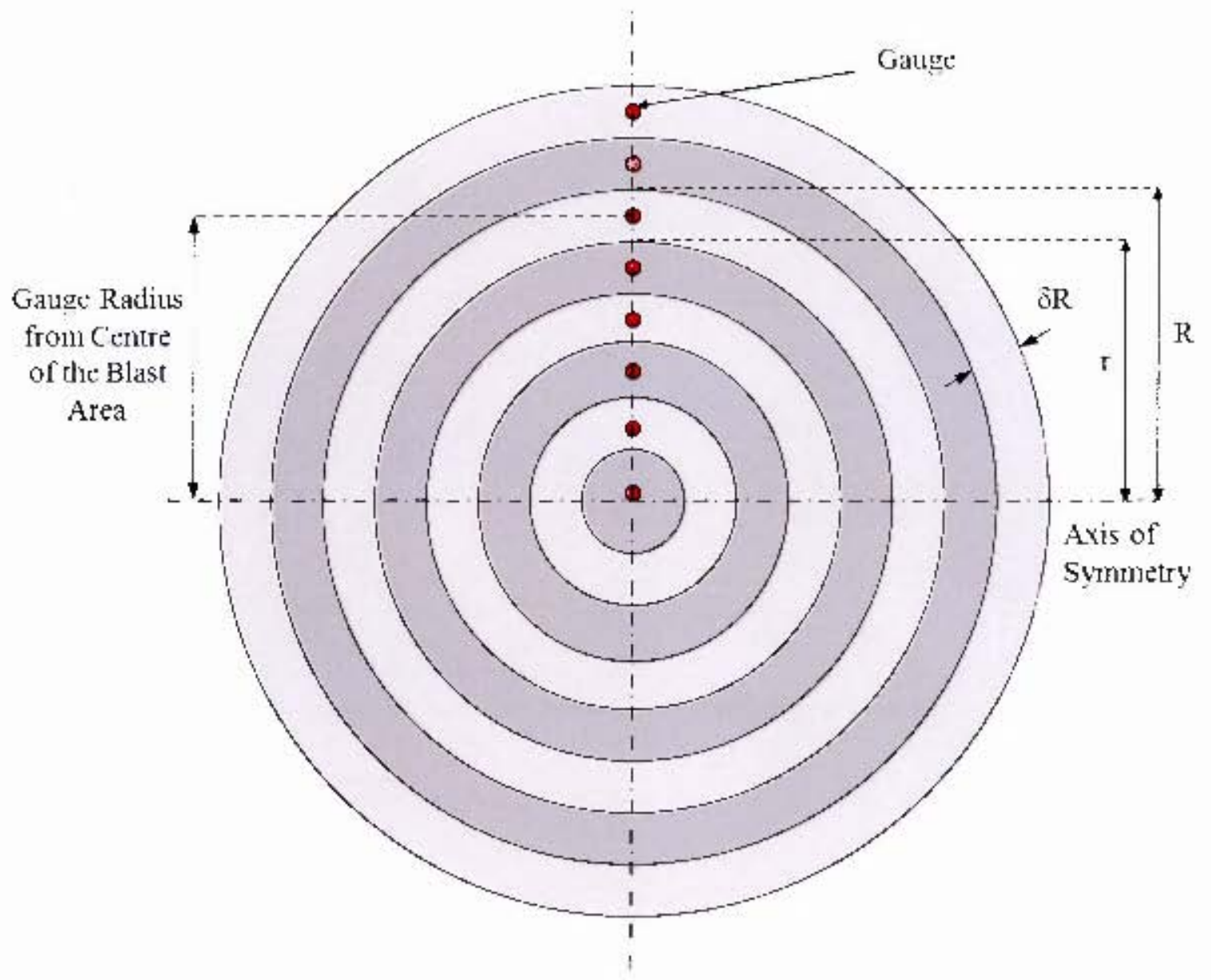

Figure 6.5: Illustration of gauge positions with respect to their corresponding atreia on the blast surface

In Figure 6.5 the incremersts of area specilic to each gauge point are hightighted by the varying shades of grey colour. These specific areas are the areat for which the pressure-time history for cach gauge poitt was integrated to give a corresponding specific impulse. The integral of specific inpulse is represented by Equation 6.1

$S=\int_{t_{i n i t i \leqslant i}}^{t_{\text {fitiril }}} F d t$

Where force $F$ is defined by pressure distribution over the small increment of area specific to cach gauge.

The pressure-lime history for each gatye point atong the reflective blast atea boundary was integrated for a specitic time after the pressure of the entive simulation subsided to near atmospheric, flaving little effect on the platce. In most casces the time of inlegration was $0.8 \mathrm{~ms}$, when the pressure-time integral 'flattened sut'. The integral of pressure-time for the gauge at the centre of the blast atrea at at blast time of $0.8 \mathrm{~ms}$ is graphically presented in Figure 6.6 . 


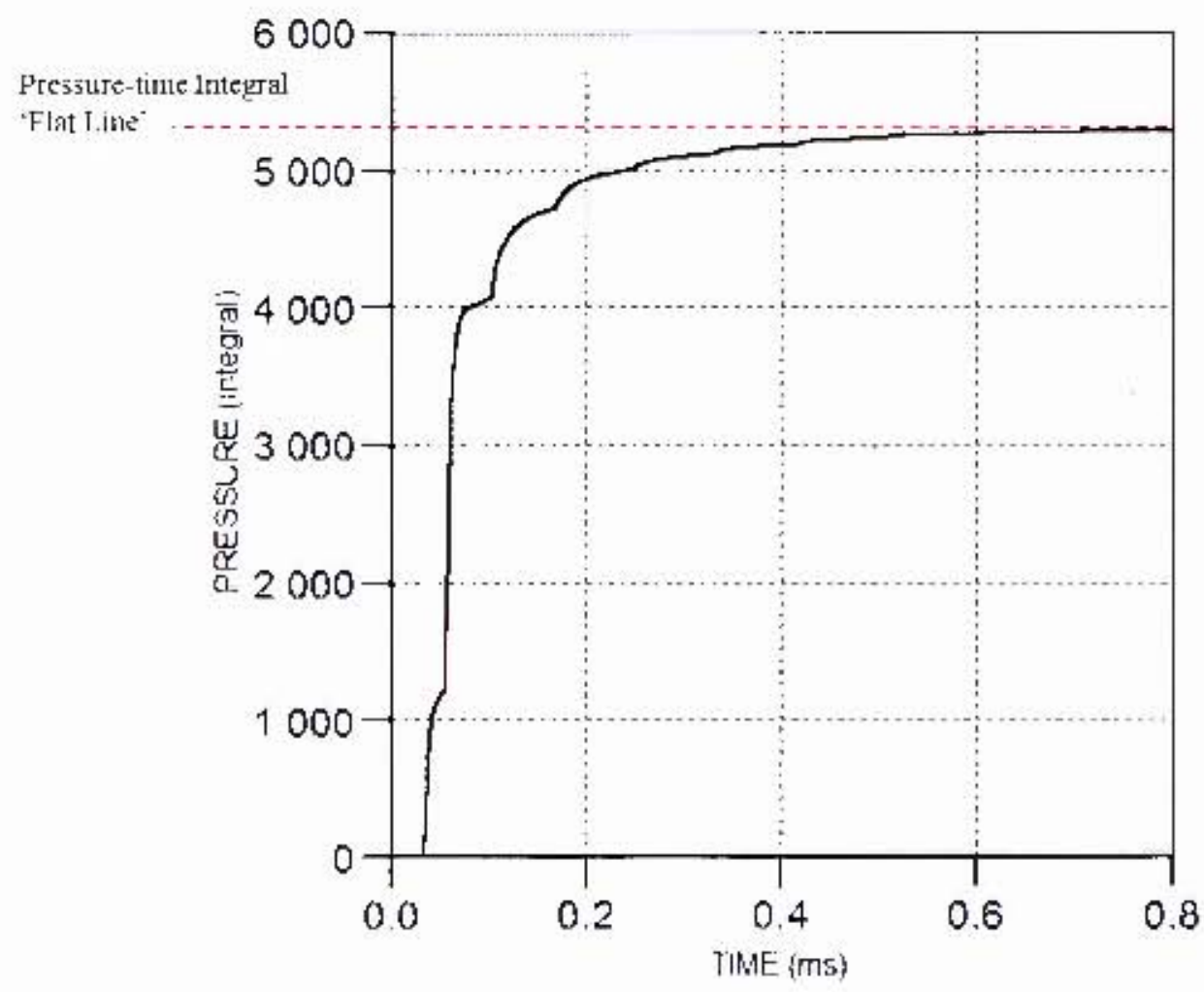

Figure 6.6: Jntegral nf pressure-time for the gauge at the centre of the blast areat

The pressurti.time history for each gauge point wats integrated with respect. 16, lime, resulling it integrated pressure specilit 1.0 each gauge point. The integrated pressures were multiplied by the areas that each gatge point represents. The areats were deperdent on the distance from the centre of the blast area and are described by Faguation 6.2 , where $R$ is the outer radius and $r$ is the inner radius of the specitic areats. as illustrated in Figure 6.5 .

$A=\pi\left(R^{2}-r^{2}\right)$

Eq. 6.2

Multiplying the integrated pressure by the specific arca, resulis in integrated force, which in tum equals specitic impulse. The surn of the incremerts of impulse per area was equal to the total inipulse distributed over the blast area.

$l=\int P d A$

Eq.6.2.1 


\subsubsection{Loading Model - Phase II}

\subsection{Geometry and Boundary Conditions}

The loading phase was modelled in an axisymmetric two dimensional set-up, similar to the detonation model. The loading model consists of an air mesh, $400 \mathrm{~mm}$ x $53 \mathrm{~mm}$, the remap detonation imported at $125 \mathrm{~mm}$ from the left (Figure 6.7) and a target plate constrained at $125 \mathrm{~mm}$ from the right (Figure 6.7). The target plate dimensions were either $2 \mathrm{~mm} \times 73 \mathrm{~mm}$ or $3 \mathrm{~mm} \times 73 \mathrm{~mm}$ depending on the plate thickness used in the experiments. The excess of $20 \mathrm{~mm}$ from the $53 \mathrm{~mm}$ radius of the blast area, for the test plate, allowed an area on the test plate to have assigned zero $x$ and zero $y$ velocity boundaries to simulate the clamping conditions of the experiments. An overview of the loading model with dimensions is illustrated in Figure 6.7.

The boundaries in the loading model included 'flow out' boundaries on the ends of the model, to allow the detonation products to escape the model constrains and simulated the free air. There was air mesh located on the right of the plate, providing room for the plate to deform. The reflective boundary simulating the rigid tube walls in the experiment were modelled identical to the detonation model and was $150 \mathrm{~mm}$ in length, providing the necessary stand-off distance. Gauges were specified along the length of the test plate and were allowed to move with the deforming plate. The gauges saved the history of the test plate with regards to displacement and velocity. This indicated the extent of the 'damage' the specific blast load imposed on the plate, including midpoint deflection. 


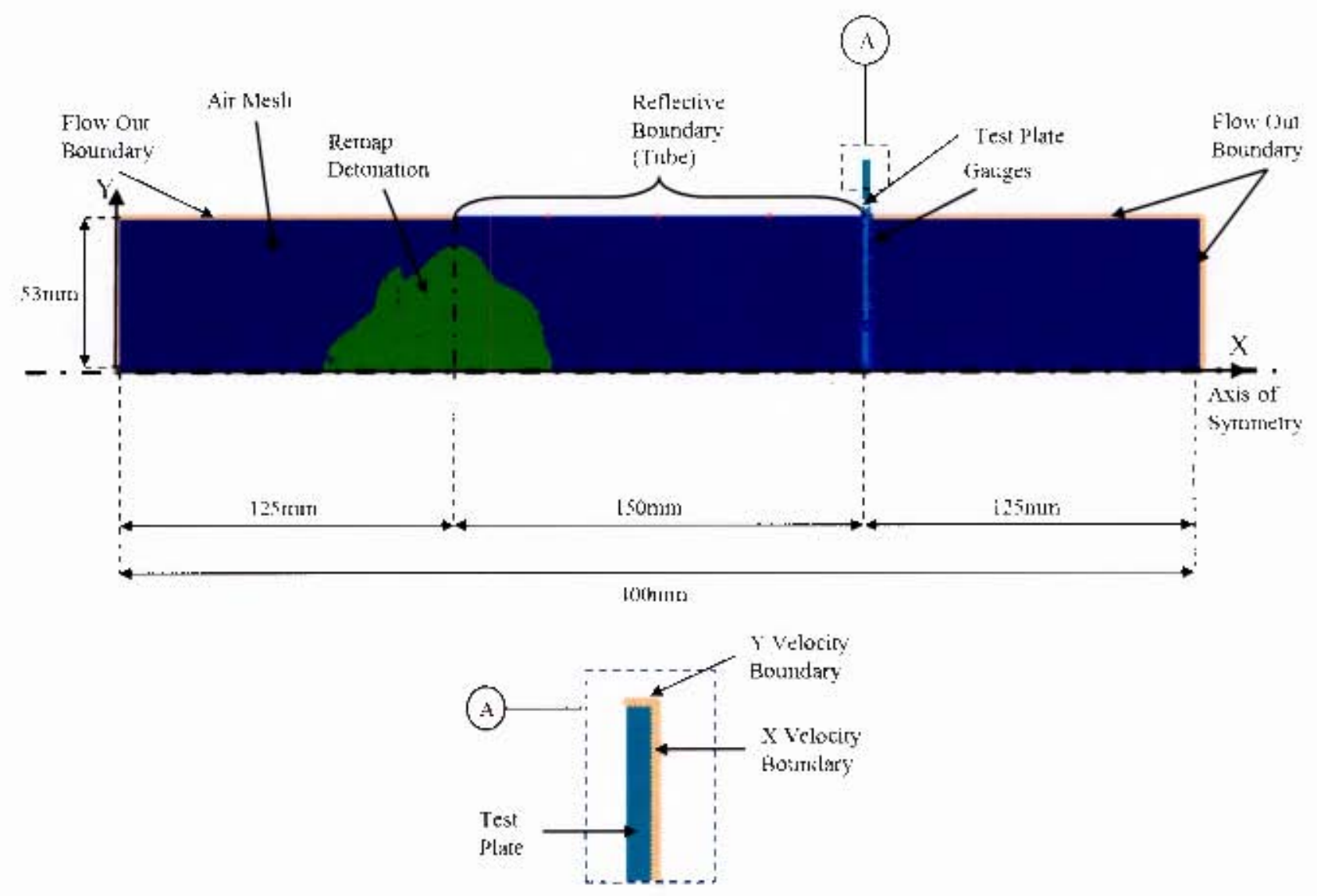

Figure 6.7: Overview of 1 .uading Mudel with remapped detonation and test plate

\subsection{Mesh Refinement}

\section{Air Mesh}

Pickering et a] $[10]$ and Langedon et al [15] carricd out extensive sensitivily andlyses on the effects of air mesh density. Hitherlu. the air mesh for this thesis was chosem as a square mesh $0.5 \mathrm{~mm} \times 0.5 \mathrm{~mm}$. based on results of Pickering et al [10] and I.angdon et al [15]. This mesh was found to have the best accur'acy to compulational expense ratio. The tinal air mesh tor the loading mudel annsists of an $\$ 00 \mathrm{i}$ $\mathrm{x} 106 \mathrm{j}$ mesh, where ' $\mathrm{i}$ represents the $\mathrm{X}$-axis inld ' $\mathrm{j}$ ' represents the $\mathrm{Y}$-axis, as is typically dejieted.

\section{Test Plate Mesh Refinement}

The test plate mesh was modelled with dimensims $7.3 \mathrm{~mm} \times 2 \mathrm{~mm}$ and $73 \times 3 \mathrm{~mm}$ for the $2 \mathrm{~mm}$ thick and 3num thick test plates respectively. In was noted that generally, the Lagritlyian mesh used in the solid test plate must nor he finer than the Euleriars mesh used to model the air [104]. Taking the tindings reported by Pickering and [ $[0 \mid$ Langdon et al $[15]$ into accuunt, the chosen mesh dersily fur 
this thesis was $0.5 \mathrm{~mm} \times 0.5 \mathrm{~mm}$. The resultant plate meshes had elements of $146 i \times 4 j$ and $146 i \times 6 j$ for the $2 \mathrm{~mm}$ and $3 \mathrm{~mm}$ thick plates respectively.

\subsubsection{Unloading - Phase III}

After the test plate had been subjected to the incident pressure wave from the blast, the pressure decreased to below $300 \mathrm{kPa}$. Even though the residual blast pressure had little effect on the loading, the plate still deformed due to inertia effects. The simulated air mesh was deactivated in this phase of the simulation, to decrease the computational expense. However, the transient velocities of the test plate whilst unloading lasted for a significant duration. The unloading duration, with regards to the extent of the effects of reloading the plate with an additional blast, was investigated. A numerical damping coefficient was introduced into the simulation to hasten the unloading process and reduce the transient velocities of the plate to zero, before reloading.

\subsection{Transient Plate Velocity and Numerical Damping}

The transient velocities may take up to $50 \mathrm{~ms}$ to subside in the experiments. To run the numerical model for $10 \mathrm{~ms}$ seconds can take up to several hours to two days to complete, causing the model to become very computationally expensive. Running a repeated blast load model, whilst the test plate was still oscillating, with an initial transient velocity from the previous blast can produce incorrect results. The model was allowed to run for a specific amount of time until the plate had lost a sufficient amount of energy and experienced velocities as close to zero as possible. To decrease the computational expense, the air mesh was deactivated and only the Lagrangian plate mesh was left active. The plate was allowed to oscillate, with the model running many times quicker as there were considerably less elements to be processed.

An ideal ratio between the effects that the transient plate velocities have on the results and the computational expense of running the models for an extended period of time was established. The post blasted plate velocity is illustrated in Figure 6.8, for a plate thickness of $2 \mathrm{~mm}$ subjected to charge mass of $10 \mathrm{~g}$. 


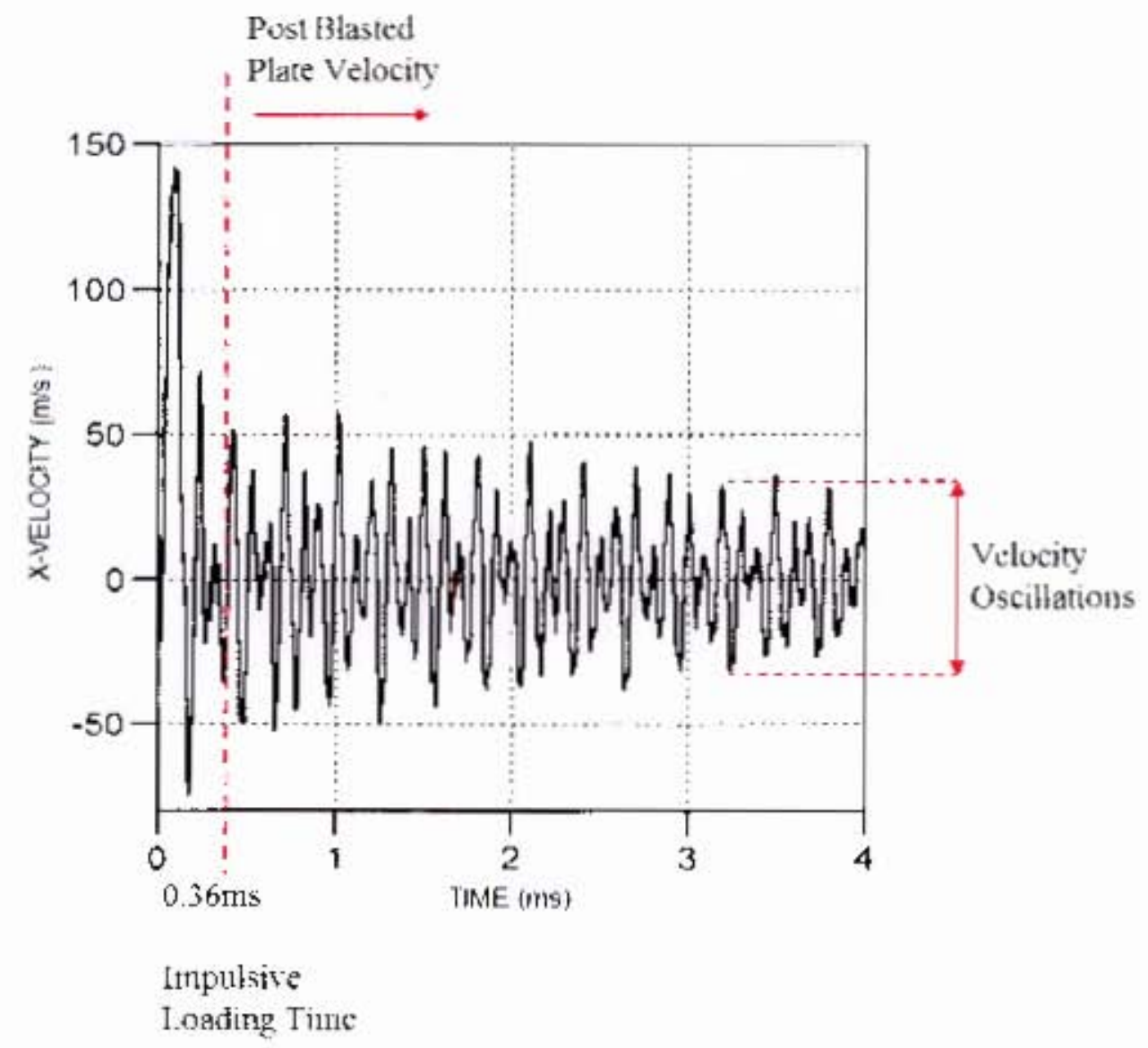

Figure 6.8: Graph of transiemt plate velocity for au extended run time of 4 ats, for plate thickness $2 \mathrm{am}$ and $10 \mathrm{~g}$ charge mass

Three different limes were observed for starting the repcated blast load (blast2), namely $2 \mathrm{~ms}$. $5 \mathrm{~ms}$ and $10 \mathrm{~ms}$. The midpoint deflections ( $10 \mathrm{~g}$ charge mass and $2 \mathrm{~mm}$ thick plate), for each blast load (biast 2 ). started at the various times are shewn in Figure 6.9-Figure 6.11. 


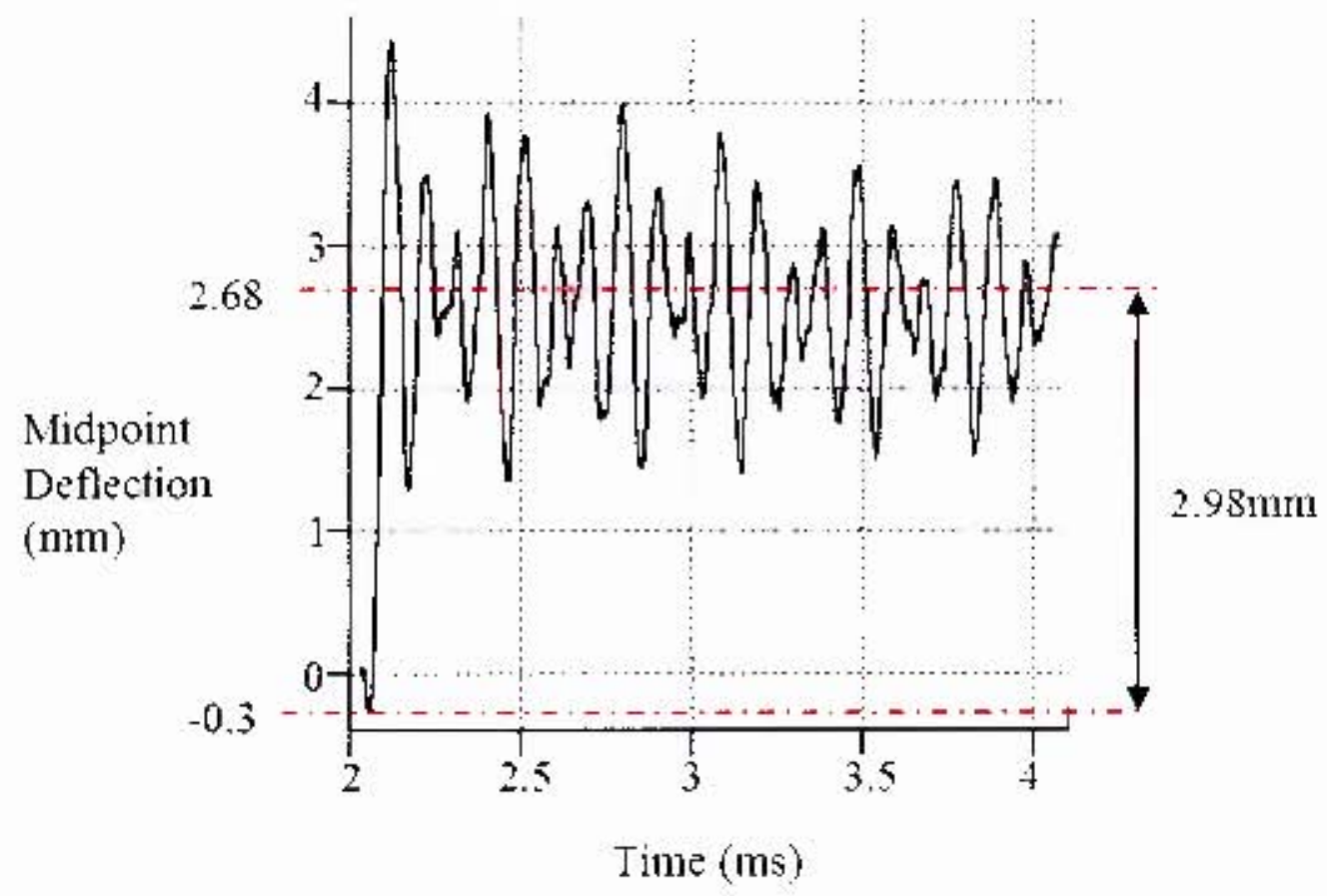

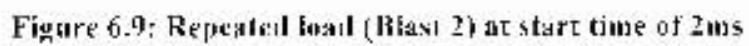

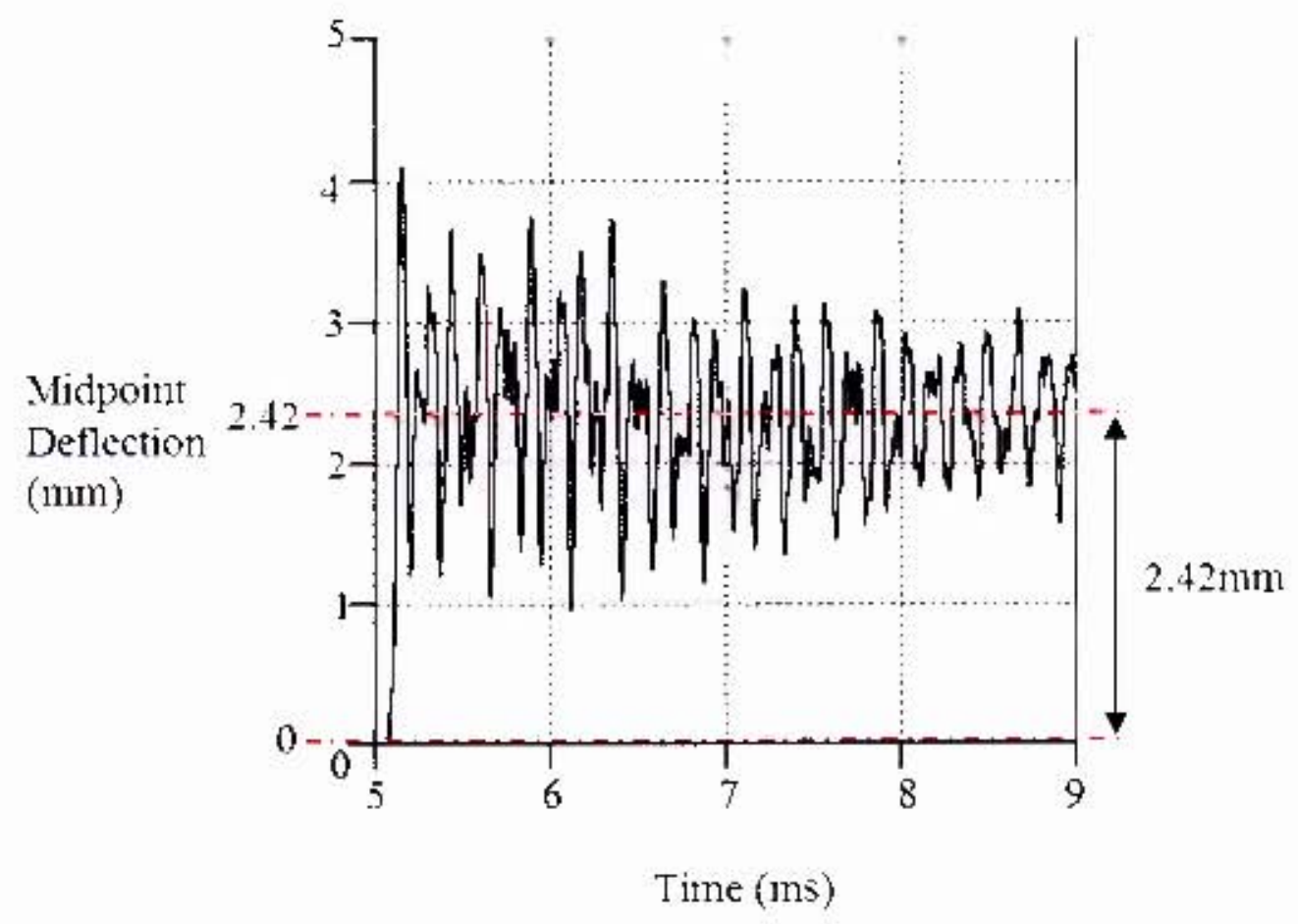

Finare 6. 10): Rapealed load (Blast 2) at start time of 5 ms 


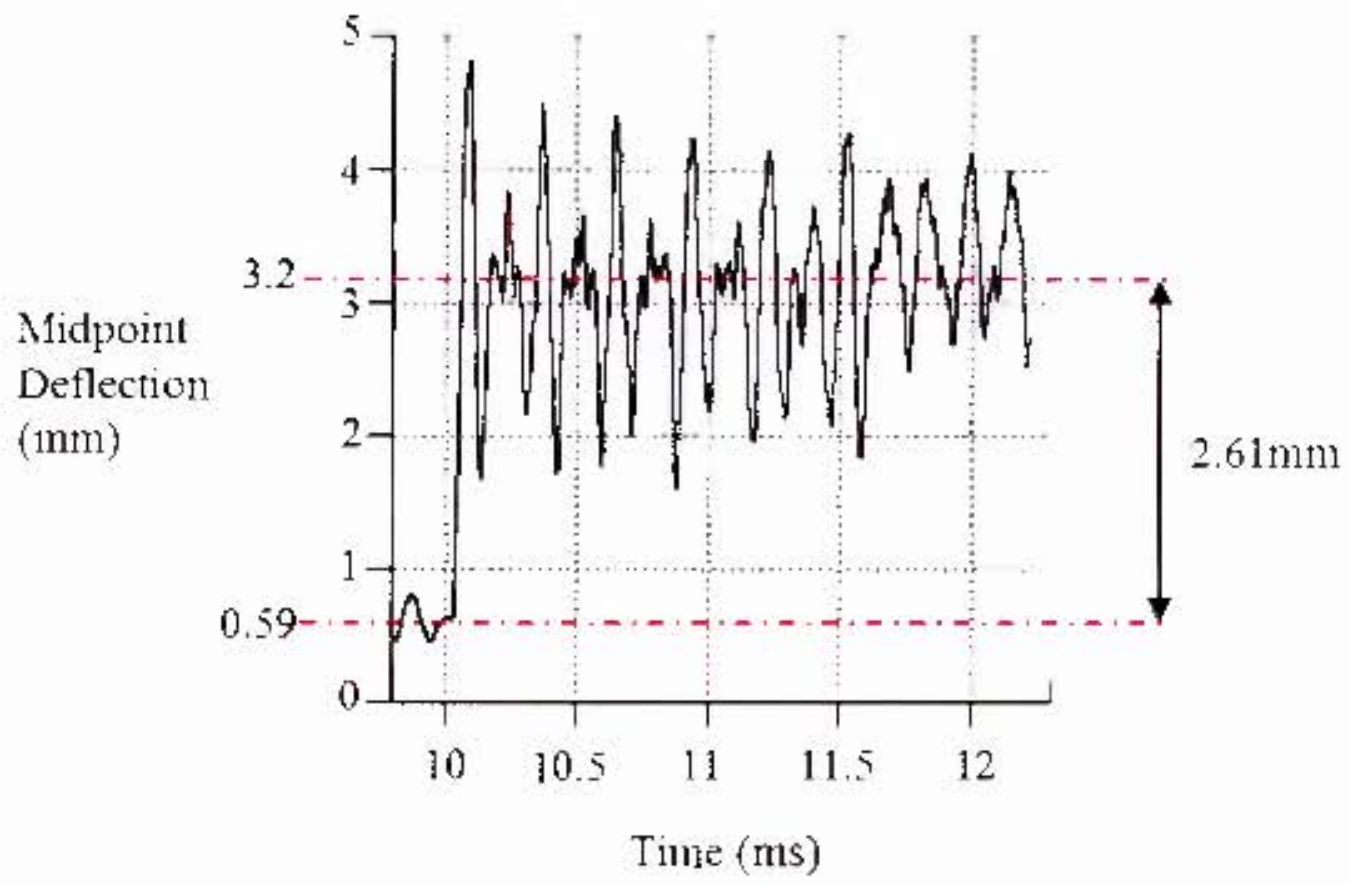

Figure 6.1I: Repeated ]nad (Blasc 2) at start time [0 ms

The results trum the repeated blast luads (blasi 2) starting at diyerent limes atter the first blast luad, suggested that there was a low repcatability confidence. The repeated load starting at 2 ms resulted in a midpoint deflection of $2.9 \mathrm{smm}, 19.5 \%$ greater than the midpoint deflection for repeated load stauting at $5 \mathrm{~ms}(2.42 \mathrm{~mm})$ and $12.4 \%$ higher thall the repeated blast load stating at $10 \mathrm{~ms}(2.61 \mathrm{~mm})$. The results also sugrtested that there was no trend as to whether allowing the incrlia of the test plate to reside with an extended run time was more beneficial to obtaining refreatable results. The reason for the non-repeatability was the fact that the platc was stil] oscillating, giving the plate an initial velocity when repeated loading was carried out. I his initial oseillating velocity could cither be in the megative or positive direction with respect 6 the oncoming blast wave, when it impacted the test plati. This negrative or positive direction could benefit the blast wave on linder the blast wave, resulting in a grteater or lesser midjoint dellection of the kst plate.

The cumputational expense was also 100 great 10 al luw the oseil lating test plate to come to a complete standstill. AUTODYN processes numerical mudels with no natural damping defined in the default settings, implying the model will oscillate for an extremely long period of timc, botore coming to rest 1104]. Unlike the ABAQUS code, that implements bulk viscosity damping in the delault sctings. Numerical damping was therefore introduced inte the models, to reduce the numerical oscillations. this would cause the plate to come 10 rest quicker. However, caution was taken when introducing numerical damping, as it may affece the results of the simulations. An investigation into the effects of mumerical dampints, with retrasds 10 midpoint dellection of the tes plate was undertaken. Introducing 
an ideal numerical damping greatly reduced the computational expense and provided accurate results when loading a repeated blast.

Four different damping fractions were chosen to determine the ideal value:

- 0.1

- $1 \times 10^{-4}$

- $1 \times 10^{-5}$

- $1 \times 10^{-6}$

The simulation using the damping fraction 0.1 did not run. The pressure wave did not move after the explosive was detonated, indicating the Eulerian mesh was static as the damping fraction was far too high. Results for the various damping fractions, including oscillating velocities and midpoint deflections, are displayed in Figure 6.12-Figure 6.15. The simulations were carried out for a charge mass of $10 \mathrm{~g}$ and plate thickness $2 \mathrm{~mm}$.

For a damping fraction of $1 \times 10^{-4}$, the plate velocity was reduced substantially, resulting in a very low midpoint deflection with no oscillations and did not follow the typical deformation characteristics of a blast loaded test plate. The damping fraction $1 \times 10^{-4}$ was too high and therefore disregarded. The damping fraction of $1 \times 10^{-5}$ showed promising results (Figure 6.13), where the velocity from the blast load was approximately $100 \mathrm{~m} / \mathrm{s}$ and tapered off nicely as the plate came to rest. However, the plate velocity was still approximately $30 \%$ less than the plate velocity (approximately $150 \mathrm{~m} / \mathrm{s}$ ) where no damping was introduced. The resultant midpoint deflection for the damping fraction of $1 \times 10^{-5}$ was $6.52 \mathrm{~mm}, 28 \%$ lower than the simulation with no damping $(9.02 \mathrm{~mm})$. The results from the damping fraction of $1 \times 10^{-6}$ resembled almost indistinguishable results from the simulation with no damping, with regards to the plate velocities (Figure 6.14 and Figure 6.15). The plate velocity graph for a damping fraction of $1 \times 10^{-6}$, showed the velocity taper off slightly (approaching zero), but still required an extensive run time, causing the simulations to remain computationally expensive. The midpoint deflection of the plate with damping fraction of $1 \times 10^{-6}(8.81 \mathrm{~mm})$ was less than a plate thickness difference from the midpoint deflection of the simulation using no damping $(9.02 \mathrm{~mm})$, thus falling within an acceptable confidence criterion and therefore selected as the damping constant used for the respective simulations. Although, the computational expense was only slightly decreased by introducing numerical damping with a damping fraction of $1 \times 10^{-6}$, it was still necessary to ensure the plate came to a standstill, before introducing the next repeated blast load. This ensured repeatability between each repeated blast load. 

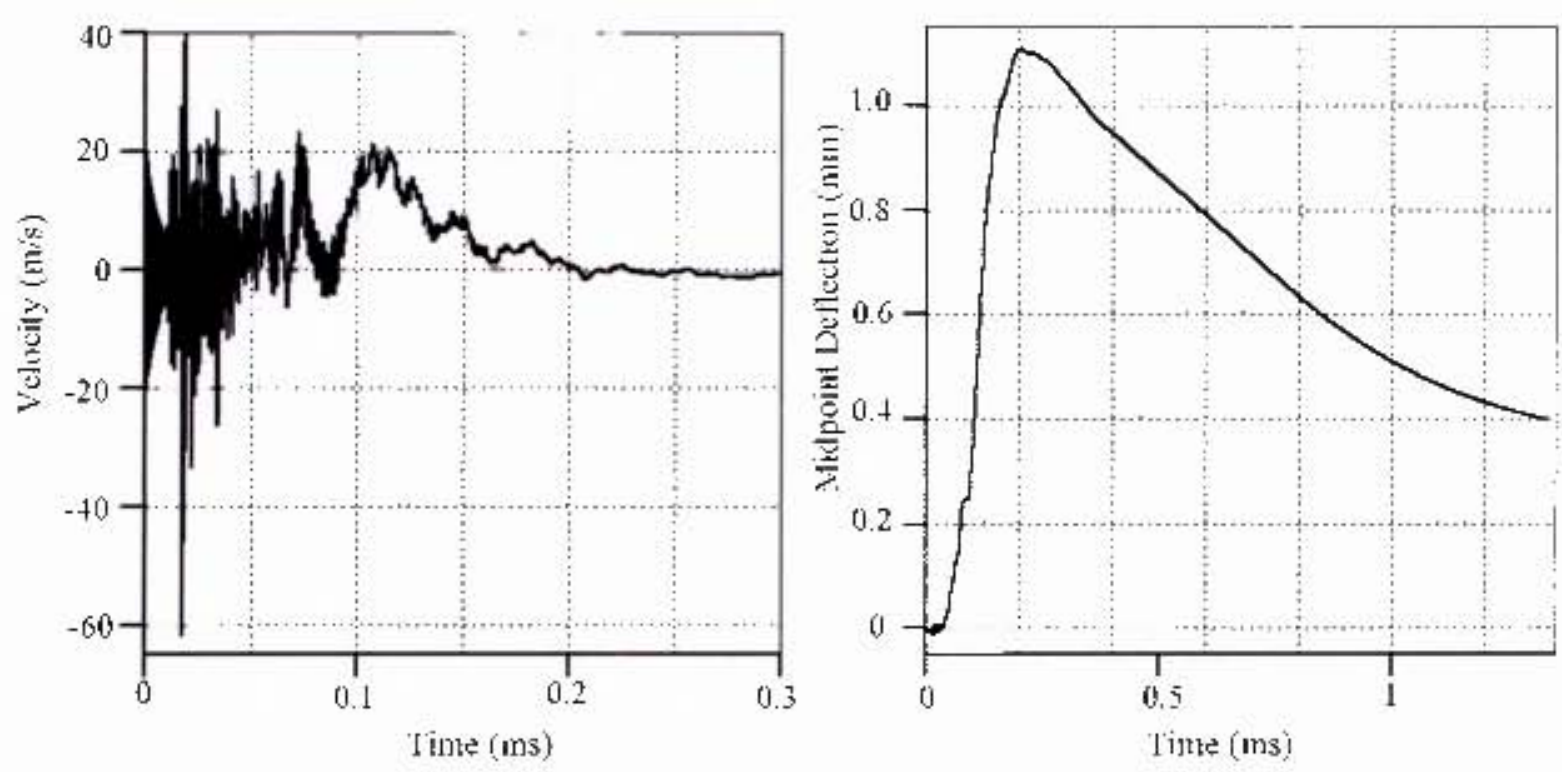

ligure 6.12: Veducity and Midpoinc Pefection graphs for Te-4 damping fraction
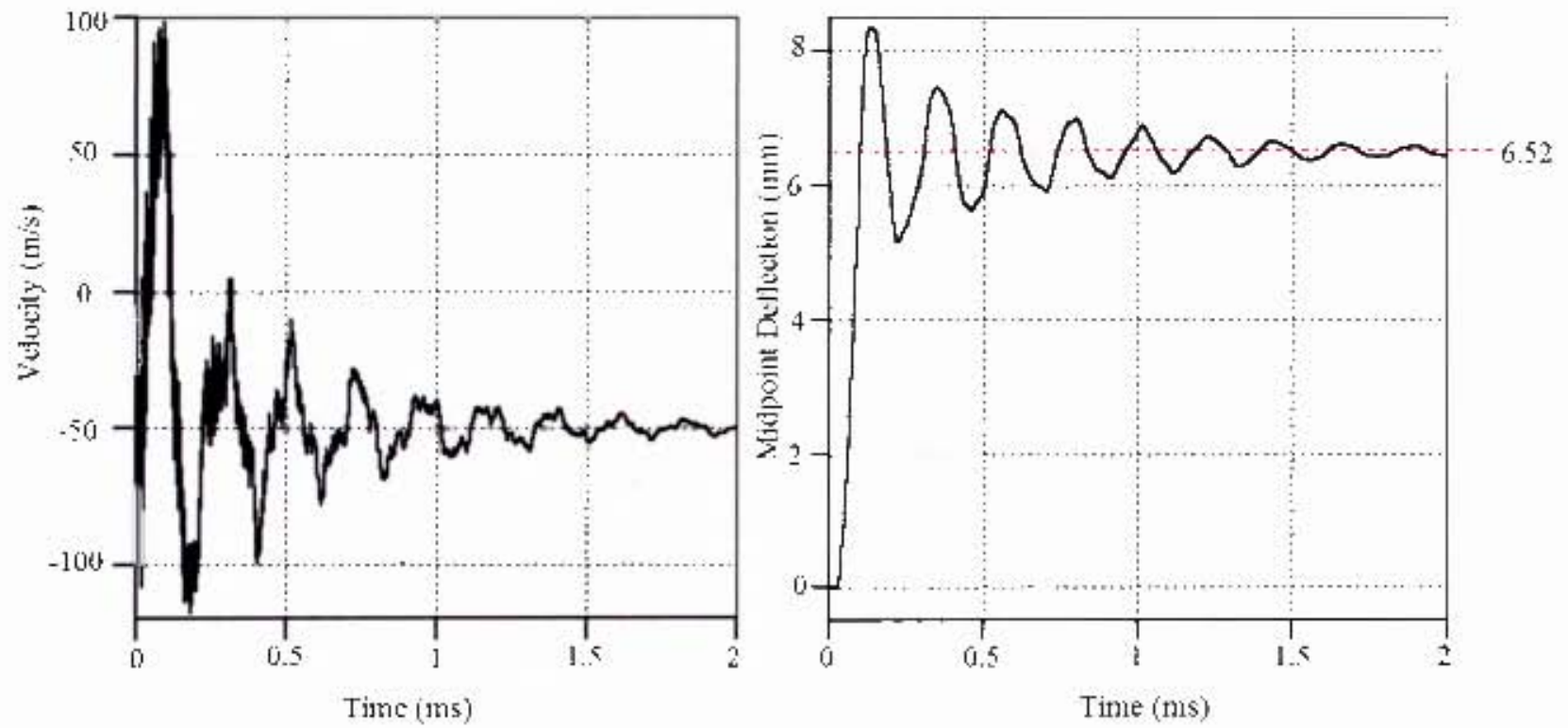

rigure 6.13: Velocity and Vlidpoint Deflection graphs for 1 e-5 damping fraction 

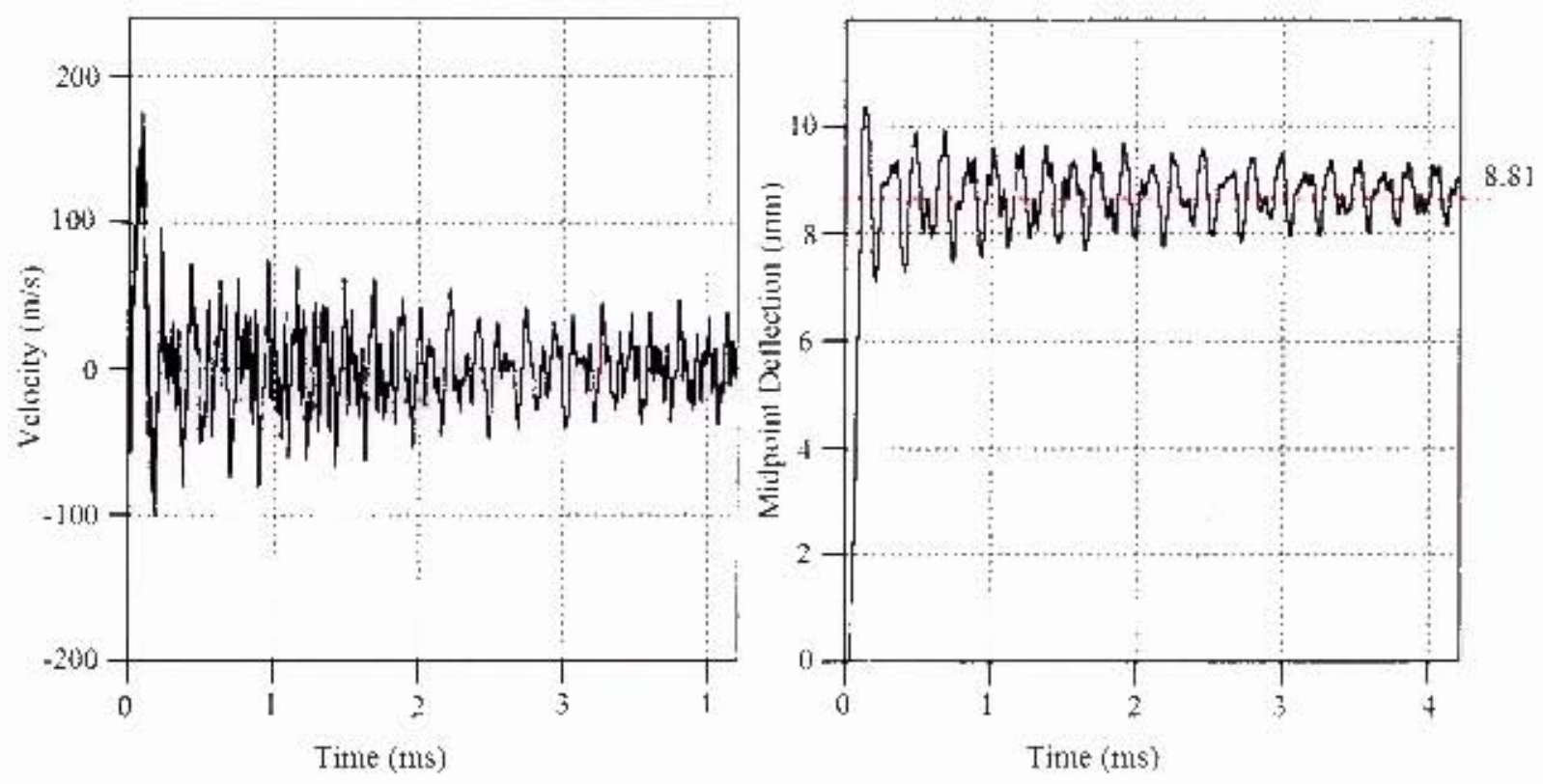

Figure 6.14: Velocity and Midpoint Deflection graphs for IE-6 damping fraction
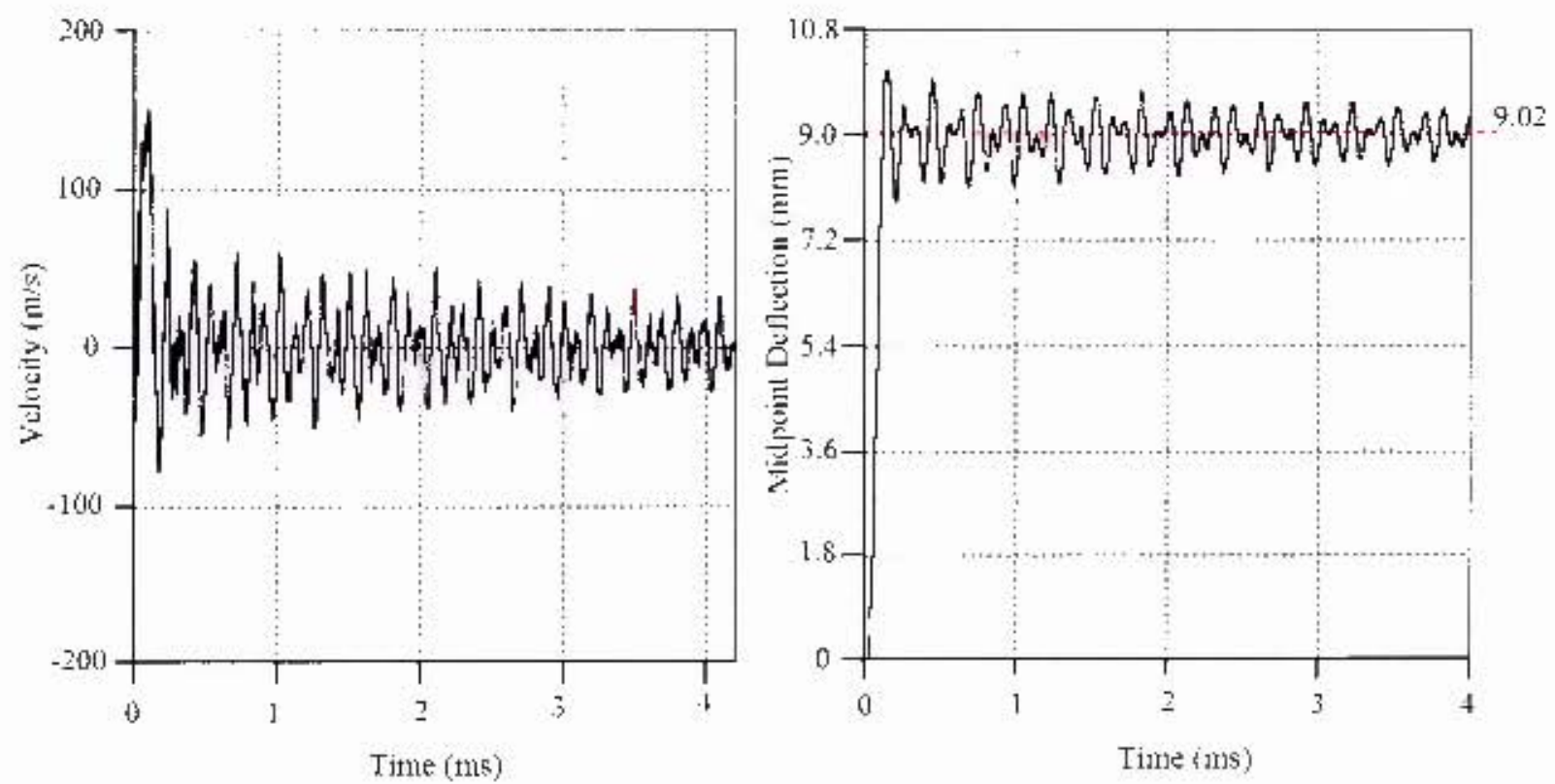

Figure 6.15: Velocity and Ylidpoint Deflection graphs for no dinmping 


\subsubsection{Repeated Loading Model-Phase IV}

Once the numerical plate was subjected to a blast load (thase 11) and the plate had undergone the unloading phase (Ploase III), the detothation file (Plhase I) was remapped into the model to simulate the repciated blast load. The repeated lodding modsl was min with the already deformed plate. The reomber of reloading phases corresponded to the number of blast loads required (up to 5 blasts). Belween each blast, the lemperature and juressuje wert set to the initial non-blasted conditions. The reloading of the already deformed test plate is illustrated in Figure 6.16.

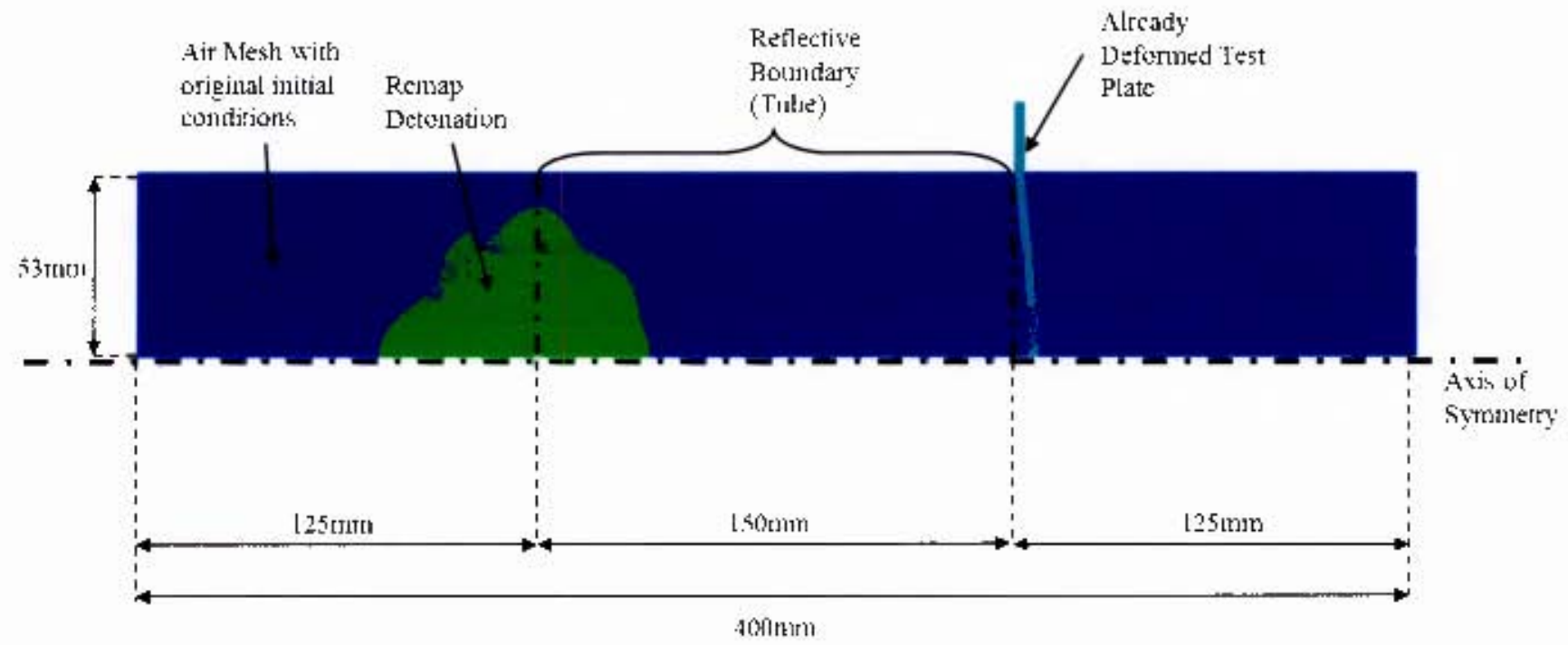

Figure 6.16: Oyerview of reloaded lest plate (Phass: IV) wilh remapped dutonation of charge mass 10g 


\subsection{ABAQUS Numerical Models}

Additional numerical analyses were carried out using ABAQUS/Explicit v6.10.1, which is a code that accounts for non-linear geometry, strain rate sensitivity, adiabatic temperature effects and material effects into its models, requiring no iterations and tolerances or global tangent stiffness matrix. ABAQUS/Explicit is computationally very efficient for the analysis of large models subjected to impulsive loads with relatively short response times, as defined in explosive blast loading. Blast loading of the ABAQUS models was carried out in two different methods:

- Rectangular Pressure Pulse Loading

- CONWEP loading

The same geometric model was used for each form of loading to ensure direct comparisons. Rectangular Pulse loading had been successfully implemented by Nurick and Chung Kim Yuen [36]. A uniform pressure load distributed over a blast area, with a specified load time produced a calculable impulse that could be compared to experimental data and easily input into an ABAQUS model in the form of a rectangular pressure pulse. CONWEP is a semi-empirical model that has been extensively used to predict the magnitude of the peak pressure and impulse delivered to a target [33]. CONWEP is ideally used for open air blasts at large stand-off distances. The charge diameter - stand-off distance ratio (0.23) falls within the capabilities of CONWEP.

\subsubsection{Geometric Modelling}

The numerical simulation consisted of a full scale 3D model. The model was made up of two parts, namely the target plate and the clamp. 


\subsubsection{Part I - Test Plate}

The plate was modelled as a circular disk shaped part with a radius of 73 mm and exposed area of radius $53 \mathrm{~mm}$. The extra $20 \mathrm{~mm}$ radius was used as the clamping area. The test filate was modelled as a "shell revolve" part. with an assigned section thickness of $210 m$ or 3mm. depending on the requirced plate thichness. The dimensions of the test plate are illustrated in Figure 6.17. The blast area is highlighted in red and the grey arca represents the clamped region.

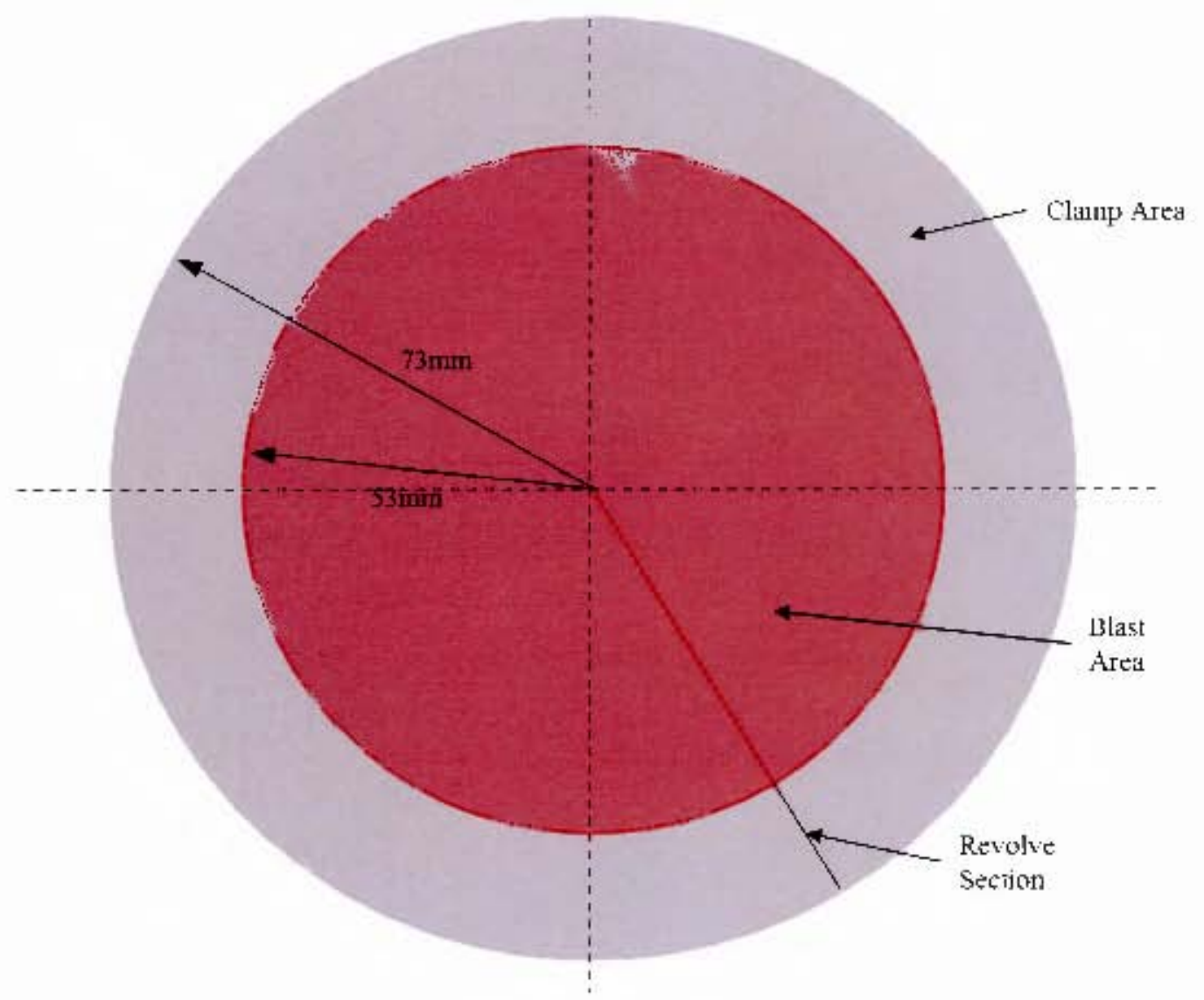

Figure 6.17: Tap view of modelled test plate dimensions

The lest plate was modelled with SAR shell elements that ase 4-nod doubly eurved thin shell elements, with reduced integration, host glass control and finite membrane strain elements [797. The $\mathrm{S} 4 \mathrm{R}$ element is a commoniy used general-purptse clement that is suitable for a wide range of applications [79]. 
The test plate was assigned the Domex 700 steel material specifications with identical material properties used in the AUTODYN model, mentioned in Chapter 6.1.1.3, with the Johnson Cook material strength model. The properties of Domex 700 are listed in Table 6.6.

Table 6.6: Johnson Cook material properties for Domex 700 steel (ABAQUS)

\begin{tabular}{|c|c|c|c|c|c|c|}
\hline$A$ & $B$ & $n$ & $\dot{\epsilon}_{0}$ & $C$ & $m$ & $T_{\text {melt }}$ \\
\hline $750 \mathrm{MPa}$ & $270.6 \mathrm{MPa}$ & 0.263 & $0.001 \mathrm{~s}^{-1}$ & 0.014 & 1.03 & $1795 \mathrm{~K}$ \\
\hline
\end{tabular}

\subsection{Meshing the Test Plate}

The number of elements used in the test plate had an effect on the pressure distribution throughout the blast area. This ultimately affected the impulse imparted to the plate and the plastic strain components present in the plate, due to deformation. If the mesh was too coarse then the pressure distribution would be integrated and applied over a larger area, allowing a greater margin for error. The finer the mesh, the more accurate the solution, as less errors can occur [36]. It was therefore important to ensure there were a sufficient number of elements assigned to the test plate in order to model a sufficient solution to the simulation. An ideal ratio between element number and computational expense was determined.

Two mesh densities were investigated to quantify and compare the effects of the mesh density on the outcome of the plate deflection and resultant impulse. A coarse mesh was used, with nodes assigned with $2 \mathrm{~mm}$ approximate global sizes, resulting in 4939 elements. A second finer mesh was used, with nodes assigned with $1.3 \mathrm{~mm}$ approximate global sizes, resulting in 11727 elements. The finer mesh had approximately 2.4 times more elements. The difference in mesh densities are illustrated in Figure 6.18.

The test plates with the different mesh densities were loaded with a rectangular pressure load of $15.4 \mathrm{MPa}$ for a duration of $360 \mu \mathrm{s}$, corresponding to an experiment using a charge mass of $30 \mathrm{~g}$ imparting an impulse of $50 \mathrm{Ns}$. These simulations were carried out on the $3 \mathrm{~mm}$ thick test plates. 
Fine Mesh

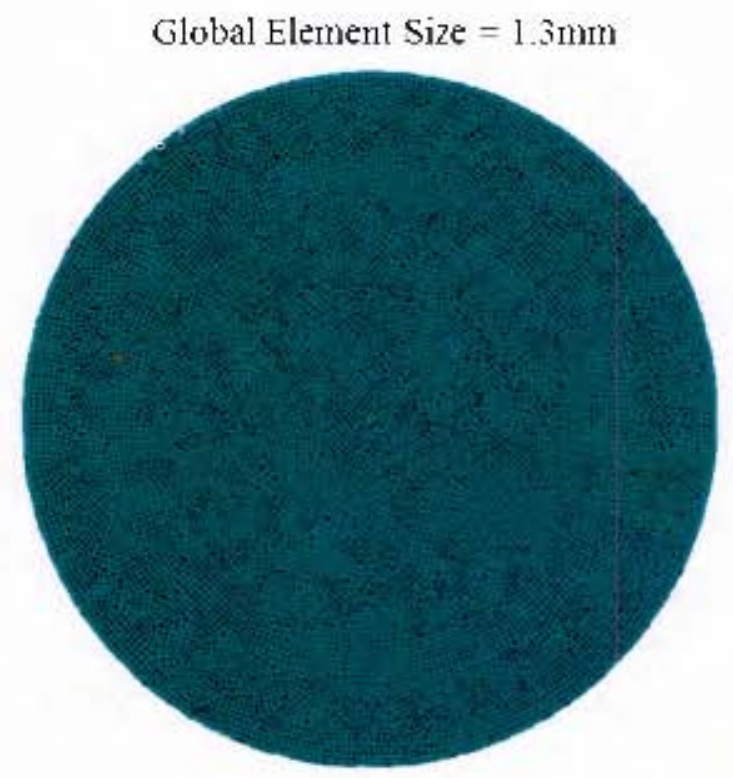

Coarse Mesh

Global Element Size $=2 \mathrm{~mm}$

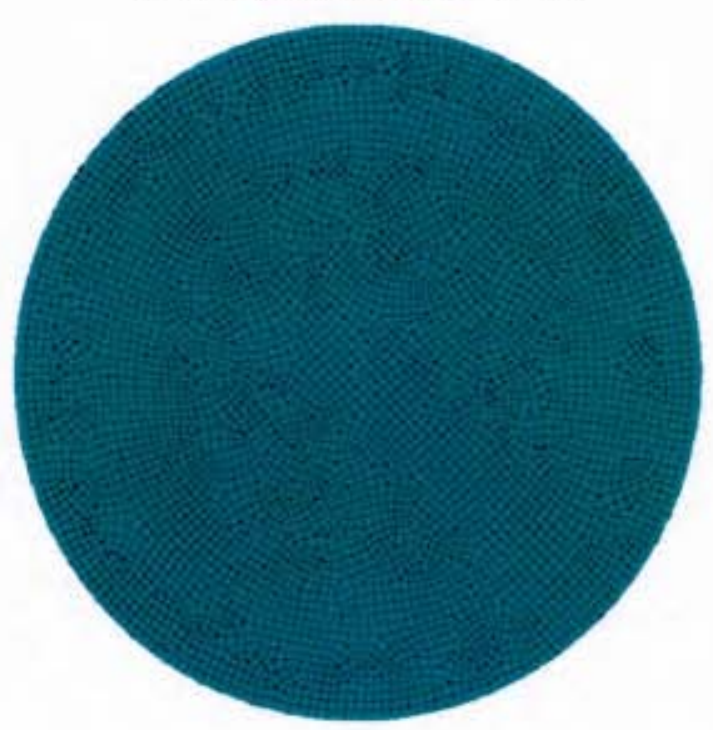

Figure 6.18: Visual difference in mesh thensitics fir the fine and toat'se meshes

The results trom the preliminary uniform load tests are listed in lable 6.7 and illustrated in Figurc 6.19. The resultant impulse from the load and midpoint dellccion of the test plate for each mesh ilensity was compared to one another and to the experimental results.

Tahle 6.7: Resuld of mesh density effects on impulse and midpoint deflection

\begin{tabular}{|c|cc}
\cline { 2 - 3 } \multicolumn{1}{c|}{} & $\begin{array}{c}\text { Impulse } \\
\text { (Ns) }\end{array}$ & $\begin{array}{c}\text { Midpoint } \\
\text { Deflection (mm) }\end{array}$ \\
\hline Coarse Mesh & 49.28 & 11.78 \\
\hline Fine Mesh & 49.5 & 12.04 \\
\hline Fxperiments & 50 & 12.8 \\
\hline
\end{tabular}




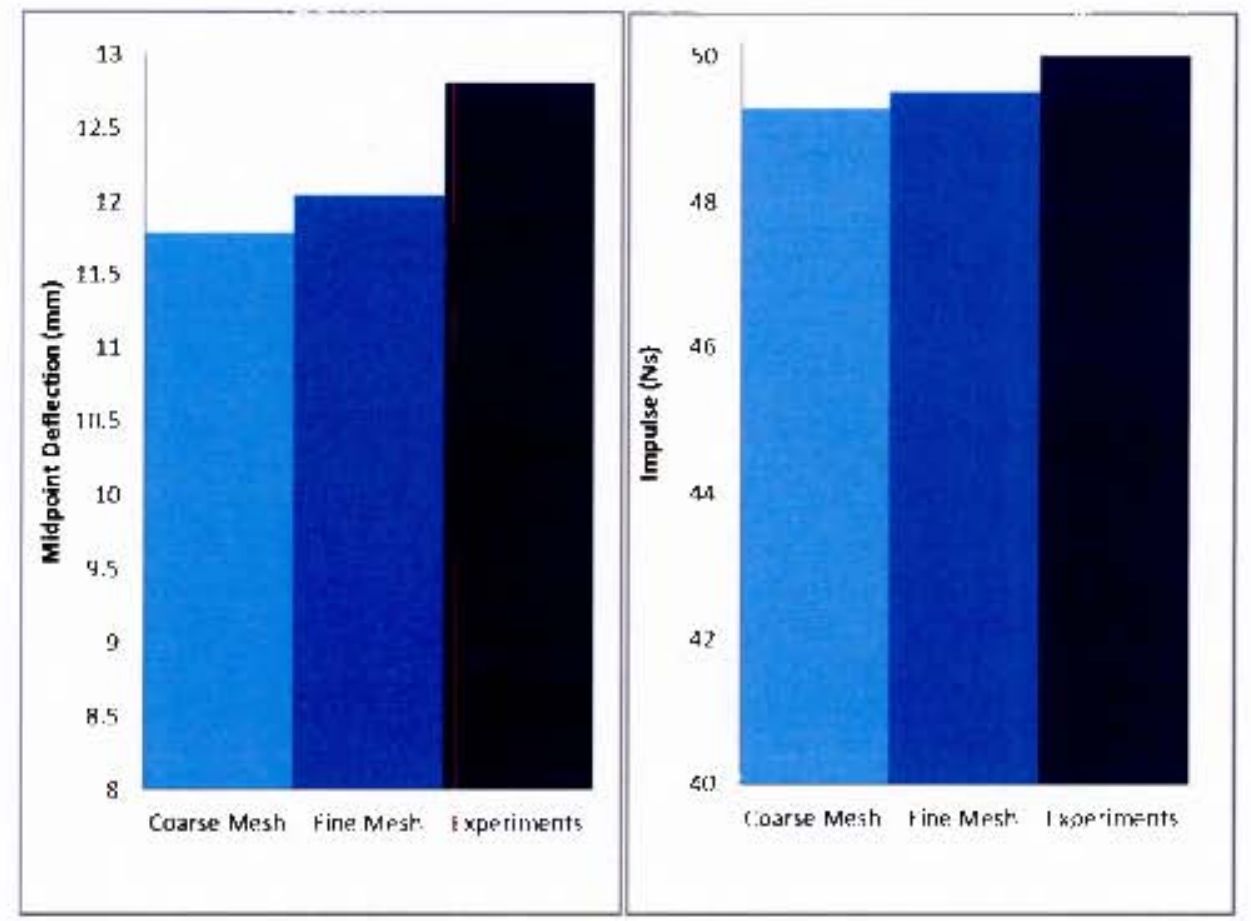

Figure 6.19: Graphs of impulse and midpoint deflection comparing results from coarse mesh. fine mesh and experimerets

Fhe run time for the time mesh ( 4.5 hour's) was approximately double the rum time for the coatse mesh (2 hours 20 min). The dine mesh was comsiderably more enmputationally expensive than the enarese meshr this becomes a significant factor when carrying out 5 blast loads, In comparison, $A B A Q U S$ wats still far more computationally efficient than AUTODYN. The tine mesh (19.5Ns) produced an impulse $0.44 \%$ higher than the coarse mesh $(49.28 \mathrm{~N}$ s), which was farly insignificant. The fone mesh impulse was $1 \%$ lower than the experimental impulse (50Ns), which can also be considered negrigible. The fine mesh (12,04mm) resulted in a midpoind deflection $2.16 \%$ higher than the coarse mesh. The difference in midpoint deflection between the fine mesh and the measured experimental value $(128 \mathrm{~mm})$ was $5.6 \%$.

From the results lisked in Table 6.7, it was evident that the chosen mesh density had a relatively small eficer on the impulse and midpoint detlection, but signitisantly aflected the compulational cxpense. Nevertheless. the line mesh (1.3mm global clement size) was chosen, as the relative computational experise was better, eompared to AL:TOTIYN, with very good correlation with the experiments. 


\subsubsection{Part II - Clamp}

In the ABAQUS/Explicit model used in this project, the clamp was designed as a single part. During the development stages of this model, the clamps were modelled as two separate parts with an initial clamping force, as implemented by Bonorchis and Nurick [14], for similar boundary conditions. The 'two separate clamps' method worked well for extracting the midpoint deflection data for the test plate, but proved difficult to determine a scaling factor for using CONWEP to calculate the resultant impulse.

The addition of the contact forces between the clamp plates and test plates was used to calculate the impulsive load when CONWEP was implemented. However, when a load was applied, the test plate experienced transient post blasted oscillations. These oscillations result in the test plate losing and regaining contact with the top and bottom clamps. This loss in contact caused large disruptions in the resultant contact forces, with huge negative and positive force 'spikes'. On the top and bottom clamps, these large force spikes corresponded to one another in an equal opposite manner. It was assumed that summing the contact forces would 'cancel out' the large force spikes. However, the expected resultant impulse did not correspond to the resultant midpoint deflection. The contact forces for the top and bottom clamps are illustrated in Figure 6.22 and the resultant impulse from the sum of the contact forces is shown in Figure 6.23.The resultant impulse was approximately $27 \mathrm{Ns}, 45 \%$ lower than the experimental impulse ( $49 \mathrm{Ns}$ ) for a charge mass of $30 \mathrm{~g}$. Initially, it was presumed the material model was incorrect, but rectangular pressure pulse loading (known impulse) carried out on the test plate, suggested the material model was correct, as favourable plate deformations were observed. The redesign of a single clamp was utilized, as the single reaction force on the clamp would account for all the loading imparted to the test plate from the CONWEP load.

The clamp was modelled as a 3D analytical rigid body, with a revolution shell cross section. The clamp was designed to house the test plate and simulate the boundary conditions used in the experiment. The clamp was assigned a clamping surface, defining the area of the clamp that interacts with the test plate. The clamp was also assigned a reference point with zero velocity $(X, Y, Z)$ boundary conditions specified, securing the clamp in space whilst the plate was loaded. The clamp cross section with dimensions is illustrated in Figure 6.20 and a 3D rendition of the clamp is shown in Figure 6.21. 


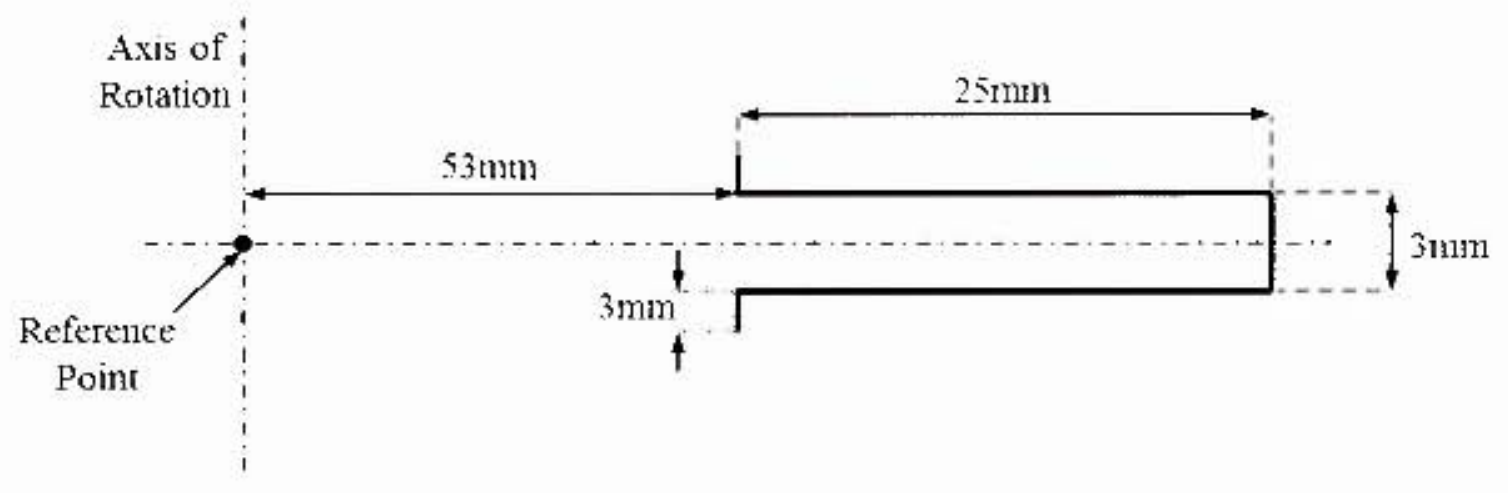

Fignre 6.20: Scluematic of ula mip erusa section (3min thick plate) relative to revolution axis inot to scale)

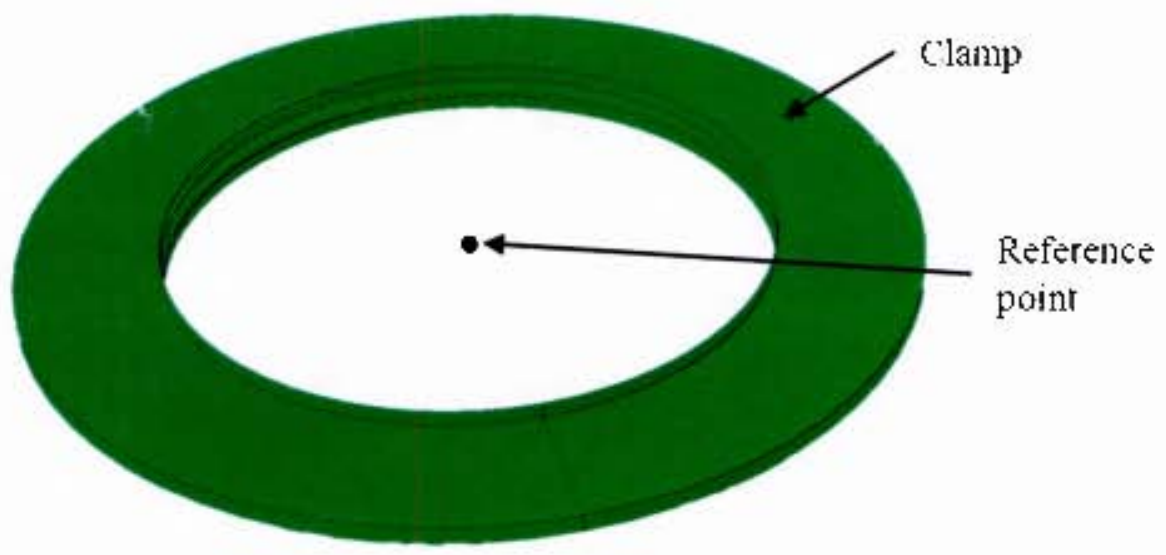

Figure 6.21: 3D renulitiun of elanp with reference point illustrated 


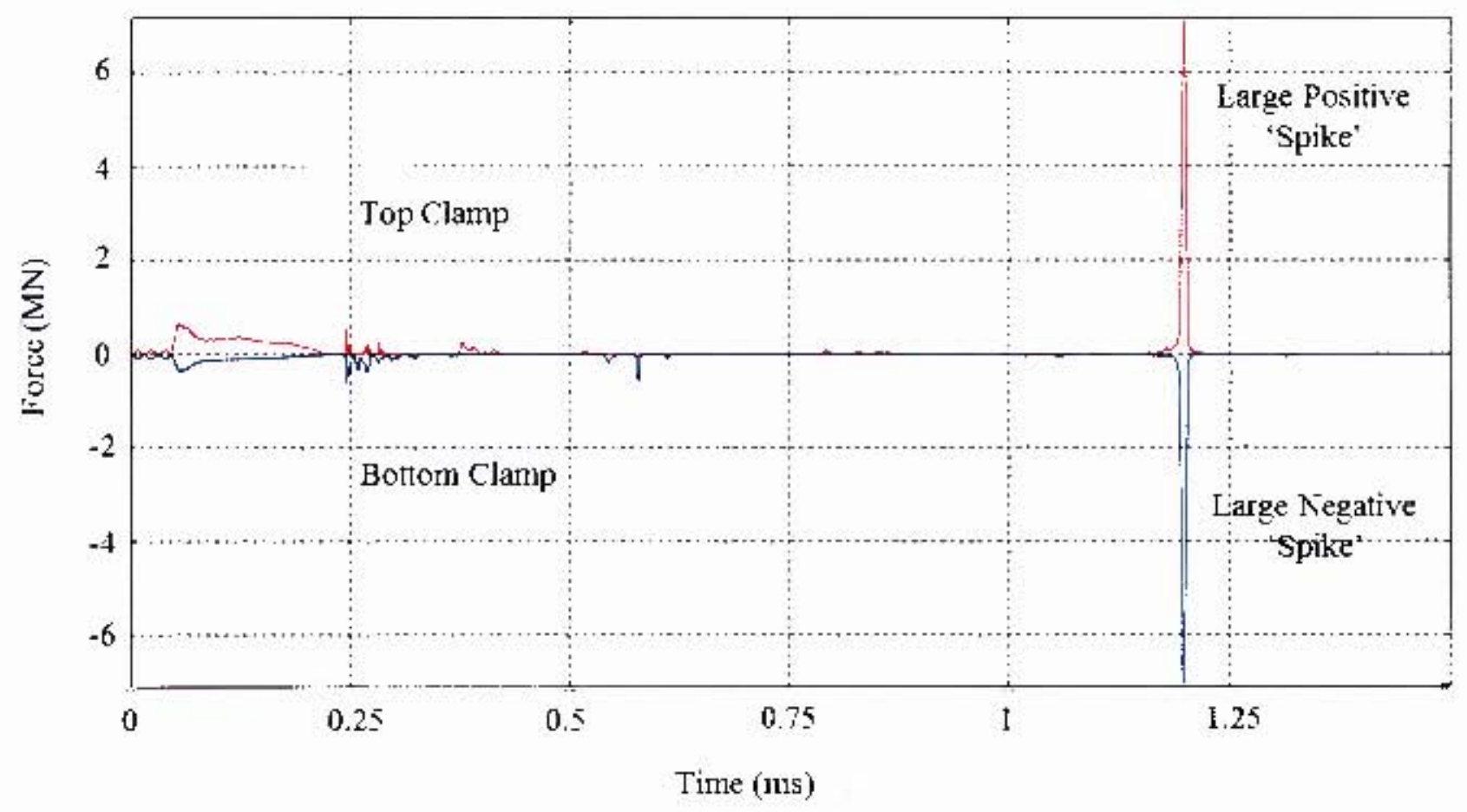

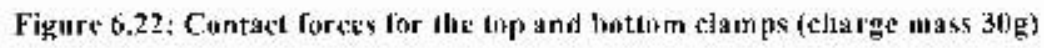

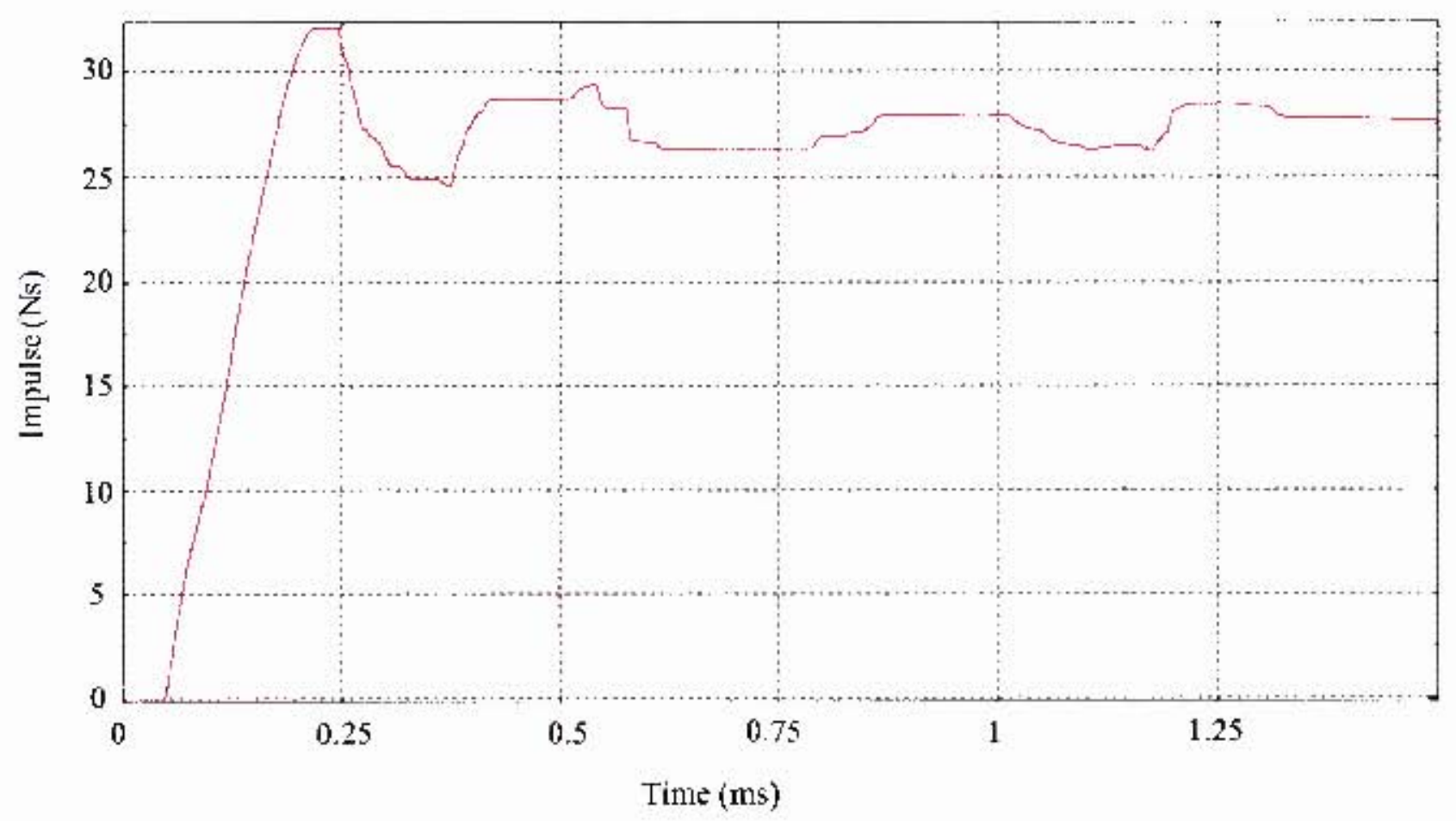

Figure 6.23: R↔sultant impulse (27Ns) [rin the sum of the contact forces (charge mass 30g) 


\subsubsection{Model Assembly}

The assembly, illustrated in Figure 6.24. was developed with the plate specified as the parenr instance and the clamp. the dependable instarse. A 'Fece to fate positional constraint was assigned to the corresponding clamping surfaces of the test plate and elamp. Two interactions were assignted to the clamping surfaes, where the plate and clanp interact. The damp surfaces wert assigned a nomal behaviour of "hard contat' allowing separation after contact. replicating as closely as possible the caperimenal plate mozements inside the clamps. A rangertial behaviour contact interaction property was also assigned to the clamp surfaces. with a coefficient of friction 0.3 [104].

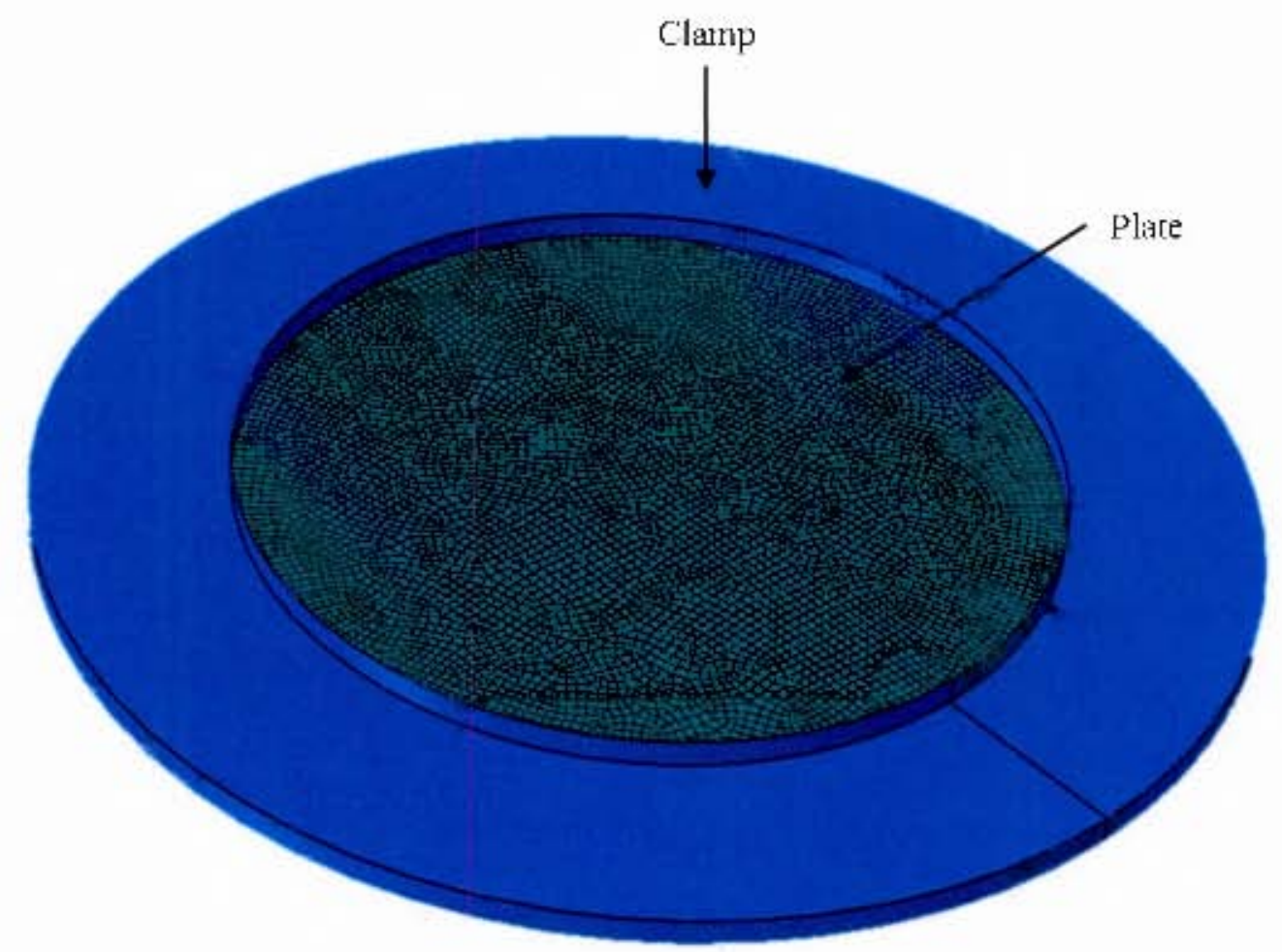

rigure 6.24: $\mathrm{ABAQLS}$ model assembly inclusing clamp and mestaed plate 


\subsubsection{Blast Load Modelling}

For comparative purposes, the ABAQUS model was loaded via two separate methods:

- Rectangular pressure pulse loading

- CONWEP loading

\subsubsection{Rectangular Pressure Pulse Loading}

The pressure distribution over the blast area as a result of the blast load was complex. Impulsive loading theory allowed for certain assumptions to be made with regards to the loading of the plate and the latency of the plate to start deforming plastically. In short, the entire blast load energy was transferred to the plate before the plate started deforming, due to inertia. This suggested that the shape of the pressure distribution did not affect the resultant impulse transferred to the plate, provided the integrated pressure over the blast area and load duration that corresponded to the impulse imparted. The load was numerically modelled as a uniform pressure distribution, in the form of a rectangular pulse, shown in Figure 6.26, applied to the exposed blast area, for a specific time. The duration of the pressure distribution, $t$, was taken from the AUTODYN pressure-time histories. The time was specified once the pressure had subsided enough for the blast to have negligible contribution to the plastic deformation of the test plate. The pressure-time history, as obtained from AUTODYN, for a charge mass of $10 \mathrm{~g}$ is shown in Figure 6.25. The chosen loading time, $t$, is highlighted in Figure 6.25, as $360 \mu \mathrm{s}$ and was kept constant throughout all the repeated blast loading simulations. This time was specified, because it accommodated for the full range of charge masses. Also, a direct comparison could be made between the ABAQUS rectangular pressure pulse loading and the AUTODYN simulated blast wave results, giving a greater insight into the idealisation of the shape of a pressure pulse and simulated Eulerian blast waves in numerical blast simulations. Further numerical investigations into the effects of changing the loading time with respect to the corresponding impulse 


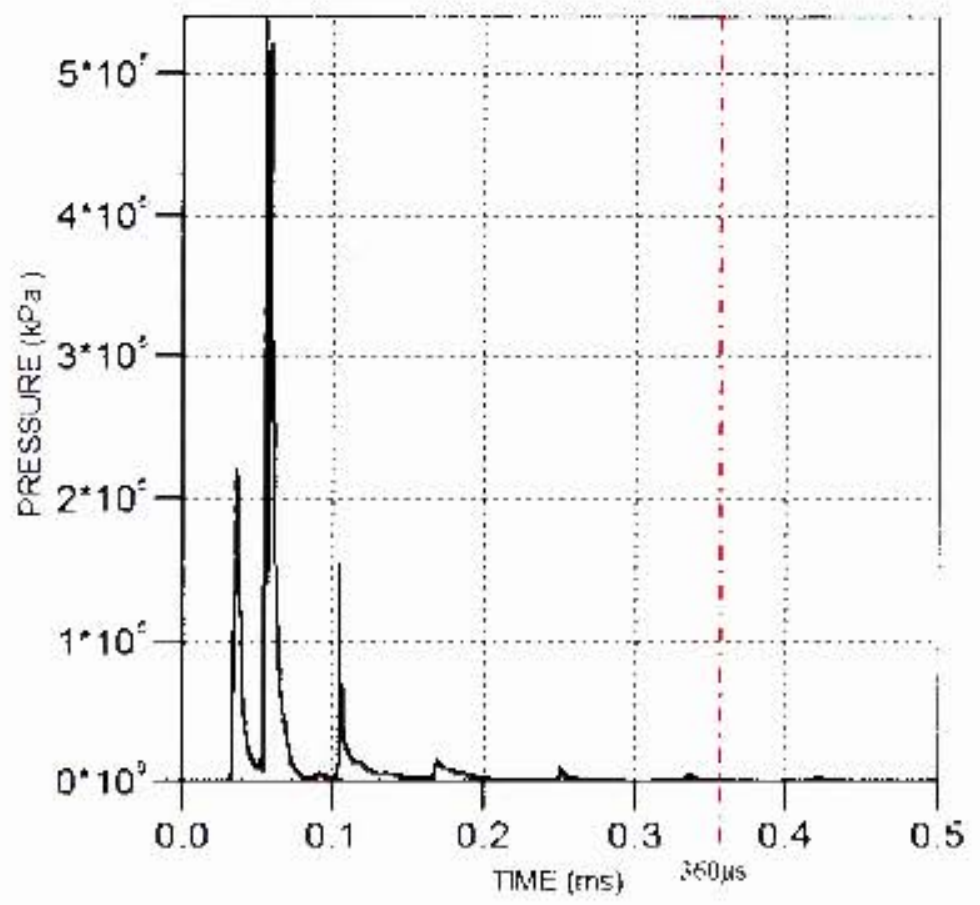

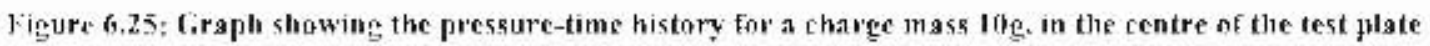

[!sing the measured impulse and the time duration, the magnitude of the applied pressure was deremitrited using Tquation 6.3 .

$P=\frac{i m}{A r}$

Eq. 6.3

Where $l_{\mathrm{m}}=$ measured impulse; $A$ - test plate blast area; $t$ - blast load duration. 


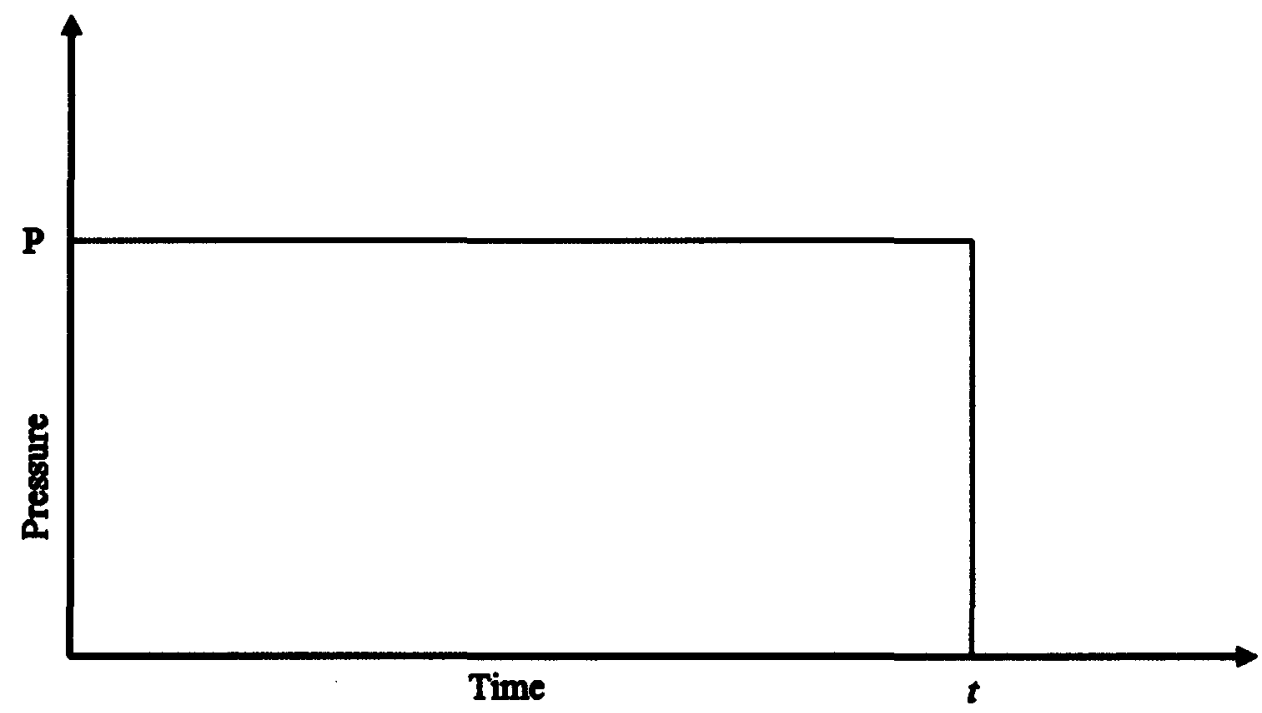

Figure 6.26: Uniform rectangular pressure distribution with respect to time

The corresponding pressure values for each charge mass at the blast loading time of $360 \mu \mathrm{s}$ are tabulated in Table 6.8.

Table 6.8: Uniform pressure values for time, $t$

\begin{tabular}{|c|c|c|}
\hline $\begin{array}{c}\text { Charge } \\
\text { Mass (g) }\end{array}$ & $\begin{array}{c}\text { Impulse } \\
\text { (Ns) }\end{array}$ & $\begin{array}{c}\text { Pressure } \\
\text { (MPa) }\end{array}$ \\
\hline 5 & 12.05 & 3.78 \\
\hline 10 & 21.03 & 6.69 \\
\hline 15 & 29.17 & 9.13 \\
\hline 20 & 35.50 & 11.2 \\
\hline 25 & 41.01 & 12.9 \\
\hline 30 & 49.82 & 15.4 \\
\hline 35 & 51.00 & 16.0 \\
\hline 40 & 60.12 & 18.9 \\
\hline
\end{tabular}




\subsubsection{CONWFP L a a ding}

Loading the model with CONWI:P allowed for the convenient loading af structures it ABAQLSExplicit, CONWEP is defrned as an incident wave interaction in ABAQUS. 1.ike all interactions, a surface was defined: therefore the blast area on the test plate was allocated for CONWEP lisaditg. A source point was detuned 150 mm nomal dislance away from the blast area, which was equivalent to the stand-off distamce in the experiments. The properties of the CON WI:P interaction were delined as an at blast and reyuired the equizalent mass of $1 \mathrm{X}$, which was allocated for cach specific charge mass. The timal step involved detining the start time of the CONWFP

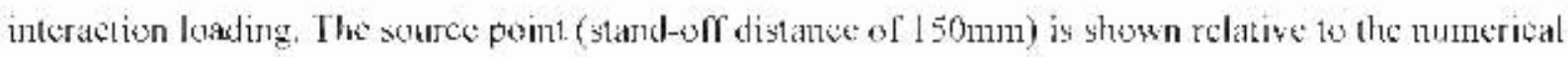
model in f'igure 6.27 .

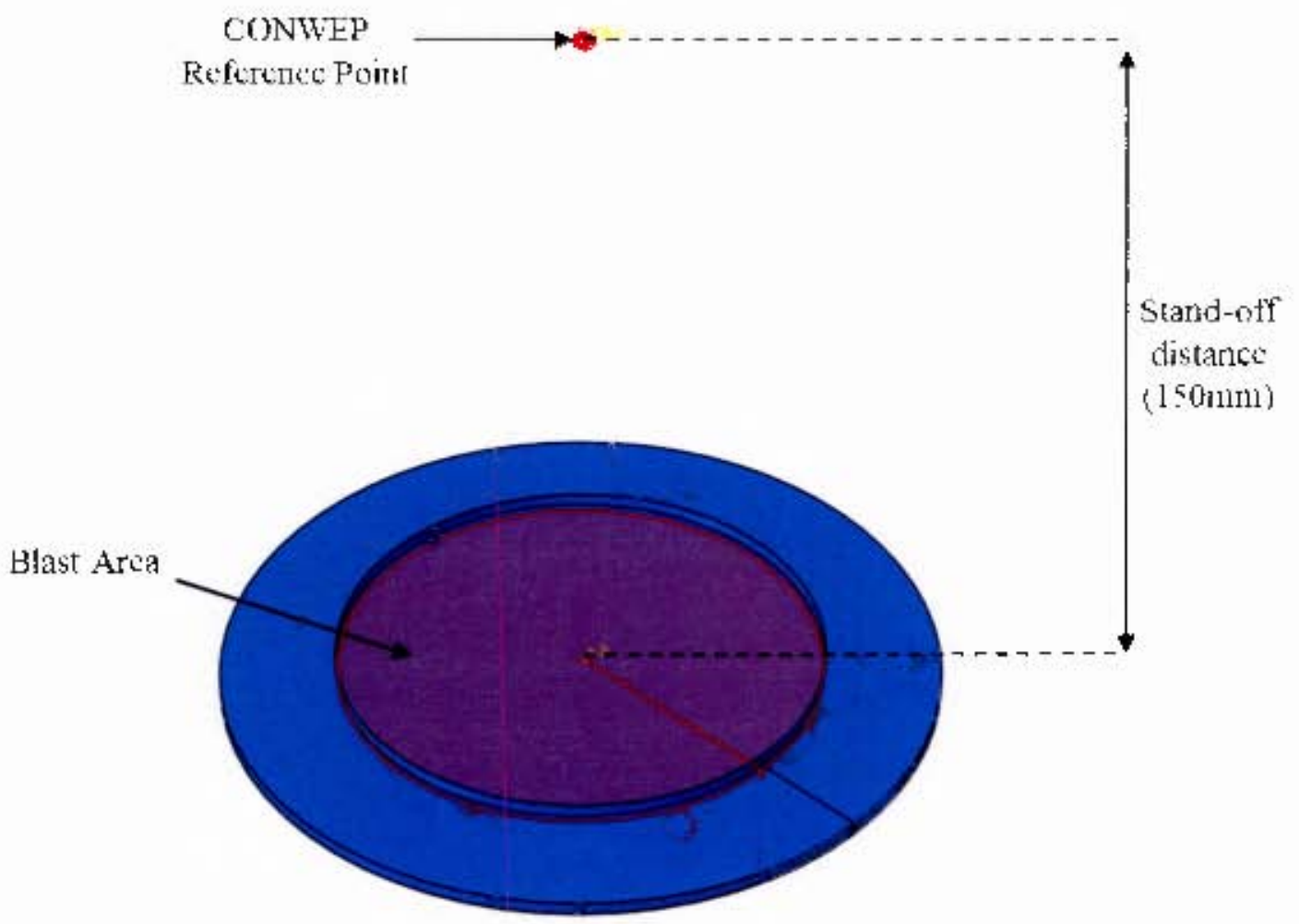

Figure 6.27: Vumerical model slowing COXWEP reference start peint relative to the blast at ra:a

Partially confined blasts haye been known to haye hislier impulsive loads than free air blasts. CONWEP was dełeloped for spherical charges delonated in unconfined frec air blast conditions. A scaling tàctor was thus used to simulate the eylindrical disk shaped charge, detonated in a fully vented tubc, as used in the experiments. The scaling factor was determined by iteratively loading the numerical model uritil the impulse abtained from COXWIP matched the experimentat impulse. 
imparted by a specific charge trass. The impulse was calculated by integrating the clamp normal reaction lorce, which can be processed and plotted within ABAQUS.

From the iturative process of scaling the CONWEP load, a scaling factor that best suitid the liull range of charge masses of 4.7 , was chosen and kept constant for the other charge masses. The impulse for the non-scaled CONWCP loading is illustrated in Figrure 6.28 and compared to the impulse for the 4.7 scaled CONWEP load for a charge mass of $10 \mathrm{~g}$. The scaled CONWEP load produced an impulse of 2 INs. The experimental impulse for a charge mass of $10 \mathrm{~g}$ is $21.02 \mathrm{Ns}$.

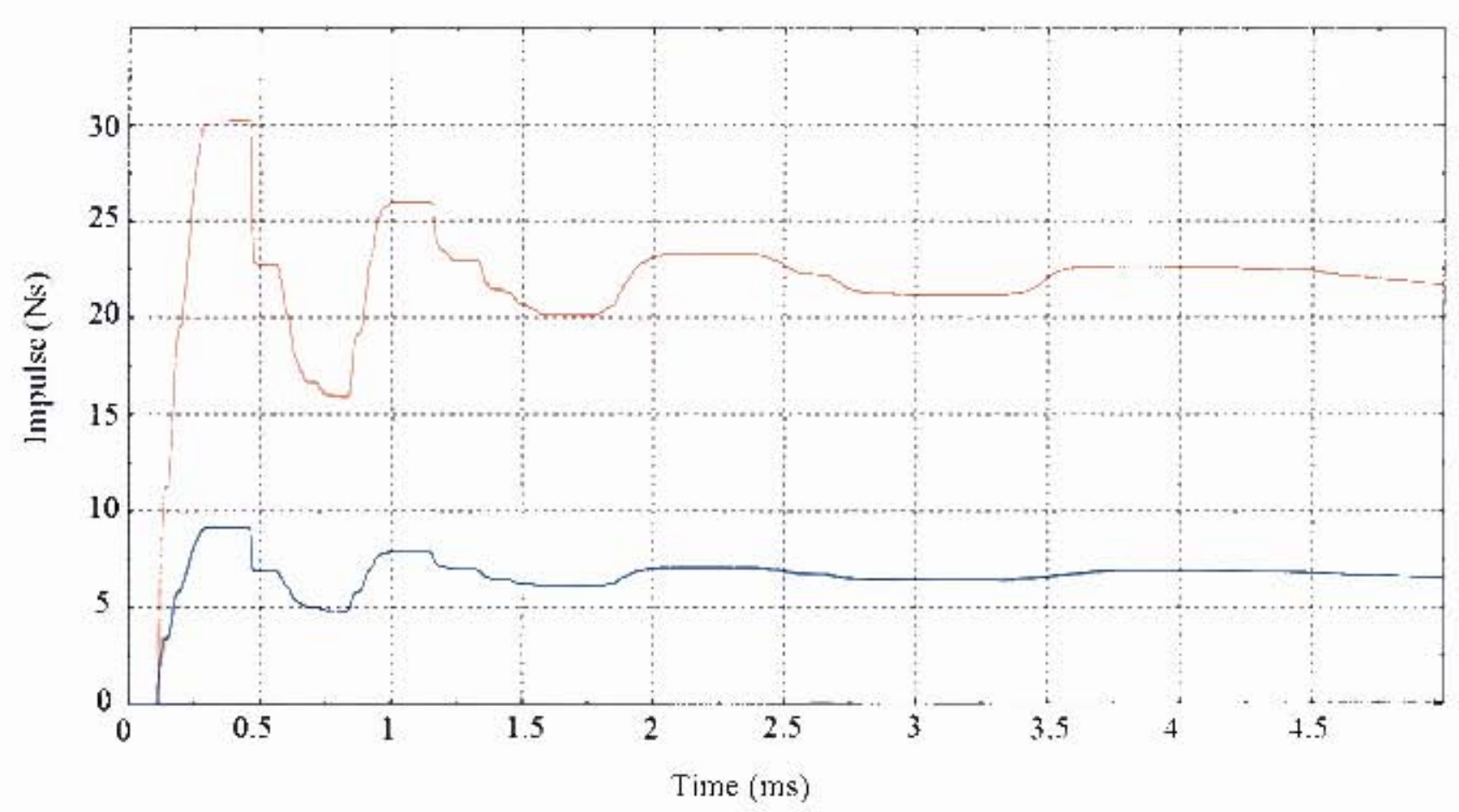

Figure 6.28: Graph cirmparing the resultant impulse of the scaled CONWEl' load yersus the non-scaled load 


\subsubsection{Repeated Blast Loading}

\section{Rectangular Pressure Puise Repeated Blast Joards}

lo simulate repoated blast bading condicions as conducted in the experiments, a multiple stop concept in the ruming process of the modet was implemented. For each hlast. at lotaling sep and 'inertia' step were specified. The blast step detincid the lodding piriod of the test plate, as the uniform pressure load was applied at this step. with a loading aluration of $360 \mu$ s. vorrelating to the blast step time. The "incria" step, allowed the test plate to oscillate under its own inestia and eventually come to rest. This process was repeated for the required number of blasts on the same lest plate. This method was cmployed for all etherge masses and buth plate thichnesses ( $2 \mathrm{~mm}$ and $3 \mathrm{~mm}$ ). The midpoint detlection graph for tive blast loads with a charge mass of $30 \mathrm{~g}$ ant platc thickness $3 \mathrm{~mm}$, is shown in rigure 6.29 .

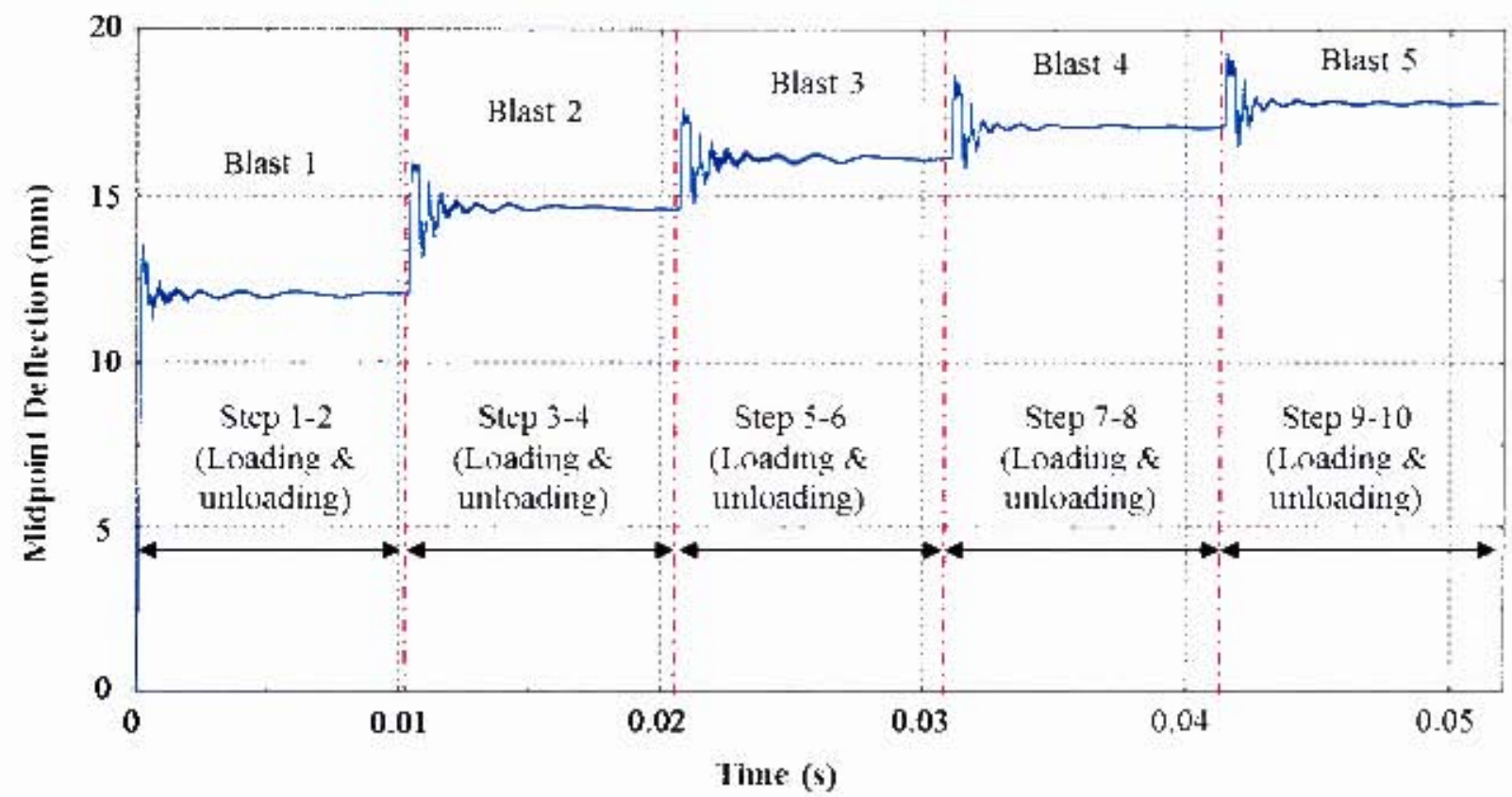

Figure 6.29: Graph of midpoint deflection tor 5 blast toats with charge rmss 34g and plate thicliness 3 mun, for unilorm toaling 


\section{CONWE.P Repeated Blast Loads}

CONWEP loading was specified by delining an interaction. Tather than at lotd. The commencement of the interaction wats specified to stat al a desired time within an ABAQLIS step. This allowed for all the repeated CONWTP blasts to be loated in at single siep, with an extended rum time. Once the first COXWEP load had propagated and the plate inertia had subsided sufficiently, the time was noted and the second CONWEP load was activated. This method was implemented for all repeated CONWEP blasts. The start of each CONWГP blast was specified in increments of 0.005 scoonds, the chosen time for the test plate to sufficiently come to rest. The first conties blast begins at time 0 s and the fifth blast at $0.02 \mathrm{~s}$. The CONWT.P loading for five consecutive blasts with a charge mass of $30 \mathrm{~g}$ and plate thichness 3 mm is displatyed in Figgure 6.30.

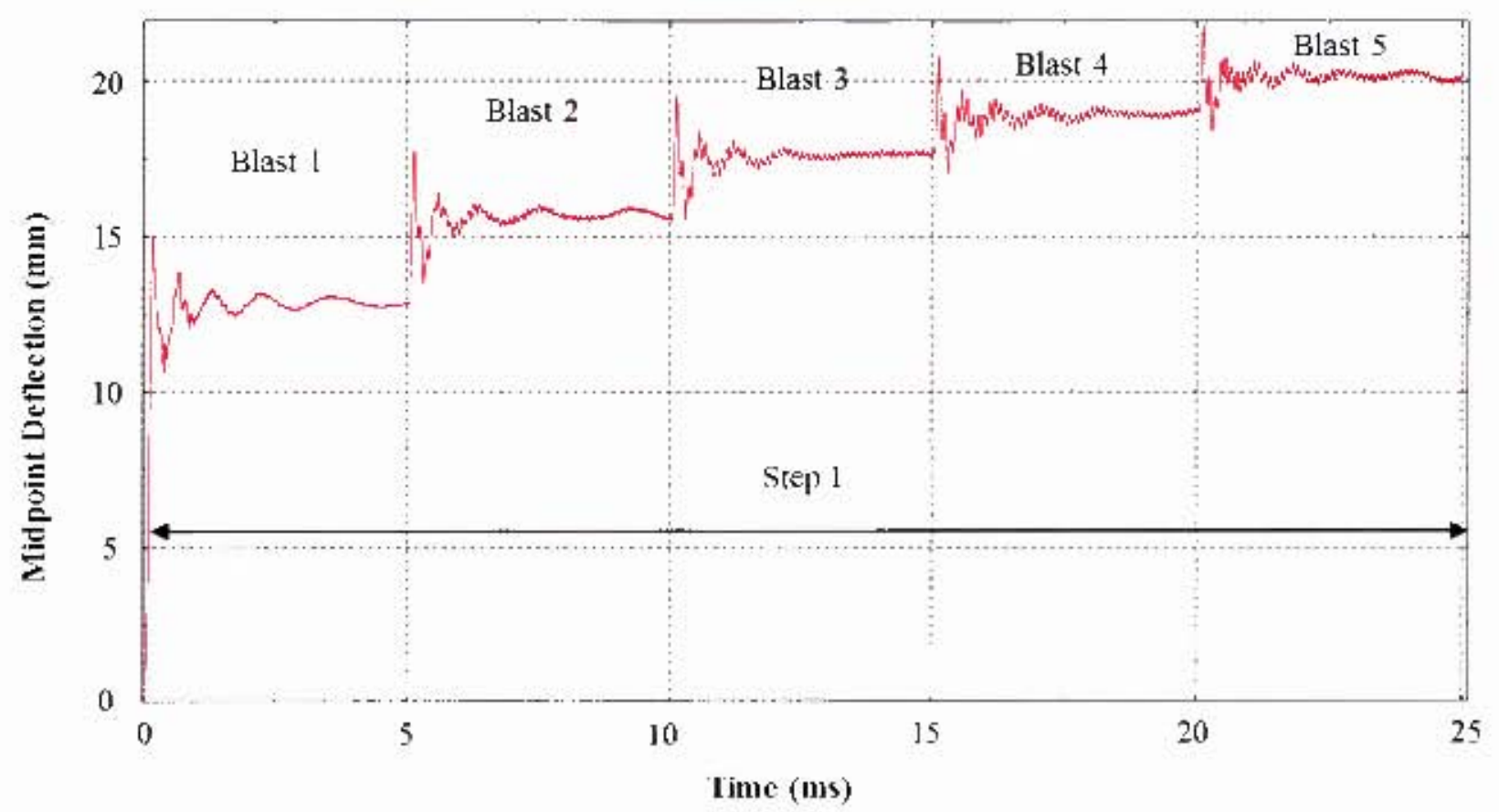

Figure 6..30: Graph "l midpoint deflection fur 5 blast loals with clarge mass $30 \mathrm{~g}$ and plate thickness $3 \mathrm{~mm}$ fror CONWEP Joatim? 


\section{Numerical Results and Discussion}

The results obtained from the various numerical simulations of uniform repeated blast loading on circular Domex 700 steel test plates are presented in this chapter. The results include resultant impulse, midpoint deflection, and deformation profiles of the test plates. The numerical results are compared to one another and the corresponding experimental data. Further numerical analyses on plastic strain and residual stresses, as a result of repeated blast loading, were carried out.

\subsection{Comparison of Experimental and Numerical Impulse Results}

The impulses obtained from the experiments were plotted against the impulse obtained from the numerical simulations for all charge masses, all repeated blasts and both plate thicknesses, shown in Figure 7.1. In general, the data showed an increasing linear trend with good correlation between the experiments and numerical results, with the majority of data points falling within a $\pm 10 \%$ confidence that is generally accepted, due to experimental variation [95]. There were a few cases where the error was greater than $10 \%$, indicative of experimental variation. Data from Figure 7.1 were plotted in a different form in Figure 7.2 and Figure 7.3, in terms of impulse versus charge mass. 


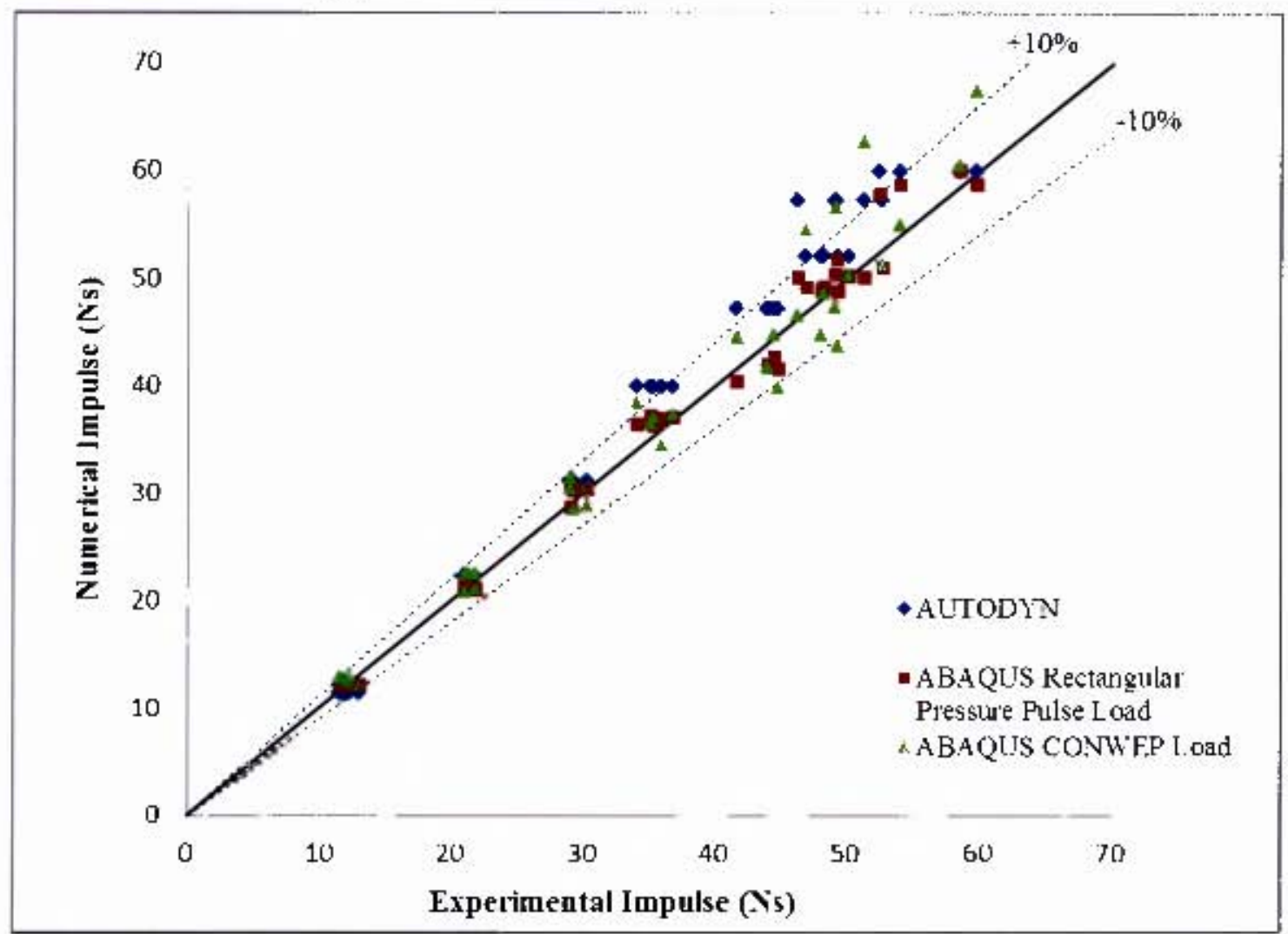

Figure ₹.1: Graph of numericial impulse yersus experimental impulse for all charge masses and repeated blasts for botil plate thickness 2 s 2 mm and 3 mus

The graphs of charge mass versus impulse for the $2 \mathrm{~mm}$ and $3 \mathrm{~mm}$ thick test plates subjected to a single blast, comparing the experimental and numerical results, are presented in fijgure 7.2 and Figure 7.3 . The impulse for each numerical loading technique was plotted alongside the experimental results, with a dincat trend line. Wore data perlatining to further repeated blast loads are presented in Appendix (i.1.

The mumerical impulse results showed good correlation utith the experimental results for the range of charge masses tested. The AljTODYN results showed a slight overestimation, in tigure 7.2 and Figure 7.3 , but wats accounted for by the ideal detonation appoximation used by the mumerical computation. CONWEP overestimated the impulse, beciase of the ideal scaling factor required when inilializing the CONWEP blasts, resuling in deviations from the meastred experimential results. The results indicated a small variation between the different modelling techniques. 


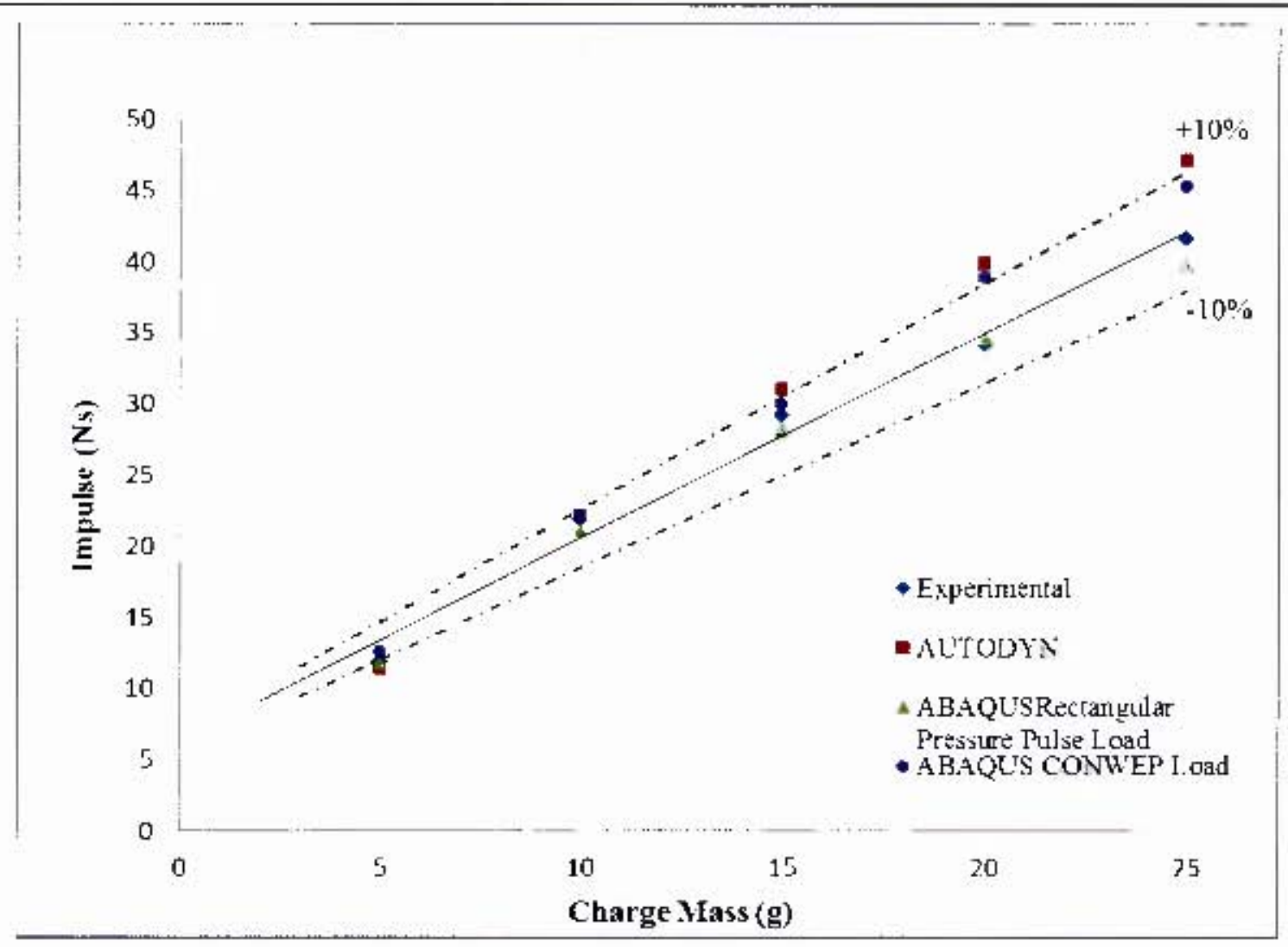

Figure 7.2: Graph of impulse versus clajage mass for a xperimental and rumereal results for a sigele blast load on 2 mm thick test plates

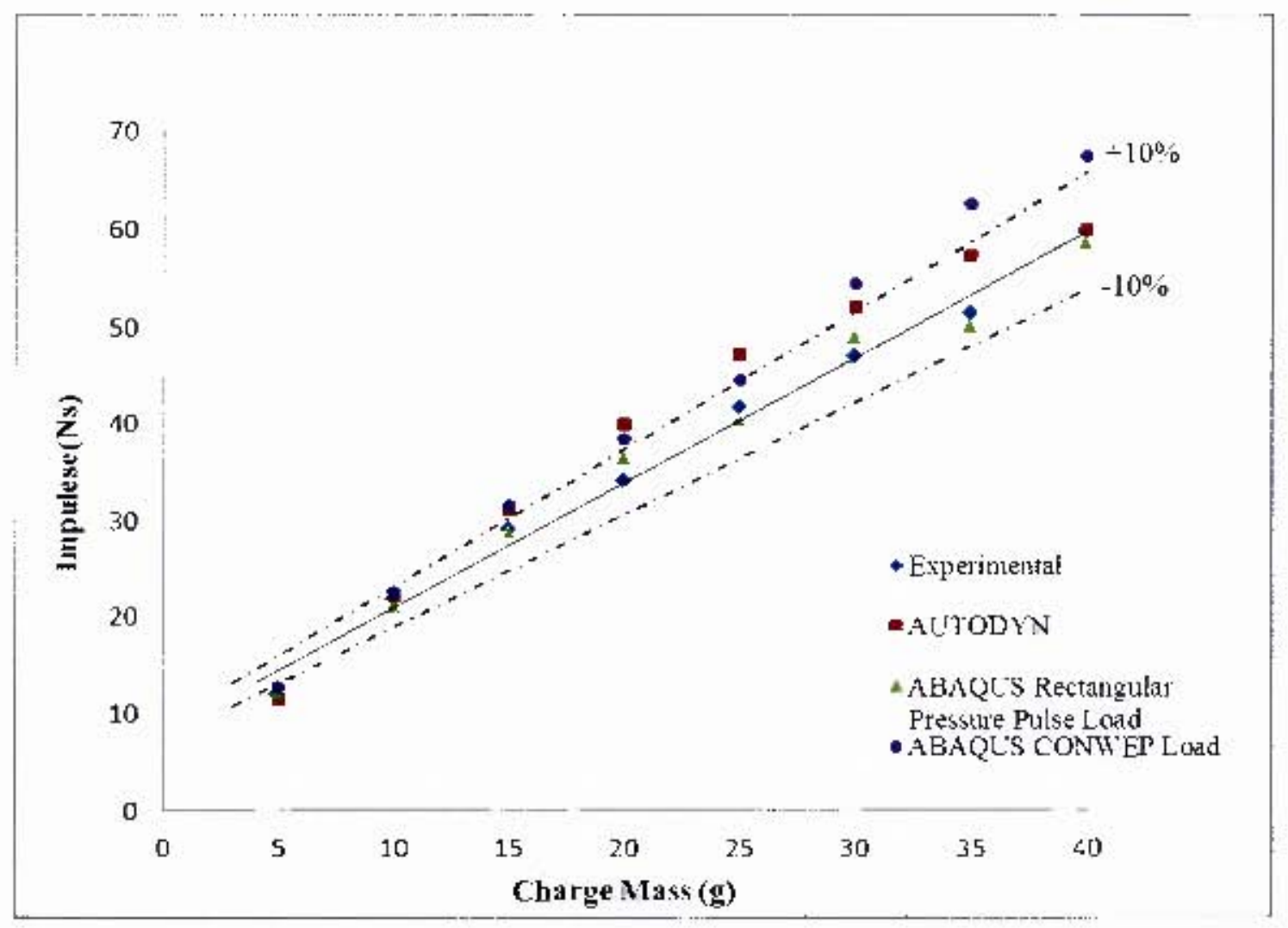

Figure 7.3: firaph of impulse versus charge mask fine experimencal and unmerical tegults for a single blast load on $3 \mathrm{~mm}$ thick test platex 


\subsection{Effect of Repeated Blast Loading on the Impulse Distribution across the Test Plate}

The extent of the change in specific impulse distribution across the test plate as a result of repeated blast loditing is presented in this section. After the test plate had how blast lotaled, it deformed plastically (Mode l) into a general uriform dome shape. Specitic impulse data frem the ALTODYX simulations was extracted from gauge points, located akang the plate firofile, to investigate the impulse distribution across the undeformed and deformed plate. The specitic area that cach gauge represented was used to detemine the specific impulse from the pressure-1ime histories. This was simnilar to the method used in calculating the resulant imsulse for it single blast loat, as described in Section 6.1.2.1.2.

The specific impulse distributions for charge masses $15 \mathrm{~g}$ for 5 hlist kads are shown in Figure 7.4 . The impulse distributions represens the specitic impulse fiom the centre of the plate to the outer climped houndiary edge.

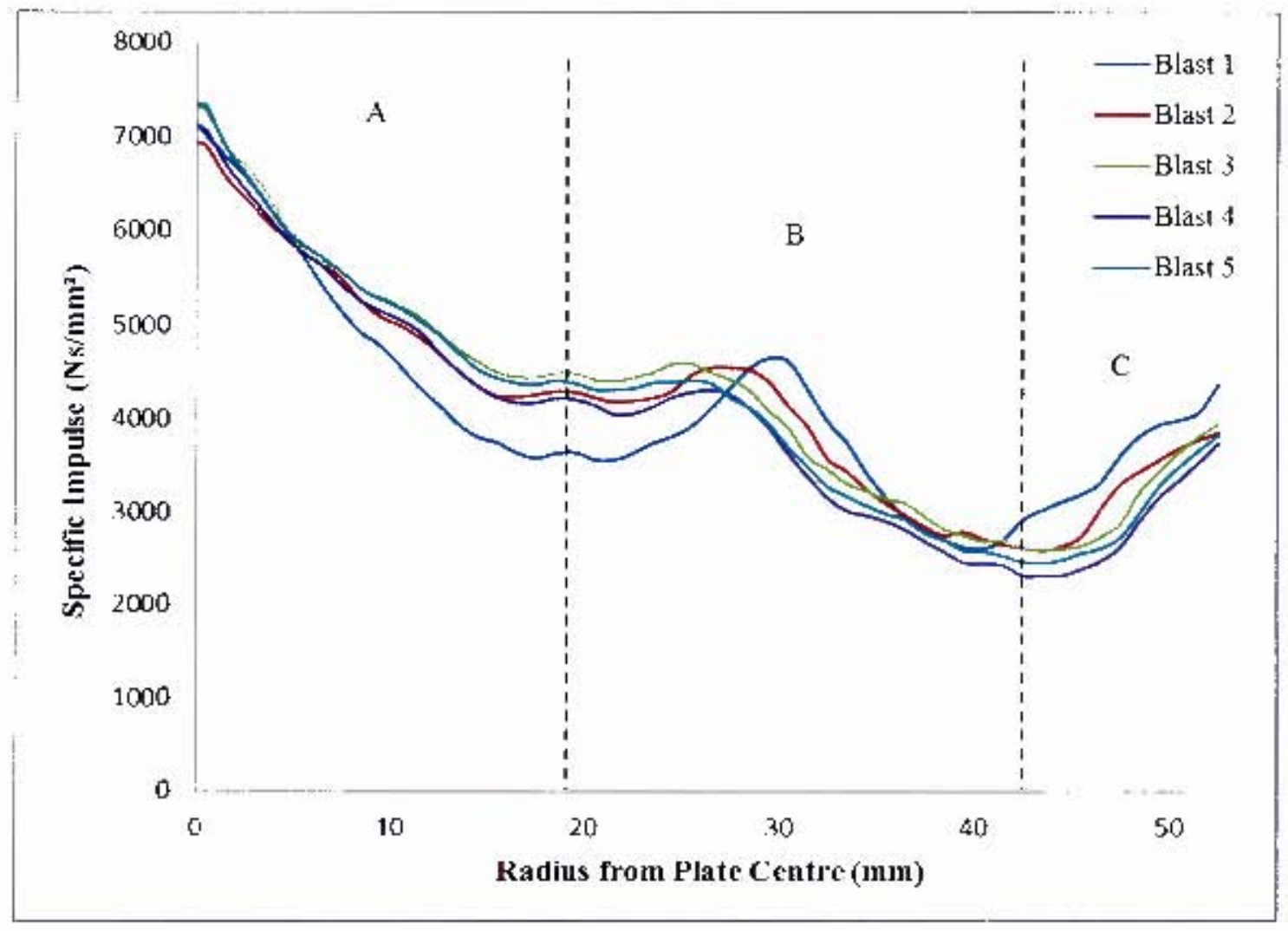

Figure 7,4: Graph of specifie impulse versus distance from the test plate centre for charge mass $15 \mathrm{~g}$ and loaded 5 tirnes 
The specific impulses for each blast load were divided into regions, namely A, B and C, specified in Figure 7.4. Region A relates to the central area of the test plate, region $B$ represents the middle of the test plate and $\mathrm{C}$ refers to the boundary area.

The maximum specific impulse was found at the centre of the test plate, in region A, the specific impulse decreased to a minimum ( approximately $19 \mathrm{~mm}$ radius). In region $A$, the specific impulse for all the repeated blasts followed a similar trend.

In region $\mathrm{B}$, the specific impulse slightly increased to a small peak or plateau before decaying further. The peaks for all the repeated blast loads occurred around $30 \mathrm{~mm}$ from the plate centre. The specific impulse reached an absolute minimum at approximately $43 \mathrm{~mm}$ from the plate centre.

After the minimum impulse was reached, the specific impulse increased in region $\mathrm{C}$, towards the clamping boundary. The increase in specific impulse was due to the transverse reflection off the reflective tube wall. As the incident pressure wave interacted with the reflective tube wall, the reflected wave was compressed, causing an increase in localised pressure and therefore increasing the specific impulse. The transverse reflection is shown in Figure 7.5, illustrating the pressure wave travelling down the tube towards the test plate and reflecting off the tube wall. Figure 7.5 shows the AUTODYN simulated propagating blast wave, towards the test plate and reflecting off the boundary walls, at various times after detonation.

There was relatively little variation in the specific impulse distribution along the radius of the plate, between each blast load. The initial impulse distribution for a single blast load had the most significant difference when compared to blast loads 2 to 5 . This was accounted for by the change in shape between the original undeformed plate and the global inelastic deformed plate subjected to repeated blasts. The extent of plate deformation from blast load 2 to 5 was minimal, corresponding to the minimal change in the specific impulse distribution between blast loads 2 to 5 . Therefore it was concluded that the shape of the blast area did have an effect on the shape of the impulse distribution along the plate profile, but had little effect on the resultant impulse, as observed in the experiments (Section 5.2). The general trends shown in Figure 7.4 were found for all charge masses and repeated blast series. 

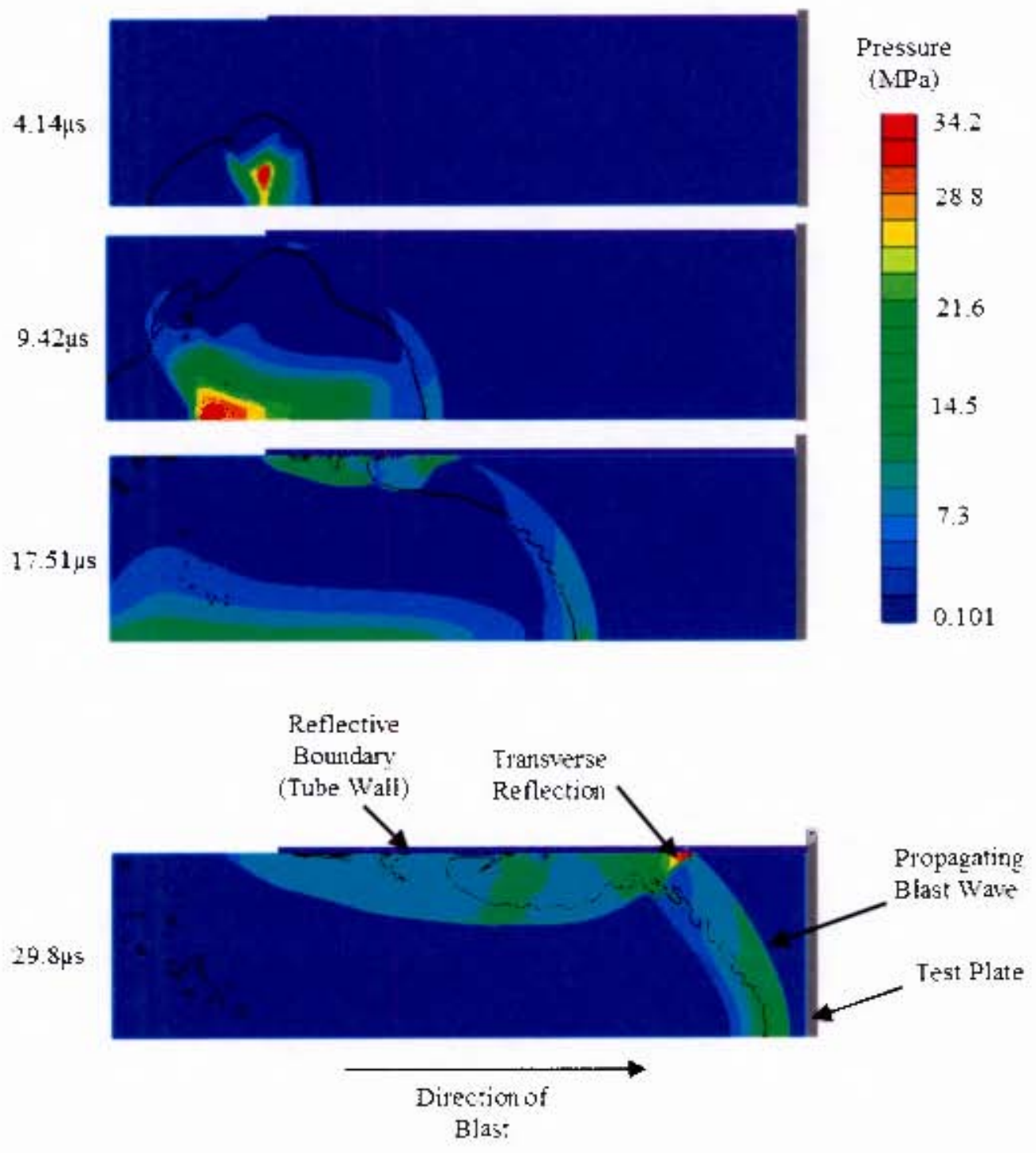

Figure 7.5: AL TODYר axisymmetric render of propagating blast wave with transwerse reflectimn off the tule wall 


\subsection{Comparison of Experimental and Numerical Midpoint Deflections}

Graphs of the numerical midpoint deflections for the various computational loading techniques versus the experimental midpoint deflections are shown in Figure 7.6 and Figure 7.7, for plate thicknesses $2 \mathrm{~mm}$ and $3 \mathrm{~mm}$ respectively. An equivalence line is projected through the data points, with the positive and negative one plate thickness ( $\pm 2 \mathrm{~mm}$ and $\pm 3 \mathrm{~mm}$ ) confidence lines running parallel. The three numerical loading techniques, namely AUTODYN, ABAQUS rectangular pressure pulse loading and ABAQUS CONWEP loading are displayed in Figure 7.6 and Figure 7.7. The detailed results are listed in Table G. 3 and Table G. 4, presented in Appendix G.2.

The numerical midpoint deflection results showed very good correlation to the experiments, illustrated in Figure 7.6 and Figure 7.7. The data points fell within one plate thickness confidence factor $( \pm 2 \mathrm{~mm}$ and $\pm 3 \mathrm{~mm})$. The data points that did not fall within the confidence factor are accounted for by experimental variation. 


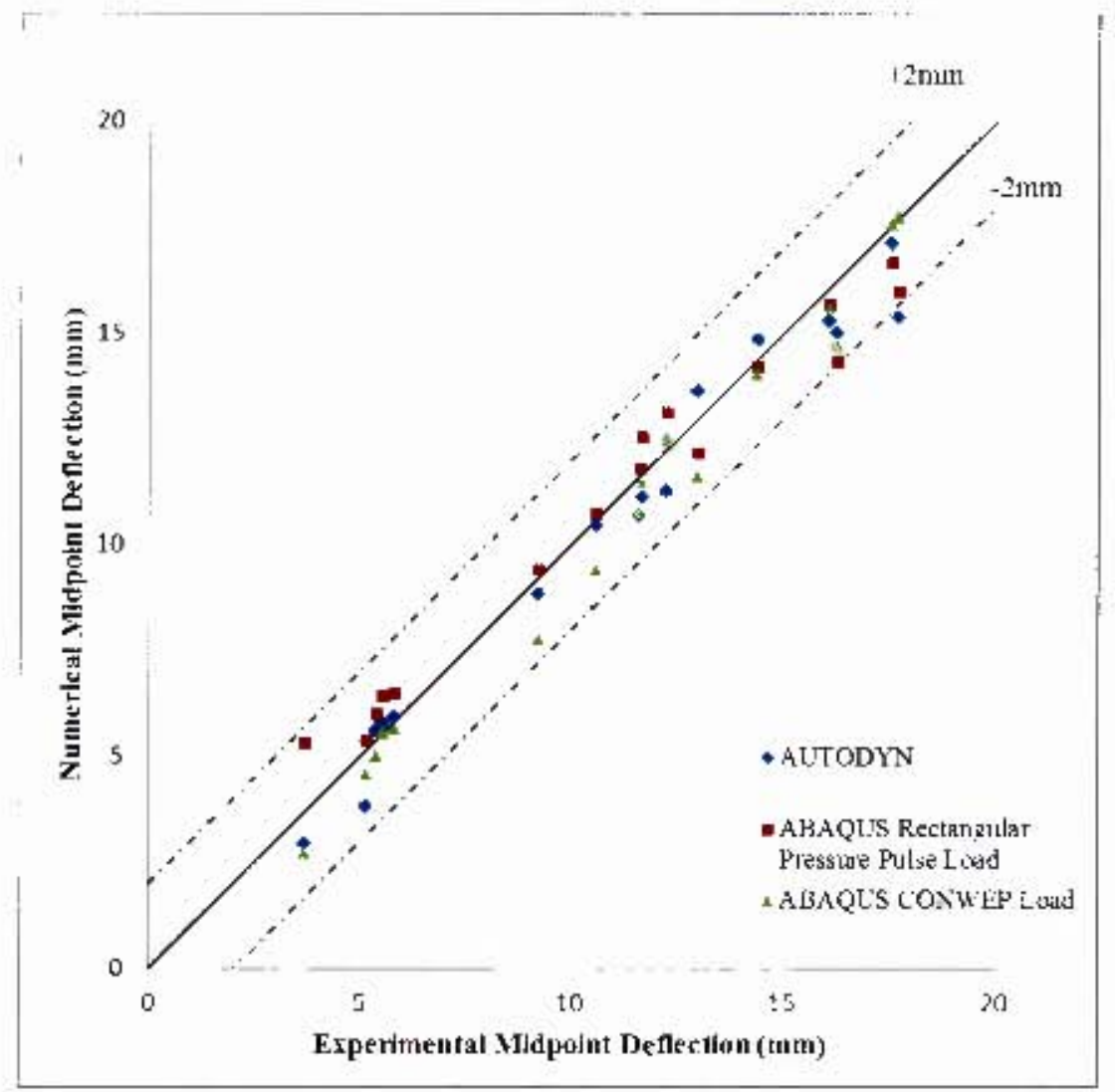

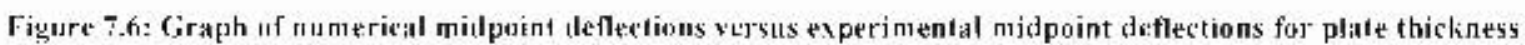
$2 m u n$ and all repeateri blast loads

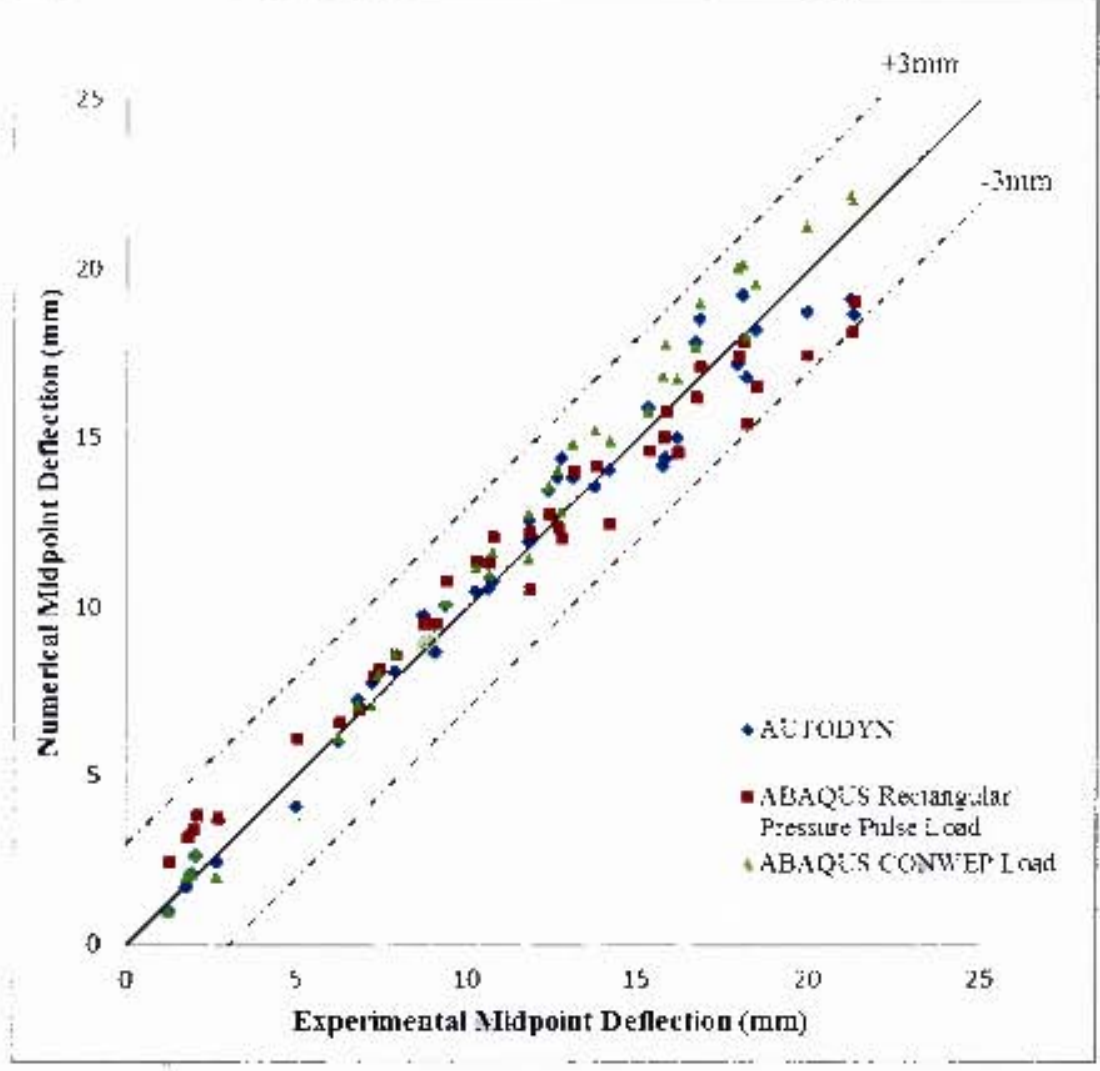

Figure 7.: Graph of numerical midpoint deflections versus experimental midpoint deflections for plate thickness 5umen and all repeated blast loads 
The different loading methods were plotted alongside the experimental data, for midpoint deflection versus charge mass, for the $2 \mathrm{~mm}$ thick test plate subjected to a single blast and the $3 \mathrm{~mm}$ thick test plate subjected to 5 blasts, in Figure 7.8 and Figure 7.9 respectively. The midpoint deflection increases linearly with an increase in charge mass, as discussed in Section 5.3. The numerical results correlate very well with the experiments, with the data falling within the one plate thickness confidence factor. CONWEP consistently overestimates the midpoint deflections for a greater number of blast loads, observed in Figure 7.9. The data points falling outside the confidence factor (Figure 7.8) related to the ABAQUS rectangular pressure pulse load and AUTODYN load for a charge mass $25 \mathrm{~g}$ and a single blast load. The test plate subjected to a single blast with $25 \mathrm{~g}$ charge mass experienced observable thinning at the clamped boundary and approached the threshold failure of the material. This was similar to the data point in Figure 7.9, for a charge mass of $35 \mathrm{~g}$ and 5 blast loads.

The general linear trends were observed for the full range of charge masses and repeated blast series on both plate thicknesses. The graphs pertaining to these results are presented in Appendix G.2. 


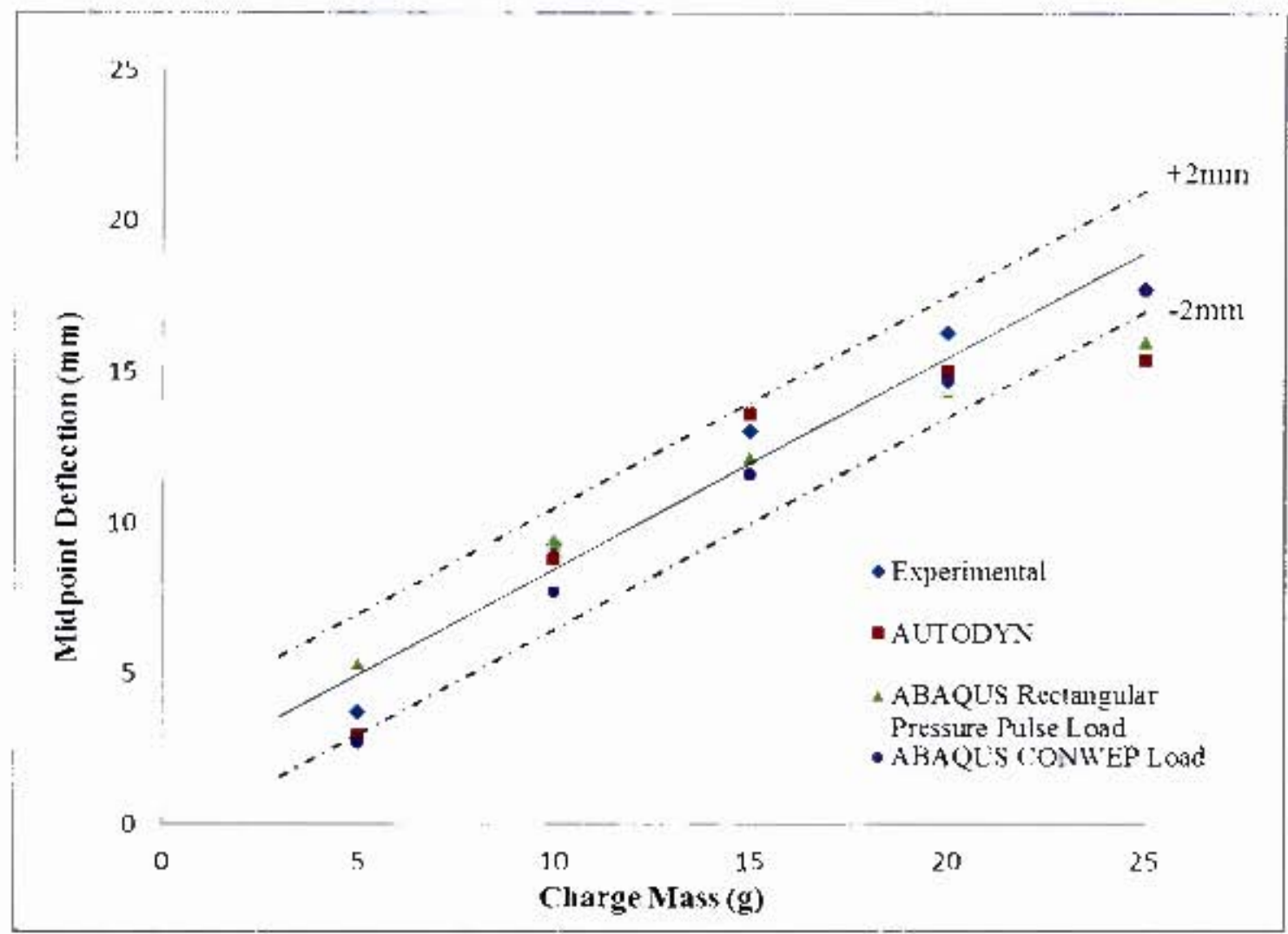

Figure ?.ষ: G;raph of midpoint detlection vetsus charge mass lor hoth uxperirmental and un merical results lor 2 m ru thick test plates subjected to a single blast load of charge masses $5 \mathrm{~g}$ to $25 \mathrm{~g}$

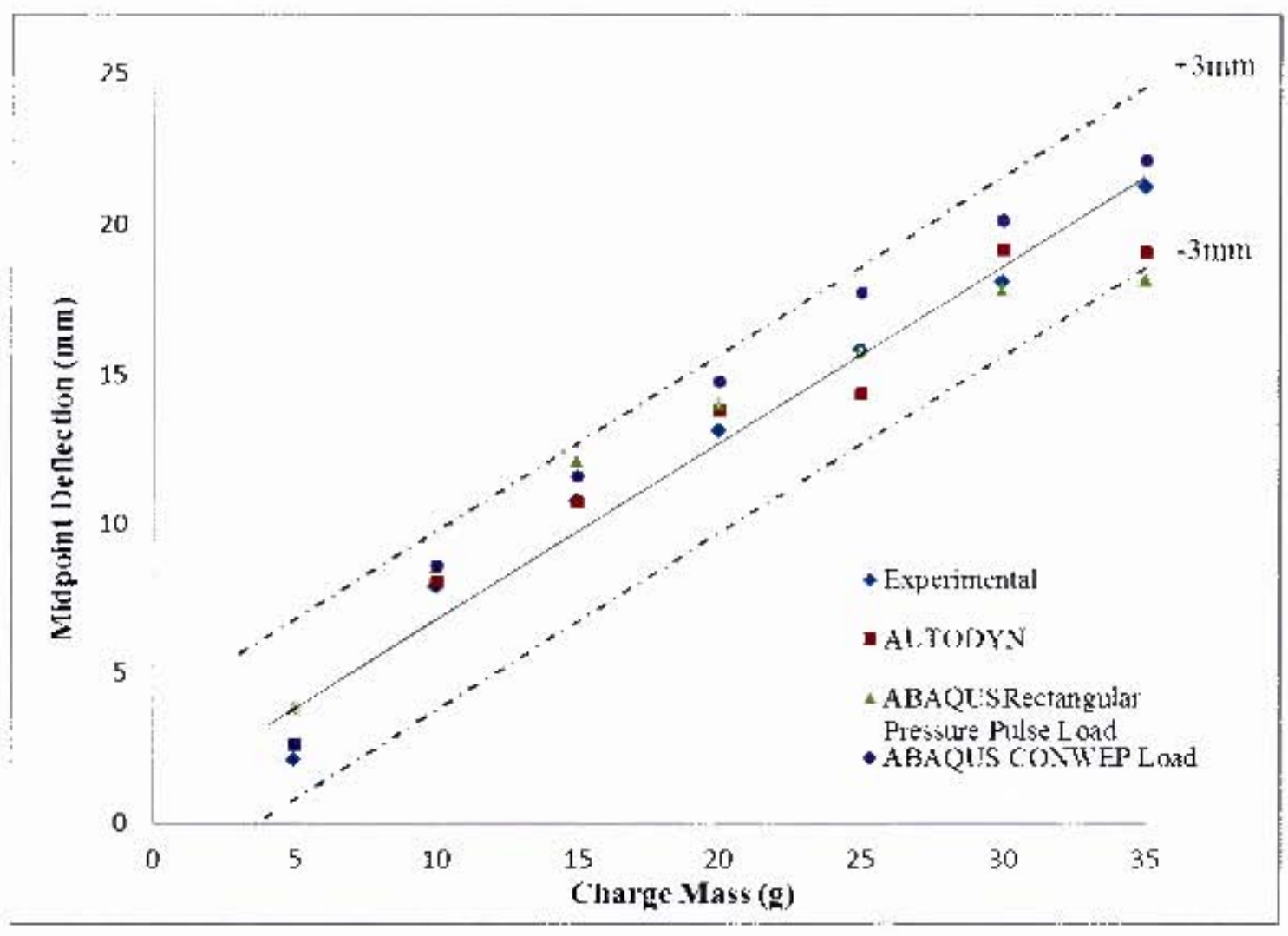

Figure 7.9: Graph of midpoint deflectien versus charge mass for both experimental and numerical results fur \$rum thick rest plates subjected to 5 blast loads of cliarge masses $5 \mathrm{~g}$ to $35 \mathrm{~g}$ 


\subsection{Test Plate Profile Comparison}

The numerical deformation profiles were comparad to the experiments, for a better deformation comparison between the experimental and numerical results. The experimental test plate subjected to chatge mass 15g and 3 blasts is illustrated in Figure 7.10 alongside the results obtained from AL TODYN for the same Ioading condition. The experimental and numerical test plate protiles for clarge mass $15 \mathrm{~g}$ and 3 blast loads exhibit large inelastic glabil dome shaped delomations (Figure 7. 10), characteristic of unitorm blast levading.
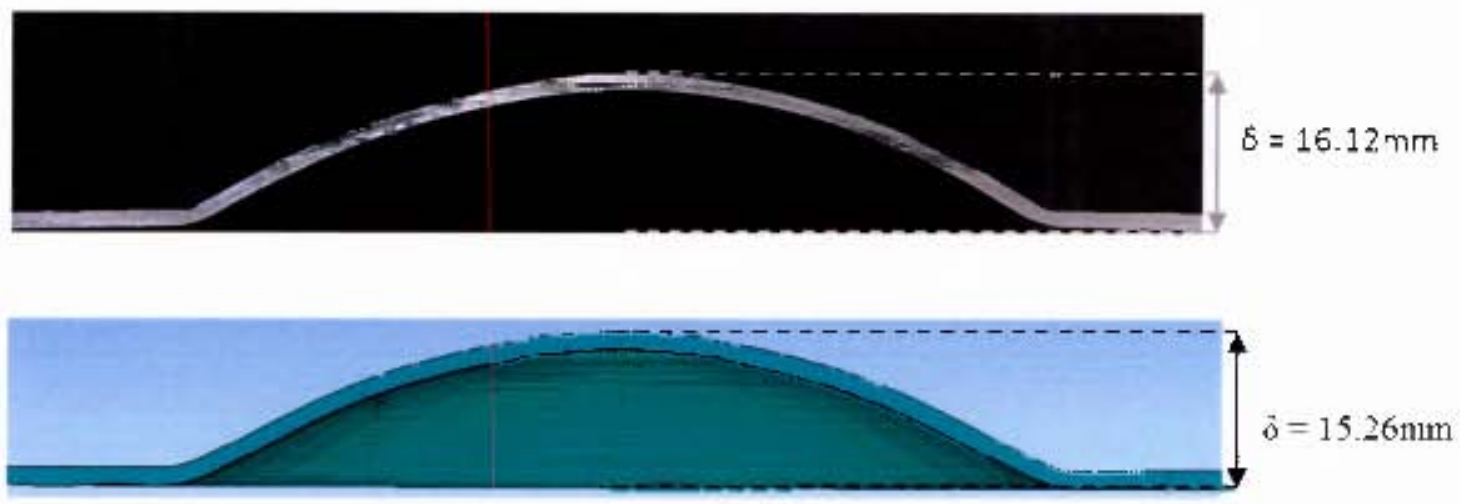

Figure 7.10: Illustrations of experimental and AL I ODYN numerical test plate subjected to 3 hlasts of $15 \mathrm{~g}$ clarge mass

The experimental and numerical test plate profiles for charge mass $5 \mathrm{~g}$ and $15 \mathrm{~g}$ for all repuated blitst loads ate shown ju Figure 7.11-Figure 7.18, respectiscly. The $2 \mathrm{~mm}$ thick lest plate subjected to repeated blast loads of charge mass 15 , withstond a maximum of three blasis betare fitilure. The comparisons were within bue plate thickness $(12 \mathrm{~mm})$, with regards to defiomation. This showed good numerical-experimental deformation correlation includiug the interaction with the elamped houndary under the specified loading techniques. There are however sthall variations in the overall deformation protiles, between the experimental and numerical results including between each numerical method. The small differences in deformation profiles can be weeunted for by experimental variation and the different loading methods, as ALTOTJN, CONWEP and the rectangular pressuse pulse load had sligltly different pressure distributions across the exposed plate surface. Similar trends (good correlation) were observed for the full range of charge masses and repeated blast loads. 


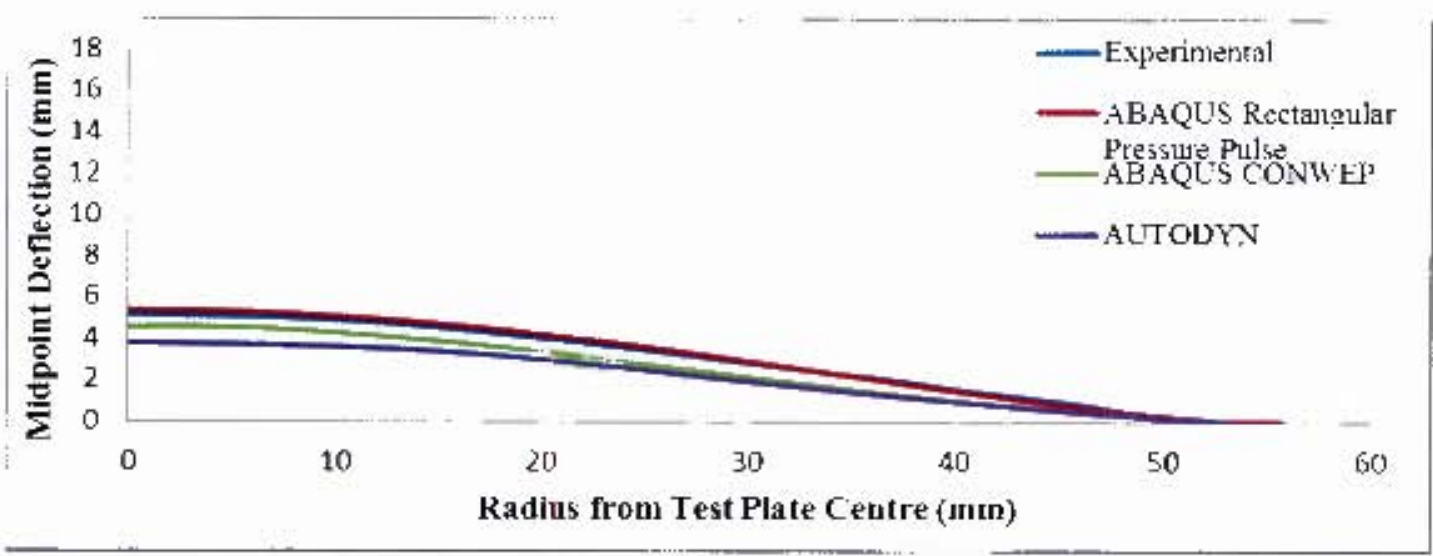

Figure T.II: Complarixen of deformed plate profiles obtained trom the experiments and simulatines for the 2 mm thicli deformed test plates sulinected to a single blast of charge miass $5 y$

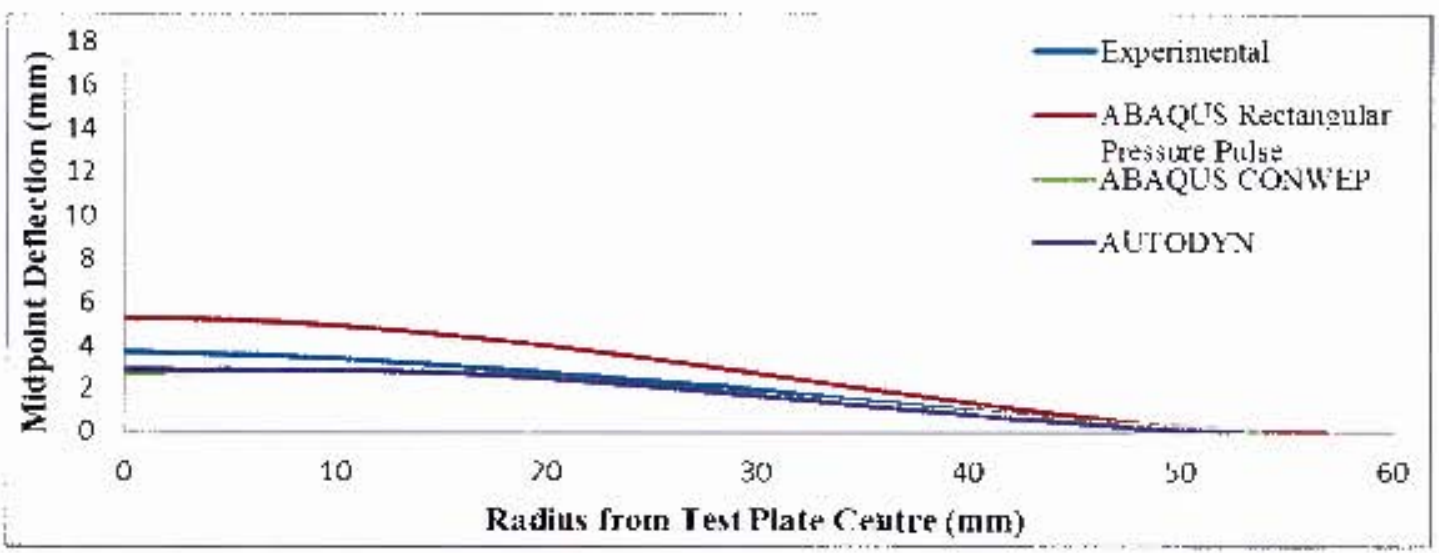

Figure 7.12: Comparian or fle Formed plate profiles oblaincol from the experiments and simulations for the $2 \mathrm{~mm}$ thjcli deformed test plates subjected to 2 blasts of charge mass 5 g

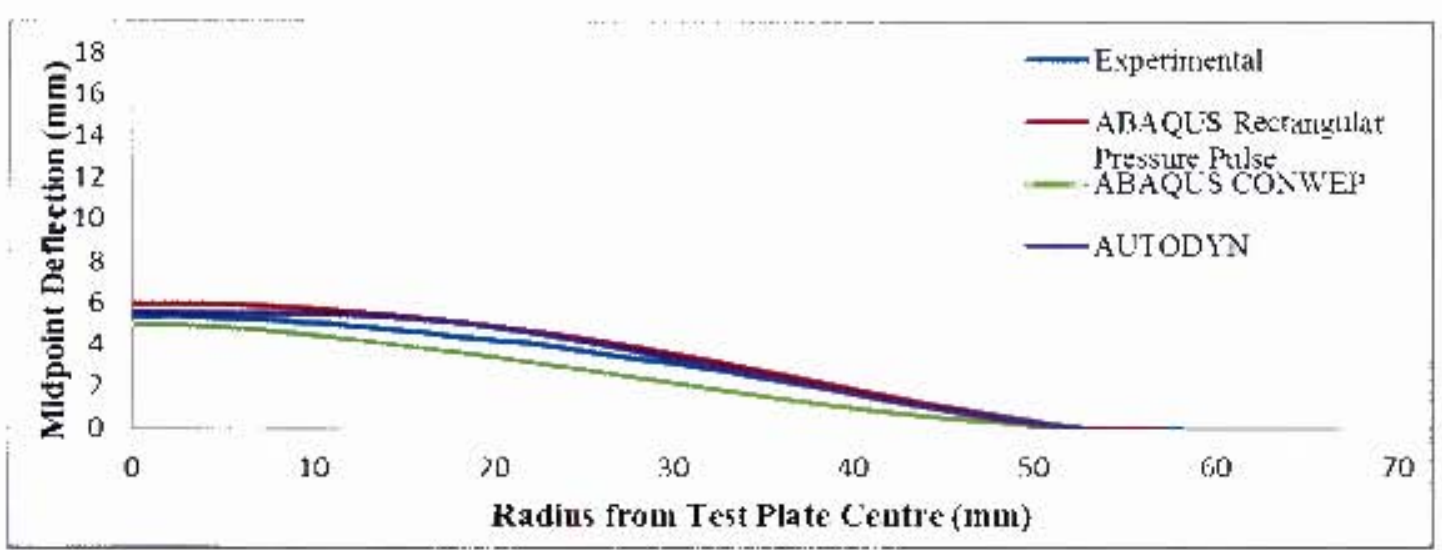

Figure 7.13: Comparison of deformed plate proteles obtatued from the expreriments and simulations for the $2 \mathrm{~mm}$ thick detor med tes plates subjected to 3 blasts of eharge mass s. 


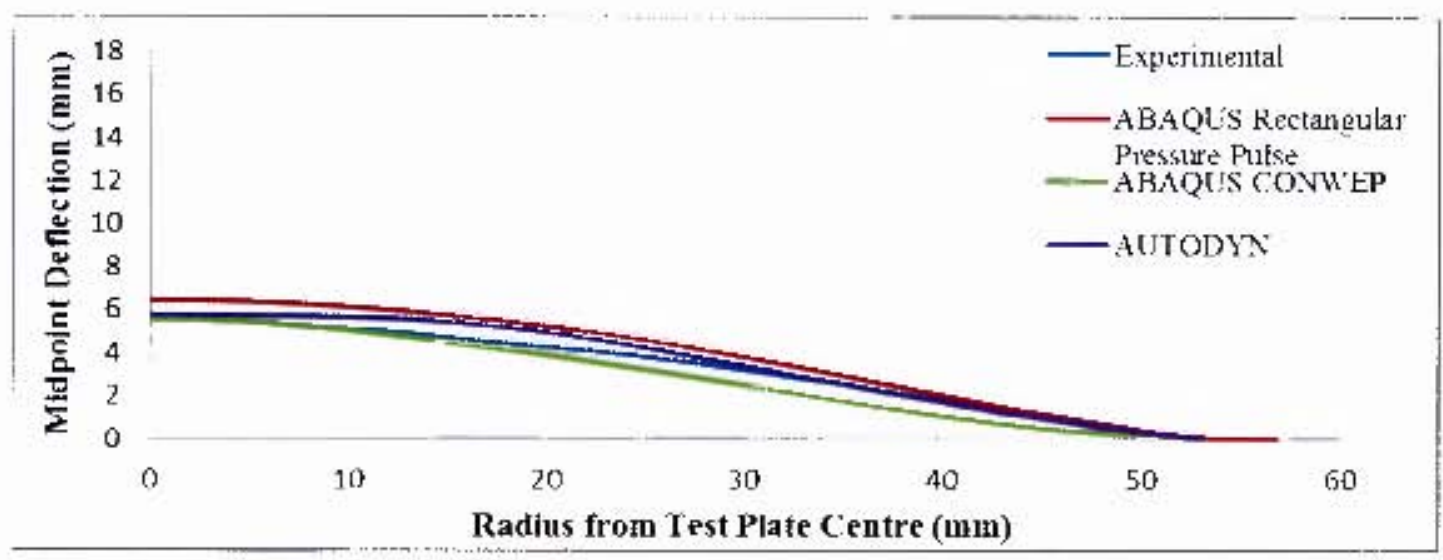

Figure 7.14: Comparison of deformed plate profiles obtained from the experimetsts and simulatims for the: $2 \mathrm{~mm}$ thick deformed rest plates subjectedl co 4 blesis, of tharge mass $5 \mathrm{~g}$

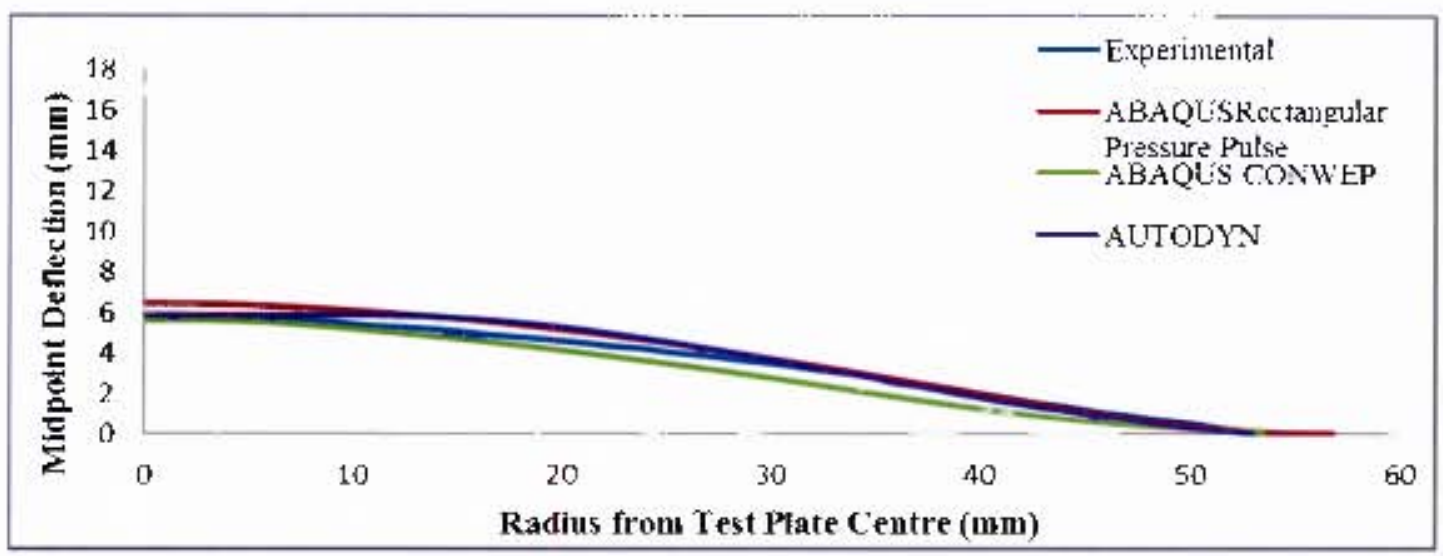

Figure 7.t5: Comparison of delirmed plate jortiles obtained from the txptriments and simulations for the 2 mem thick deformed test plates subjected to 5 blasts of charge mass $5 \mathrm{gg}$ 


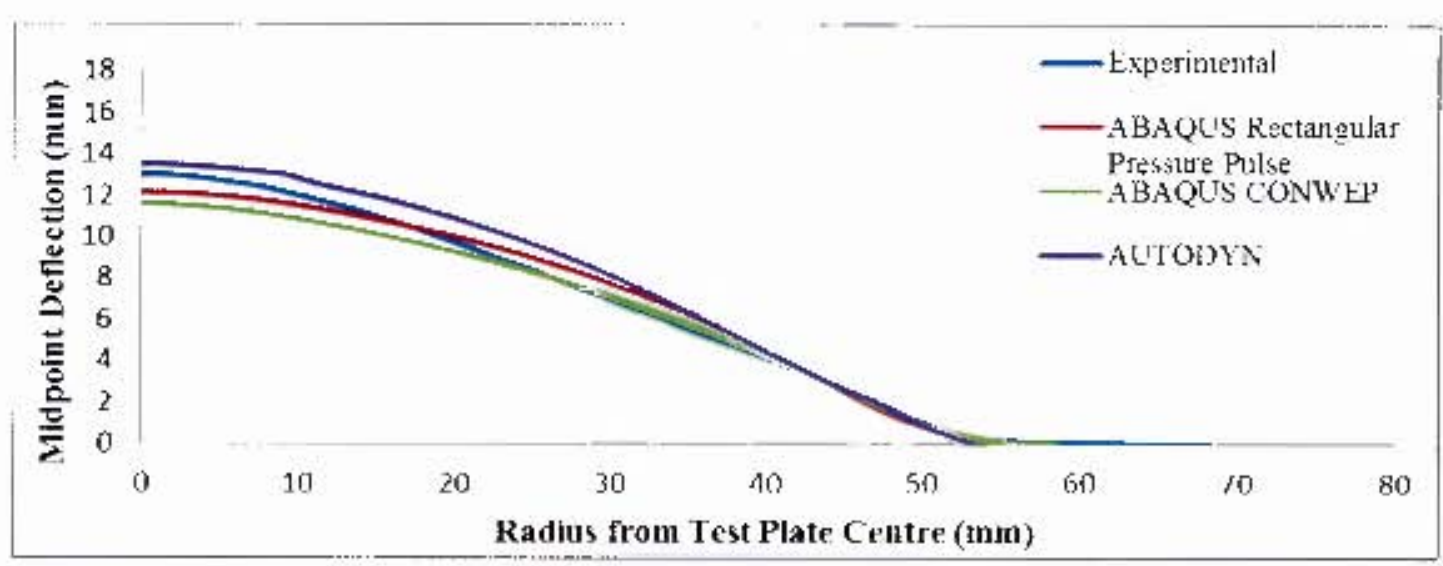

Figure 7,16: Comparison of deformed pate profites obsaimed from the experiments and simulations for the $2 \mathrm{~mm}$ thich deformul tew plates subjected to a single buast of charge mass $15 \mathrm{~g}$

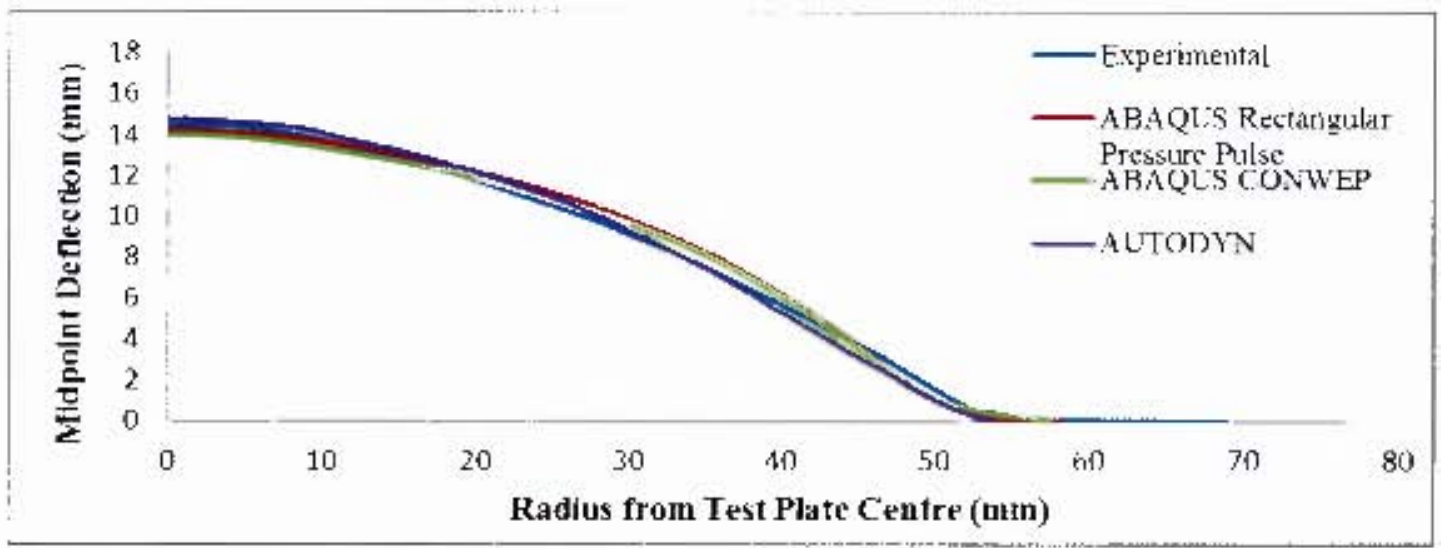

Figure 7,17 : Comparison of deformel plate profiles obtained from the experiments and simulations for che $2 \mathrm{~mm}$ thick deformed test plates subjetted to 2 blasts of charge mas $15 \mathrm{~g}$

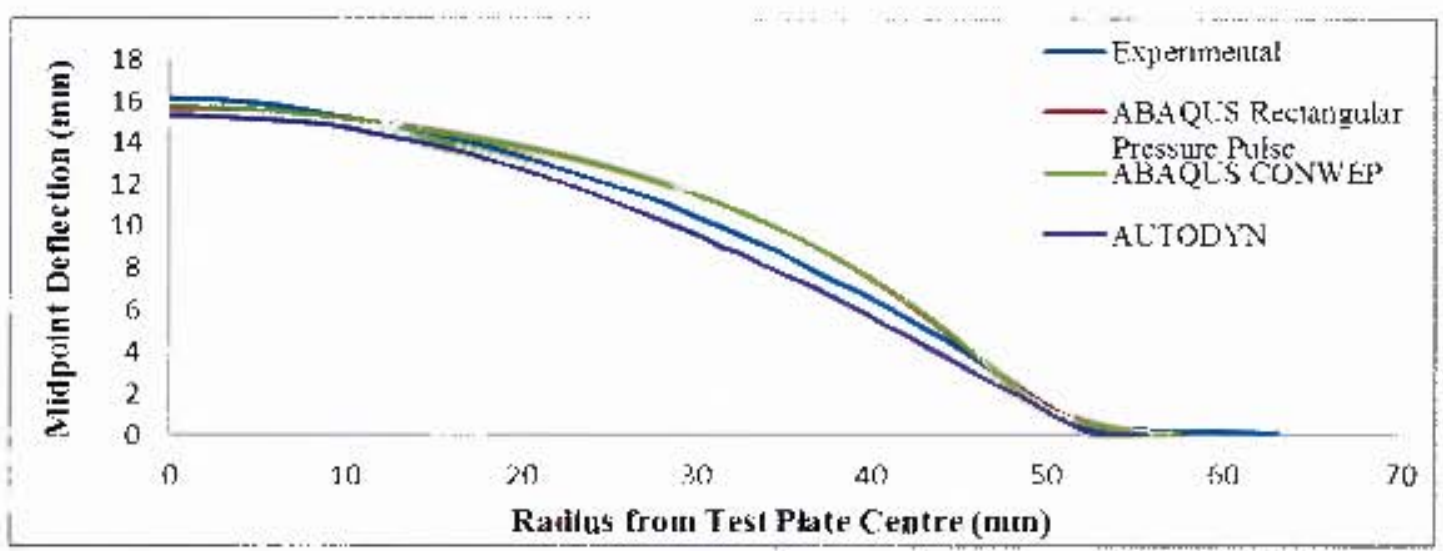

Figure 7. Is: fomparison of deformed plate profiles obtaintd frotu the expreituten1s and simulations for the 2 met thick deformed test plates subjected to 3 blasts of charge mass 5 g 


\subsection{Comparison of Numerical Strain Components}

The lest plates underwent large plastic deformation when subjected to repeated blast loads, resulting in strain hardening of the Domex steel. The effeet of repeated blast lirading un the hardness of the steel was discussed in Section 5.7. It was reported that the hardness of the plate increased with an increase in the number of blasts. This section discusses the extent to which the lest plate is strained when subjicted to repeatat blast loading. From the ABAOUS numerical models, it was possible to extract the equivalent plastic strain components throughout the deformed plate protile, from the Lertire of the plate to the outer edge. The progressim of strain lor 5 blast loads with charge mass $30 \mathrm{~g}$ on the $3 \mathrm{~mm}$ thick plate is illestrated in Figure 7.19. using the ABAQLS rectangulat pressure pulso linding nodel. The strain visibly incrensed as the number of blasts increased, as observed in rigure 7.19 .

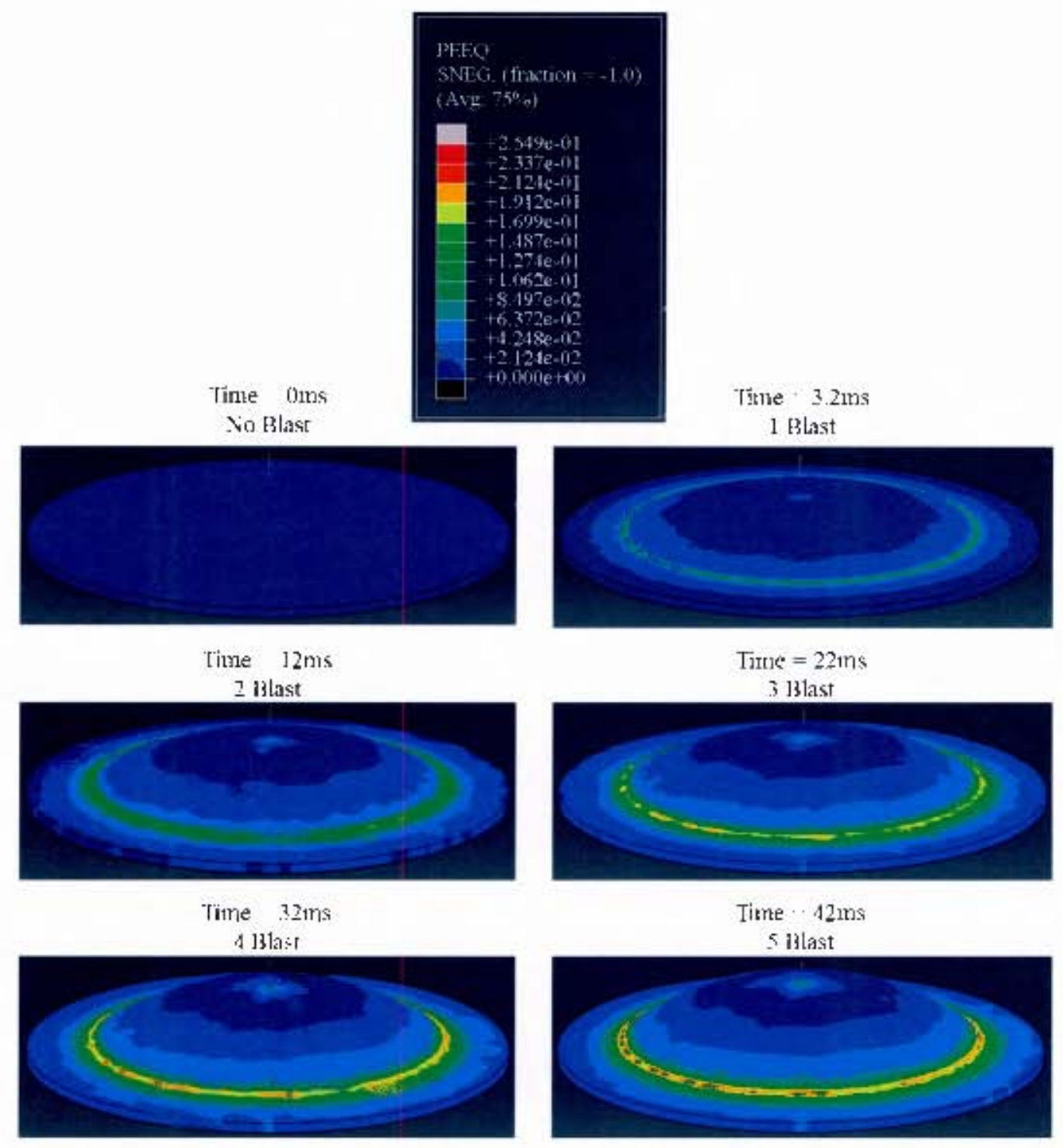

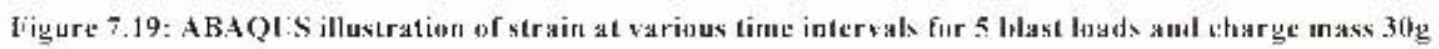




\subsubsection{Comparison between Experimental Vickers IIardness and Numerical Strain}

[n Section 5.7 it was reported that the majority of the increase in hardness was recorded at the damped boundaries, with the centre of the plate experiencing some hardening. Thi extracted straim protile results from the ABAQUS numerical simulation's were compajed to the experimental Vickers hardness test results. This comparison was made for a qualitative analysis, as Vickers hardness indicates the exlent to which the matcrial was harderled after being subjected to repeated blast loads. similarly work hardening occurs when the material plastically deforms. Figurc 7,20 shows the Vickers hardness results for the Zmin thick list plate subjected to a charge mass $15 \mathrm{~g}$ and 3 blasts compared to the strain obtained from the numerical simulation of the experiment. Figure 7.21 shows similar findings for charge mass $20 \mathrm{~g}$ and 2 blasks. The stratis oblatined from the simulations were plotted on the primary: axis, whilst the vickers hardness results from the experiments were ploted on the secondary axis.

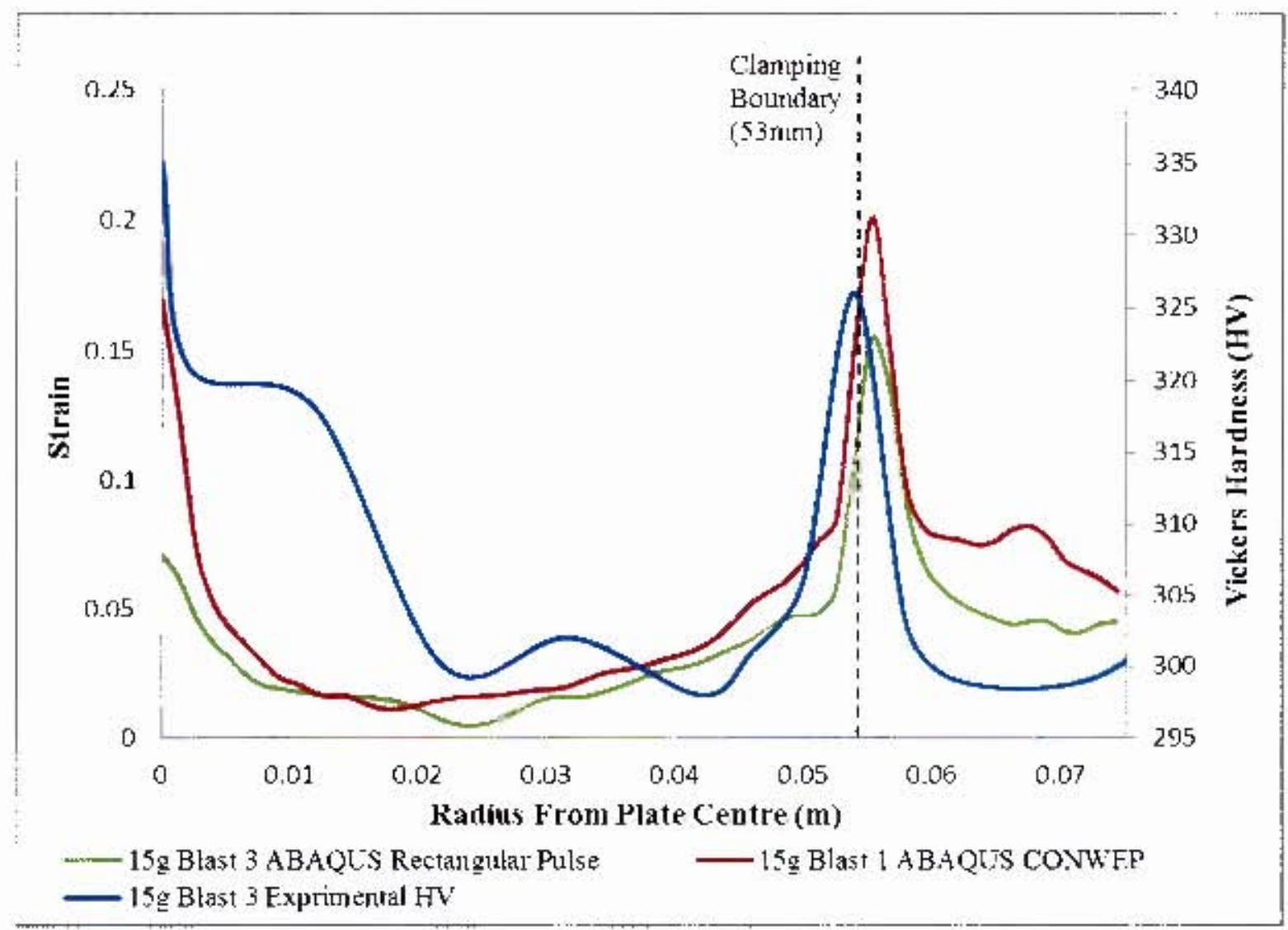

Higure 7,20; Graph of Experimental Yickers hardness and ABAQLS plastic strain com ponents for 3 blast loads with chatge mass $15 \mathrm{~g}$ 


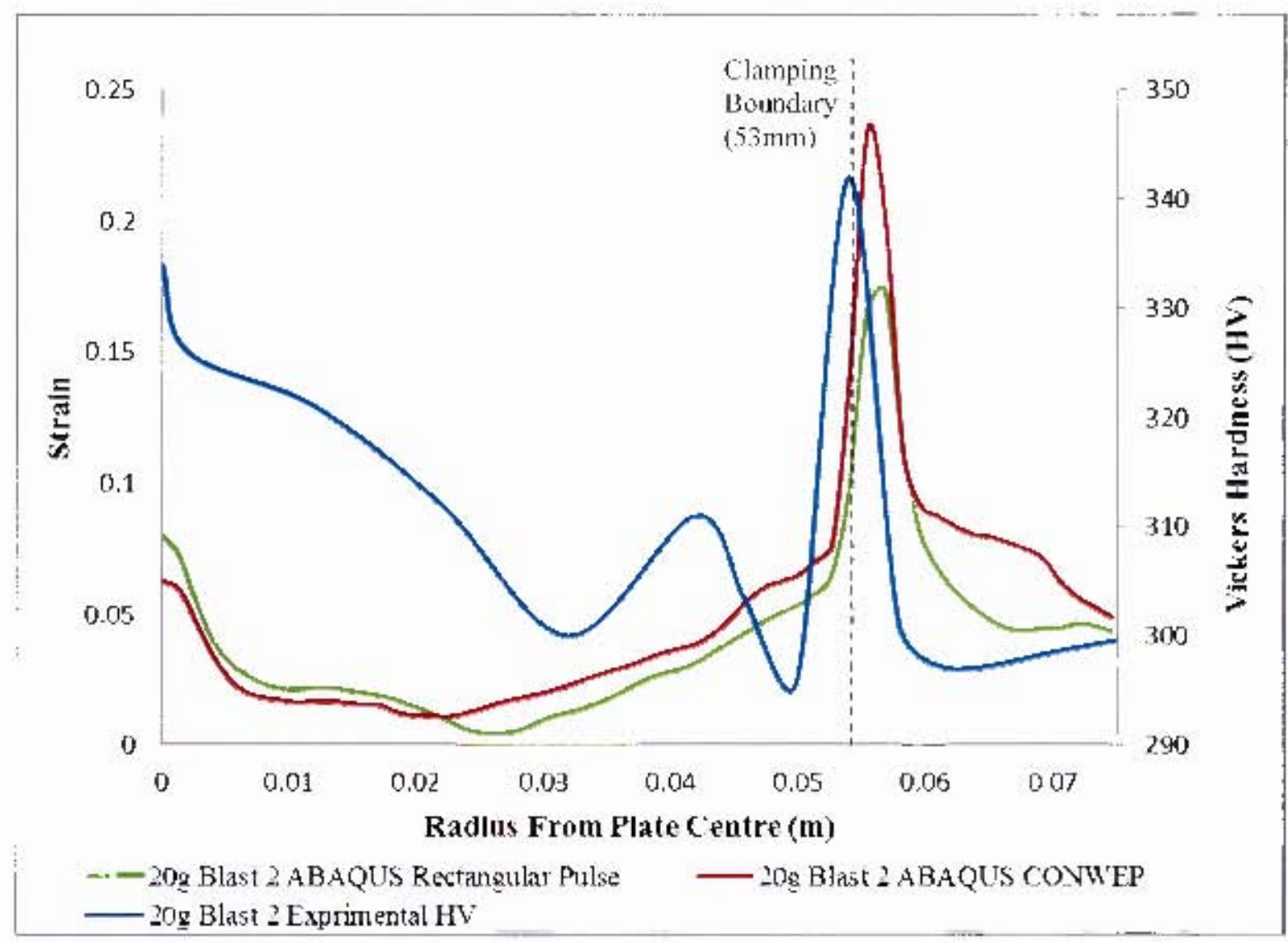

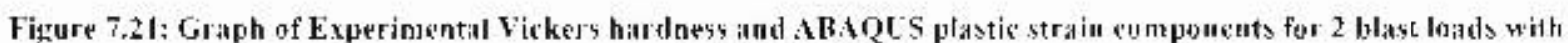
cluarge mass $21 j g$

The curves of the numerical and experimental results (Figure 7.20 and Figure 7.21 ) had similat

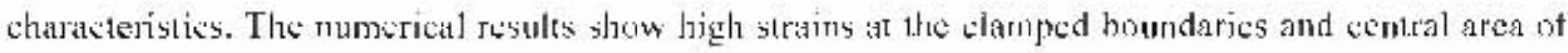
the test plate, corresponding to high Vickers hardness at the clamped boundaries and central region abtained from the experiments. Similat findings were observed fur the full range of chatge misses $(50-40 \mathrm{~g})$ and al] repeated blast kouds. 


\subsubsection{Strain Comparisons between ABAQUS Rectangular Pressure Pulse Loading and ABAQUS CONWEP Loading}

An investigation into the differences in numerical strain measurements between ABAQUS rectangular pressure pulse loading and ABAQUS CONWEP loading was carried out. Comparisons of the strain experienced by the test plate subjected to a single blast and 5 blasts for a charge mass $10 \mathrm{~g}$ and a single blast and 3 blasts for a charge mass $15 \mathrm{~g}$, for plate thickness $2 \mathrm{~mm}$, between the ABAQUS CONWEP and ABAQUS rectangular pressure pulse loading, are shown in Figure 7.22 and Figure 7.23, respectively.

The Figure 7.22 and Figure 7.23 showed similar trends. The ABAQUS CONWEP strain profiles indicated greater strains in the central area of the test plate than the ABAQUS rectangular pressure pulse strain profiles. For a single blast load the strain profiles at the clamped boundary were similar in shape and maximum peak strain values were alike for both charge masses. The maximum strain peaks at the clamped boundaries became more dissimilar as the number of blasts increased, with the ABAQUS CONWEP peak strain being greater than the ABAQUS rectangular pressure pulse peak strain. From Figure 7.20 the ABAQUS CONWEP strain profile showed better correlation with the shape of the Vickers Hardness test than the ABAQUS rectangular pressure pulse strain profile. The difference in strain profiles between the different loading methods is due to the manner in which the pressure is distributed across the exposed surface of the test plate. The rectangular pressure pulse load is evenly spread across the surface, whilst the CONWEP pressures are applied in varied magnitudes along the radius of the exposed plate surface. Similar trends were noted throughout the full range of charge masses and both plate thicknesses. 


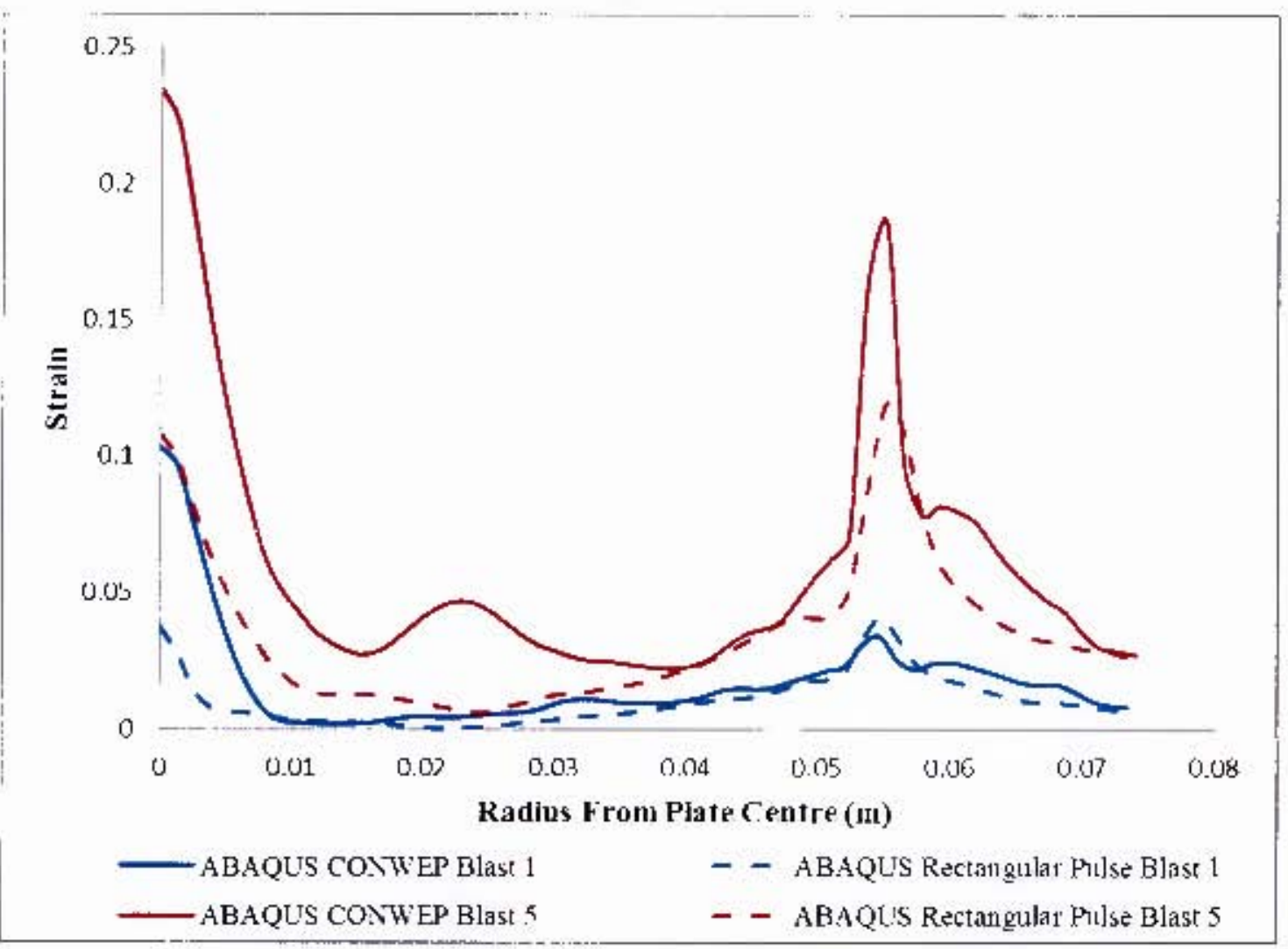

Figure 7.22: Grapls of strain comparisons between ABłOIS CONWF.P and A BaQCIS Redangular Pressure Pulse liading for charge mass $10 \mathrm{~g}$. blasts 1 and 5

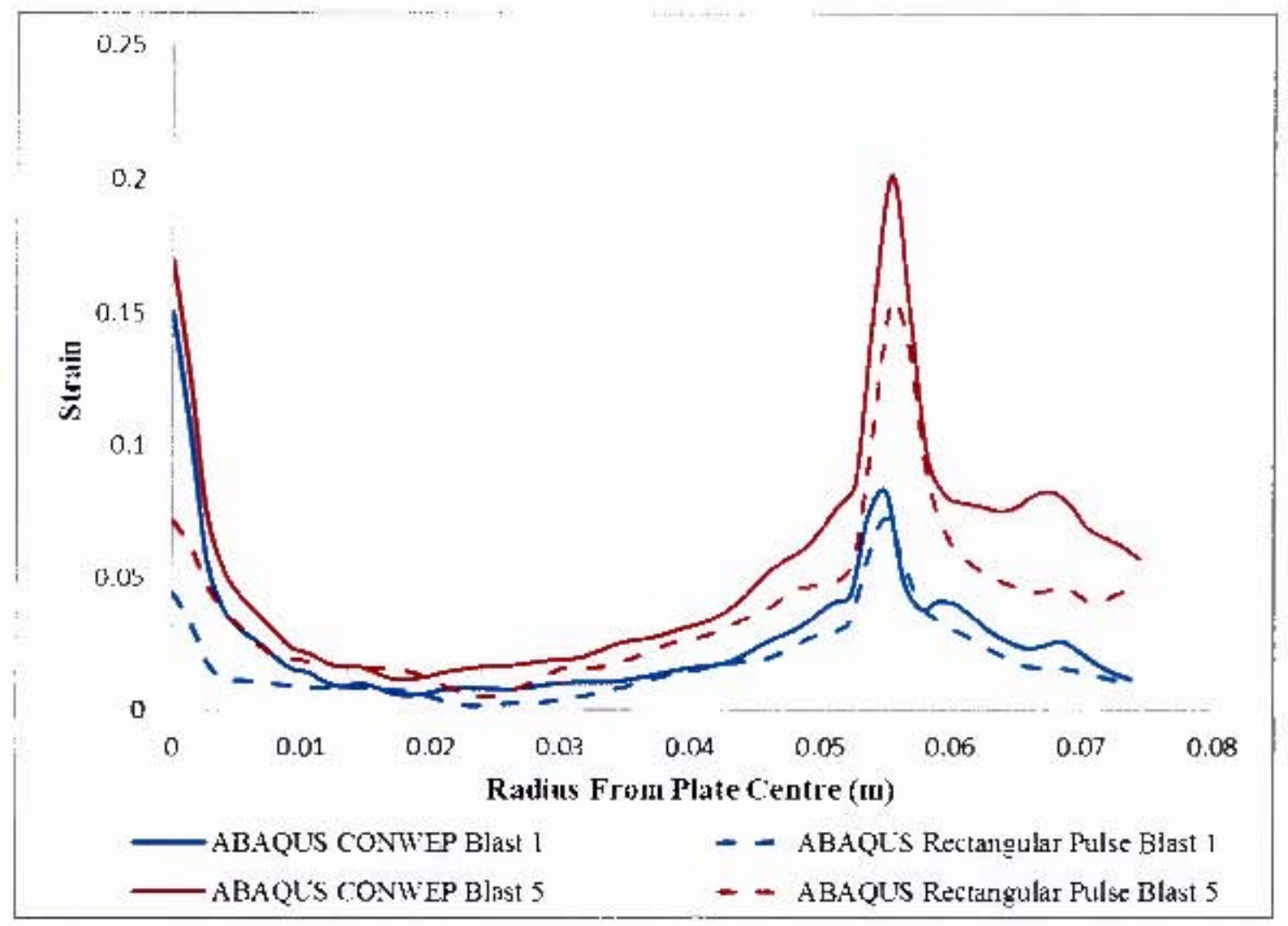

Figure 7.23: Giraph of strain comparisons between ABAQLS CONWEP and ABAQI S Rectangular Pressure Pulse loading for charge mass 15g. blasts I and 3 


\subsubsection{The Effect of Repeated Blast Luading on the Plastic Strain}

The Figure 7.24 and rigure 7.25 . show the equivalent plastic strais profiles for the test plates subjected to 5 blast loads with charge masses $5 \mathrm{~g}$ and $10 \mathrm{~g}$, respectively. The strain profiles were exteacted from the numerical simulations carried oal using the ABAQUS CONWEP loading technique.

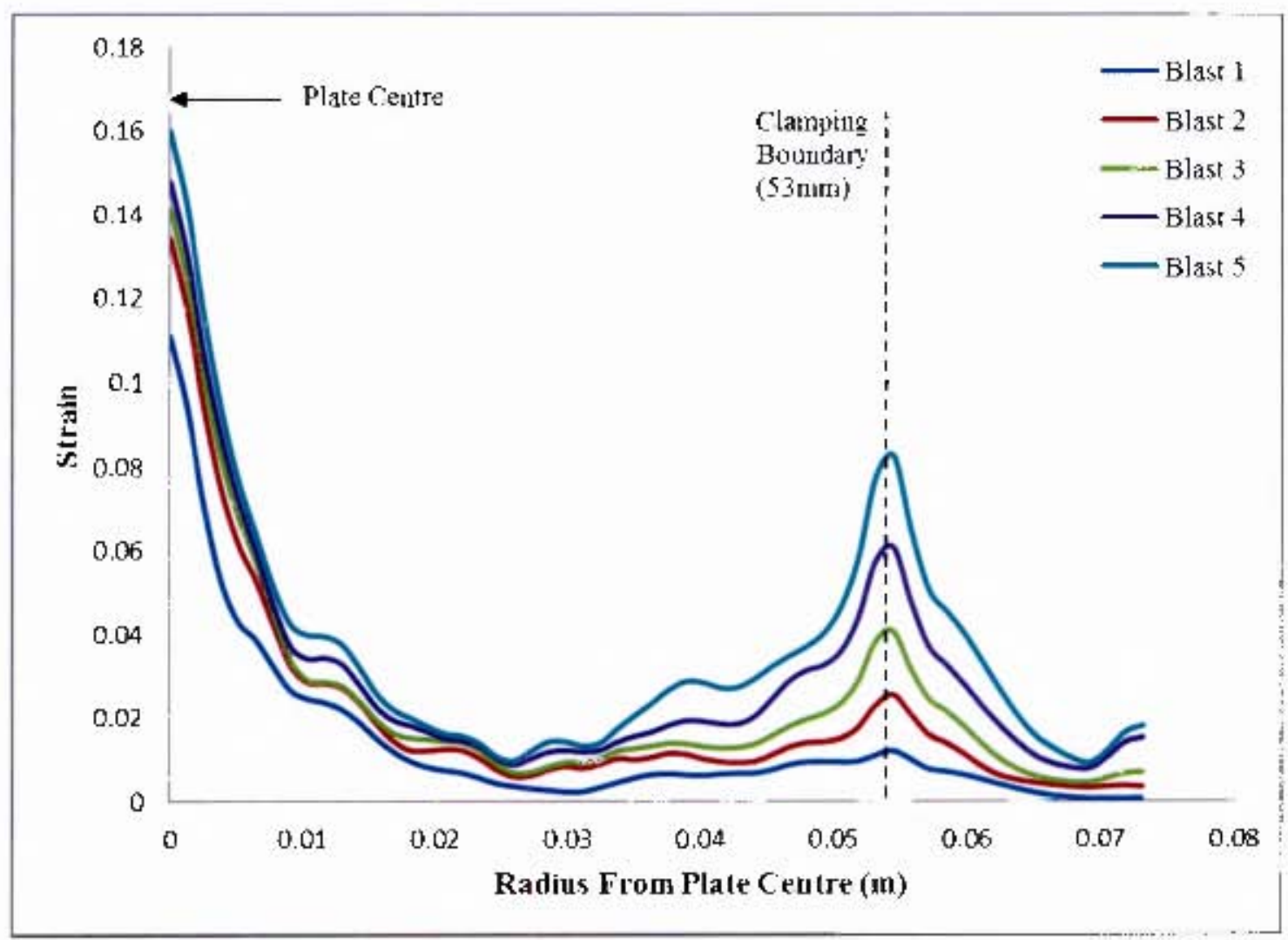

Figure 7.24: Ciraph of plastic strain profiles for 5 btast leads with sharge mass $5 g$ 


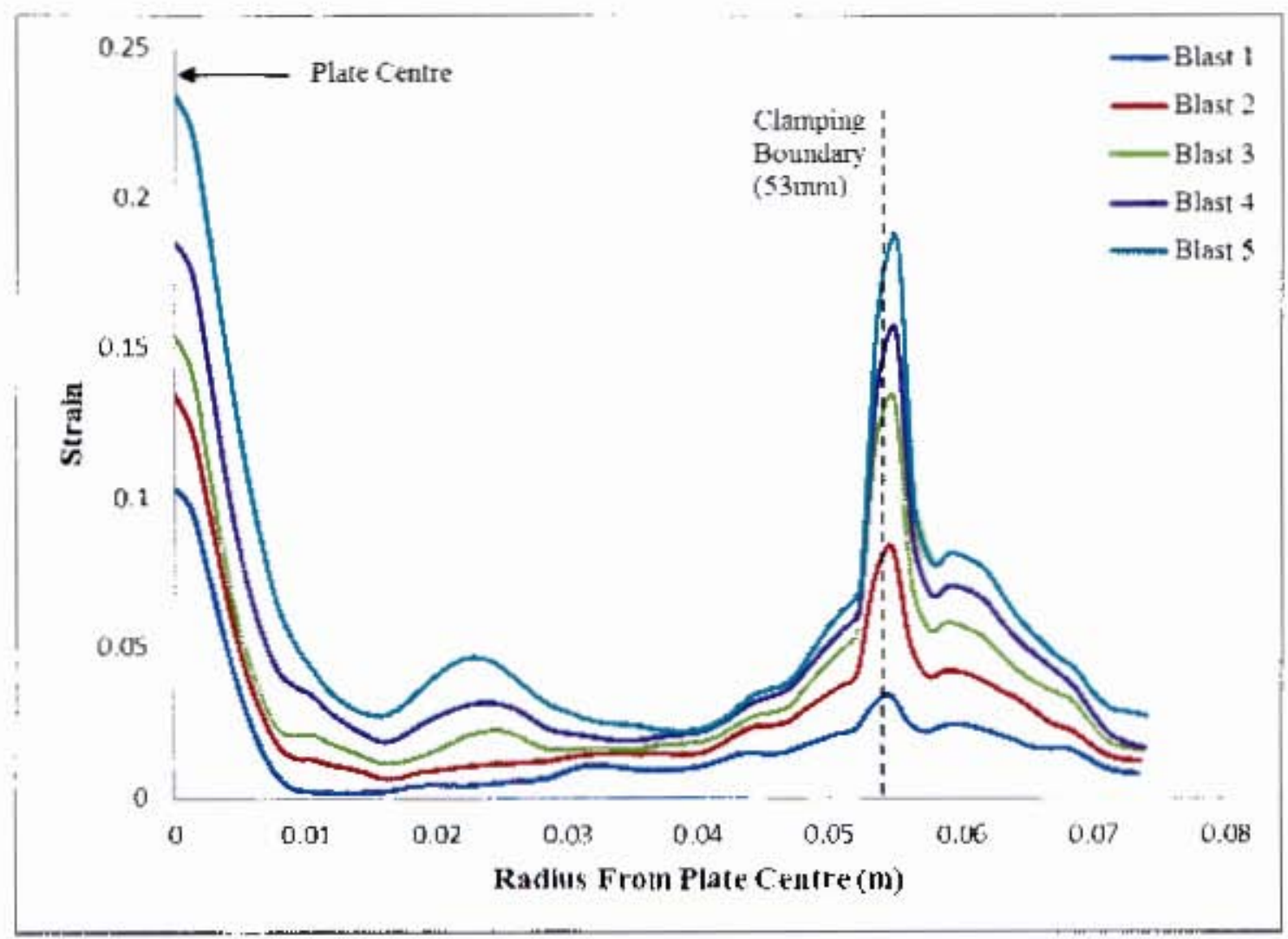

Figure 7.25: (iraph of plastie at rain profiles for 5 blast loads with charge mass $10 \mathrm{~g}$

It was observed in Figtre 7.24 and Figure 7.25 that the plastic strain increased along the plate prulile with inercasing nuruber of blist loads. The increase in plastic strain was more significant at the boundary than at the centre of the test plate, between blast 1 and blast 5 . The inerease in straiu correlated to the increase in hardncss, as determined in 5.7 from the Vichers hardness tests. The rate at which the strain increased for the claruped botndary region and plate centre is listed in lable 7.1 and illustrated in Figure 7.26 and Figure 7.27 for charge masses $5 \mathrm{~g}$ th $25 \mathrm{~g}$ and plate thickness $2 \mathrm{~mm}$. 
Table 7.1: Peak plastic strains for the plate centre and clamped boundary for charge masses 5g to 250 and plate thickness 2 mim

\begin{tabular}{|c|c|c|c|}
\hline \multirow[b]{2}{*}{$\begin{array}{c}\text { Charge } \\
\text { Vlass } \\
\text { (g) }\end{array}$} & \multirow[b]{2}{*}{$\begin{array}{c}\text { Total } \\
\text { number of } \\
\text { Blasts }\end{array}$} & \multicolumn{2}{|c|}{ Peak Strain $\left(\mathrm{s}^{-1}\right)$} \\
\hline & & $\begin{array}{l}\text { Plate } \\
\text { Centre }\end{array}$ & $\begin{array}{l}\text { Clamped } \\
\text { Boundary }\end{array}$ \\
\hline 5 & 1 & 0.111 & 0.012 \\
\hline 5 & 2 & 0.134 & 0.025 \\
\hline 5 & 3 & 0.141 & $0.041^{-}$ \\
\hline 5 & 4 & 0.148 & 0.061 \\
\hline 5 & 5 & 0.160 & 0.082 \\
\hline 10 & 1 & 0.103 & 0,034 \\
\hline 10 & 2 & 0.134 & 0.083 \\
\hline 10 & 3 & 0.153 & 0.134 \\
\hline 10 & 4 & 0.185 & 0.156 \\
\hline 10 & 5 & 0.234 & 0,186 \\
\hline 15 & 1 & 0.150 & 0.083 \\
\hline 15 & 2 & 0.164 & 0.156 \\
\hline 15 & 3 & 0.169 & 0.202 \\
\hline 20 & 1 & 0.059 & 0.137 \\
\hline 20 & 2 & 0.063 & 0.236 \\
\hline 25 & 1 & 0,072 & 0.195 \\
\hline
\end{tabular}

The graphs illustrated in Figure 7.26 and Figure 7.27 show increasing linear trends of the peak strairls at the certute of the plate and clamping houndary, as the rumber of blats increase. The linear trends indicated the increase in strain hardening experienced by the test plate as the number of blasts increase. 


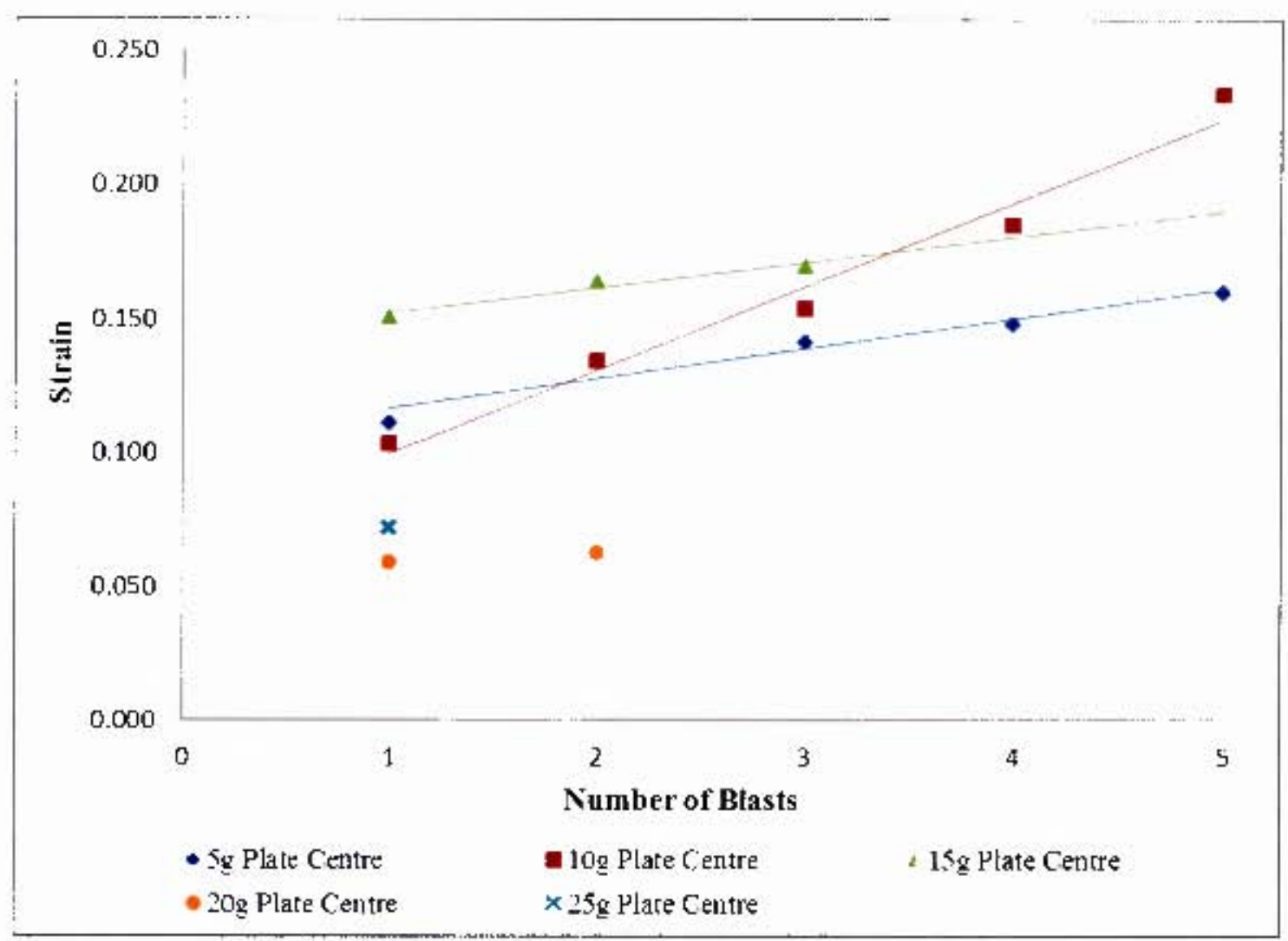

Figure 7.26: Graph of strain versus number of blasts for strains ficcurring at the cenire of the test plate for charge minses $591025 \mathrm{~g}$

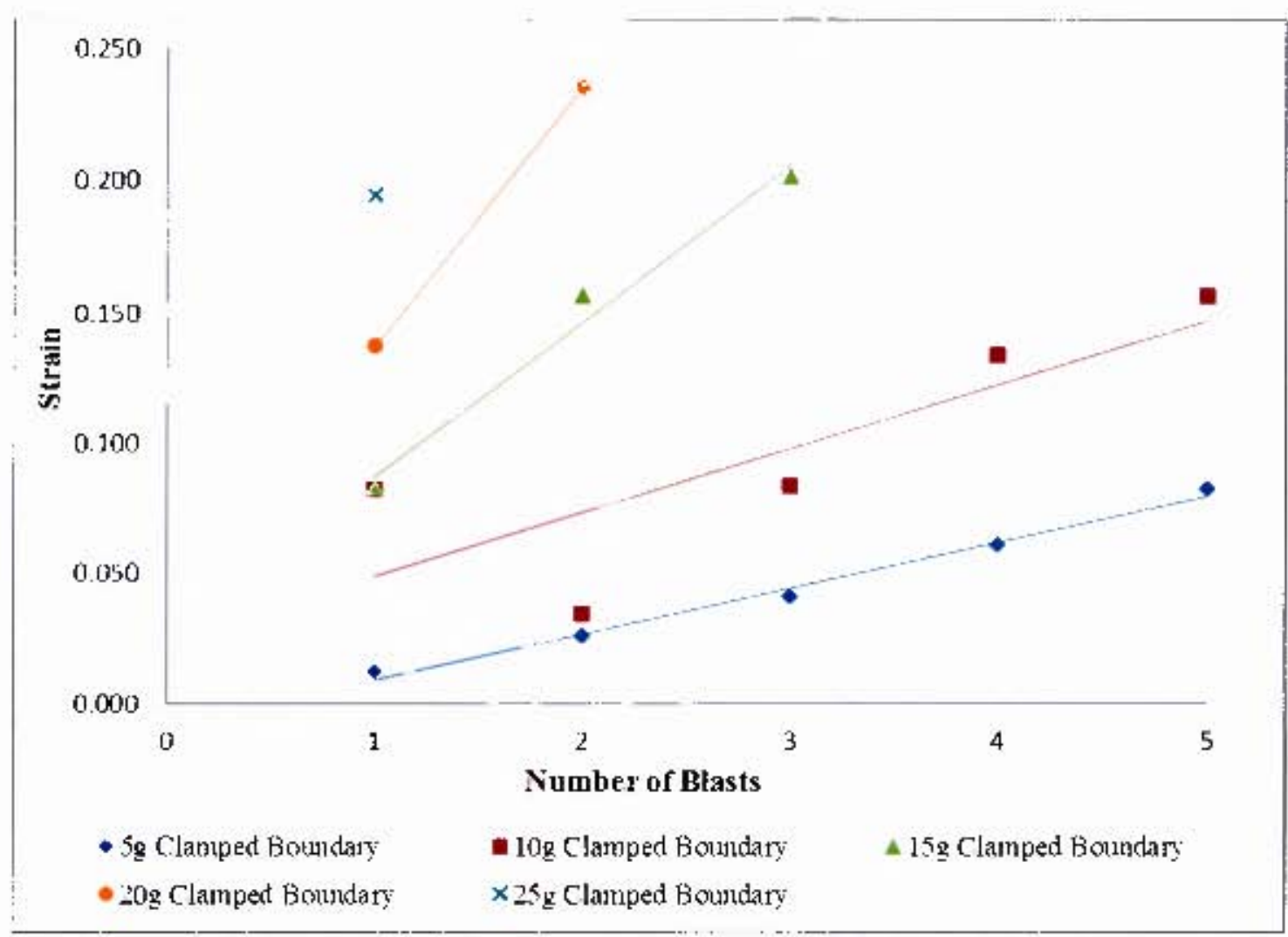

Figure 7.27 : firaph of strain versus $n$ umber of hasts for strains necurring at the clauped houndary of the test plate for tharge masses $5 \mathrm{~g}$ to $25 \mathrm{~g}$ 


\subsection{Dffect of Blast Loaded Residual Stress on P'late Deformation}

The eflices of the chatrece in material stress states on deformation of the test plates subjectiod to repeated blast loads was irvestigated. Comparisons were made between the progressive midpoint dethetions of two stparate simulations where different material conditions have bect specilied. In the first series of simulations, the material propertics of lbe specimen werc left unaltered afler eacli blast wat cycle allowing the matcrial to work harden after each detormation cycle, as in the experiments and presented in Section 5.7. In the second serics of simulations the matcrial properties of the specimen were reset to the original malcrial state prior to any blast loading, thus simulating the response of a "deformed" plate with the original material state.

The results from these series of simulations ats compatwal to investgate the material effect on the plat response to repeated blast load, using $\mathrm{ABAQCS} / \mathrm{l}$ xplicit and the rectangular pressure julsu blast loading parameters as described in Scetion 6.2.2.1.

Deformed plate meshes, shown in Figure 7.28. Were imported into the ABAQUS model as a now part, assigned with the original matsrial propertics before being subjected to the respective blast load by means of at uniform pressure distribution. The deformed plate was assigned the same boundary conditions and clamping conditions as the plates in the tirst series of simulations, to make a direct comparison between the effects of changing material properties as a result of the repeated blast lowding.

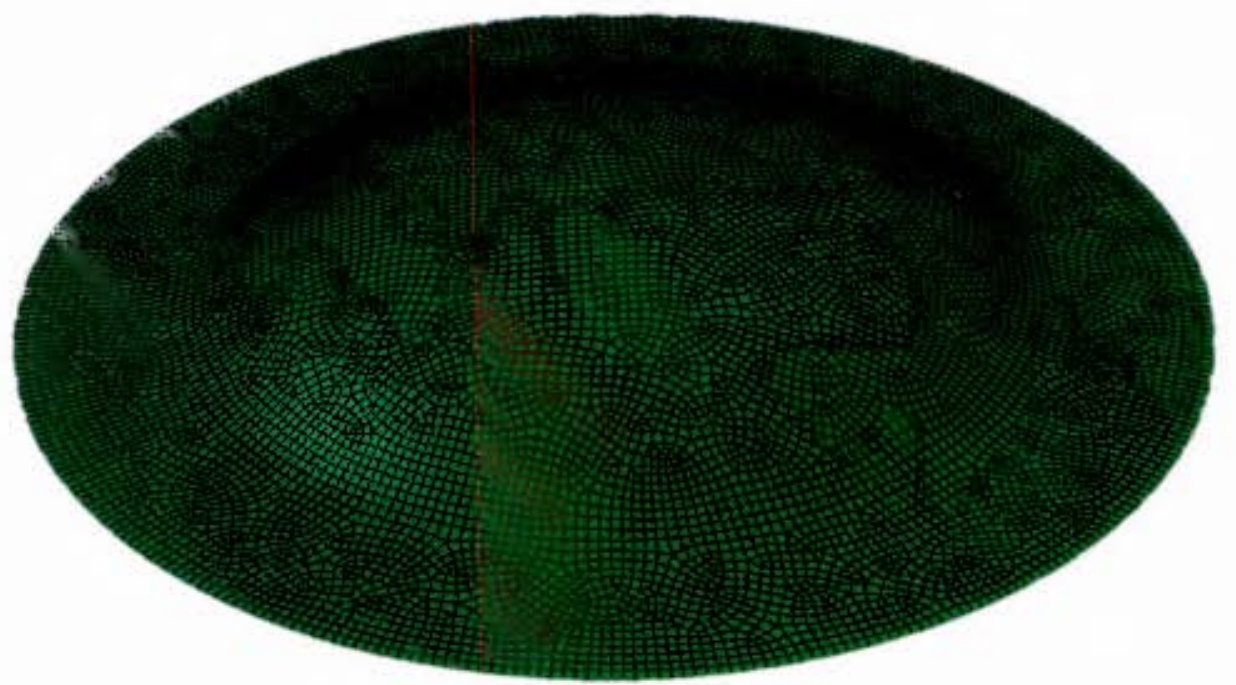

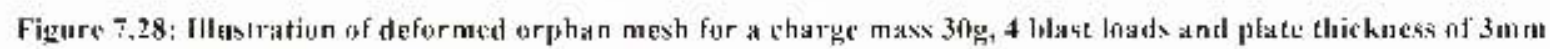


The results for the first series of simulations where the material properties were allowed to change with the repeated blast loads is referred to as the "blasted material properties" (BMP) and the second series of simulations where the material properties were reset to their original material conditions after each successive blast load, is referred to as the "non-blasted material properties" (NBMP). The results comparing the differences in the non-blasted (NBMP) and blasted (BMP) material properties are summarized in Table 7.2 and Table 7.3, showing the percent difference in progressive midpoint deflection, for plate thicknesses $2 \mathrm{~mm}$ and $3 \mathrm{~mm}$ respectively. 
Table 7.2: Results for blasted and non-blasted progressive deflections for numerical simulations carried out on 3 mm thick test plates

\begin{tabular}{|c|c|c|c|c|c|}
\hline \multirow[b]{2}{*}{$\begin{array}{l}\text { Charge } \\
\text { Mass } \\
\text { (g) }\end{array}$} & \multirow[b]{2}{*}{$\begin{array}{l}\text { Plazle } \\
\text { Thickness } \\
\text { (mni) }\end{array}$} & \multirow[b]{2}{*}{$\begin{array}{c}\text { Tolal } \\
\text { Number of } \\
\text { Blasts }\end{array}$} & \multicolumn{2}{|c|}{$\begin{array}{l}\text { ABAQLS Rectangular } \\
\text { Pressure Pulse I obad } \\
\text { Progressive Midpoint } \\
\text { Deflection }(\mathrm{mm})\end{array}$} & \multirow[b]{2}{*}{$\begin{array}{c}\text { Perecntage } \\
\text { Difference } \\
(\%)\end{array}$} \\
\hline & & & $\begin{array}{l}\text { Blasted } \\
\text { Material } \\
\text { Properties }\end{array}$ & $\begin{array}{c}\text { Non-blasted } \\
\text { Material } \\
\text { Propertics }\end{array}$ & \\
\hline 5 & 3 & 2 & 0.73 & 3.84 & 175 \\
\hline 5 & 3 & 3 & 0.24 & 2.64 & 135 \\
\hline 5 & 3 & 4 & 0.33 & 2.45 & 119 \\
\hline 5 & $?$ & 5 & 0.07 & 1.86 & 101 \\
\hline 10 & 3 & 2 & 0.42 & 3.01 & 146 \\
\hline 10 & 3 & 3 & 0.39 & 2.72 & 131 \\
\hline 10 & 3 & 4 & 1.22 & 1.64 & 24 \\
\hline 10 & 3 & 5 & 0.41 & 0.73 & 18 \\
\hline 15 & 3 & 2 & 1.46 & 1.78 & 18 \\
\hline 15 & 3 & 3 & 0.65 & 1.92 & 71 \\
\hline 15 & 3 & 4 & 0.9 & 1.09 & 11 \\
\hline 15 & 3 & 5 & 0.48 & 1.15 & 38 \\
\hline 20 & 3 & 2 & 1.81 & 2.47 & 37 \\
\hline 20 & 3 & 3 & 0.85 & 1.11 & 15 \\
\hline 20 & 3 & 4 & 0.18 & 1.73 & 87 \\
\hline 20 & 3 & 5 & 1.63 & 0.98 & -37 \\
\hline 25 & 3 & 2 & 2.24 & 2.88 & 36 \\
\hline 25 & 3 & 3 & 1.56 & 2.9 & 75 \\
\hline 25 & 3 & 4 & 0.93 & 1.79 & 48 \\
\hline 25 & 3 & 5 & 0.73 & 1.64 & 51 \\
\hline 30 & 3 & 2 & 2.56 & 3.51 & 27 \\
\hline 30 & 3 & 3 & 1.56 & 2.21 & 29 \\
\hline 30) & 3 & 4 & 0.93 & 1.46 & 36 \\
\hline 30 & 3 & 5 & 0.73 & 1.11 & 34 \\
\hline 35 & 3 & 2 & 2.97 & 3.8 & 47 \\
\hline 35 & 3 & 3 & 1.08 & 1.46 & 21 \\
\hline 35 & 3 & 4 & 0.92 & 1.53 & 34 \\
\hline 35 & 3 & 5 & 1.08 & 1.14 & 3 \\
\hline 40 & 3 & 2 & 2.85 & 4.37 & 85 \\
\hline 40 & 3 & 3 & 1.65 & 2.41 & 43 \\
\hline
\end{tabular}


Table T.3: Results for Hasted and nom--3hasted progressive deflections for numerical simulations carrit:1 ।nut an 3 mum thick test plates

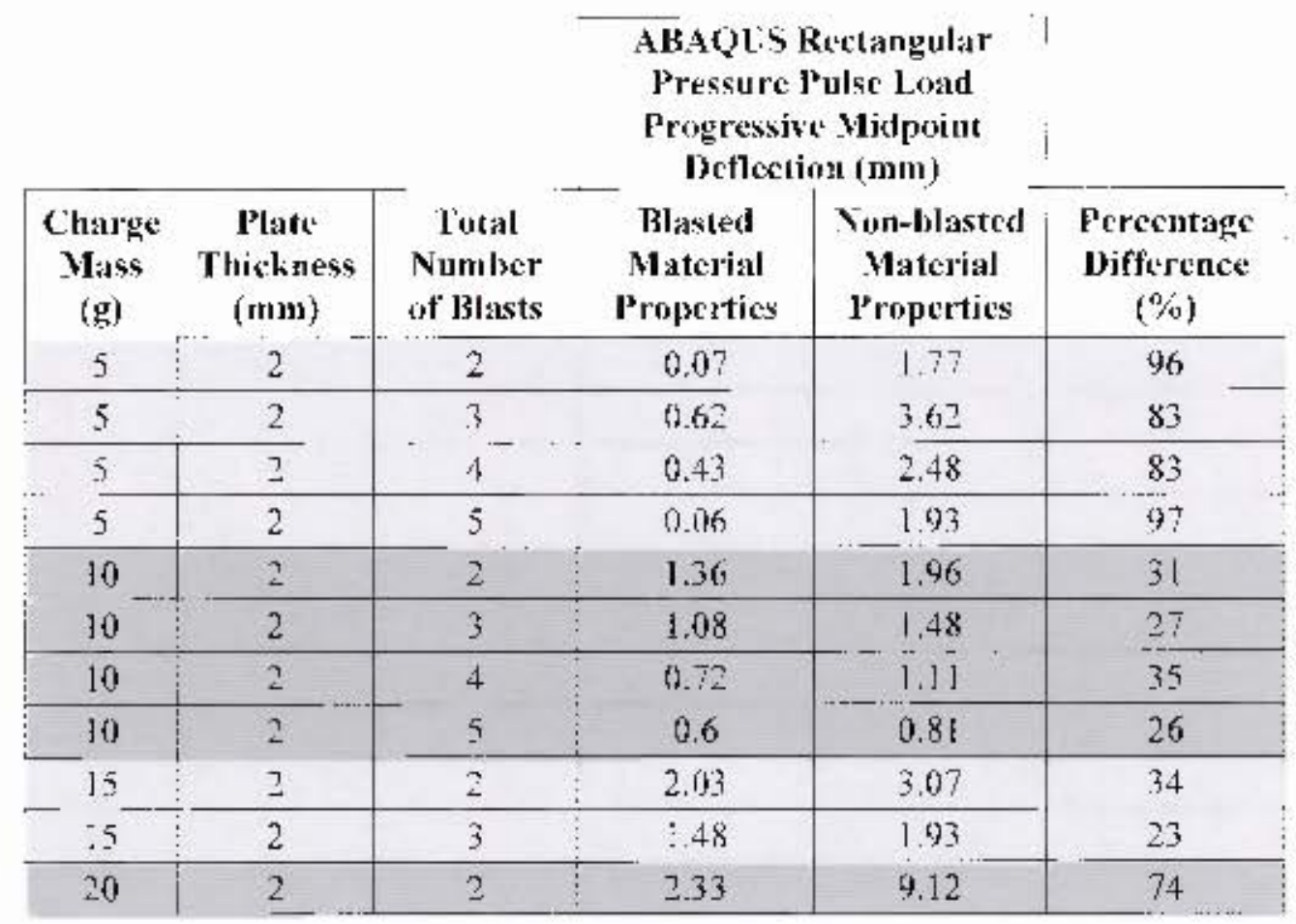

The results consistently showed that the progreszive midpoint deflections for the simalations of nonblasted material properties (X/3 MJ3) were greater than thost of the blasled material properties (13.jP). for example, a 3 mm thick test plate subjected to 2 blast loads of charye mass 15 gt rtsulted ill a progrtssive midpoint det]ection (difference in midpoint du[lection bet ween 2 blasts and a single blast)

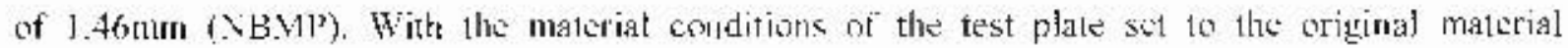
conditions aftur a single blas leat, the progressive midpoint dellection was $1.78 \mathrm{~mm}$ or $18 \%$ griatior (BMP). This slowed that the test plate underwent a considerable amount of strain hardening when subjected to rupcatud blast laads, changing the stress state of the material.

Thers were variations in the percentage difterence in progressive midpoint detlections between NBMP and BMP simulations. These ean be accounted for by the repuatability of the txperimental results, where the difference's ill progressive delleetions were often less than ons platis lhickness.

Figure 7.29 shows the comparisons of test plate defomations betwetn BMP and VBMP simulations; for charge mass of $5 \mathrm{~g}$ with plates subjected to $1 /$ blast loads, charge mass 15 gr with 5 blast loads and charage mass $35 \mathrm{~g}$ with 3 blasi lowads.

This was conclusibe ceidence that the residual stresses present in the lest plates as a result of the impulsive repeated blast loading, inhibited the deformation of the test plates. 


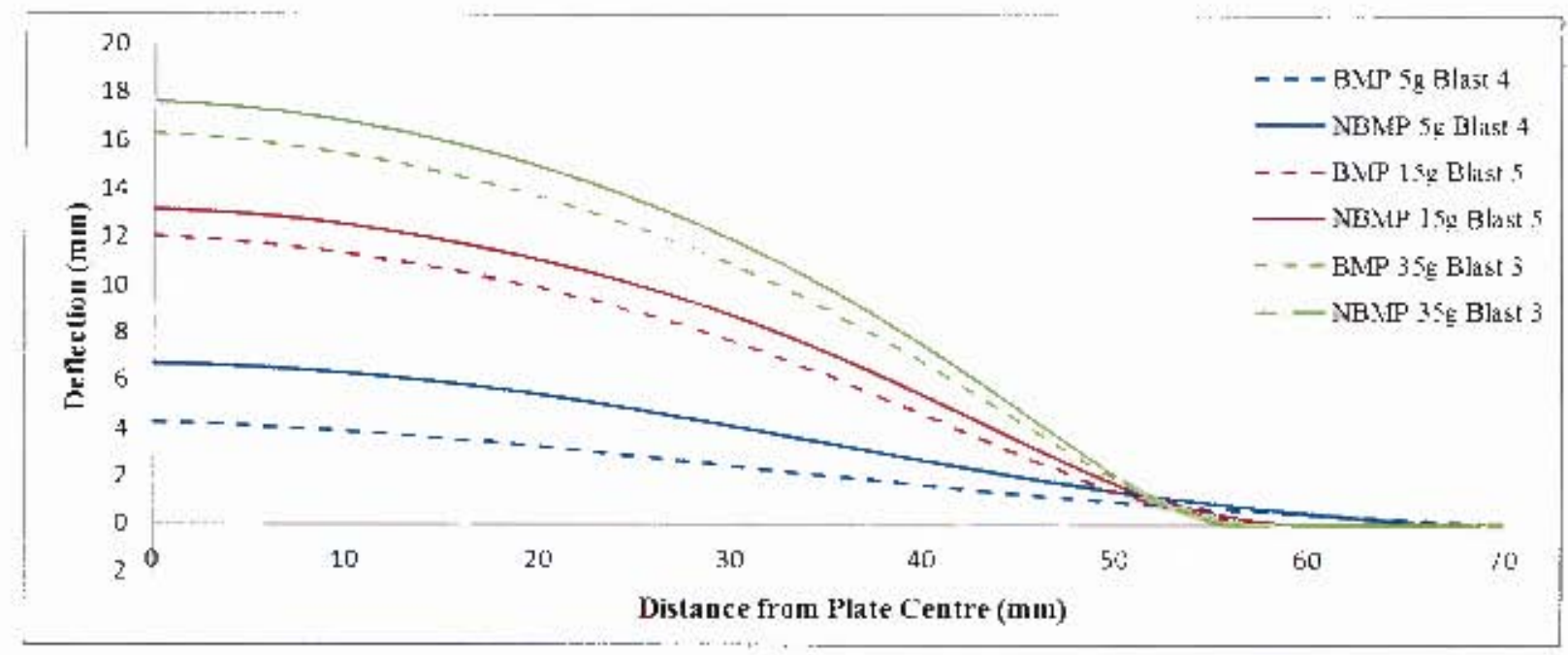

Figure 7.29: Graph of plate deflectiort, comparing BMIP artal VRMP simulations for charge masses $5 \mathrm{~g}$. 15 gig and $35 \mathrm{~g}$ for various repeated blast loads

Residual stresses necurred in the test plates as a result of plastic (intelastic) defommation from explosive blas lodding. Localised yielding occumed where the test plate experienced the most plastic strain. Once the plate had heen impulsively loaded, elastic "spring batck" ociurted which produced both tersile and compressive residua] stresses in the test plate [1051. The residual stresses strengthened the Domex ateel test plates' rustiventess lo delormution. An txample in industry where it is desired to iuttroduce residual stresses is shot peening. Shot peenimg is the process of mechanically hardening the surtace layer of the stect. 10 improve fatigue strerngth and resistatce to craching. The residual stresses's present in the post blasted test plates could be related to the same areas that experience extensive strain hardening trom repeated blast lnads, as both residual stress and straitt hardeming occuned where the test plate material underwent plastic deformation.

The combination of residual stritugth athl work harderimg bastud the lest plates progressive midpoint defichion to be less thatr if there were no residual stresses or stratu hardenimg effects on the test plate. As discussed in Section 7.5.3 and shown in Figure 7.24. the peak plastic strain. at the plate boundaries and central region, increased with an increase in the number of blast 'oads. If the residual stresses correspond to the behaviour of the plastic strain, then it conld be suggested that the residual stresses had a greater effect on the progressive midpoint detlection as the number of blasis increased. It can be cottcluded that the change it material properties (strain hardenitg and residual stresces) have a greater effect ot the progressive plate deformation than the shape of the test plate, itt these experiments. 


\subsection{Numerical Methods Overview}

A concise discussion on the advantages and disadvantages of using the various numerical loading techniques, namely: AUTODYN, ABAQUS rectangular pressure pulse loading and ABAQUS CONWEP loading, for simulating repeated blast loading on circular steel plates is presented in this section. Various aspects of simulating repeated blast loading of steel structures are better suited to a specific numerical technique, depending on the application and desired outcome.

\subsubsection{Blast Loading and Repeated Blast Loading}

AUTODYN has various explosive materials readily available in its material library, allowing for the simulation of the detonation of an explosive, making it possible to analyse the behaviour of the resultant blast wave travelling toward the target. This is more important in cases where explosive experiments are carried out in semi-vented or fully confined loading conditions, as shock wave reflections off the boundary walls are important in gauging the extent of the resultant loading of the test plate. In contrast, there is no detonation model available in ABAQUS, despite having Eulerian air-mesh capabilities. Therefore, if the nature of the explosive is unknown or the resultant impulse that the test specimen is subjected to is unknown, specifying a load in ABAQUS is difficult to do.

With regards to specifying repeated blast loads on the test plate, all three numerical techniques are compared. The method used in this report to specify repeated blast loads in AUTODYN is relatively difficult and is computationally expensive to implement, due to the long run times. Once an initial detonation has commenced and the plate deforms under the specified blast load, it experiences transient oscillations that propagate for over $10 \mathrm{~ms}$. This can result in numerically very expensive simulations. Simulations with a fine air mesh take a great deal of time to run. Turning the air mesh off saves time. Nevertheless, the total runtime of the simulations are still far greater than the ABAQUS equivalents. In AUTODYN, there is no natural numerical damper, resulting in the oscillations not subsiding. A numerical damping co-efficient has to be assigned, based on a series of initial runs, which can be time consuming. Specifying repeated blast loads for the ABAQUS rectangular pressure pulse loading is relatively easy compared to AUTODYN. The test plate can be loaded with multiple load steps in the form of a rectangular pressure pulse or multiple CONWEP loads can be initiated at specific times. ABAQUS has a natural numerical damper specified in the code that allows the plate oscillations to subside enough for the next repeated blast load to be specified, without affecting the final results. 
CONWEP is an empirical relationship that was developed from experiments carried out in free air conditions with spherical charge masses. In this project, disk shaped explosives were detonated in semi-vented conditions. Therefore a scaling factor is required when loading the simulated plates (chosen as 4.7). This requires extra run time in calibrating the scaling factor to match the known experimental impulse from the corresponding experiments.

The ABAQUS rectangular pressure pulse loading technique was the easiest to implement and the most efficient to use in the application pertaining to this project. However on a larger scale (larger target structure), in free air conditions, CONWEP would be the easiest to implement providing adequate results. If the behaviour of the explosive detonation is required or the resultant blast load imparted to the target structure is unknown, then AUTODYN is the best method to use.

With regards to setting up a numerical model the ABAQUS interface is easier to use than the AUTODYN interface. The ABAQUS interface provides the set-up as a 'step by step' process. Also, the ABAQUS input deck code can be easily manipulated to change any aspect of the model. In AUTODYN, one has to start from the initial step. 


\subsubsection{Numerical Results and Analysis}

The numerical repeated loading techniques showed good correlation with the experimental results. The deformation profiles presented in Section 7.4 highlight the relatively small differences in deformation profiles between each numerical loading technique. AUTODYN and the ABAQUS loading techniques are equally good to obtain the structural deformation response of the target structure, but further simulations on structures with greater complexity should be analysed to confirm this statement.

For the application of repeated blast loading of a simple steel structure, the ABAQUS CONWEP loading technique proved to be the best, as the numerical results showed good correlation to the experimental results and the set up and run time of the ABAQUS CONWEP model is computationally inexpensive when compared to AUTODYN.

Obtaining stress and strain components, as presented in Sections 7.4 and 7.6, is easier to carry out in ABAQUS than in AUTODYN. To record the desired stress-strain data separate gauges were needed to be placed within the simulated test plate. The data from the AUTODYN trial runs showed inconclusive results. ABAQUS however, proved to be very useful in obtaining the desired stressstrain data. Sets and paths are created along the profile of the test plate, or any feature on the test plate, defining the specific elements where the necessary data is to be recorded. The user needs to define these features and the desired outputs before the model is run.

Depending on the application and desired output of the simulation, the different loading techniques are better suited in some areas. AUTODYN has good pressure distribution measurement capabilities. This allows for the analysis of the behaviour of the blast waves, including complex geometries with unexpected reflections, to be accurately undertaken. ABAQUS however does not have that capability. Therefore if the resultant pressure distribution is unknown, then loading the target can only be approximated through literary theory. For an efficient and quick simulation, that is reliable and well tested, the ABAQUS CONWEP loading technique provides good results. ABAQUS in general, is more suited to material deformation behaviour and the analysis of post blasted internal material properties. 


\section{Conclusions}

This report investigated the response of circular plates to uniform repeated blast loads. The study was conducted by the experimental investigation of subjecting the plates to repeated blast loads, whilst varying the charge mass and target plate thickness, but maintaining a constant stand-off distance, the outcomes of subjecting a plate to repeated blasts. Numerical models developed in both ANSYS AUTODYN and ABAQUS were validated against the experimental results providing further understanding into the transient response and the fluctuating material properties of the plate subjected to repeated blast loads. Based on the results of this thesis the following conclusions are drawn.

\section{Effect of Repeated Blast Loading on Impulse}

Impulse measured by the ballistic pendulum increased linearly with an increase in charge mass for all repeated blast series on both $3 \mathrm{~mm}$ and $2 \mathrm{~mm}$ thick test plates. Repeated blast loading had an insignificant effect on the resultant impulse imparted to the test plates with negligible variation in impulse for a single blast up to 5 blasts.

\section{Effect of Repeated Blast loading on Midpoint Deflection}

Midpoint deflection of the test plates for all experiments increased linearly with an increase in resultant impulse (increase in charge mass) for all repeated blast series. Midpoint deflection increased in a power trend per blast load, for a single blast up to 5 blasts, for all charge masses. The progressive midpoint deflection between each blast load decreased in a power trend, with the maximum progressive deflection occurring for a single blast load and the minimum for 5 blasts.

Equivalent midpoint deflections exist between blast experiments of varying charge mass and the number of blasts. Test plates subjected to lower charge masses and a higher number of blast loads have similar midpoint deflections to plates subjected to higher charge masses and less blasts. 


\section{Effect of Repeated Blast Loading on Analytical Predictions}

Test plates subjected to a single blast load showed good correlation to Nurick and Martin's modified dimensionless impulse $\phi_{c s}$ relation. The experimental results showed an increase in deviation from the dimensionless impulse as the number of blast loads increased, indicating the necessity for a dimensionless impulse factor to be introduced into the relation, accounting for repeated blast loading conditions. A similar conclusion can be made for the modified Jones number relation. Good correlation between the experimental results and the modified Jones number was noted for plates subjected to a single blast load, but increased deviation to the relation occurred as the number of blasts increased.

\section{Effect of Repeated Blast Loading on Strain Hardening}

Hardness test results showed a significant increase in strain hardening at the clamped boundary and central region of the test plate. The hardness of the test plates generally increased for an increase in charge mass. The hardness linearly increased with an increase in blast loads at the clamped boundary region.

\section{Correlation between Numerical and Experimental Results}

The numerical modelling of the test plates subjected to repeated blast loads using AUTODYN and ABAQUS showed good correlation between numerical and experimental impulse, midpoint deflection, deformation profiles and strain hardening.

The majority of numerical estimates of impulse were within $\pm 10 \%$ of the experimental results, for all charge masses, repeated blast series and numerical modelling techniques. Increased deviation between the experimental and numerical impulse results occurred for greater charge masses. The numerical impulse results mostly overestimated the experimental results, as the ideal numerical models use empirical relationships and do not take into account effective mass of the explosive.

The numerical test plate midpoint deflections showed very good correlation with the experimental midpoint deflections, for both plate thicknesses, all charge masses and all repeated blast series. All but two numerical simulations of the entire range of experiments correlated to the experimental midpoint deflections within a plate thickness confidence factor. The ABAQUS CONWEP loading results displayed the most consistent correlation to the experimental results.

The numerical deformation profiles showed good correlation to the experimental profiles, for charge masses $15 \mathrm{~g}$ to $30 \mathrm{~g}$ and all repeated blast loads. Differences in deformation profiles occurred for charge masses $5 \mathrm{~g}$ and $10 \mathrm{~g}$ where the test plates underwent predominantly elastic deformation and for charge masses $35 \mathrm{~g}$ and $40 \mathrm{~g}$, where thinning at the clamped boundary was present. 


\section{Effect of Repeated Blast Loading on Numerical Plastic Strain}

There is a significant increase in numerical plastic strain at the central and clamped boundary regions of the simulated test plates. The peak plastic strain at the centre and clamped boundary increases linearly with an increase in blast loads. The numerical plastic strain graph showed similar trends to the Vickers Hardness graph, indicating good correlation between numerical plastic strain and experimental strain hardening in the test plates.

\section{Effect of Repeated Blast Loading on Residual Stress}

Two separate series of simulations were carried out to quantify the effects of the post blast loaded material property changes in the test plate on the midpoint deflections. The residual stresses present in the test plate due to blast loading inhibited the midpoint deflection of the test plate. The simulations with material properties reset to original conditions showed a greater midpoint deflection than simulations with material properties affected by residual stress states. This indicated that the change in material properties as a result of repeated blast loading has a greater effect on the plate deformation than the change in deformation shape of the test plate. 


\section{Recommendations}

As a result of the findings and conclusions of this report, the following recommendations are made:

- Tests should be extended to include test plates with an increase number of repeated blasts to investigate progressive deflections and material hardness trends up to tearing of the plate.

- The geometry of the test plate should be extended to include curved (deformed) profile to investigate the influence of the stiffness effects due to a change in shape of the test plates and compare to the work hardening effects of the blasted plates.

- The transient effects of the test plate should be carried out in ABAQUS with various loading time integrals to investigate the impulsive loading theory.

- Micro material analysis should be carried out to better understand the effects of repeated blast loading on the change in material conditions (work hardness and residual stress states) and the effects on the deformation response of the plates. The results of the micro analysis test should be extended to correlate effects of strain rate along the profile of the plates with micro hardness and grain size effects.

- The finite element simulation should be extended to include a material failure model to simulate tearing of the plate and gain insights into the extent of work hardening before failure. 


\section{References}

[1] Landmine \& Cluster Munition Monitor. Victim-activated IED Casualties. Ottawa: International Campaign to Ban Landmines - Cluster Munition Coalition; 2011. Available from: www.the-monitor.org.

[2] Jones N. Structural Impact. United Kingdom: Cambridge University Press; 1989.

[3] Nurick GN, Martin JB. Deformation of Thin Plates Subjected to Impulsive Loading - A Review: Part II Experimental Studies. International Journal of Impact Engineering. 1989;8(2):171-186.

[4] Rajendran R, Lee JM. Blast Loaded Plates. Marine Structures. 2009;22(1):99-127.

[5] Teeling-Smith RG, Nurick GN. The deformation and tearing of thin circular plates subjected to impulsive loads. International Journal of Impact Engineering. 1991;11(1):77-91.

[6] Olson MD, Fagnan JR, Nurick GN. Deformation and rupture of blast loaded square platespredictions and experiments. International Journal of Impact Engineering. 1993;13(2):279291.

[7] Thomas BM, Nurick GN. The effect of boundary conditions on thin plates subjected to impulsive loads. In: The 5th International Symposium on Plasticity and its current application; 1995; Osaka, Japan.

[8] Nurick GN, Gelman NE, Marshall NS. Tearing of blast loaded plates with clamped boundary conditions. International Journal of Impact Engineering. 1996;18(7-8):803-827.

[9] Nurick GN, Radford AM. Circular plates subjected to localised central blast loads. Transient Loading and Response of Structures. 1998;3(2):503-548.

[10] Pickering EG, Chung Kim Yuen S, Nurick GN, Haw P. The response of quadrangular plates to buried charges. International Journal of Impact Engineering. 2011;49(1):103-114.

[11] Langdon GS, Nurick GN, Pickering EG, Balden VH. Response of V-shape plates to localised blast load: Experiments and numerical simulation. International Journal of Impact Engineering. 2012;46(1):97-109. 
[12] Gharababaei H, Darvizeh A, Darvizeh M. Analytical and experimental studies for deformation of circular plates subjected to blast loading. Journal of Mechanical Science and Technology. 2010;24(9):1855-1864.

[13] Kazemahvazi S, Radford D, Deshpande V, Fleck N. Dynamic Failure of clamped circular plates subjected to an underwater shock. Journal of Mechanics of Materials and Structures. 2007;2(10):1-18.

[14] Bonorchis D, Nurick GN. Analysis and Simulation of welded plates subjected to blast loading. International Journal of Impact Engineering. 2009;37(1):260-273.

[15] Langdon GS, Rossiter IB, Balden VH, Nurick GN. Performance of mild steel perforated plates as a blast wave mitigation technique: experimental and numerical investigation. International Journal of Impact Engineering. 2010;37(1):1021-1036.

[16] Lemanski SL, Nurick GN, Langdon GS, Simmons MS, Cantwell WJ. Understanding the behaviour of fibre metal laminates subjected to localisedblastloading. Composite Structures. 2006;76(1-2):82-87.

[17] Hanssen AG, Enstock L, Langseth M. Close-range blast loading of aluminium foam panels. International Journal of Impact Engineering. 2002;27(6):593-618.

[18] Razaqpur GA, Tolba A, Contestabile E. Blast loading response of reinforced concrete panels reinforced. Ontario, Canada: Canadian Explosives Research Laboratory; 2006.

[19] Langseth M, Berstad T, Hopperstad OS, Clausen AH. Energy absorption in axially loaded square thin walled aluminium extrusions. Structures Under Shock Impact III (SUSI III). 1994;3(1):401-410.

[20] Langseth M, Hopperstad OS, Berstad T. Crashworthiness of aluminium extrusion: Validation of numerical simulation, effect of mass ratio and impact velocity. International Journal of Impact Engineering. 1999;22(9):829-854.

[21] Otubushin A. A detailed validation of non-linear finite element code using dynamic axial crushing of a square tube. International Journal of Impact Engineering. 1998;21(5):349-368.

[22] Marsolek J, Reimerdes HG. Energy absorption of metallic cylindrical shells with induced non-axisymmetrical folding patters. 8th International Symposium on Plasticity and Impact Mechanics. 2003 454-464. 
[23] Abah L, Limam A, Dejeammes M. Effects of cutouts on static and dynamic behaviour of square aluminium extrusions. 5th International Conference on Structures Under Shock and Impact. 1998 133-142.

[24] Markiewicz E, Ducrocq P, Drazetic P. An inverse approach to determine the constitutive model parameters from axial crushing of thin walled square tubes. International Journal of Impact Engineering. 1998;21(6):433-449.

[25] Miyazaki M, Endo H, Negishi H. Dynamic axial plastic buckling of square tube. Journal of Materials Processing Technology. 1999;85(1):213-216.

[26] Nannucci PR, Marshall NS, Nurick GN. A computational investigation of the progressive buckling of square tubes with geometric imperfections. 3rd Asia Pacific conference on Shock and Impact Loads on structures. 1999 335-342.

[27] Karagiozova D. Velocity and mass sensitivity of circular and square tubes under axial impact. Proceedings of the Eighth International Symposium on Plasticity and Impact Mechanics. 2003 403-410.

[28] Karagiozova D. Dynamic buckling of elastic plastic square tubes under axial impact-I: stress wave propagation phenomenon. International Journal of Impact Engineering. 2004;30(2):143166.

[29] Ambrosini D, Luccioni B, Nurick GN, Langdon GS, Jacob N. The effect of confinement and stand-off distance in blast tests. Mechanica Computational. 2009;28:343-362.

[30] Fairlie G, Bergeron D. Numerical Simulation of Mine Blast Loading on Structures: Report. Report. Las Vegas 2002.

[31] Luccioni BM, Luege M. Concrete pavement slab under blast loads. International Journal of Impact Engineering. 2006;32(1):1248-1266.

[32] Cabello B. Dynamic Stress Analysis of the effect of an air blast wave on a stainless steel plate. Hartford, Connecticut: Rensselaer Polytechnic Institute; 2011.

[33] Huntington-Thresher WK, Cullis IG. TNT blast scaling for small charges. In: 19th International Symposium of Ballistics; 2001; Interlaken, Switzerland.

[34] Kingery CN, Bulmash G. Airblast parameters from TNT spherical air burst and hemispherical surface burst. Maryland: US Army Armament Research and Development Centre, Ballistics Research Lab; 1984. 
[35] Tabatabaei ZS, Volz JS. A comparison between three different blast methods in LS-DYNA: LBE, MM-ALE, Coupling of LBE and MM-ALE. In: 12th International LS-DYNA Users Conference; 2011.

[36] Nurick GN, Chung Kim Yuen S. Deformation and tearing of uniformly blast-loaded quadrangular stiffened plates. In: International Conference on Structural Engineering, Mech. and Comp.; 2001; Cape Town, South Africa.

[37] Kinney KF. Explosive Shocks in Air. New York: The Macmillan Company; 1962.

[38] Akhavan J. The Chemstry of explosives. United Kingdom: Royal society of Chemistry Paperbacks; 2004.

[39] Baker WE, Cox PA, Westine PS, Kulesz JJ, Strehlow RA. Explosive Hazards and Evaluation. Elsevier Scientific Publishing Company; 1983.

[40] Davis WC. Explosive Effects and Applications. In: Introduction to Explosives. New York: J.A. and Walters Zuka; 203.

[41] Nurick GN. The prediction of the deformation response of a structure subjected to an explosive load using a light interference technique. In: Proceedings of the SEM Soring Conference on Experimental Mechanics; 1986.

[42] Jacinto AC, Ambrosini RD, Danesi RF. Experimental and computational analysis of plates under air blastloading. International Journal of Impact Engineering. 2001;25(10):927-947.

[43] Guruprasad S, Mukherjee A. Layered sacrificial claddings under blastloading Part I analytical studies. International Journal of Impact Engineering. 2000;24(9):957-973.

[44] Balden VH, Nurick GN. Numerical simulation of the post failure motion of steel plates subjected to blast loading. International Journal of Impact Engineering. 2005;32(1):14-34.

[45] Lu Y, Wang Z, Chong K. A comparative study of buried structure in soil subjected to blast load using 2D and 3D numerical simulations. Soil Dynamics and Earthquake Engineering. 2005;25(4):275-288.

[46] Houlston R, Slater JE. On analysis of structural response of ship panels subjected to air blast loading. Computers \& Structures. 1985;21(1-2):273-289.

[47] Smith PD, Hetherington JG. Blast and Ballistic Loading of Structure. Oxford: ButterworthHeinemann; 1994.

[48] Gregory CE. Explosives for Engineers. 1993. 
[49] Lee PR. Explosives Development and Fundementals of Explosive Technology. In: Explosive Effects and Applications. New York: J.A. and Walters Zukas; 2003.

[50] Mondial Defence Systems. Plastic Explosive No. 4 (PE4). [Internet]. 2012 Available from: www.Mondial-Defence.com.

[51] Jacob N, Nurick GN, Langdon GS. The effect of stand-off distance on the failure of fully clamped circular mild steel plates subjected to blast loads. Engineering Structures. 2007;29:2723-2736.

[52] Defence M. Boostering and Detonation: Plastic Explosive Number 4 (PE4). [Internet]. 2010 Available from: www.mondial-defence.com.

[53] Kennedy JE. Explosive Output for driving Metal. Albuquerque: Sandia Laboratories; 1972.

[54] Cooper PW, Kurowski SR. Introduction to the Technology of Explosives. Canada: WileyVCH; 1996.

[55] Khan F, Abbasi S. Risk Assessment in Chemical Process Industries - Advanced Techniques. Discovery Publishing House; 1998. p. 152.

[56] Cooper PW. Explosive Engineering. USA: Wiley-VCH; 1996.

[57] Langdon GS, Chung Kim Yuen S, Nurick GN. Experimental and numerical studies on the response of quadrangular stiffened plates. Part II: localised blast loading. International Journal of Impact Engineering. 2005;31(1):85-111.

[58] Shen WQ, Jones N. Dynamic response and failure of fully clamped circular plates under impulsive loading. International Journal of Impact Engineering. 1993;13(2):259-278.

[59] Kleinschmit NN. A shock tube technique for blast wave simulation and study of flow structure interactions in shock tube blast experiments. Nebraska: University of Nebraska; 2011.

[60] Marchand KA, Alfawakhiri F. Facts for Steel Buildings-Blast and Progressive Collapse No.2. United States of America: American Institute of Steel Construction; 2004.

[61] Friedrichs G. Christian Albrechts Universitat- Shock tube and reaction kinetics. [Internet]. 2010 [cited 2012]. Available from: http://wwwl.phc.uni-kiel.de/.

[62] Nurick GN, Shave GC. Deformation and tearing of thin square plates subjected to impulsive loads. Interantional Journal of Impact Engineering. 1996;18(2):99-116. 
[63] Bowman RM. Investigation of shock front topography in a shock tube. California, USA: California Institute of Technology; 1966.

[64] Ahrens TJ. Shock wave techniques for geophysics and planetary physics. Pasadena, California: California Institute of Technology.

[65] Maidanik G, Dickey J. Reflection of Incident Pressure Waves. USA: Propulsion and Auxiliary Systems Department; 1991.

[66] PCB Piezotronics. PCB Tecnical Support - Pressure Sensors. [Internet]. 2012 [cited 2012 February]. Available from: www.pcb.com/techsupport/tech_pres.php.

[67] PCB Piezotronics. Charge Output dynamic pressure transducer installation and operation manual [Internet]. 2012.

[68] Chavko M, Koller W, Prusackzyk K, McCarron R. Measurement of blast wave by miniature fiber optic pressure transducer in a rat brain. Journal of Neuroscience Methods. 2006.

[69] Opsens. Fibre optic sensors. [Internet]. 2011 [cited 2011 September]. Available from: www./opsens.com/en/technology.

[70] Charles C, inventor; Archive OP, assignee. Blast Pressure Gauge. 2011. 06925887.

[71] Menkes SB, Opat HJ. Tearing and shear failure in explosively loaded clamped beams. Experimental Mechanics. 1973;1(1):480-486.

[72] Neuberger A, Peles S, Rittel D. Springback of circular clamped armour steel plates subjected to spherical air-blast loading. International Journal of Impact Engineering. 2009;36(1):53-60.

[73] Bwalya KD. Investigation into the response of steel plates to repeated blast loads- BSc Thesis. Cape Town, South Africa: University of Cape Town; 2004.

[74] Ranwaha N. The response of steel plates to repeated blast loads- BSc Thesis. Cape Town, South Africa: University of Cape Town; 2011.

[75] Larcher M. Simulation of the effects of an air blast wave. Luxembourg: European Commision; 2007 Joint Research Centre-Institute for Protection and Security of the Citizen. ISSN 1018-5593.

[76] Gupta NK, Nagesh. Deformation and tearing of circular plates with varying support conditions under uniform impulsive loads. International Journal of Impact Engineering. 2007;34(1):42-59. 
[77] Rajendran R, Nasimhan K. Damage prediction of clamped circular plates subjected to contact underwater explosions. The Journal of Strain Analysis for Engineering Design. 2009;44(3):211-220.

[78] AUTODYN. AUTODYN-The interactive software for non-linear dynamic analysis. Century Dynamics; 2006.

[79] ABAQUS/Explicit v6.10.1. Abaqus/CAE- Model Database. 2012.

[80] Cichocki K. Effects of underwater blast loading on structures with protective elements. International Journal of Impact Engineering. 1999;22(6):609-617.

[81] Xing Luo Z, Sheng Luo K, Tang Zhao Y, Huang JJ. Comparative Analysis of the numerical simulation results using ConWep algorithm with the experimental results. Applied Mechanics and Materials. 2011;90-93(1):3180-3185.

[82] Farrow GH, Nurick GN, Mitchell GP. Modelling of impulsively loaded circular plates using the ABAQUS finite element code. In: Symposium Finite element methods in South Africa; 1995; Stellenbosch, South Africa.

[83] Grobbelaar WP, Nurick GN. An Investigation of structures subjected to blast loads incorporating an equation of state to model the material behaviour of the explosive. Structural Failure and Plasticity. 2000;1(1):185-194.

[84] Mougeotte C, Carlucci P, Recchia S, Ji H. Novel approach to conducting blast load analyses using ABAQUS/Explicit-CEL. Picatinny: Dassault Systemes Simulia Corp; 2010 US ArmyARDEC.

[85] Protective Design Centre. ConWep-Conventional Weapons Effects. [Internet]. 2002 [cited 2012 June]. Available from: https://pdc.usace.army.mil/software/conwep/.

[86] O'Grady HJ, Hayhurst CJ, Fairlie GE. The numerical simulation of warheads, impact and blast phenomena using AUTODYN-2D and AUTODYN-3D. West Sussex: Century Dynamics Ltd; 2007.

[87] Bornstein H, Montoya D, Ackland K. Mitigation of loads due to near field blast: Report. Victoria, Australia: Defence Science and Technology Organisation; 2012 Monash University.

[88] Nystrom U, Gyltoft K. Numerical studies of the combined effects of blast and fragment loading. International Journal of Impact Engineering. 2009;36(8):734-743. 
[89] Hu Y, Wu C, Lukaszewicz M, Dragos J, Ren J, Haskett M. Characteristics of confined blast loading in unvented structures. International Journal of Protective Structures. 2011;2(1):2143.

[90] Ackland K, St John N. Experimental and Numerical Investigation into Polymeric Coatings for Blast Protection. Defence Science and Technology Organisation. 2011;1(1):30.

[91] Oskouei V, Kiakojouri F. Steel plates subjected to uniform blast loading. Applied Mechanics and Materials. 2011;108(35):35-40.

[92] Martineau R, Prime M, Anderson C. An explicit model of expanding cylindrical shells subjected to high explosive detonations. NM United States: Los Alamos National Lab; 1999. LA-UR--99-564.

[93] Ferri E, Antinucci E, He M, Hutchinson J, Zok F, Evans A. Dynamic buckling of impulsively loaded prismatic cores. Journal of Mechanics of Materials and Structures. 2006;1(8):13451365.

[94] Kadid A. Stiffened plates subjected to uniform blast loading. Journal of Civil Engineering and Management. 2008;14(3):155-161.

[95] Nurick GN. An empirical solution for predicting maximum central deflections of impulsively loaded plates. Interational Conference of Mechanical Engineering Properties: Materials at High Rates of Strain. 1989;102(9):456-464.

[96] Jacob N, Chung Kim Yuen S, Nurick GN, Bonorchis D, Desai SA, Tait D. Scaling aspects of quadrangular plates subjected to localised blast loads-experiments and predictions. International Journal of Impact. 2004;30(8-9):1179-1208.

[97] Mahoi S. Influence of shape of solid explosive on deformation of circular steel platesexperimental and numerical investigations. Cape Town: University of Cape Town; 2006.

[98] Degarmo EP, Black JT, Kohser RA, Klamecki BE. Materials and Process in Manufacturing Update. John Wiley \& Sons Inc; 2003.

[99] Encyclopaedia Britannica. Encyclopaedia Britannica: Work Hardening. [Internet]. 2012 [cited 2012 February 2]. Available from: www.britannica.com/EBchecked/topic/648052/workhardening.

[100] Furness J. Work Hardening of Engineering Steels. [Internet]. 2012 [cited 2012 February 1]. Available from: www.azom.com/article.aspx. 
[101] Baudin G, Serradeill R. Review of Jones-Wilkins-Lee Equation of State. New Models and Hydrocodes for Shock Wave Processes in Condensed Matter. 2010;10(21):1-4.

[102] SSAB Swedish Steel. GB421Domex 700 MC, Technical Report. 2008.

[103] Alia A, Souli M. High explosive simulation using multi-material formulations. Applied Thermal Engineering. 2006;26(1):1032-1042.

[104] Balden V. Private Communication. 2012.

[105] Johnson W, Yu TX. On springback after the pure bending of beams and plates of elastic work-hardening materials-III. International Journal of Mechanical Sciences. 1981;23(11):687-695.

[106] Purdue University. Engineering Research: Shock Tube Background. [Internet]. 2010 [cited 2011 August 21]. Available from: www.engineering.purdue.edu. 


\section{Appendix A-Johnson Cook Parameters}

\section{A.1 Uni-Axial Tensile Tests}

Tensile lests were cartied nut an "dog bone" shaped tensile specimens, eut fion the same sheet metal used in the manufacture of the blast test plates. The tensile tests were conducted on the Zwick Roell 1484 tensile 1ester. The tenside specimens were placed in the 7wick and subjected to at tensjle forece at various crosshead sjeeds, ranying from 5 mm mbasuring the displacement of the gange length (5it mm) of the de forming tensile specmen and hence nutput force-displacement data for the yiven specimen. illusirated in Figure A.1. The forccdisplacement data was used to determine the true stress and tue strain characteristics of the steel, until failure.

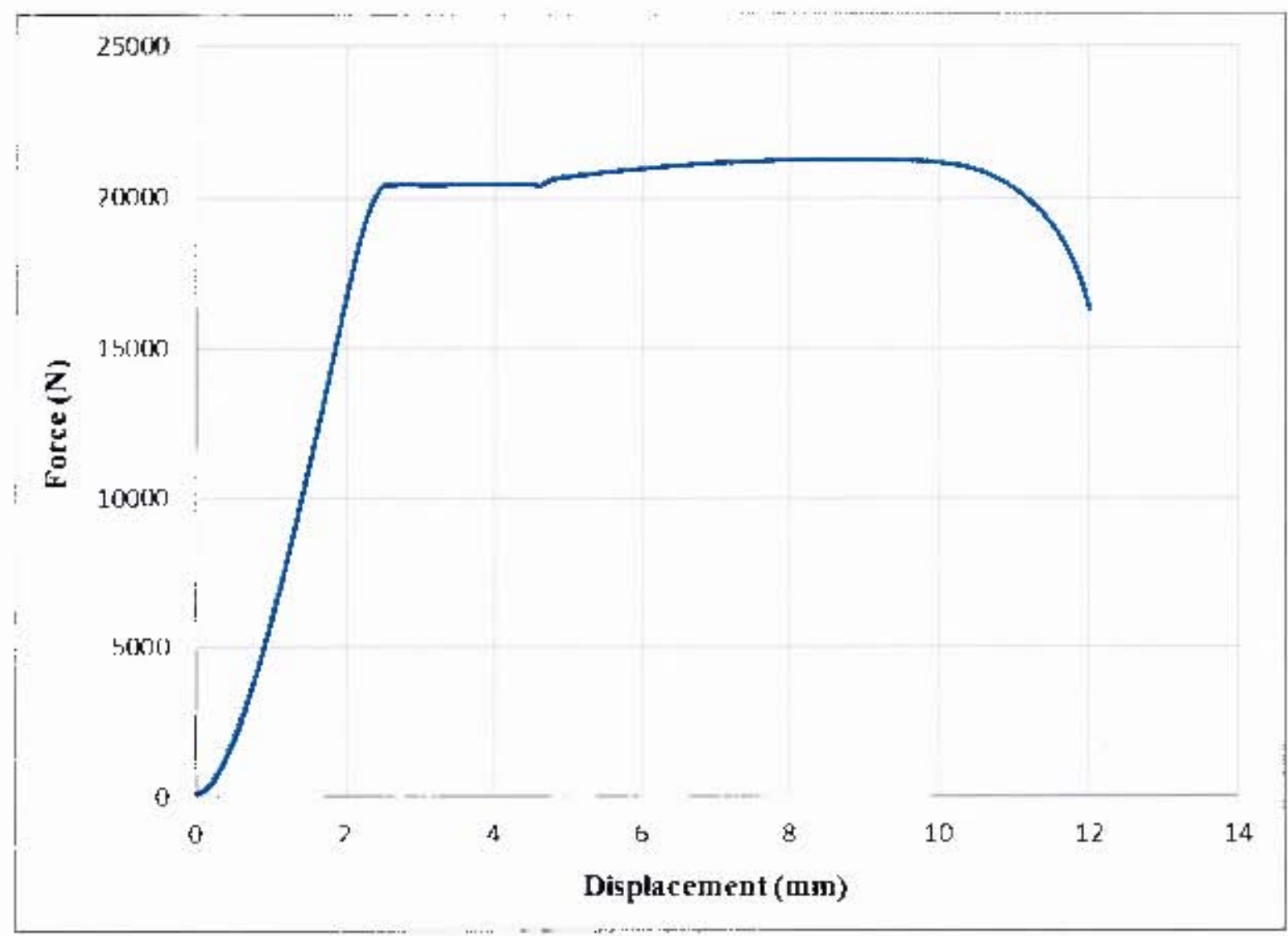

ligure A.J: (iraph of force displacement output data tor the tensile test sarried out al 1 filomminin 


\section{A.2 Machine Compliance Correction}

Due to the stiffness of both the Zwick tensile tester and tensile specimen, the initial rise in force was not linear, as can be seen in Figure A.1. This non-linear rise was accounted for with the use of Hooke's Law. The force-displacement graph was adjusted in order to produce a linear rise in force, starting at zero displacement. This was carried out by fitting a linear slope from the upper linear section of the graph and extending it to the zero displacement intercept [10], using the gradient of the linear region of the graph. The graph was then shifted such that the intercept corresponded to the zero force-displacement point (origin).

Extending the linear force rise, did not correct the elastic displacement of the Zwick tensile test machine, both before and after the tensile specimen had undergone non-linear deformation. As reviewed by Langdon et al [10], "Bonorchis and Nurick [14] accounted for the compliance by subtracting the displacement at each point by the force at that point divided by the gradient of the linear slope." Langdon et al [10] noted that Bonorchis and Nurick [14] assumed the stiffness of the machine was equal to the stiffness of the machine and specimen in series or the gradient of the slope. If the stiffness of the specimen was estimated by assigning it a Young's Modulus of $200 \mathrm{GPa}$, then the stiffness as a result of the machine could be more accurately estimated by Equation A.1, as reported by Langdon et al [10].

The compliance of the machine could therefore be accounted for by subtracting the displacement at each point by its corresponding force, divided by the machine stiffness. The curve post compliance adjustment is shown in Figure A.2.

$$
\begin{gathered}
\frac{1}{k_{\text {eff }}}=\frac{1}{k_{\text {specimen }}}+\frac{1}{k_{\text {machine }}} \\
E=\frac{\sigma}{\epsilon} \\
E=\left(\frac{\frac{F}{A}}{\frac{\Delta L}{L}}\right) \\
K_{\text {specimen }}=\left(\frac{F}{\Delta L}\right) \\
K_{\text {specimen }}=\left(\frac{E A}{L}\right)
\end{gathered}
$$




$$
\begin{gathered}
K_{\text {machine }}=\left(\frac{1}{k_{\text {eff }}}-\frac{1}{k_{\text {specimen }}}\right)^{1} \\
K_{\text {machune }}=\left(\frac{1}{\text { gradient }}-\frac{\delta}{E A}\right)^{-1}
\end{gathered}
$$

The corrected displacement after the compliance of the machine has bect accounted for is represented by Equation $A .2$.

$$
d_{\text {corrected }}(i)=d(i)-\frac{F(\mathrm{i})}{k_{\text {machere }}}
$$

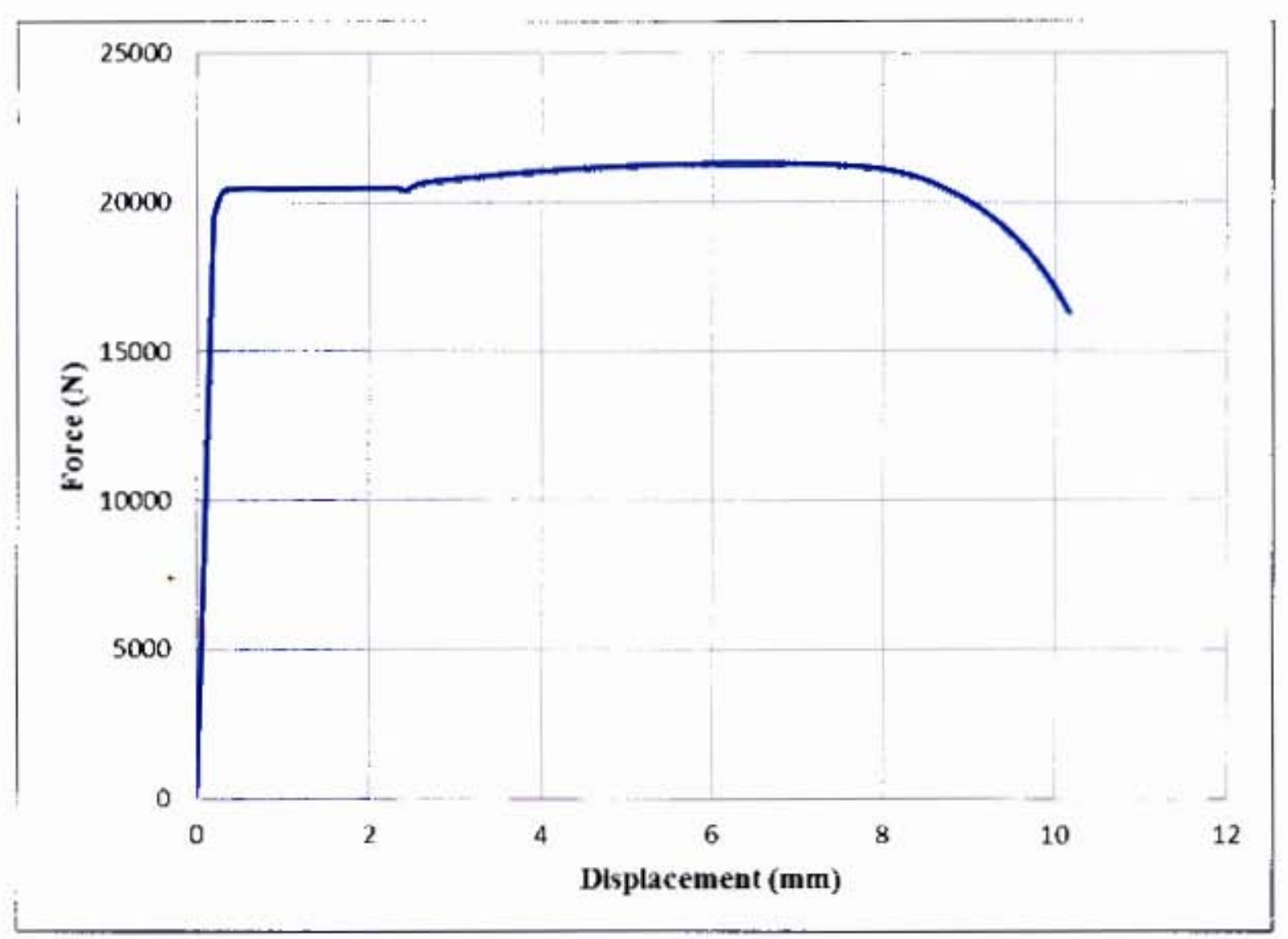

Figure A. 2: Ciraph of forre-displacement curve post compliance adjusted for tensile test carried out at $100 \mathrm{~mm} / \mathrm{min}$ 


\section{A.3 Yicld Stress}

When determining the Johnson-Cook material properties, the yithl stretnth of the [Dombx 700 steel was required. 'The yield point was the true stress valuc, whit the curve progressed from linear to non[inear, indicating that the material had surpassed its elistic deformation capabilities and was now undergoing plastic deformation. Lüders bands occured in the strength curves fiom the tensile test datat as at result of dislowitions within the material lattice. [o account for these 'deviarions' in slress values, when whoosing a yield point, an average of the data contained in the I. iders band region was laken from the engineering stress-strain curve. betore the data was converted to true stress-strain vitues.

The most consistent method of determining the yichl point was lo use the $0.2 \%$ offset strain method. This method involved projecting a lincar line with the same gradient ats the linear region werresponding to the stress-strain curve, of $f$ st by $0.2 \%$ of the strain. This linear oftset was extended untif it intercepts the stress-strain curve. This interceprion print was laken as the yjeld stress of the material. Figure $A .3$ shows the $0.2 \%$ of 5 set yieid intercept.

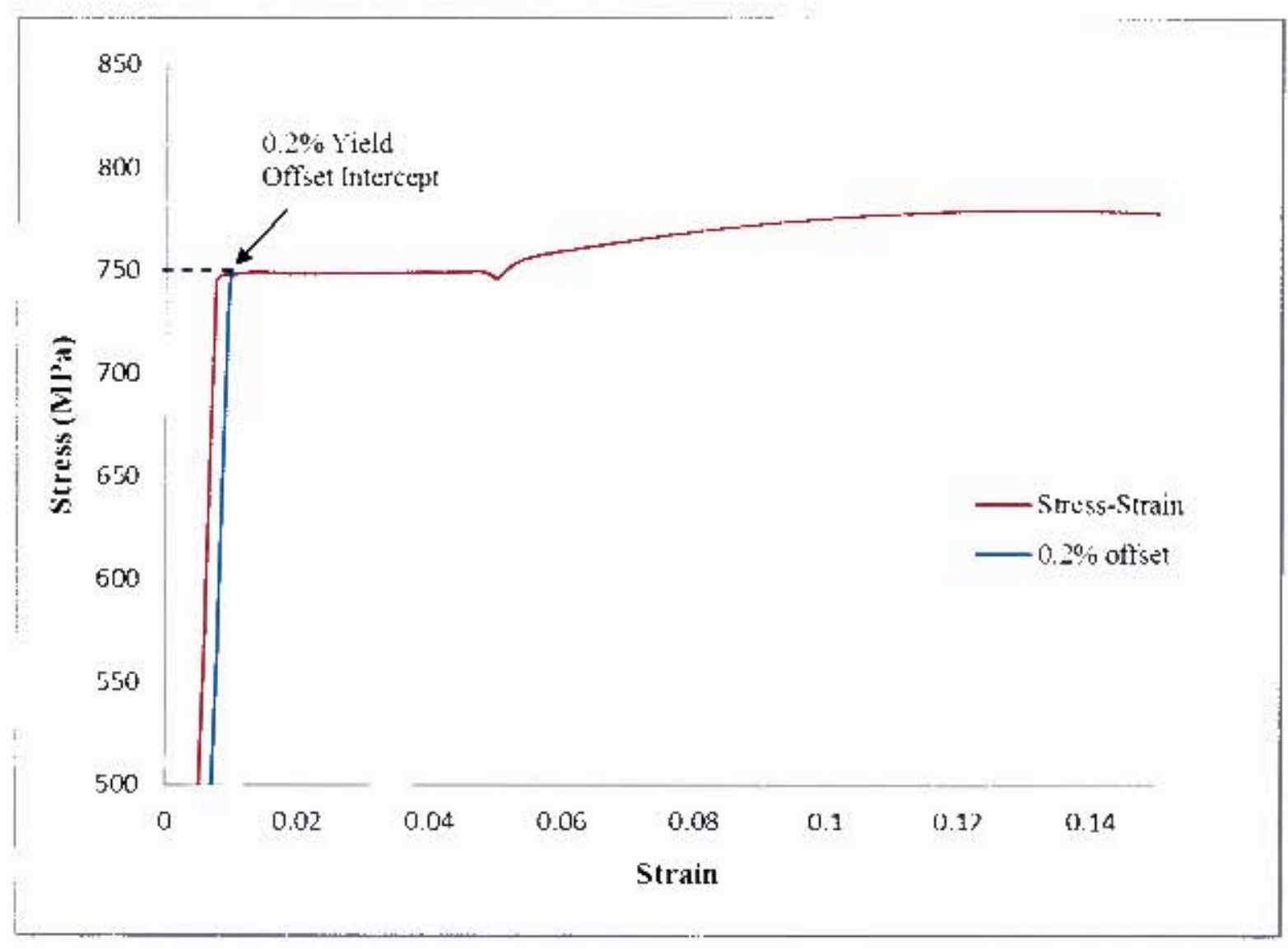

Figure A 3: Graph showing the $0.2 \%$ offset yield on the engineering strexs-strain curve 
When simulating the deformation characteristics of the material, the numerical models required the corresponding true stress ( $\left.\sigma_{\text {true }}\right)$ and true plastic strain ( $\epsilon_{\text {true }}$ ) properties as input data. Plastic strain occurred when the material was stressed beyond the yield point or the deformation that occurred after the elastic region. The Equations A.3 and A.4 were used to manipulate the engineering data to true stress-strain.

$$
\begin{array}{ll}
\epsilon_{\text {true }}=\ln \left(1+\epsilon_{\text {plastic }}\right) & \text { Eq. A.3 } \\
\sigma_{\text {true }}=\sigma_{\text {eng }}\left(1+\epsilon_{\text {true }}\right) & \text { Eq. A.4 }
\end{array}
$$




\section{A.4 Post Ultimate Tensile Stress Characteristics}

The ultimate tensile stress (UTS) was taken as the maximum stress in the plastic region, from the engineering stress-strain curve. Necking occurred in the material once the tensile specimen was deformed or stressed beyond the material's UTS, resulting in a significant change in the tensile specimen's cross sectional area. This change in area cannot be accounted for by the Zwick tensile test machine, therefore the tensile test must be numerically modelled to obtain the post UTS material characteristics. The post UTS stress-strain behaviour was estimated, where the estimated UTS data points were used as input data for a numerical simulation of the tensile test and iteratively adjusted to correspond to the experimental tensile tests.

The output data from the numerical simulation came in the form of force-displacement data and was thus compared to the experimental force-displacement data. The comparison was analysed and if applicable, the initial post UTS estimate was adjusted and new force-displacement data was acquired. This process was iteratively repeated until the numerical force-displacement matches the experimental data.

The initial post UTS estimate was obtained by the approximated measurement of the failed cross sectional area of the tensile specimen and the final force the tensile specimen was subjected to before failure. This is described by Equation A.5.

$$
\sigma_{\text {estimate }}=\frac{\text { Force }_{\text {final }}}{\text { Area }_{\text {approxtmated }}} \quad \text { Eq. A.5 }
$$

The transition between the post and pre UTS data was kept as smooth as possible to ensure the most realistic estimated stress-strain behaviour. To numerically model the true stress-strain curve, a power function was used as described by Pickering [10], similar to the power function used in defining the Johnson-Cook relation. 


\section{A.5 ABAQUS Numerical Model}

ABAQUS/Standard was used to simulate the tensile tests experimentally carried out on tensile specimens. The implicit method was used instead of the explicit method, for greater time efficiency [104]. ABAQUS allowed the user to input stress-strain data directly into the numerical material model, allowing for the easy manipulation of the data, required in the iterative process.

The geometry of the experimental tensile specimen made it possible to develop the numerical model as an eighth symmetry (quarter section through the thickness and half section through the length), as used by Pickering [10]. The velocity boundary was therefore specified as half the experimental speed. The symmetry face located on the length of the model was assigned a zero $x$ - displacement, whilst the symmetry faces through the thickness were assigned $\mathrm{y}$ and $\mathrm{z}$ symmetry boundaries. This is illustrated in Figure A 4.

In order for the model to successfully fail in the central area (one eighth $\mathbf{x}$ constrained face), a slight defect was introduced. The thickness of the specimen was reduced by $0.2 \%$, inducing necking at the defect, as implemented by Pickering [10]. To reduce the mesh size and make the model more time efficient, part of the specimen which was located by the grips of the tensile test machine are excluded. C3D8R brick elements were used and geometric non-linearity was chosen, which reduced the completion time of the simulation. The mesh had a single bias in the direction of the $\mathrm{x}$-constrained face containing the defect, as illustrated in Figure A 4. 


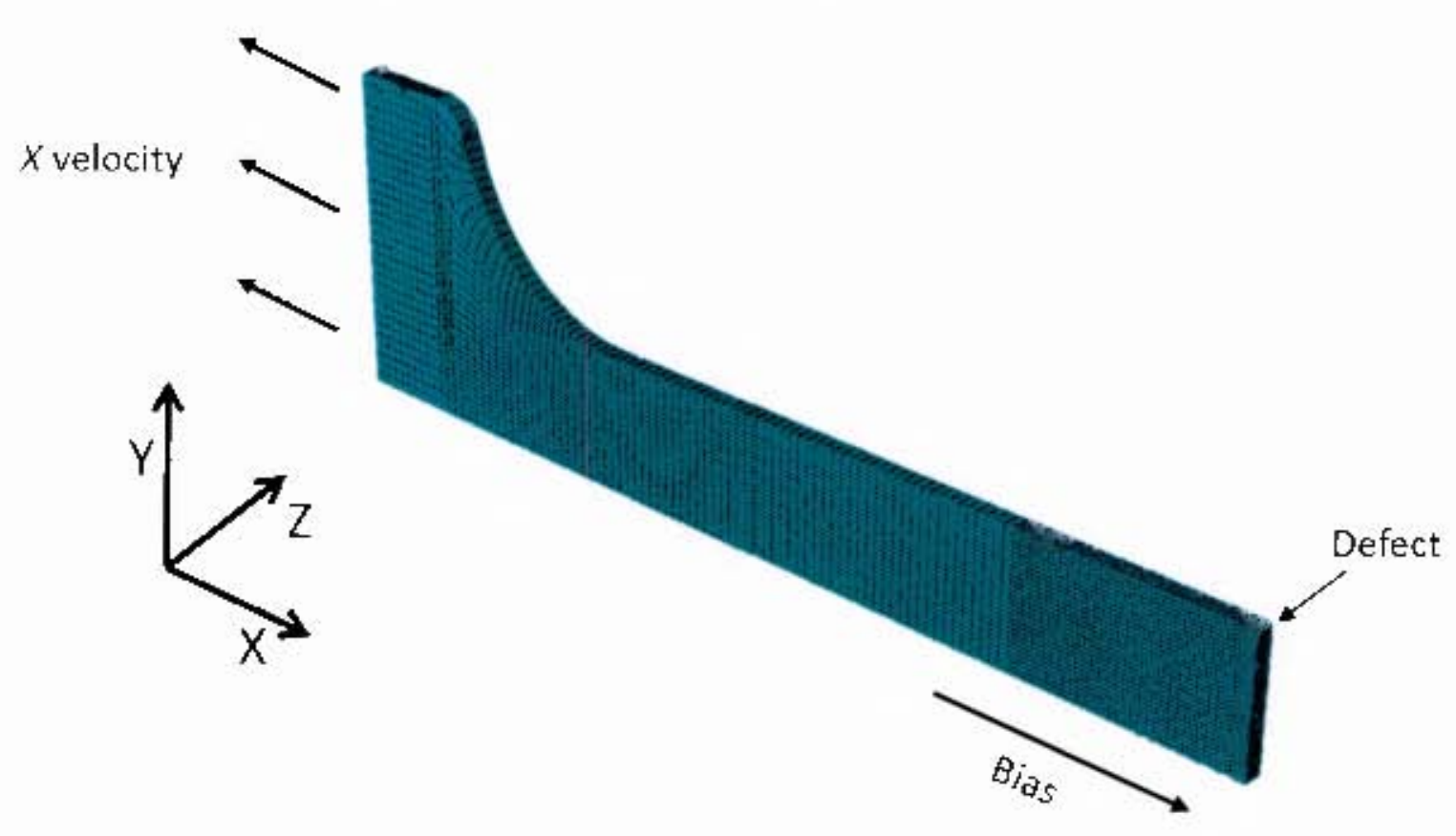

Fignre A 4: Image of eighth symnetry ABAQI s tensile teat specimen showing bias, defect and planat boundaries

The post Ij IS stress-sirain eurves were modelled with a power curve relation in the form of $A+B^{\text {ri }}$, similitr to the Johnsous Cook strain tatdening term. The power curve was fitted from the IITS 1n a point at $300 \%$ strain. The intititl gritdient of the pourer cuse was manipulated to mitke a smowits transilion between the pre UIS curve and the posi l.TS curve, its sllcossifilily carried out by Pickering [10]. The initial closen point stowed force-displacement results that did mot math the forcedisplacement data of the cxperimental tensile tests. The gradient of the pre-CTS datat wats increitsed and the model was run again with the new inpul. Incjeasing the pre-UTS data resulted in the simulated maximum force to increase, but the shape and failuse point of the simulated forcedisplacement data, still did not mituch the experimental data. Therefore a new point at $300 \%$ wiritin was chosen and a past UIS curve was lited to the dati. I'his method proved to positively change the shape of the simulated torce-displitcement curve. More points were iteratively chosen and the resultant post UTS curves were used as input ditta for the simulated tensile tests until the simulated force-displacement data correspondcd to the experimental furce-displacement data. There were many data points chosen. but the data points that showed the most promisingr results al $300 \%$ strain are 1110 MPa, $1200 \mathrm{MPa}$ and 1220 MPa. The exponential curves were fitted to the closen data points and the resultant post-l.TS eurves were used as input data for the tensile tes simulations and are shown in Tigure A.S. The corresponding force-displacement output cusves from the tensile test simulations for the futrious dala points chosen are shown in ligure A.6. 


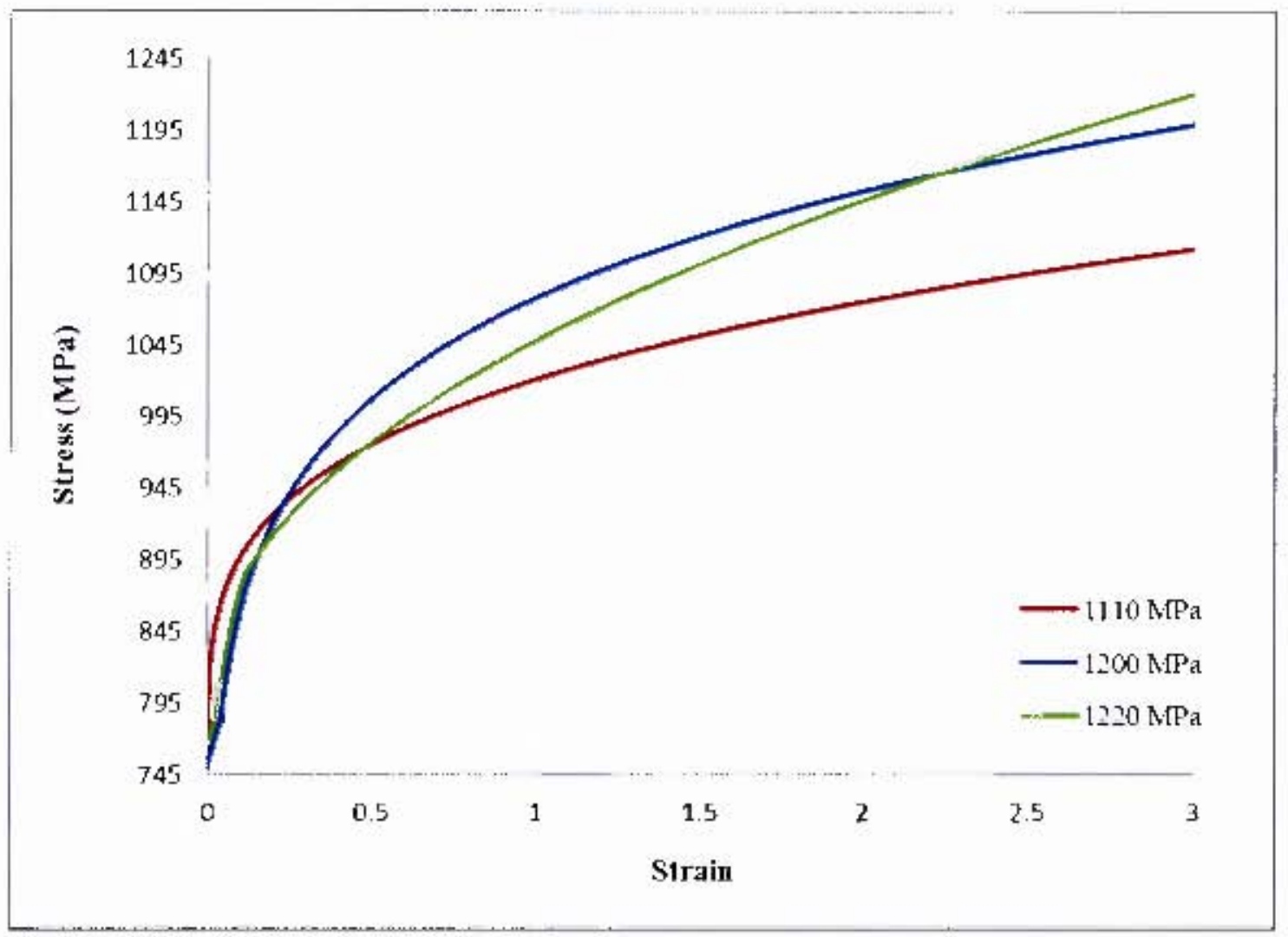

Figure A.5: Post-l!'TS stress strain curves fitted to the elosen data points for the tensile cest simulations

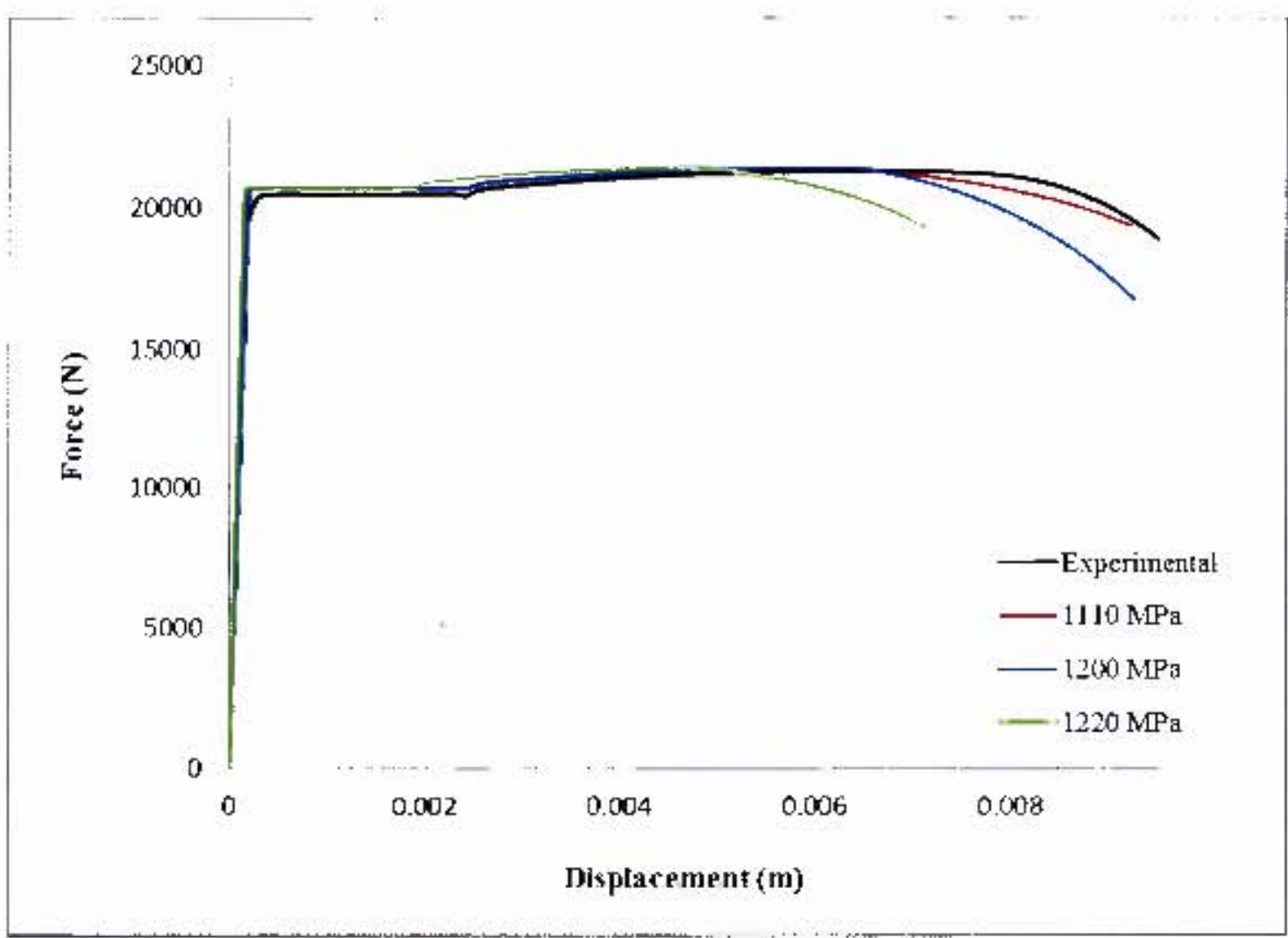

Figure A, 6: Graph of forec versus displacement for the various data poists chosen: plotted against the experimental force-displacement datit 
From Figure A.6 it was clear that the ditlit point $1110 \mathrm{MPa}$ produced the closest correlating forchdisplacenent curve (red curve) with respect to the experimental force-displitiement curve (black line). Therefore, the post-[ITS stress-strain curve for the ditla point 11 loMPa, visible in Figure $A .5$ (red curve), was used to determine the Johnson Cook parameters.

\section{A.6 Determining the Johnson Cook Parameters}

The Johnson Cook parameters $B$ ind $n$ were delenmined by fitting a power curse to the post-UTS stress-strain curve, in the form of $A+B^{n}$. The power curte was lited to the post-UTS stress-stritin curve using the 'difference of squares' method. The parameter $A$ was set as the yield stress and determined from the experimental ternsile tests as discussed in Section A.3. The power eurve fitted against the post-UTS stress-straje data is shown in Figure A.7.

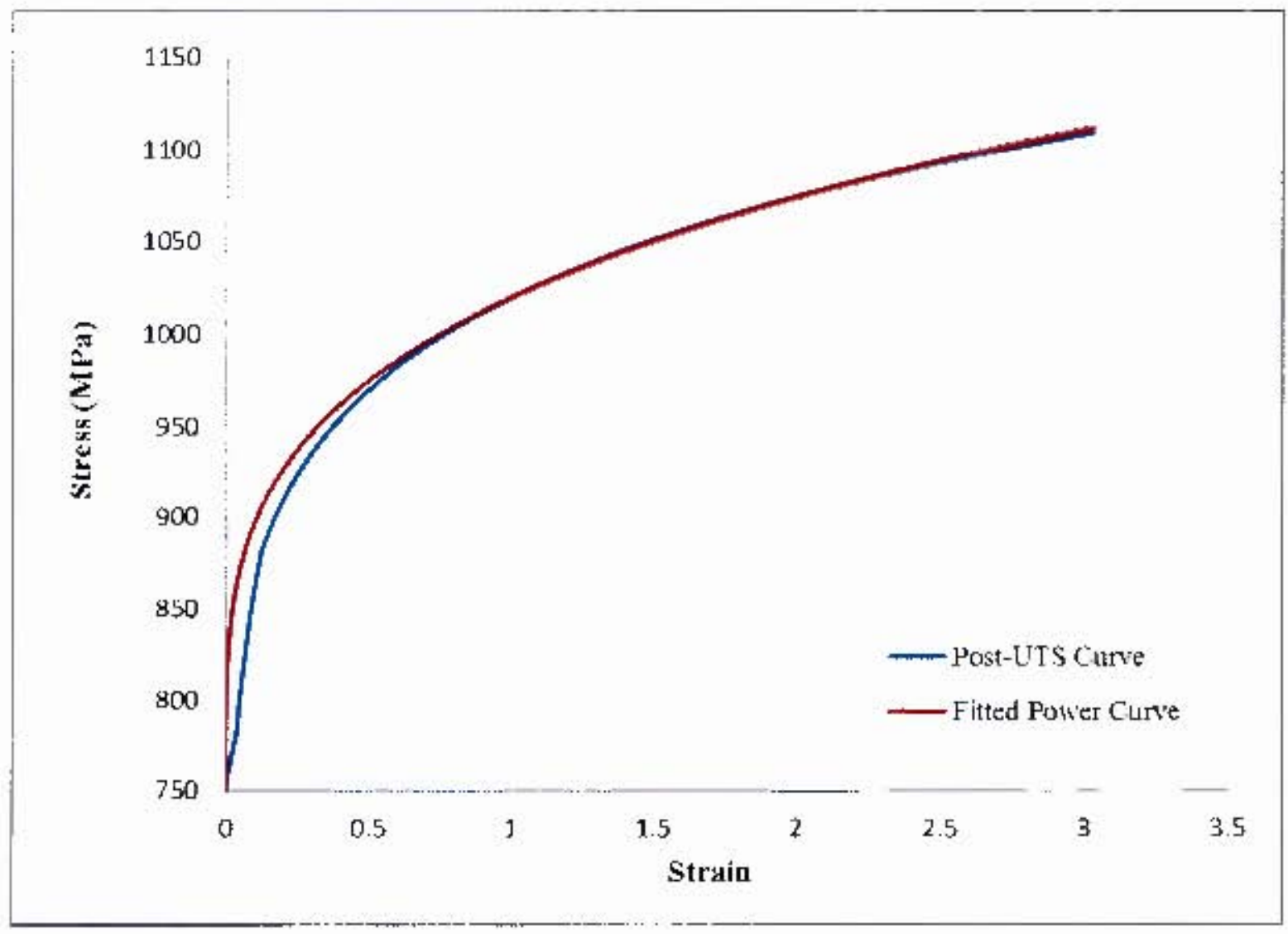

Figure A. 
The strain rate hardening constant $C$ was obtained from research carried out by Pickering [10]. Data provided by the manufacturers of Domex 700 was validated from experimental tensile tests carried out at varying strain rates on the Zwick/Roell tensile tester. It was determined that the linear gradient of the trend line fitted to the resultant yield points of Domex at each tensile test speed, was 0.014 , which corresponded to a $C$ value with a reference strain rate of $0.001 \mathrm{~s}^{-1}$. This $C$ value was identical to the value used for steel 4340 , in the AUTODYN library and was used successfully by Langdon et al [11], with simulations carried out on ' $V$ ' shaped Domex 700 steel structures. The thermal properties $m$ and $T_{m e l t}$ were taken as the values used for Steel 4340 as found in the AUTODYN material library. The final Johnson Cook values, as used in the numerical simulations of this project are listed in Table A.1.

Table A.1: Johnson Cook material parameters

\begin{tabular}{|c|c|c|c|c|c|c|}
\hline$A$ & $B$ & $n$ & $\epsilon_{0}$ & $C$ & $m$ & $T_{\text {melt }}$ \\
\hline $750 \mathrm{MPa}$ & $270.6 \mathrm{MPa}$ & 0.263 & $0.001 \mathrm{~s}^{-1}$ & 0.014 & 1.03 & $1795 \mathrm{~K}$ \\
\hline
\end{tabular}




\section{Appendix B- Horizontal Ballistic Pendulum}

The resultant impulse imparted onto the ballistic pendulum by the explosive can be determined by various measured variables. A photograph of the pendulum, as shown in Chapter 3.2.2. is displaycd in Figure B.1. A schematic, defining the necessary variables to be measured is shown in Figurc B.2.

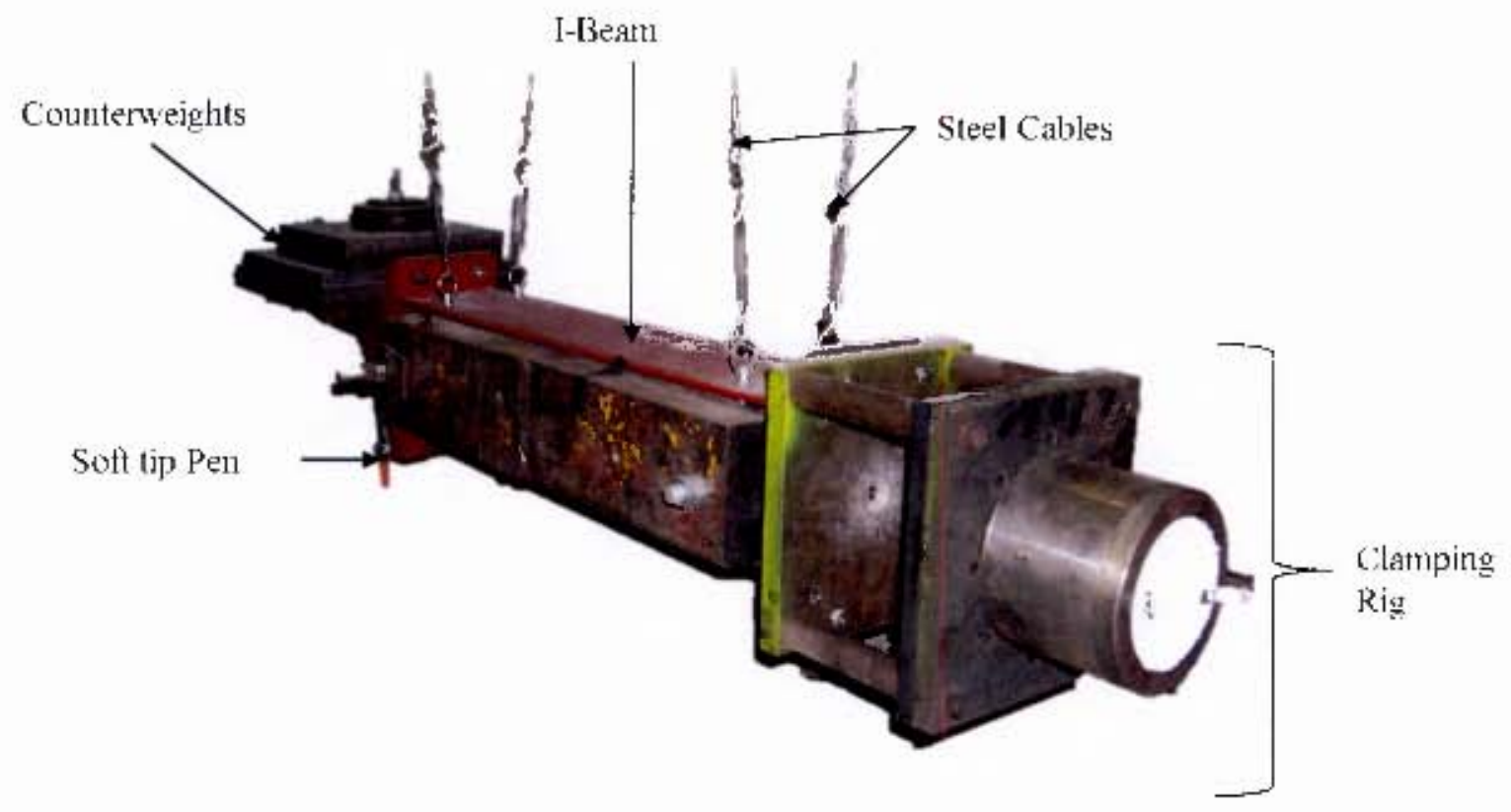

Figure B.I: Plotograph of himrizontal ballistic ptondulum 


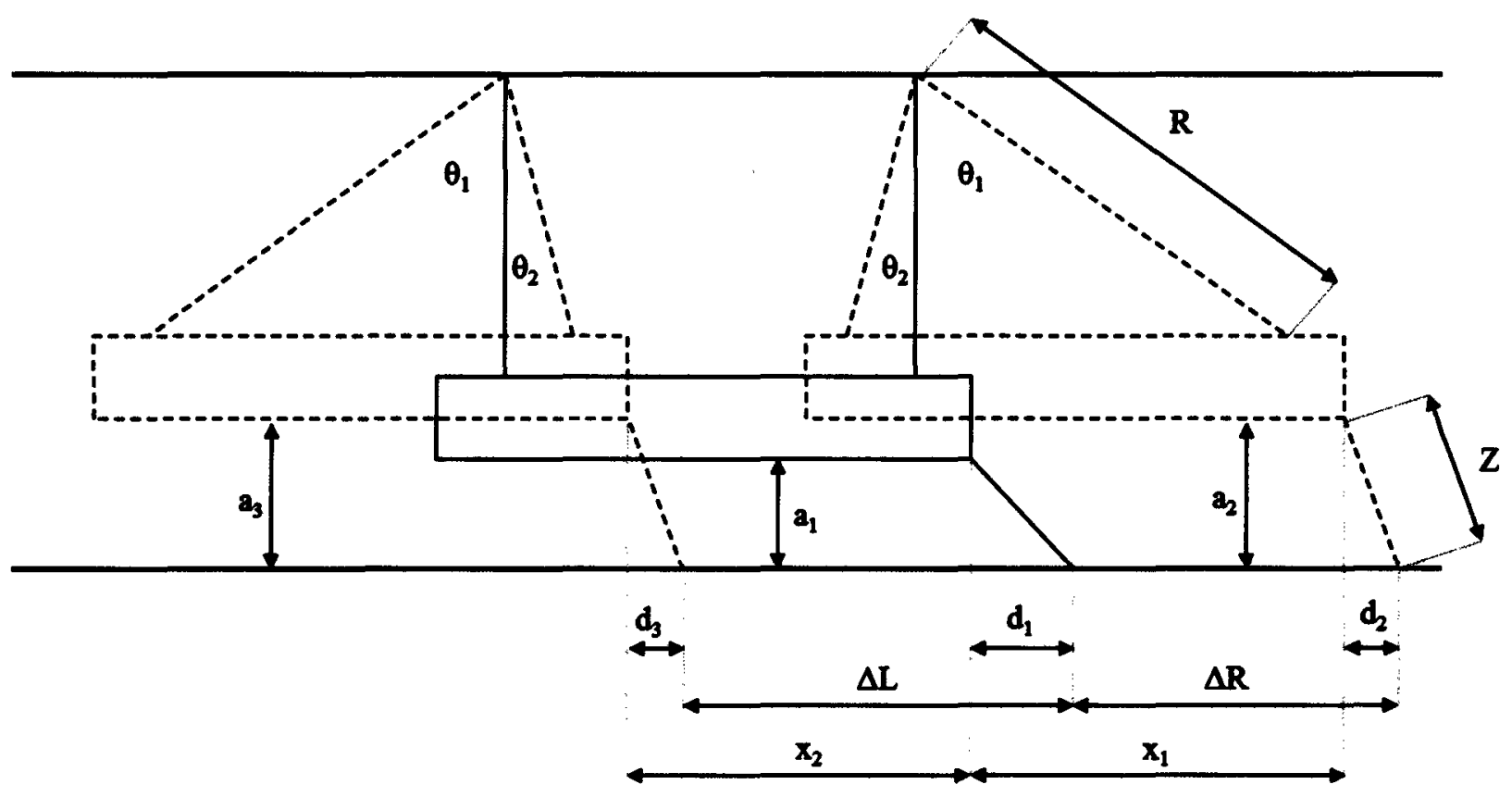

Figure B.2: Schematic of ballistic pendulum

From Figure A.3, the horizontal distance between the end of the pendulum and the pen is given as:

$d_{1}=\sqrt{\left(Z^{2}-a^{2}\right)}$

Eq. B.1

While at the pendulum's maximum amplitude, the distance decreases and is given as:

$d_{2}=\sqrt{\left(Z^{2}-[a+y]^{2}\right)}$

Eq. B.2

In blast testing the pendulum oscillates at low amplitudes, giving a small angle on the suspension wires and therefore:

$x_{1}=R \theta$

$y=\frac{R \theta^{2}}{2}$

Substituting equation A.3 into A.4:

$y=\frac{x_{1}^{2}}{2 R}$

Substituting equation A.5 into A.2:

$d_{2}=\left[Z^{2}-\left(a+\frac{x_{1}^{2}}{2 R}\right)^{2}\right]^{0.5}$

From Figure A.3:

$x_{1}=\Delta R+d_{1}-d_{2}$

$x_{2}=\Delta L-d_{1}+d_{2}$

Eq. B.8 
Substituting equation A.1 and A.6 into A.7 and A.8:

$$
\begin{aligned}
& x_{1}=\Delta R+\sqrt{\left(Z^{2}-a^{2}\right)}-\left[Z^{2}-\left(a+\frac{x_{1}^{2}}{2 R}\right)^{2}\right]^{0.5} \\
& x_{2}=\Delta L-\sqrt{\left(Z^{2}-a^{2}\right)}+\left[Z^{2}-\left(a+\frac{x_{1}^{2}}{2 R}\right)^{2}\right]^{0.5}
\end{aligned}
$$

The linear equation of motion of the pendulum assuming viscous damping is given as:

$\ddot{X}+2 \beta \dot{X}+\omega_{n} X=0$

Where:

$\beta=\frac{c}{2 M}$

$\omega_{n}=\frac{2 \pi}{T}$

Eq. B.13

$\omega_{d}=\left(\omega_{n}^{2}-\beta^{2}\right)^{0.5}$

$C$ is the damping coefficient, $M$ is the total mass of the pendulum and $T$ is the natural period of the pendulum's oscillation.

The solution for the $2^{\text {nd }}$ order differential equation A.11 is:

$X=\frac{e^{-\beta t_{x_{0}} \sin \left(\omega_{d} t\right)}}{\omega_{d}}$

Where $\dot{x}_{0}$ is the initial velocity of the pendulum. Then if $x_{1}$ is the horizontal displacement at $t=T / 4$ and $x_{2}$ be the horizontal displacement at $t=3 T / 4$. Substituting these values into equation A.15:

$x_{1}=\frac{x_{0}^{\prime} T}{2 \pi} e^{-0.25 \beta T}$

$x_{1}=\frac{x_{0}^{\prime} T}{2 \pi} e^{-0.25 \beta T}$

And therefore:

$\frac{x_{1}}{x_{2}}=e^{0.5 \beta T}$

Rearranging gives:

$\beta=\frac{2}{T} \ln \left(\frac{x_{1}}{x_{2}}\right)$

From equation A.17:

$\dot{x}_{0}=\frac{2 \pi}{T} x_{1} e^{-0.25 \beta T}$

The impulse can be determined from the mass and the initial velocity of the pendulum:

$l=M \dot{x}_{0}$ 


\section{Appendix C- Pressure Measurement Blast tests}

This section explores the behaviour of the resultant pressure wave from a detonated blast, travelling down a tube. Due to the stand-off distance- charge diameter ratio of the blast loading experiments, the test plates were assumed to be impulsively uniformly loaded, allowing for certain approximations to be made with regards to the resultant energy transferred to the plate. Therefore, little was known about the behaviour of the pressure wave before and the moment it interacts with the test plate. This had given rise to the necessity of measuring the blast load incident pressure impacting the test plate. The experimental pressures could be compared to the numerical equivalents, used in the numerical modelling of the blast load experiments.

\section{C.1 Experimental Configuration}

The blast experiments were conducted by placing a mass of PE4 plastic explosive, centrally located at one end of a mild steel cylindrical tube. The tube was $150 \mathrm{~mm}$ in length (supplying a constant standoff distance) and had an inner diameter of $106 \mathrm{~mm}$ (constraining the blast area). The other end of the tube was fastened to the front clamp plate, also made of mild steel. The front clamp plate was fastened to the rear clamp pate. The rear clamp plate has specialised fittings that housed the pressure transducers, used to measure the incident blast wave pressure. The front clamp plate, rear clamp plate and tube are all attached to the horizontal blast pendulum. The pendulum was freely suspended by steel cables, which allowed the pendulum to evenly oscillate once an explosive charge had been detonated. The resultant impulse from the blast was calculated from the amplitude of the pendulum's oscillations. The set-up was exactly the same as the experimental set-up described in Section 3.2.2, for the deformable test plate experiments, save the rear clamp plate that houses the pressure transducers. A diagram of the Blast loading rig was visible in Figure C.1. 


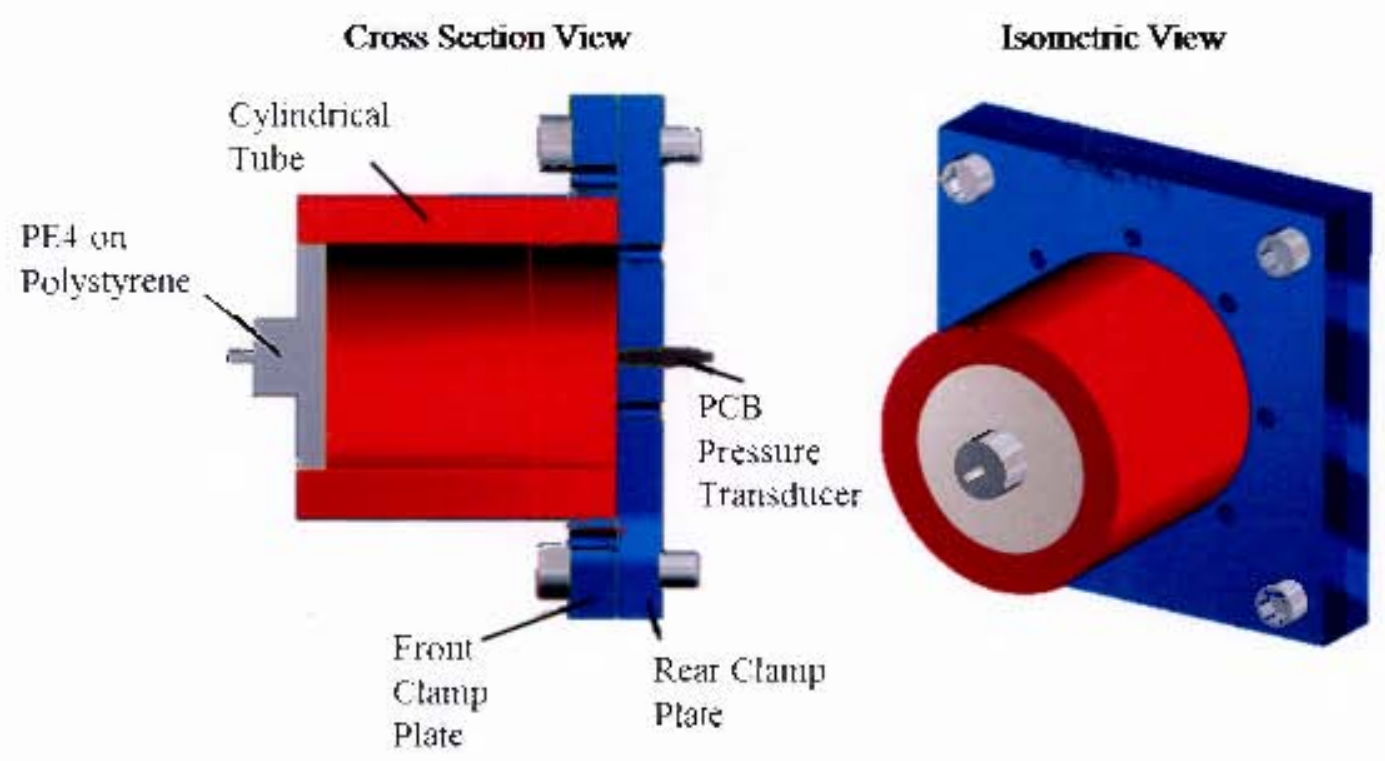

Figure C.I: Diagram of blast loading rig wich pressure transducer inserted

Various parameters regarding the charge set up have been kept constant to illuminate as many variables as possible. The parameters are displayed in Table C.2.

Table C.2: Constant experimental parameters

\begin{tabular}{|ll|}
\hline Stand-0ff Distance (mm) & 150 \\
\hline Charge Diameter (mm) & 34 \\
Charge Mass (g) & 10 \\
\hline
\end{tabular}

\section{C.2 Pressure Transducer Set $\mathrm{I}_{\mathbf{P}}$}

The incident blast wave pressure was medsured with $\mathrm{PCB} 119 \mathrm{~B} 12$ pressure transducers. The pressure transducers were placed in three different locations on the rear clamp plate within the cylindrical aubc; the centre of the blast area and at radij of $25 \mathrm{~mm}$ and $49 \mathrm{~mm}$ from the centre. The locations are schematically shown in rigure C.1. 


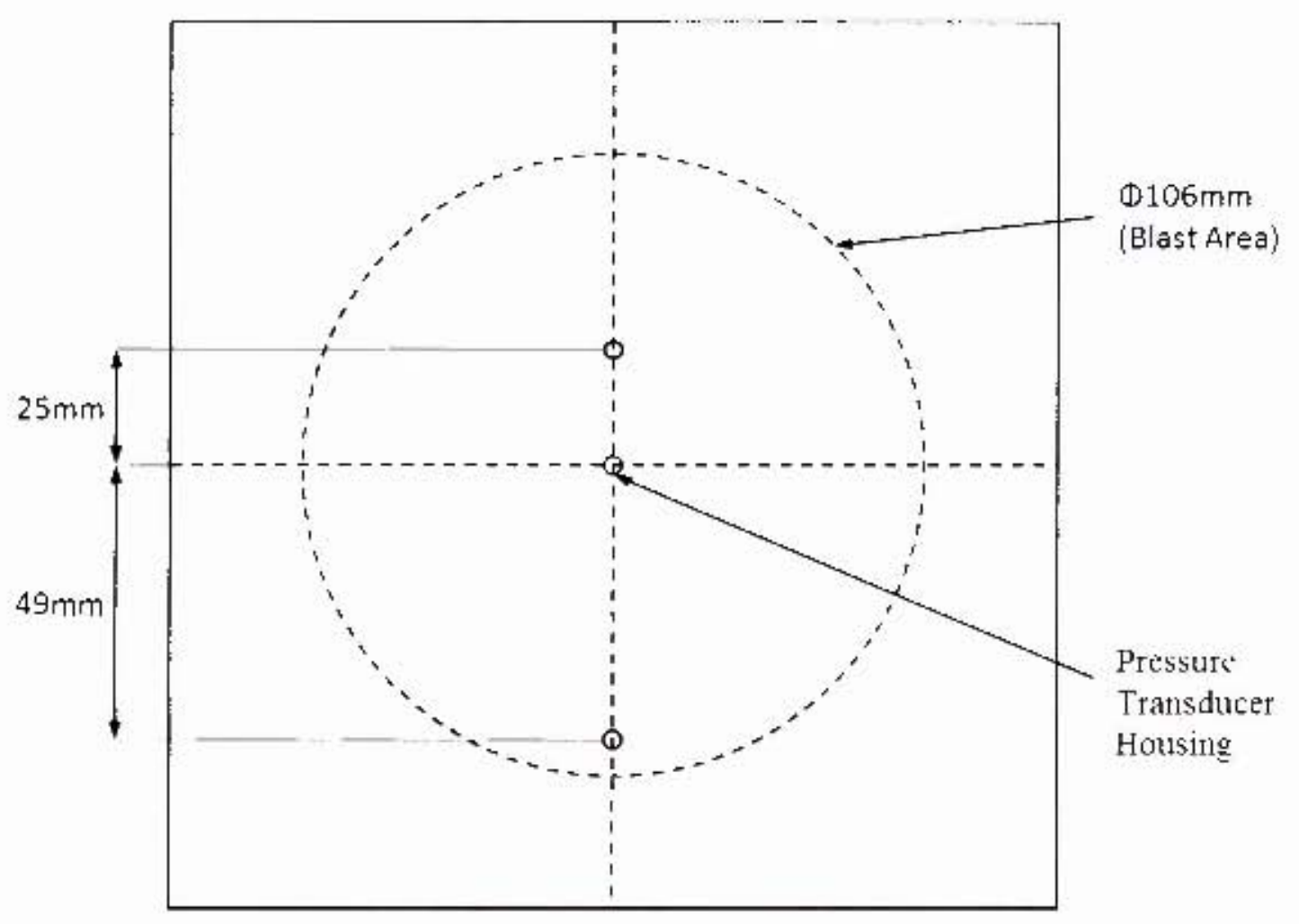

Figure C..1: schematic "l presure tranoducer placement in rear clamp plate

To successfully measure and record the incident pressures, the transducers have to be comnected to a series of components to amplify the signal, capture and process the incoming diata. The signal from the pressure transducers was amplified using a Kistler charge amplifier, model (1015A), with a sample rate frequency of $200 \mathrm{hH} \%$ (used due 10 atyailability). The necessary sentings were calibrated using a shock tulbe and the certified sensitivity of the transducer was given as $35.4 \mathrm{pCMP}$ it (pressut: transducer serial $H: 63 ! 0$ ), as specified by PCB Pie\%otronics. The required settings for the Kistler charge amplifier were correctly entered to accusately amplify the eftarge. Firstly the correct units (MPa) and the expected pressure range were chosen for the required measurement. The sensitivity specified by the transducer manufacturers was set $(35.4 \mathrm{pC} / \mathrm{MP}$ a) and the magnification fitctor wits chosen ( : OOMPa:V).

The pressure transducer was connected to the input BNC connection of the charge amplifier, $A$ PC with a data capturc card was connected to the output $\mathrm{BNC}$ connection of the charge amplifier. A photograph of the Kistler charge amplifier is shown in Figuse $C .2 .1$ and the front input console for the amplifier is given in Figure C:2.2. 


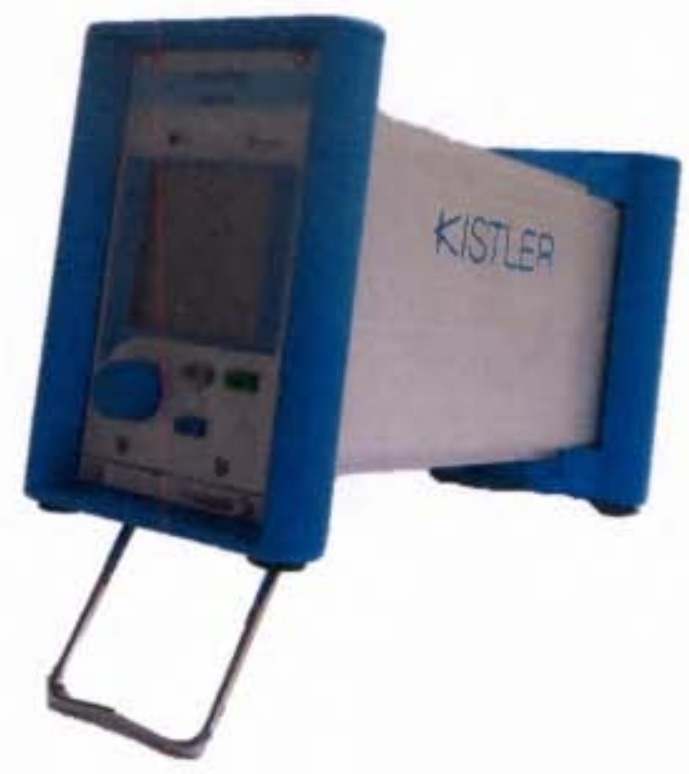

Figure C.2.1: Plotograph of Kistler Charge Amplifier, model I015.

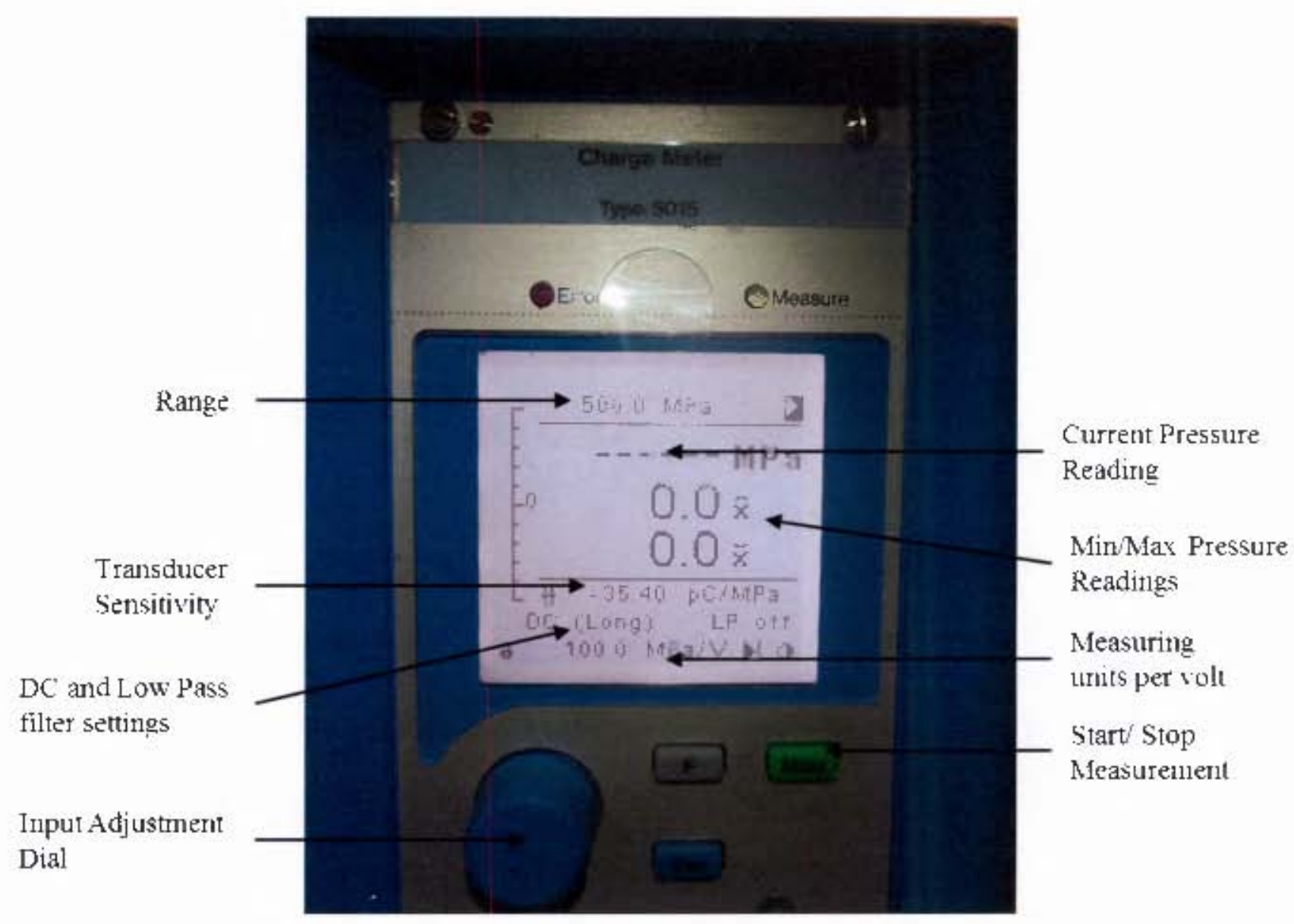

Figure C.2.2: Front imput console of Kistler clarge amplitier 
The dala recording was stamed using a simple trigger system. The trigger asled like a "trip wire", as the circuit broke, the resultant voltage dropped to a specific valte where the data capture commenced. The "trip wire" was placed directly in front of the explosive chatge and therefore broke instantateously as the charge was detonated. This also allowed for the dath recording to start hefore the blast wave interacted with the pressure transducer, ensuring the intial peak pressure was tor

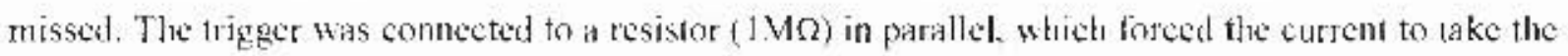
least resistance through the less reststive "trip wire". Once the "trip wire" was broken, as at result of the blast, the current travelled through the resistor, producing a woltage spike of approximately. $3 \mathrm{~V}$. This voltate spike acted as the stant trigger for DAQPilot to star recoding the voltage (pressure) transmitted by the transducer. The trigger system, with the "trip wire" is presented in figure $\mathrm{C} .23 . \mathrm{A}$ simple setermatic of the circust diagram for the connectivity of the pressure tranaducer and the trigger system is shoum in Figure C.2.4.

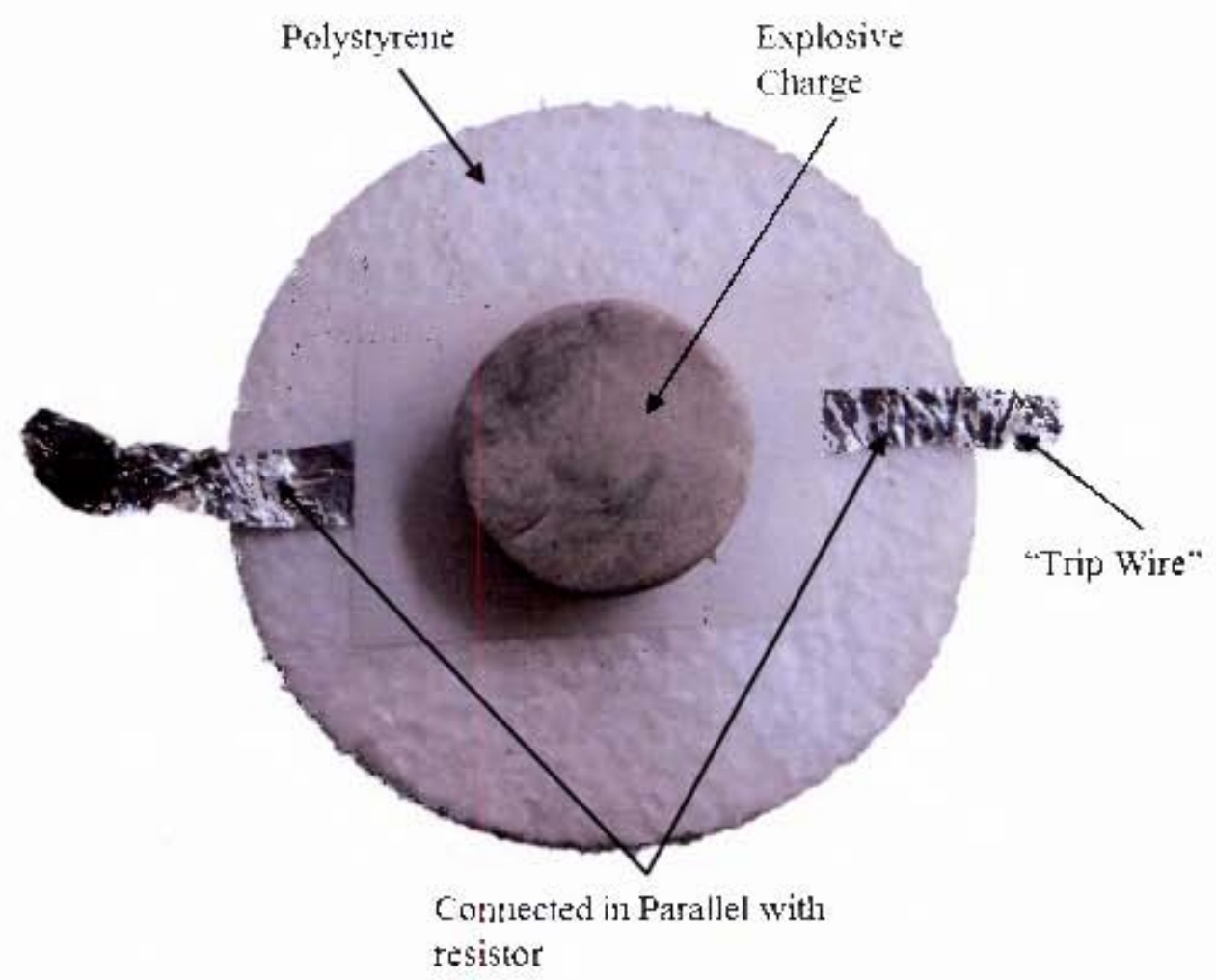

Figure C.2.3: Photograph of "trip wire" relative to cxplosive charge and polystyrene 


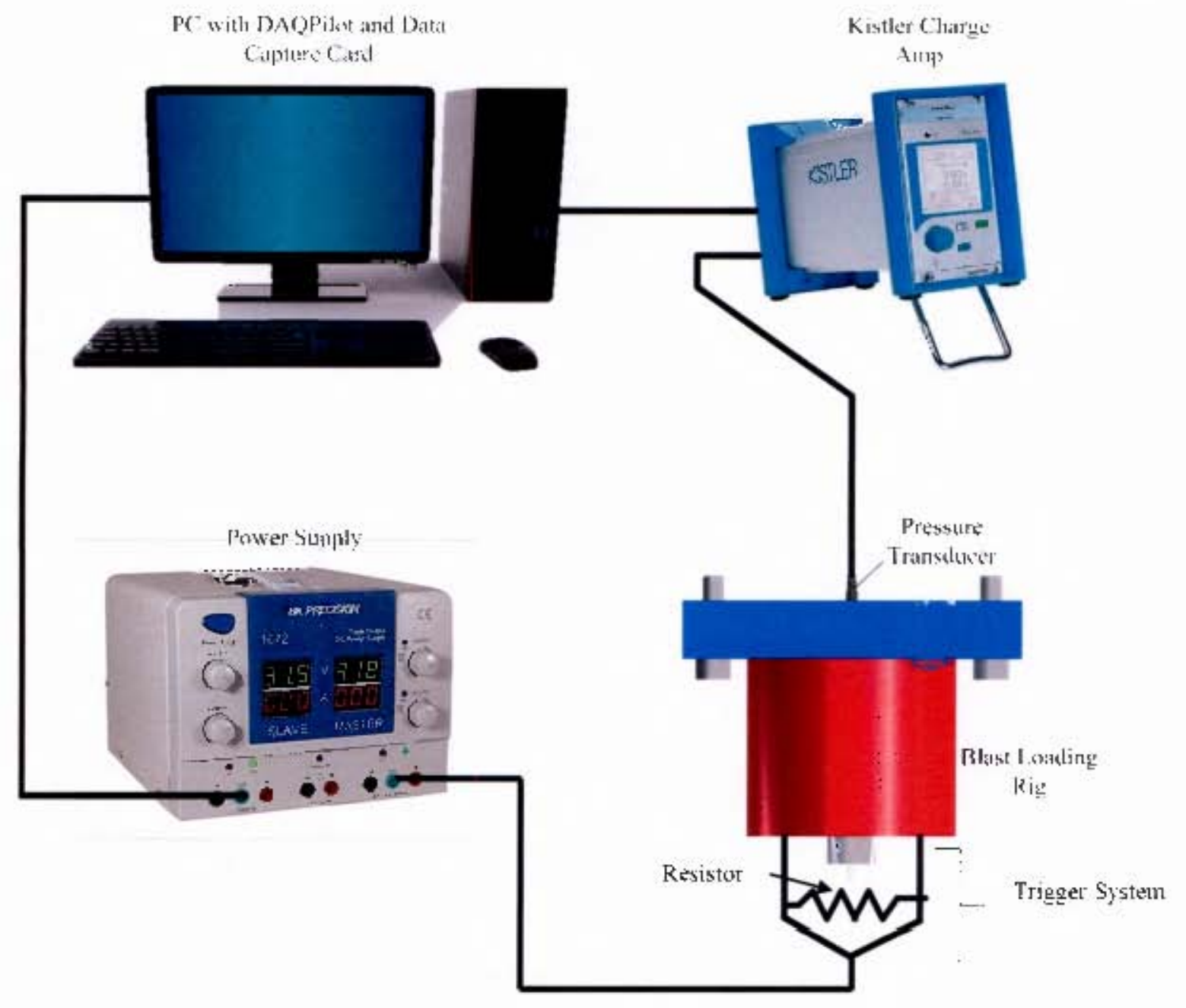

ligure (.2.4: Simple schematic of pressure transducer connectivity and all necessary components

1'he amplitied signal was recorded using DAQl'ilot software with a P'C19812 data capture card installed, capable of measuring up to $5 \mathrm{MH}$ lz frequency sample rate. The DAOPilot software reguired an initial set-up that was easily navigable through a software wizard. Two chands were chosen, onc for the input signal and one for the output signal (A] 0 and AI I). The sampling rate was specified as $1 \mathrm{Ml17}$, ideally the sampling rate must be as thigh as possible to capture the blast wave event that occurred within micro-seconds. The sampling rate was constrained by the available equipment. A trigger source was chosen as channel 0 and the trigger mode was selected as "middle", enabling recording to start before the trigger was activated, again ensuring no initial data was lost. ]'he trigger polarity was set to negative and the trigger activation voltage was defined as $3 \mathrm{~V}$, corresponding to the voltage from the resistor in the trigger system. The incoming data was then oreanised and processed using MATLAB, which recorded the raw data and graphically represerted the resulls as an $\mathrm{X}-\mathrm{Y}$ data set. 


\section{C.3 Pressure Measurement Results}

Blast loading experiments were carried out using the cylindrical tube (fully vented explosion) and without the cylindrical tube (free air explosion). This attempted to eliminate any of the unknown effects caused by the tube. The peak pressures from the constrained explosion experiments were tabulated in Table C.3. The free air explosions, along with the predicted incident pressures were determined using Bakers equations for free air explosions and the results are listed in Table C.4. The results from the experiments are graphically represented in Figure C.2-Figure C.4. The numbers presented in the graphical legends indicate the number of the experiments carried out on the pressure transducer. Several experiments were conducted in order to obtain experimental repeatability confidence in the pressure measurements to ensure the accuracy was acceptable. 


\section{C.3.1 Constrained Explosions}

Table C.3: Peak pressures for constrained explosions

\section{Ratius frum Centre (mm)}

\begin{tabular}{|c|c|c|c|}
\hline Blast \# & 0 & 25 & 49 \\
\hline 1 & 168.95 & 136.17 & 78.71 \\
\hline 2 & 248.05 & 19.29 & 71.04 \\
\hline 3 & 109.86 & \multirow[t]{2}{*}{62.99} & \\
\hline 4 & 130.62 & & \\
\hline
\end{tabular}

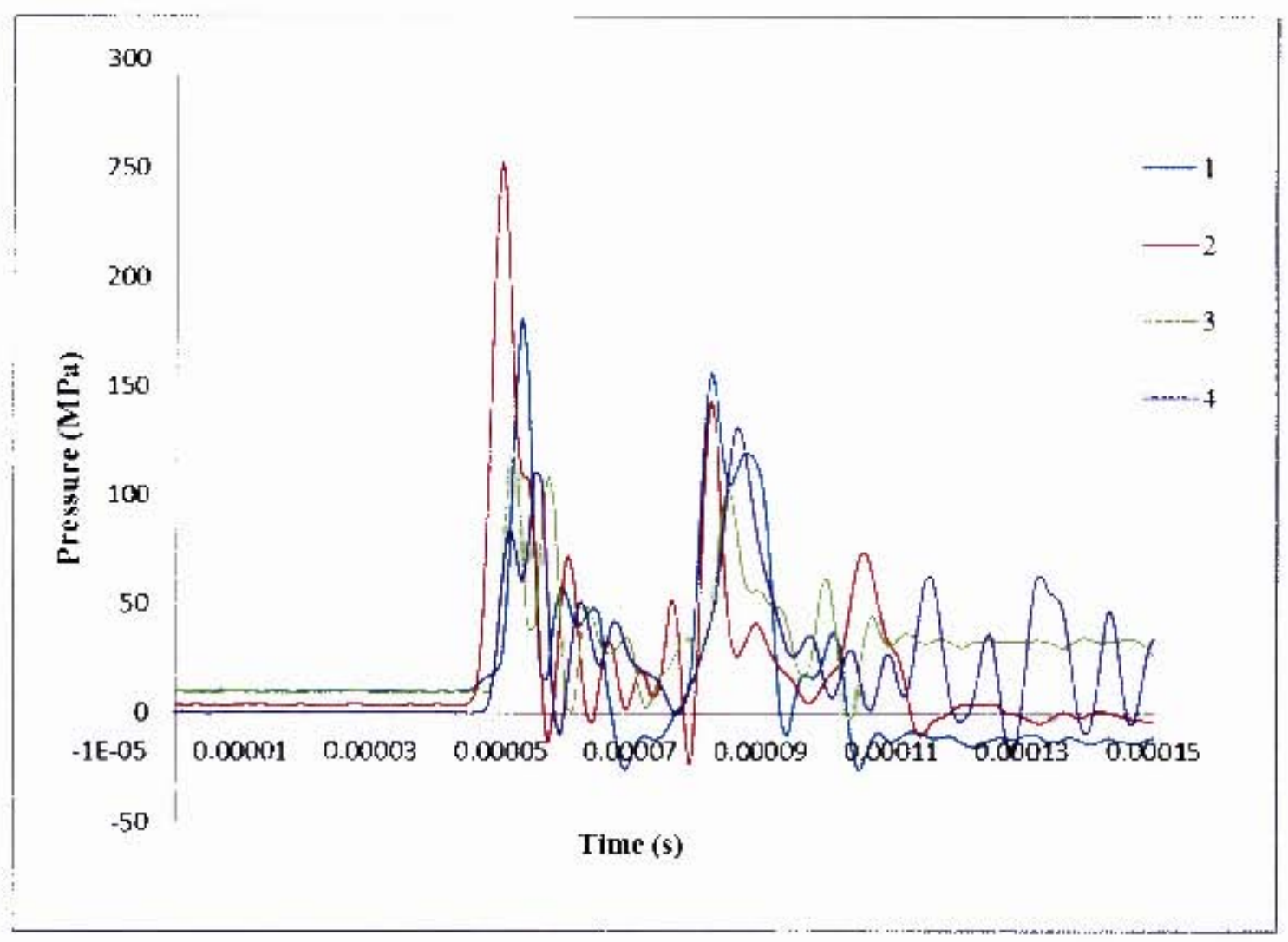

Figure $\mathrm{C.2:Gr}$ Gph of blast pressure clarge located at centre (Tube) 


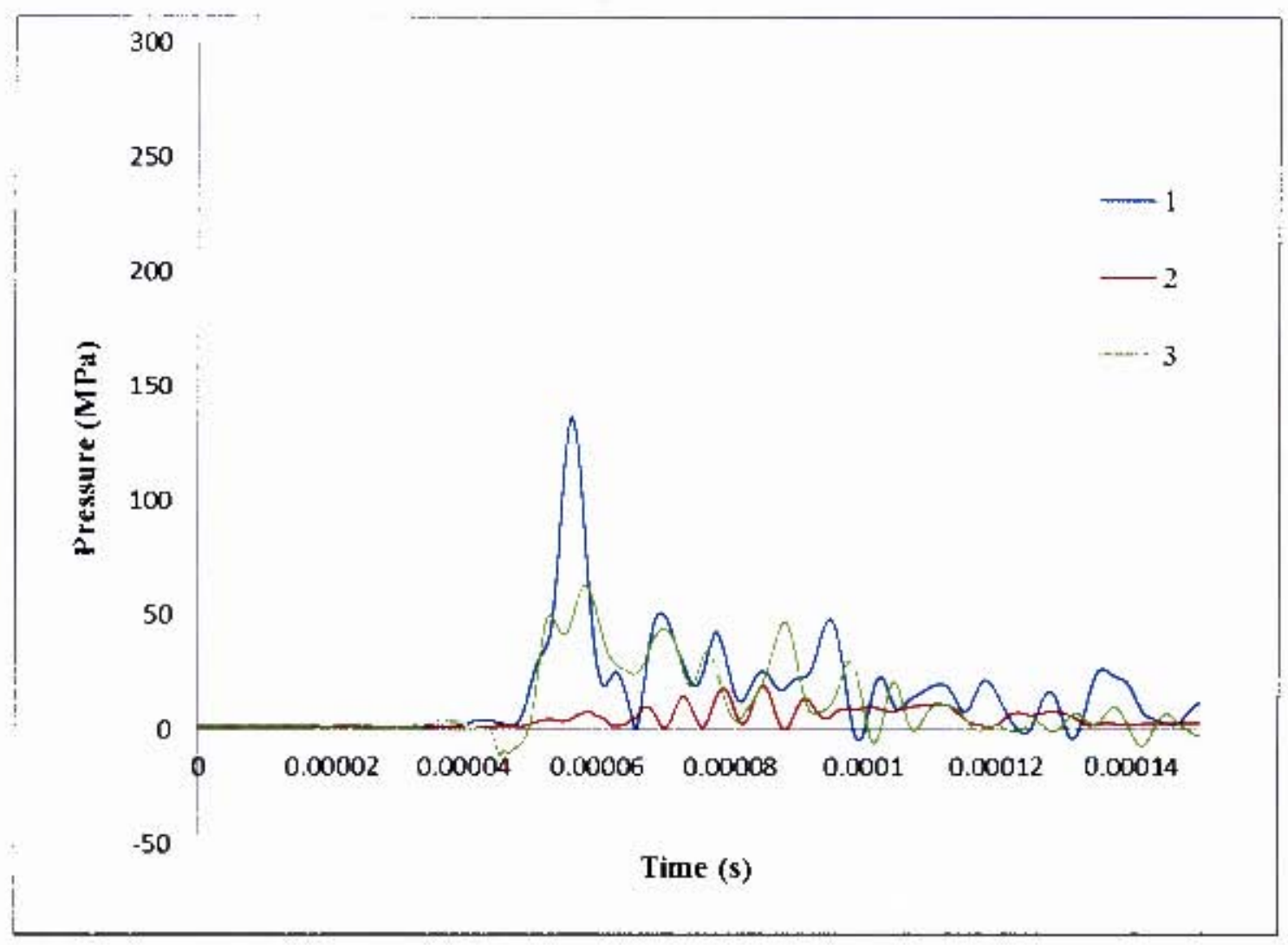

Figure (.3: firaph of blast pressure charge lncated at radius of 25 man (Tulbe)

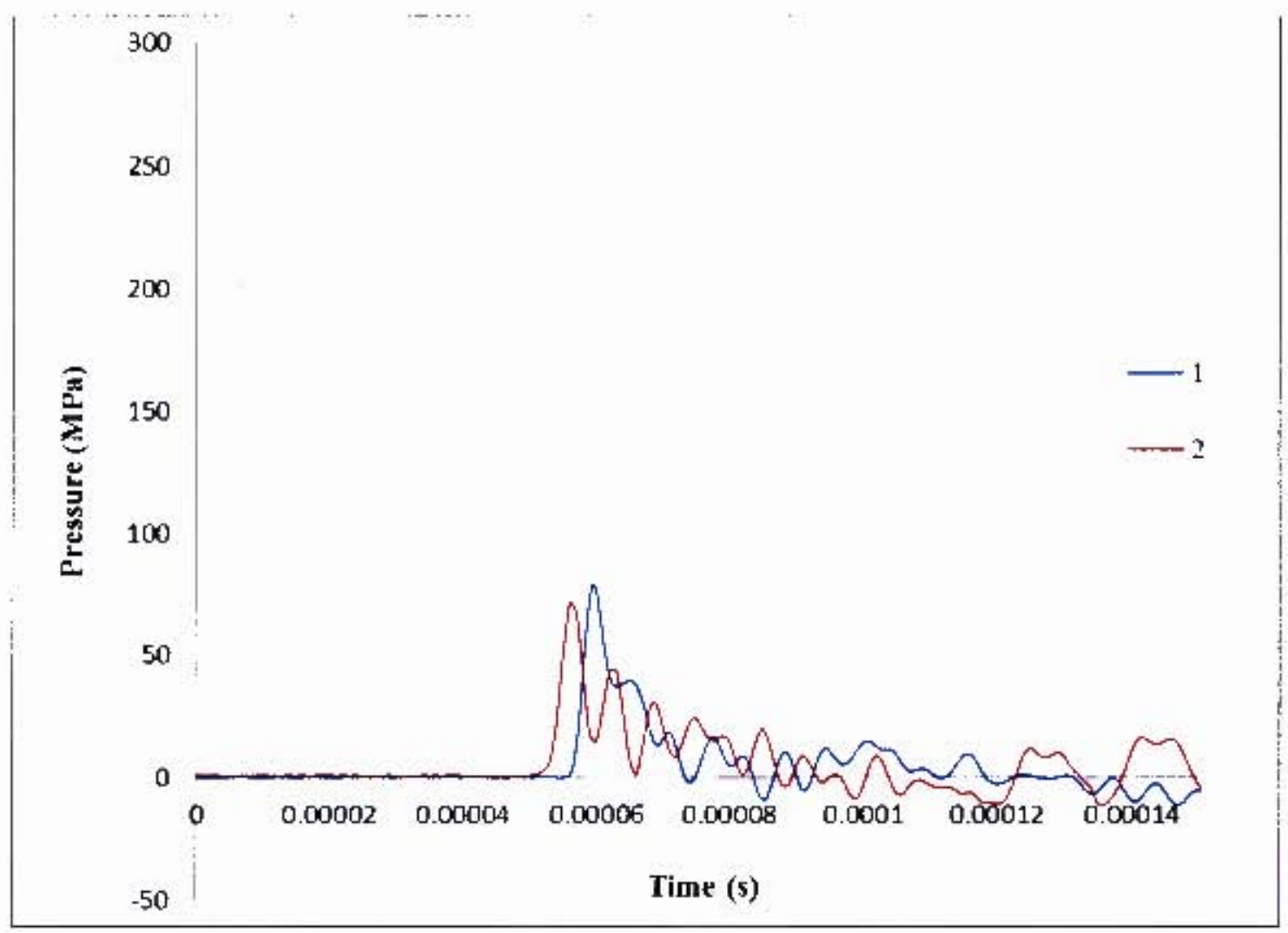

Figure (.4: (iraph of blast pressure charge located at radius of 49 num (Tube) 


\section{C.3.2 Free Air Explosions}

Table C.4: Peak pressures for fres air explesions

\begin{tabular}{ll|}
\cline { 2 - 2 } & $\begin{array}{l}\text { Radius } \\
(\mathbf{m m})\end{array}$ \\
\hline Blast \# & $\mathbf{0}$ \\
\hline 1 & 21.48 \\
\hline 2 & 4.98 \\
\hline 3 & 29.20 \\
\hline Baker's & 24.56 \\
Eg. & \\
\hline
\end{tabular}

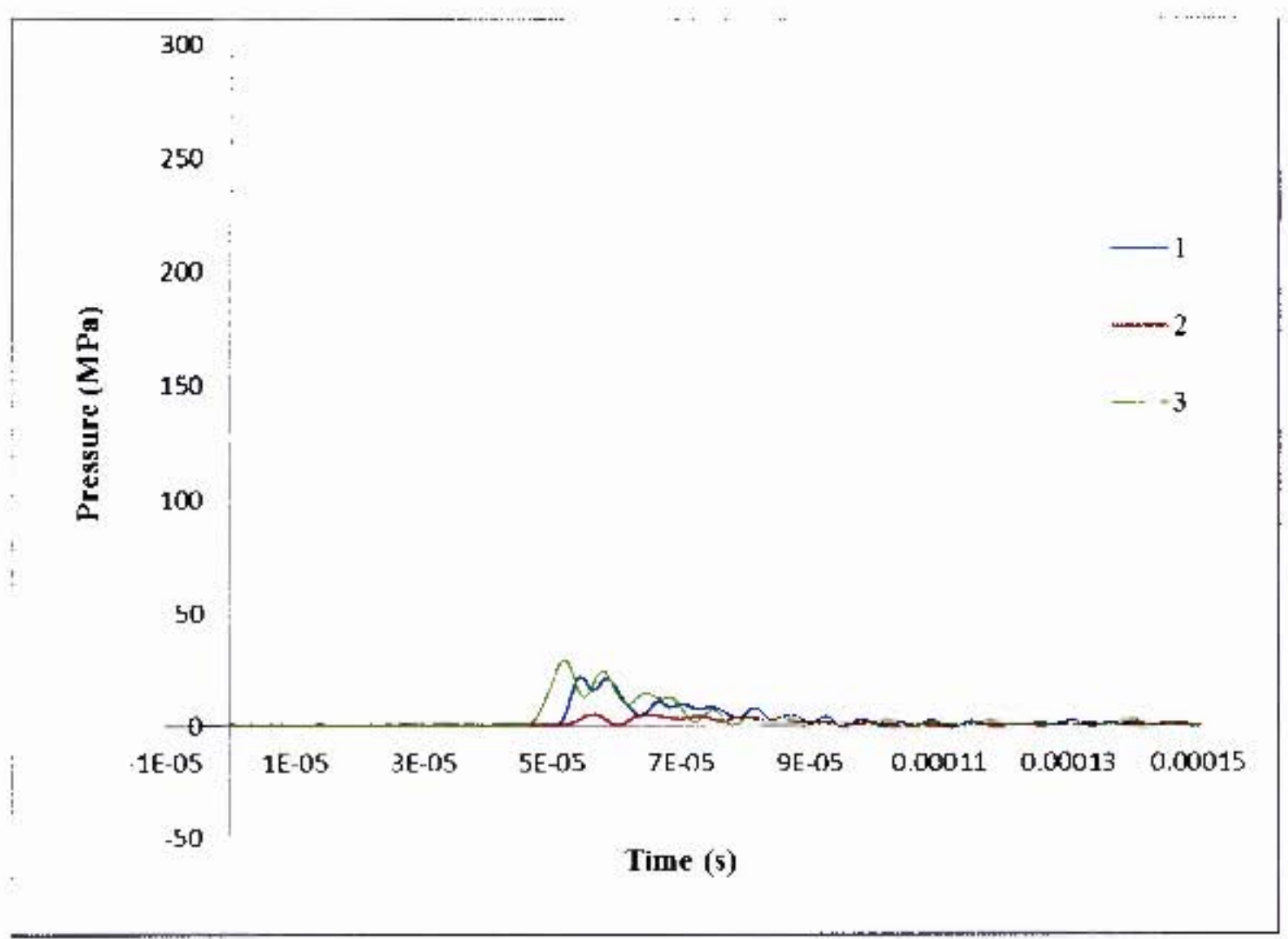

Figure (..5: Graph of blast pressure charge located at the cent re of the test plate (free air explosion) 


\section{C.4 Discussion}

\section{C.4.1 Constrained Explusions}

From the graphs in Figure $\mathrm{C} .2$ - rigure $\mathrm{C}, 5$. The results confirmed the incident pressures from the explosive detonation in eorstrained loading conditions were successfully measured using a. PC.B pressure transducer. Also, it was evident that the centre of the plate experienced greater pressures than the outer regions of the plate which is visible from ligure C.6. The dectease in pressure was fitted with a second order polynomial trend linc. As the radius of the plate increased from the centre, so the incident pressure decreased from $248.05 \mathrm{Ml}$ 'a (centre) to $78.01 \mathrm{MPa}$ (radius of $49 \mathrm{~mm}$ ). I his was approximately a $69 \%$ drop in pressure.

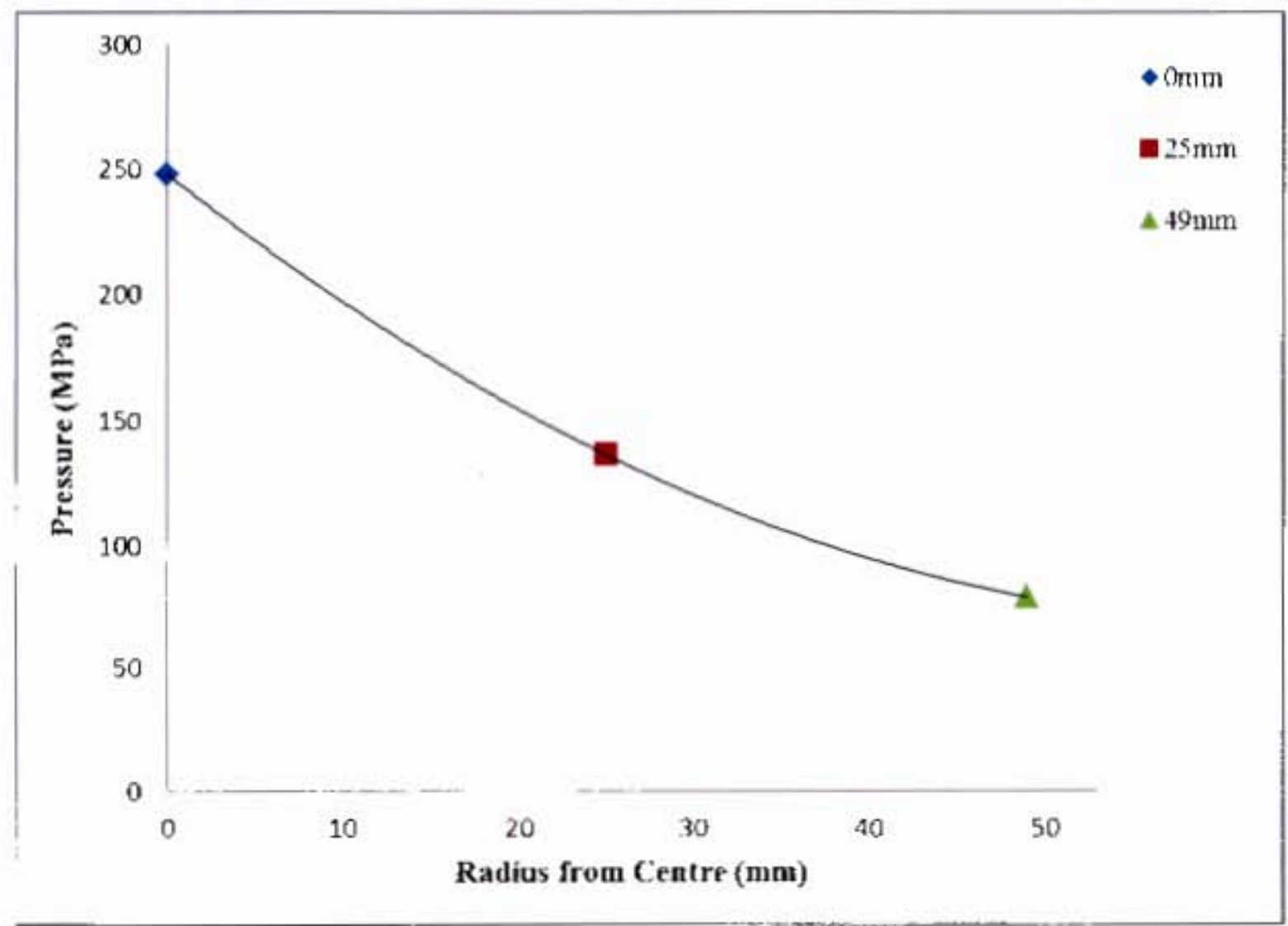

Figure C:6: Graph shewing the decrease in pressure from the centre of the blast area to the euter region

However, the results from the constrained explosion experiments displayed some inconsistencies. These inconsistencies cane in the form of the lack of repeatability between each eonsecutive 
experiment where the same loading conditions and recording methods had been implemented. For a charge placement at the centre of the blast area, the percentage difference between the maximum peak pressure (248.05 $\mathrm{MPa}$ ) and the minimum peak pressure (109.86) was $56 \%$, between two consecutive blasts under the same loading conditions. More concerning was the fact that no other results from all four of the blast experiments correlated with one another. The peak pressures for experiments conducted using the tube and charge detonated at the centre of the plate seemed to vary drastically with no repeatability and fell in a rather wide range of possible values. The same could be said for the constrained experiments carried out using the tube and charge detonated at a radius of $25 \mathrm{~mm}$ from the centre. The percentage difference between the maximum pressure (136.47 $\mathrm{MPa})$ and minimum pressure (19.29 $\mathrm{MPa}$ ) was $86 \%$. The experiments conducted with the charge detonated at a radius of $49 \mathrm{~mm}$ from the centre displayed somewhat repeatable results with a maximum-minimum peak pressure difference of $10 \%$.

\section{C.4.2 Free Air Explosions}

The free air explosion experiments showed a similar inconsistency as the constrained experiments using the tube, which were graphically represented in Figure C.5. The results for the free air blasts 1 and 3 correlated acceptingly with Baker's predicted results, as the values fall within $18 \%$ above and below the predicted value $(24.56 \mathrm{MPa})$. However, blast 2 of the free air experiments, fell far below the predicted value and measured only $4.98 \mathrm{MPa}$, which was not consistent with blast 1 and 3.

A reason for the inconsistencies in the experimental pressure measurements, for each blast area location, was due to the ability of the hardware to effectively capture the extremely high speed of the blast. The sampling rate of the charge amplifier $(200 \mathrm{kHz})$ was simply not high enough to successively capture all of the pressure-time data from the incoming blast wave. If the sampling rate was not high enough, then the initial peak of the incident pressure would be 'missed' or not processed by the charge amplifier, as the initial peak 'event' occurred in an extremely small time differential, resulting in the inconsistencies between each consecutive blast test. From the graphical representations of the pressure-time histories of the experimental results, in some cases where the incident pressure peaks varied considerably with one experimental value being far greater than the next, the decay region of the measured pressures seemed to correlate with one another. The decay correlation is evident in Figure C.3, between experiments 1 and 3. This reconfirms the theory of the initial incident peak pressure not being captured by the hardware, due to insufficient sample rate capabilities. 


\section{C.5 Comparison with Yumerical P'ressure}

The pressures measured from the fully vented and free air loading experiments were compared with the numerically simulated pressure values. The pressure-time histories were extracted from Al: TODYN simulations. The comparisons are illusirated in Figures C.7-C.10.

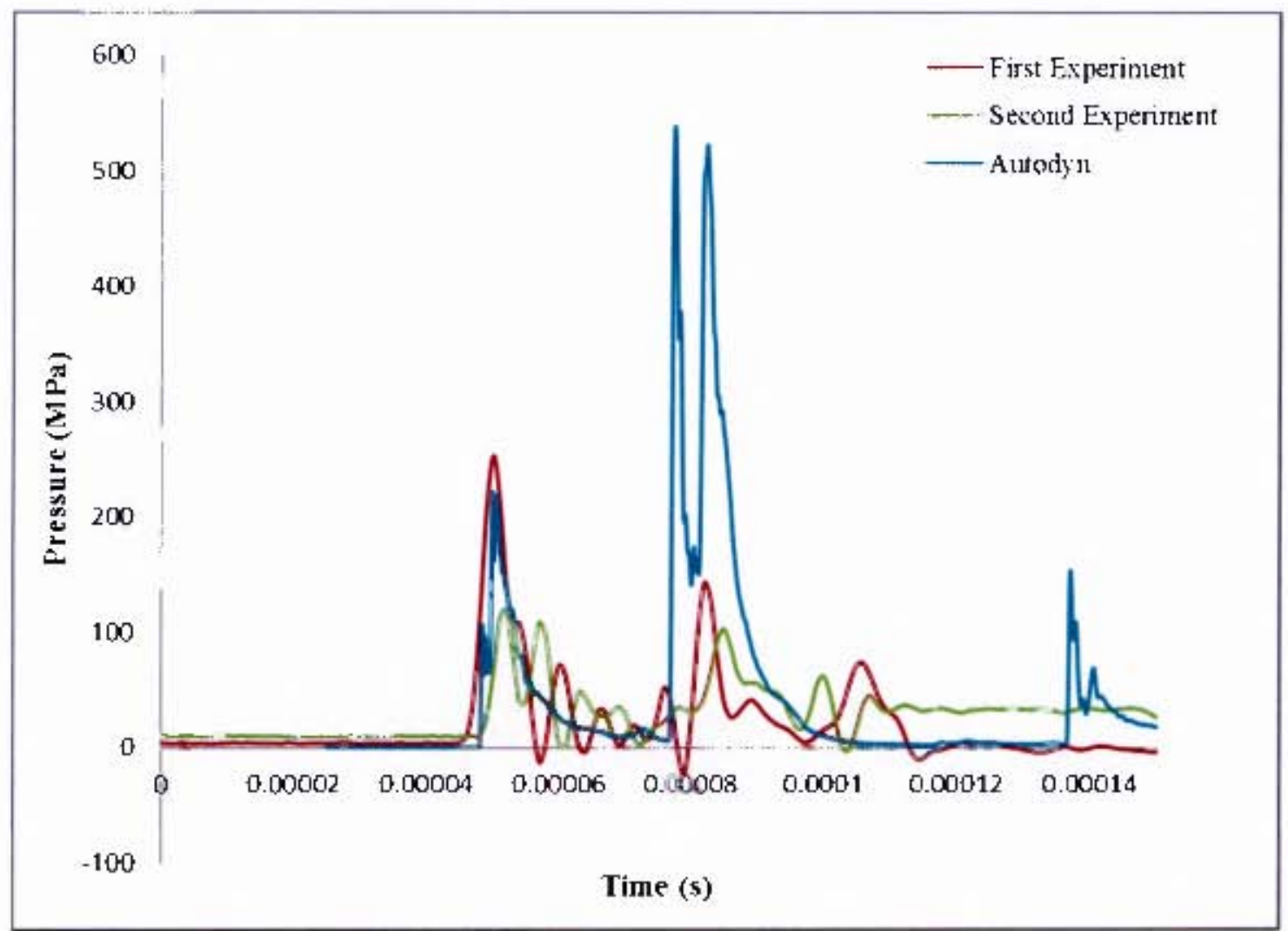

Figure C.7: Graph comparing experimental and ALTODYY numericil pressure-time fistories for the sentre of the: blast area 


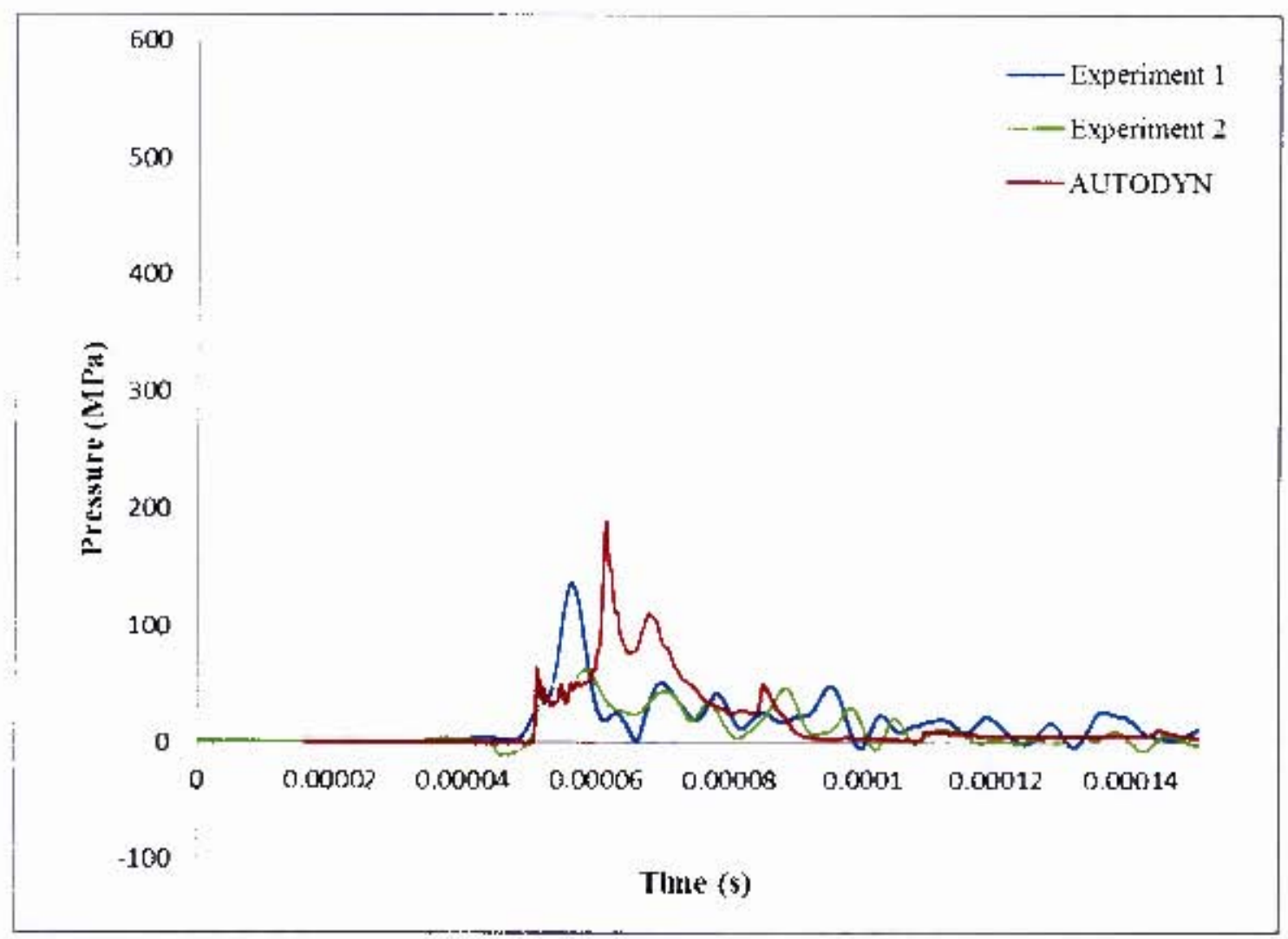

Figure C 8: Graph comparing experimental and Al TODYN numericil pressure-time bistories for a radius of $25 \mathrm{~mm}$ from the centre

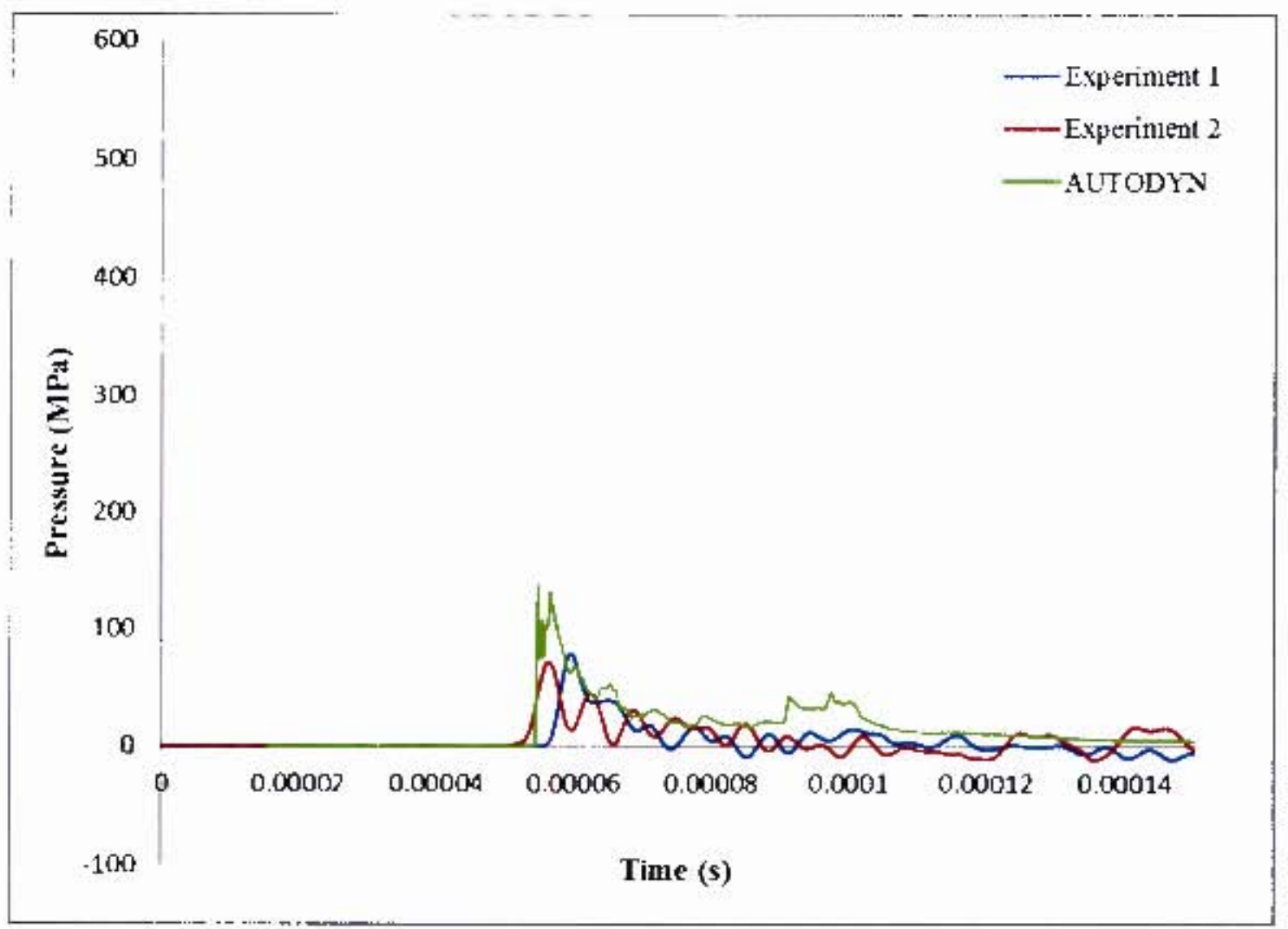

Figure C.9: (irapls cornparing experimental and ACITODYY numerical pressure-time bistories for a radius of $49 \mathrm{cmm}$ from the centre 


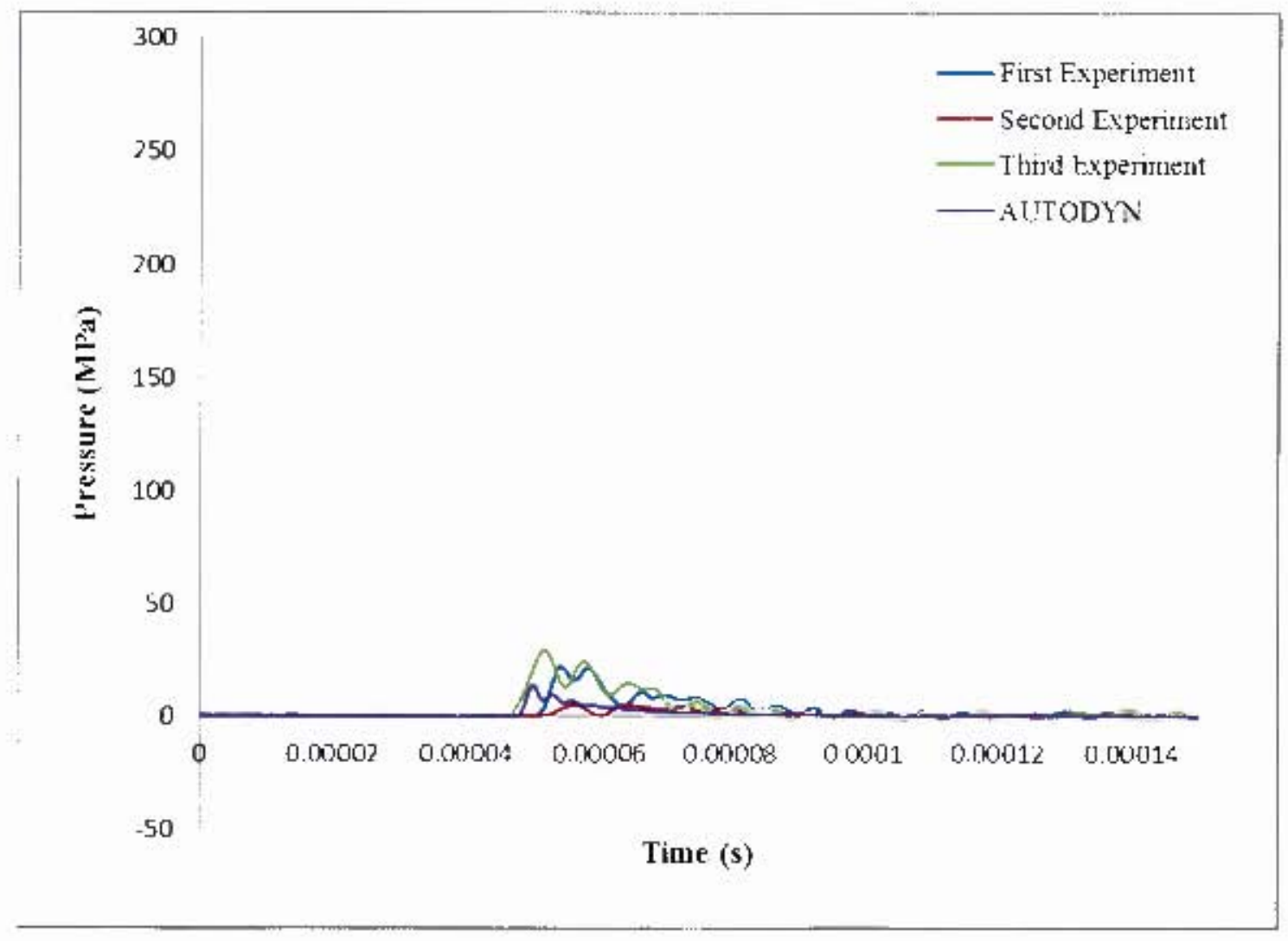

Figure C.10: Graph comparing experimental and AllOOYN numerical pressure-time historit: for frat ar blasl loads

Figure $\mathrm{C} .7$ illustrates a reasonable correlation between the initial peak pressures of the experiments (248.05 MPa) and numerical sinulations (222.MPa), with a $10.5 \%$ difference in the range of blast loading times up 1070 s. Disregarding the inconsistency or non-sepeatability between the experimental pressure readings, the correlation between numerical and experimental results indicatcd the pressures were measured successfully. This showed the numerical work could he implemented in simulating the explosive blast experiments.

At a radius of $25 \mathrm{~mm}$ from the centre of the blast area. the numerical (Al!'OODYN) incident pressure peak $(185 \mathrm{MPa})$ was $26 \%$ higler than the experimental equivalent (137.MPa) and the comparative pressure-time histories had a vastly different shape to one another. At a radius of $49 \mathrm{~mm}$ from the blast centre, the numerical ( $131 \mathrm{MPa}$ ) and experimental (73 $4 \mathrm{~Pa}$ incident peak pressures diftered by $44^{\text {th }} \%$.

The pressure-time comparisons between the experimental and mumerical results, beyond $70 \mu 5$ at the centre of the blast area, did nol correlare. Frum Figurc C.7, secondary pressurc spities were observed as a result of tompunat pressure reflections withim the rigid cylindrical tube. The numerica] (ALTODYX) peak pressure for the secondary spike (538.MPa) was $73.4 \%$ grealer than the experimental secondary reflective pressure spike (143.02.MPa). Due to the complications in various 
transverse reflections occurring inside the cylindrical tube, AUTODYN may have difficulties in simulating the pressure history in exactly the same manner as the experimental values at specific locations on the blast area, but was more successful in simulating the pressure holistically throughout the blast area. The impulse resulting from a charge mass of $10 \mathrm{~g}$ for the experimental results (21.91Ns) correlated within $1 \%$ of the numerical results $(22.14 \mathrm{Ns})$, as can be seen in Section 7 , allowing the assumption that the simulated blast load and the experimental blast load imparted similar damage to the respective test plates. These inconsistencies may have also occurred from assumptions made with respect to numerically modelling the cylinder walls as perfectly rigid and reflective boundaries, with all the energy maintained throughout the course of the blast event. In reality, during the experimental blast loading tests, the cylindrical tube was not perfectly rigid and reflective. There were imperfections along the tube walls and microscopic gaps where the tube was fastened to the test plate, allowing gas to escape. These factors may have caused the incident pressure wave to behave differently in the experiments when compared to the numerical simulated scenario. These ideal assumptions may have also explained the different shapes of the pressure-time histories between the experimental and numerical results at radii $25 \mathrm{~mm}$ and $49 \mathrm{~mm}$ from the centre of the blast area. The large secondary numerical pressure spike seemed to only be present towards the centre of the blast area, as can be observed in Figure C.7 - Figure C.10, where at the outer regions of the blast area, the numerical pressure decay seemed to follow the experimental pressure decay.

The numerical results for the fully vented explosion simulations, generally over predicted the incident pressure and at the centre of the blast area, produced large secondary pressure spikes, assumed to be reflective complications inside the cylindrical tube. This was not the case for the numerical simulations of the free air explosions. From Figure C.10, the numerical incident peak pressure (13.6 MPa) under predicted the experimental peak pressure $(29.2 \mathrm{MPa})$ by $53 \%$. There was also no evidence of any reflective pressure spikes in the free air explosion simulation, only a smooth pressure decay, correlating to the experimental equivalents. This further reinforced the issue of the complications involved with compound pressure reflection off the cylindrical tube walls, by assuming ideal reflective boundaries and rigid bodies. 


\section{Appendix D - Drawings}

D.1 Test Plate
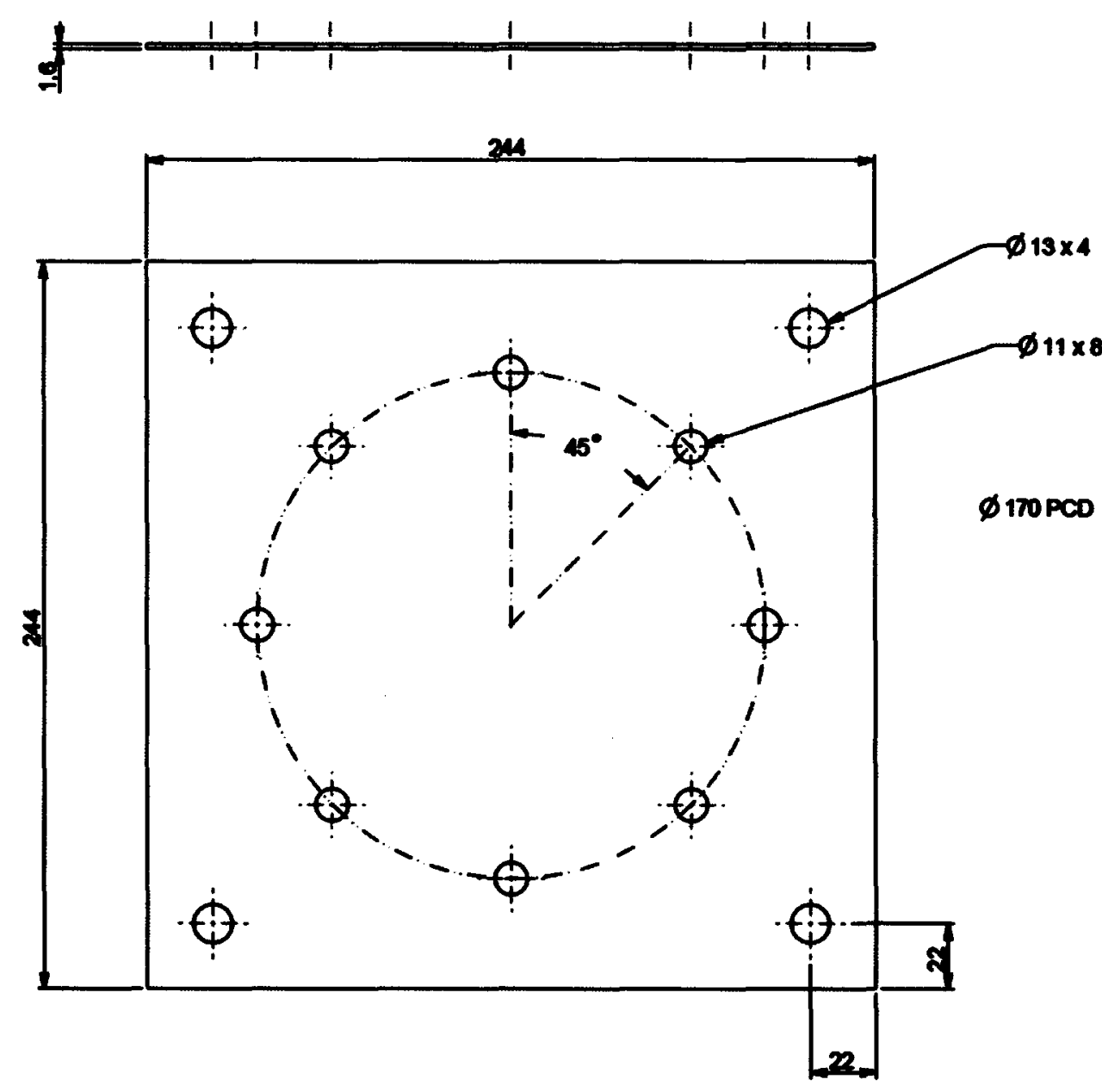

\begin{tabular}{|c|c|c|}
\hline 20 & Dom & Shal \\
\hline \multicolumn{3}{|c|}{ Plate } \\
\hline monsons & VCT & 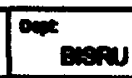 \\
\hline in & 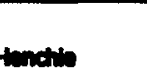 & 1 \\
\hline
\end{tabular}




\section{D.2 Tensile Test Specimen}
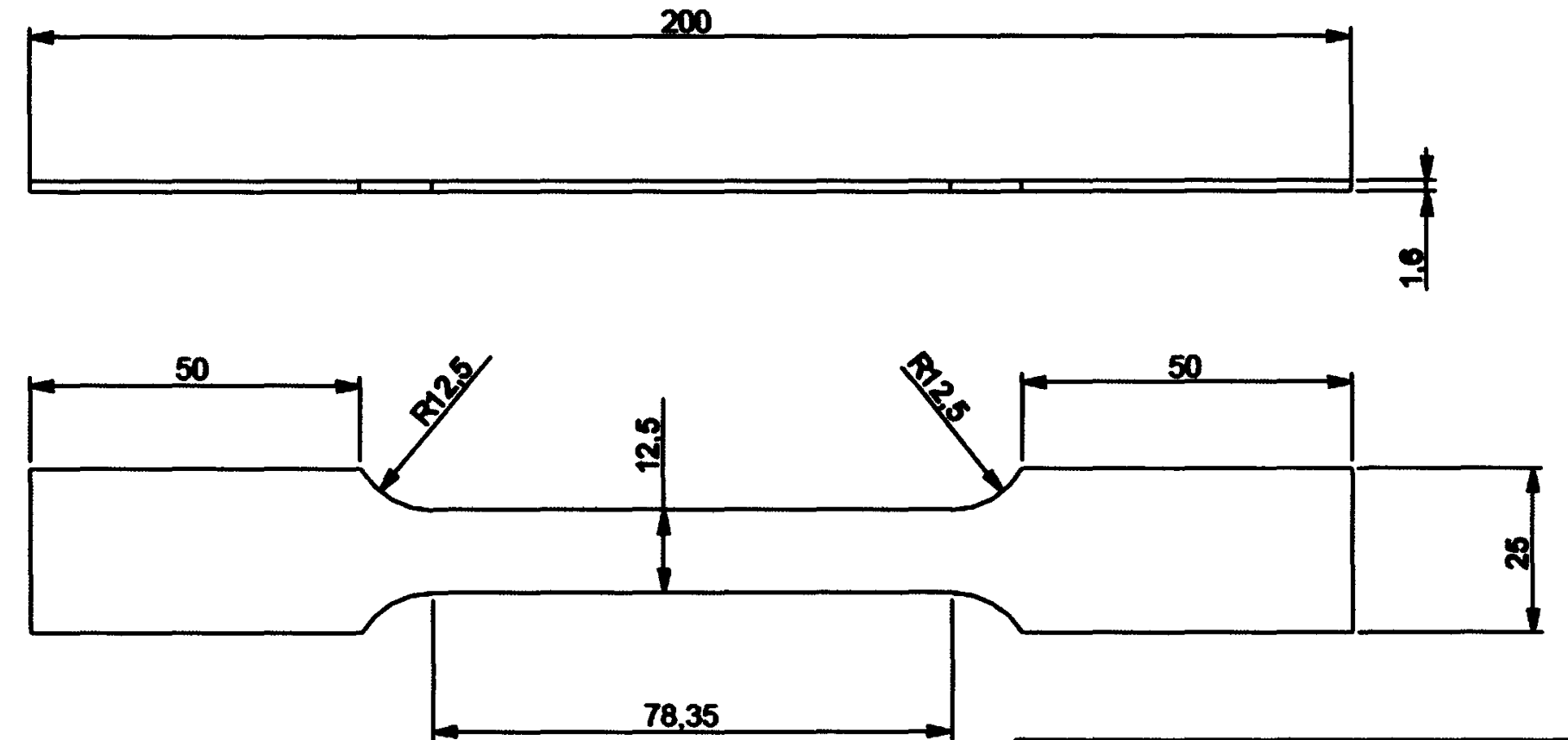

\begin{tabular}{|c|c|c|}
\hline $\begin{array}{l}\text { ar. } \\
5 \text { per Sheet }\end{array}$ & \multicolumn{2}{|c|}{ Domex 700 Steel } \\
\hline \multicolumn{3}{|c|}{ Tensile Test Specimen } \\
\hline Descrourzo12 & UCT & \begin{tabular}{|l} 
Dent \\
BISRU
\end{tabular} \\
\hline \multicolumn{2}{|c|}{ Trevis Henchio } & 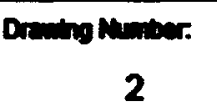 \\
\hline
\end{tabular}




\section{Appendix E - Theoretical Formulations}

\section{E.1 Rankine - Hugoniot Jump Equations for Detonation Wave Conservations}

Conservation of mass:

$$
\begin{aligned}
& \rho_{0} D \rho_{1}\left(D-U_{d}\right) \\
& \therefore \rho_{1}=\frac{\rho_{0} D}{D-U_{d}}
\end{aligned}
$$

Conservation of momentum:

$$
\begin{gathered}
P_{1}-P_{0}=\rho_{0} D U_{d} \\
\therefore P_{0}=P_{1}-\rho_{0} D U_{d}
\end{gathered}
$$

Eq. E.4

Conservation of energy

$$
\begin{gathered}
\frac{P_{1}}{\rho_{1}}+\frac{\left(U_{d}-D\right)^{2}}{2}+e_{1}=\frac{P_{0}}{\rho_{0}}+\frac{D^{2}}{2}+e_{0} \\
\therefore e_{1}-e_{0}+\frac{U_{d}^{2}}{2}-\frac{2 U_{d} D}{2}=\frac{P_{0}}{\rho_{0}}-\frac{P_{1}}{\rho_{0}} \\
e_{1}-e_{0}+\frac{U_{d}^{2}}{2}=\frac{P_{0}}{\rho_{0}}-\frac{P_{1}}{\rho_{0}}+U_{d} D
\end{gathered}
$$

$\therefore$ Substituting Equation E.5 and E.6 into equation E.7 and utilizing the specific volume of the material, $v=\frac{1}{\rho}$, hence the Hugoniot equation can be written as: 


$$
e_{1}-e_{0}=\frac{1}{2}\left(P_{1}-P_{2}\right)\left(v_{0}-v_{1}\right)
$$

\section{E.2 Reflected Pressure Wave}

Blast loading experiments conducted with the use of a blast tube, are primarily carried out to direct the blast wave accurately and consistently towards the test specimen. The use of a blast tube eliminates any undesirable variables that may influence test results and tests can be easily repeated at a known stand-off distance and charge placement. This following information is obtained from publically available information supplied by Perdue University, school of aeronautics and astronautics [106], and is an exercise developed to better understand reflected shock waves in a shock tube. The pressure and velocity characteristics of the reflected shock wave are derived using the incident shock wave's velocity measurements.

Incident Shock

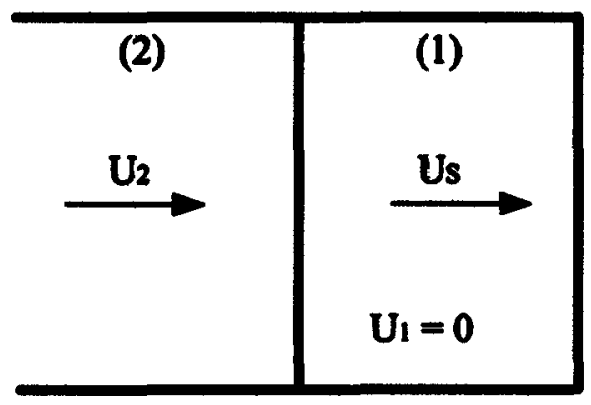

S1

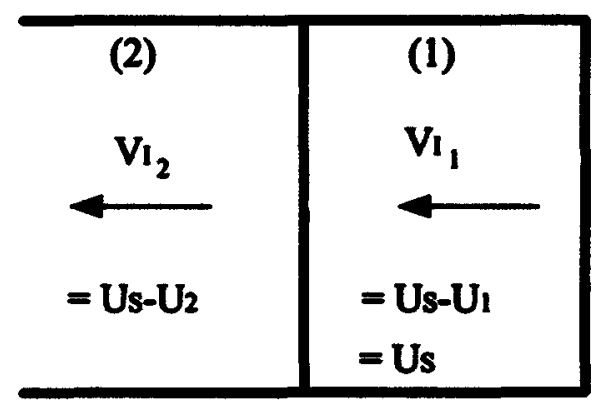

S1

\section{Reflected Shock}

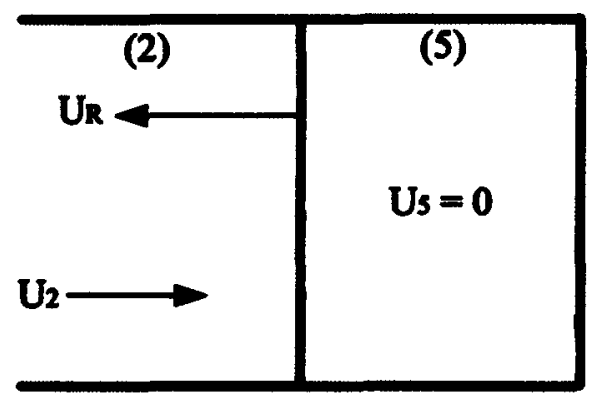

$S_{R}$

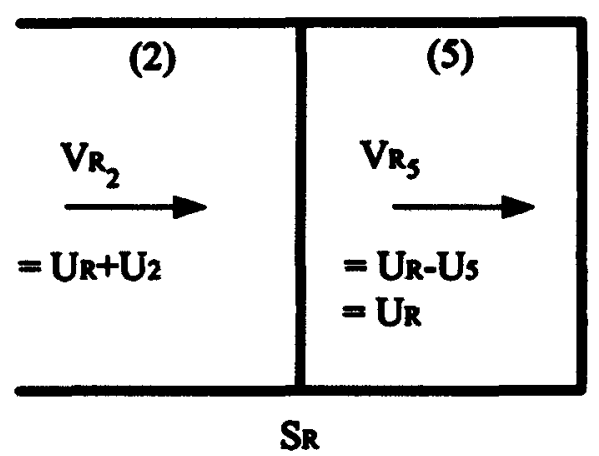

Figure E. 1: Flow Situation Before and After the Reflection of a Shock Wave from a Rigid Wall. Region 5 is Behind the Reflected Shock Wave [106] 
Figure E. 1 depicts the idealised particle flow velocities associated with the reflection of a normal shock wave in a uniform tube, from a rigid body at the end of a tube. When the normal shock wave SI (Figure E. 1), traveling at a velocity Us relative to the stationary tube, impacts the rigid end wall, it is reflected as a normal shock wave SR (Figure E. 1), which travels in the opposite direction into region (2), with a decreased velocity UR. The remaining gas flows into the shock wave with a relative velocity, $V_{R_{2}}$, where $V_{R_{2}}=U_{R}+U_{2}$. When the particles impact the end wall, their relative velocity is zero $\left(U_{5}=0\right)$, therefore it is stated, the gas transfers all of its kinetic energy on passing through the shock front SR into the region of the reflected shock, therefore increasing the properties of state the gas in this region, above those in the incident region, as mentioned before. The reflected shock front can then be treated as a renewed shock wave advancing out away from the impacted end wall, with high temperature, density and pressure gas. The flow velocities relative to the reflected shock front are written as:

$$
\begin{aligned}
& \mathrm{V}_{\mathrm{R}_{3}}=\mathrm{U}_{\mathrm{R}} \\
& \mathrm{V}_{\mathrm{R}_{2}}=\mathrm{U}_{\mathrm{R}}+\mathrm{U}_{2}
\end{aligned}
$$

Thus the Mach number of the gas ahead of the reflected shock is defined by:

$$
\mathrm{M}_{\mathrm{R}_{2}}=\frac{\mathrm{V}_{\mathrm{R}_{2}}}{\mathrm{a}_{2}}
$$

NOTE: $\mathbf{M}_{\mathbf{R}_{2}} \neq \mathbf{M}_{\mathrm{R}}$

Writing the conservation of mass for the flow through the reflected wave we have:

$$
\rho_{2} V_{R_{2}}=\rho_{5} V_{R_{5}}
$$

Substitution of Equations E.12 and E.13 into Equation E.15 gives:

$$
\rho_{2}\left(U_{R}+U_{2}\right)=\rho_{5} U_{R}
$$


This can be rewritten in the form:

$$
\mathrm{U}_{2}=\left(\mathrm{U}_{\mathrm{R}}+\mathrm{U}_{2}\right)\left[1-\frac{\rho_{2}}{\rho_{5}}\right]
$$

Multiplying and dividing the right hand side of Equation E.12 by $\mathrm{a}_{2}$ and making use of the definition of $M_{R_{2}}$ we can further write that:

$$
\mathrm{U}_{2}=\mathrm{a}_{2} \mathrm{M}_{\mathrm{R}_{2}}\left[1-\frac{\rho_{2}}{\rho_{5}}\right]
$$

$\rho_{2} / \rho_{5}$ may be found by relating reflected shock to Equation E.29, i.e.

$$
\frac{\rho_{2}}{\rho_{5}}=\frac{(\gamma-1) \mathbf{M}_{R_{2}}^{2}+2}{(\gamma+1) M_{R_{2}}^{2}}
$$

Thus substitution of Equation E.19 into E.18 and using E.19 gives finally the important relation that:

$$
\mathrm{U}_{2}=\frac{2 \mathrm{a}_{2}}{\gamma+1}\left[\mathrm{M}_{\mathrm{R}_{2}}-\frac{1}{\mathrm{M}_{\mathrm{R}_{2}}}\right]=\frac{2 \mathrm{a}_{1}}{\gamma+1}\left[\mathrm{M}_{\mathrm{s}}-\frac{1}{\mathrm{M}_{3}}\right]
$$

Using the relation that $\mathrm{a}^{2}=\gamma \mathrm{RT}$ and the equation of state, we can write that:

$$
\left(\frac{a_{2}}{a_{1}}\right)^{2}=\frac{p_{2}}{p_{1}} \frac{\rho_{1}}{\rho_{2}}
$$

Substituting for $\rho_{1} / \rho_{2}$ from Equation E.4 yields:

$$
\left(\frac{a_{2}}{a_{1}}\right)^{2}=\frac{p_{2}}{p_{1}}\left[1+\frac{\gamma-1}{\gamma+1} \frac{p_{2}}{p_{1}}\right]\left[\frac{\gamma-1}{\gamma+1}+\frac{p_{2}}{p_{1}}\right]^{-1}
$$


From the normal shock relations we had:

$$
\frac{\mathrm{p}_{2}}{\mathrm{p}_{1}}=\frac{2 \gamma \mathrm{M}_{\mathrm{s}}^{2}-(\gamma-1)}{\gamma+1}
$$

Relating this to the reflected shock we have:

$$
\frac{\mathrm{p}_{5}}{\mathrm{p}_{2}}=\frac{2 \gamma \mathrm{M}_{\mathrm{R}_{2}}^{2}-(\gamma-1)}{\gamma+1}
$$

Solving Equations E.20, E.21, E.22, E.23, and E.24 for $p_{5} / p_{2}$ gives:

$$
\frac{p_{5}}{p_{2}}=\frac{\frac{\gamma+1}{\gamma-1}+2-\frac{p_{1}}{p_{2}}}{1+\frac{\gamma+1}{\gamma-1} \frac{p_{1}}{p_{2}}}
$$




\section{Appendix F - Additional Experimental Results and Graphs}

\section{F.1 Relationship between Impulse and Charge Mass for each Repeated Blast Series}

The linear trends for the impulse versus charge mass of each repeated blast load (plate thicknesses $2 \mathrm{~mm}$ and $3 \mathrm{~mm}$ ) are compared and illustrated in Figure F. L-Figure F, 5 .

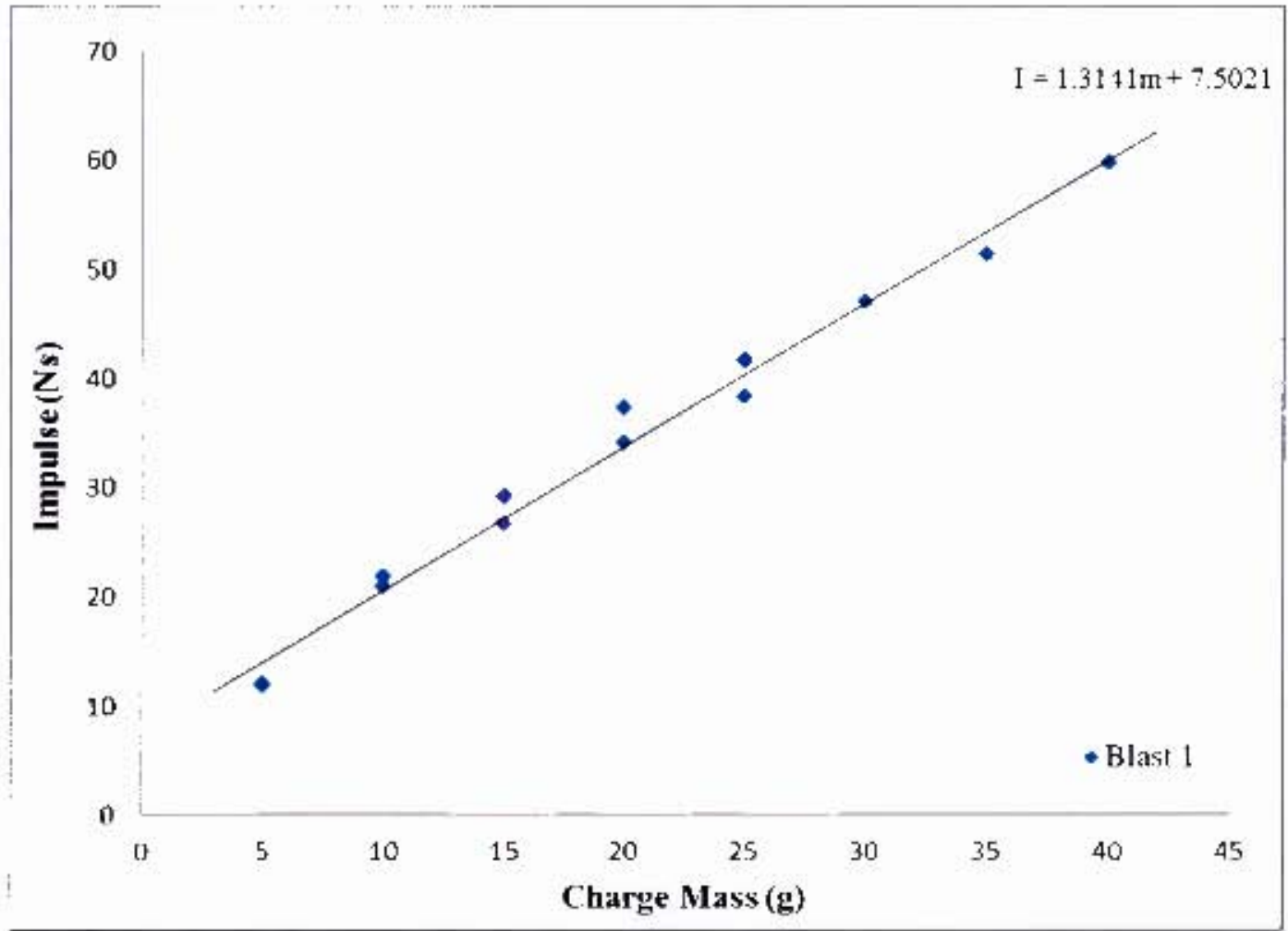

Figure F. 1:Graph of impulse versus charge ross for plates subjected to a single blast 


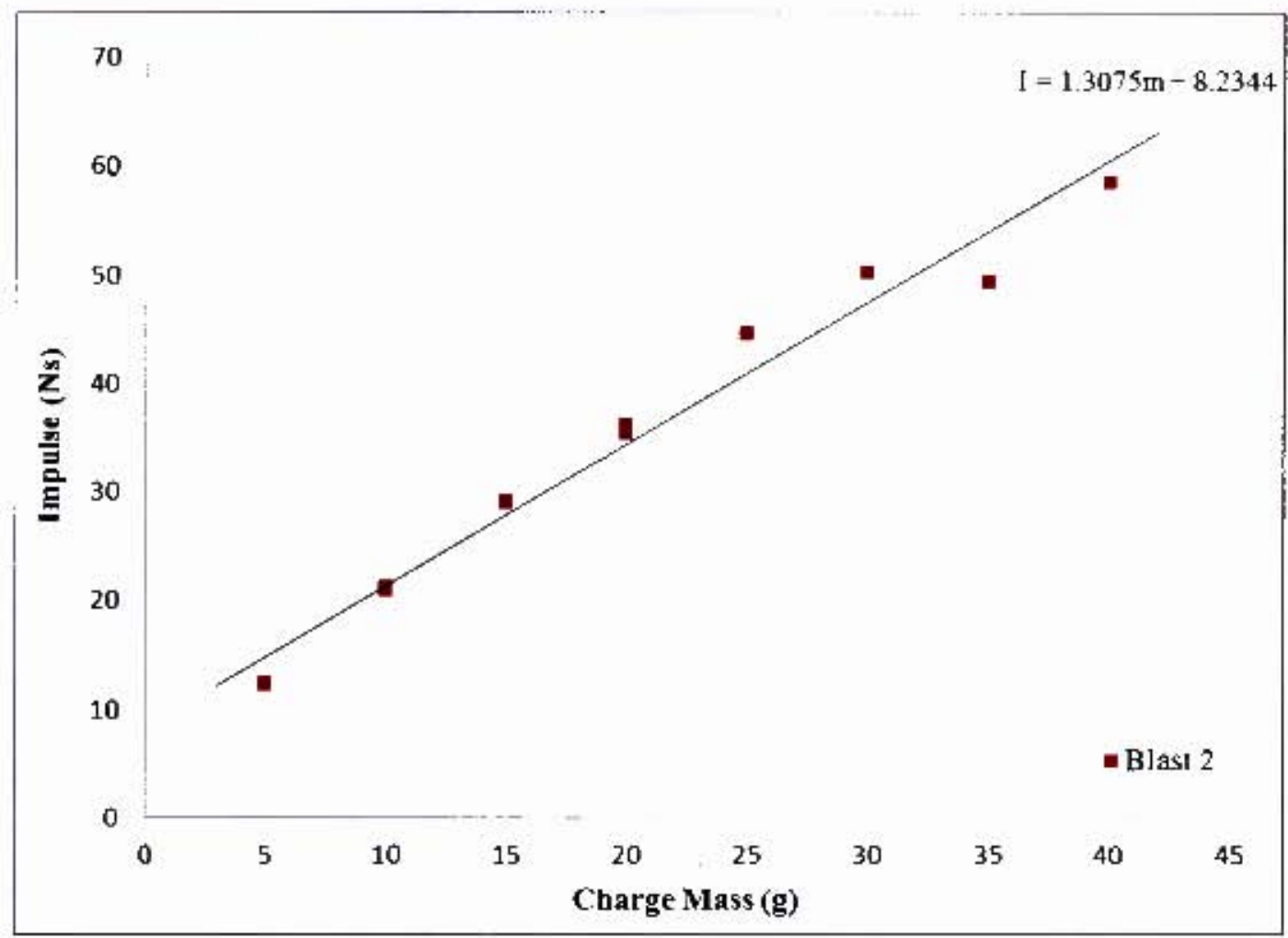

Figure F. 2: Giraph of impulse versus cliarge inass for plates subjected to 2 hlasts

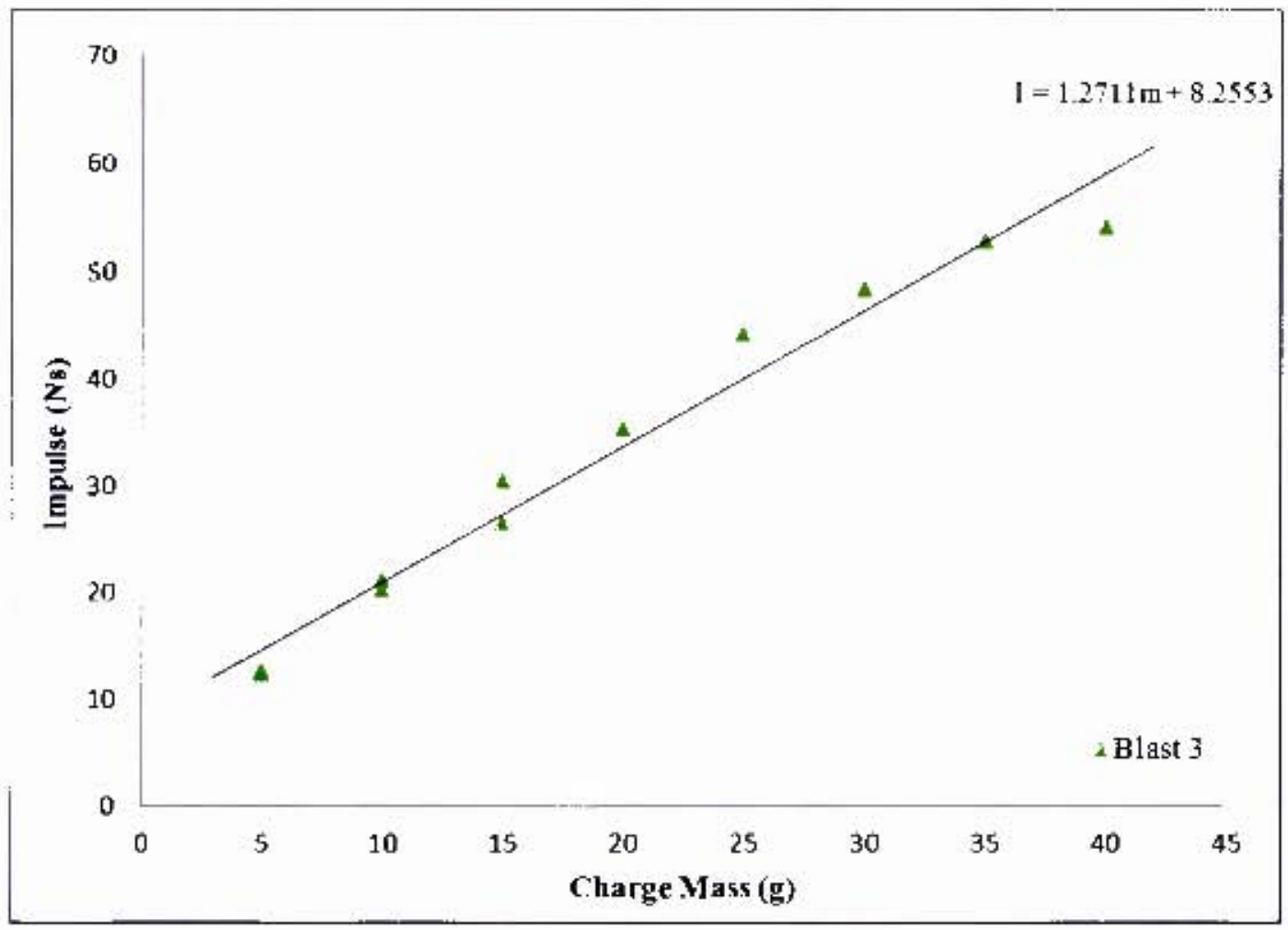

Figure F. 3:C.raph of impulse versus charge mass for plates sulijected to 3 blasts 


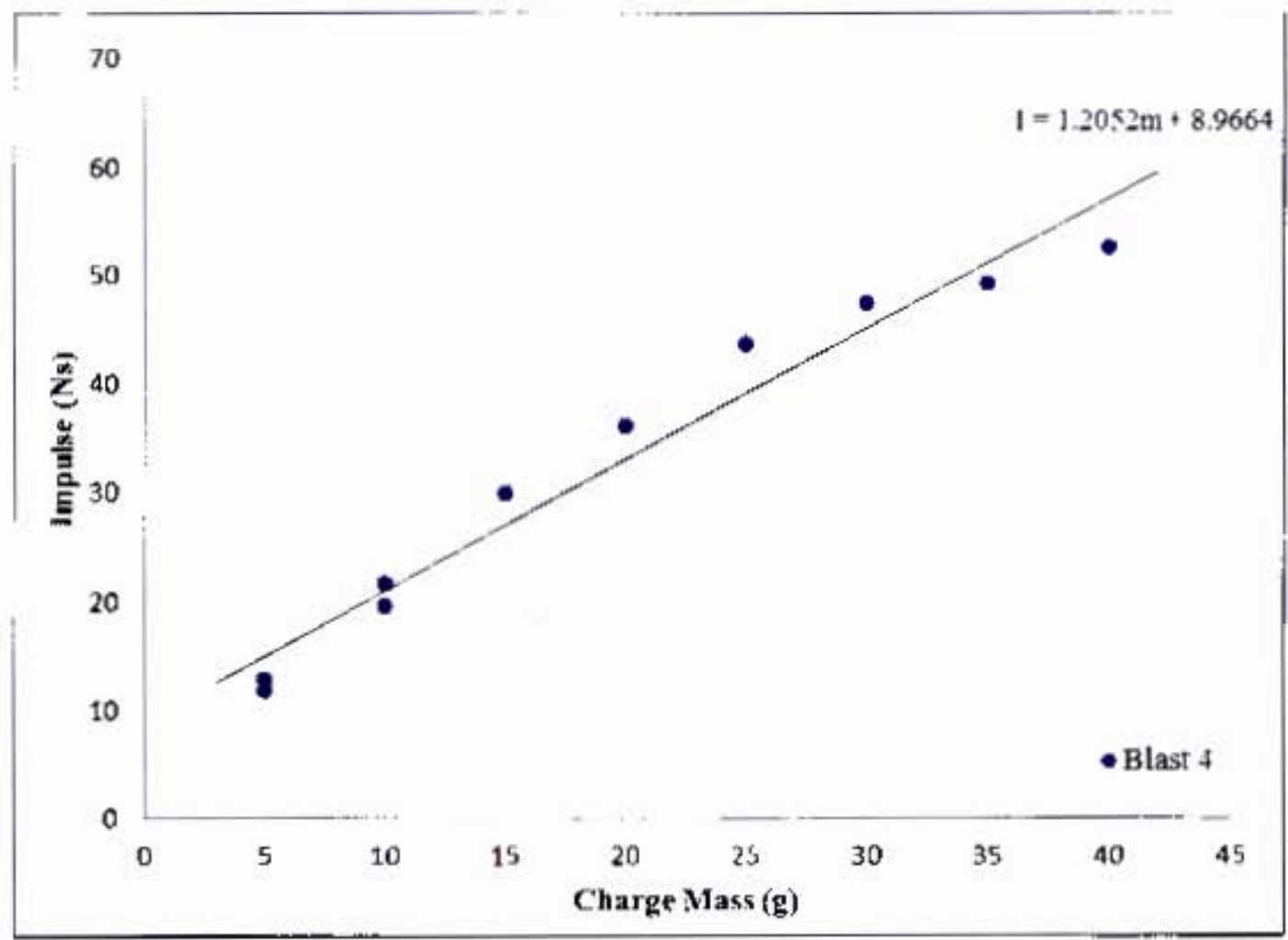

Figure F. 4:Graph of impulse versus charge mass for plates subjected to 4 blasts

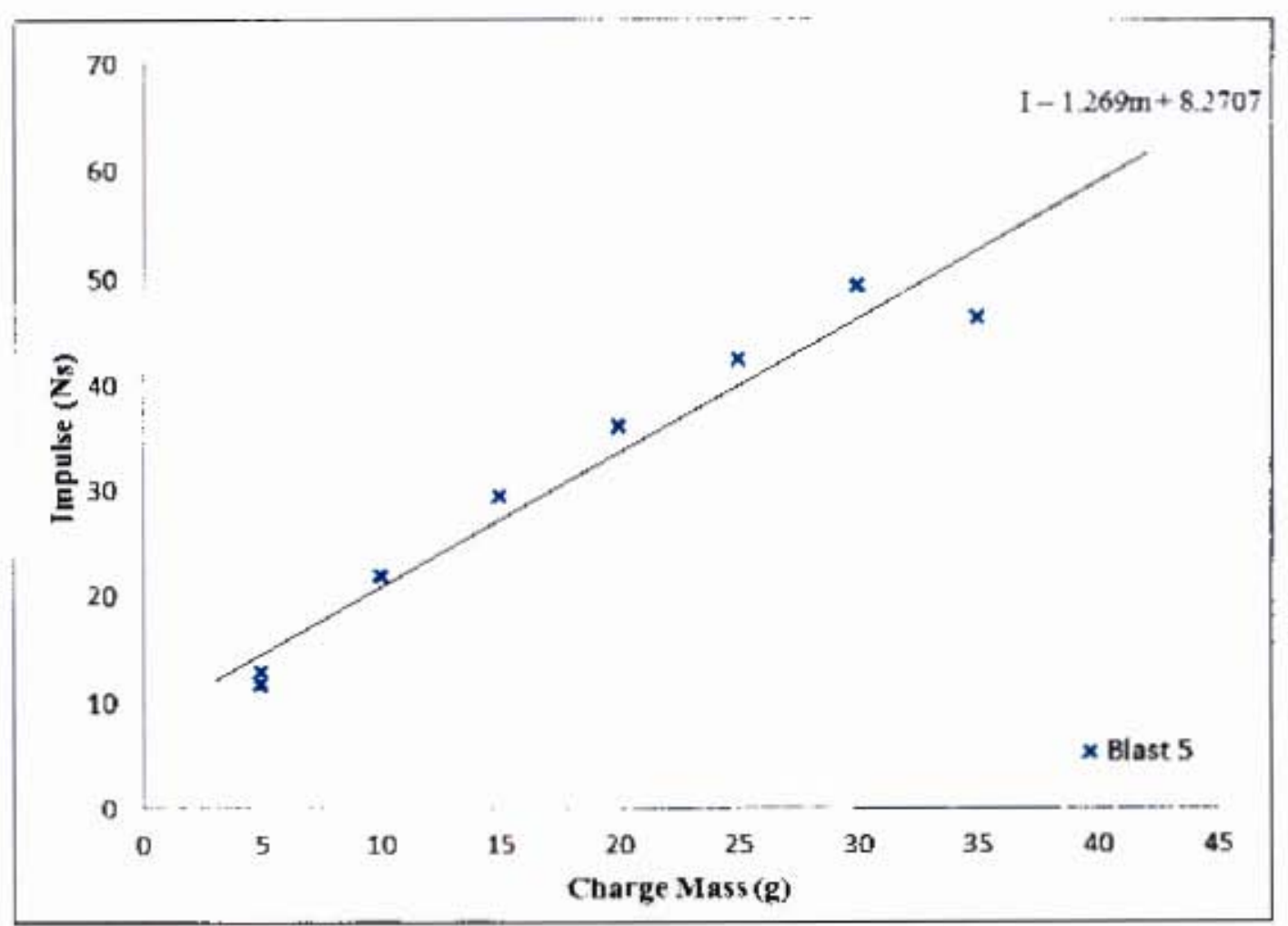

Figure F. 5:Graph of impulse versus charge mass for plates subjected to 5 blasts 


\section{F.2 Relationship between Vlidpoint Deflection and Repeated Blast}

Alternative graphical representations of midpoint deflection versus the number of blasts, displaying positive power trends. are presented.

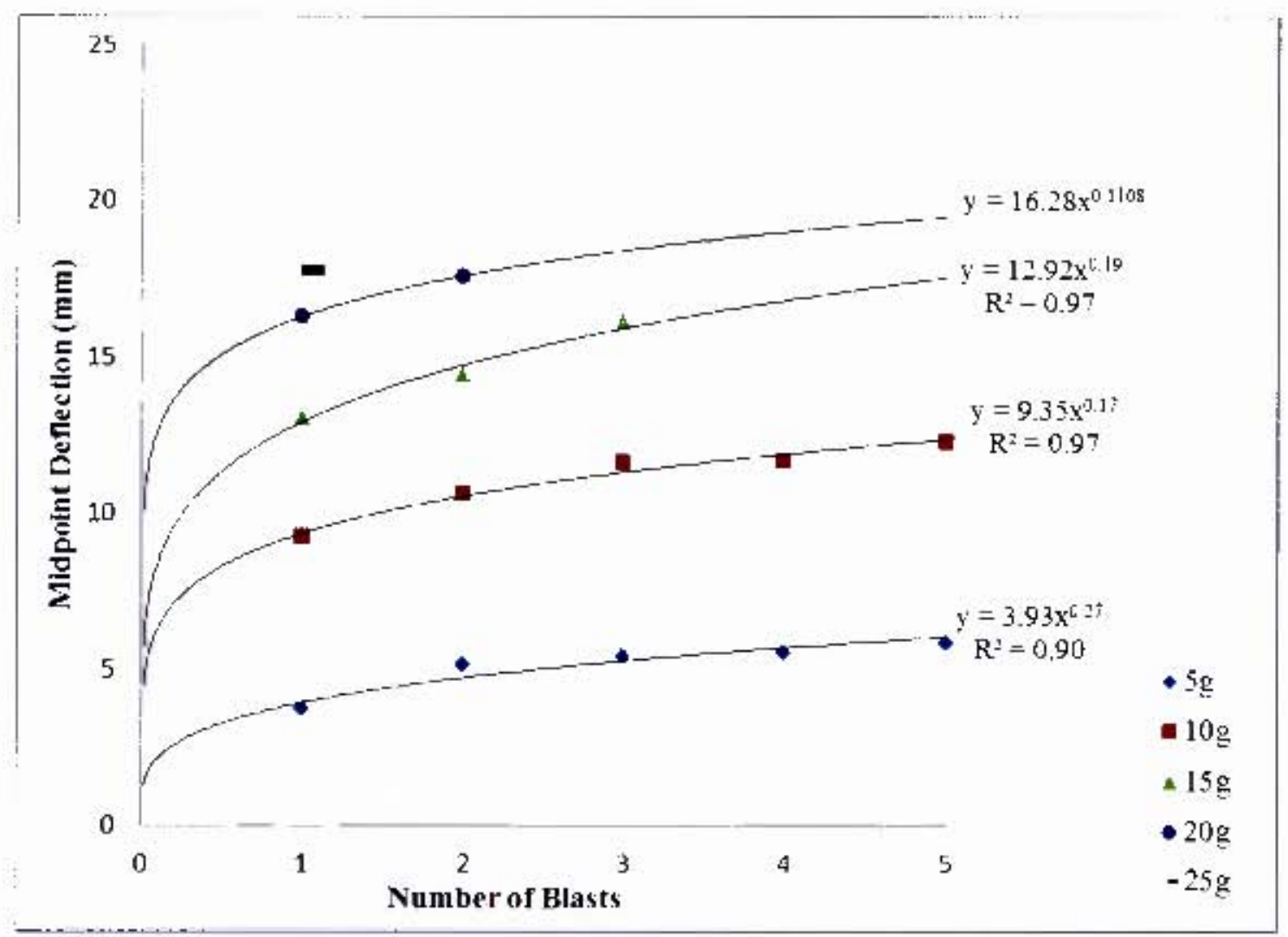

Figure F, 6: Graph of midpoint deflection ver'sus the nu mber of blasts for all charge masses and plate thickness of $2 m$ m 


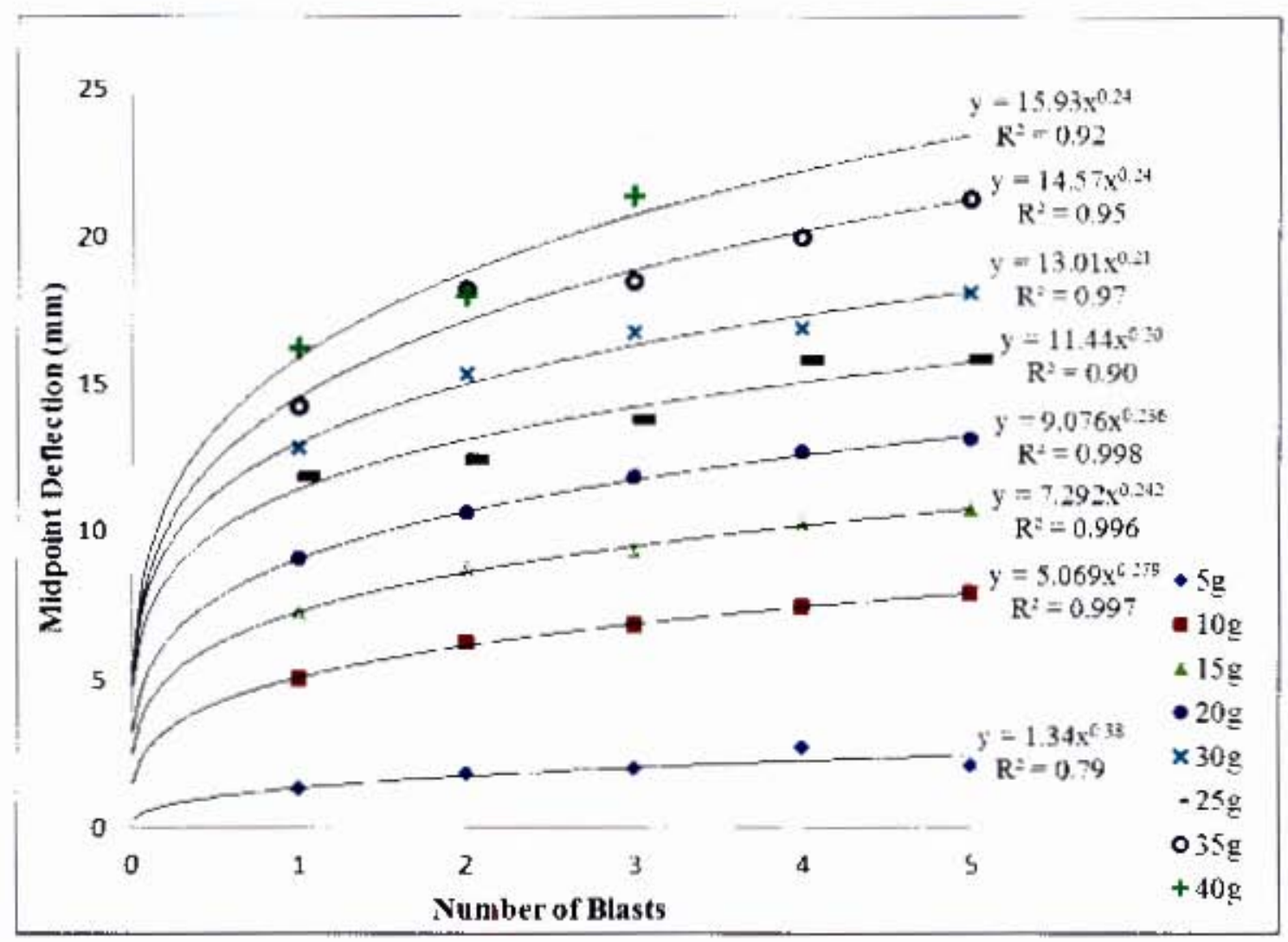

Figure F. 7: Ciraph of midpoint deflection versus the number of blasts for all eharge masses and plate thichncks of $3 \mathrm{~mm}$ 


\section{F.3 Equivalent Midpoint Deflections of Repeated Blasts}

Figure F, 8 and figure F. 9 display the eross sectional test plate profiles for various charge masses at various tepeated blast loads. The milpoint deflections are similar for each example, but the overall global deformation shape differs for different repeated blast loads. As the number of blast loads increase, so the deformation profile become 'Tounder', Vartitions in deformatom profiles were discussed in chapter 5.4 . The number of blast loads had an effect on the doformation shape of the test plate.

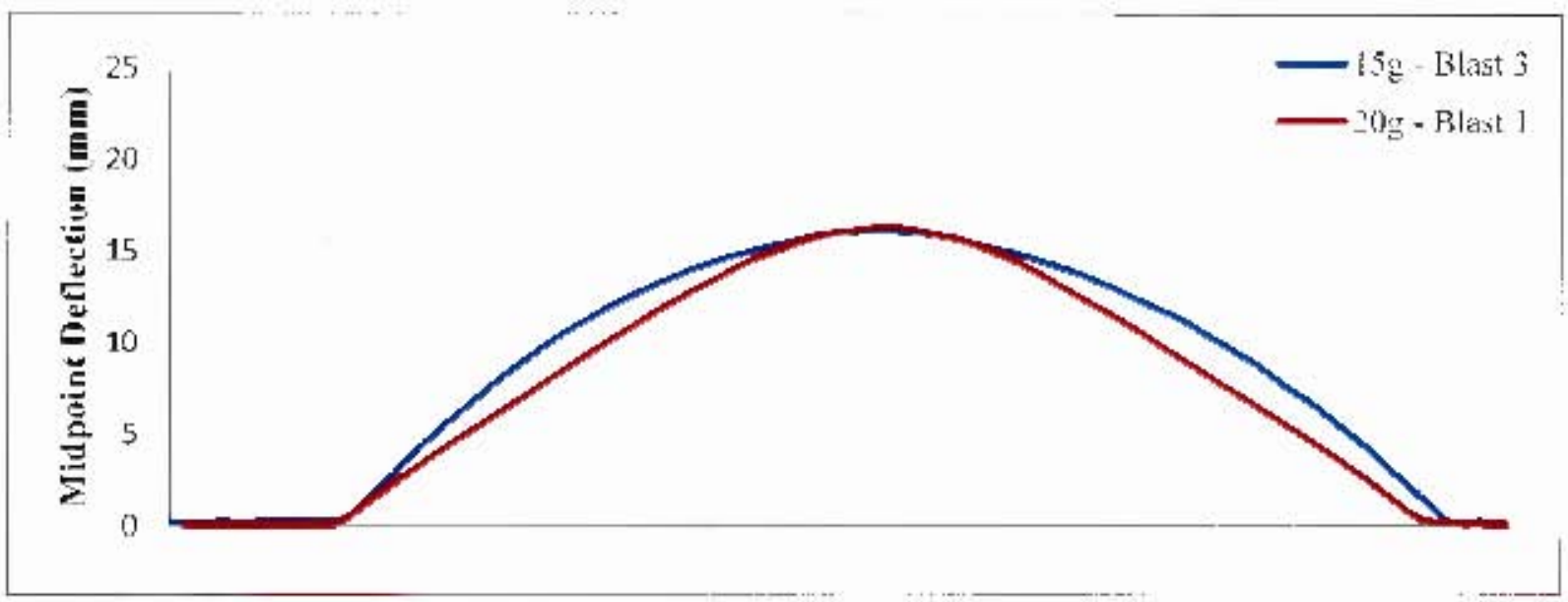

Figure F, 8: Griphiseia illustration of midpoint deflection equiralencies for $2 \mathrm{~mm}$ thicli test plate subjected to 3 lsg blasts and $120 \mathrm{lg}$ blasi

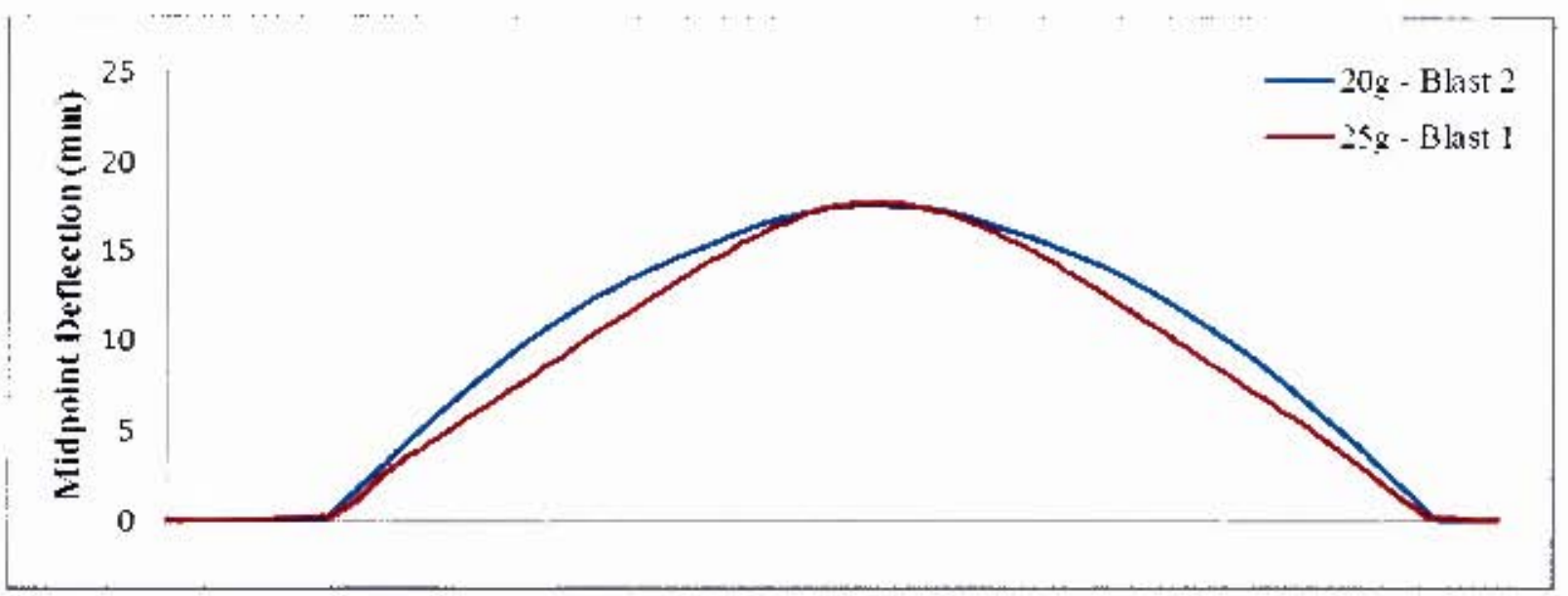

Figure F. 9: (iraphit-d illustrution of midpoint defection eguivalencies for $2 \mathrm{~mm}$ thisk test plate subjected to 2 20g blasts and 1 25̄e biast 


\section{F.4 Relationship between Progressive Deflection and Repeated Blast Load}

Table F. I: Results for the progressive deflection between each sucessive blast load. for $2 \mathrm{~m}$ ro thick plates

\begin{tabular}{|c|c|c|c|c|c|}
\hline $\begin{array}{l}\text { Charge } \\
\text { Mass (g) }\end{array}$ & $\begin{array}{c}\text { Plate } \\
\text { Thicliness } \\
\text { (mm) }\end{array}$ & $\begin{array}{l}\text { Number } \\
\text { of Blasts }\end{array}$ & $\begin{array}{c}\text { Impulse } \\
\text { (Ns) }\end{array}$ & $\begin{array}{c}\text { Midpoint } \\
\text { Deflection } \\
\text { (mm) }\end{array}$ & $\begin{array}{l}\text { Progressive } \\
\text { Deflection } \\
(\mathrm{mm})\end{array}$ \\
\hline \multirow{5}{*}{5} & 2 & 1 & 12.07 & 3.73 & 3.73 \\
\hline & 2 & 2 & 12.32 & 5.15 & 1.42 \\
\hline & 2 & 3 & 12.60 & 5.4 & 0.25 \\
\hline & 2 & 4 & 12.75 & 5.56 & 0.16 \\
\hline & 2 & 5 & 12.85 & 5,83 & 0.27 \\
\hline \multirow{5}{*}{10} & 2 & 1 & 21.02 & 9.25 & 9.25 \\
\hline & 2 & 2 & 21.01 & 10.61 & 1.36 \\
\hline & 2 & 3 & 20.24 & 11.64 & 1.03 \\
\hline & 2 & 4 & 19.61 & 11.68 & 0.04 \\
\hline & 2 & 5 & 20.24 & 12.27 & 0.59 \\
\hline \multirow{3}{*}{15} & 2 & 1 & 26.79 & 13.02 & 1302 \\
\hline & 2 & 2 & 29,04 & 14.43 & 1,41 \\
\hline & 2 & 3 & 26.45 & 16.12 & 1.69 \\
\hline \multirow{2}{*}{20} & 2 & 1 & 37.32 & 16.28 & 16.28 \\
\hline & 2 & 2 & 36.13 & 17.58 & 1.30 \\
\hline 25 & 2 & 1 & 38.33 & 17.73 & 17,73 \\
\hline
\end{tabular}


Tudble l. 2: Results for the progressine dedlection hetween each successive blast load. for $3 \mathrm{~mm}$ thick plates.

\begin{tabular}{|c|c|c|c|c|c|}
\hline $\begin{array}{l}\text { Charge } \\
\text { Mass (g) }\end{array}$ & $\begin{array}{l}\text { Plate } \\
\text { Thickness } \\
\text { (mm) }\end{array}$ & $\begin{array}{c}\text { Number of } \\
\text { Blasts }\end{array}$ & Impulse & $\begin{array}{c}\text { Midpoint } \\
\text { [beflection } \\
\text { (mm) }\end{array}$ & $\begin{array}{l}\text { Progressive } \\
\text { Deflection } \\
\text { (III) }\end{array}$ \\
\hline \multirow{5}{*}{5} & 3 & 1 & 11.89 & 1.28 & 1.28 \\
\hline & 3 & 2 & 12,40 & 1.82 & 0.54 \\
\hline & 3 & 3 & 12.28 & 1.98 & 0.16 \\
\hline & 3 & 4 & 11.76 & 2.72 & 0.74 \\
\hline & 3 & 5 & 11.63 & 2.10 & 0.63 \\
\hline \multirow{5}{*}{10} & 3 & \multirow{2}{*}{$\begin{array}{l}1 \\
2\end{array}$} & 21.91 & 5.03 & 5.03 \\
\hline & -.. & & 21.25 & 6.25 & 1.22 \\
\hline & 3 & 3 & 21.12 & 6.85 & 0.60 \\
\hline & 3 & 4 & 21.64 & 7.46 & 0.61 \\
\hline & 3 & 5 & 21.91 & 7.91 & 0.45 \\
\hline \multirow{5}{*}{15} & 3 & \multirow{3}{*}{$\begin{array}{l}1 \\
2 \\
3\end{array}$} & 29.17 & 7.27 & 7.27 \\
\hline & 3 & & 29.17 & 8.73 & 1.46 \\
\hline & 3 & & 30.41 & 9.38 & 0.65 \\
\hline & 3 & 4 & 29.99 & 10.28 & 0.90 \\
\hline & 3 & 5 & 29.37 & 10.76 & 0.48 \\
\hline \multirow{5}{*}{20} & 3 & \multirow{2}{*}{$\begin{array}{l}1 \\
2\end{array}$} & 34.19 & 9.07 & 9.07 \\
\hline & 3 & & 35.48 & 10.64 & 1.57 \\
\hline & 3 & 3 & 35.28 & 11.84 & 1.20 \\
\hline & 3 & 4 & 36.12 & 12.68 & 0.84 \\
\hline & 3 & 5 & 36.12 & 13.14 & 0.46 \\
\hline \multirow{5}{*}{25} & 3 & 1 & 41.69 & 11.84 & 11.84 \\
\hline & 3 & \multirow{2}{*}{$\begin{array}{l}2 \\
3 \\
3\end{array}$} & 44.60 & 12.43 & 0.59 \\
\hline & 3 & & 44.19 & 13.80 & 1.37 \\
\hline & 3 & 4 & 43.56 & 15.79 & 1.99 \\
\hline & 3 & 5 & 42.51 & 15.85 & 0.06 \\
\hline \multirow{5}{*}{$30 \mathrm{~g}$} & 3 & 1. & 47,00 & 12.80 & 12.80 \\
\hline & 3 & 2 & 50.26 & 15.36 & 2.56 \\
\hline & 3 & 3 & 48.33 & 16.73 & 1.37 \\
\hline & 3 & 4 & 47.46 & 16.86 & 0.13 \\
\hline & 3 & 5 & 49.39 & 18.11 & 1.25 \\
\hline & 3 & 1 & 51.40 & 14.21 & 14.21 \\
\hline & 3 & 2 & 49.32 & 18.21 & 4.00 \\
\hline $35 \mathrm{~g}$ & 3 & 3 & 52.75 & 18.47 & 0.26 \\
\hline & 3 & 4 & 49.22 & 19.96 & 1.49 \\
\hline & 3 & 5 & 46.39 & 21.28 & 1.32 \\
\hline & 3 & 1 & 59.84 & 16.20 & 16.20 \\
\hline & 3 & 2 & 58.56 & 17.97 & 1.77 \\
\hline 4III & 3 & 3 & 54.10 & 21.36 & 3.39 \\
\hline & 3 & 4 & 52.57 & $\mathrm{VA}$ & $\mathrm{NA}$ \\
\hline
\end{tabular}




\section{F.5 Relationship between Vickers Hardness and Repeated Blast Loading}

The graphs of Vickers hardness for charge masses $15 \mathrm{~g}, 20 \mathrm{~g}$ and $25 \mathrm{~g}$, for the corresponding repeated blasts are presented here.

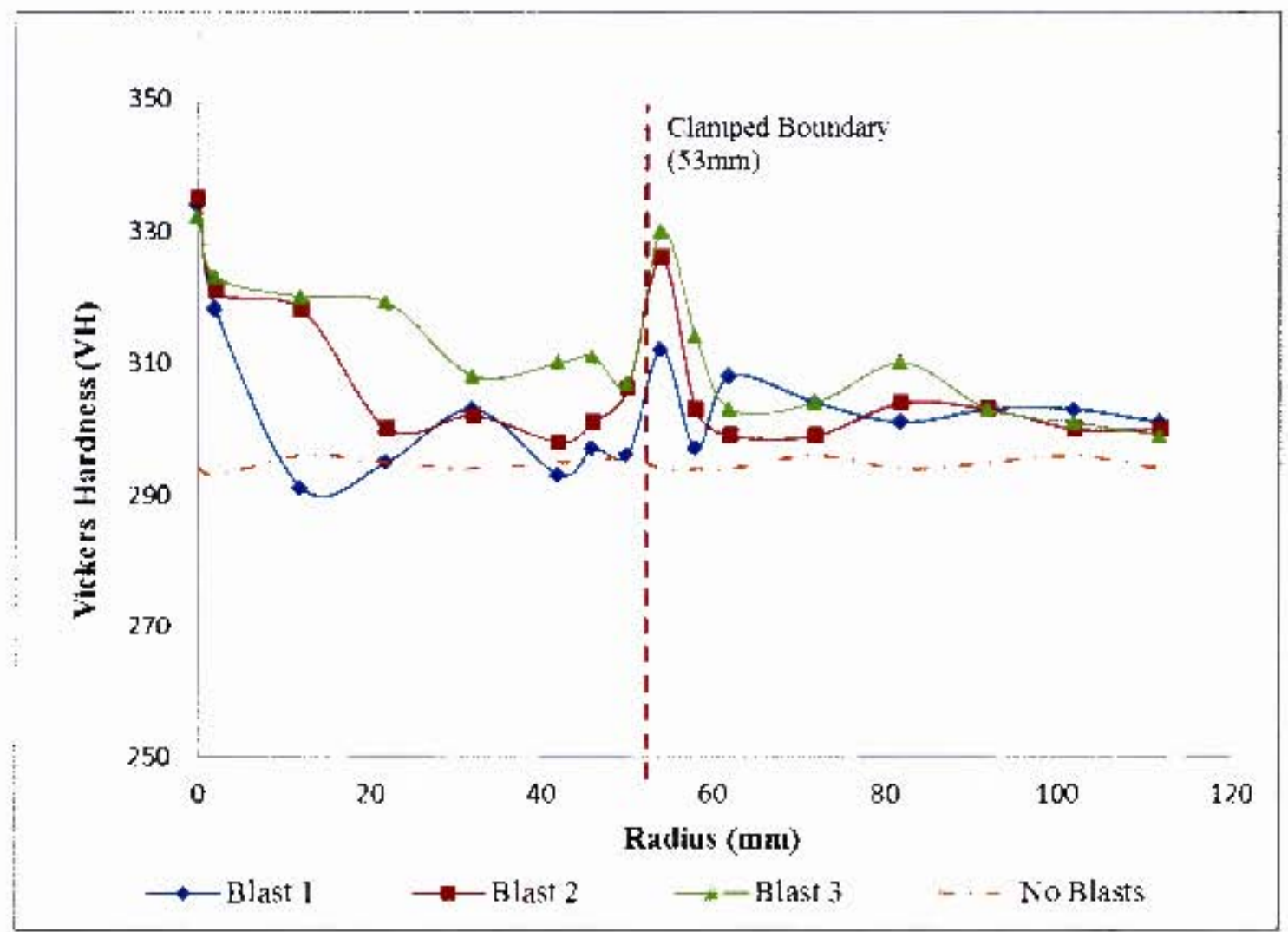

Figure $\mathrm{r} .10$ : Graph of Vicker's Hardness from the centre of the plate to the cla noped boundary for sharge mass $15 \mathrm{gg}$ and all repanted blast loads 


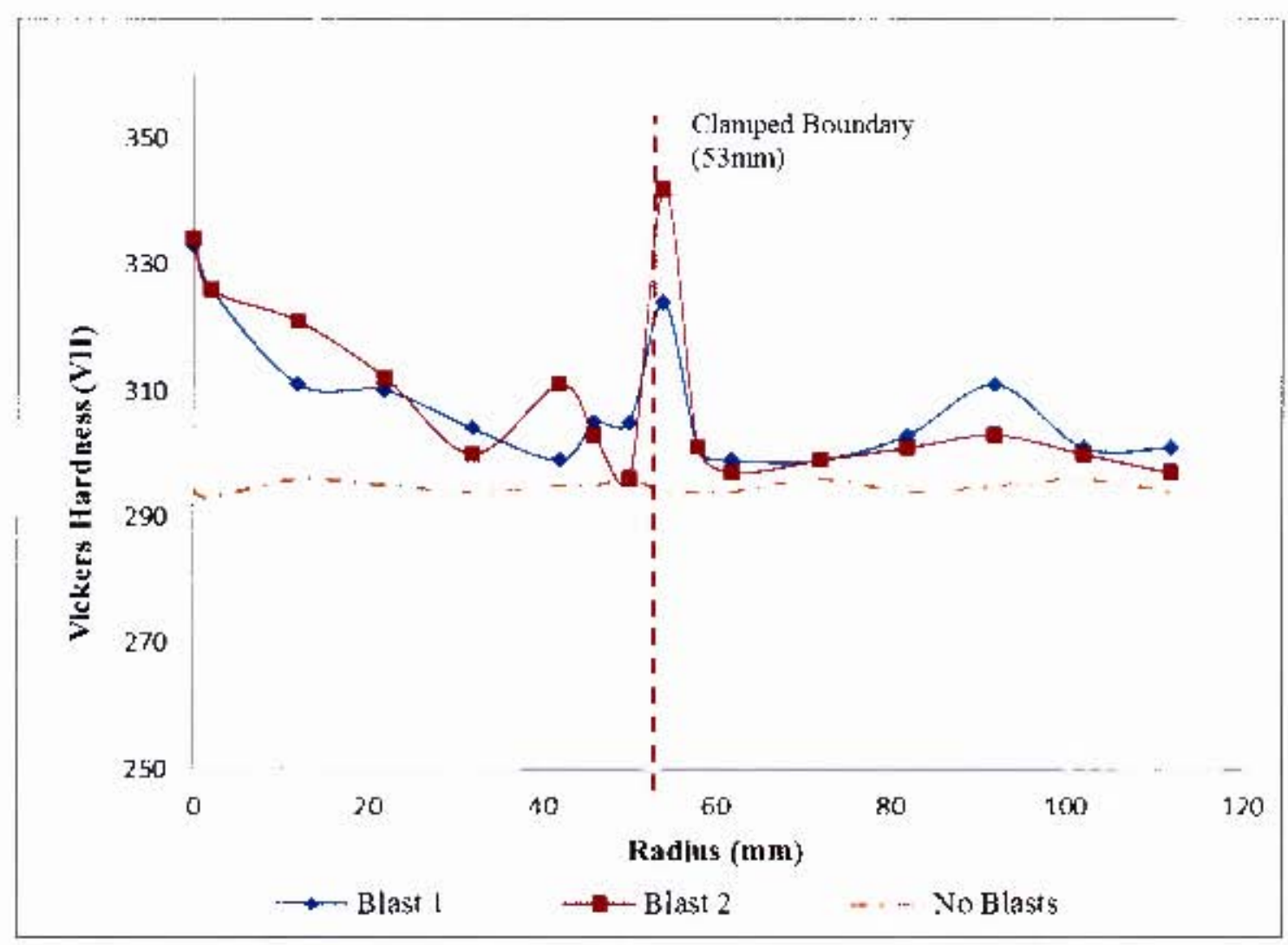

Figure F. 11: Graph of Vickers Hardness from the centre of the plate to the clamped boundary fur eharge misss $20 \mathrm{~g}$ aud all repeated blast loads

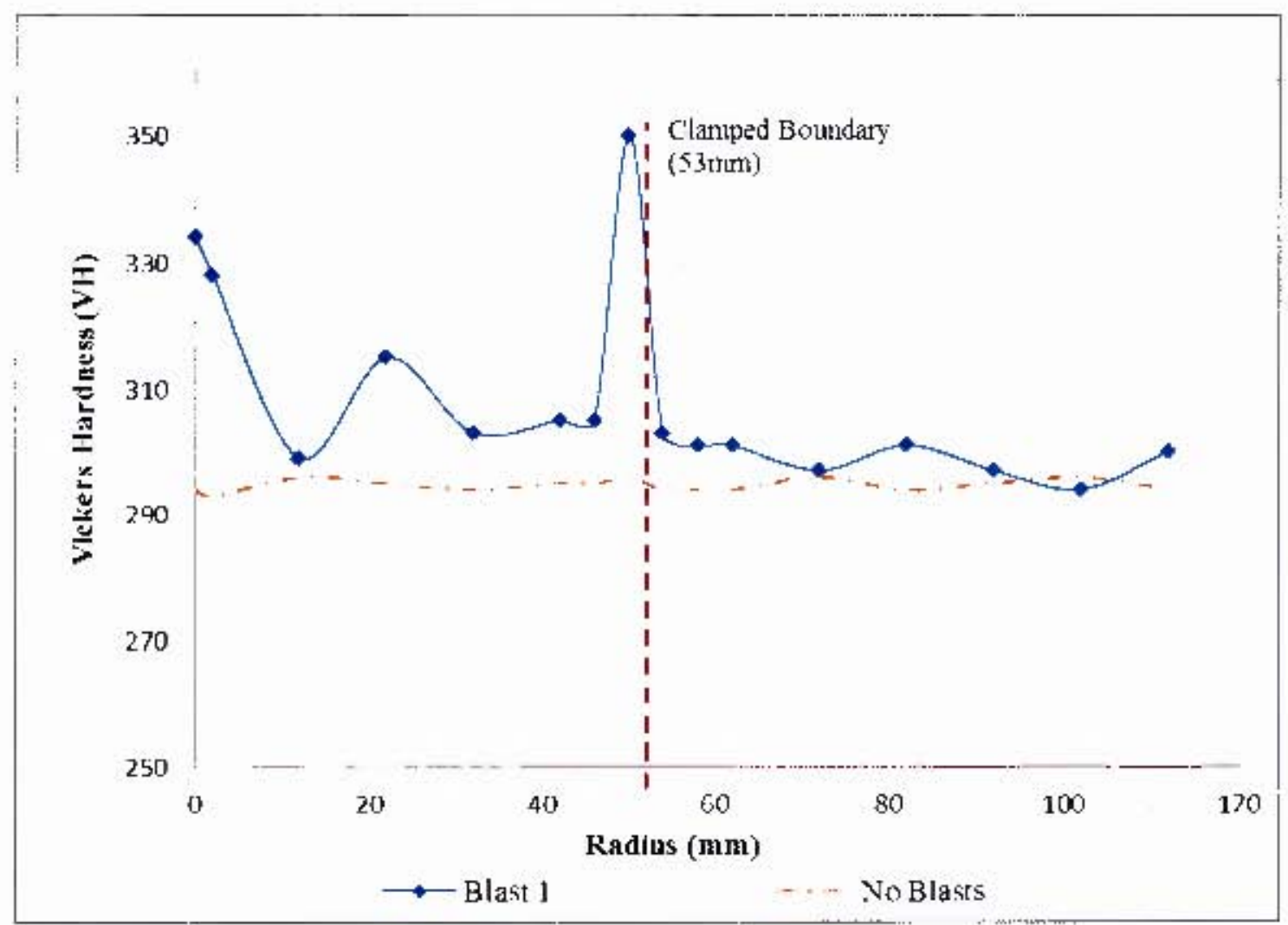

Figure F. 12: Graph of Vickers Hardness from the centre of the plate to the clamped briundary for charge mass $25 \mathrm{~g}$ and all repeated blast loads 


\section{Appendix G - Additional Numerical Results and Graphs}

\section{G.1 Comparison of Experimcntal and Numerical Impulse Results}

The rumerical impulse compared with the experimental impulse results are graphically shown in Figure (r. 1 -Figure (r. 8 and listed in Table G, I and Table G. 2 for plate thicknesses 2 mm and 3 mm. The impulse differerces between each numerical loading technique and the experimental results are presented alongside the impulse resulrs.

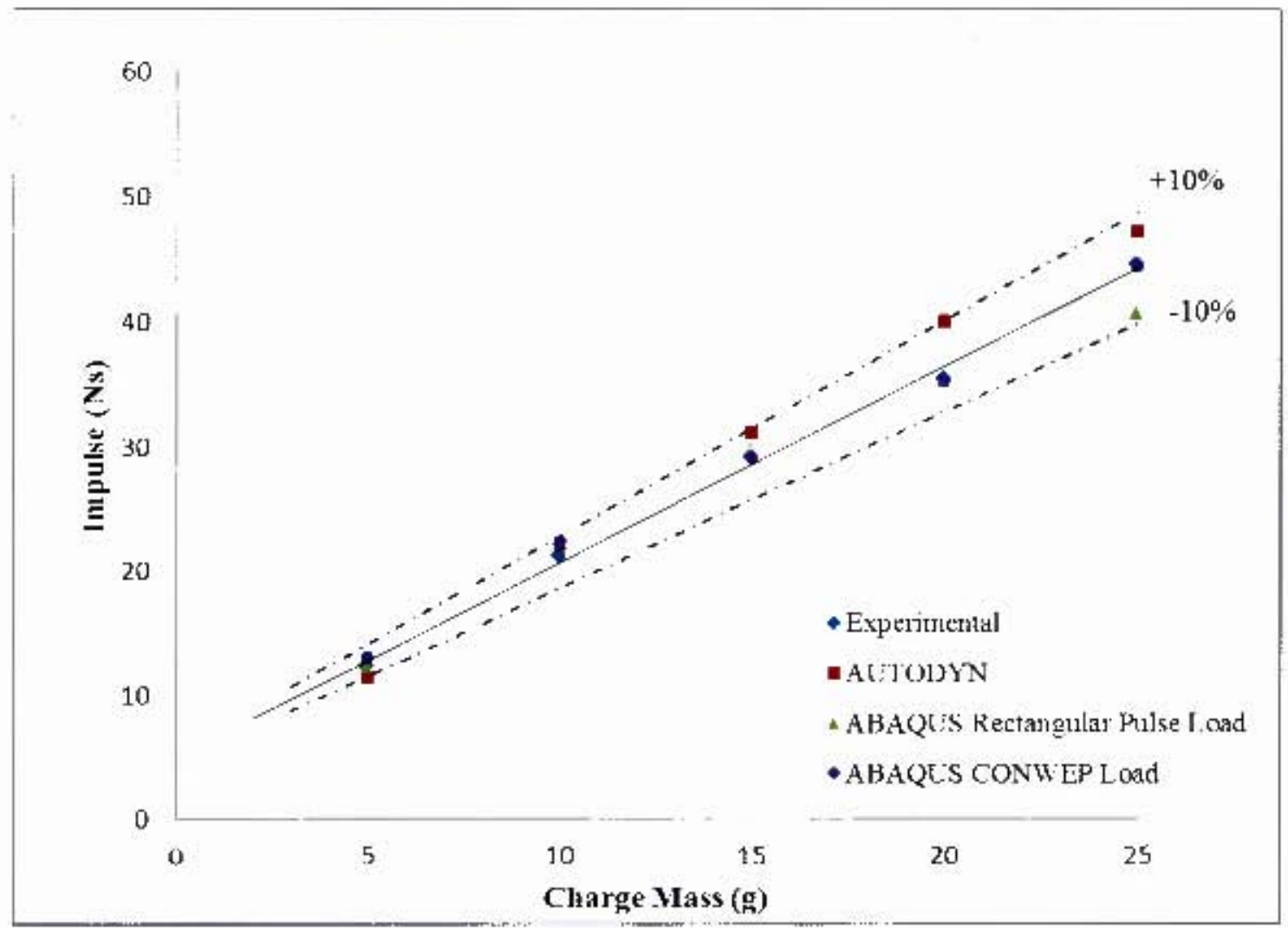

Figure (:. 1: Ciraph if jempulse veraux tharge mass fir experimental aud un merical results for 2 blast loads on $2 \mathrm{~mm}$ thick test pliates 


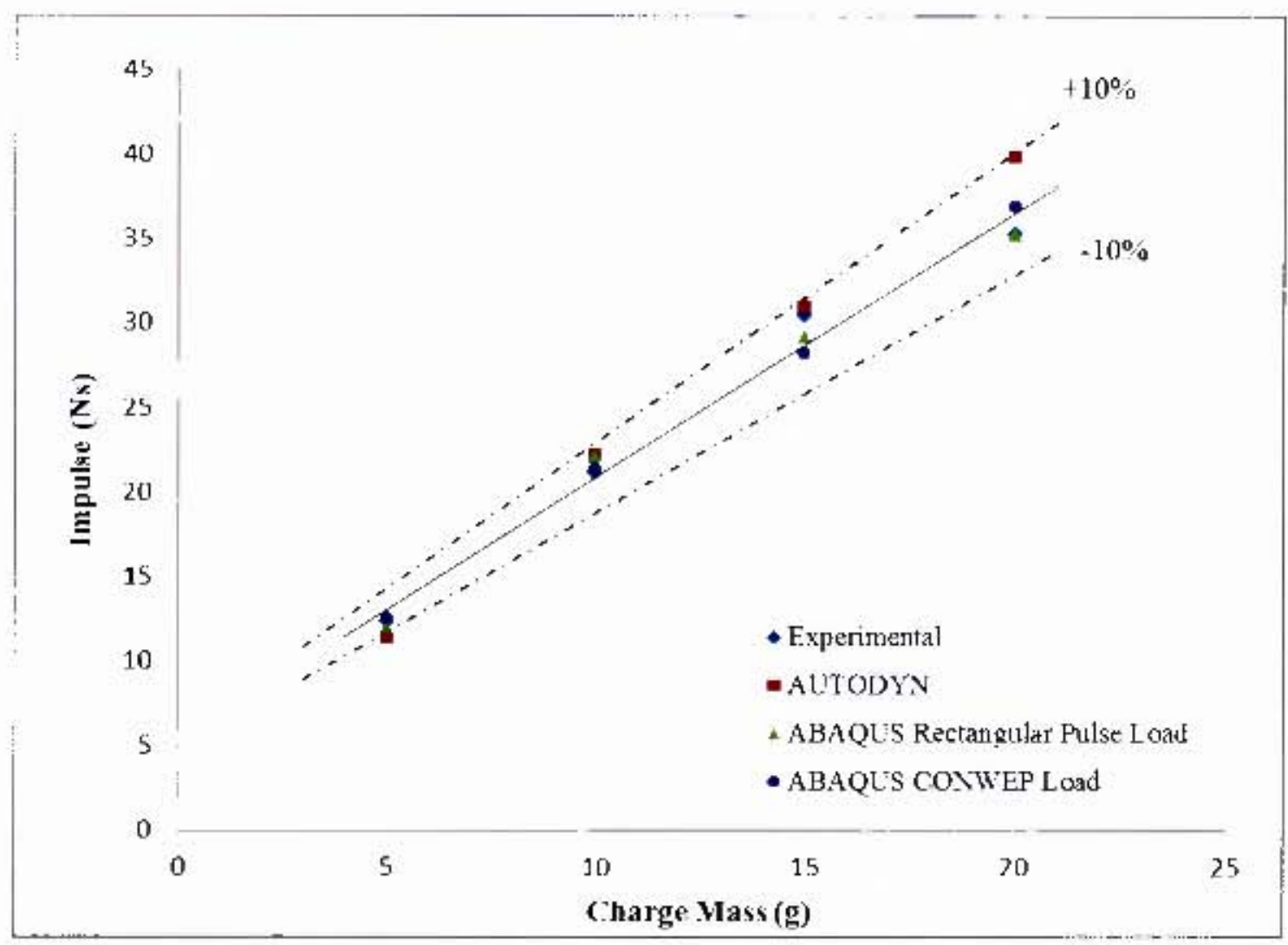

Jigure (i. 2:Ciraph of impulse versus charge mass for experimental and numerical results for 3 blast loads on $2 \mathrm{~mm}$ thick test plates

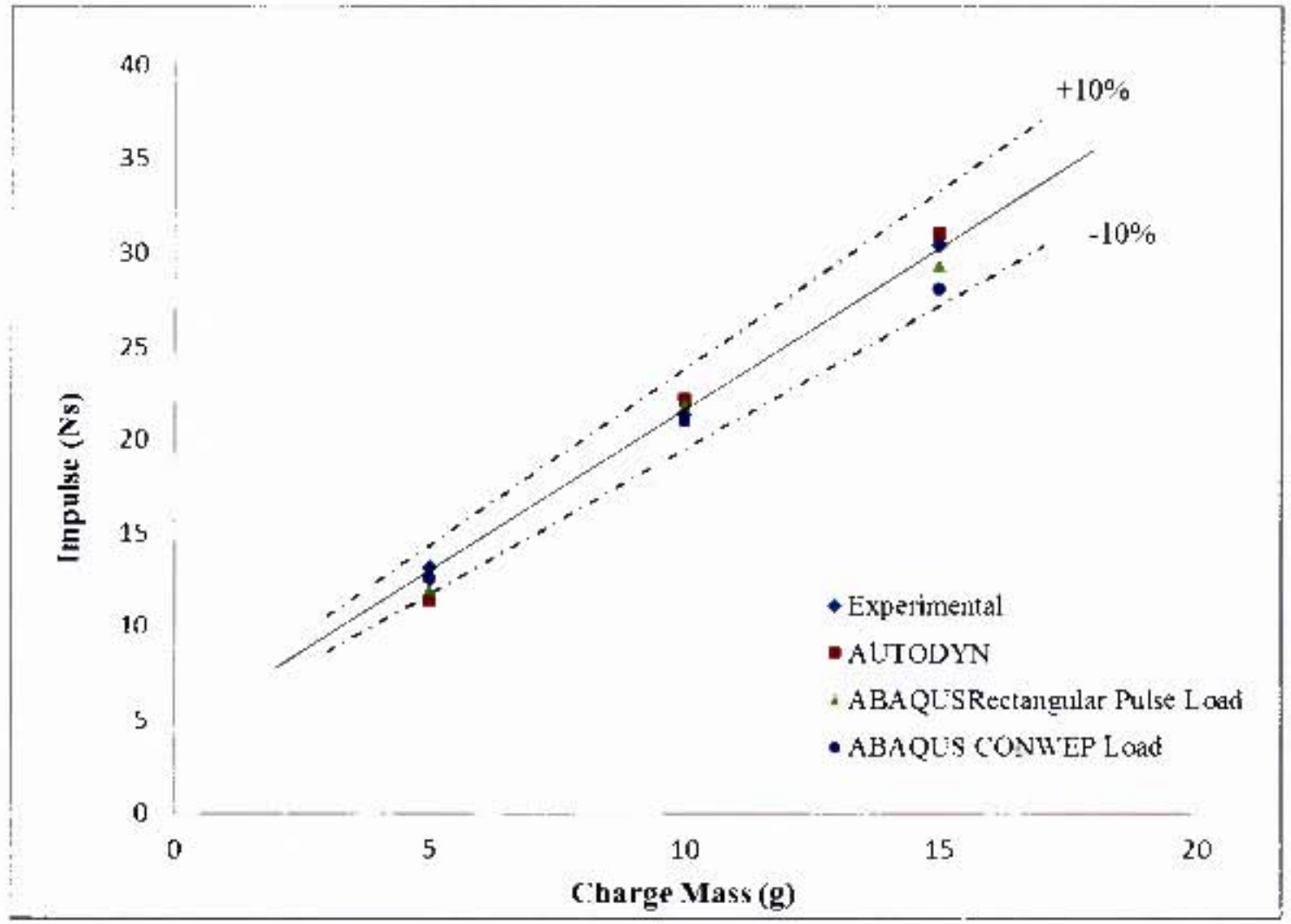

Figure G, 3: Graph of impulse versus charge mass for experimental atd aumerical result; for 4 biast loads on 2 m in Ahivik fest pilates 


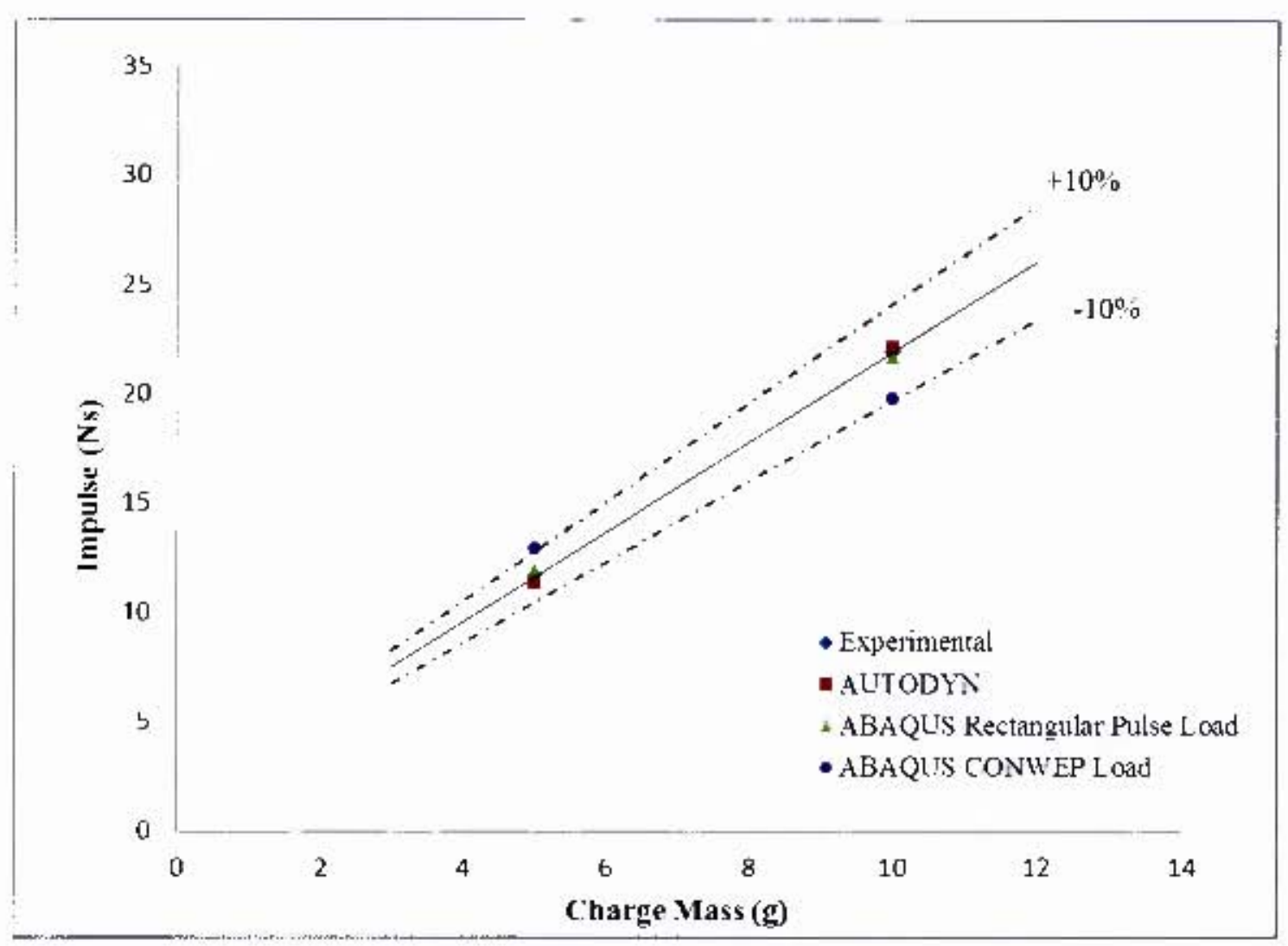

Figure G. 4:Grajth of impolse versus charge mass fur experimental and numericual results for 5 blast loads on 2 mm thick tesi plates

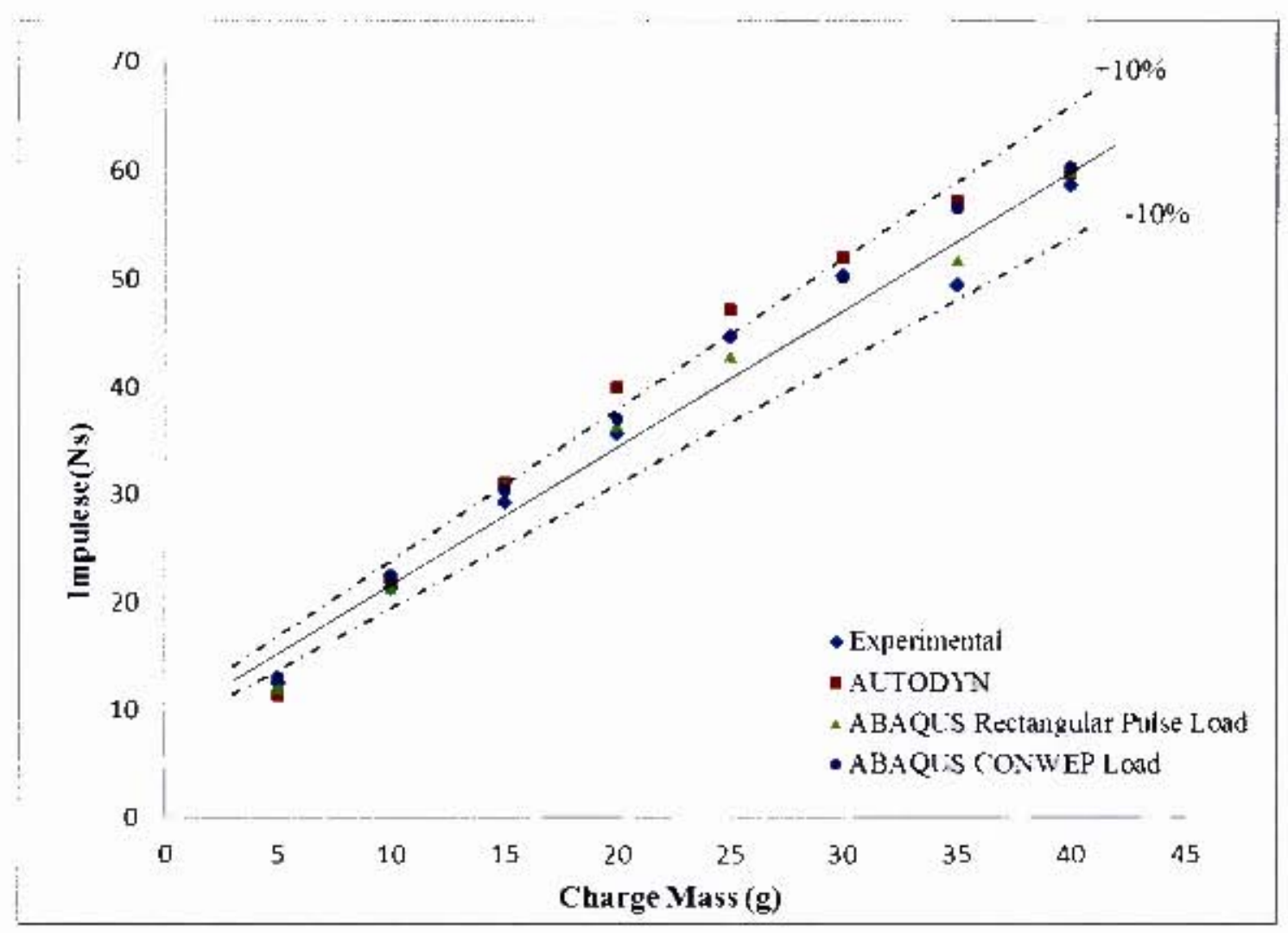

Figure 6. 5:Grajih +5 impulse versus charge mass for experimential and nu merical results frir 2 blast Irads inn 3 in m thick test plates 


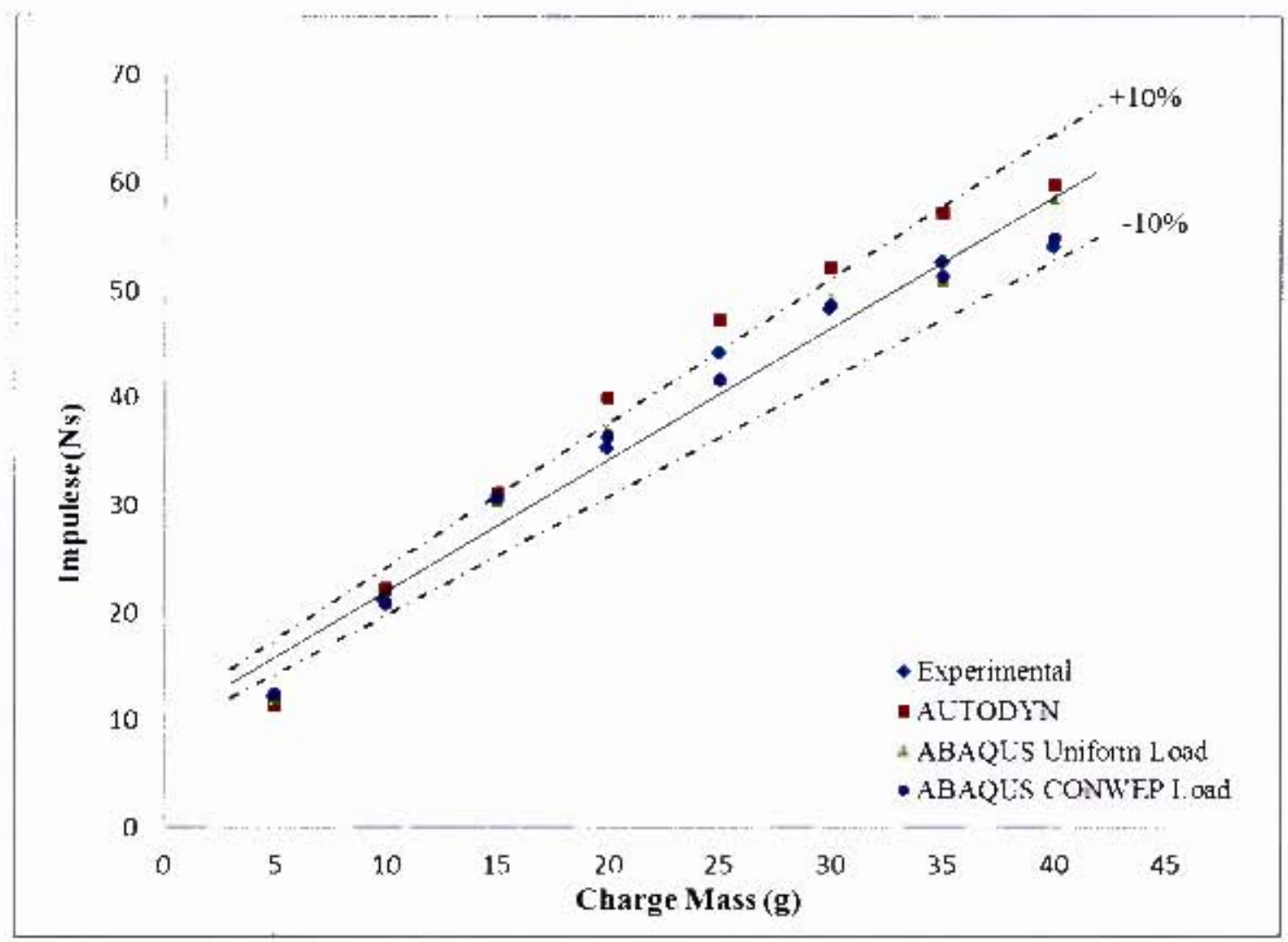

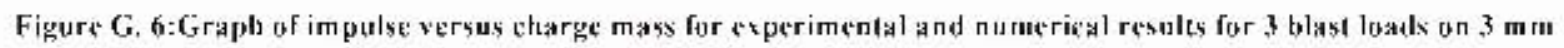
thick test plates

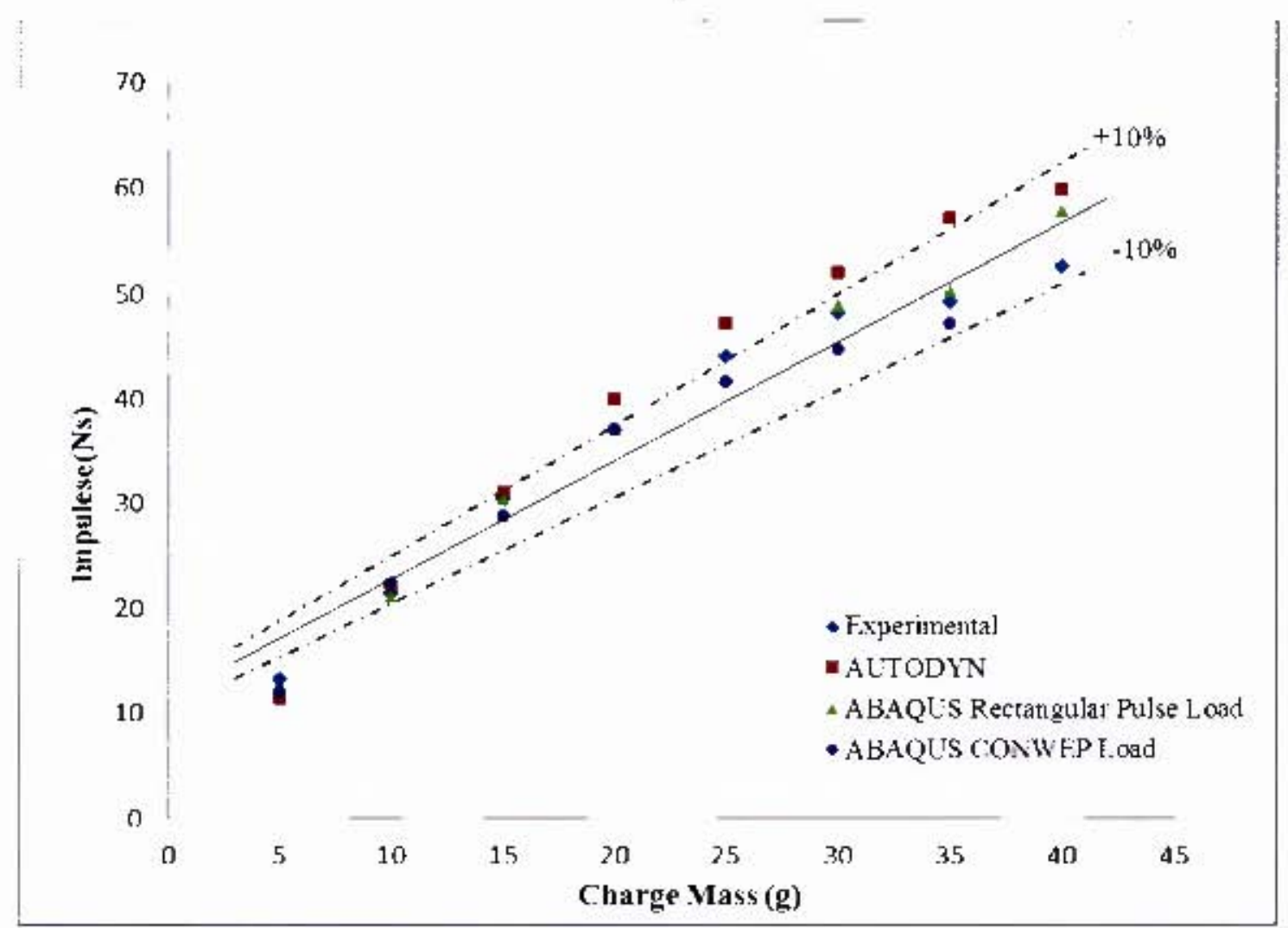

Figure G. 7:Graph of impulse versus charge nuss for experimental and numerical restuls for 4 blast loids on $3 \mathrm{~mm}$ thick test plates 


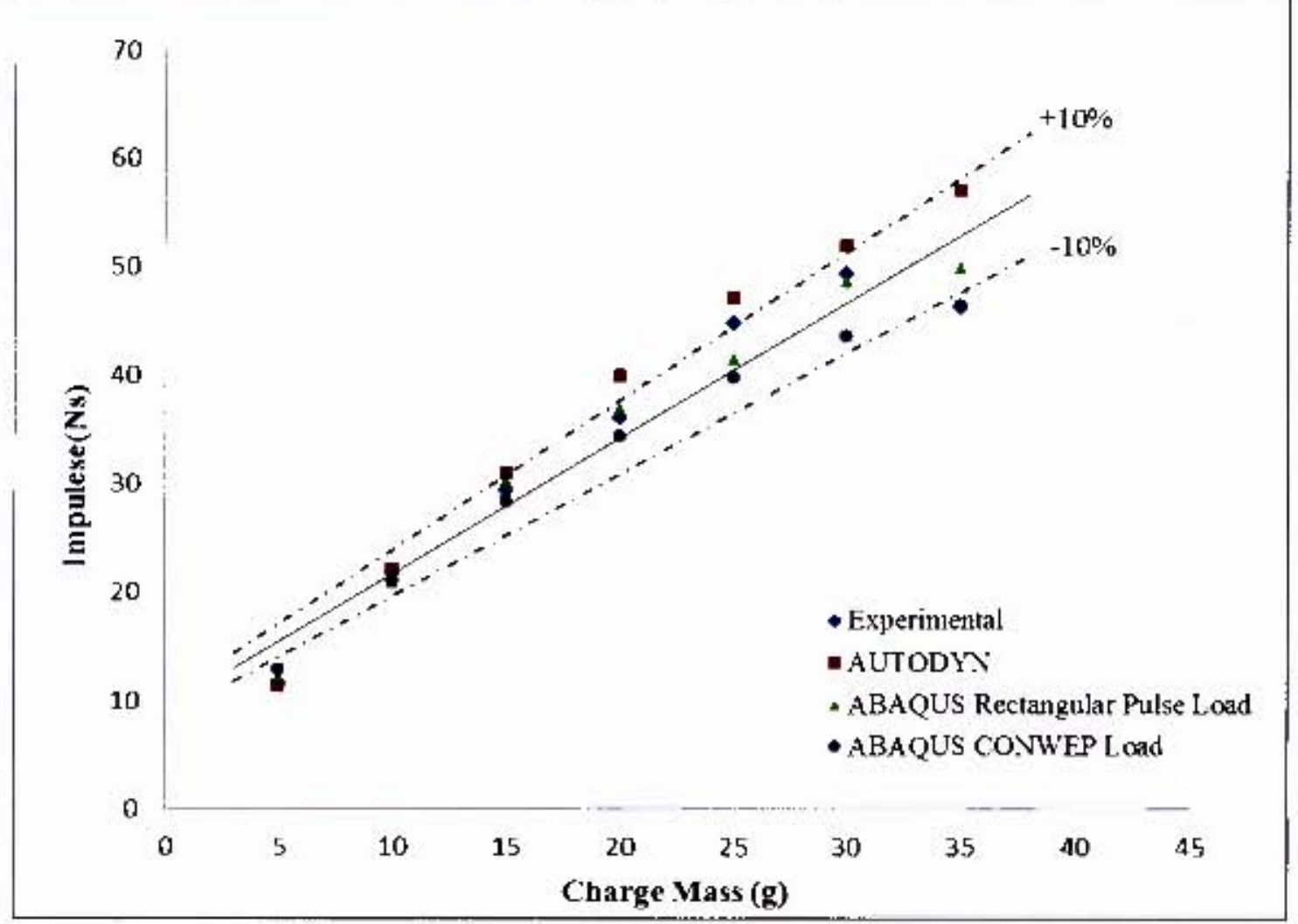

Figure G. 8: Graph of impulse versus charge mass for experimental and nunierical results for 5 blast loads on $3 \mathrm{num}$ thick test plates 
lable f. I: Cimpar ison of experimental and murmerical impulse results for a plate thickness Imm, charge masses $5 g$ to $25 \mathrm{~g}$ and all repeated blast loads

\begin{tabular}{|c|c|c|c|c|c|c|c|c|c|}
\hline & & & & & & Impulse (Xis & & & \\
\hline $\begin{array}{l}\text { Number of } \\
\text { Blasts }\end{array}$ & $\begin{array}{l}\text { Charge } \\
\text { Mass } \\
\text { (a) }\end{array}$ & $\begin{array}{c}\text { Plale } \\
\text { Thicliness } \\
\text { (mm) }\end{array}$ & $\begin{array}{l}\text { Fxperimental } \\
\text { (Ns) }\end{array}$ & $\begin{array}{c}\text { AlTOOEY } \\
(\mathrm{Ns})\end{array}$ & $\begin{array}{l}\text { AUTOLY:- } \\
\text { Dxperimental } \\
\text { Difference (Ns) }\end{array}$ & $\begin{array}{c}\text { ABAQUS- } \\
\text { Rectangular } \\
\text { Pressuie } \\
\text { Pulse Loading } \\
\text { (Ns) }\end{array}$ & $\begin{array}{c}\text { ABAQIS } \\
\text { Rectaugular } \\
\text { Pressure Pulse } \\
\text {-Experiment:t? } \\
\text { Difference (Ns) }\end{array}$ & $\begin{array}{l}\text { ABAOUS- } \\
\text { CONHEL' } \\
\text { Loading } \\
\text { (Vis) }\end{array}$ & $\begin{array}{c}\text { ABAQLS } \\
\text { CONWLP- } \\
\text { Experimental } \\
\text { Difference (Ys) }\end{array}$ \\
\hline 1 & 5 & 2 & 11.89 & 11.39 & -0.5 & 11.8 & -0.09 & 12.59 & 0.7 \\
\hline 2 & 5 & 2 & 12.4 & 11.39 & -1.01 & 12.27 & -0.13 & 13.09 & 0.69 \\
\hline 3 & 5 & 2 & 12.28 & 11.39 & -0.89 & 11.93 & -0.35 & 12.58 & 0.3 \\
\hline 4 & 5 & 2 & 13.13 & 11.39 & -1.74 & 11.91 & -1.22 & 12.55 & -0.58 \\
\hline 5 & 5 & 2 & 11.63 & 11.39 & -0.24 & 11.85 & 0.22 & 12.94 & 1.31 \\
\hline 1 & 10 & 2 & 21.91 & 22.14 & 0.23 & 21.1 & -0.81 & 22.2 & 0.29 \\
\hline 2 & 10 & 2 & 21.25 & 22.14 & 0.89 & 22.2 & 0.45 & 22.2 & 0.95 \\
\hline 3 & 10 & 2 & 21.12 & 22.14 & 1.02 & 22 & 0.88 & 21.4 & 0.28 \\
\hline 4 & 10 & 2 & 21.38 & 22.11 & 0.76 & 21.85 & 0.47 & 21 & -0.38 \\
\hline 5 & 10 & 2 & 21.91 & 22.14 & 0.23 & 21.64 & -0.27 & 19.8 & -2.11 \\
\hline 1 & 15 & 2 & 29.17 & 31.02 & 1.85 & 28.15 & -1.02 & 30 & 0.83 \\
\hline 2 & 15 & 2 & 29.17 & 31.02 & 1.85 & 29,62 & 0.45 & 29.1 & -0.07 \\
\hline 3 & 15 & 2 & 30.41 & 31.02 & 0.61 & 29.68 & -1.33 & $2 \times .2$ & -2.21 \\
\hline 4 & 15 & 2 & 30.41 & 31.02 & $0.6]$ & 24.31 & -1.1 & 28.06 & -2.35 \\
\hline 1 & 20 & 2 & 34.19 & 39.93 & 5.74 & 34.62 & 0.43 & 38.91 & 4.72 \\
\hline 2 & 20 & 2 & 35.48 & 39.93 & 4.15 & 35.24 & -6.24 & 35.22 & -0.26 \\
\hline 3 & 20 & 2 & 35.28 & 39.43 & 4.65 & 35,19 & -0.099 & 36,98 & 1.7 \\
\hline 1 & 25 & 2 & 41.69 & 47.17 & 5.48 & 39.75 & -1.94 & 45.3 & 3.61 \\
\hline 2 & 25 & 2 & 44.6 & 47.17 & 2.57 & 40.63 & -3.97 & 44.37 & -0.23 \\
\hline
\end{tabular}




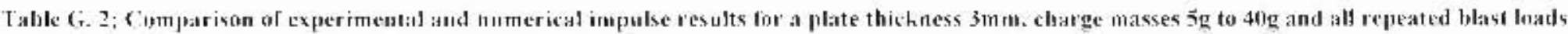

\begin{tabular}{|c|c|c|c|c|c|c|c|c|c|}
\hline \multirow[b]{3}{*}{$\begin{array}{l}\text { Number of } \\
\text { Bliasts }\end{array}$} & \multirow[b]{3}{*}{$\begin{array}{l}\text { Charge } \\
\text { Mass } \\
\text { (g) }\end{array}$} & \multirow[b]{3}{*}{$\begin{array}{c}\text { Plate } \\
\text { Thickness } \\
(\mathrm{mm})\end{array}$} & \multirow[b]{3}{*}{$\begin{array}{c}\text { Experimental } \\
\text { (Ns) }\end{array}$} & \multirow[b]{3}{*}{$\begin{array}{l}\text { AITOI)YN } \\
\text { (Xs) }\end{array}$} & \multirow[b]{3}{*}{$\begin{array}{l}\text { AUTODVN- } \\
\text { Experimental } \\
\text { Difference (Ns) }\end{array}$} & \multirow{2}{*}{\multicolumn{2}{|c|}{ Impulse (Ns) }} & \multirow[b]{3}{*}{$\begin{array}{l}\text { ABAQLS- } \\
\text { CONWFP } \\
\text { Loading } \\
\text { (Ns) }\end{array}$} & \multirow[b]{3}{*}{$\begin{array}{l}\text { ABAQES } \\
\text { CONWFP- } \\
\text { Experimental } \\
\text { Differenee (Xs) }\end{array}$} \\
\hline & & & & & & & & & \\
\hline & & & & & & $\begin{array}{l}\text { ABAQUS- } \\
\text { Rectangular } \\
\text { Pressure } \\
\text { Pulse Ioading } \\
\text { (Ns) }\end{array}$ & $\begin{array}{c}\text { ABAQLS } \\
\text { Rectangular } \\
\text { Pressure Pulse } \\
\text {-Explerimental } \\
\text { Difference (Ns) }\end{array}$ & & \\
\hline 1 & 5 & 3 & 11.89 & 11.36 & -0.50 & 12.03 & 0.14 & 12.62 & 0.73 \\
\hline 2 & 5 & 3 & 12.4 & 11.39 & -1.01 & 11.92 & -0.48 & 13.07 & 0.67 \\
\hline 3 & 5 & 3 & 12.28 & 11.39 & -0.89 & 12.01 & -10.27 & 12.42 & 0.14 \\
\hline 4 & 5 & 3 & 13.13 & 11.39 & -1.74 & 12.05 & -1.08 & 12.04 & -1.09 \\
\hline 5 & 5 & 3 & 11.63 & 11.39 & -0.24 & 12.07 & 0.44 & 12.86 & 1.23 \\
\hline 1 & 10 & 3 & 21.91 & 22.14 & 0.23 & 21 & -0.91 & 22.4 & 0.49 \\
\hline 2 & 10 & 3 & 21.25 & 22.14 & 0.89 & 21.2 & -0.05 & 22.5 & 1.25 \\
\hline 3 & 10 & 3 & 21.12 & 22.14 & 1.02 & 21.1 & -0.02 & 20.79 & -0.33 \\
\hline 4 & 10 & 3 & 21.38 & 22.1 .4 & 0.76 & 21.05 & $-0,33$ & 22,47 & 1.09 \\
\hline 5 & 10 & 3 & 21.91 & 22.14 & 0.23 & 2092 & -0.99 & 21.04 & -0.87 \\
\hline 1 & 15 & 3 & 29.17 & 31.02 & 1.85 & 28.62 & -0.55 & 31.42 & 2.25 \\
\hline 2 & 15 & 3 & 29.17 & 31.02 & 1.85 & 30.69 & 1.52 & 30.42 & 1.25 \\
\hline 3 & $! 5$ & 3 & 30.41 & 31.02 & 0.61 & 30.33 & -0.08 & 30.68 & 0.27 \\
\hline 4 & 15 & 3 & 30.41 & $31.0 \mathrm{~d}$ & 0.61 & 30.35 & -0.06 & 28.83 & -1.58 \\
\hline 5 & 15 & 3 & 29.37 & 31.02 & 1.65 & 30.16 & 0.79 & 28.45 & -0.92 \\
\hline 1 & 20) & 3 & 34.19 & 39.93 & 5.74 & 36.3 & 2.11 & 38.39 & 4.20 \\
\hline 2 & 20 & 3 & 35.48 & 39.93 & 4.45 & 36.23 & 0.75 & 37.06 & 1.58 \\
\hline 3 & 20 & 3 & 35.28 & 39.93 & 4.65 & 37.04 & 1.76 & 36.4 & 1.12 \\
\hline 4 & 20 & 3 & 36.95 & 39.93 & 2.98 & 36.94 & -0.01 & 37.16 & 0.21 \\
\hline 5 & 20 & 3 & 36.12 & 39.93 & 3.81 & 36.82 & 0.70 & 34,39 & -1.73 \\
\hline
\end{tabular}




\begin{tabular}{|c|c|c|c|c|c|c|c|c|c|}
\hline $\begin{array}{c}\text { Number of } \\
\text { Blasts }\end{array}$ & $\begin{array}{l}\text { Charge } \\
\text { Mass } \\
\text { (g) }\end{array}$ & $\begin{array}{c}\text { Plate } \\
\text { Thickness } \\
\text { (min) }\end{array}$ & $\begin{array}{c}\text { Experimental } \\
\text { (Xis) }\end{array}$ & $\begin{array}{l}\text { AUNOOYX } \\
\text { (Ns) }\end{array}$ & $\begin{array}{l}\text { AUTomyN- } \\
\text { Experimental } \\
\text { Difference (Ns) }\end{array}$ & $\begin{array}{c}\text { ABNQSS- } \\
\text { Rectingular } \\
\text { Prissure } \\
\text { Pulse Toading } \\
\text { (Ns) }\end{array}$ & $\begin{array}{c}\text { ABAQus } \\
\text { Rectangular } \\
\text { Pressure P'ulsu' } \\
\text { - Fxperinental } \\
\text { Difference (Vs) }\end{array}$ & $\begin{array}{l}\text { ABAQUS- } \\
\text { CONWEP } \\
\text { Lualing } \\
\text { (Ns) }\end{array}$ & $\begin{array}{l}\text { ABAQUS } \\
\text { CONWFP- } \\
\text { Experimental } \\
\text { Difference (Xs) }\end{array}$ \\
\hline 1 & 25 & 3 & 11.69 & 47.17 & 5.48 & 40.25 & -1.44 & 44.48 & 2.79 \\
\hline 2 & 25 & 3 & 44,6 & 47.17 & 2.57 & 42.66 & -1.94 & 44.69 & 0.09 \\
\hline 3 & 25 & 3 & 44.19 & 47.17 & 2.98 & 41.81 & 2.38 & 41.63 & -2.56 \\
\hline 4 & 25 & 3 & 44.02 & 47.17 & 3.15 & 41.8 & -2.22 & 41.68 & -2.34 \\
\hline 5 & 25 & 3 & 44.85 & 17.17 & 2.32 & 41.45 & -3.40 & 39.82 & -5.03 \\
\hline 1 & 30 & 3 & 47 & 52.01 & 501 & 49 & 2.00 & 54.41 & 7.41 \\
\hline 2 & 30 & 3 & 50.26 & 52.01 & 1.75 & 50.05 & -0.21 & 50.24 & -0.02 \\
\hline 3 & 30 & 3 & 48.33 & 52.01 & 3.68 & 19.05 & 0.72 & 48.56 & 0.23 \\
\hline 4 & 30 & 3 & 48.14 & 52.01 & 3.87 & 48.82 & 0.68 & 44.71 & -3.43 \\
\hline 5 & 30 & 3 & 49.39 & 52.01 & 2.62 & 48.61 & -0.78 & 43.65 & -5.74 \\
\hline 1 & 35 & 3 & 51.40 & 57.16 & 5.76 & 50 & -1.40 & 62.19 & 11.09 \\
\hline 2 & 35 & 3 & 49.32 & 57.16 & 7.84 & 51.62 & 2.30 & 56.53 & 7.21 \\
\hline 3 & 35 & 3 & 52.75 & 57.16 & 4.41 & 50.86 & -1.89 & 51.25 & -1.50 \\
\hline 4 & 35 & 3 & 49.22 & 57.16 & 7.94 & 50.20 & 1.04 & 47.24 & $-1,98$ \\
\hline 5 & 35 & 3 & 46.39 & 57.16 & 10.77 & 49.91 & 352 & 46.52 & 0.13 \\
\hline 1 & 40 & 3 & 59.84 & $54 \times 1$ & 0.00 & 58.6 & -1.24 & 67.32 & 7.48 \\
\hline 2 & 40 & 3 & 58.56 & 59.84 & 1.28 & 59.83 & 1.27 & 60.32 & 1.76 \\
\hline 3 & 40 & 3 & 54.10 & 59.84 & 5.74 & 58.5 & 4.40 & 54.89 & 0.79 \\
\hline 4 & 40 & 3 & 52.57 & 59.84 & 7.27 & 57.71 & 5.14 & $\mathrm{NA}$ & $N A$ \\
\hline
\end{tabular}




\section{G.2 Comparison of Experimental and Numerical Midpoint Deflections}

The graphs of numerical and experimcrulal midpoin deflection versus charge mass, for the plate thicknesses $2 \mathrm{~mm}$ and $3 \mathrm{~mm}$; all charge masses and the remaining repeated blast scrics are prosinted in Figure G. 9-Figurs (i, 16. The rosults are lisled in lable $\mathrm{G} .3$ and $\mathrm{lable} G .4$.

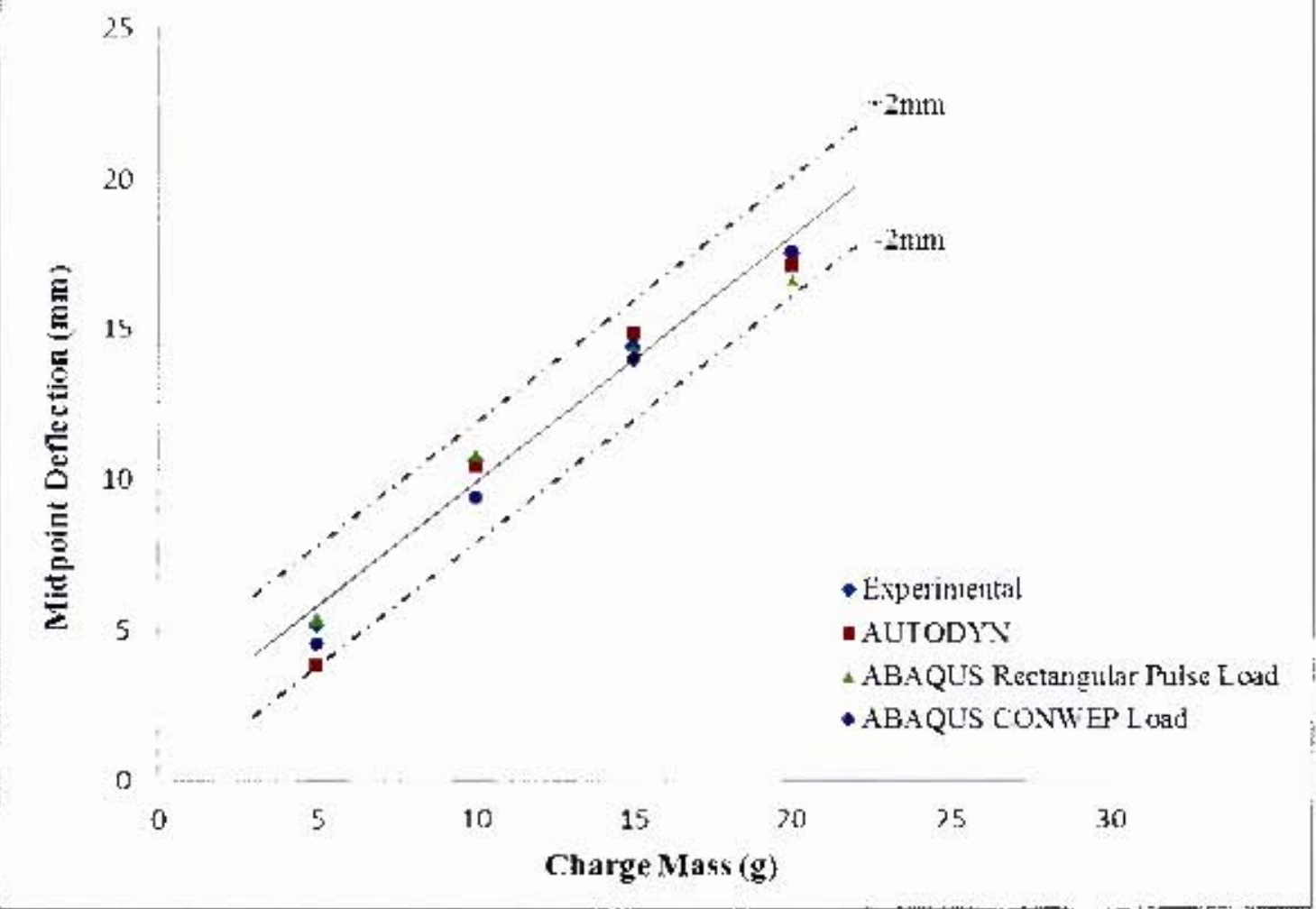

Figne $G, 9$, Graph of midpoirut deflection versms charge mass for both expcrimcutal and numerical results for $2 \mathrm{~mm}$ thick test plates subjected to 2 blast loads of charge unsses 5 g to 250 


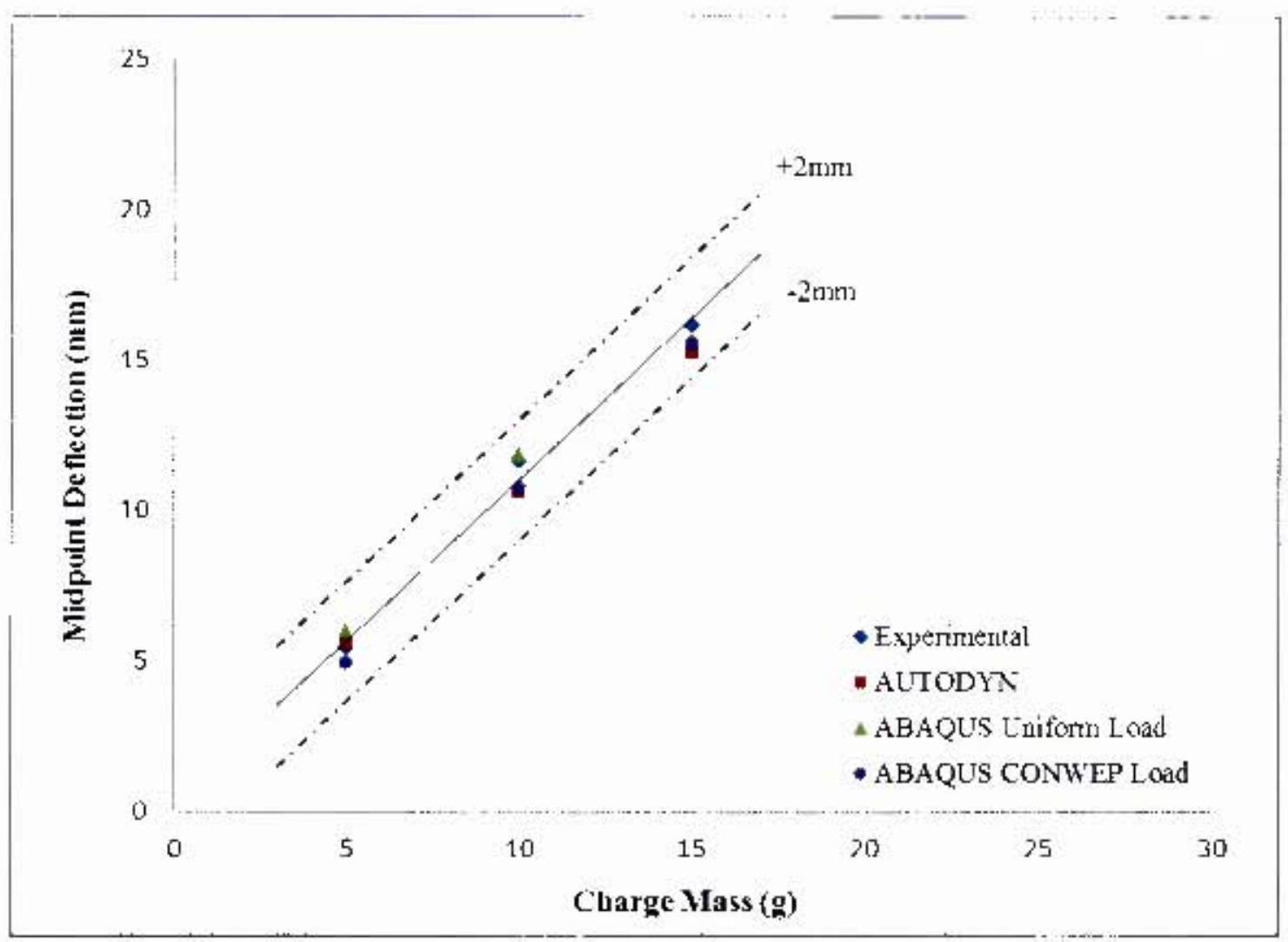

Figure G. 10: Graph of midpoint deflection yersus charge mass for batl experimental and numerical results for $2 \mathrm{~mm}$ thit:k teat plates sulpjected to 3 libst loads of tharge masses $5 \mathrm{~g}$ to $25 \mathrm{~g}$

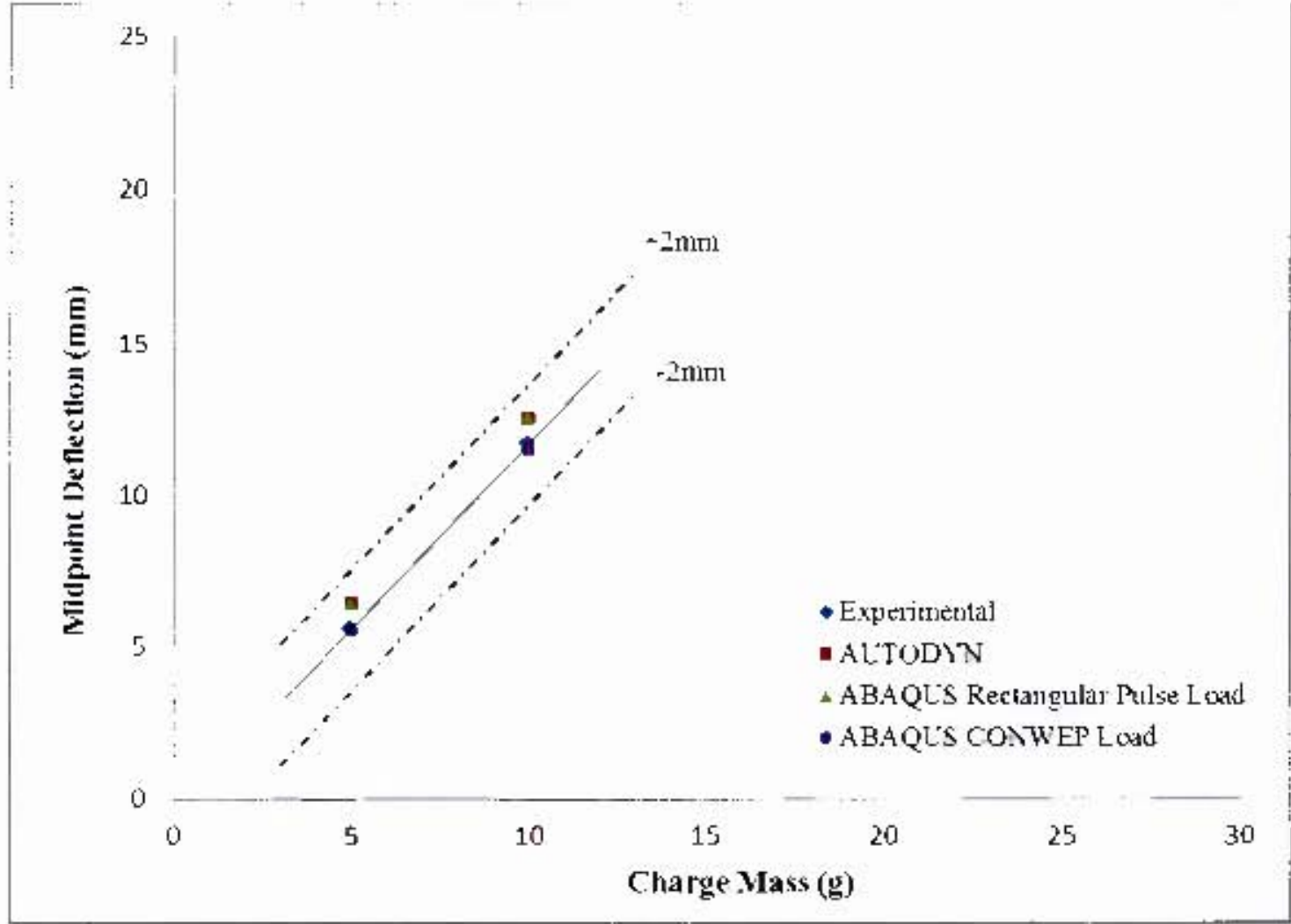

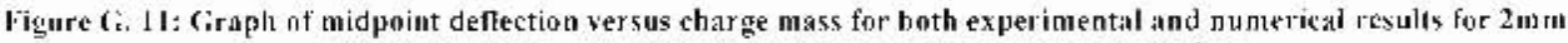
thic kitest plates sulojected to 4 lilast loads of charge masses $5 \mathrm{~g}$ to $25 \mathrm{~g}$ 


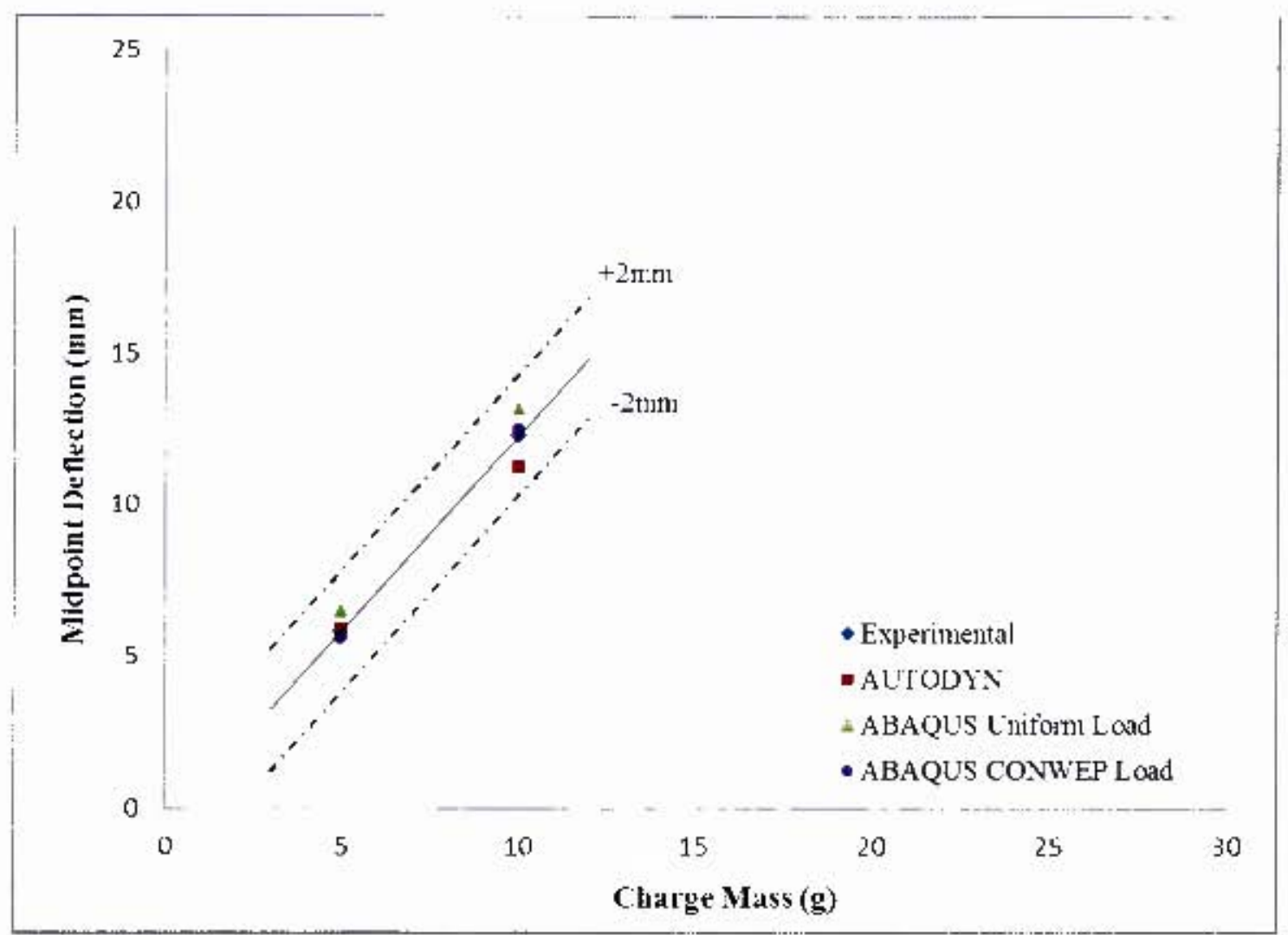

Figure (i. 12:Giraph of midpuinc ditllectiun versus charge mass fur both experimental and un umerical results for $2 \mathrm{mum}$ thicli test plates subjected to 5 blast loads of cluarge masses $5 \mathrm{~g}$ to $25 \mathrm{~g}$

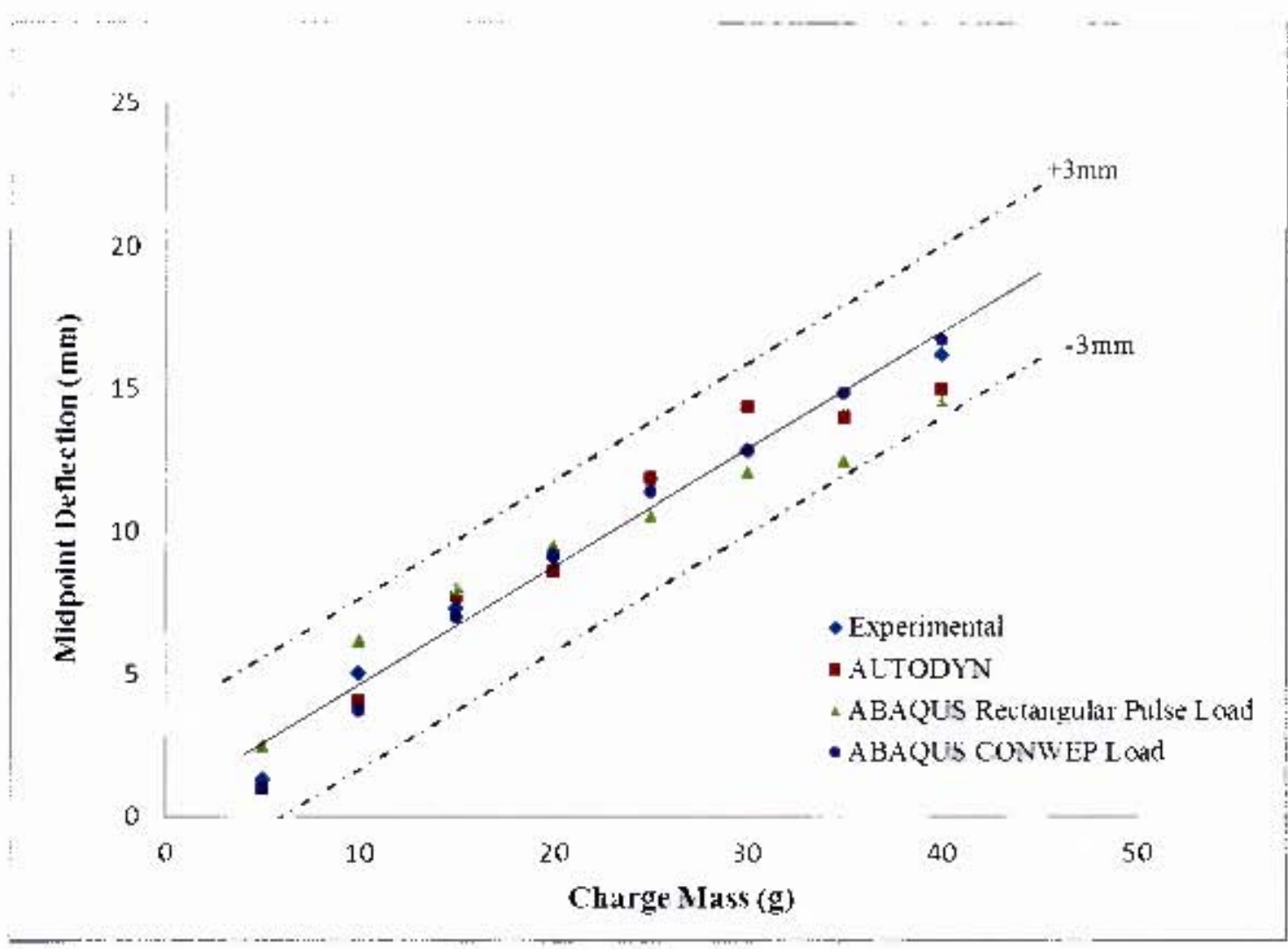

Figure C. 13:Ciraph of midpoint deflection versus charge mass tor both experimental and mumerical results for $3 \mathrm{~mm}$ thick test plates subjected tir a sirngle blast load of tuarge masses $5 \mathrm{~g}$ to $40 \mathrm{~g}$ 


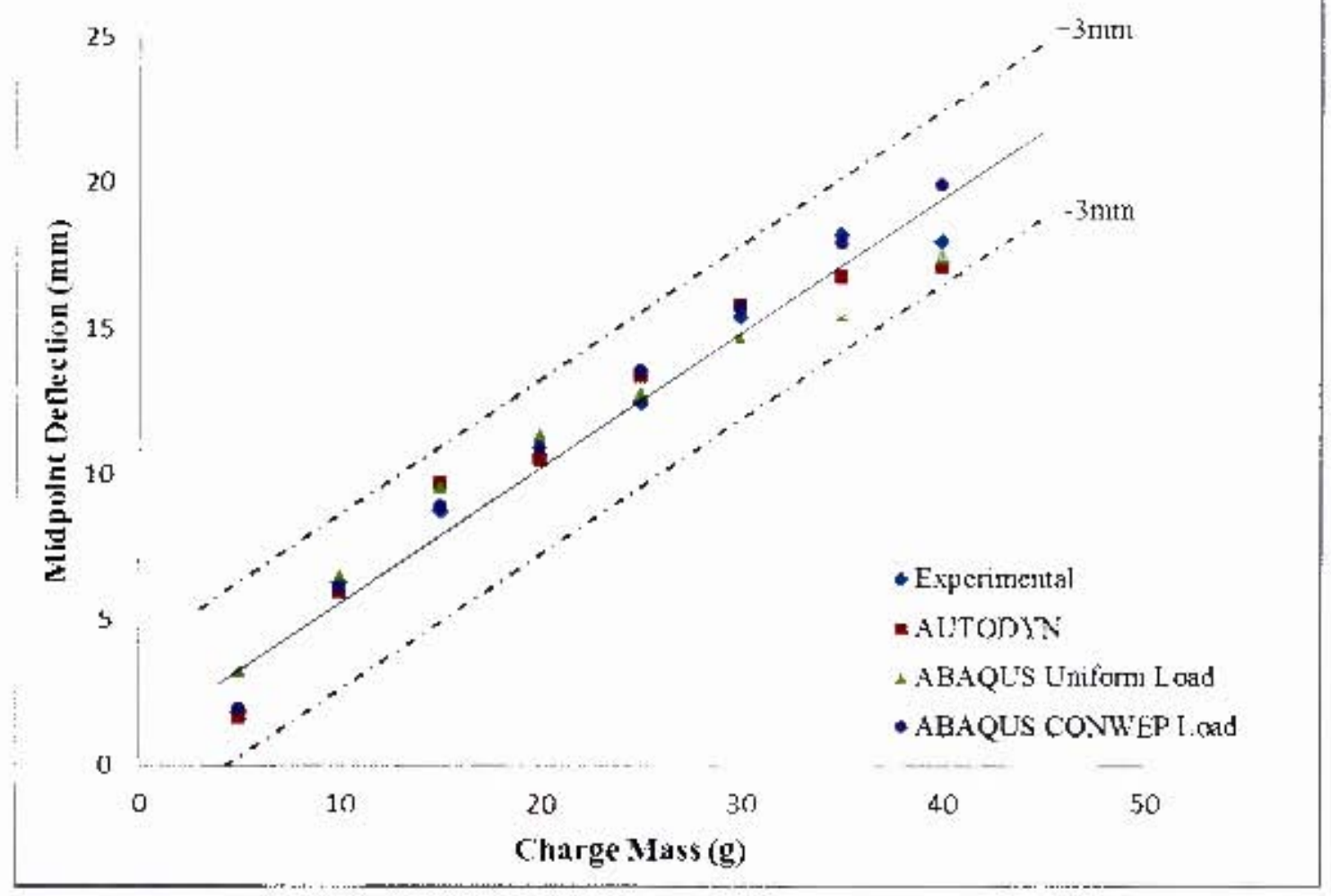

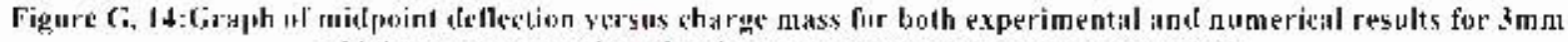
thicli test plates subjected to 2 blast loads of cluarge masges $5 \mathrm{~g}$ to $4 \mathrm{lgg}$

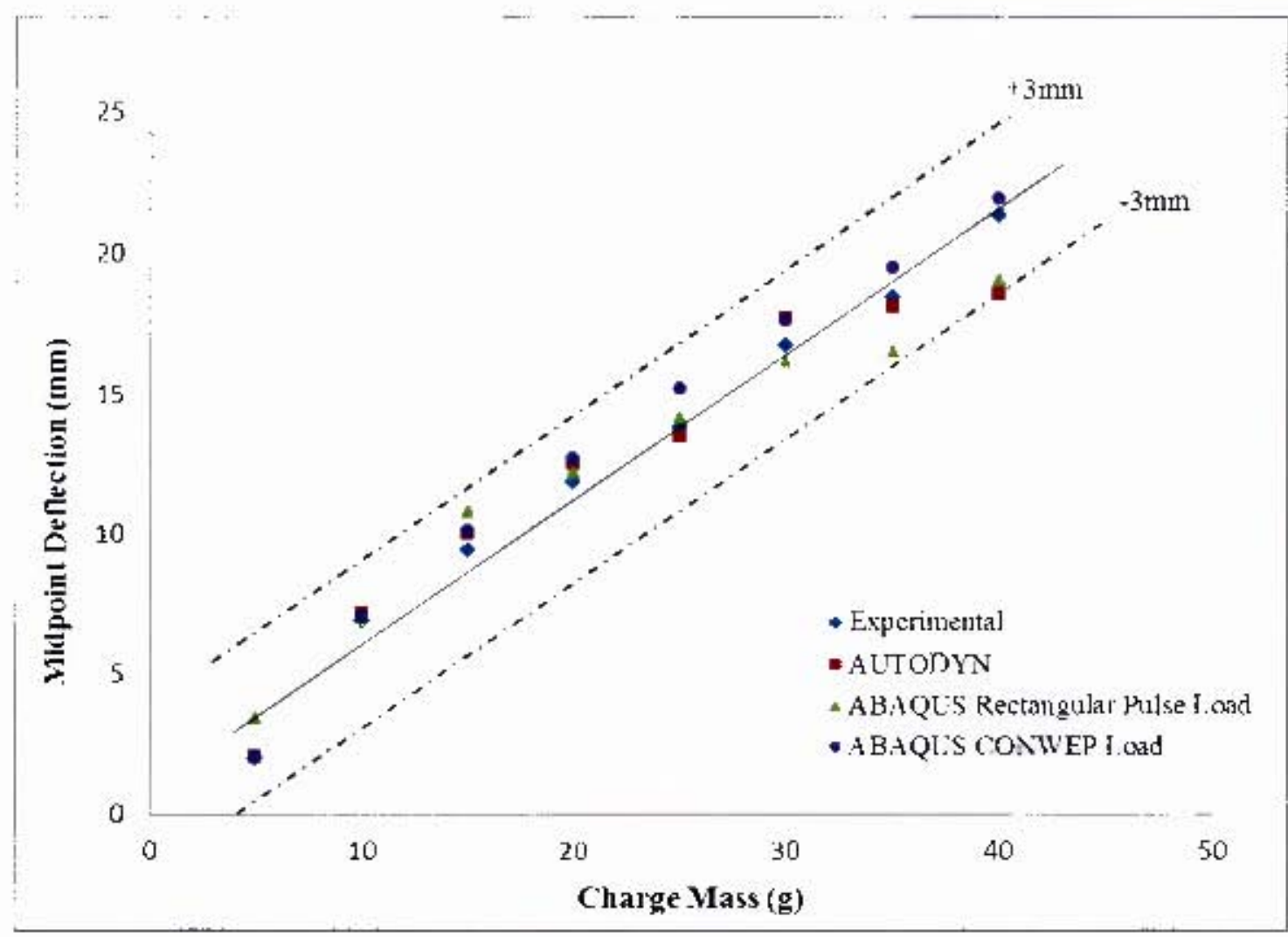

Figure G. 15:Griph of midpoint deflection yersus charge mass for both experimental and oumericial results for $3 \mathrm{~mm}$ thick test plates subjected to 3 blast loads of charge masses $5 \mathrm{~g}$ to $4 \mathrm{lgg}$ 


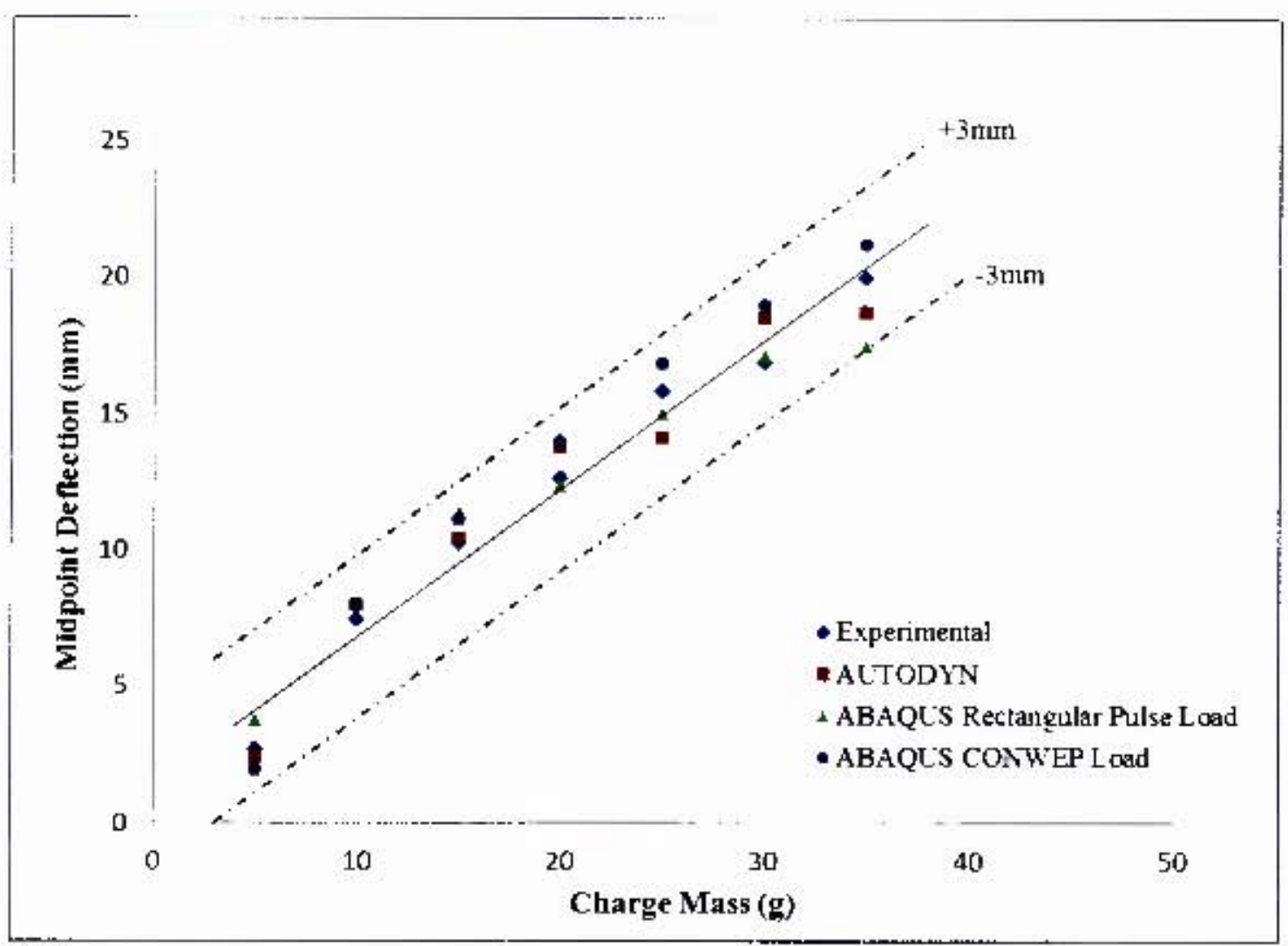

Figure f. 16: Graph of midpoint deflection versus charge mass for both experimental and numerical resules for $3 \mathrm{mum}$ thick test plates subjected to 4 blast loads of charge masses so to 4 ing 
Table G. 3:Comparison of experimental und numerical midpoint deflection results for a plate thichniss 2 rum, charge masses $5 \mathrm{~g}$ to $25 \mathrm{~g}$ and all repeated blast loads

\begin{tabular}{|c|c|c|c|c|c|c|c|c|c|}
\hline \multirow[b]{2}{*}{$\begin{array}{l}\text { Number of } \\
\text { Blasts }\end{array}$} & \multirow{3}{*}{$\begin{array}{c}\text { Charge } \\
\text { Mass } \\
\text { (g) } \\
{ }_{5}\end{array}$} & \multirow[b]{2}{*}{$\begin{array}{c}\text { Plate } \\
\text { Thickness } \\
\text { (inm) }\end{array}$} & \multirow[b]{2}{*}{$\begin{array}{c}\text { Experimental } \\
(\mathrm{mm})\end{array}$} & \multirow[b]{2}{*}{$\begin{array}{l}\text { AUIODYN } \\
\text { (mm) }\end{array}$} & \multicolumn{3}{|c|}{ Midpoint Deflection (mm) } & \multirow[b]{2}{*}{$\begin{array}{l}\text { ABAQLS- } \\
\text { CONWEP } \\
\text { Louding } \\
\text { (mm) }\end{array}$} & \multirow[b]{2}{*}{$\begin{array}{l}\text { ABAQES } \\
\text { CONWFP- } \\
\text { Experimental } \\
\text { Diflerenesit } \\
\text { (min) }\end{array}$} \\
\hline & & & & & $\begin{array}{l}\text { AUTODVN- } \\
\text { Experimental } \\
\text { Difference/t } \\
(\text { nim) }\end{array}$ & $\begin{array}{l}\text { ABAQUS- } \\
\text { Rectangular } \\
\text { Pressure } \\
\text { Pulse Loading } \\
\text { (mm) }\end{array}$ & $\begin{array}{c}\text { ABAQLS } \\
\text { Rectangular } \\
\text { Pressure Puise } \\
\text {-Fxperimentul } \\
\text { Bifterence/t } \\
\text { (mm) }\end{array}$ & & \\
\hline 1 & & 2 & 3.73 & 2.92 & $-1) .41$ & 5.29 & 0.78 & 2.71 & -0.51 \\
\hline 2 & 5 & 2 & 5.15 & 3.79 & $-0.6 \mathrm{~s}$ & 5.36 & 0.11 & 4.54 & -0.31 \\
\hline 3 & 5 & 2 & 5.4 & 5.59 & 0.09 & 5.98 & 0.29 & 4.98 & -0.21 \\
\hline 4 & 5 & 2 & 5.56 & 5.75 & 0.10 & 6.41 & 0.43 & 5.51 & -0.02 \\
\hline 5 & 5 & 2 & 5.83 & 5.88 & 0.02 & 6.17 & 0.32 & 5.6 & -0.12 \\
\hline 1 & 10 & 2 & 9.25 & 8.81 & -0.22 & 9.37 & 0.06 & 7.72 & $-0.7 ?$ \\
\hline 2 & 10 & 2 & 10.61 & 10.42 & -0.09 & 10.73 & 0.06 & 9.35 & -0.63 \\
\hline 3 & 10 & 2 & 11.64 & 10.68 & -10.48 & 11.81 & 0.09 & 10.74 & -ी. 45 \\
\hline 4 & 10 & 2 & 11.68 & 11.10 & -0.29 & 12.53 & 0.43 & 11.47 & -0.11 \\
\hline 5 & 10) & 2 & 12.27 & 11.25 & -10.51 & 13.13 & 0.43 & 12.45 & 0.09 \\
\hline 1 & 15 & 2 & 13.02 & 13.62 & 0.30 & 12.16 & -0.43 & 11.6 & -0.71 \\
\hline 2 & 15 & 2 & 14.43 & 11.85 & 0.21 & 14.19 & -0.12 & 14 & -11.22 \\
\hline 3 & 15 & 2 & 16.12 & 15.26 & -0.13 & 15.67 & -0.23 & 15.76 & -0.18 \\
\hline 4 & 15 & 2 & $\mathrm{NA}$ & $\checkmark A$ & $\mathrm{NA}$ & $\mathrm{NA}$ & IA & $\mathrm{N} \wedge$ & VA \\
\hline 1 & 20 & 2 & 16.28 & 15.00 & -0.64 & 14,32 & -0.98 & 14.71 & -0.79 \\
\hline 2 & 20 & 2 & 17.58 & 17.11 & -0.23 & 16.65 & $0.4 ?$ & 17.54 & -0.02 \\
\hline 3 & 20 & 2 & $\mathrm{~N} A$ & VA & $\mathrm{XA}$ & VA & $\mathrm{NA}$ & $\mathrm{N} A$ & NA \\
\hline 1 & 25 & 2 & 17.73 & 1536 & -1.19 & 15.98 & -0.88 & 17.7 & -0.02 \\
\hline 2 & 25 & 2 & $\mathrm{NA}$ & $\mathrm{VA}$ & $\mathrm{VA}$ & $\mathrm{VA}$ & $\mathrm{NA}$ & $\mathrm{NA}$ & NA \\
\hline
\end{tabular}




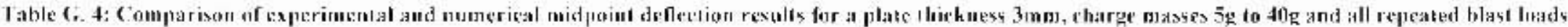

\begin{tabular}{|c|c|c|c|c|c|c|c|c|c|}
\hline \multirow[b]{2}{*}{$\begin{array}{l}\text { Dumber of } \\
\text { Btasts }\end{array}$} & \multirow[b]{2}{*}{$\begin{array}{l}\text { Charge } \\
\text { Mass } \\
\text { (a) }\end{array}$} & \multirow[b]{2}{*}{$\begin{array}{c}\text { Plaile } \\
\text { Thickuess } \\
\text { (mom) }\end{array}$} & \multicolumn{7}{|c|}{ Midpoint Detlection (mm) } \\
\hline & & & $\begin{array}{l}\text { Iixperimental } \\
(\mathrm{mm})\end{array}$ & $\begin{array}{l}\text { AL:TGDYN } \\
\text { (mm) }\end{array}$ & $\begin{array}{l}\text { AUlOUiN- } \\
\text { Experimental } \\
\text { Difference/t } \\
(\mathrm{mm})\end{array}$ & $\begin{array}{l}\text { ARAQLS- } \\
\text { Rectingular } \\
\text { Pressure Pulse } \\
\text { Loading (mm) }\end{array}$ & $\begin{array}{c}\text { ABAGUS } \\
\text { Ikectangular } \\
\text { Pressure Pulse } \\
\text {-Fxperimental } \\
\text { Difference/t } \\
\text { \{mm) }\end{array}$ & $\begin{array}{l}\text { ABAQLS- } \\
\text { CONWEP } \\
\text { I orating } \\
\text { (nm) }\end{array}$ & $\begin{array}{l}\text { ABAOUS } \\
\text { CONWEP- } \\
\text { Fxperimental } \\
\text { Difference/t } \\
\text { (mm) }\end{array}$ \\
\hline 1 & 5 & 3 & 1.28 & 0.94 & -0.11 & 2.43 & 0.38 & 0.96 & -0.11 \\
\hline \multirow{3}{*}{2} & 5 & 3 & 1.82 & 1.68 & -0.05 & 3.16 & 0.45 & 1.98 & 0.05 \\
\hline & 5 & 3 & 1.98 & 2.04 & 0.02 & 3.4 & 0.47 & 2.07 & 0.03 \\
\hline & 5 & 3 & 2.77 & 2.34 & -0.11 & 3.73 & 0.34 & 1.92 & -0.27 \\
\hline 5 & 5 & 3 & 2.1 & 2.60 & 0.17 & 3.8 & 0.57 & 2.61 & 0.17 \\
\hline 1 & 10 & 3 & 5.03 & 4.04 & -0.33 & 6.11 & 0.36 & 3.73 & .0 .43 \\
\hline 2 & 10 & 3 & 6.25 & 5.97 & -0.04 & 6.53 & 0.09 & 6.11 & -0.05 \\
\hline 3 & 10 & 3 & 6.85 & 7.19 & 0.11 & 6.92 & 0.02 & 7.05 & 0.07 \\
\hline 4 & 10 & 3 & 7.46 & 8.00 & 0.18 & 8.14 & 0.23 & 7.96 & 0.17 \\
\hline 5 & 10 & 3 & 7.91 & 8.03 & 0.04 & 8.5 .5 & 0.21 & 8.57 & 0.22 \\
\hline 1 & 15 & 3 & 7.27 & 7.70 & $0.1 \%$ & 7.94 & 0.22 & 7 & -0.09 \\
\hline 2 & 15 & 3 & 8.73 & 4.70 & 0.32 & 9.49 & 0.25 & 8.93 & 0.07 \\
\hline 3 & 15 & 3 & 9.38 & 10.03 & 0.22 & 10.77 & 0.46 & 10.11 & 0.24 \\
\hline 4 & 15 & 3 & 10.28 & 10.43 & 0.05 & 11.36 & 0.36 & 11,12 & 0.28 \\
\hline 5 & 15 & 3 & 10.76 & 10.70 & -0.02 & 12.07 & 0.44 & 11.57 & 0.27 \\
\hline 1 & 20 & 3 & 9.07 & 8.59 & -0.16 & 9.51 & 0.15 & 9.17 & 0.03 \\
\hline 2 & 20 & 3 & 10.64 & 10.53 & -0.04 & 11.32 & 0.23 & 10.92 & 0.09 \\
\hline 3 & 20 & 3 & 11.84 & 12.52 & 0.23 & 12.17 & 0.11 & 12.71 & 0.29 \\
\hline 4 & 20 & 3 & 12.68 & 13.78 & 0.37 & 12.35 & -0.11 & 14 & 0.44 \\
\hline 5 & 20 & 3 & 13.14 & 13.80 & 0.22 & 13.98 & 0.28 & 14.76 & 0.54 \\
\hline
\end{tabular}




\begin{tabular}{|c|c|c|c|c|c|c|c|c|c|}
\hline $\begin{array}{l}\text { Number of } \\
\text { Blasts }\end{array}$ & $\begin{array}{l}\text { Charge } \\
\text { Mass } \\
\text { (g) }\end{array}$ & $\begin{array}{c}\text { Plate } \\
\text { Thickness } \\
\text { (mm) }\end{array}$ & $\begin{array}{l}\text { Experimental } \\
\text { (mm) }\end{array}$ & $\begin{array}{l}\text { AUIODY } \\
\text { (mm) }\end{array}$ & $\begin{array}{l}\text { AUTOUYN- } \\
\text { Experimental } \\
\text { Diflerenceit } \\
\text { (mm) }\end{array}$ & $\begin{array}{c}\text { ABAQUS- } \\
\text { Rectangular } \\
\text { Pressure } \\
\text { Pulse loadling } \\
\text { (mm) }\end{array}$ & $\begin{array}{c}\text { ABAQLS } \\
\text { Reetangular } \\
\text { Pressure Pulse - } \\
\text { Fxperimenial } \\
\text { Differencelt } \\
\text { (mm) }\end{array}$ & $\begin{array}{l}\text { ABAQLS- } \\
\text { CONWWEP } \\
\text { loarling } \\
\text { (mm) }\end{array}$ & $\begin{array}{l}\text { ABAQLS } \\
\text { CONWEP- } \\
\text { Experimental } \\
\text { Difference/t } \\
\text { (min) }\end{array}$ \\
\hline 1 & 25 & 3 & 11.84 & 11.88 & 0.01 & 10.5 & -0.45 & 11.38 & -0.15 \\
\hline 2 & 25 & 3 & 12.43 & 13.41 & 0.33 & 12.74 & 0.10 & 13.54 & 0.37 \\
\hline 3 & 25 & 3 & 13.8 & 13.53 & -0.09 & 14.16 & 0.12 & 15.2 & 0.47 \\
\hline 4 & 25 & 3 & 15.79 & 14.12 & -0.56 & 15.01 & -0.26 & 16.81 & 0.34 \\
\hline 5 & 25 & 3 & 15.85 & 14.35 & -0.50 & 15.78 & 0.02 & 17.75 & 0.63 \\
\hline 1 & 30 & 3 & 12.8 & 14.35 & 0.52 & 12.45 & -0.25 & 12.8 & 0.00 \\
\hline 2 & 30 & 3 & 15.36 & 15.83 & 0.16 & 14.61 & -0.25 & 15.72 & 0.12 \\
\hline 3 & 30 & 3 & 16.73 & 17.77 & 0.35 & 16.17 & -0.19 & 17.65 & 0.31 \\
\hline 4 & 30 & 3 & 16.86 & 18.51 & 0.55 & 17.1 & 0.08 & 18.96 & 0.70 \\
\hline 5 & 30 & 3 & 18.11 & 19.18 & 0.36 & 17.83 & -0.09 & 20.13 & 0.67 \\
\hline 1 & 35 & 3 & 14.21 & 14.00 & -0.07 & 12.46 & -0.58 & 14.85 & 0.21 \\
\hline 2 & 35 & 3 & 18.21 & 16.77 & -0.48 & 15.43 & -0.93 & 17.97 & -0.08 \\
\hline 3 & 35 & 3 & 18.47 & 18.18 & -0.10 & 16.51 & -0.65 & 19.54 & 0.36 \\
\hline 4 & 35 & 3 & 19.96 & 18.70 & -0.42 & 17,43 & -0.84 & 21.21 & 0.42 \\
\hline 5 & 35 & 3 & 21.28 & 19.07 & -0.74 & 18.15 & -1.04 & 22.14 & 0.29 \\
\hline 1 & 40 & 3 & 16.2 & 14.98 & -0.41 & 14.56 & -0.55 & 16.73 & 0.18 \\
\hline 2 & 40 & 3 & 17.97 & 17.13 & -0.78 & 17.41 & -0.19 & 19.98 & 0.67 \\
\hline 3 & 40 & 3 & 21.36 & 18.61 & -0.92 & 19.06 & -0.77 & 21.99 & 0.21 \\
\hline 4 & 40 & 3 & $Y A$ & $\mathrm{~N} \wedge$ & $\mathrm{VA}$ & $N A$ & NA & $\mathrm{NA}$ & VA \\
\hline
\end{tabular}

